\title{
FINAL REPORT INSPECTION OF AGED/DEGRADED CONTAINMENTS PROGRAM
}

\section{SEPTEMBER 2005}

\section{Prepared by}

D. J. Naus, Metals and Ceramics Division, Oak Ridge National Laboratory, Oak Ridge, TN 37831

C. B. Oland, Engineering Science \& Technology Division, Oak Ridge National Laboratory, Oak Ridge, TN 37831

B. R. Ellingwood, School of Civil and Environmental Engineering, Georgia Institute of Technology, Atlanta, Georgia 30332 


\section{DOCUMENT AVAILABILITY}

Reports produced after January 1, 1996, are generally available free via the U.S. Department of Energy (DOE) Information Bridge:

Web site: http://www.osti.gov/bridge

Reports produced before January 1, 1996, may be purchased by members of the public from the following source:

National Technical Information Service

5285 Port Royal Road

Springfield, VA 22161

Telephone: 703-605-6000 (1-800-553-6847)

TDD: $703-487-4639$

Fax: 703-605-6900

E-mail: info@ntis.fedworld.gov

Web site: $\mathrm{http}: / /$ www.ntis.gov/support/ordernowabout.htm

Reports are available to DOE employees, DOE contractors, Energy Technology Data Exchange (ETDE) representatives, and International Nuclear Information System (INIS) representatives from the following source:

Office of Scientific and Technical Information

P.O. Box 62

Oak Ridge, TN 37831

Telephone: $865-576-8401$

Fax: 865-576-5728

E-mail: reports@adonis.osti.gov

Web site: $\mathrm{http}: / /$ www.osti.gov/contact.html

This report was prepared as an account of work sponsored by an agency of the United States Government. Neither the United States government nor any agency thereof, nor any of their employees, makes any warranty, express or implied, or assumes any legal liability or responsibility for the accuracy, completeness, or usefulness of any information, apparatus, product, or process disclosed, or represents that its use would not infringe privately owned rights. Reference herein to any specific commercial product, process, or service by trade name, trademark, manufacturer, or otherwise, does not necessarily constitute or imply its endorsement, recommendation, or favoring by the United States Government or any agency thereof. The views and opinions of authors expressed herein do not necessarily state or reflect those of the United States Government or any agency thereof. 
ORNL/TM-2005/520

FINAL REPORT INSPECTION OF AGED/DEGRADED CONTAINMENTS PROGRAM

\author{
D. J. Naus \\ Metals and Ceramics Division \\ Oak Ridge National Laboratory \\ Oak Ridge, TN 37831 \\ C, B. Oland \\ Engineering Science \& Technology Division \\ Oak Ridge National Laboratory, \\ Oak Ridge, TN 37831 \\ B. R. Ellingwood \\ School of Civil and Environmental Engineering \\ Georgia Institute of Technology \\ Atlanta, Georgia 30332
}

Date Published: September 2005

\author{
Prepared by \\ OAK RIDGE NATIONAL LABORATORY \\ P.O. Box 2008 \\ Oak Ridge, Tennessee 37831-6285 \\ managed by \\ UT-Battelle, LLC \\ for the \\ U.S. DEPARTMENT OF ENERGY \\ under contract DE-AC05-00OR22725
}





\section{TABLE OF CONTENTS}

\section{Page}

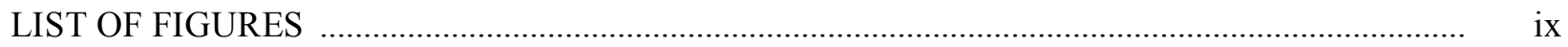

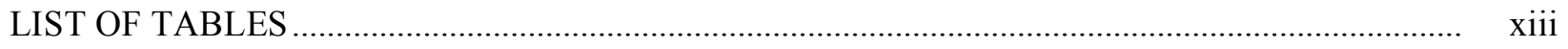

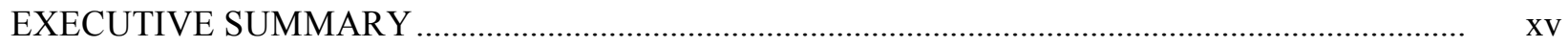

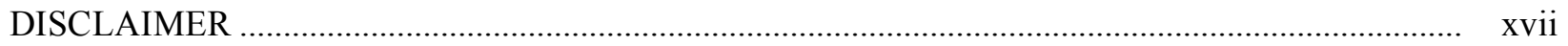

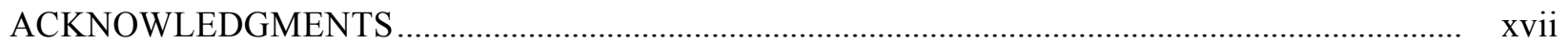

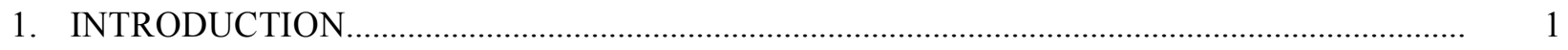

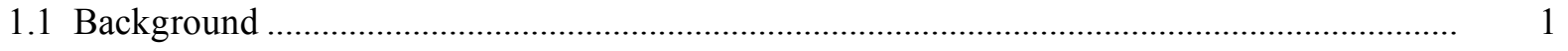

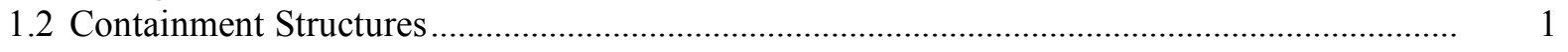

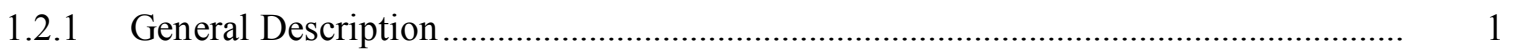

1.2.2 Potential Degradation Factors ................................................................................... 2

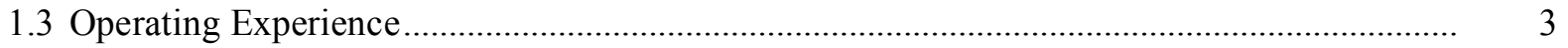

1.4 Objective and Potential Application of Results........................................................................ 3

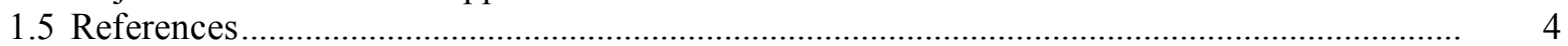

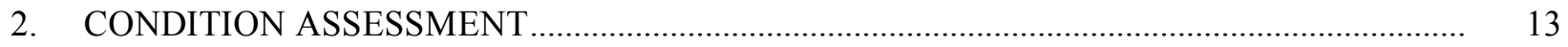

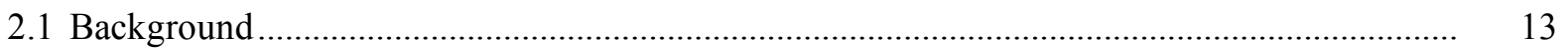

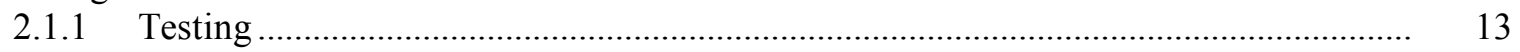

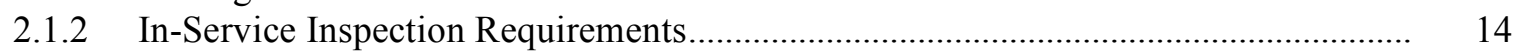

2.1.3 Continued Service Assessments ..................................................................... 15

2.2 Structural Component Classification ................................................................................... 15

2.2.1 Containment Metallic Pressure Boundary Structural

2.2.1.1 Containment metallic pressure boundary materials ........................................ 15

2.2.1.2 Classification and identification of metallic pressure boundary materials ................................................................. 16

2.2.1.3 Representation of material properties and data ........................................... 17

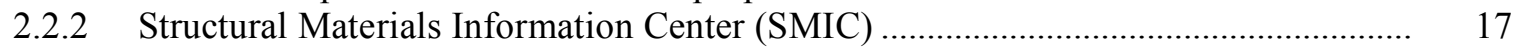

2.2.2.1 Description of SMIC ................................................................................... 17

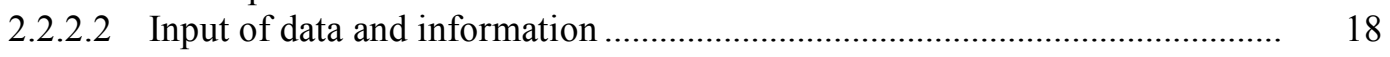

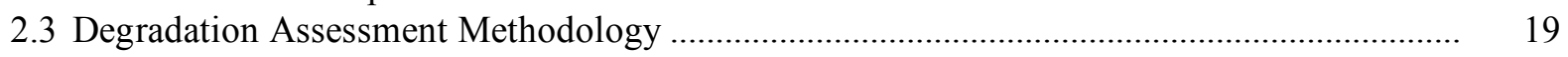

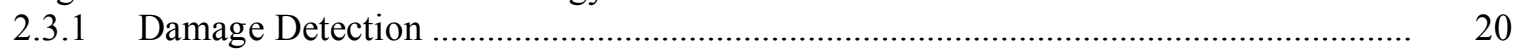

2.3.1.1 Component configuration ....................................................................... 20

2.3.1.2 Environmental and operating conditions ................................................ 21

2.3.1.3 Leakage-rate testing ............................................................................. 22

2.3.1.4 Preservice and in-service inspection ...................................................... 22

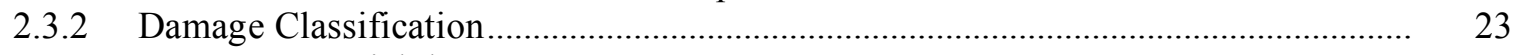

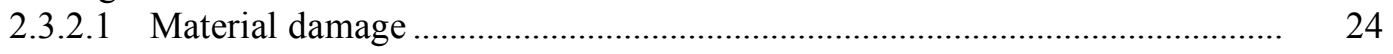

2.3.2.2 Physical damage ........................................................................................ 24

2.3.2.2.1 General corrosion ................................................................. 24

2.3.2.2.2 Localized corrosion ................................................................ 25

2.3.2.2.3 Mechanically-assisted degradation............................................ 25

2.3.2.2.4 Environmentally-induced cracking .......................................... 25

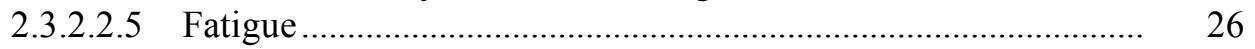

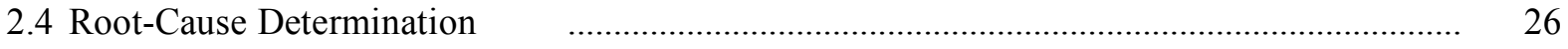

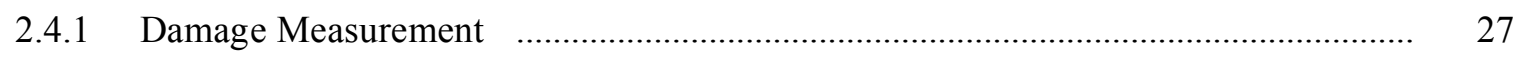

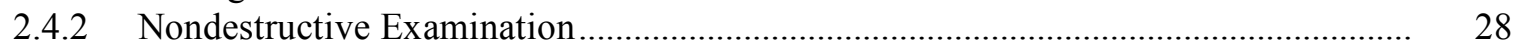

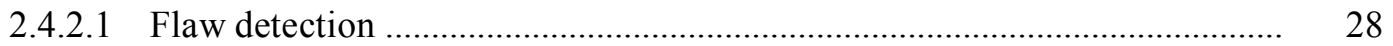

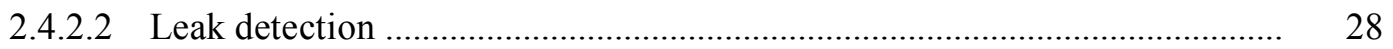

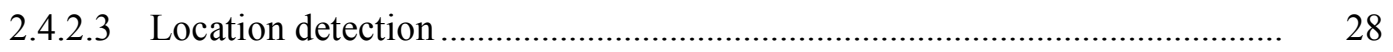




\section{TABLE OF CONTENTS (CONT)}

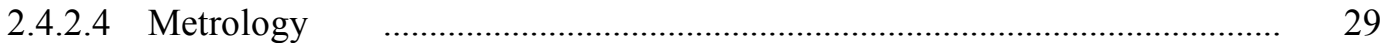

2.4.2.5 Structure or microstructure characterization ....................................................... 29

2.4.2.6 Estimation of mechanical and physical properties .......................................... 29

2.4.2.7 Stress-strain and dynamic response determination ......................................... 29

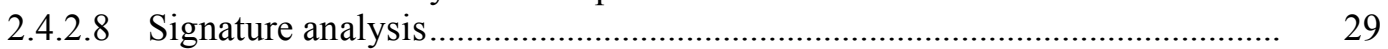

2.4.2.9 Chemical composition determination ........................................................ $\quad 30$

2.4.2.10 Corrosion characterization .................................................................. $\quad 30$

2.4.2.10.1 General corrosion .................................................................... 30

2.4.2.10.2 Pitting corrosion.................................................................... $\quad 30$

2.4.2.10.3 Crevice corrosion........................................................... 31

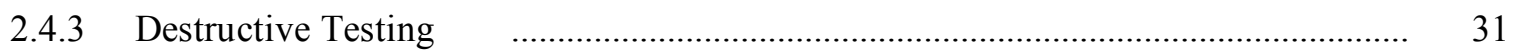

2.4.3.1 Tension testing................................................................................. 31

2.4.3.2 Hardness testing......................................................................... 31

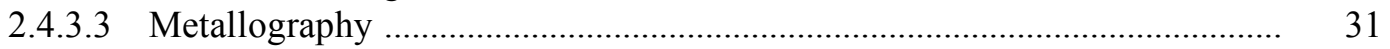

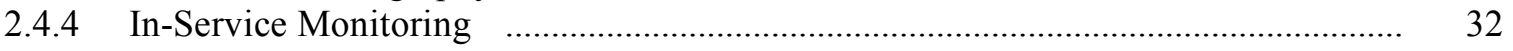

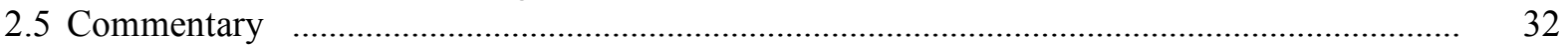

2.6 References

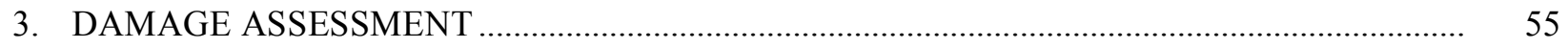

3.1 In-Service Inspection Techniques and Methodologies ...................................................... 55

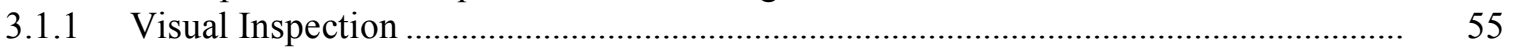

3.1.2 Liquid Penetrant Testing ....................................................................................... 56

3.1.3 Eddy Current Inspection...................................................................................... 56

3.1.4 Magnetic Particle Testing.......................................................................................... 56

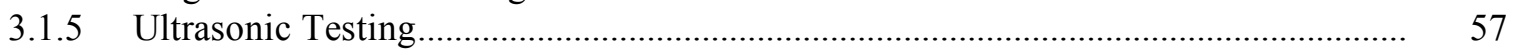

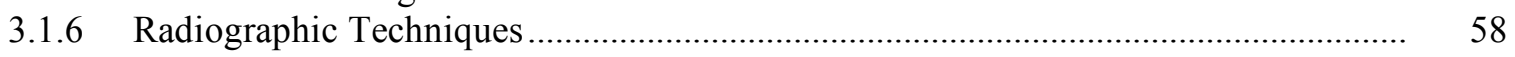

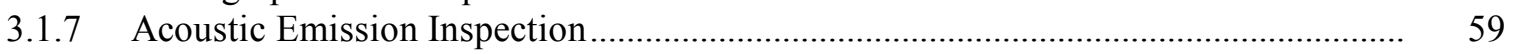

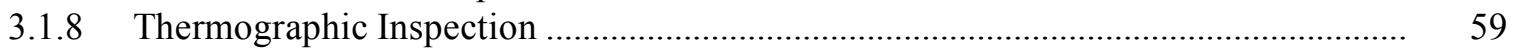

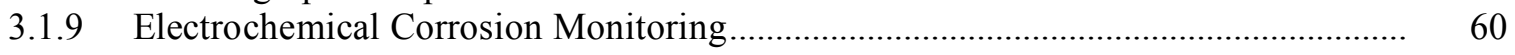

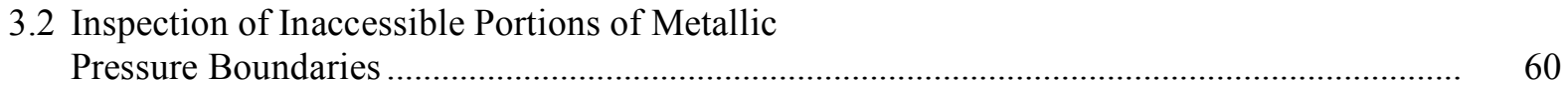

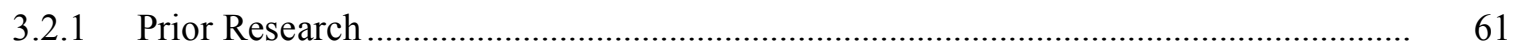

3.2.1.1 Ultrasonic testing ................................................................................ 61

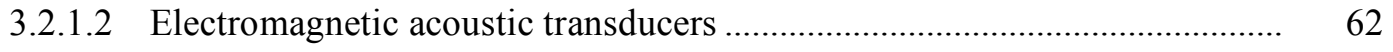

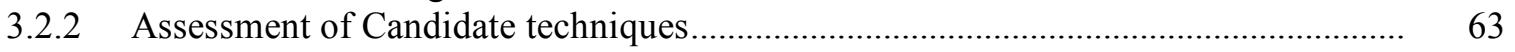

3.2.2.1 High-frequency acoustic imaging ………..................................................... 63

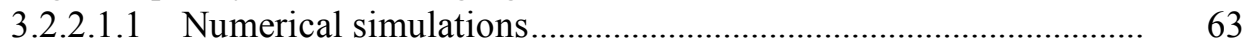

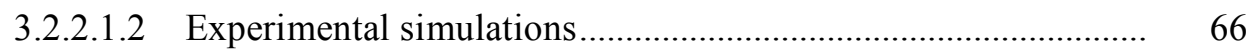

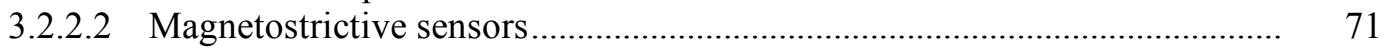

3.2.2.2.1 Modeling studies................................................................... 72

3.2.2.2.2 Experimental studies ............................................................... 73

3.2.2.3 MsS system and time requirements for containment inspection .................................................................... 76

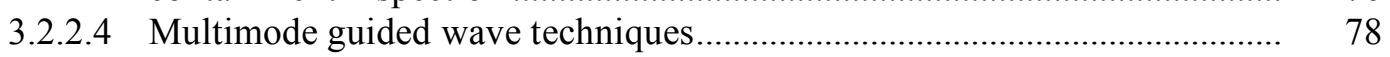

3.2.2.4.1 Multimode guided waves ........................................................ 78

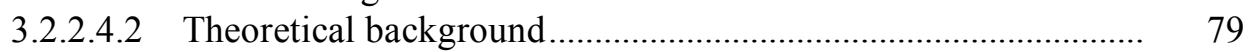

3.2.2.4.3 Experimental studies ....................................................... 80 


\section{TABLE OF CONTENTS (CONT)}

3.2.2.4.4 Elements of defect sizing in a wave guide Using SH guided waves ....................................................................................... 81

3.3 Commentary

3.4 References

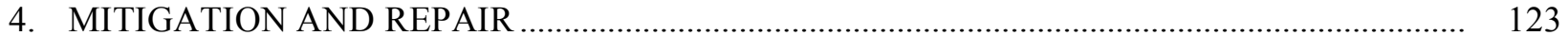

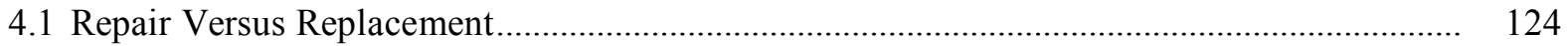

4.2 Containment Pressure Boundary Restoration ................................................................... 125

4.2.1 Conditions for Continued Service ….................................................................. 125

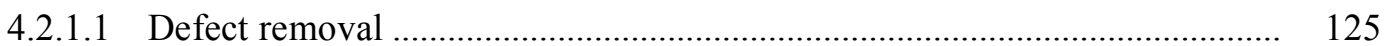

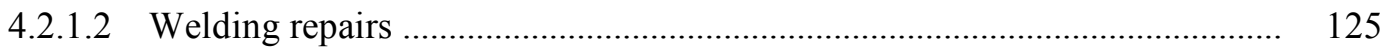

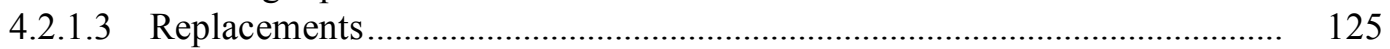

4.2.1.4 Engineering evaluation ......................................................................... 126

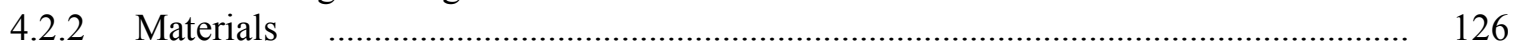

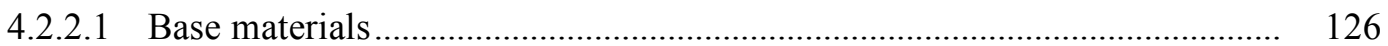

4.2.2.2 Welding materials...................................................................... 126

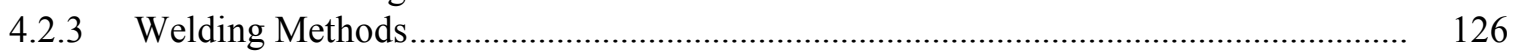

4.2.3.1 Shielded metal-arc welding (SMAW) .................................................. 127

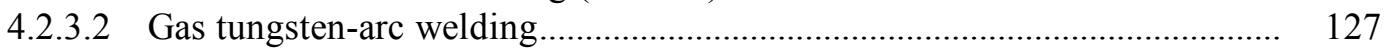

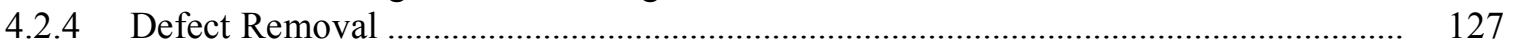

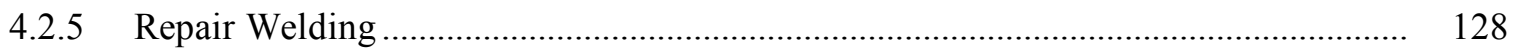

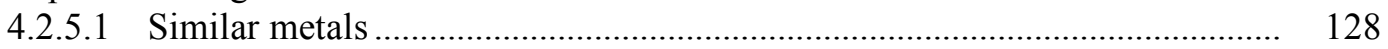

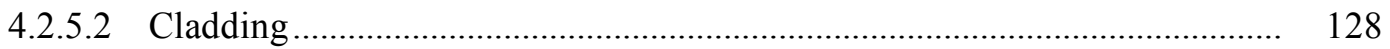

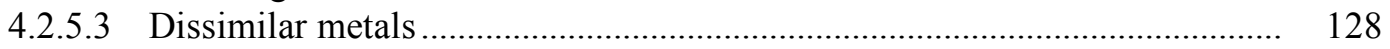

4.2.5.4 Butter bead - temper bead ………............................................................ 129

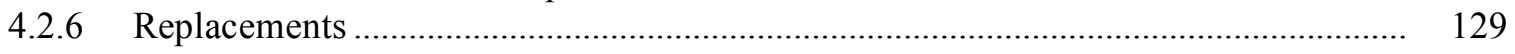

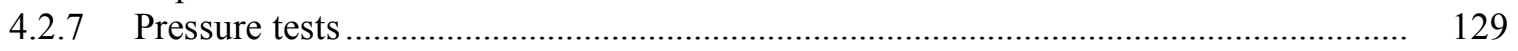

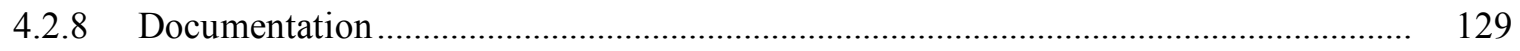

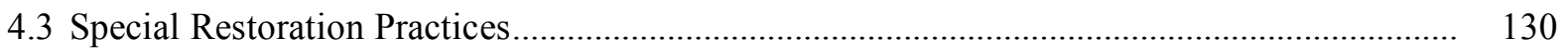

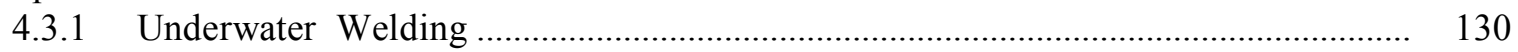

4.3.1.1 Underwater welding qualification .............................................................. 131

4.3.1.2 Filler metal qualification ............................................................................ 131

4.3.1.3 Confirmation weld............................................................................... 131

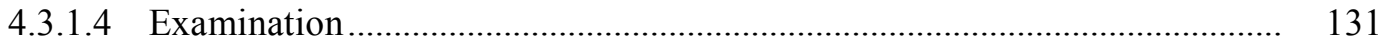

4.3.2 Welding With Concrete Backing ............................................................................ 131

4.3.2.1 Concrete temperature limits..................................................................... 132

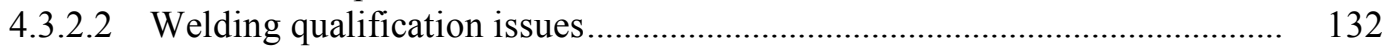

4.3.3 Welding Repair Alternatives for Inaccessible Areas............................................... 132

4.3.3.1 Replacement plate welding ..................................................................... 132

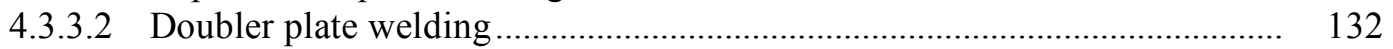

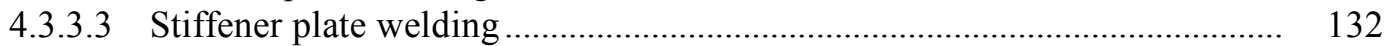

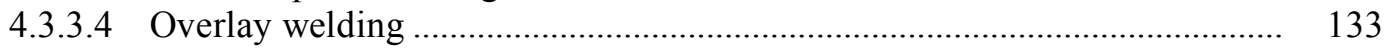

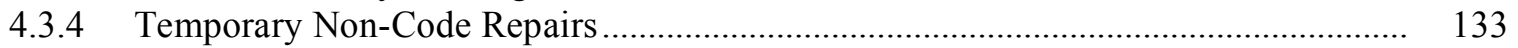

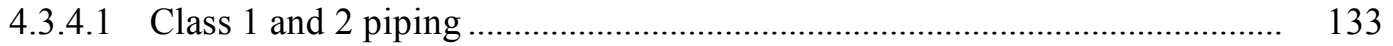

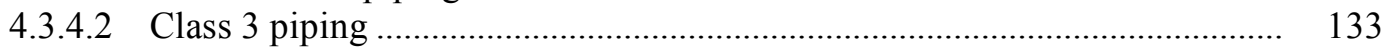

4.3.4.3 Containment pressure boundary components ............................................. 134

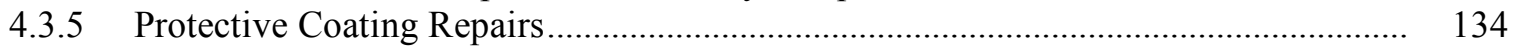

4.3.5.1 Regulatory overview ............................................................................ 134

4.3.5.2 Potential degradation mechanisms and failure criteria ............................. 135 


\section{TABLE OF CONTENTS (CONT)}

$\underline{\text { Page }}$

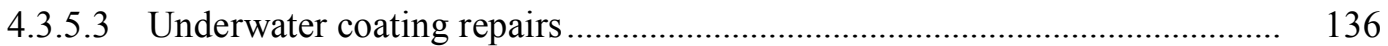

4.3.6 Options for Restoring Damaged Bellows................................................................... 136

4.3.6.1 Replacement of penetration assembly........................................................... 137

4.3.6.2 Replacement of damaged bellows .......................................................... 137

4.3.6.3 Installation of new enveloping bellows ........................................................ 137

4.3.6.4 In-place welding repairs to damaged bellows ........................................... 138

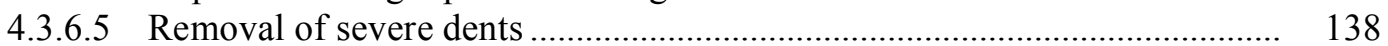

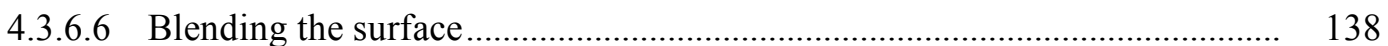

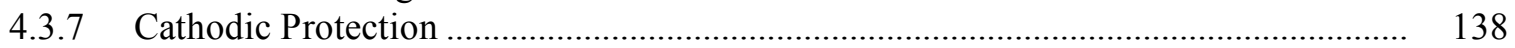

4.3.7.1 Sacrifical anode cathodic protection system............................................... 139

4.3.7.2 Impressed current cathodic protection system............................................. 139

4.3.7.3 Stray electrical current ...................................................................... $\quad 140$

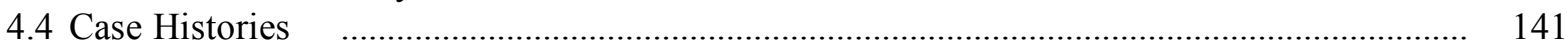

4.4.1 Metal Containment Corrosion........................................................................... 141

4.4.1.1 Drywell corrosion at Oyster Creek............................................................... 141

4.4.1.2 Torus corrosion at Nine Mile Point Unit 1 .................................................... 143

4.4.1.2.1 Corrosion inhibitors............................................................... 143

4.4.1.2.2 Inerting the torus .............................................................. 144

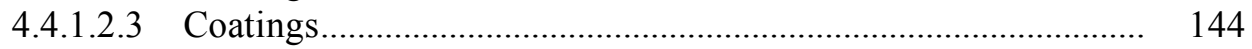

4.4.1.2.4 Cathodic protection ................................................................... 144

4.4.1.2.5 Structural modifications ............................................................ 145

4.4.1.3 Metal containment corrosion in Germany ……........................................... 145

4.4.2 Liner Plate Corrosion in Concrete Containments .................................................. 146

4.4.2.1 U.S experience........................................................................................ 146

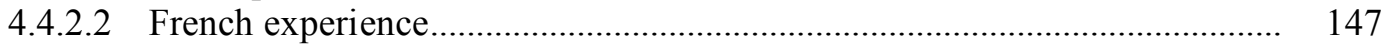

4.5 Commentary

4.5.1 Routine Welding Repair and Replacement Topics................................................... 147

4.5.2 Special Welding Repair and Replacement Topics................................................. 148

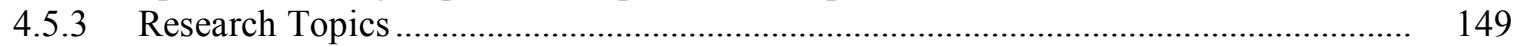

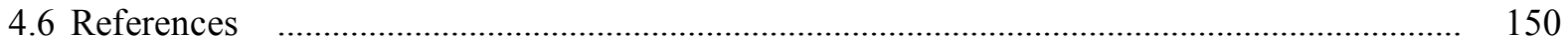

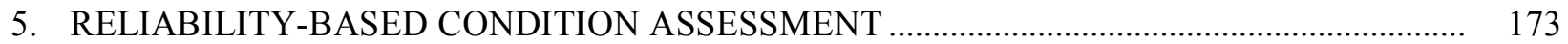

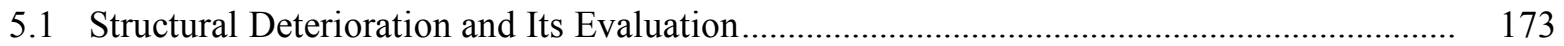

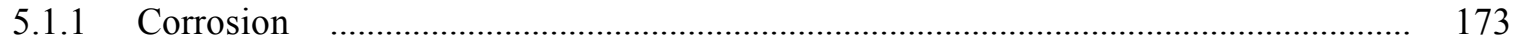

5.1.1.1 Uniform Corrosion .................................................................................. 174

5.1.1.2 Localized Corrosion - Pitting and Crevice ................................................. 175

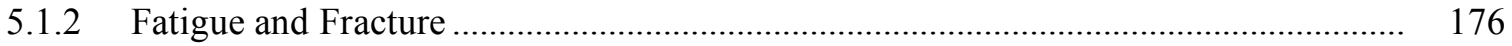

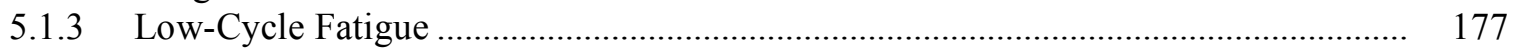

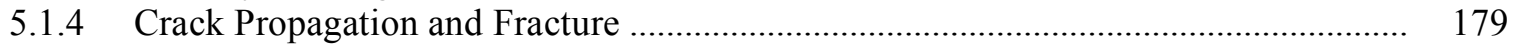

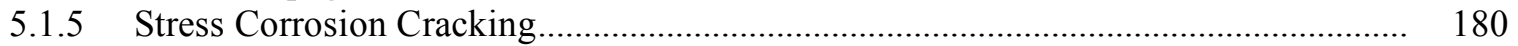

5.1.6 Elevated Temperature and Irradiation Effects ..................................................... 181

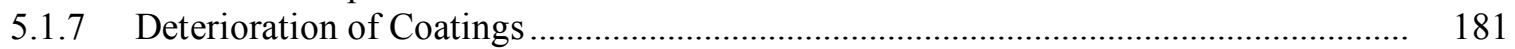

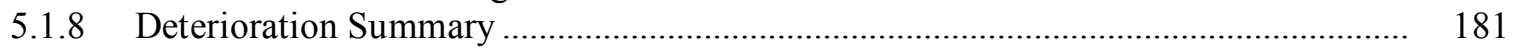

5.2 Time-Dependent Reliability Analysis and Fragility Modeling .......................................... 182

5.2.1 Probabilistic Models of Loads ................................................................... 182

5.2.1.1 Discrete load models ........................................................................... 182

5.2.1.2 Continuous load models .................................................................... 182

5.2.2 Probabilistic Models of Resistance.............................................................. 183 


\section{TABLE OF CONTENTS (CONT)}

$\underline{\text { Page }}$

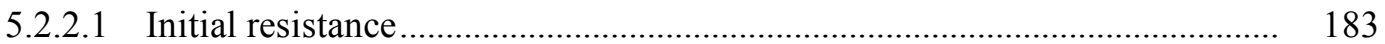

5.2.2.2 Time-dependent deterioration in resistance................................................. 184

5.2.3 Time-Dependent Reliability Analysis of Degrading Structures ................................. 185

5.2.3.1 Degradation independent of service loads ................................................ 185

5.2.3.2 Illustration of time-dependent reliability - corrosion ................................... 186

5.2.3.3 Degradation dependent on service loads......................................................... 188

5.2.3.4 Illustration of time-dependent reliability - fatigue .................................... 190

5.2.4 Fragility Modeling of Steel Containments and Liners ............................................ 191

5.2.4.1 Role of fragility in probabilistic safety assessment...................................... 191

5.2.4.2 Fragility modeling concepts ..................................................................... 191

5.2.4.3 Example fragility of structural component - steel

containment with localized corrosion ...................................................... 194

5.2.4.3.1 Present design criteria ............................................................... 194

5.2.4.3.2 Structural limit states, analysis, and

performance requirements ........................................................ 194

5.2.4.3.3 Statistical databases and experimental design ............................ 198

5.2.4.3.4 Fragility analysis of steel containment........................................ 200

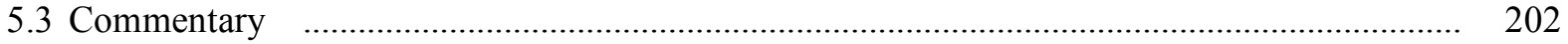

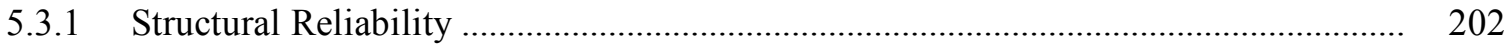

5.3.1.1 Appraisal of structural reliability methods ............................................... 202

5.3.1.2 Challenges in structural reliability ....................................................... 203

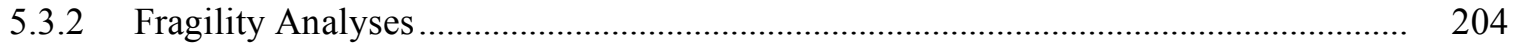

5.4 References

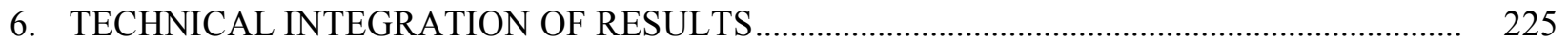

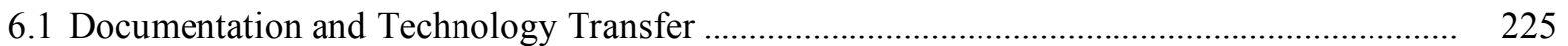

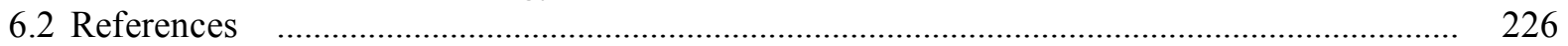

$\begin{aligned} \text { APPENDIX A - } & \text { REPORTS, PAPERS, AND PUBLICATIONS DEVELOPED UNDER THE } \\ & \text { INSPECTION OF AGED/DEGRADED CONTAINMENTS PROGRAM ............ } 229\end{aligned}$

$\begin{aligned} \text { APPENDIX B }- & \text { PRESENTATIONS MADE UNDER THE } \\ & \text { INSPECTION OF AGED/DEGRADED CONTAINMENTS PROGRAM ............ } 239\end{aligned}$

APPENDIX C - APPROXIMATE FRAGILITY ANALYSIS ……........................................... 245

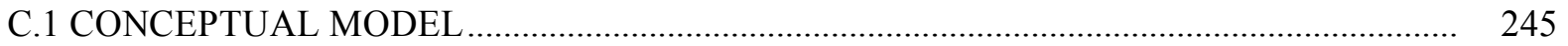

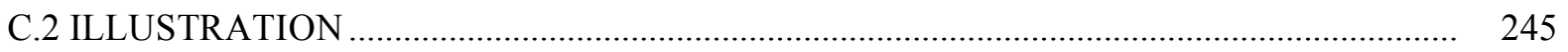

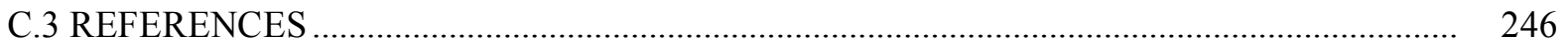




\section{LIST OF FIGURES}

Figure

2.1 Continued service evaluation process for containment pressure boundary components.......... 38

2.2 Material code arrangement for containment steels .................................................................. 38

2.3 Major topics pertaining to in-service condition assessment ................................................... 39

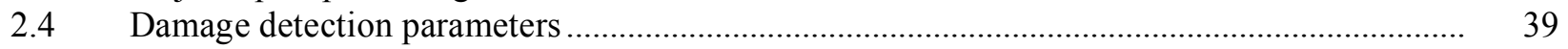

2.5 Damage categories and potential degradation mechanisms............................................... 40

2.6 Factors to be considered in determining the root cause for component degradation ................ 40

2.7 Issues related to measurement of containment pressure boundary component damage ........... 41

Interpretations that could be made when a nondestructive
examination produces an indication ...........................................................................

3.1 Guided wave generation and detection in a plate using piezoelectric transducers................... 87

3.2 Common EMAT setup for guided waves............................................................................ 88

3.3 Range-independent OASES simulation scenario for steel containment scenario .................... 88

3.4 Range-dependent numerical simulation scenario for steel containment scenario ..................... 89

3.5 Results of simulation scenario for a steel layer surrounded by air only .................................... 89

3.6 Results of simulation scenario for embedded steel containment ........................................... 90

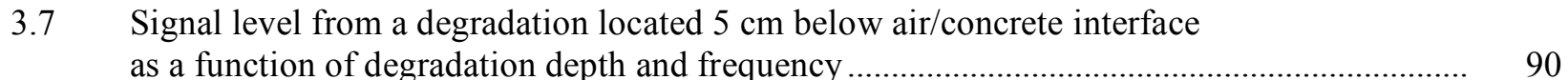

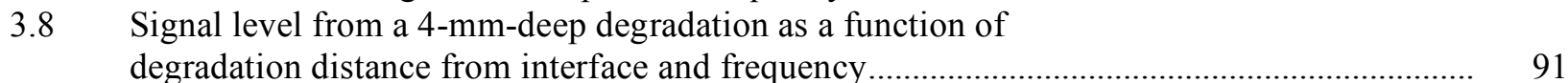

Simulation scenario for steel-lined concrete containment with
6-mm-thick steel layer backed by a concrete halfspace below ..............................................

3.10 Results of simulation scenario for steel-lined concrete containment ...................................... 92

3.11 Illustration of localization by means of beam steering for bearing determination and range gating for distance determination.................................................. 93

3.12 Illustration of beam-forming parameters and their effect on beam shape ................................ 93

3.13 Sensor array cut from a single piezoelectric block, with left side showing initial bonding of piezoelectric material to wires and substrate, and right side the array cut into individual elements prior to potting ......

3.14 Array spacing and beam overlap for a scannable array system with maximum penetration dictated by propagation physics ................................................. 94

3.15 Proposed approach for detection of degradation below air/concrete interface......................... 94

3.16 Procedure used for angle-beam inspections...................................................................... 94

3.17 Test setup and measured return for thickness measurement ................................................. 95

3.18 Power spectral densities of maximum and minimum signals ................................................. 95

3.19 Received signal ratios for different source/receiver separation distances ............................ 96

3.20 Test setup for monitoring forward-traveling waves in free plate .......................................... 96

3.21 Combined envelopes of received signals at several locations

3.22 Combined envelopes of received signals at several locations

relative to a fixed source (backward-traveling reflected waves) ............................................ 97

$3.23 \quad$ Schematic of test setup for degradation shape study ........................................................... 97

3.24 Sample reflected return signal from rectangular notch ...................................................... 98

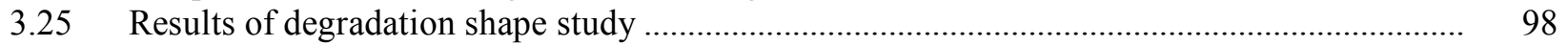

3.26 Time-windowed returns from different notch geometries ................................................... 98

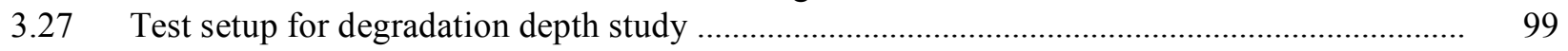

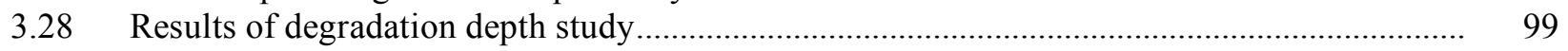

3.29 Molds for embedding portions of steel plates in concrete ...................................................... 99 


\section{LIST OF FIGURES (CONT)}

3.30 Test setup for concrete effects tests.

3.31 Transmitted signal level: (a) free-standing steel plates and

(b) steel plates embedded in concrete over part of their length

3.32 Effect of coupling wedge angle on transmitted signal levels for a bonded steel plate embedded in concrete over part of its length....

3.33 Test setup for simulated field conditions to investigate role of competing signals.................. 101

3.34 Mechanisms of source "self noise"

3.37 Bistatic measured return from rectangular notch in a bonded-steel plate embedded in concrete over part of its length

3.38 Time histories of signals transmitted through free-standing steel plate, unbonded steel plate with concrete, and bonded steel plate with concrete.....

3.39 Schematic of magnetostrictive sensor setup for generation and detection of guided waves in pipes.

3.40 Calculated dispersion curves for longitudinal guided waves in a plate for three conditions: (a) plate is free, (b) plate is backed by concrete on one side, (c) plate is backed by concrete on both sides....

3.41 Displacements of antisymmetric (A) and symmetric (S) wave modes across plate thickness .

Calculated wave attenuation for: (a) plate backed by concrete

on one side and (b) plate backed by concrete on both sides

3.48 Time-frequency representation of data in Fig. 3.47

obtained by using short-time fourier transform (STFT)...

3.49 Illustration of mode conversion at the lateral boundaries of a finite-sized plate.....

3.50 MsS data using pulse-echo mode for steel plate prior to introducing a defect. Dotted lines indicate that signals continue to occur

3.51 Pulse-echo data for $40-\mathrm{kHz}$ S0 mode obtained from plate containing different length notches

3.52 Pulse-echo data for $20-\mathrm{kHz}$ A0 mode obtained from plate containing different length notches

3.53 Plots of signal amplitude versus notch length ...

3.54 Conceptual drawing of MsS system deployed for liner inspections

3.55 SH wave propagation mode where propagation is along $\mathrm{x}_{1}$ and particle displacements are along $\mathrm{x}_{3}$ 


\section{LIST OF FIGURES (CONT)}

Figure

Page

3.65 SH phase and group velocity dispersion curves for $10-\mathrm{mm}$-thick steel plate......................... 116

3.66 Reflection and transmission coefficients ........................................................................ 116

3.67 Reflection and transmission coefficients showing linear increase in amplitude with percent through-wall depth.

3.68 Reflection and transmission coefficients for 6.35 -mm elliptical defect width and either 10,30 or 50 percent through-plate thickness depth .

3.69 Reflection and transmission coefficients for 12.7-mm elliptical defect width and either 10,30 or 50 percent through-plate thickness depth......

3.70 Experimental setup

3.71 Through-transmission signal from 0.3 -mm-wide notch

10 percent through depth of 10 -mm-thick plate

3.72 Pulse-echo signal from 0.3 -mm-wide notch30 percent through depth of 10 -mm-thick plate..

3.73 Theoretical and experimental relative amplitude results for $12.7-\mathrm{mm}, 6.35-\mathrm{mm}$, and 0.3 -mm-wide notches of different depth in a 10 -mm-thick plate

3.74 Theoretical and experimental through-transmission signal amplitude versus through-plate flaw depth for 0.3 -mm-wide notch.

3.75 Theoretical and experimental pulse-echo signal amplitude versus through-plate flaw depth for 0.3 -mm-wide notch.

4.1 Steps to be taken in a repair process.................................. requiring welding repair due to corrosion.....

4.3 Items potentially affected by high-temperatures produced by repair or replacement welding.

4.4 Inaccessible area of a metal containment shell corroded to point that its structural capacity is no longer considered adequate and a repair is required.

4.5 Replacement plate repair welding technique

4.6 Doubler plate repair welding technique

4.7 Stiffener plate repair welding procedure.

4.8 Surface overlay repair welding technique.

4.9 Proposed non-code repairs for welds in ASME Class 3 stainless steel piping damaged by microbilogically-induced corrosion

4.10 Proposed non-code repair for welds at containment penetrations in ASME Class 3 stainless steel piping damaged by microbiologically-induced corrosion...

4.11 Repair technique used to replace drywell shell material removed by coring and restore leaktight integrity to the Oyster Creek containment ....

4.12 Conceptual view showing how four of eight stiffener rings would be installed on the outside surface of each bay of the Nine Mile Point Unit 1 torus

4.13 Cross-sectional view of the drywell liner repair performed inside the

Brunswick, Unit 1 concrete containment

4.14 Recommended anchor stud test section configuration...

4.15 Recommended embedment anchor test section configuration ............................................. 164

4.16 Recommended liner plate configuration ....................................................................... 164

4.17 Recommended liner plate repair welding technique .............................................................. 165

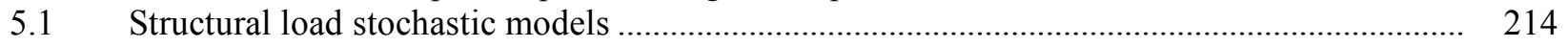

5.2 Sample functions representing structural loads and degrading resistance ............................. 214

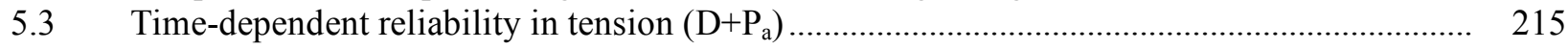

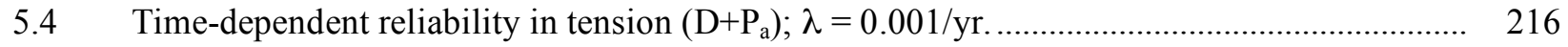

5.5 Time-dependent reliability in tension, with and without induction period for corrosion ......... 216 


\section{LIST OF FIGURES (CONT)}

Figure

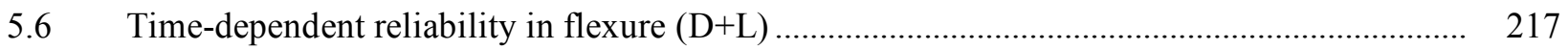

5.7 Time-dependent reliability in flexure, with and without induction period for corrosion ......... 217

$5.8 \quad$ Fragilities for progressive performance limits ..................................................................... 218

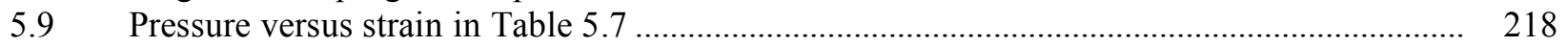

5.10 Benchmark fragility of steel ice condenser containment ....................................................... 219

5.11 Containment fragility for postulated corrosion patterns ......................................................... 219

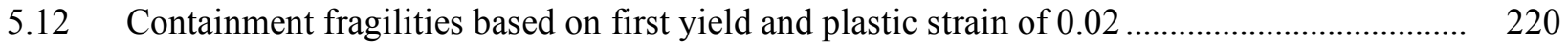

C.1 Scaling factors for approximate containment fragility analysis ............................................. 247 


\section{LIST OF TABLES}

Table

Page

1.1 Instances of containment pressure boundary component degradation at commercial nuclear power plants in the United States ....

1.2 Summary of metal and concrete containment pressure boundary

component degradation occurrences ....

Class indexes for containment steels

Material property code ranges and descriptions

42

Property codes for mechanical property values of containment steels.............................................. 43

Property codes for mechanical property graphs and plots for containment steels ............................... 43

General information property codes....

Steels used to construct metal and concrete containment pressure boundary components ..

Factors associated with pressure-retaining steel component degradation.

Elements of in-service condition assessments for metal and concrete

containment pressure boundary components

43

44

45

Accessible containment surface areas and pressure-retaining welds

that require visual examination

2.9 Containment surface areas that could experience

accelerated degradation and aging.....

Degradation mechanisms that can potentially cause material damage to

2.10

Types of general corrosion that can potentially cause physical damage

to containment pressure boundary components

2.12 Types of localized corrosion that can potentially cause physical damage

to containment pressure boundary components

2.13

2.14

2.15

physical damage to containment pressure boundary components..

Environmentally-induced and fatigue degradation mechanisms that potentially can cause

cracking of containment metallic pressure boundary components

Possible cyclic loads on containment metallic pressure boundary components.

3.1 Applicability and important material characteristics of

selected metallic materials NDE methods.

Dominant sources of variance of selected metallic materials NDE methods

Equipment used to aid visual inspection

Material properties used in OASES models

Piezoelectric sensor characteristics

Measured spreading loss values.

Material properties used for DISPERSE calculations.....

54

Reasons for replacement of nuclear power plant components....

Welding processes permitted by Code Case N-516 for underwater repairs

and replacements of P-No. 8 and P-No. 4X materials

166

Instantaneous cooling rates for bead-on-plate surface welds at a nominal

material temperature of $760 \mathrm{C}$

166

Ways in which welding induced high-temperature exposure can

Rules and requirements pertaining to high-temperature exposure of

Issues that need to be considered in a repair/replacement plan for welding repairs

of containment pressure boundary components backed by concrete.

Advantages and disadvantages of cathodic protection systems.

Basic components of a sacrificial anode cathodic protection system

Basic components of an impressed current cathodic protection system

4.9

4.10

Potential sources of stray electrical current at nuclear power plants.

171

Potential water sources and remedial actions taken to eliminate water from the sandbed at the Oyster Creek nuclear power plant. 


\section{LIST OF TABLES (cont.)}

Table

4.12 Recommended test section configurations for the liner plate

welding repair experimental investigation ............................................................................... 172

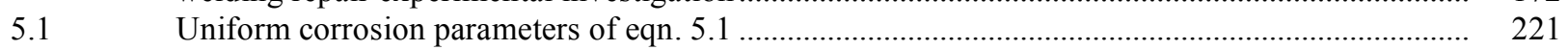

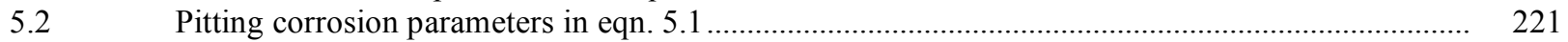

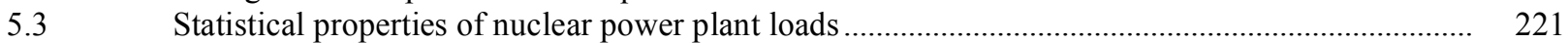

5.4 Initial resistance of steel shapes and plates ............................................................................. 222

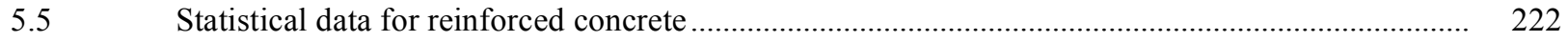

5.6 Measures of uncertainty in fragility assessment ............................................................................. 223

5.7 Latin hypercube samples (LHS) used in fragility analysis .............................................................. 223

$5.8 \quad$ Summary of IPE fragilities for undegraded containments ............................................................... 224

5.9 Fragilities for corroded steel ice-condenser containment ................................................................ 224 


\section{EXECUTIVE SUMMARY}

The Inspection of Aged/Degraded Containments Program had primary objectives of (1) understanding the significant factors relating corrosion occurrence, efficacy of inspection, and structural capacity reduction of steel containments and liners of reinforced concrete containments; (2) providing the United States Nuclear Regulatory Commission (USNRC) reviewers a means of establishing current structural capacity margins or estimating future residual structural capacity margins for steel containments, and concrete containments as limited by liner integrity; (3) providing recommendations, as appropriate, on information to be requested of licensees for guidance that could be utilized by USNRC reviewers in assessing the seriousness of reported incidences of containment degradation; and (4) providing technical assistance to the USNRC (as requested) related to concrete technology.

Primary program accomplishments have included development of a degradation assessment methodology; reviews of techniques and methods for inspection and repair of containment metallic pressure boundaries; evaluation of high-frequency acoustic imaging, magnetostrictive sensor, electromagnetic acoustic transducer, and multimode guided plate wave technologies for inspection of inaccessible regions of containment metallic pressure boundaries; development of a continuum damage mechanics-based approach for structural deterioration; establishment of a methodology for reliability-based condition assessments of steel containments and liners; and fragility assessments of steel containments with localized corrosion. In addition, data and information assembled under this program has been transferred to the technical community through review meetings and briefings, national and international conference participation, technical committee involvement, and publications of reports and journal articles. Appendix A provides a listing of program reports, papers, and publications; and Appendix B contains a listing of program-related presentations. 


\section{ACKNOWLEDGMENTS}

The authors would like to acknowledge the continuing support and guidance throughout the program provided by the U.S. Nuclear Regulatory Commission Technical Monitors, Mr. Wallace E. Norris and Mr. Herman L. Graves, III. Appreciation is also extended to the organizations that participated in the program through subcontracted activities: Cambridge Acoustical Associates (Cambridge, Mass.), Johns Hopkins University (Baltimore, Mary.), Southwest Research Institute (San Antonio, Tex.), and The Pennsylvania State University, University Park, Penn.).

\section{DISCLAIMER}

Research sponsored by the Office of Nuclear Regulatory Research, U.S. Nuclear Regulatory Commission, under Interagency Agreement 1886-N604-3J with the U.S. Department of Energy under Contract No. DEAC05-00OR22725.

This report was prepared as an account of work sponsored by an agency of the U.S. Government. Neither the United States Government nor any agency thereof, or any of their employees, makes any warranty, expressed or implied, or assumes any legal liability or responsibility for any third party's use, or the results of such use, of any information, apparatus, product or process disclosed in this report, or represents that its use by such third party would not infringe privately owned rights. 


\section{INTRODUCTION}

\subsection{BACKGROUND}

Nuclear power provides in excess of 20 percent of the net electricity generation in the United States. In 2002 about $25 \%$ of the 103 nuclear power plants (NPPs) that have been licensed for commercial operation are less than 20 years old, with over one-third of the plants being over 30 years old (1.1). Starting in 2006, the first of these plants is scheduled to reach the end of its initial 40-year operating license period. By 2010 ten percent of the plants will reach the end of their initial operating license period with this number rising to forty percent by 2015. Faced with the prospect of having to replace the lost generating capacity from other sources and the potential for substantial shutdown and decommissioning costs, many utilities are expected to seek extensions to their initial plant operating licenses. In fact this is what is happening. As of July 2004, 44 plants have either been through the license renewal process or submitted an application to renew their operating license for an additional 20 years, and 30 additional plants have announced that they intend to do so.

The importance of nuclear power and the necessity for ensuring continued satisfactory operation is thus clearly established. One of the primary factors that could affect the continued operation and development of nuclear power relates to aging of the plants and its potential impact on performance. Nuclear power plants are designed, built, and operated to standards that aim to reduce the releases of radioactive materials to levels as low as reasonably achievable. Nuclear power plants, however, involve complex engineering structures and components operating in demanding environments that potentially can challenge the high level of safety (i.e., safety margins) required throughout the operating life of the plant. It is necessary that safety issues related to plant aging and continuing the service of the nuclear plants are resolved through development of sound scientific and engineering understanding. One specific area that has been noted is the aging behavior of structural materials - particularly those in pressure-retaining structures. Although major mechanical and electrical equipment items in a plant could be replaced, if necessary, replacement of many of the safety-related structural components would be economically unfeasible. Approval for a continuation of service must be supported by evidence that these structures will continue to be capable of withstanding potential future extreme events.

\subsection{CONTAINMENT STRUCTURES}

From a safety standpoint, the containment is one of the most important components of a nuclear power plant because it serves as the final barrier to the release of fission products to the outside environment under postulated accident conditions. Ensuring that the structural capacity and leak-tight integrity of the containment has not deteriorated unacceptably due either to aging or environmental stressor effects is essential to reliable continued service evaluations and informed aging management decisions.

\subsubsection{General Description}

Each boiling-water reactor (BWR) or pressurized-water reactor (PWR) unit in the US is located within a much larger metal or concrete containment that also houses or supports the primary coolant system components. Although the shapes and configurations of the containment can vary significantly from plant-to-plant, leak-tightness is assured by a continuous pressure boundary consisting of nonmetallic seals and gaskets, and metallic components that are either welded or bolted together. There are several Code of Federal Regulations (CFR) (1.2) General Design Criteria (GDC) and American Society of Mechanical Engineers (ASME) Code sections that establish minimum requirements for the design, fabrication, construction, testing, and performance of containment structures. The GDC serve as fundamental underpinnings for many of the most important safety commitments in licensee design and licensing bases. General Design Criterion 16, "Containment Design," requires the provision of reactor containment and associated systems to establish an essentially leak-tight barrier against the uncontrolled release of radioactivity into the environment and to ensure that the containment design conditions important to safety are not exceeded for as long as required for postulated accident conditions. Criterion 53, "Provisions for Containment Testing and Inspection," requires that the reactor containment be designed to permit: (1) appropriate periodic inspection of all important areas, such as penetrations; (2) an appropriate surveillance program; and (3) periodic testing at containment design pressure of leak-tightness of penetrations that have resilient seals and expansion bellows.

Prior to 1963, metal containments for nuclear power plants were designed according to rules for unfired pressure vessels that were provided by the ASME in Section VIII of the ASME Code (1.3). Subsequent metal containments were designed either as Class B vessels or as Class MC components according to rules provided in Section III of the ASME 
Code (1.4). Almost every aspect of metal containment design is addressed by the Code. The Code also recognizes that service-related degradation to pressure retaining components is possible, but rules for material selection and in-service degradation are outside its scope. It is the Owner's responsibility to select materials suitable for the service conditions and to increase minimum required thickness of the base metal to offset material thinning due to corrosion, erosion, mechanical abrasion, or other environmental effects. Current rules for construction of metal containments are provided in Section III, Division 1, Subsection NE of the ASME Code. Currently operating metal containments are freestanding, welded steel structures that are enclosed in a reinforced concrete reactor or shield building. The reactor or shield buildings are not part of the pressure boundary and their primary function is to provide protection for the containment from external missiles and natural phenomena (e.g., tornadoes or site-specific environmental events). Thirty-two of the NPPs licensed for commercial operation in the US employ a metal containment.

Concrete containments are metal lined, reinforced concrete pressure-retaining structures that in some cases may be posttensioned. The concrete vessel includes the concrete shell and shell components, shell metallic liners, and penetration liners that extend the containment liner through the surrounding shell concrete. The reinforced concrete shell, which generally consists of a cylindrical wall with a hemispherical or ellipsoidal dome and flat base slab, provides the necessary structural support and resistance to pressure-induced forces. Leak-tightness is provided by a steel liner fabricated from relatively thin plate material (e.g., 6-mm thick) that is anchored to the concrete shell by studs, structural steel shapes, or other steel products. Initially, existing building codes, such as American Concrete Institute (ACI) Standard 318, Building Code Requirements for Reinforced Concrete (1.5), were used in the nuclear industry as the basis for design and construction of concrete structural members. However, because the existing building codes did not cover the entire spectrum of design requirements and because they were not always considered adequate, the USNRC developed its own criteria for design of seismic Category 1 (i.e., safety related) structures (e.g., definitions of load combinations for both operating and accident conditions). Plants that used early ACI codes for design were reviewed by the USNRC through the Systematic Evaluation Program to determine if there were any unresolved safety concerns (1.6). Current rules for construction of concrete containments are provided in Section III, Division 2 of the ASME Code. The USNRC has developed supplemental load combination criteria and provides information related to concrete and steel internal structures of steel and concrete containments $(1.7,1.8)$. Rules for design and construction of the metal liner that forms the pressure boundary for the reinforced concrete containments are found in ASME Section III, Division 1, Subsection NE of the ASME Code. Seventy-one of the NPPs licensed for commercial operation in the US employ either a reinforced concrete (34 plants) or post-tensioned concrete (37 plants) containment.

\subsubsection{Potential Degradation Factors}

Service-related degradation can affect the ability of a nuclear power plant containment to perform satisfactorily in the unlikely event of a severe accident by reducing its structural capacity or jeopardizing its leak-tight integrity. Degradation is considered to be any phenomenon that decreases the load-carrying capacity of a containment, limits its ability to contain a fluid medium, or reduces the service life. The root cause for containment degradation can generally be linked to a design or construction problem, inappropriate material application, a base-metal or weld-metal flaw, maintenance or inspection activities, or excessively severe service conditions.

Steel containment degradation can be classified as either material or physical damage. Material damage occurs when the microstructure of the metal is modified causing changes in its mechanical properties. Degradation mechanisms that can potentially cause material damage to containment steels include (1) low-temperature exposure, (2) high-temperature exposure, (3) intergranular corrosion, (4) dealloying corrosion, (5) hydrogen embrittlement, and (6) neutron irradiation. Material damage to the containment pressure boundary from any of these sources is not considered likely, however. Physical damage occurs when the geometry of a component is altered by the formation of cracks, fissures, or voids, or its dimensions change due to overload, buckling, corrosion, erosion, or formation of other types of surface flaws. Changes in component geometry, such as wall thinning or pitting caused by corrosion, can affect structural capacity by reducing the net section available to resist applied loads. In addition, pits that completely penetrate the component can compromise the leak-tight integrity of the component. Primary degradation mechanisms that potentially can cause physical damage to containment pressure boundary components include (1) general corrosion (atmospheric, aqueous, galvanic, stray-electrical current, and general biological); (2) localized corrosion (filiform, crevice, pitting, and localized biological); (3) mechanically-assisted degradation (erosion, fretting, cavitation, corrosion fatigue, surface flaws, arc strikes, and overload conditions); (4) environmentally-induced cracking (stress-corrosion and hydrogen-induced); and (5)

fatigue. Material degradation due to either general or pitting corrosion represents the greatest potential threat to the containment pressure boundary. 
Primary mechanisms that can produce premature deterioration of reinforced concrete structures include those that impact either the concrete or steel reinforcing materials (i.e., mild steel reinforcement or post-tensioning system). Degradation of concrete can be caused by adverse performance of either its cement-paste matrix or aggregate materials under chemical or physical attack. Chemical attack may occur in several forms: efflorescence or leaching; attack by sulfate, acids, or bases; salt crystallization; and alkali-aggregate reactions. Physical attack mechanisms for concrete include freeze/thaw cycling, thermal expansion/thermal cycling, abrasion/erosion/cavitation, irradiation, and fatigue or vibration. Degradation of mild steel reinforcing materials can occur as a result of corrosion, irradiation, elevated temperature, or fatigue effects. Post-tensioning systems are susceptible to the same degradation mechanisms as mild steel reinforcement plus loss of prestressing force, primarily due to tendon relaxation and concrete creep and shrinkage. Degradation of the concrete materials and structures was addressed under the Structural Aging Program (1.9).

\subsection{OPERATING EXPERIENCE}

As nuclear plant containments age, degradation incidences are starting to occur at an increasing rate, primarily due to environmental-related factors. There have been at least 66 separate occurrences of degradation in operating containments (some plants may have more than one occurrence of degradation). One-fourth of all containments have experienced corrosion, and nearly half of the concrete containments have reported degradation related to either the reinforced concrete or post-tensioning system (1.10).

Since 1986, there have been over 36 reported occurrences of corrosion of steel containments or liners of reinforced concrete containments. In two cases, thickness measurements of the walls of steel containments revealed areas that were below the minimum design thickness. Two instances have been reported where corrosion has completely penetrated the liner of reinforced concrete containments. There have been four additional cases where extensive corrosion of the liner has reduced the thickness locally by nearly one-half (1.10). Only four of the reported degradation occurrences were detected through containment inspection programs prior to Type A leakage-rate testing conducted according to requirements in effect at the time [i.e., preadoption by reference of basic requirements in Subsection IWE (1.11)]. Nine of these occurrences were first identified by the USNRC through its inspections or audits of plant structures. Eleven occurrences were detected by licensees while performing an unrelated activity, or after they were alerted to a degraded condition at another site. Examples of problems identified include corrosion of the steel containment shell in the drywell sand cushion region (Oyster Creek), shell corrosion in ice condenser plants (Catawba and McGuire), corrosion of the torus of the steel containment shell (Fitzpatrick, Cooper, and Nine Mile Point Unit 1), coating degradation (Dresden 3, Fitzpatrick, Millstone 1, Oyster Creek, Pilgrim, and H. B. Robinson), and concrete containment liner corrosion (Brunswick, Beaver Valley, North Anna 2, Brunswick 2, and Salem). Also there have been incidences of transgranular stress corrosion cracking in bellows (Quad Cities 1 and 2, and Dresden 3). Table 1.1 presents a listing of reported instances of containment pressure boundary degradation at commercial nuclear power plants in the U.S as of 2003. A summary of metal and concrete containment pressure boundary-related component degradation occurrences grouped by type degradation and component affected is provided in Table 1.2.

\subsection{OBJECTIVE AND POTENTIAL APPLICATION OF RESULTS}

The Inspection of Aged/Degraded Containments Program has primary objectives of (1) understanding the significant factors relating corrosion occurrence, efficacy of inspection, and structural capacity reduction of steel containments and liners of concrete containments; (2) providing the USNRC reviewers a means of establishing current structural capacity margins or estimating future residual structural capacity margins for steel containments, and concrete containments as limited by liner integrity; (3) providing recommendations, as appropriate, on information to be requested of licensees for guidance that could be utilized by USNRC reviewers in assessing the seriousness of reported incidences of containment degradation; and (4) providing technical assistance to the USNRC (as requested) related to concrete technology. The results of this study will provide an improved basis for the USNRC staff to evaluate nuclear power plants for continued service. More specifically, potential regulatory applications of this research include (1) improved predictions of longterm material and structural performance and available safety margins at future times, (2) establishment of limits on exposure to environmental stressors, (3) reduction in total reliance by licensing on inspection and surveillance through development of a methodology that will enable the integrity of structures to be assessed (either pre- or post-accident), and (4) improvements in damage inspection methodology through potential incorporation of program results into national standards that could be referenced by Standard Review Plans. 


\subsection{REFERENCES}

$1.1 \quad$ U.S. Nuclear Regulatory Commission, Information Digest, NUREG-1350, Vol. 14, Division of Budget and Analysis, Office of the Chief Financial Officer, Washington, D.C., 1995.

1.2 Code of Federal Regulations, Title 10-Energy, Office of the Federal Register, National Archives and Records Administration, Washington, DC, January 1, 1995.

1.3 American Society of Mechanical Engineers, "Rules for Construction of Unfired Pressure Vessels," $A S M E$ Boiler and Pressure Vessel Code, Sect. VIII, New York, New York, 1965.

1.4 American Society of Mechanical Engineers, "Rules for Construction of Nuclear Power Plant Components," ASME Boiler and Pressure Vessel Code, Sect. III, New York, New York, 1998.

1.5 American Concrete Institute, Building Code Requirements for Reinforced Concrete, ACI Standard 318-71, ACI Committee 318, Detroit, Michigan, 1971.

1.6 "Containment Integrity of SEP Plants Under Combined Loads," in Proceedings of the ASCE Conference on Structural Engineering in Nuclear Facilities, J. Ucciferro (ed.), American Society of Civil Engineers, New York, New York, 1984.

1.7 U.S. Nuclear Regulatory Commission, "Concrete Containment," Sect. 3.8.1 in Regulatory Standard Review Plan, NUREG-0800, Directorate of Licensing, Washington, D.C., 1981.

$1.8 \quad$ U.S. Nuclear Regulatory Commission, "Concrete and Steel Internal Structures of Steel and Concrete Containments," Sect. 3.8.3 in Regulatory Standard Review Plan, NUREG-0800, Directorate of Licensing, Washington, DC, 1981.

1.9 D. J. Naus, C. B. Oland and B. R. Ellingwood, Report on Aging of Nuclear Power Plant Concrete Structures, NUREG/CR-6424 (ORNL/TM-13148), Lockheed Martin Energy Research Corporation, Oak Ridge National Laboratory, Oak Ridge, Tennessee, 1996.

1.10 U.S. Nuclear Regulatory Commission, Issuance of Final Amendment to 10 CFR $\$ 50.55$ a to Incorporate by Reference the ASME Boiler and Pressure Vessel Code (ASME Code), Section XI, Subsection IWL, SECY 96080, Washington, D.C., 1996

1.11 American Society of Mechanical Engineers, "Rules for Inservice Inspection of Nuclear Power Plant Components," ASME Boiler and Pressure Vessel Code, Section XI, Subsection IWE, Requirements for Class $\mathrm{MC}$ and Metallic Liners of Class CC Components of Light-Water Cooled Power Plants, American Society of Mechanical Engineers, New York, New York, 1995.

1.12 Examination of Mark-1 Containment Torus Welds, U.S. Nuclear Regulatory Commission, Office of Inspection and Enforcement, IE Bulletin 78-11, pp. 1-3, July 24, 1978.

1.13 Cracks in Boiling Water Reactor Mark I Containment Vent Headers, U.S. Nuclear Regulatory Commission, Office of Inspection and Enforcement, IE Bulletin No. 84-01, February 3, 1984, pp. 1-2.

1.14 Problems with Liquid Nitrogen Cooling Components Below the Nil Ductility Temperature, U.S. Nuclear Regulatory Commission, Office of Inspection and Enforcement, IE Information Notice No. 84-17, March 5, 1984, pp. 1-2.

1.15 Cracking in Boiling-Water-Reactor Mark I and Mark II Containments Caused by Failure of the Inerting System, U.S. Nuclear Regulatory Commission, Office of Inspection and Enforcement, IE Information Notice No. 85-99 including Attachment 1, December 31, 1985, pp. 1-3. 
1.16 Shah, V. N. and MacDonald, P. E., Eds., Residual Life Assessment of Major Light Water Reactor Components - Overview, NUREG/CR-4731 (EGG-2469), Vol. 2, Idaho National Engineering Laboratory, Idaho Fall, Idaho, November 1989.

1.17 Fire in Compressible Material at Dresden Unit 3, U.S. Nuclear Regulatory Commission, Office of Inspection and Enforcement, IE Information Notice No. 86-35, May 15, 1986, pp. 1-2.

1.18 Degradation of Steel Containments, U.S. Nuclear Regulatory Commission, Office of Inspection and Enforcement, IE Information Notice No. 86-99 including Attachment 1, December 8, 1986, pp. 1-3.

1.19 Generic Letter 87-05, U.S. Nuclear Regulatory Commission To All Licensees of Operating Reactors, Applicants for Operating Licenses, and Holders of Construction Permits for Boiling Water Reactors (BWRs) with Mark I Containments, Subject: Request for Additional Information-Assessment of Licensee Measures to Mitigate and/or Identify Potential Degradation of Mark I Drywells, March 12, 1987, pp. 1-8.

1.20 U.S. Nuclear Regulatory Commission, Docket No. 50-219, August 2, 1991, Summary of July 24, 1991 Meeting with GPU Nuclear Corporation (GPUN) to Discuss Matters Related to Oyster Creek Drywell Corrosion and Containment Reliability, (Fishe 58722, Frame 320 to Fishe 58723, Frame 039).

1.21 Survey of Licensees for Torus Coating and Surveillance, letter dated May 19, 1988, from J. P. Durr, Chief, Engineering Branch, Region I, U.S. Nuclear Regulatory Commission, to G. Bagchi, Chief, Structural and Geosciences Branch, Office of Nuclear Reactor Regulation, U.S. Nuclear Regulatory Commission, Washington, DC.

1.22 NRC Inspection Report Nos. 50-325/93-02 and 50-324/93-02, Brunswick Units 1 and 2, March 4, 1993 , U.S. Nuclear Regulatory Commission, Region II, Atlanta, Georgia.

1.23 Torus Shells with Corrosion and Degraded Coatings in BWR Containments, U.S. Nuclear Regulatory Commission, Office of Inspection and Enforcement, IE Information Notice No. 88-82, October 14, 1988, pp. 1-2.

1.24 Heat Damage to Upper Elevation Drywell Components Due to Closed Ventilation Hatches, Dresden Nuclear Station, Unit 2, Licensee Event Report (LER) 88-022-02, Docket No. 50-237, December 13, 1988, pp. 1-28.

1.25 Bent Anchor Bolts in Boiling Water Reactor Torus Supports, U.S. Nuclear Regulatory Commission, Office of Inspection and Enforcement, IE Information Notice No. 89-06, January 24, 1989, pp. 1-2.

1.26 Degraded Coatings and Corrosion of Steel Containment Vessels, U.S. Nuclear Regulatory Commission, Office of Nuclear Reactor Regulation, IE Information Notice No. 89-79, December 1, 1989, pp. 1-3.

1.27 Abnormal Degradation of Steel Containment Vessels Due to Corrosion Caused by Standing Water in the Annulus Area, Catawba Nuclear Station, Unit 1, Licensee Event Report (LER) 89-020-00, Docket No. 50-413, January 9, 1990, pp. 1-5.

1.28 Abnormal Degradation of Steel Containment Vessels Due to Corrosion Caused by Standing Water in the Annulus Area Because of Unknown Causes, McGuire Nuclear Station, Unit 1, Licensee Event Report (LER) 89-020-00, Docket No. 50-369, September 25, 1989, pp. 1-9.

1.29 Degraded Coatings and Corrosion of Steel Containment Vessels, U.S. Nuclear Regulatory Commission, Office of Nuclear Reactor Regulation, NRC Information Notice No. 89-79, Supplement 1, June 29, 1990, pp. 1-2.

1.30 Corrosion Occurred on the Steel Containment Vessel because of Design Deficiency Caused by Unanticipated Environmental Interactions, McGuire Nuclear Station, Unit 1, Licensee Event Report (LER) 90-006-00, Docket No. 50-369, May 30, 1990, pp. 1-9. 
1.31 Quad Cities Nuclear Power Station Unit 1 and 2, 10 CFR Part 21 Notification, letter dated March 27, 1991, from T. J. Kovach, Nuclear Licensing Manager, Commonwealth Edison, to A. B. Davis, Regional Administrator, U.S. Nuclear Regulatory Commission, Lisle, Illinois.

1.32 Quad Cities Nuclear Power Station Unit 1, Primary Containment Penetration Bellows Assembly, letter dated April 19, 1991, from R. Stols, Nuclear Licensing Administrator, Commonwealth Edison, to T. E. Murley, Director, Office of Nuclear Reactor Regulation, U.S. Nuclear Regulatory Commission, Washington, DC.

1.33 Ashar, H and Bagchi, G., Assessment of Inservice Conditions of Safety-Related Nuclear Plant Structures, NUREG-1522, U.S. Nuclear Regulatory Commission, Washington, DC, July 1995.

1.34 Beaver Valley Power Station Trip Report; Assessment of Structures and Civil Engineering Features at Operating Plants; FIN L-1521, Task Assignment No. 6, letter dated July 24, 1992, from J. Braverman, Engineering Research and Applications Division, Brookhaven National Laboratory Associated Universities, Inc., to H. Polk, U.S. Nuclear Regulatory Commission, Washington, DC.

1.35 Ninety-Day Containment Integrated Leak Rate Report, Ninth Refueling Outage, Salem Generating Station, Unit No. 1, Docket No. 50-272, letter dated July 3, 1991, from S. LaBruna, Vice President Nuclear Operations, Public Service Electric and Gas Company, to Document Control Desk, U.S. Nuclear Regulatory Commission, Washington, DC.

1.36 NRC Inspection Report Nos. 50-327/93-52 and 50-328/93-52, Sequoyah Units 1 and 2, December 23, 1993, U.S. Nuclear Regulatory Commission, Region II, Atlanta, Georgia.

1.37 NRC Inspection Report Nos. 50-325/93-31 and 50-324/93-31, Brunswick Units 1 and 2, September 28, 1993, U.S. Nuclear Regulatory Commission, Region II, Atlanta, Georgia.

1.38 McGuire Nuclear Station, Units 1 and 2, Proposed Technical Specification Change, letter dated June 23, 1993, from T. C. McMeekin, Duke Power Company, to Document Control Desk, U.S. Nuclear Regulatory Commission, Washington, DC.

1.39 Integrated Leak Rate Test Report for Braidwood 1, March 4 to April 22, 1994, Commonwealth Edison provided ILRT report to the U.S. Nuclear Regulatory Commission, Washington, DC.

1.40 Docket No. 50-330, North Anna-2, Virginia Power, Richmond, Virginia, 1999.

1.41 Docket No. 50-324, Brunswick-2, Carolina Power \& Light Co., Raleigh, North Carolina, April, 27, 1999. 
Table 1.1 Instances of containment pressure boundary component degradation at commercial nuclear power plants in the United States.

\begin{tabular}{|c|c|c|c|}
\hline $\begin{array}{l}\text { Plant Designation } \\
\text { (Occurrence Date) } \\
\text { Plant Type } \\
\text { (Source) }\end{array}$ & $\begin{array}{l}\text { Containment } \\
\text { Description } \\
\text { (No. of Similar } \\
\text { Plants) }\end{array}$ & $\begin{array}{l}\text { Degradation } \\
\text { Description }\end{array}$ & $\begin{array}{l}\text { Detection } \\
\text { Method }\end{array}$ \\
\hline $\begin{array}{c}\text { Vermont Yankee } \\
(1978) \\
\text { BWR/4 } \\
\text { (Ref. 1.12) } \\
\end{array}$ & $\begin{array}{c}\text { Mark I } \\
\text { Steel drywell } \\
\text { and wetwell } \\
(22) \\
\end{array}$ & $\begin{array}{l}\text { Surface cracks in the overlay } \\
\text { weld-to-torus base metal heat- } \\
\text { affected zone }\end{array}$ & $\begin{array}{l}\text { Visual examination } \\
\text { (As part of modifications to } \\
\text { restore the originally intended } \\
\text { design safety margins) }\end{array}$ \\
\hline $\begin{array}{c}\text { Hatch } 2 \\
(1984) \\
\text { BWR/4 } \\
\text { (Refs. 1.13, } \\
1.14 \text {, and 1.15) }\end{array}$ & $\begin{array}{c}\text { Mark I } \\
\text { Steel drywell } \\
\text { and wetwell } \\
(22)\end{array}$ & $\begin{array}{l}\text { Through-wall cracks around } \\
\text { containment vent headers within } \\
\text { the containment torus (Brittle } \\
\text { fracture caused by injection of } \\
\text { cold nitrogen into torus during } \\
\text { inerting) }\end{array}$ & $\begin{array}{l}\text { Visual examination of torus } \\
\text { interior }\end{array}$ \\
\hline $\begin{array}{c}\text { Hatch } 1 \\
(1985) \\
\text { BWR/4 } \\
\text { (Ref. 1.15) } \\
\end{array}$ & $\begin{array}{c}\text { Mark I } \\
\text { Steel drywell } \\
\text { and wetwell } \\
(22) \\
\end{array}$ & $\begin{array}{l}\text { Through-wall crack in nitrogen } \\
\text { inerting and purge line (Brittle } \\
\text { fracture caused by injection of } \\
\text { cold nitrogen during inerting) }\end{array}$ & $\begin{array}{l}\text { In-service inspection testing using } \\
\text { magnetic particle method }\end{array}$ \\
\hline $\begin{array}{l}\text { Monticello } \\
(1986) \\
\text { BWR/3 } \\
\text { (Ref. 1.16) } \\
\end{array}$ & $\begin{array}{c}\text { Mark I } \\
\text { Steel drywell } \\
\text { and wetwell } \\
(22) \\
\end{array}$ & $\begin{array}{l}\text { Polysulfide seal at the concrete- } \\
\text { to-shell interface became brittle } \\
\text { allowing moisture to reach the } \\
\text { steel shell }\end{array}$ & $\begin{array}{l}\text { Visual examination } \\
\text { (A small portion of the drywell } \\
\text { shell was excavated as a part of a } \\
\text { life extension study) }\end{array}$ \\
\hline $\begin{array}{c}\text { Dresden } 3 \\
(1986) \\
\text { BWR/3 } \\
\text { (Ref. 1.17) }\end{array}$ & $\begin{array}{c}\text { Mark I } \\
\text { Steel drywell } \\
\text { and wetwell } \\
(22)\end{array}$ & $\begin{array}{l}\text { Coating degradation due to } \\
\text { exposure to fire with peak metal } \\
\text { temperatures of } 260^{\circ} \mathrm{C}\left(500^{\circ} \mathrm{F}\right) \\
\text { and general corrosion of metal } \\
\text { shell by water used to extinguish } \\
\text { fire }\end{array}$ & $\begin{array}{l}\text { Visual examination } \\
\text { (Polyurethane between the } \\
\text { drywell shell and concrete shield } \\
\text { wall was ignited by arc-air cutting } \\
\text { activities producing smoke and } \\
\text { heat) }\end{array}$ \\
\hline $\begin{array}{c}\text { Oyster Creek } \\
(1986) \\
\text { BWR/2 } \\
\text { (Refs. 1.18, } \\
1.19, \text { and } 1.20) \\
\end{array}$ & $\begin{array}{c}\text { Mark I } \\
\text { Steel drywell } \\
\text { and wetwell } \\
(22)\end{array}$ & $\begin{array}{l}\text { Defective gasket at the refueling } \\
\text { pool allowed water to eventually } \\
\text { reach the sand cushion region } \\
\text { causing drywell shell corrosion }\end{array}$ & $\begin{array}{l}\text { Visual examination of uncoated } \\
\text { areas and ultrasonic inspection }\end{array}$ \\
\hline \begin{tabular}{|c|} 
Fitzpatrick \\
(1987) \\
BWR/4 \\
(Refs. 1.16 and 1.21)
\end{tabular} & $\begin{array}{c}\text { Mark I } \\
\text { Steel drywell } \\
\text { and wetwell } \\
(22)\end{array}$ & $\begin{array}{l}\text { Degradation of torus coating with } \\
\text { associated pitting }\end{array}$ & $\begin{array}{l}\text { Visual examination of uncoated } \\
\text { areas and ultrasonic inspection } \\
\text { (Technical specification } \\
\text { surveillance performed during } \\
\text { outage) }\end{array}$ \\
\hline $\begin{array}{l}\text { Millstone 1 } \\
(1987) \\
\text { BWR/3 } \\
\text { (Ref. 1.21) } \\
\end{array}$ & $\begin{array}{c}\text { Mark I } \\
\text { Steel drywell } \\
\text { and wetwell } \\
(22) \\
\end{array}$ & Degradation of torus coating & $\begin{array}{l}\text { Visual examination of uncoated } \\
\text { areas and ultrasonic inspection } \\
\text { (The torus had been drained for } \\
\text { modifications) }\end{array}$ \\
\hline $\begin{array}{c}\text { Oyster Creek } \\
(1987) \\
\text { BWR/2 } \\
\text { (Ref. 1.21) } \\
\end{array}$ & $\begin{array}{c}\text { Mark I } \\
\text { Steel drywell } \\
\text { and wetwell } \\
(22)\end{array}$ & $\begin{array}{l}\text { Degradation of torus coating with } \\
\text { associated pitting }\end{array}$ & $\begin{array}{l}\text { Visual examination of uncoated } \\
\text { areas and ultrasonic inspection }\end{array}$ \\
\hline
\end{tabular}


Table 1.1 Instances of containment pressure boundary component degradation at commercial nuclear power plants in the United States (cont.).

\begin{tabular}{|c|c|c|c|}
\hline $\begin{array}{l}\text { Plant Designation } \\
\text { (Occurrence Date) } \\
\text { Plant Type } \\
\text { (Source)* }\end{array}$ & $\begin{array}{l}\text { Containment } \\
\text { Description } \\
\text { (No. of Similar } \\
\text { Plants) }\end{array}$ & $\begin{array}{l}\text { Degradation } \\
\text { Description }\end{array}$ & $\begin{array}{l}\text { Detection } \\
\text { Method }\end{array}$ \\
\hline $\begin{array}{c}\text { Brunswick 1 } \\
(1987) \\
\text { BWR/4 } \\
\text { (Ref. 1.22) } \\
\end{array}$ & $\begin{array}{l}\text { Reinforced concrete } \\
\text { with steel liner } \\
\text { (9) }\end{array}$ & Corrosion of steel liner & $\begin{array}{l}\text { General visual examination of } \\
\text { coated areas }\end{array}$ \\
\hline $\begin{array}{c}\text { Nine Mile Point } 1 \\
(1988) \\
\text { BWR/5 } \\
\text { (Ref. 1.23) } \\
\end{array}$ & $\begin{array}{l}\text { Steel drywell } \\
\text { and wetwell } \\
(22)\end{array}$ & $\begin{array}{l}\text { Corrosion of uncoated torus } \\
\text { surfaces }\end{array}$ & $\begin{array}{l}\text { Visual examination of uncoated } \\
\text { areas and ultrasonic inspection }\end{array}$ \\
\hline $\begin{array}{c}\text { Pilgrim } \\
(1988) \\
\text { BWR/3 } \\
\text { (Ref. } 1.21) \\
\end{array}$ & $\begin{array}{l}\text { Steel drywell } \\
\text { and wetwell } \\
\text { (22) }\end{array}$ & Degradation of torus coating & $\begin{array}{l}\text { Visual examination of uncoated } \\
\text { areas and ultrasonic inspection } \\
\text { (Licensee inspection as a result of } \\
\text { occurrences at similar plants) }\end{array}$ \\
\hline $\begin{array}{c}\text { Brunswick } 2 \\
(1988) \\
\text { BWR/4 } \\
\text { (Ref. 1.22) } \\
\end{array}$ & $\begin{array}{l}\text { Reinforced concrete } \\
\text { with steel liner } \\
\text { (9) }\end{array}$ & Corrosion of steel liner & $\begin{array}{l}\text { General visual examination of } \\
\text { coated areas }\end{array}$ \\
\hline $\begin{array}{c}\text { Dresden } 2 \\
(1988) \\
\text { BWR/3 } \\
\text { (Ref. } 1.24)\end{array}$ & $\begin{array}{l}\text { Steel drywell } \\
\text { and wetwell } \\
(22)\end{array}$ & $\begin{array}{l}\text { Coating, electrical cable, and } \\
\text { valve operator component } \\
\text { degradation due to excessive } \\
\text { operating temperatures }\end{array}$ & $\begin{array}{l}\text { Visual examination of uncoated } \\
\text { areas and ultrasonic inspection } \\
\text { (Ventilation hatches in the } \\
\text { drywell refueling bulkhead } \\
\text { inadvertently left closed) }\end{array}$ \\
\hline $\begin{array}{l}\text { Hatch } 1 \text { and } 2 \\
\text { (1989) } \\
\text { BWR/4 } \\
\text { (Ref. 1.25) } \\
\end{array}$ & $\begin{array}{l}\text { Steel drywell } \\
\text { and wetwell } \\
\text { (22) }\end{array}$ & $\begin{array}{l}\text { Bent anchor bolts in torus } \\
\text { supports (due to weld induced } \\
\text { radial shrinkage) }\end{array}$ & Visual examination \\
\hline $\begin{array}{c}\text { McGuire } 2 \\
\text { (1989) } \\
\text { PWR } \\
\text { (Ref. 1.26) }\end{array}$ & $\begin{array}{c}\text { Ice Condenser } \\
\text { Reinforced concrete } \\
\text { with steel liner } \\
(4)\end{array}$ & $\begin{array}{l}\text { Corrosion on outside of steel } \\
\text { cylinder in the annular region at } \\
\text { the intersection with the concrete } \\
\text { floor }\end{array}$ & $\begin{array}{l}\text { General visual examination } \\
\text { prior to Type A leakage rate test }\end{array}$ \\
\hline $\begin{array}{l}\text { McGuire 1 } \\
\text { (1989) } \\
\text { PWR } \\
\text { (Ref. 1.26) } \\
\end{array}$ & $\begin{array}{c}\text { Ice Condenser } \\
\text { Reinforced concrete } \\
\text { with steel liner } \\
(4) \\
\end{array}$ & $\begin{array}{l}\text { Corrosion on outside of steel } \\
\text { cylinder in the annular region at } \\
\text { the intersection with the concrete } \\
\text { floor }\end{array}$ & $\begin{array}{l}\text { General visual examination } \\
\text { (Inspection initiated as a result of } \\
\text { corrosion detected } \\
\text { at McGuire 2) }\end{array}$ \\
\hline $\begin{array}{c}\text { Catawba 1 } \\
(1989) \\
\text { PWR } \\
\text { (Refs. } 1.26 \text { and 1.27) } \\
\end{array}$ & $\begin{array}{l}\text { Ice Condenser } \\
\text { Steel cylinder } \\
\text { (5) }\end{array}$ & $\begin{array}{l}\text { Corrosion on outside of steel } \\
\text { cylinder in the annular region }\end{array}$ & $\begin{array}{l}\text { General visual examination } \\
\text { (Inspection initiated as a result of } \\
\text { corrosion detected } \\
\text { at McGuire 2) }\end{array}$ \\
\hline $\begin{array}{c}\text { Catawba } 2 \\
\text { (1989) } \\
\text { PWR } \\
\text { (Ref. 1.26) } \\
\end{array}$ & $\begin{array}{l}\text { Ice Condenser } \\
\text { Steel cylinder } \\
\text { (5) }\end{array}$ & $\begin{array}{l}\text { Corrosion on outside of steel } \\
\text { cylinder in the annular region }\end{array}$ & $\begin{array}{l}\text { General visual examination } \\
\text { (Inspection initiated as a result of } \\
\text { corrosion detected } \\
\text { at McGuire 2) }\end{array}$ \\
\hline
\end{tabular}


Table 1.1 Instances of containment pressure boundary component degradation at commercial nuclear power plants in the United States (cont.).

\begin{tabular}{|c|c|c|c|}
\hline $\begin{array}{l}\text { Plant Designation } \\
\text { (Occurrence Date) } \\
\text { Plant Type } \\
\text { (Source)* }\end{array}$ & $\begin{array}{l}\text { Containment } \\
\text { Description } \\
\text { (No. of Similar } \\
\text { Plants) }\end{array}$ & $\begin{array}{l}\text { Degradation } \\
\text { Description }\end{array}$ & $\begin{array}{l}\text { Detection } \\
\text { Method }\end{array}$ \\
\hline $\begin{array}{l}\text { McGuire } 1 \\
\text { (1990) } \\
\text { PWR } \\
\text { (Ref. } 1.28)\end{array}$ & $\begin{array}{l}\text { Ice Condenser } \\
\text { Reinforced concrete } \\
\text { with steel liner } \\
\text { (4) }\end{array}$ & $\begin{array}{l}\text { Corrosion on outside of steel } \\
\text { cylinder in the annular region }\end{array}$ & $\begin{array}{l}\text { General visual examination } \\
\text { (Follow-up inspection by } \\
\text { licensee) }\end{array}$ \\
\hline \begin{tabular}{|c|} 
McGuire 1 \\
$(1990)$ \\
PWR \\
(Ref. 1.29, 1.28, and \\
$1.30)$ \\
\end{tabular} & $\begin{array}{l}\text { Ice Condenser } \\
\text { Reinforced concrete } \\
\text { with steel liner } \\
\text { (4) }\end{array}$ & $\begin{array}{l}\text { Corrosion on inside surface of } \\
\text { coated containment shell under } \\
\text { the ice condenser and between the } \\
\text { floors near the cork filler material }\end{array}$ & $\begin{array}{l}\text { Visual examination and ultrasonic } \\
\text { inspection } \\
\text { (Degradation possibly caused by } \\
\text { moisture from the ice condenser } \\
\text { or condensation) } \\
\end{array}$ \\
\hline \begin{tabular}{|c|} 
Quad Cities 1 \\
$(1991)$ \\
BWR/3 \\
(Refs. $1.31,1.32$, and \\
$1.33)$ \\
\end{tabular} & $\begin{array}{l}\text { Steel drywell } \\
\text { and wetwell } \\
(22)\end{array}$ & $\begin{array}{l}\text { Two-ply containment penetration } \\
\text { bellows leaked due to } \\
\text { transgranular stress-corrosion } \\
\text { cracking }\end{array}$ & $\begin{array}{l}\text { General visual examination } \\
\text { (Excessive leakage detected) }\end{array}$ \\
\hline \begin{tabular}{|c|} 
Quad Cities 2 \\
$(1991)$ \\
BWR/3 \\
(Refs. 1.31 and 1.32) \\
\end{tabular} & $\begin{array}{l}\text { Steel drywell } \\
\text { and wetwell } \\
\text { (22) }\end{array}$ & $\begin{array}{l}\text { Two-ply containment penetration } \\
\text { bellows leaked due to } \\
\text { transgranular stress-corrosion } \\
\text { cracking }\end{array}$ & $\begin{array}{l}\text { General visual examination } \\
\text { (Excessive leakage detected) }\end{array}$ \\
\hline $\begin{array}{c}\text { Dresden } 3 \\
(1991) \\
\text { BWR/3 } \\
\text { (Ref. 1.32) } \\
\end{array}$ & $\begin{array}{l}\text { Steel drywell } \\
\text { and wetwell } \\
(22)\end{array}$ & $\begin{array}{l}\text { Two-ply containment penetration } \\
\text { bellows leaked due to } \\
\text { transgranular stress-corrosion } \\
\text { cracking }\end{array}$ & $\begin{array}{l}\text { General visual examination } \\
\text { (Excessive leakage detected) }\end{array}$ \\
\hline $\begin{array}{c}\text { Point Beach } 2 \\
\text { (1992) } \\
\text { PWR } \\
\text { (Ref. 1.33) } \\
\end{array}$ & $\begin{array}{l}\text { Post-tensioned } \\
\text { concrete cylinder } \\
\text { with steel liner } \\
(35)\end{array}$ & $\begin{array}{l}\text { Liner plate separated from } \\
\text { concrete }\end{array}$ & General visual examination \\
\hline $\begin{array}{l}\text { H. B. Robinson } \\
\text { (1992) } \\
\text { PWR } \\
\text { (Ref. 1.33) }\end{array}$ & $\begin{array}{l}\text { Post-tensioned } \\
\text { concrete cylinder } \\
\text { (vertical only) with } \\
\text { steel liner } \\
(35) \\
\end{array}$ & Degradation of liner coating & General visual examination \\
\hline $\begin{array}{c}\text { Cooper } \\
(1992) \\
\text { BWR/4 } \\
\text { (Ref. 1.33) } \\
\end{array}$ & $\begin{array}{l}\text { Steel drywell } \\
\text { and wetwell } \\
(22)\end{array}$ & $\begin{array}{l}\text { Corrosion of interior torus } \\
\text { surfaces and corrosion stains on } \\
\text { exterior torus surface in one area }\end{array}$ & General visual examination \\
\hline $\begin{array}{c}\text { Beaver Valley } 1 \\
\text { (1992) } \\
\text { PWR } \\
\text { (Refs. } 1.33 \text { and 1.34) }\end{array}$ & $\begin{array}{c}\text { Subatmospheric } \\
\text { Reinforced concrete } \\
\text { cylinder with steel } \\
\text { liner } \\
\text { (7) } \\
\end{array}$ & $\begin{array}{l}\text { Corrosion of steel liner, } \\
\text { degradation of liner coating, and } \\
\text { instances of liner bulging }\end{array}$ & $\begin{array}{l}\text { General visual examination prior } \\
\text { to Type A leakage rate test }\end{array}$ \\
\hline $\begin{array}{c}\text { Salem 2 } \\
(1993) \\
\text { PWR } \\
\text { (Ref. 1.35) } \\
\end{array}$ & $\begin{array}{c}\text { Reinforced concrete } \\
\text { cylinder with steel } \\
\text { liner } \\
(13) \\
\end{array}$ & Corrosion of steel liner & $\begin{array}{l}\text { General visual examination prior } \\
\text { to Type A leakage rate test }\end{array}$ \\
\hline
\end{tabular}


Table 1.1 Instances of containment pressure boundary component degradation at commercial nuclear power plants in the United States (cont.).

\begin{tabular}{|c|c|c|c|}
\hline $\begin{array}{c}\text { Plant Designation } \\
\text { (Occurrence Date) } \\
\text { Plant Type } \\
\text { (Source)* } \\
\end{array}$ & $\begin{array}{c}\text { Containment } \\
\text { Description } \\
\text { (No. of Similar Plants) }\end{array}$ & $\begin{array}{l}\text { Degradation } \\
\text { Description }\end{array}$ & $\begin{array}{l}\text { Detection } \\
\text { Method }\end{array}$ \\
\hline $\begin{array}{c}\text { Sequoyah 1 } \\
\text { (1993) } \\
\text { PWR } \\
\text { (Ref. 1.36) }\end{array}$ & $\begin{array}{c}\text { Ice Condenser } \\
\text { Steel cylinder with } \\
\text { concrete shield building } \\
\text { (5) }\end{array}$ & $\begin{array}{l}\text { Degradation of moisture barriers } \\
\text { resulting in corrosion of the steel } \\
\text { shell }\end{array}$ & $\begin{array}{l}\text { General visual examination and } \\
\text { visual examination of coated } \\
\text { areas }\end{array}$ \\
\hline $\begin{array}{l}\text { Sequoyah } 2 \\
\text { (1993) } \\
\text { PWR } \\
\text { (Ref. 1.36) } \\
\end{array}$ & \begin{tabular}{|c|} 
Ice Condenser \\
Steel cylinder with \\
concrete shield building \\
(5) \\
\end{tabular} & $\begin{array}{l}\text { Degradation of moisture barriers } \\
\text { resulting in corrosion of the steel } \\
\text { shell }\end{array}$ & $\begin{array}{l}\text { General visual examination and } \\
\text { visual examination of coated } \\
\text { areas }\end{array}$ \\
\hline $\begin{array}{c}\text { Brunswick } 2 \\
(1993) \\
\text { BWR } \\
\text { (Refs. } 1.22 \text { and 1.37) }\end{array}$ & $\begin{array}{l}\text { Reinforced concrete } \\
\text { drywell and wetwell } \\
\text { with steel liner } \\
\text { (9) }\end{array}$ & Corrosion of steel liner & $\begin{array}{l}\text { General visual examination and } \\
\text { visual examination of coated } \\
\text { areas } \\
\text { (Follow-up inspection based on } \\
\text { conditions noted in 1988) }\end{array}$ \\
\hline $\begin{array}{l}\text { Brunswick } 1 \\
(1993) \\
\text { BWR/4 } \\
\text { (Ref. 1.37) }\end{array}$ & $\begin{array}{l}\text { Reinforced concrete } \\
\text { drywell and wetwell } \\
\text { with } \\
\text { steel liner } \\
\text { (9) }\end{array}$ & Corrosion of steel liner & $\begin{array}{l}\text { General visual examination and } \\
\text { visual examination of coated } \\
\text { areas } \\
\text { (Inspection initiated as a result of } \\
\text { corrosion detected } \\
\text { at Brunswick 2) }\end{array}$ \\
\hline $\begin{array}{l}\text { McGuire } 1 \\
\text { (1993) } \\
\text { PWR } \\
\text { (Ref. 1.38) }\end{array}$ & $\begin{array}{c}\text { Ice Condenser } \\
\text { Reinforced concrete } \\
\text { with steel liner } \\
\text { (4) }\end{array}$ & $\begin{array}{l}\text { Main steam isolation line } \\
\text { bellows leakage }\end{array}$ & $\begin{array}{l}\text { Leakage testing conducted on } \\
\text { bellows following successful } \\
\text { Type A leakage rate test }\end{array}$ \\
\hline $\begin{array}{l}\text { Braidwood 1 } \\
\text { (1994) } \\
\text { PWR } \\
\text { (Ref. 1.39) } \\
\end{array}$ & $\begin{array}{c}\text { Post-tensioned } \\
\text { concrete cylinder with } \\
\text { steel liner } \\
(35) \\
\end{array}$ & $\begin{array}{l}\text { Liner leakage detected but not } \\
\text { located }\end{array}$ & Type A leakage rate test \\
\hline $\begin{array}{l}\text { North Anna } 2 \\
\text { (1999) } \\
\text { PWR } \\
\text { (Ref. 1.40) } \\
\end{array}$ & $\begin{array}{c}\text { Subatmospheric } \\
\text { Reinforced concrete } \\
\text { with steel liner } \\
(7) \\
\end{array}$ & $\begin{array}{l}\text { 6-mm-diameter hole in liner due } \\
\text { to corrosion }\end{array}$ & $\begin{array}{l}\text { General visual examination and } \\
\text { visual examination of coated } \\
\text { areas }\end{array}$ \\
\hline $\begin{array}{l}\text { Brunswick } 2 \\
(1999) \\
\text { BWR/4 } \\
\text { (Ref. 1.41) }\end{array}$ & $\begin{array}{l}\text { Reinforced concrete } \\
\text { drywell and wetwell } \\
\text { with steel liner } \\
\text { (9) }\end{array}$ & $\begin{array}{l}\text { Corrosion of liner ranging from } \\
\text { clusters of surface pitting } \\
\text { corrosion to a 2-mm-diameter } \\
\text { hole }\end{array}$ & $\begin{array}{l}\text { General visual examination and } \\
\text { visual examination of coated } \\
\text { areas (Inspection initiated as a } \\
\text { result of corrosion detected } \\
\text { at Surry) }\end{array}$ \\
\hline
\end{tabular}


Table 1.2 Summary of metal and concrete containment pressure boundary component degradation occurrences.

\begin{tabular}{|c|l|l|c|}
\hline $\begin{array}{c}\text { Containment } \\
\text { Type }\end{array}$ & \multicolumn{1}{|c|}{ Degradation Description } & \multicolumn{1}{|c|}{ Affected Component } & $\begin{array}{c}\text { Number of Similar } \\
\text { Occurrences }\end{array}$ \\
\hline \hline Metal & Corrosion & $\begin{array}{l}\text { Steel shell or other pressure- } \\
\text { retaining component }\end{array}$ & 9 \\
\hline Metal & Cracking & Bellows & 4 \\
\hline Metal & Coating degradation in high- & Steel shell & 2 \\
\hline Metal & Coating degradation in aqueous & Steel shell (torus) & 4 \\
\hline Metal & Cracking & Steel shell (torus) & 1 \\
\hline Metal & Brittle fracture & $\begin{array}{l}\text { Vent header (inside torus) or } \\
\text { nitrogen purge line }\end{array}$ & 2 \\
\hline Metal & Torus anchor bolt deformation & Anchor bolts (torus) & 1 \\
\hline Metal & Moisture barrier & Stell shell & 4 \\
\hline Concrete & Corrosion & Steel liner & 13 \\
\hline Concrete & Coating degradation & Steel liner & 2 \\
\hline Concrete & Liner plate separation & Steel liner & 2 \\
\hline Concrete & Liner leakage & Steel liner & 1 \\
\hline
\end{tabular}




\section{CONDITION ASSESSMENT}

\subsection{BACKGROUND}

Proper maintenance is essential to the safety of nuclear power plant containments, and a clear link exists between effective maintenance and safety. To reduce the likelihood of failures due to degradation, the "Maintenance Rule" was issued by the USNRC as 10 CFR 50.65 ("Requirements for Monitoring the Effectiveness of Maintenance at Nuclear Power Plants") on July 10, 1991. As discussed in the rule summary, in order to maintain safety, it is necessary to monitor the effectiveness of maintenance, and to take timely and appropriate corrective action, when necessary, to ensure that the maintenance process continues to be effective for the lifetime of nuclear power plants, particularly as plants age. The rule requires that plant owners monitor the performance or condition of structures, systems, and components (SSCs) against owner-established goals, in a manner sufficient to give reasonable assurance that such SSCs are capable of fulfilling their intended functions. It is further required that the licensee take appropriate corrective action when the performance or condition of a SSC does not conform to established goals. In order to verify the implementation of 10 CFR 50.65, the USNRC issued Inspection Procedure 62002, "Inspection of Structures, Passive Components, and Civil Engineering Features at Nuclear Power Plants."

Subsequently, on May 8, 1995, the USNRC published a final rule amending 10 CFR Part 54, "Requirements for Renewal of Operating Licenses for Nuclear Power Plants," that contained the requirements an applicant must meet to renew an operating license. The final rule is intended to ensure that important SSCs will continue to perform their intended function in the period of extended operation. Only passive, long-lived structures and components are subject to an aging management review for license renewal, and the USNRC license renewal review will focus on the adverse effects of aging. The USNRC concluded that passive, long-lived components should be subject to an aging management review because, in general, functional degradation of these components may not be apparent so that the regulatory process and existing licensee programs may not adequately manage detrimental effects of aging in the period of extended operation.

In June 1995, the USNRC published NUREG-1522, "Assessment of Inservice Conditions of Safety-Related Nuclear Plant Structures." The report contains information from various sources on the condition of structures and civil engineering features at operating nuclear plants. The most significant information came from inspections performed by the USNRC Staff of six plants licensed before 1977. Types of containment-related potential problem areas found included coating degradation and base metal pitting, leakage of tendon corrosion inhibitor, lower than anticipated tendon prestressing forces, bulging and spot corrosion of liner plate, concrete surface cracking, deteriorating concrete repair patches, and torus corrosion. The main conclusion of the report was that a properly established and periodically applied inspection and maintenance program would be beneficial to the plant owners in ensuring the integrity of the plant structures. The importance of periodic inspections of structures, as part of the systematic maintenance program, cannot be over emphasized. Substantial safety and economic benefit can be derived if the scope of the investigations is comprehensive and includes degradation sites having difficult access that may not otherwise be inspected. Timely remedial actions to arrest continuing or address benign degradations will ensure continued safety of the structures, particularly in areas of difficult access.

Most of the degradation occurrences such as noted in Chapter 1 were first identified by the USNRC through its inspections or audits of plant structures, or by licensees while performing an unrelated activity or after they were alerted to a degraded condition at another site. Since none of the existing requirements for containment inspection provided specific guidance on how to perform the necessary containment examinations, there was a large variation with regard to the performance and effectiveness of licensee containment examination programs. Furthermore, based on results of the inspections and audits, the USNRC was concerned because many licensee containment examination programs did not appear to be adequate to detect degradation that could potentially compromise the containment leak-tight integrity. The number of occurrences and extent of degradation experienced by a few of the structures at some plants resulted in the USNRC publishing new rules regarding testing and in-service inspection.

\subsubsection{Testing}

One of the conditions of all operating licenses for water-cooled power reactors is that the primary reactor containments shall meet the containment leakage test requirements set forth in Appendix J, "Primary Reactor Containment Leakage Testing for Water-Cooled Power Reactors," to 10 CFR 50 (2.1). These test requirements provide for preoperational and periodic verification by tests of the leak-tight integrity of the primary reactor containment, and systems and components that penetrate containment of water-cooled power reactors, and establish the acceptance criteria for such tests. The 
purpose of these tests is to assure that (1) leakage through the primary reactor containment and the systems and components penetrating primary reactor containment shall not exceed allowable leakage-rate values as specified in the technical specifications or associated bases, and (2) periodic surveillance of reactor containment penetrations and isolation valves is performed so that proper maintenance and repairs are made during the service life of the containment, and systems and components that penetrate primary containment.

Contained in this regulation are requirements pertaining to Type $\mathrm{A}, \mathrm{B}$, and $\mathrm{C}$ leakage-rate tests that must be performed by each licensee as a condition of their operating license. Type A tests are intended to measure the primary reactor containment overall integrated leakage rate (1) after the containment has been completed and is ready for operation, and (2) at periodic intervals thereafter. Type B tests are intended to detect local leaks and to measure leakage across each pressure-containing or leakage-limiting boundary for primary reactor containment penetrations (e.g., penetrations that incorporate resilient seals, gaskets, or sealant compounds; and air lock door seals). Type C tests are intended to measure containment isolation valve leakage rates. Requirements for system pressure testing and criteria for establishing inspection programs and pressure-test schedules are contained in Appendix J.

On September 26, 1995, the USNRC amended Appendix J (60 FR 49495) to provide a performance-based option for leakage-rate testing as an alternative to the existing prescriptive requirements. The amendment is aimed at improving the focus of the body of regulations by eliminating prescriptive requirements that are marginal to safety and by providing licensees greater flexibility for cost-effective implementation methods for regulatory safety objectives. Now that Appendix $\mathrm{J}$ has been amended, either Option A-Prescriptive Requirements or Option B-Performance-Based Requirements can be chosen by a licensee to meet the requirements of Appendix J. Option B allows licensees with good integrated leakage-rate test performance histories to reduce the Type A testing frequency from three tests in ten years to one test in 10 years. For Type B and C tests, Option B allows licensees to reduce testing frequency on a plant-specific basis based on the operating experience for each component and establishes controls to ensure continued performance during the extended testing interval. However, a general inspection of accessible interior and exterior surfaces of the containment structure and components must be performed prior to each Type A test and during two other refueling outages before the next Type A test if the interval for the Type A test has been extended to ten years. The USNRC position on performance-based containment leakage-rate testing is discussed in Regulatory Guide 1.163 (2.2). Methods considered acceptable to the USNRC Staff for complying with the provisions of Option B are provided in guidance documentation prepared by the Nuclear Energy Institute (2.3).

The NEI document (2.3) presents an industry guideline for implementing the performance-based option and contains an approach that includes continued assurance of the leak-tight integrity of the containment without adversely affecting public health and safety, licensee flexibility to implement cost-effective testing methods, a framework to acknowledge good performance, and utilization of risk and performance-based methods. The guideline delineates the basis for a performance-based approach for determining Type A, B, and C containment leakage-rate surveillance testing frequencies using industry performance data, plant-specific performance data, and risk insights. It does not address how to perform the tests because these details can be found in existing documents (2.4). Licensees may elect to use other suitable methods or approaches to comply with Option B, but they must obtain USNRC approval prior to implementation.

\subsubsection{In-Service Inspection Requirements}

Appendix J to 10 CFR Part 50, requires a general inspection of the accessible interior and exterior surfaces of the containment structures and components to uncover any evidence of structural deterioration that may affect either the containment structural integrity or leak-tightness. The large number of reported occurrences (over 60) and the extent of the degradation led the USNRC to conclude that this general inspection was not sufficient. Thus, on August 8, 1996, the USNRC published an amendment (61 FR 41303) to 10 CFR 50.55a of its regulations to require that licensees use portions of the American Society of Mechanical Engineers Boiler and Pressure Vessel Code (ASME Code) (2.5) for containment in-service inspection. The regulations were amended to assure that critical areas of the containments are routinely inspected to detect and to take corrective action for defects that could compromise a containment's structural integrity. The amended rule became effective September 9, 1996. Specifically, the rule requires that licensees adopt the 1992 Edition with the 1992 Addenda of Subsection IWE, "Requirements for Class MC and Metallic Liners of Class CC Components of Light-Water Cooled Power Plants," and Subsection IWL, "Requirements for Class CC Concrete Components of Light-Water Cooled Power Plants, “" of Section XI, of the ASME Code. In addition, several supplemental requirements with respect to the concrete and metal containments were included in the rule. A five-year implementation period was permitted for licensees to develop and implement the examinations of Subsections IWE and IWL (i.e., no later than September 9, 2001). Also, any repair and replacement activity to be performed on a containment after the 
effective date of the amended rule has to be carried out in accordance with respective requirements of Subsections IWE and IWL of the ASME Code. However, the Director of the Office of Nuclear Reactor Regulation, at his discretion, can grant relief from the requirements of 10 CFR 50.55a relative to repair and replacement activities to licensees who submit a justifiable need to use an alternative that provides an acceptable level of safety or who encounter extreme hardship or unusual difficulty without a compensating increase in the level of quality or safety. In September 2002, the USNRC published another amendment (67 FR 6052) to 10 CFR 50.55a of it regulations to require licensees to adopt the 1997 Addenda, the 1998 Edition, the 1999 Addenda, and the 2000 Addenda of Section XI of the ASME Code. Subsequent amendments to 10 CFR 50.55a published by the NRC presently require licensees to adopt the 2000 Code.

\subsubsection{Continued Service Assessments}

Operating experience has demonstrated that periodic inspection, maintenance, and repair are essential elements of an overall program to maintain an acceptable level of reliability over the service life of a nuclear power plant containment, or in fact, of any structural system. Knowledge gained from conduct of an in-service condition assessment can serve as a baseline for evaluating the safety significance of any degradation that may be present, and defining subsequent in-service inspection programs, and maintenance strategies.

Effective in-service condition assessment of a containment requires knowledge of the expected type of degradation, where it can be expected to occur, and application of appropriate methods for detecting and characterizing the degradation. Degradation is considered to be any phenomenon that decreases the containment load-carrying capacity, limits its ability to contain a fluid medium, or reduces its service life. Degradation detection is the first and most important step in the condition assessment process. Routine observation, general visual inspections, leakage-rate tests, and nondestructive examinations are techniques used to identify areas of the containment that have experienced degradation. Techniques for establishing time-dependent change such as section thinning due to corrosion, or changes in component geometry and material properties, involve monitoring or periodic examination and testing. Knowing where to inspect and what type of degradation to anticipate often requires information about the design features of the containment as well as the materials of construction and environmental factors. Figure 2.1 provides a flow diagram of one approach to the continued service evaluation process for nuclear power plant containments (2.6). Basic elements of the condition assessment process for nuclear power plant pressure boundary components include development of a structural component classification system and application of destructive and nondestructive test methods in areas of concern.

\subsection{STRUCTURAL COMPONENT CLASSIFICATION}

The structural component classification system that has been developed addresses containment metallic pressure boundary material identification and characterization, expansion of the Structural Materials Information Center, and formulation of a degradation assessment methodology.

\subsubsection{Containment Metallic Pressure Boundary Structural Component Classification System}

An approach has been developed for use in collection and presentation of data and information on ferrous alloys permitted for use in construction of pressure-retaining components in concrete and metal containments (2.7). The approach consists of identification of applicable materials, development of classifications and designations for the materials, representation of material properties and data, utilization of the Structural Materials Information Center (SMIC) (2.8), and input of pertinent data and information into SMIC.

\subsubsection{Containment metallic pressure boundary materials}

All containments include pipes, electrical penetration assemblies, equipment hatches, manways, and airlocks, as part of the pressure boundary. These components generally are either welded or bolted to the liners and shells and typically have compositions and properties that are different from those of the liner and shell materials. These materials must conform to American Society of Mechanical Engineers (ASME) or American Society for Testing and Materials (ASTM) specifications. Section II, Parts A and D of the ASME Code (2.5) provide specifications and property values for ferrous materials that are acceptable for use. Part A contains material specifications for ferrous materials that were developed by ASTM and adopted by ASME. ASTM specifications represent a consensus among producers, specifiers, fabricators, and users of steel products, and provide designations to distinguish a material and to group together materials with similar compositions and characteristics. 
The ASME Code only permits the use of certain materials for fabrication of containment pressure boundary components. In addition to the material type, the Code also states explicitly which grade, class, or type of steel is permitted for a particular application. Although the list of acceptable materials for construction of concrete and metal containment pressure boundary components is fairly extensive, metal containments have been primarily fabricated of low- or unalloyed steels such as ASME SA-516 (Grades 60 or 70), ASTM A 212 (Grade B),* and ASME SA-537 (Grade B) materials. Mark III free-standing steel containments primarily use ASME SA-516 (Grade 70) material for construction, with the shell plate in the pressure suppression pool clad with ASME SA-240 (Type 304) stainless steel** to avoid contact of the carbon steel plate with water. The liners of reinforced concrete containments are typically composed of carbon steel (e.g., ASME-SA-285, Grade 70; ASME-SA-516, Grade 70) plate stock less than 13-mm thick. Liners in certain BWR suppression pools are made of carbon steel plate with a stainless steel cladding. Closure heads, access airlocks, and penetrations are also normally made of low-alloy steels with the exception of the expansion bellows of piping penetrations that are made of Type 304 stainless steel.

\subsubsection{Classification and identification of metallic pressure boundary materials}

Ferrous metals are composed of iron and carbon plus other elements introduced during the manufacturing process as part of the raw materials or intentionally added as alloying elements. Steel is a common ferrous metal that is used extensively in the construction industry because it can be manufactured relatively inexpensively in large quantities according to standard specifications. The properties of steel can be varied over a wide range by the addition of carbon and alloying elements and by heat treatment and mechanical operations. Most ferrous alloys produced and shipped in the US are carbon steels. Typically these steels contain up to two percent total alloying elements. The high-alloy steels include a broad family of materials known as stainless steels. Stainless steels are iron-based alloys that contain at least 10.5 percent chromium. Corrosion resistance and extreme-temperature mechanical properties are the most important characteristics of stainless steels. Stainless steel types include martensitic, ferritic, austenitic, duplex, and precipitationhardening.

Classification systems for steels are typically based on either chemical composition, manufacturing method, finishing method, product form, deoxidation practice, microstructure, required strength level, heat treatment, or quality descriptor (2.9). A standard guide (ASTM E 1338) for the identification of metals and alloys in computerized materials property databases has been adopted by ASTM (2.10). This guide contains a sample format that includes 37 information fields considered necessary for the generic identification of metals and alloys. The information fields in the guide are subdivided into eight data segments that represent (1) primary identifiers, (2) specifications, (3) characterization, (4) material source, (5) processing history, (6) part details, (7) fabrication and service history, and (8) supplemental information. Certain of these fields are essential for the database to be complete while others represent information that is considered desirable. In general, as the amount of essential and desirable information reported for a particular material increases, the uncertainty and confusion related to identification of a specific material decreases.

Although material specifications and a unified numbering system (UNS) designation generally provides relatively simple yet effective ways to distinguish one metal from another, when data and information from many different sources are compiled and stored in a computerized database additional identification parameters are often required to establish a unique identity for the material. Unique identification is also required for efficient retrieval of information and to allow meaningful comparisons of data and information from different sources. As existing classifications or designations were considered to be adequate for use with a material property database, a material code approach was developed to identify steels used to fabricate containment pressure boundary components.

The Material Code concept was adopted because it provides a convenient way to categorize and organize materials based on compositional and processing information rather than simply by material specification designations. Figure 2.2 shows a typical material code arrangement for a low-alloy carbon steel plate material permitted for the use in construction of containment pressure boundary components. The first two characters of the material code are the

* Steel conforming to ASTM A 212 requirements was used in the 1960s for containment construction. This material specification, which included requirements for Grades A and B steel plates, was discontinued in 1966 and replaced by ASTM A 515 and A 516.

** Stainless steel components are not normally used in nuclear power plant containments except for bellows, penetration assemblies (e.g., electrical and piping), and seal components between the pressure vessel flange and drywell of some BWR designs. 
Chapter Index. This two-digit number corresponds to the chapter in the Structural Materials Handbook(described later) where properties for this material are reported. For steel materials used to construct containment pressure boundary components the chapter index is 06 . The second parameter (third character in the material code) is the Group Index. This single-letter designation is used to subdivide materials in Chapter 06 into groups of materials with common compositional characteristics. Carbon and low-alloy steels are assigned to the " $\mathrm{A}$ " group index and stainless steels are assigned to the "B" group index. The third parameter (fourth character in the material code) is the Class Index. This single-letter designation is used to organize materials with the same group index into types of materials that have the same processing history. Table 2.1 presents the various class indexes that have been developed for containment steels. The fourth parameter (fifth, sixth, and seventh characters in the material code) is the Identifier Index. Identifiers are three-digit numbers in the range from 000 to 999 that are used to distinguish materials within the same group and class from each other.

\subsubsection{Representation of material properties and data}

Structural integrity and load-carrying capacity of containment pressure boundary materials are influenced by the mechanical properties of the construction materials. Changes in material properties resulting from severe environments can also affect component performance. Test methods for determining the mechanical properties of steel products have been established by ASTM and adopted by ASME $(2.11,2.12)$ even though the ASME Code $(2.13,2.14)$ does not require testing of production materials to establish property values for use in design calculations. Values for use in design calculations are tabulated in Section II, Part D, Subparts 1 and 2 of the Code (2.15) and include maximum allowable stress, design stress intensity, tensile strength, modulus of elasticity, and yield strength over a fairly wide temperature range. Design fatigue curves for various types of steels for use in analysis of cyclic operation and thermal stress ratcheting are provided in Section III, Division 1, Appendix I of the Code (2.16).

In order to ensure material-to-material presentation format consistency and compatibility, a four-digit Property Code is used to represent individual data fields and specific information entries. Table 2.2 identifies the property code ranges and the corresponding property categories covered by each range. Tables 2.3 (a) and 2.3 (b) list property codes and corresponding property descriptions for various mechanical properties, and certain types of engineering graphs that can be reported for a particular containment steel, respectively.

General and bibliographic information is also reported for each containment steel included in the database. Table 2.4 presents general information property codes and corresponding property descriptions used to categorize and systematically represent containment steel data and information. Bibliographic information is also reported for each containment steel included in the database.

\subsubsection{Structural Materials Information Center (SMIC)}

\subsubsection{Description of SMIC}

Results of a review and assessment of materials property data bases (2.17) and a plan that had been prepared (2.18) were used under the Structural Aging Program (3.19) to develop the Structural Materials Information Center (SMIC) (2.8). A general description of the Structural Materials Handbook and the Structural Materials Electronic Database that form the SMIC is provided below.

The Structural Materials Handbook was developed as an expandable, hard-copy reference document that contains complete sets of data and information for each material in the SMIC. The handbook consists of four volumes that are provided in loose-leaf binders for ease of revision and updating. Volume 1 contains design and analysis information useful for structural assessments and safety margins evaluations (e.g., performance curves for mechanical, thermal, physical, and other properties presented as tables, graphs, and mathematical equations). Test results and data used to develop the performance curves in Volume 1 are provided in Volume 2. Volume 3 contains material data sheets that provide general information, as well as material composition and constituent material properties, for each material system contained in the handbook. Volume 4 contains appendices describing the handbook organization, as well as updating and revision procedures. With the addition of steels for fabrication of containment pressure boundary components, Volumes 1, 2, and 3 of the handbook contain six chapters of materials property data and information, with 
the chapters consistent between the volumes.* As noted previously, each material in the database is assigned a unique seven-character material code that is used to organize materials with common characteristics. Also, each material property has been identified by a unique four-digit property code selected from an established set of material property categories.

The Structural Materials Electronic Database is an electronically accessible version of the Structural Materials Handbook. It has been developed on an IBM-compatible personal computer using a commercially-available database management system designed specifically for maintaining and displaying properties of engineering materials. To ensure that the handbook and electronic database are compatible, each material included in the electronic database is identified by the same common name and material code that have been used to represent the material in the handbook. Also, each electronic database material record contains data and information taken directly from the handbook. Due to software limitations, the electronic database is not as comprehensive as the handbook, but it does provide an efficient means for searching the various database files to locate materials with similar characteristics or properties. The electronic database management system includes two software programs: Mat.DB (2.21) and EnPlot (2.22). Mat.DB is a menu-driven program that employs window overlays to access data searching and editing features. This software is capable of maintaining, searching, and displaying textual, tabular, and graphical information and data contained in electronic database files. EnPlot is a program that incorporates pop-up menus for creating and editing engineering graphs. This software includes curve-fitting and scale-conversion features for preparing engineering graphs and utility features for generating output files. The engineering graphs generated with EnPlot can be entered directly into the Mat.DB database files. These graphs are compatible with Microsoft Word, the word processing software used to prepare the handbook.

Associated with each entry of data (numerical results of tests) or values (results of evaluation of data) into the database is an assessment of the quality of the entries presented in the form of a letter grade. Although the criteria for assessing the quality of data and values are somewhat subjective, five quality levels have been developed. These levels are represented, in order of descending quality, by the letters A through E. Eleven requirements are utilized in the evaluation of the quality of data and values with specific criteria for each of the quality levels having been developed. Each reference document that is used as an information source is assigned a unique integer identifier. In Volumes 1 and 2, reference numbers are listed to identify each information source, and all references that are used to develop a reported property for a particular material are provided in Volume 3. Since each reference may be used for more than one property or structural material, a complete listing of references appears in Appendix E of Volume 4. The integer identifier assigned to each reference source is consistent in both the handbook and the electronic database.

\subsubsection{Input of data and information}

Data and information on steels used to fabricate containment pressure boundary components have been collected from open-literature reports and published references. As a minimum requirement for entry into the database, general information must be reported for each steel so that a unique material identification can be established and experimental results, test data, or nominal property values must be available. Mechanical and physical property values provided in Section II, Part D of the Code have been used to supplement data and information collected.

Data collection for input into SMIC is an ongoing research effort. To date, handbook pages and electronic database files have been prepared for nine materials: ASME SA-36, ASME SA-516 (Grades 55, 60, 65, and 70), ASME SA-537 (Classes 1 and 2), and ASME SA-442 (Grades 55 and 60). Properties available for each of these materials include tensile yield strength versus temperature and ultimate tensile strength versus temperature. Tensile yield strength ratio versus temperature results (ratio between elevated- and ambient-temperature values) are also available for the ASME SA-36 material. Table 2.5 provides a list of the materials most widely used for the construction of containment pressure boundary components. Although the materials contained in this table represent only a small number of the steels permitted for use by the Code, it presents the most commonly used steels, as compiled from information contained in Final Safety Analysis Reports (FSARs) representing both BWR and PWR plant types.

\footnotetext{
* Material families included in the handbook as Chapters 1 to 5 include Portland cement concretes, metallic reinforcements, prestressing tendons, structural steels, and rubbers. A summary of materials that have been included in SMIC is available (2.20).
} 
Metal containments and liners of reinforced concrete containments under normal operating conditions are subject to various operating and environmental stressors, such as ambient pressure fluctuations and temperature variations. The mechanical stresses and strains generated by transients under normal operating conditions and the effects of highprobability external influences are a small fraction of the limiting conditions for which the containment is designed. Loads incurred during normal plant operation therefore generally are not significant enough to cause appreciable degradation. However, these structures are susceptible to aging by various processes depending on the operating environment and service conditions.

The containment is subjected to various types of internal degradation (i.e., aging-related) caused by its inherent material characteristics, fabrication processes, and construction methods. The rate and extent of such degradation* are influenced by the sustained environmental conditions (e.g., temperature, humidity, water leakage, and acid spills). Thus, the ability of the containment pressure boundary to perform satisfactorily under the design basis as well as under higher loading conditions, such as resulting from a severe accident and seismic margin earthquake, are

influenced by the complex interaction between its inherent ability and the various stressors and degradation mechanisms that are present. Analysis of the potential impact of age-related effects must be done in conjunction with all the appropriate system parameters, including the types of material, history of the materials, mechanical and thermal stresses, stress cycles, environment (e.g., chemistry, radiation, humidity, and flow rate), and the local geometry. The effects of these processes may accumulate within these structures over time to cause failure under design conditions, or lead to costly repair. Table 2.6 lists several factors associated with pressure-retaining steel component degradation.

Contained in the balance of this section is a description of a degradation assessment methodology intended for use in characterizing the in-service condition of metal and concrete containment pressure boundary components and quantifying the amount of damage present (2.23). Condition assessments are essential to reliable continued service evaluations and informed aging-management decisions. From an aging management viewpoint, metal and concrete containment pressure boundary components that exhibit satisfactory long-term performance and do not experience in-service degradation can be considered acceptable for continued service. However, components found by routine examination or in-service inspection to be deteriorated or damaged must be evaluated to determine whether continued service is appropriate, or whether repairs, replacements, or retrofits are needed. Requirements for corrective actions that are to be taken when evidence of structural deterioration is discovered are provided in 10 CFR 50, Appendix J (2.1). More detailed acceptance standards and evaluation criteria for use in determining the acceptability of degraded components for continue service are provided in Section XI, Division 1, Subsection IWE of the Code (2.6, 2.24).

Continued service evaluations are performed by qualified engineers and authorized personnel who determine the adequacy of degraded components for their intended use (2.25). The decision-making process begins with an understanding of the in-service condition of each containment component. Condition assessments that provide essential information for continued service evaluations involve detecting damage in areas of the containment pressure boundary that are potentially vulnerable to in-service deterioration or attack, classifying the types of damage that may be present, determining the root cause of the problem, and quantifying the extent of degradation that may have occurred. Knowledge gained from condition assessments can serve as a baseline for evaluating the safety significance of any damage that may be present and defining in-service inspection programs and maintenance strategies. Condition assessment results can also be used to estimate future performance and remaining service life.

Table 2.7 identifies and defines four elements associated with in-service condition assessments for metal and concrete containment pressure boundary components. These elements focus on damage detection, damage classification, rootcause determination, and damage measurement. Major topics pertaining to each element are listed in Fig. 2.3. Because information required to characterize and quantify the condition of degraded components must be established on a case-by-case basis taking into consideration unique containment design features and plant operating constraints, some of the topics addressed below may not always be relevant while other issues that are considered important may not be addressed. For this reason, the degradation assessment methodology developed does not include a step-by-step

\footnotetext{
* Degradation is considered to be any phenomenon that decreases the load-carrying capacity of a pressure-retaining component, limits its ability to contain a fluid medium, or reduces its service life. The root cause for component degradation can generally be linked to a design or construction problem, inappropriate material application, a base-metal flaw, or an excessively severe service condition.
} 
procedure for performing in-service condition assessments or conduct of continued service evaluations, but provides general, non-prescriptive guidance with respect to the four elements associated with in-service condition assessments.

\subsubsection{Damage Detection}

Detection of deteriorated or damaged containment pressure boundary components is the first and most important step in the condition assessment process. Certain types of damage such as grooves and gouges that can potentially jeopardize containment structural capacity or leak-tight integrity are often easy to identify by visual inspection, particularly when they occur in areas that are readily accessible. However, damage occurring in less accessible areas such as beneath nuts and washers, between flanges, or adjacent to seals and gaskets can be difficult to detect unless the components are disassembled. Damage that occurs in enclosed spaces such as corrosion of steel liner plate embedded in concrete or steel covered by flashing or caulking can only be reliably detected by removing the obstruction and exposing the suspect area. Routine observation, general visual inspections, leakage-rate testing, and nondestructive examinations are techniques frequently used to identify areas of the containment that have experienced degradation.

Knowing where to inspect and what type of damage to anticipate often requires information about the design features of the containment and the materials used to construct its pressure-retaining components. Design basis documentation is an important source of plant-specific information. As a living document, the design basis includes information such as the original design codes, material standards, fabrication drawings, design calculations, stress analyses, loading combinations, safety margins, corrosion allowances, and inspection reports as well as subsequent design changes and plant modifications. Construction details and dimensions of suspect areas can usually be obtained from design or as-built drawings, construction specifications, inspection reports, and plant logs. Areas of the containment pressure boundary considered suspect may include carbon and stainless steel component surfaces located along the path of borated water leaks, carbon steel surfaces exposed to water or condensation, and regions where the relative humidity is high (e.g., above 60 percent). USNRC documents such as Office of Inspection and Enforcement Bulletins, Information Notices, inspection and test reports, Generic Letters, Licensee Event Reports (LERs), NUREG reports, Federal Register notices, correspondence, and docket files describing degradation that has occurred at one or more plants can also be helpful in identifying suspect areas and preparing effective in-service inspection plans and programs. Several of these documents were listed in references for Chapter 1 as well as a listing of instances of containment pressure boundary component degradation (Table 1.1). Factors that contributed to the discovery of these instances of containment degradation (e.g., steel corrosion, coating degradation, bellows leakage, steel liner corrosion, liner plate separation, or liner leakage) are among the damage detection parameters identified in Fig. 2.4.

\subsubsection{Component configuration}

The leak-tightness of concrete and metal containment systems is ensured by a continuous pressure boundary consisting primarily of steel components that are either welded or bolted together. Each containment system includes the containment vessel and all penetration assemblies and appurtenances attached to the containment vessel as well as pipes, valves, and pumps required to complete the pressure boundary. Appurtenances are items intended to be attached to a component. An attachment is an element that is in contact with or connected to the inside or outside of the pressureretaining portion of a containment vessel. It may be either a pressure-retaining or nonpressure-retaining element that provides either a structural or nonstructural function (2.13). Attachments with a pressure-retaining function include items such as stiffeners and vessel opening reinforcement. Those with nonpressure-retaining function include items such as thermal sleeves, turning vanes, and containment vessel supports. The boundary between the containment vessel and an attachment is defined in the design specification. Design specifications are documents that provide the basis for design and construction of a containment vessel in accordance with requirements provided in the ASME Boiler and Pressure Vessel Code. Specific rules for defining the containment vessel boundary are provided in Section III, Division 1, Subsection NE and Division 2, Subsection CC of the ASME Code (2.13 and 2.14).

Relatively thin low-carbon steel plates ranging in thickness from about 6 to $51 \mathrm{~mm}$ are used to construct metal containment shells and concrete containment liners. Dimensions and locations of pressure boundary components are shown in the design drawings. These drawings illustrate the structural and mechanical details described in the design specifications. Terms commonly used to designate components that may be represented in design drawings and specifications include liners, electrical and mechanical penetration assemblies, piping penetrations, equipment hatches, airlocks, manways, leak-chase channels, nozzles, knuckles, closures, shells, heads, welds, bellows, torus, covers, supports, liner anchors, and embedments. As noted previously, containment pressure boundary components are fabricated primarily from carbon steel plates, shapes, bars, strips, pipes, tubes, castings, and forgings. However, low- 
and high-alloy steels are used in certain bolting applications, and high-alloy or stainless steels are used to fabricate special components such as bellows expansion joints. One way to identify the type, class, or grade of steel used to fabricate a particular component is to examine the design drawings and construction specifications. These documents generally use ASTM or ASME material specification designations to distinguish one steel from another. Accurate material identification is a very important damage detection parameter because it establishes baseline properties for the material, characterizes expected material performance, and focuses the search for possible degradation mechanisms.

\subsubsection{Environmental and operating conditions}

Knowledge about the environmental and operating conditions inside and outside the containment and information from operating experience, maintenance activities, and past service failures can provide valuable guidance on where to anticipate degradation, how to identify damage, and what degradation mechanisms caused the damage.

Environmental conditions inside BWR and PWR containments are controlled during normal plant operations. In certain plants, the containment is maintained under a slight vacuum and in others a small overpressure is applied. Heat generated by the nuclear reactor is removed by a ventilation and cooling system. The average temperature inside BWR Mark I containments ranges from about 57 to $66^{\circ} \mathrm{C}$ while the average temperature inside PWR containments is about $49^{\circ} \mathrm{C}$. Acceptable service temperature limits for the metallic materials used in containment construction are provided in applicable codes and standards (e.g., $A S M E$ Code). These limits have a significant influence on the allowable operating temperature range of the containment. One area of potential elevated temperature concern is in the containment shell near high temperature piping penetrations where temperatures can also fluctuate. To minimize the temperature effects, most plants insulate the pipes within the penetrations. Air chemistry inside the containment is also monitored and continuously adjusted to maintain a nearly constant environment. BWR Mark I and Mark II containments are inerted with nitrogen to prevent hydrogen-oxygen recombination. The oxygen content inside these containments is generally maintained at a level of less than four percent by volume (2.26). BWR Mark III and PWR containments are filled with air. During normal plant operations, water is usually not present inside PWR containments and relative humidity levels generally range from about 15 to 40 percent except for PWRs with ice-condensers where levels can range up to 60 percent. However, under certain conditions, condensate can form on colder surfaces located near the ice-condensers, or steam can be released inside the containment as a result of leaky flanges, valves, and pumps. Water produced in these instances is considered undesirable because it can create potentially corrosive situations as it flows over safety-related items or accumulates on pressure-retaining component surfaces. Unlike PWR containments, water is normally present inside BWR containments in the pressure suppression pools and chambers. The quality and chemistry of the water can influence the rate of corrosion of pressure boundary components that are in contact with the water. The relative humidity inside BWR containments can range up to 60 percent, but the humidity level varies from one location to another because the average temperature inside the containments does not always remain constant, and because the operating temperature in one area may be different from that in another. Although high radiation levels are generated inside the nuclear reactor, biological shielding effectively limits exposure of the containment pressure boundary materials to levels that are considered safe for occupational workers. Consequently, end-of-life fluence effects on containment components is anticipated to be quite small (2.27). Only in the unlikely event of a severe accident can the radiation levels inside the containment become significant.

Environmental conditions outside the containment can be significantly different from the conditions on the inside. All BWR and PWR metal containments are enclosed in a reactor shield building that protects the vessel from sun, wind, rain, sleet, and snow, but the atmospheric conditions inside these buildings may or may not be controlled, so certain local environments within these structures can be relatively harsh.* Outer surfaces of metal containments are either exposed directly to the reactor shield building environment, in contact with compressible filler material that separates the steel shell from the concrete reactor shield building, or embedded in the basemat concrete. The distance between the metal containment shell and the reactor shield building varies from one plant to another. In BWR Mark III and PWR plants with cylindrical steel containments, there is a large annular space between the steel shell and the reactor shield building. This space, which can be as large as 1.8 meters, allows access to the outer surface of the containment for direct

\footnotetext{
* Although the plants have been shut down, the spherical containments at Big Rock Point, San Onofre 1, and Yankee Rowe were exposed to the natural environment because they were constructed without reactor shield buildings. Exposed surfaces of these containments were protected by an extensive coating system that could be periodically inspected and maintained. Part of the Big Rock Point steel shell is embedded in the concrete basemat, but the other two containments are supported on steel columns.
} 
inspection and maintenance. The annular space between the steel shell and the reactor shield building in BWR Mark I and Mark II plants is much smaller and in some cases impossible to inspect or maintain. During construction of the reactor shield building of these plants (e.g., BWR MK I), a compressible filler material was placed against the steel shell to form a permanent 51- to 76-mm gap between the steel shell and the concrete shield wall. The gap was sized to accommodate differences in thermal expansion and contraction between the concrete and the steel shell and to permit unrestricted deformation during design-basis accidents. In some plants, the filler material was removed after construction, but in others it was left in place. Although water is not usually present in these gaps, the upper regions of BWR drywells are generally flooded during refueling causing cycles of wetting and drying in these areas. In addition, leaks from failed penetration seals, piping gaskets, and bellows expansion joints** may have introduced water into the gap areas creating potentially corrosive environments. In plants where the compressible filler material has not been removed, water can become trapped against the steel shell and cause corrosion. Contaminants (e.g., $\mathrm{Na}, \mathrm{K}, \mathrm{Mg}, \mathrm{SO}_{4}$, or $\mathrm{Cl}$ ) leached from the filler materials can accelerate the corrosion process (2.26). Water that eventually flows through the gap can end up accumulating in the sand pocket creating another potentially corrosive situation. These sand pockets are connected to drains that keep excess moisture from accumulating near the carbon steel shell. When the drains function properly, corrosion of the shell is usually not significant. However, when the drains fail or the water is not promptly removed, significant thinning of the shell can occur as a result of general or localized corrosion. In some BWR Mark I containments, galvanized steel plates cover the sand pockets and prevent moisture from entering these potentially vulnerable areas. For reinforced and post-tensioned concrete containments, outer surfaces of the pressure boundary are in direct contact with hardened concrete that protects the carbon steel liner and other metallic components from exposure to the natural environment and provides the necessary structural support. Carbon steel shells, anchors, and concrete containment liners that are embedded in Portland cement concrete are normally exposed to a high $\mathrm{pH}$ environment that ranges from about 12.5 to 13 . This environment promotes the formation of a passive iron oxide film that tends to inhibit corrosion. However, even in this high $\mathrm{pH}$ environment, chloride ions that penetrate the concrete can destroy the passive film on the steel and produce corrosion. Potential sources of chloride ion contamination include seawater for plants affected by ocean environments and ground water contaminated with chloride ions that permeates through the concrete to the level of the embedded carbon steel components. Fluid intrusion (e.g., water, cleaning fluids, and decontamination fluids) between the carbon steel shell of metal containments and the adjacent concrete can also produce corrosion (2.29). For this reason, caulking, flashing, and sealants are provided at concrete-to-steel interfaces to restrict access of fluids to steel surfaces in contact with concrete.

\subsubsection{Leakage-rate testing}

Regulations for preservice and subsequent periodic containment leakage-rate testing are provided in 10 CFR 50, Appendix J (2.1). This regulation contains requirements pertaining to Type A, B, and C leakage-rate tests that must be performed by each licensee as a condition of their operating license. As noted earlier (Sec. 2.1.1), the NRC amended Appendix $\mathrm{J}$ to provide a performance-based option for leakage-rate testing aimed at improving the focus of the body of regulations by providing an alternative to the prescriptive requirements that are marginal to safety and providing licensees greater flexibility for cost-effective implementation methods for regulatory safety objectives.

\subsubsection{Preservice and in-service inspection}

Preservice and in-service inspection requirements for metal and concrete containment pressure boundaries and rules for containment pressure testing are provided in Section XI, Division 1, Subsection IWE of the ASME Code (2.6). This consensus standard addresses examination of accessible metal surfaces; seals, gaskets, and moisture barriers; dissimilar metal welds; and pressure-retaining bolting. Requirements for system pressure testing and criteria for establishing inspection programs and pressure test schedules are also included. The inspections are intended to detect problems that could adversely affect the structural capacity of the containment and to periodically verify its leak-tight integrity.

\footnotetext{
**Containment bellows are susceptible to low-cycle fatigue and stress-corrosion cracking during normal plant operation. Since each ply of the bellows is relatively thin, scratches or indentations incurred during fabrication, installation, or operation can cause stress concentrations that reduce the fatigue life. Also, misalignment during installation can reduce the fatigue life by inducing additional stresses. Corrosion of stainless steel bellows is more likely to occur if stresses such as residual stresses from the cold-forming process are present, or mechanical wear or deformations are present. Transgranular stress-corrosion cracking of bellows has occurred resulting from exposure to chlorides, sulfides, or fluorides, that might have accumulated over time, in the presence of high residual and tensile stress (2.28).
} 
Inspection requirements for piping, pumps, and valves that complete the pressure boundary are provided elsewhere in Section XI.

Containment surface inspection requirements apply to metal containment pressure-retaining components and their integral attachments, and to metallic shell and penetration liners of concrete containments. Areas requiring periodic examination from at least one side of the vessel are listed in Table 2.8 (2.6, 2.24). A general visual examination of all accessible containment surfaces (not including surface areas that are submerged or insulated) is performed either directly or remotely by an examiner with visual acuity sufficient to detect evidence of degradation that could adversely affect either the containment structural capacity or leak-tight integrity. In areas that are painted or coated, evidence of flaking, blistering, peeling, discoloration, and other signs of distress may be considered suspect and could require further evaluation, repair, or replacement. In areas that are not coated or painted, evidence of cracking, discoloration, wear, pitting, excessive corrosion, arc strikes, gouges, surface discontinuities, dents, and other signs of surface irregularities may also require further evaluation, repair, or replacement. When surface flaws or suspect areas requiring further evaluation are detected, supplemental surface or volumetric nondestructive examinations may be required to determine the character of the flaw or to measure the extent of degradation. Magnetic particle and liquid penetrant are examples of surface examination techniques that could be used to establish the size, shape, and orientation of flaws. Radiography and ultrasonics are examples of volumetric examination techniques that are commonly used to measure the extent of subsurface degradation. Additional information about these and other nondestructive examination and inspection techniques is provided in Section 3.1. Decisions to accept, repair, or replace defective areas are often based on comparisons between current nondestructive examination results and recorded results from preservice and prior in-service examinations. Areas that have experienced change but are considered acceptable can be placed back into service without repair or replacement. However, the nondestructive examination results must be recorded for use in future evaluations.

Surface areas likely to experience accelerated degradation and aging require augmented examinations. These areas are specifically identified in the inspection program document prepared by the licensee and may include interior and exterior containment surfaces such as those identified in Table 2.9 (2.6, 2.33-3.36). Coated and uncoated areas requiring augmented examination are visually examined for evidence of coating degradation or surface flaws. Areas requiring further evaluation are then inspected using supplemental surface or volumetric examination techniques. Examinations that reveal material loss exceeding 10 percent of the nominal containment wall thickness must be documented, evaluated, and then either accepted, repaired, or replaced. Flaws or degraded areas that are evaluated and considered nonstructural in nature or have no effect on the structural integrity of the containment may be considered acceptable for continued service without repair or replacement. However, areas that contain these flaws or degradation must be reexamined during subsequent inspections.

Containment seals, gaskets, and accessible surfaces of moisture barriers are required to be visually examined during each in-service inspection to detect wear, damage, erosion, tear, surface cracks, or other defects that could affect leak-tight integrity. Seals and gaskets that are used to prevent leakage through airlocks, hatches, and other devices must be examined over their entire length. However, disassembly of sealed or gasketed connections is not required just to provide access for inspection. Surfaces of containment moisture barriers such as flashing, caulking, and other sealants must be inspected if they are accessible. Moisture barriers, which may be located on the inside or outside of the containment, are used at concrete-to-metal interfaces to prevent intrusion of moisture between the steel shell or liner and the concrete. Items considered defective must either be repaired or replaced.

Surfaces of pressure-retaining dissimilar metal welds subject to cyclic loads and thermal stresses during normal plant operations must be visually examined during each in-service inspection. Dissimilar metal welds include those between carbon or low-alloy steels and high-alloy steels, carbon or low-alloy steels and high nickel alloys, and high-alloy steels and high nickel alloys. The examination area includes the weld metal and the base metal for $12.7 \mathrm{~mm}$ beyond the edge of the weld. Surface examinations are performed to detect planar flaws, but during any particular in-service inspection, only 50 percent of the dissimilar metal welds require inspection. Allowable flaw sizes are provided in Section XI, Division 1, Subsection IWB of the ASME Code (2.37).

\subsubsection{Damage Classification}

Service-related degradation can affect the ability of a containment to perform satisfactorily in the unlikely event of a severe accident by reducing its structural capacity or jeopardizing its leak-tight integrity. The significance of component degradation can be assessed by comparing its in-service condition to its condition immediately after construction, or 
following a repair. Condition assessments require knowledge about potential degradation mechanisms and an understanding of environmental conditions that can promote deterioration. The root cause for component degradation can generally be linked to a design or construction problem, inappropriate material application, a base-metal flaw, or an excessively severe service condition. Determining what caused the degradation can help identify the type of damage that has occurred and define actions to be taken to reduce or eliminate further deterioration.

Damage occurs when the microstructure of a material is modified by exposure to a severe environment or when the geometry of a component is altered. Component degradation can be classified as either material or physical damage. Determining whether material or physical damage has occurred often requires information about the service conditions to which the component was exposed and an understanding of the degradation mechanisms that could cause such damage. Figure 2.5 lists the potential degradation mechanisms associated with material and physical damage.

\subsubsection{Material damage}

Material damage occurs when the microstructure of a metal is modified causing changes in its mechanical properties. When produced under controlled conditions, changes in the microstructure of a metal can have a beneficial effect. For example, metals such as high-carbon steels and certain alloy steels are heat treated to produce a specified hardness. However, when the exposure conditions are not controlled, such as in a fire, the mechanical properties (e.g., tensile and yield strength) of the affected metal can degrade to such an extent that the component is no longer suitable for its intended use.

Indications that material damage has occurred can occasionally be detected by visual examination or other nondestructive inspection techniques. For example, color variations in a metal surface may indicate that a component has been exposed to elevated temperatures (2.39), and microscopic examination of a metal section may show differences in microstructure caused by chemical attack. However, the effects of changes in microstructure on mechanical properties can only be determined by testing samples of the affected material. The magnitude of change in a mechanical property value is generally determined by comparing results obtained from specimens subjected to the environmental conditions of interest to results obtained from companion specimens tested under controlled laboratory conditions. Potential sources of material damage include excessive low- or high-temperature exposure, metallurgically-influenced corrosion (intergranular or dealloying), hydrogen embrittlement, and neutron irradiation. Table 2.10 provides information on each of these degradation mechanisms, however, material damage to metal containment pressure boundary components from any of these sources is not considered likely.

\subsubsection{Physical damage}

Physical damage occurs when the geometry of a component is altered by the formation of cracks, fissures, or voids, or its dimensions change due to overload, buckling, corrosion, erosion, or formation of other types of surface flaws. Changes in component geometry, such as wall thinning or pitting caused by corrosion, can affect structural capacity by reducing the net section that is available to resist applied loads. In addition, pits that completely penetrate through the component can compromise the leak-tight integrity of the containment.

Detection of physical damage is routinely accomplished by visual inspection, nondestructive examination, or destructive testing. However, the effects of physical damage on structural capacity or leak-tight integrity must be assessed on a case-by-case basis because its significance is a function of the magnitude of the damage and the location where the damage has occurred. For example, because stresses in a metal containment vessel vary from one location to another, uniform wall thinning over a relatively large area is more significant at locations where tensile stresses are the highest. Potential degradation methods associated with physical damage are summarized below and include general corrosion, localized corrosion, mechanically-assisted degradation, environmentally-induced cracking, and fatigue.

\subsection{General corrosion}

Corrosion is a chemical or electrochemical reaction between a material, usually a metal, and its environment that produces a deterioration of the material, and in some cases its properties. General corrosion of steel is degradation that

. Flaws are imperfections or unintentional discontinuities that are detectable by nondestructive examination (2.32). A defect is a flaw, discontinuity, or group of discontinuities whose indications do not meet specified acceptance criteria (2.38). 
produces uniform thinning and proceeds without appreciable localized attack. This type of corrosion is characterized by slow, nearly uniform loss of metal thickness over a wide area. Historical data for corrosion of carbon steel exposed to an industrial environment indicate general corrosion rates in the range of 0.003 to $0.03 \mathrm{~mm} / \mathrm{yr}$ (2.9). Damage caused by general corrosion is relatively easy to detect and quantify because it affects large areas that can usually be seen at arms length (2.40). General corrosion begins at an exposed metal surface and progressively alters the geometry of the affected component without changing the chemical composition of the material or its microstructure. Degradation initiates with the formation of a corrosion product layer and continues as long as at least one of the reactants is able to diffuse through the layer and sustain the reaction. The composition and characteristics of the layer can have a significant influence on the corrosion rate.

The most significant consequence of general corrosion of steels used to construct containment pressure boundary components is loss of section. This type of physical damage can result in reduced load-carrying capacity and possible containment leakage. Significant physical damage to carbon and low-alloy steel fasteners and pressure-retaining components of the primary system has occurred at a number of PWR plants $(2.41,2.42)$. The damage was attributed to boric acid $\left(\mathrm{H}_{3} \mathrm{BO}_{3}\right)$ attack. In a typical situation, as cooling water from the primary system seeped through leaky seals or gaskets, it flashed to steam leaving behind a sludge or paste consisting of dissolved boric acid and lithium hydroxide $(\mathrm{LiOH})$. The boric acid solution, which had a pH of 3 at $93^{\circ} \mathrm{C}$, caused general corrosion or wastage of carbon and lowalloy steel components and contributed to galvanic corrosion of carbon steel components that were welded to dissimilar metals. Although the physical damage caused by general corrosion of containment steels can be significant, this type of corrosion is thought to have no measurable affect on the mechanical properties of these metals. Specific forms of general corrosion that could potentially affect containment steel components are identified in Table 2.11. The table also describes the likelihood of physical damage to containment pressure boundary components caused by each form of general corrosion. Forms of general corrosion of most significance to containment metallic pressure-boundary components include atmospheric, aqueous, galvanic, and stray current.

\subsection{Localized corrosion}

Localized corrosion is similar to general corrosion except the rate of attack is usually much faster and the size of the affected area is significantly smaller. Damage caused by localized corrosion is often difficult to detect and quantify because visible surface flaws tend to be small and often do not provide a good indication of the extent of damage that has occurred under the surface (2.40).

The most significant consequence of localized corrosion of steels used to construct containment pressure boundary components is loss of section caused by crevice or pit formation. This type of physical damage is more likely to result in containment leakage than reduced load-carrying capacity. Pits and crevices caused by localized corrosion are thought to have no measurable effect on the strength or elastic properties of containment steels, but may reduce their ductility somewhat. Specific forms of localized corrosion that could potentially affect containment steel components are identified in Table 2.12. The table also describes the likelihood of physical damage to containment metallic pressure boundary components caused by each form of localized corrosion.

\subsection{Mechanically-assisted degradation}

Any type of physical damage that is caused by mechanical action is considered mechanically-assisted degradation. Actions that involve both a corrosion mechanism and mechanical wear or fatigue also fall into this category (2.40). Under certain conditions, mechanical wear, maintenance and repair activities, and equipment failures can cause loss of net section, wall thinning, discontinuities, stress concentrations, and dimensional changes in component geometry. A list of mechanically-assisted degradation mechanisms that could potentially cause physical damage to containment metallic pressure boundary components is presented in Table 2.13 .

\subsection{Environmentally-induced cracking}

Environmentally induced cracking is a type of degradation that occurs when cracks are produced in metals as a result of exposure to an environment. Stress-corrosion cracking, hydrogen damage, liquid-metal embrittlement, and solid metalinduced embrittlement are four forms of degradation commonly associated with environmentally-induced cracking (2.40). In general, as the yield strength and stress applied to a metal increase, its resistance to environmentally-induced cracking decreases. 
For steels in light-water reactor nuclear power plants, only two of these phenomena, stress-corrosion cracking and hydrogen damage, are possible because liquid metals are not present. The likelihood of physical damage to containment pressure boundary components caused by stress-corrosion cracking and hydrogen damage is described in Table 2.14.

\subsection{Fatigue}

Fatigue is the progressive, localized, and permanent structural change that occurs in a material subjected to repeated or fluctuating strains at normal stresses that have maximum values less than the tensile strength of the material (2.9). Fatigue failure is a three-step process. During the crack initiation phase, initial fatigue damage leads to crack formation. During the crack propagation phase, the crack increases in size. Finally, when the crack reaches the critical size, dependent on various factors including the material, temperature, and stress level, and the remaining uncracked section can no longer sustain the load, sudden failure of the remaining cross section occurs. Enhanced fatigue performance can be achieved by eliminating stress concentrations, avoiding the development of discontinuities, reducing residual stresses, and protecting the component from corrosion, erosion, or chemical attack. The likelihood of physical damage to containment pressure boundary components caused by fatigue is summarized in Table 2.14.

In most cases, the factors that cause changes in concrete containment vessel liner stress and strain levels with time (fatigue) occur only a small number of times and produce only minor changes in magnitude. The design of liners for reinforced concrete containments therefore is generally not controlled by fatigue considerations. However, fatigue may be considered a design issue in certain parts or areas of metal containments where thermal stress ratcheting occurs. Combinations of steady-state and cyclic loadings that produce a ratcheting action can cause a continuing increase in component deformation eventually leading to component failure. Guidance for performing fatigue evaluations under these conditions is provided in Section III, Division 1 of the ASME Code (2.13).

The suitability of a component for cyclic operations can be determined in two ways - using rules presented in the ASME Code, or conduct of cyclic load tests. In a fatigue analysis, allowable stress limits and corresponding numbers of permitted stress cycles are evaluated using fatigue design curves presented in Section III, Division 1, Appendix I(2.16). These curves reflect actual material performance because they were developed using results from uniaxial strain cycling tests. Values obtained from these curves include an appropriate safety factor. The fatigue resistance of a material or component can also be evaluated by cyclic load testing. The test sample should be fabricated using a material having similar properties and composition to that of the prototype. Results of cyclic load testing, however, cannot be used as justification for exceeding the allowable values of primary or primary plus secondary stresses provided by the fatigue design curves contained in Appendix I.

Although design rules for fatigue of steels used to construct containment pressure boundary components are included in the ASME Code, fatigue resulting from cyclic loads such as the ones listed in Table 2.15 is not expected to be a generic concern for either liners of reinforced concrete containments or the shells of metal containments (2.26).

\subsection{ROOT-CAUSE DETERMINATION}

Component degradation generally can be related to a design feature or deficiency, improper material selection, defective base metal, an incorrect fabrication practice or assembly technique, or an excessively severe service condition (2.43). Factors to be considered in determining the root cause for component degradation were listed in Fig. 2.6. Under certain conditions, degradation can be attributed to a combination of factors. For example, corrosion of the drywell shell in some Mark I metal containments has occurred near the sand cushion (2.44). The corrosion appears as general wastage of the carbon-steel drywell shell caused by a severe service condition in which water that leaked from a higher elevation within the containment accumulated in the sand. This type of degradation is more likely to occur in containments where the sand cushion is open to the gap between the drywell shell and the surrounding concrete than in containments where the sand cushion is covered with galvanized steel plates that are sealed to the drywell shell and the surrounding concrete. Differences in performance can be attributed to variations in the seal designs and the way in which the drainage systems function when a leak develops. Drains connected to the galvanized steel plates remove water before it reaches the sand cushion whereas drains located at the bottom of the sand cushion remove water after it has accumulated in the sand.

Degradation resulting from improper structural design can occur when mechanical or thermal loads are not accurately predicted or when features such as notches or sharp corners are specified. Buckling, necking, cracking, and fracture are examples of physical damage that can be caused by a problem related to design. Occasionally, structural modifications 
are required to eliminate potentially serious design deficiencies (2.45), but in general, degradation resulting from improper structural design is not a common aging issue.

Material selection plays a significant role in the long-term performance of structural components, especially when they are exposed to corrosive or severe environments. Except in situations where alternative materials are being considered for use in repair or replacement applications, material selection is generally not considered a containment aging issue. Ferrous metals permitted for construction of concrete and metal pressure boundary components are provided in Section III of the ASME Code $(2.13,2.14)$. Carbon steels are excellent structural materials because they are ductile, weldable, and relatively inexpensive. However, without adequate surface or cathodic protection, they will corrode. The only question is at what rate.

Base-metal flaws and differences in microstructure can be introduced during the ingot stage of manufacturing or during subsequent rolling or forming operations. Flaws are usually related to discontinuities or separations in the material whereas differences in metallurgy are influenced by localized heat treatment that produces areas of high hardness adjacent to areas of lower hardness. Terms commonly used to describe base-metal flaws include laminations, laps, slivers, scabs, seams, bark, or cracks. Material specifications often include acceptance criteria and repair procedures for flaws caused by the manufacturing process. However, some of these flaws are difficult, if not impossible, to detect during manufacture or inspection. Differences in the microstructure of a metal can cause variations in its properties from one location to another. These differences can be introduced by the manufacturing process, welding and heat treating operations, or an event such as an electrical short that produces an arc. Rules for inspection and testing of materials used in containment construction are provided in Section III of the ASME Code $(2.13,2.14)$. However, because all metals contain some type of base-metal flaw, their presence in pressure boundary components can potentially be responsible for in-service containment degradation.

Incorrect fabrication methods or faulty assembly techniques can cause structural failures or be responsible for in-service component degradation. Because of the importance of sound fabrication and construction practices on containment reliability and serviceability, rules for fabrication and construction of concrete and metal containments were established. These rules are provided in Section III of the ASME Code $(2.13,2.14)$ and address issues that involve welding, bolting, shop forming, hot or cold bending, end preparation for welding, heat treatment, and cleaning operations. Welding operations are particularly important because they can cause both physical and material damage, but in certain instances, weld flaws may have little or no consequences on containment performance. Bolting problems are generally related to torquing or tensioning operations with under tensioning causing problems such as leakage and over tensioning causing possible bolt failure. Heat treatment of containment pressure boundary components is generally not required because the sections are relatively thin. However, when heat treatment is required, it is usually performed to relieve or reduce residual stresses. Improper heat treatment or elimination of heat treatment when it is specified can be a serious concern because of its potential impact on structural performance. After welding and heat treating operations are completed, surface cleaning is often required to remove surface scale or to prepare the surface for coating. Cleaning operations may involve pickling in acid, grinding, or shot or sand blasting. These operations are usually not detrimental unless thinning of the component occurs or cleaning chemicals are not used properly.

Probably the most common cause for component degradation is an excessively severe service condition. When conditions are more severe than anticipated, the design could be inadequate, the materials could be inappropriate, or base-metal flaws could become sites for corrosion or fracture initiation. Conditions involving excessive stresses resulting from overpressurization of the containment, mechanical loads, fatigue, shock, or impact; overheating; leakage of corrosive fluids from the primary system or condensation; or other unanticipated environmental effects can cause significant component degradation. Documented case histories of degradation caused by exposure to severe environments can sometimes be used to help establish the root cause of the problem, identify other suspect locations, and provide suggested remedies. Detailed descriptions of the affected components and the degradation phenomena are especially valuable, particularly when illustrations or sharp color photographs of the problem areas are included (2.46).

\subsubsection{Damage Measurement}

One way to evaluate the significance of containment pressure boundary component degradation is by comparing its preservice condition to its condition after degradation has occurred. Condition assessment accuracy depends on the availability of quantifiable evidence such as dimensions of corroded surface areas, depths of corrosion penetration, or changes in material properties that indicate the extent and magnitude of the degradation. Methods for quantifying component degradation involve either nondestructive examination or destructive testing. Results from these 
investigations provide a measure of the extent of degradation at the time the component was examined. Techniques for establishing time-dependent change, such as corrosion and wear rates, involve periodic examination or testing. In-service monitoring provides a way to measure time-dependent changes in component geometry or material properties and to detect undesirable changes in operating conditions that may affect useful service life. Issues related to damage measurement are identified in Fig. 2.7. Details about specific examination procedures, test methods, and inspection techniques are provided later in this report.

\subsubsection{Nondestructive Examination.}

Nondestructive examination (NDE) is the development and application of technical methods to examine materials or components in ways that do not impair future usefulness and serviceability in order to detect, locate, measure, and evaluate discontinuities, defects, and other imperfections; to assess integrity, properties, and composition; and to measure geometrical characteristics (2.38). The objective of a nondestructive examination is to identify indications or evidence of a discontinuity that requires interpretation to determine its significance. Discontinuities are interruptions that may be either intentional or unintentional in the physical structure or configuration of a component (2.38). The diagram in Fig. 2.8 shows interpretations that can be made when a nondestructive examination produces an indication. A false indication is interpreted to be caused by a discontinuity at a location where no discontinuity exists. Nonrelevant indications are caused by a condition or discontinuity that is not rejectable. False indications are considered nonrelevant. Relevant indications are caused by a condition or discontinuity that requires evaluation resulting in a decision to either accept or reject the material or component. Flaws are imperfections or unintentional discontinuities that are detectable by a nondestructive examination (2.32). A defect is a flaw, discontinuity, or group of discontinuities whose indications do not meet specified acceptance criteria (2.38).

Rules for preoperational and in-service examination of pressure-retaining components are provided in Section XI, Division 1, Subsection IWA of the ASME Code (2.32). These rules include standards for examination evaluation, significant digits for limiting values of component thickness and flaw size, and characterization procedures for flaws detected by surface or volumetric examinations. According to these standards, flaw dimensions are determined by the size of a rectangle or square that fully contains the area of the flaw. Surface planar, subsurface planar, multiple planar, nonplanar, parallel planar, multiple nonaligned coplanar, multiple aligned separate, and laminar flaws are addressed in the standard.

\subsubsection{Flaw detection}

Flaw detection is one of the most important objectives of a nondestructive examination. Some of the techniques that have been used to detect flaws include visual inspection, replication microscopy, liquid penetrant, magnetic particle, magnetic field, eddy current, ultrasonic, radiography, X-radiography computed tomography, neutron radiography, thermography, optical holography, speckle metrology, digital image enhancement, electric current perturbation, magabsorption, and acoustic emission. Selection of a suitable flaw detection technique depends on the flaw's anticipated size, shape, orientation, and location, and whether it is expected to be a volumetric or planar flaw. Practical and effective flaw detection often requires use of a variety of techniques that yield complementary information.

\subsubsection{Leak detection}

Leak detection is a nondestructive examination technique that can be used to detect special types of flaws such as through-wall discontinuities or passages through which fluid flows or permeates. These flaws allow liquids or gases to escape from pressurized (or into evacuated) components or systems intended to contain these fluids. Leak testing is generally performed to locate a leak, determine the leakage rate, or monitor for leakage. Leakage rate is the amount of fluid that flows through a flaw per unit of time under a prescribed set of conditions. Containment-related leakage-rate testing was discussed earlier.

\subsubsection{Location detection}

Location detection is occasionally used to verify that an assembly actually contains the required parts. This technique is particularly useful when the parts are not accessible for visual examination. In nuclear power plants, it could be necessary to use location detection techniques to verify the presence or determine the location of liner anchors or attachments embedded in a concrete containment. Some of the techniques that have been used for location detection include X-radiography, X-radiography computed tomography, and neutron radiography (2.47). 


\subsubsection{Metrology}

Metrology is the measurement of dimensions. It is a widely used nondestructive examination technique for establishing the size and shape of objects including flaws and discontinuities. Tools for dimensional measurements include conventional hand-held devices such as rulers, gages, and micrometers as well as coordinate measuring machines and sophisticated systems based on laser technology. Dimensions are an important part of a condition assessment because they provide an accurate description of the size of an affected area or the characteristics of a detected flaw. Precise flaw dimensions are vital to fracture mechanics evaluations.

\subsubsection{Structure or microstructure characterization.}

Field replication microscopy is a nondestructive examination technique that was developed for use in characterizing the structure or microstructure of a material while it remains in service (2.48). This technique does not involve removal of material for laboratory examination but records and preserves the topography of a metallographic specimen as a negative relief on a plastic film. Results from field replication microscopy can be used to accurately characterize the microstructure of damaged material and to help establish the root cause for the degradation. The results also may be used to determine whether a crack resulted from creep, fatigue, or corrosion. Cracks caused by creep begin as small holes or cavities at the grain boundaries and eventually link up to cause failure. Fatigue cracks are generally singular defects that extend across many grain boundaries. Intergranular cracking tends to follow the grain boundaries. Transgranular cracks such as those caused by stress corrosion extend across grain boundaries forming an interconnected random pattern.

\subsubsection{Estimation of mechanical and physical properties}

Material properties potentially can be estimated using results from nondestructive examination techniques provided the results are influenced by material microstructure (2.47). Eddy current, ultrasonic, X-radiography and neutron radiography, computed tomography, thermography, and acoustic microscopy techniques are likely candidates because the results can be related to mechanical or physical properties. However, these techniques are more suited for locating areas where the microstructure is different by comparison.

\subsubsection{Stress-strain and dynamic response determination}

The response of a component to a specific set of loading conditions can be determined using sensing techniques such as photoelastic coatings, brittle coatings, and strain gages or displacement transducers. Resulting strain or displacement values combined with known applied stresses can be used to establish the stress-strain characteristics of the material. Strain sensing and displacement measuring techniques also can be used to characterize the dynamic response of a component subjected to shock, impact, or vibration.

Residual stresses in metallic materials can be determined using nondestructive and "semi-destructive" examination techniques. Near-surface residual stresses can be measured using nondestructive examination techniques that involve either X-radiography diffraction or electromagnetic methods (2.47). Residual stresses just below the surface can be measured using the hole-drilling strain gage technique (2.49). This technique is often described as "semi-destructive" because the damage that it causes is very localized and in many cases does not significantly affect the usefulness of the component.

\subsubsection{Signature analysis}

The dynamic response of a component is called a signature. Accelerometers, acoustic and displacement transducers, and strain gages can be used to establish the signature of a component produced by a specified set of loading conditions. Analysis of the signature can be correlated with machine noise, shock, vibrations, or structural instability such as buckling or cracking. Time-dependent signature differences may indicate that the component's geometry has changed as a result of cracking, fracture, or buckling or that its mass has changed due to corrosion or erosion. Changes in elastic properties can also affect the signature because the structural stiffness of a component is a function of the modulus of elasticity of the material. 


\subsubsection{Chemical composition determination}

The chemical composition of a metal can be determined using a sample of the metal obtained during the pouring of the heat (heat analysis) or a sample of the finished product (product analysis). Chemical requirements for heat and product analyses are provided in the material specification.

\subsubsection{Corrosion characterization}

Damage caused by general and localized corrosion can often be detected using the same nondestructive examination techniques that are used to detect flaws. However, the amount of corrosion that has occurred can be difficult to characterize or quantify depending on the specific type of corrosion involved. The types of general and localized corrosion that can potentially affect containment pressure boundary components were identified and described in Tables 2.11 and 2.12 .

\subsection{General corrosion}

General corrosion, which is one of the most common forms of corrosion, is characterized by uniform thinning. Thickness variations caused by general corrosion and the size of the affected area can generally be measured by metrology. However, when access is limited, other techniques such as ultrasonics may be required (2.50). The rate at which general corrosion attacks metal is often expressed in units of length per unit of time such as millimeters per year $(\mathrm{mm} / \mathrm{y})$, but a variety of other units may also be used. Equations for determining average corrosion rates from test specimen data have been developed (2.51). These equations factor in exposure time, surface area, material density, and mass loss of the specimen. However, corrosion rates calculated from mass loss can be misleading especially when deterioration is highly localized, as in pitting or crevice corrosion.

A means for quantifying the amount of rust present on a painted steel surface also has been developed (2.52). This test method covers the evaluation of the degree of rusting using visual standards and descriptions of 11 rust grades. In this method, Rust Grade 10 corresponds to no rust or less than 0.01 percent of surface rusted, Rust Grade 4 corresponds to rusting to the extent of 10 percent of surface rusted, and Rust Grade 0 corresponds to approximately 100 percent of surface rusted.

\subsection{Pitting corrosion}

Pitting corrosion is localized corrosion of a metal surface, confined to a point or small area, that takes the form of cavities. The extent of pitting corrosion can be determined while the affected component remains in service or in a laboratory using representative samples of the pitted metal. Pits may be round, elongated, or irregularly shaped and have cross-sectional variations (i.e., narrow and deep, elliptical, wide and shallow, subsurface, undercutting, horizontal, and vertical).

Whenever possible, visual inspection is performed to establish the location and density of pits and to identify affected areas. Nondestructive examinations based on radiographic, electromagnetic, ultrasonic, and penetrant techniques can also be used to detect pitting and to establish pit shapes and densities, but these techniques may not be as effective as visual inspections combined with metallographic examinations that use representative portions of the affected metal. Results from metallographic examinations can be particularly important because they can be used to determine whether there is a relationship between pits and inclusions or microstructure, or whether the cavities are true pits or might have resulted from effects such as metal dropout caused by intergranular corrosion or dealloying. The extent of pitting is not usually related to mass loss unless general corrosion is slight and pitting is fairly severe. Under these conditions, mass loss data can be valuable, particularly in a laboratory investigation. Pit depth can be determined by metallographic examination of a pitted region of metal removed from the affected component, or by machining operations that gradually remove layers of metal exposing the pitted cross section. Nondestructive examination techniques involving metrology and microscopy also can be effective in determining pit depth, as long as the base or bottom of the pit can be established. Pitting can be described or quantified in terms of density, size, and depth using standard rating charts (2.53); as well as by depth measurements, statistical methods, and changes in mechanical properties. The ratings offer an effective means for reporting data for comparison with other test results, but measurements required to establish the ratings are time consuming and tedious to obtain. Depth measurements of the deepest pits are particularly important when the affected component is part of the containment pressure boundary because a through-thickness hole could lead to loss of leak-tight integrity. 


\subsection{Crevice corrosion}

Crevice corrosion is localized corrosion of a metal surface at, or immediately adjacent to, an area that is shielded from full exposure to the environment because of close proximity between the metal and the surface of another material. Visual detection of crevice corrosion can be difficult or impossible because locations where it occurs are often inaccessible. Crevices generally can be classified either as naturally occurring or man made. Some naturally occurring sources of cervices are biofouling, sediment, debris, and deposits. Man-made crevices are created during manufacturing, fabrication, assembly or service. The geometry of a crevice can be described by the dimensions of the crevice gap and crevice depth (2.54).

\subsubsection{Destructive Testing.}

Tests that alter the shape, form, size, or structure of the material being tested are considered destructive tests (2.55). These tests may be performed to determine mechanical, physical, chemical, thermal, or other properties of the material, or to examine the material for microstructural imperfections, voids, or inclusions. Destructive tests commonly used to determine mechanical properties of metallic materials involve tension, compression, ductility, shear, torsion, bend, creep, stress-relaxation, hardness, fatigue, or fracture testing. Test methods that require the removal and testing of representative portions of material from a component are also considered destructive tests when the affected component is rendered useless or unfit for future service.

\subsubsection{Tension testing}

Tension testing involves the gradual application of increasing uniaxial elongation to a test specimen until failure occurs (2.56). Measurements obtained during tension testing can be used to develop stress-strain curves and to establish mechanical property values such as the modulus of elasticity, ultimate tensile elongation, ultimate tensile strength, yield strength, yield point, and reduction of area.

Property values obtained from tension testing are generally used to determine conformance or nonconformance with material specifications. However, test results can also be used to compare the performance and properties of replicate specimens tested under a variety of exposure conditions or using different testing methods. Replicate specimen results can provide a basis for establishing limits on environmental exposure, working stresses, or operating temperatures.

\subsubsection{Hardness Testing}

Hardness testing is widely used for determining the relative quality of a metallic component and to establish the uniformity of its material properties. It is relatively easy to perform, requires very little material or surface preparation, and usually causes minimal surface damage to the material or component. Testing usually involves an indention hardness tester that uses small diamond points or hardened round steel balls to produce permanent indentations or deformations in the surface of the material being tested. Because a hardness test does not measure a well-defined property, caution should be exercised when hardness indications or numbers obtained using one test method are converted to those obtained using another (2.57) or when hardness test results are used to approximate material property values such as tensile strength (2.55). Numerous hardness test methods have been developed, but the Brinell and the Rockwell hardness tests are commonly used (2.55).

\subsubsection{Metallography}

Metallography is the branch of science that relates to the constitution and structure, and their relation to the properties of metals and alloys (2.58). Metallographic testing begins with the selection of material for examination. After selection and removal, the sample is firmly mounted for grinding and polishing (2.59). The polished surface is then examined visually using a microscope to reveal imperfections such as cracks, voids, or entrapped nonmetallics. This is followed by treatment with an etchant, such as a two-percent solution of nitric acid in alcohol, and reexamination. A photograph of the polished surface showing the observed microstructure is usually prepared to serve as a record of the examination. Metallography is probably the most useful destructive testing method available for identifying differences in material microstructure caused by exposure to high temperatures or severe environments. 


\subsubsection{In-Service Monitoring.}

In-service monitoring involves periodic examination of a containment pressure boundary component while it remains in service. This type of examination is different from the preservice inspection that is conducted before a containment is placed into service and the in-service inspections that are performed on a regular basis over the operating life of the plant. In-service monitoring generally involves repeated examination of a flawed component or suspect area using one or more nondestructive examination techniques. Data collection can be performed on a case-by-case basis at irregular intervals, or at prescribed times using a computer-controlled data acquisition system. Results obtained from individual in-service examinations can be used to determine the status of a degraded component and to accurately assess its current condition. Time-dependent results can be used to establish instantaneous or average degradation rates for use in estimating remaining service life. As an aging-management tool, results obtained from in-service monitoring can be used to guide the selection of appropriate examination techniques, specify testing methods, and establish the frequency of subsequent inspections. One of the most important potential benefits from in-service monitoring is the detection of undesirable changes in the operating conditions that can adversely affect the performance and useful life of containment pressure boundary components. Selection of nondestructive examination techniques for in-service monitoring requires an understanding of the capabilities and limitations of the various examination options, the types of data that are needed, the frequency and accuracy with which the data are to be collected, and the configuration of the component being monitored.

\subsection{COMMENTARY}

In-service condition assessments play an important part in the aging management of nuclear power plants by providing vital information for continued service evaluations and service life estimations. Knowledge gained from condition assessments can serve as a baseline for evaluating the safety significance of any damage that may be present and defining in-service inspection programs and maintenance strategies. Condition assessment results can also be used in estimating future performance and remaining service life.

Condition assessments involve detecting damage in areas that are potentially vulnerable to in-service deterioration or attack, classifying the types of damage that may be present, determining the root cause of the problem, and quantifying the extent of degradation that may have occurred. Degradation is considered to be any phenomenon that decreases the load-carrying capacity of a pressure-retaining component, limits its ability to contain a fluid medium, or reduces its service life. The four elements of an in-service condition assessment include:

Damage Detection - Damage detection is the first and most important step in the condition assessment process. Routine observation, general visual inspections, leakage rate testing, and nondestructive examinations are techniques frequently used to identify areas of the containment that have experienced degradation. However, damage such as wall thinning caused by corrosion can occur in inaccessible locations making detection difficult or impossible. Knowing where to inspect and what type of damage to anticipate often requires information about the design features of the containment and the materials used to construct its pressure-retaining components.

Damage Classification - Damage occurs when the microstructure of a material is modified by exposure to a severe environment or when the geometry of a component is altered. Determining whether material or physical damage has occurred often requires information about the service conditions to which the component was exposed and an understanding of the degradation mechanisms that could cause such damage.

Root-Cause Determination - The root cause for component degradation can generally be linked to a design or construction problem, inappropriate material application, a base-metal flaw, or an excessively severe service condition. Determining what caused the degradation can help in identifying the type of damage that has occurred and defining appropriate actions to be taken to reduce or eliminate further deterioration.

Damage Measurement - One way to evaluate the significance of containment pressure boundary component degradation on structural capacity and leaktight integrity is by comparing its preservice condition to its condition after degradation has occurred. Condition assessment accuracy depends on the availability of quantifiable evidence such as dimensions of corroded surface areas, depths of corrosion penetration, or changes in material properties that indicate the extent and magnitude of the degradation. Methods for quantifying component degradation involve either nondestructive examination or destructive testing. Results from these 
investigations provide a measure of the extent of degradation at the time the component was examined. Techniques for establishing time-dependent change such as corrosion and wear rates involve periodic examination or testing. In-service monitoring provides a way to measure time-dependent changes in component geometry or material properties and to detect undesirable changes in operating conditions that could affect useful service life.

Current requirements for in-service condition assessments and continued service evaluations of metal and concrete containment structures and components in nuclear power plants are provided in 10 CFR 50, Appendix J (2.60,2.61). According to these regulations, a general inspection of accessible containment surfaces must be performed prior to each Type A leakage rate test and at two other refueling outages before the next Type A test, if the interval for the Type A test has been extended to 10 years (2.62), to uncover any evidence of structural deterioration that may affect either the containment structural integrity or leaktightness. When evidence of degradation is detected, corrective actions involving either repair, nondestructive examination, or testing must be taken before the containment can be returned to service. Safety-related structures in NPPs present special challenges for development of acceptance criteria because of their massive size, limited accessibility in certain areas, stochastic nature of past and future loads, randomness in strength, uncertainty in material changes due to aging and possibly degradation, and qualitative nature of many nondestructive evaluation techniques.

More detailed inspection requirements, acceptance standards, and evaluation criteria for use in determining the acceptability of degraded components for continued service are provided in Section XI, Division 1, Subsection IWE of the Code $(2.63,2.64)$. According to these. rules, components that are not damaged can be considered acceptable for continued service, but damaged components must be evaluated. Evaluations are performed to determine whether the damage is significant enough to adversely affect structural capacity, leaktight integrity, or remaining service life. Components without significant damage are allowed to remain in service, but components with significant damage must be evaluated further to determine whether repairs, replacements, or retrofits are needed.

\subsection{REFERENCES}

2.1 "Primary Reactor Containment Leakage Testing for Water-Cooled Power Reactors," Nuclear Regulatory Commission, Federal Register, Vol. 60, No. 186, Tuesday, September 26, 1995, pp. 49495-49505.

2.2 Performance-Based Containment Leak-Test Program, Regulatory Guide 1.163, U.S. Nuclear Regulatory Commission, Washington, DC, September 1995.

2.3 Industry Guideline for Implementing Performance-Based Option of 10 CFR Part 50, Appendix J, NEI 94-01, Revision 0, Nuclear Energy Institute, July 26, 1995.

2.4 Containment System Leakage Testing Requirements, ANSI/ANS-56.8, American Nuclear Society, La Grange Park, Illinois, 1994.

2.5 ASME Boiler and Pressure Vessel Code, American Society of Mechanical Engineers, New York, New York, 1988.

2.6 "Rules for Inservice Inspection of Nuclear Power Plant Components," ASME Boiler and Pressure Vessel Code, Section XI, Division 1, Subsection IWE, Requirements for Class MC and Metallic Liners of Class CC Components of Light-Water Cooled Power Plants, American Society of Mechanical Engineers, New York, New York, July 1, 1995.

2.7 Oland, C.B. and Naus, D.J., Plan for Collecting and Presenting Properties of Containment Pressure Boundary Steels, ORNL/NRC/LTR-95/2, Oak Ridge National Laboratory, Oak Ridge, Tennessee, April 1995.

2.8 Oland, C.B. and Naus, D.J., Structural Materials Information Center for Presentation of the Time Variation of Material Properties, ORNL/NRC/LTR-90/22, Oak Ridge National Laboratory, Oak Ridge, Tennessee, November 1990.

2.9 "Volume 1 - Properties and Selection: Irons, Steels, and High-Performance Alloys," Metals Handbook, Tenth Edition, ASM International, Materials Park, Ohio, March 1990. 
2.10 "Standard Guide for the Identification of Metals and Alloys in Computerized Material Property Databases," ASTM Designation: E 1338-90, 1991 Annual Book of ASTM Standards, Vol. 14.01, American Society for Testing and Materials, West Conshohocken, Pennsylvania, 1991.

2.11 "Standard Test Methods and Definitions for Mechanical Testing of Steel Products," ASTM Designation: E 370-89, 1990 Annual Book of ASTM Standards, Vol. 01.02, American Society for Testing and Materials, West Conshohocken, Pennsylvania, 1990.

2.12 "Materials," ASME Boiler and Pressure Vessel Code, Section II, Part A - Ferrous Materials Specifications, American Society of Mechanical Engineers, New York, New York, July 1, 1992.

2.13 "Rules for the Construction of Nuclear Power Plant Components," ASME Boiler and Pressure Vessel Code, Section III, Division 1 - Subsection NE, Class MC Components, American Society of Mechanical Engineers, New York, New York, July 1, 1995.

2.14 "Rules for Construction of Nuclear Power Plant Components," ASME Boiler and Pressure Vessel Code, Section III, Division 2 - Subsection CC, Code for Concrete Reactor Vessels and Containments (Prestressed or Reinforced), American Society of Mechanical Engineers, New York, New York, July 1, 1995.

2.15 "Materials," ASME Boiler and Pressure Vessel Code, Section II, Part D - Properties, American Society of Mechanical Engineers, New York, New York, July 1, 1995.

2.16 "Division 1 - Appendices," ASME Boiler and Pressure Vessel Code, Section III, American Society of Mechanical Engineers, New York, New York, July 1, 1995.

2.17 Marchbanks, M.F., A Review and Assessment of Materials Property Databases with Particular Reference to Concrete Material Systems, ORNL/NRC/LTR-89/3, Oak Ridge National Laboratory, Oak Ridge, Tennessee, March 1989.

2.18 Oland, C.B., Marchbanks, M.F., and Naus, D.J., Plan for Use in Development of the Structural Materials Information Center, ORNL/LTR-89/8, Oak Ridge National Laboratory, Oak Ridge, Tennessee, September, 1989.

2.19 Naus, D.J., Oland, C.B., and Ellingwood, B.R., Report on Aging of Nuclear Power Plant Reinforced Concrete Structures, NUREG/CR-6424 (ORNL/TM-13148), Oak Ridge National Laboratory, Oak Ridge, Tennessee, March 1996.

2.20 Oland, C.B. and Naus, D.J., Summary of Materials Contained in the Structural Materials Information Center, ORNL/LTR-94/22, Oak Ridge National Laboratory, Oak Ridge, Tennessee, November 1994.

2.21 Mat.DB, Version 1.22, ASM International, ASM/Center for Materials Data, Materials Park, Ohio, 1992.

2.22 EnPlot, Version 3.5, ASM International, ASM/Center for Materials Data, Materials Park, Ohio, 1993.

2.23 Oland, C.B. and Naus, D.J., Degradation Assessment Methodology for Application to Steel Containments and Liners of Reinforced Concrete Structures in Nuclear Power Plants, ORNL/NRC/LTR-95/29, Oak Ridge National Laboratory, Oak Ridge, Tennessee, February 1996.

2.24 Sammataro, R.F., "Updated ASME Code Rules for Inservice Inspection of Steel and Concrete Containments," Proceeding of the Fifth Workshop on Containment Integrity, NUREG/CP-0120, (SAND92-0173) U.S. Nuclear Regulatory Commission, Washington, DC, July 1992.

2.25 Guidelines for Structural Condition Assessment of Existing Buildings, ANSI/ASCE 11-90, American Society of Civil Engineers, New York, New York, August 1, 1991. 
2.26 Shah, V.N., Smith, S.K., and Sinha, U.P., Insights for Aging Management of Light Water Reactor Components, NUREG/CR-5314, (EGG-2562), Vol. 5, Idaho National Engineering Laboratory, Idaho Falls, Idaho, March 1994.

2.27 Science Applications Inc., Study of Radiation Dosage to Structural Components in Nuclear Reactors, EPRINP-152, Electric Power Research Institute, Palo Alto, California, 1977.

2.28 Brown, J.A. and Tice, G.A., "Containment Penetrations - Flexible Metallic Bellows Testing, Safety, Life Extension Issues," Proceeding of the Fifth Workshop on Containment Integrity, NUREG/CP-0120, (SAND92-0173) U.S. Nuclear Regulatory Commission, Washington, DC, July 1992.

2.29 Swiat, W., Young, W., Pajak, J., Funahashi, M., Burke, D., and Wagner, J., State-of-the-Art-Report Corrosion of Steel in Concrete, ORNL/NRC/LTR-93/2, Oak Ridge National Laboratory, Oak Ridge, Tennessee, May 1993.

2.30 Guidelines on Nuclear Safety-Related Coatings, EPRI TR-109937, Electric Power Research Institute, Palo Alto, California, April 1998.

2.31 Stuart, C.O., "Underwater Coating Repair Cuts Nuclear Maintenance Costs," Power Engineering, Vol. 97, No. 7, pp. 31-34, July 1993.

2.32 "Rules for Inservice Inspection of Nuclear Power Plant Components," ASME Boiler and Pressure Vessel Code, Section XI, Division 1, Subsection IWA, General Requirements American Society of Mechanical Engineers, New York, New York, July 1, 1995.

2.33 Shah, V.N. and MacDonald, P.E., Eds., Residual Life Assessment of Major Light Water Reactor Components Overview, NUREG/CR-4731, (EGG-2469) Vol. 2, Idaho National Engineering Laboratory, Idaho Fall, Idaho, November 1989.

2.34 Shah, V.N. and MacDonald, P.E., Eds., Residual Life Assessment of Major Light Water Reactor Components Overview, NUREG/CR-4731, (EGG-2469) Vol. 1, Idaho National Engineering Laboratory, Idaho Fall, Idaho, June 1987.

2.35 Smith, S. and Gregor, F., BWR Containments License Renewal Industry Report; Revision 1, EPRI TR-103840, prepared by MDC-Ogden Environmental and Energy Services Co., Inc., for the Electric Power Research Institute, Palo Alto, California, July 1994.

2.36 Deng, D., Renfro, J., and Statton, J., PWR Containments License Renewal Industry Report; Revision 1, EPRI TR-103835, prepared by Bechtel Power Corporation for the Electric Power Research Institute, Palo Alto, California, July 1994.

2.37 Rules for Inservice Inspection of Nuclear Power Plant Components," ASME Boiler and Pressure Vessel Code, Section XI, Division 1, Subsection IWB, Requirement for Class 1 Components of Light-Water Cooled Power Plants, American Society of Mechanical Engineers, New York, New York, July 1, 1995.

2.38 "Standard Terminology for Nondestructive Examinations," ASTM Designation: E 1316-91b, 1991 Annual Book of ASTM Standards, Vol.03.03, pp. 587-620, American Society for Testing and Materials, West Conshohocken, Pennsylvania, 1991.

2.39 Modern Steels and Their Properties, Sixth Edition, Handbook 268-H, Bethlehem Steel Corporation, Bethlehem, Pennsylvania, 1967.

2.40 "Volume 13 - Corrosion," ASM Handbook (formerly ninth edition, Metals Handbook), ASM International, Materials Park, Ohio, September 1987.

2.41 Neill, A.S. and Hall, J.F., Boric Acid Corrosion of Carbon and Low-Allow Steel Pressure-Boundary Components in PWRs, EPRI NP-5985, Electric Power Research Institute, Palo Alto, California, August 1988. 
2.42 Czajkowski, C.J., Survey of Boric Acid Corrosion of Carbon Steel Components in Nuclear Plants, NUREG/CR-5576 (BNL-NUREG-52239), Brookhaven National Laboratory, Upton, New York, June 1990.

2.43 Thielsch, H., Defects and Failures in Pressure Vessels and Piping, Reinhold Publishing Corporation, New York, New York, 1965.

2.44 Generic Letter 87-05, U.S. Nuclear Regulatory Commission To All Licensees of Operating Reactors, Applicants for Operating Licenses, and Holders of Construction Permits for Boiling Water Reactors (BWRs) with Mark I Containments, Subject: Request for Additional Information-Assessment of Licensee Measures to Mitigate and/or Identify Potential Degradation of Mark I Drywells, pp. 1-8, March 12, 1987.

2.45 Examination of Mark-1 Containment Torus Welds, U.S. Nuclear Regulatory Commission, Office of Inspection and Enforcement, IE Bulletin 78-11, pp. 1-3, July 24, 1978.

2.46 During, E.D.D. (Editor), Corrosion Atlas, Vols. 1 and 2, Elsevier Science Publishers, Amsterdam, The Netherlands, 1991.

2.47 "Volume 17 - Nondestructive Evaluation and Quality Control," ASM Handbook (formerly ninth edition, Metals Handbook), ASM INTERNATIONAL, Materials Park, Ohio, 1989.

2.48 "Standard Practice for Production and Evaluation of Field Metallographic Replicas," ASTM Designation: E 1351-90, 1992 Annual Book of ASTM Standards, Vol. 03.01, pp. 988-993, American Society for Testing and Materials, West Conshohocken, Pennsylvania, 1992.

2.49 "Standard Test Method for Determining Residual Stresses by the Hole-Drilling Strain-Gage Technique," ASTM Designation: E 837-92, pp. 747-753, 1992 Annual Book of ASTM Standards, Vol. 03.01, American Society for Testing and Materials, West Conshohocken, Pennsylvania, 1992.

2.50 Gordon, B.M., "Corrosion Issues in the BWR and Their Mitigation for Plant Life Extension," Proceedings of the Topical Meeting on Nuclear Power Plant Life Extension, held in Snowbird, Utah, July 31-August 3, 1988, pp. 180-187, American Nuclear Society, LaGrange Park, Illinois.

2.51 "Standard Practice for Preparing, Cleaning, and Evaluating Corrosion Test Specimens," ASTM Designation: G 1-90, 1991 Annual Book of ASTM Standards, Vol. 03.02, pp. 35-41, American Society for Testing and Materials, West Conshohocken, Pennsylvania, 1991.

2.52 "Standard Test Method for Evaluating Degree of Rusting on Painted Steel Surfaces," ASTM Designation: D 610-85, 1991 Annual Book of ASTM Standards, Vol. 06.01, pp. 65-67, American Society for Testing and Materials, West Conshohocken, Pennsylvania, 1991.

2.53 "Standard Practice for Examination and Evaluation of Pitting Corrosion," ASTM Designation: G 46-76, 1991 Annual Book of ASTM Standards, Vol. 03.02, pp. 166-172, American Society for Testing and Materials, West Conshohocken, Pennsylvania, 1991.

2.54 "Standard Guide for Crevice Corrosion Testing of Iron-Based and Nickel-Base Stainless Alloys in Seawater and Other Chloride-Containing Aqueous Environments," ASTM Designation: G 78-89, 1991 Annual Book of ASTM Standards, Vol. 03.02, pp.318-323, American Society for Testing and Materials, West Conshohocken, Pennsylvania, 1991,.

2.55 Anderson, R.C., Inspection of Metals, Volume II: Destructive Testing, ASM International, Materials Park, Ohio, 1988.

2.56 "Standard Test Method for Tension Testing of Metallic Materials," ASTM Designation: E 8-91, 1992 Annual Book of ASTM Standards, Vol.03.01, pp. 130-149, American Society for Testing and Materials, West Conshohocken, Pennsylvania, 1992. 
2.57 "Standard Hardness Conversion Tables for Metals," ASTM Designation: E 140-88, 1992 Annual Book of ASTM Standards, Vol. 03.01, pp. 334-349, American Society for Testing and Materials, West Conshohocken, Pennsylvania, 1992.

2.58 “Standard Terminilogy Relating to Metallography," E 7-92, 1992 Annual Book of ASTM Standards, Vol. 03.01, pp. 103-129, American Society for Testing and Materials, West Conshohocken, Pennsylvania, 1992.

2.59 "Standard Method of Preparation of Metallographic Specimens," ASTM Designation: E 3-80, 1992 Annual Book of ASTM Standards, Vol.03.01, pp. 82-86, American Society for Testing and Materials, West Conshohocken, Pennsylvania, 1992.

2.60 Nuclear Regulatory Commission, "Part 50 - Domestic Licensing of Production and Utilization Facilities," pp. 634 - 784, in Code of Federal Regulations, 10 CFR, January 1, 1995.

2.61 Nuclear Regulatory Commission, "Primary Reactor Containment Leakage Testing for Water-Cooled Power Reactors,” Federal Register, Vol. 60, No. 186, pp. 49495 - 49505, September 26, 1995.

2.62 Nuclear Regulatory Commission, Performance-based Containment Leak-Test Program, Regulatory Guide 1.163, Washington, DC, September 1995.

2.63 Rules for Inservice Inspection of Nuclear Power Plant Components, "ASME Boiler and Pressure Vessel Code," Section XI, Subsection IWE, Requirements for Class MC and Metallic Liners of Class CC Components of Light-Water Cooled Plants, American society of Mechanical Engineers, New York, New York, July1, 1995.

2.64 Sammataro, R.F., "Updated ASME Code Rules for Inservice Inspection of Steel and Concrete Containments," Proceedings of the Fifth Workshop on Containment Integrity, NUREG/CP-0120, U.S. Nuclear Regulatory Commission, Washington, DC, July 11992. 


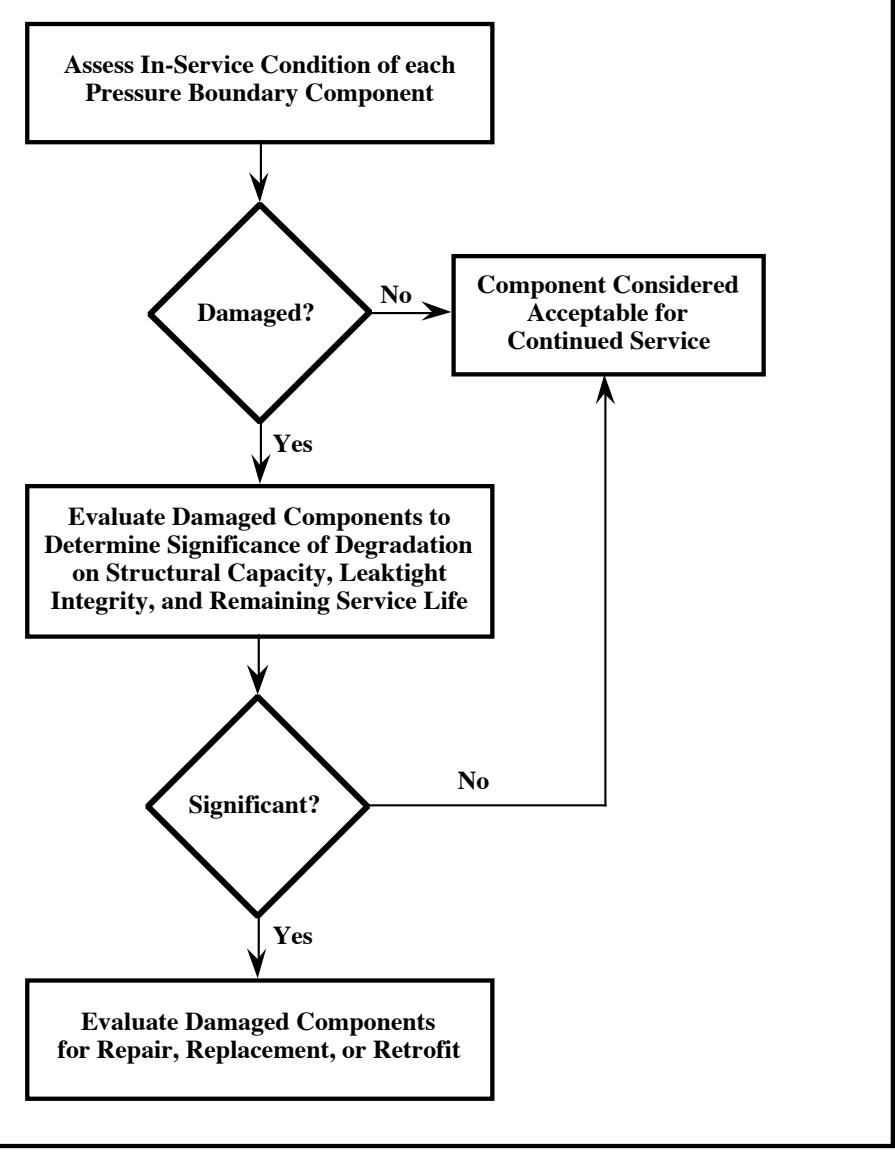

Fig. 2.1 Continued service evaluation process for containment pressure boundary components.

Typical Material Code (06AA001) for a Low-Alloy Carbon Steel Plate Material Permitted for use in Construction of Containment Pressure Boundary Components

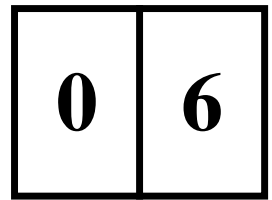

Chapter Index

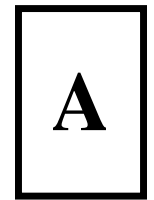

Group

Index

(A-Z)

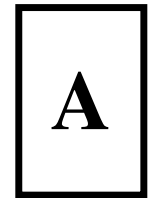

Class

Index

(A-Z)

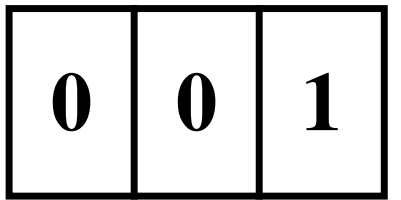

Identifier

Index

(001-999)

Fig. 2.2 Material code arrangement for containment steels. 


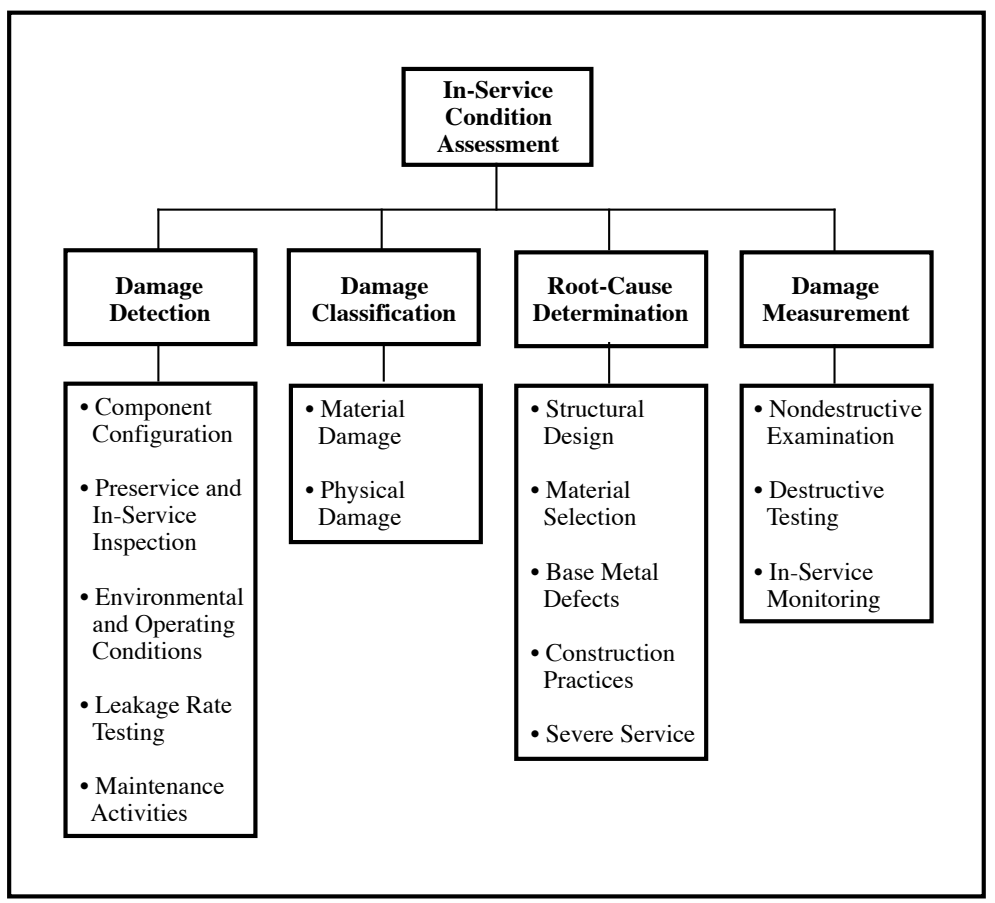

Figure 2.3 Major topics pertaining to in-service condition assessments.

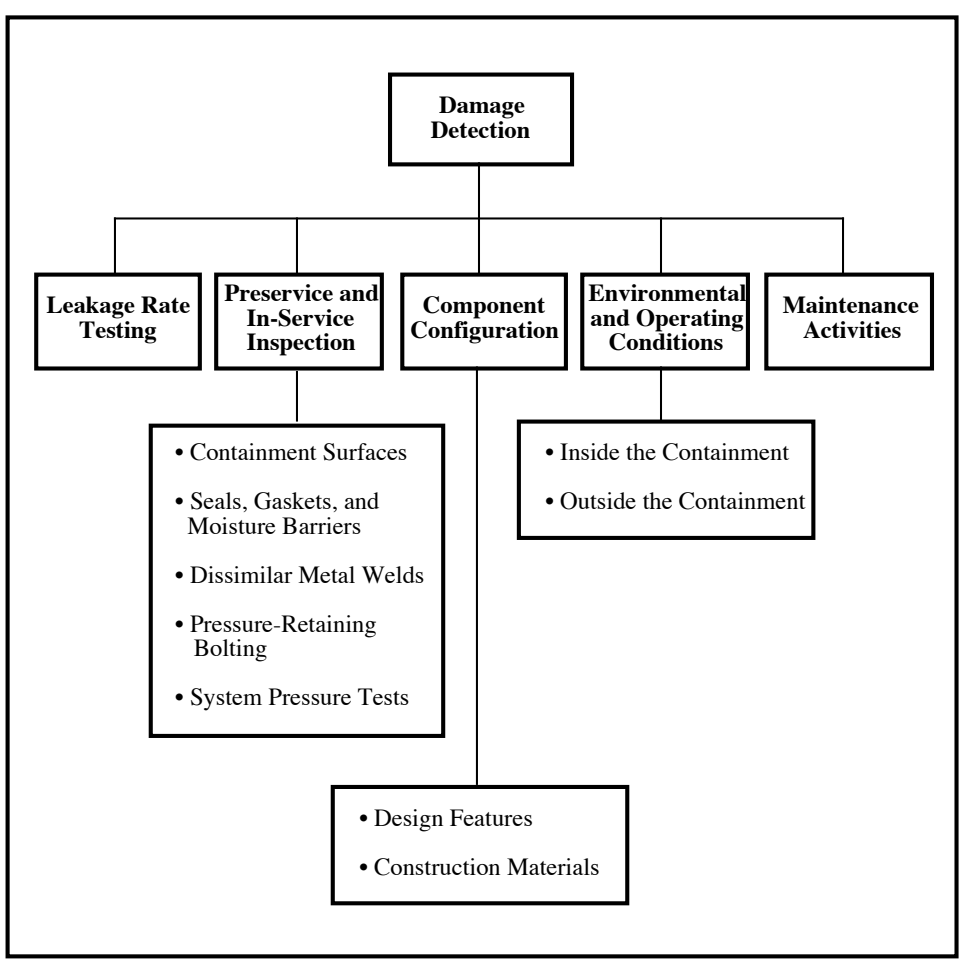

Figure 2.4 Damage detection parameters. 


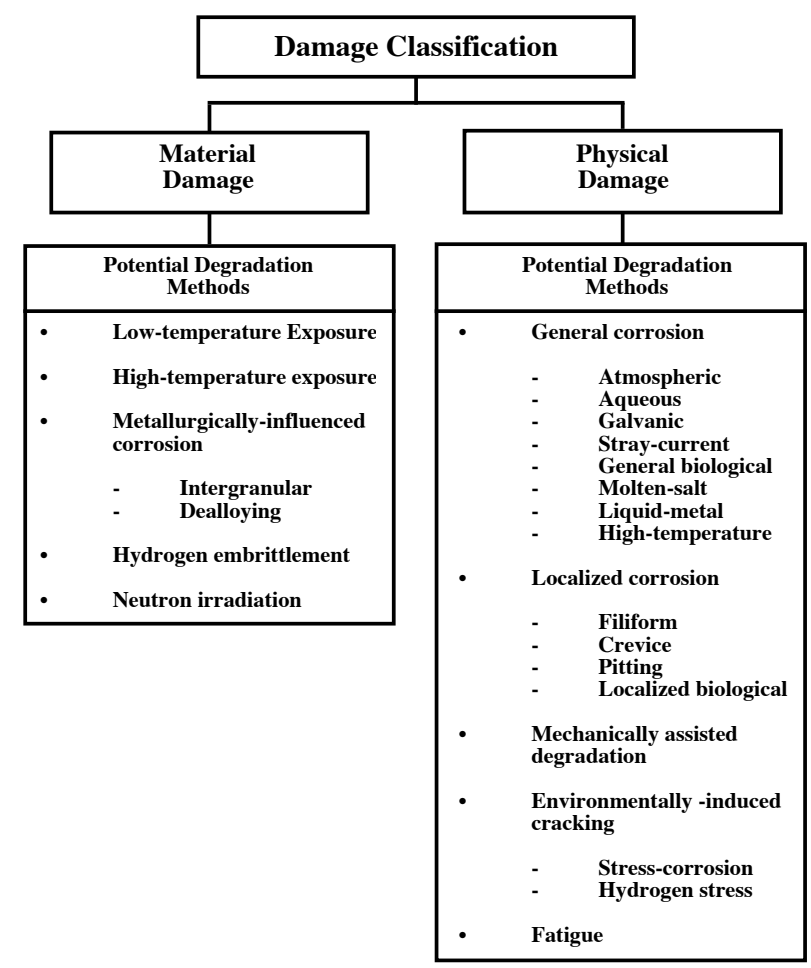

Figure 2.5 Damage categories and potential degradation mechanisms.

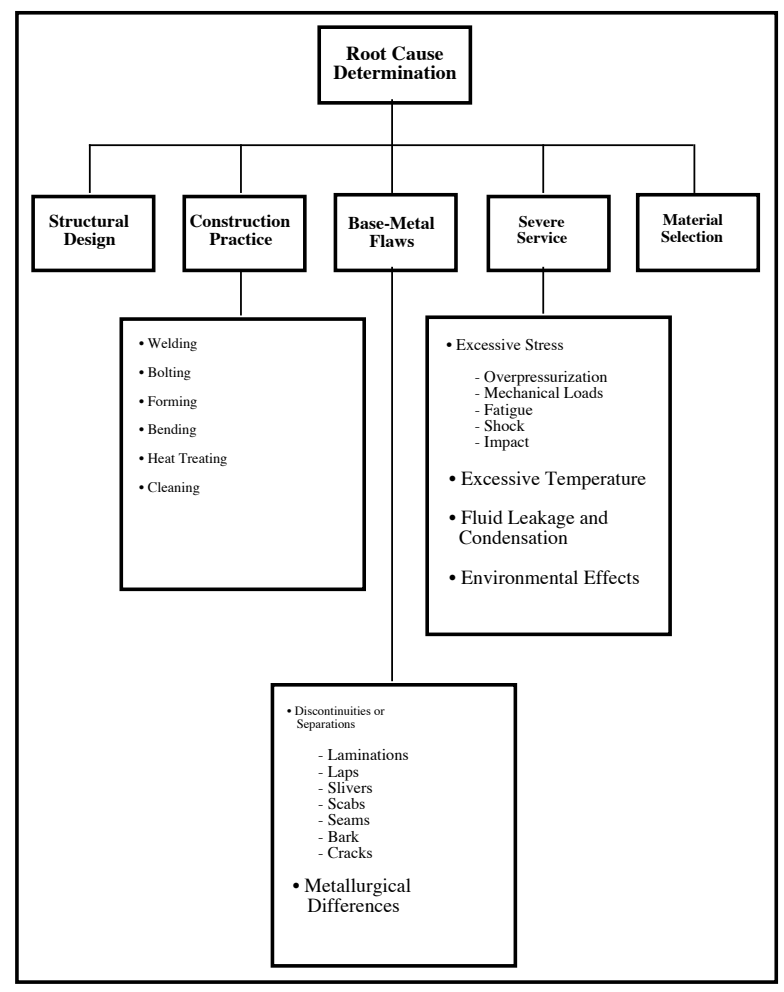

Figure 2.6 Factors to be considered in determining root cause for component degradation. 


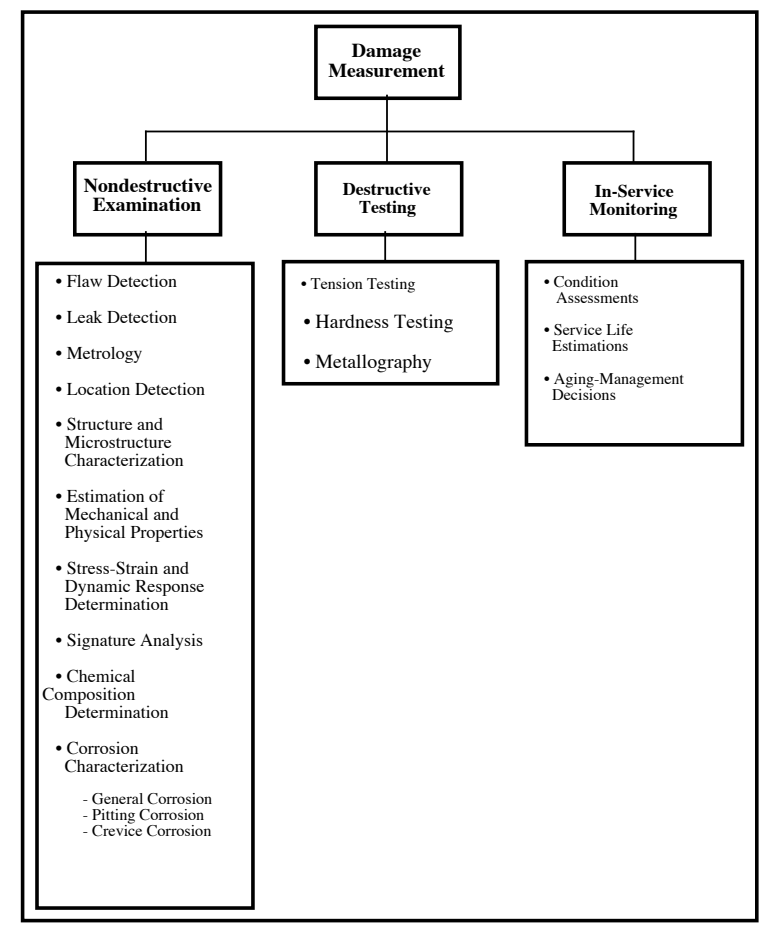

Figure 2.7 Issues related to the measurement of containment pressure boundary component damage.

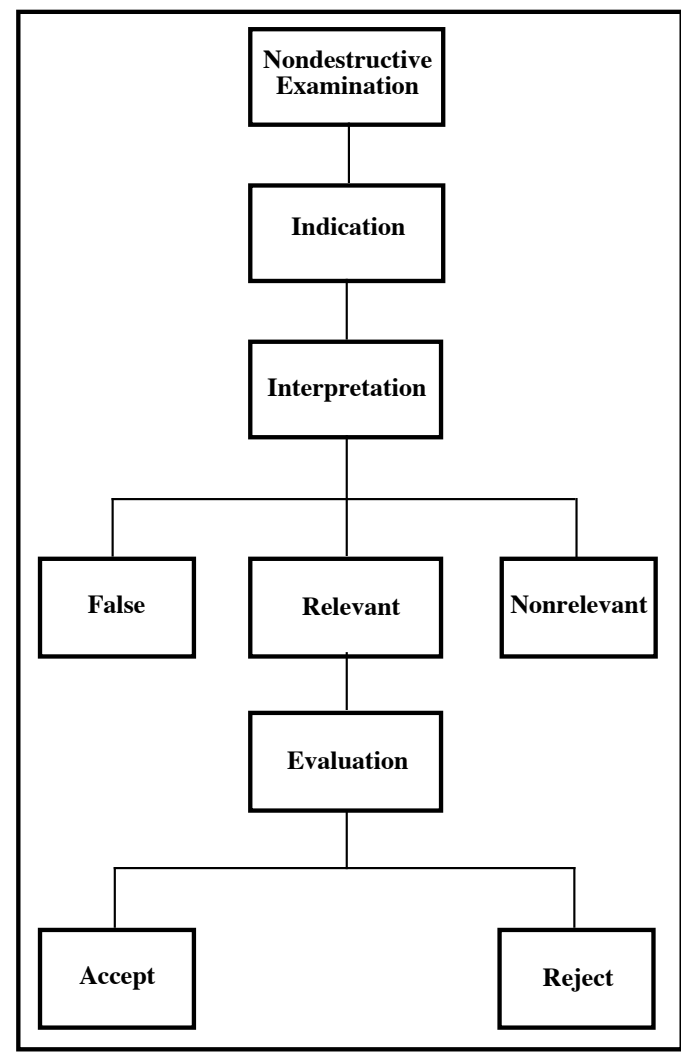

Figure 2.8 Possible interpretations when a nondestructive examination produces an indication (2.37). 
Table 2.1 Class indexes for containment steels.

\section{Class Index}

\section{A}

B

C

D

E

\section{Characteristic Feature}

Hot- or cold-rolled plates, shapes, bars, sheets, and strips

Forgings and castings

Pipes, tubes, and, fittings

Bolting materials

Special materials

Table 2.2 Material property code ranges and descriptions.

\begin{tabular}{lll}
\hline Property Code Ranges & & Property Code Range Description \\
$1000-1999$ & & General Information \\
$2000-2999$ & Reserved for use with Concrete \\
$3000-3999$ & Mechanical Properties \\
$4000-4999$ & Thermal, Physical, and Other Properties \\
$5000-9999$ & Available for Data Base Expansion \\
\hline
\end{tabular}


Table 2.3 (a) Property codes for mechanical property values of containment steels.

\begin{tabular}{|c|c|c|c|}
\hline \multirow{2}{*}{$\begin{array}{l}\text { Property } \\
\text { Code }\end{array}$} & \multicolumn{2}{|c|}{ Units } & \multirow{2}{*}{ Property Description } \\
\hline & Metric & Customary & \\
\hline $3100-3199$ & & & $\begin{array}{l}\text { Static Mechanical Properties of } \\
\text { Metallic Materials }\end{array}$ \\
\hline $3100-3109$ & & & Modulus of Elasticity \\
\hline 3101 & $\mathrm{GPa}$ & $\mathrm{ksi}$ & Young's Modulus of Elasticity \\
\hline 3102 & $\mathrm{GPa}$ & ksi & Strain-Hardening Modulus \\
\hline 3103 & $\mathrm{GPa}$ & ksi & Shear Modulus \\
\hline $3110-3119$ & & & Poisson's Ratio \\
\hline 3111 & - & - & Poisson's Ratio \\
\hline $3120-3129$ & & & Ultimate Strength \\
\hline 3121 & MPa & ksi & Ultimate Tensile Strength \\
\hline 3122 & MPa & ksi & Breaking Tensile Strength \\
\hline 3123 & MPa & ksi & Ultimate Compressive Strength \\
\hline $3130-3139$ & & & Yield Strength \\
\hline 3131 & MPa & ksi & Tensile Yield Point \\
\hline 3132 & MPa & ksi & Tensile Yield Strength \\
\hline 3133 & $\mathrm{MPa}$ & $\mathrm{ksi}$ & Compressive Yield Point \\
\hline 3134 & $\mathrm{MPa}$ & $\mathrm{ksi}$ & Compressive Yield Strength \\
\hline $3140-3149$ & & & Shear Strength \\
\hline 3141 & $\mathrm{MPa}$ & ksi & Shear Yield Strength \\
\hline 3142 & $\mathrm{MPa}$ & ksi & Ultimate Shear Strength \\
\hline $3150-3159$ & & & Elongation \\
\hline 3151 & $\%$ & $\%$ & $\begin{array}{l}\text { Tensile Elongation } \\
\text { in } 51 \mathrm{~mm}(2 \text { in. })\end{array}$ \\
\hline 3152 & $\%$ & $\%$ & $\begin{array}{l}\text { Tensile Elongation } \\
\text { in } 203 \mathrm{~mm} \text { ( } 8 \text { in.) }\end{array}$ \\
\hline 3153 & - & - & $\begin{array}{l}\text { Bending Test Elongation } \\
\text { (diameter/thickness ratio) }\end{array}$ \\
\hline 3154 & - & - & Bending Test Elongation \\
\hline 3155 & $\%$ & $\%$ & $\begin{array}{l}\text { Tensile Elongation } \\
\text { in } 250 \mathrm{~mm}(10 \mathrm{in} .)\end{array}$ \\
\hline
\end{tabular}

Table 2.3 (b) Property codes for mechanical property graphs and plots for containment steels.

\begin{tabular}{|c|c|c|c|}
\hline \multirow{2}{*}{$\begin{array}{l}\text { Property } \\
\text { Code }\end{array}$} & \multicolumn{2}{|c|}{ Units } & \multirow{2}{*}{ Property Description } \\
\hline & Metric & Customary & \\
\hline $3700-3799$ & & & $\begin{array}{l}\text { Plots and Graphs of Mechanical } \\
\text { Properties for Metallic Materials }\end{array}$ \\
\hline $3700-3709$ & & & Stress-Strain Diagram \\
\hline 3701 & $\mathrm{MPa}$ & ksi & $\begin{array}{l}\text { Engineering Stress-Strain Diagram } \\
\text { (Ambient Conditions) }\end{array}$ \\
\hline 3702 & $\mathrm{MPa}$ & ksi & $\begin{array}{l}\text { Engineering Stress-Strain Diagram } \\
\text { (Temperature Dependent) }\end{array}$ \\
\hline 3703 & MPa & ksi & $\begin{array}{l}\text { True Stress-Strain Diagram } \\
\text { (Ambient Conditions) }\end{array}$ \\
\hline $3710-3719$ & & & $\begin{array}{l}\text { Strength } \\
\text { vs Temperature }\end{array}$ \\
\hline 3711 & MPa & ksi & $\begin{array}{l}\text { Tensile Yield Strength } \\
\text { vs Temperature }\end{array}$ \\
\hline 3712 & $\mathrm{MPa}$ & ksi & $\begin{array}{l}\text { Ultimate Tensile Strength } \\
\text { vs Temperature }\end{array}$ \\
\hline 3713 & - & - & $\begin{array}{l}\text { Tensile Yield Strength Ratio } \\
\text { vs Temperature }\end{array}$ \\
\hline 3714 & - & - & $\begin{array}{l}\text { Ultimate Tensile Strength Ratio } \\
\text { vs Temperature }\end{array}$ \\
\hline $3720-3729$ & & & \\
\hline 3721 & $\%$ & $\%$ & $\begin{array}{l}\text { Elongation } \\
\text { vs Temperature }\end{array}$ \\
\hline 3722 & - & - & $\begin{array}{l}\text { Ultimate Tensile Elongation } \\
\text { vs Temperature } \\
\text { Ultimate Tensile Elongation Ratio } \\
\text { vs Temperature }\end{array}$ \\
\hline $\begin{array}{c}3730-3739 \\
3731\end{array}$ & $\mathrm{MPa}$ & ksi & $\begin{array}{l}\text { Fatigue } \\
\text { S-N Diagram }\end{array}$ \\
\hline
\end{tabular}


Table 2.4 General information property codes.

Property Code

1010

1110

1210

1220

1230

1310

1320
Description

Descriptive Information

Material Characteristics

Material Composition

Processing Information

Welding Information

Baseline Information

Dimensional Standards

\section{Types of Data and Information}

Introductory and background comments including material specification designations, specification exceptions, and UNS designations (if available)

Material applications, fabrication practices, available product forms, notes, and comments

Chemical requirements contained in material specifications, notes, and comments

Manufacturing, heat treatment, quality, marking, weight, supplementary, and other requirements contained in the material specification

Weldability and welding procedures

Room-temperature reference mechanical, thermal, physical, and other property values, notes, and comments

Dimensional standards contained in material specifications

Table 2.5 Steels used to construct metal and concrete containment pressure boundary components.

ASME SA-285

ASME SA-333

ASME SA-442

ASME SA-516

ASME SA-537 
Table 2.6 Factors associated with pressure-retaining steel component degradation.

Factor

Pressure-Retaining

Steel Components

Damage Characteristics

Damage Indicators

Potential Problem Areas

Damage Detection

Mitigation Procedures

Potential Failure Modes

\section{Description}

Degradation can adversely affect the structural capacity or leak-tight integrity of metal containment shells, concrete containment liners, penetration liners, heads, nozzles, structural and non-structural attachments, embedment anchors, pipes, tubes, fittings, fasteners, and bolting items that are used to join other pressure-retaining components.

Damage could involve loss of net section or wall thinning, cracks, pits, crevices, erosion, cavitation, surface flaws, arc strikes, plastic deformation, buckling, fracture, or bulging.

Rust, discoloration, staining, blistering and peeling of coatings, spalling of concrete, buckling or separation of liners, leakage from drains, and clogged drains.

Locations where degradation could be suspect include areas of water accumulation; surfaces exposed to chemical or borated water spills; flashed, caulked, or sealed joints; dissimilar metal connections; penetrations; condensation and leakage paths; sand pockets or cushions; heat trace areas; and locations with stray electrical currents.

Damage detection techniques include leakage-rate testing, visual inspection, destructive testing, and nondestructive examination.

Effects of degradation can potentially be mitigated by eliminating leaks; repairing or replacing defective components; removing and replacing cracked or torn seals, gaskets, and caulked joints; opening clogged drains; providing additional drains; repairing or replacing damaged coatings; providing improved spill response; and installing cathodic protection systems.

Degradation can cause cracking, fracture, instability, distortion, or excessive displacement that could result in loss of leaktight integrity, decreased loadcarrying capacity, or reduced service life.

Source: Ref. 2.24 
Table 2.7 Elements of in-service condition assessments for metal and concrete containment pressure boundary components.

\section{Element \\ Designation}

Damage Detection

Damage Classification

Root-Cause Determination

Damage Measurement

\section{Element \\ Definition}

Containment pressure boundary components that have experienced in-service degradation are generally detected by routine visual examination, in-service inspection, leakage-rate testing, or other nondestructive examination techniques. Knowledge about component design and in-service performance can be useful in identifying components that are susceptible to degradation. Information from past service failures can also provide valuable guidance on the types of damage to expect.

Degradation can be classified as either material or physical damage. Material damage occurs when the microstructure of a metal is modified causing its properties to change. Physical damage occurs when the geometry of a component is altered due to formation of cracks, fissures, or voids, or its dimensions change due to fracture, buckling, corrosion, oxidation, erosion, or other surface damage.

Degradation of containment pressure boundary components can generally be related to a design deficiency, improper material selection, defective base metal, an incorrect construction practice, or excessively severe service conditions. Determining the root cause of the degradation can be helpful in classifying the type of damage that has occurred and defining actions to be taken to reduce or eliminate further deterioration. Normal operations, maintenance procedures, and repair activities can cause physical damage including general and localized corrosion, mechanically assisted degradation, and environmentally-induced cracking that can adversely affect the ability of containment pressure boundary components to perform satisfactorily during an accident. Time-dependent change can occur as a result of metallurgicallyinduced corrosion, fatigue, neutron irradiation, hydrogen embrittlement, and extreme-temperature exposure.

The degree of degradation can be measured by destructive testing of material samples or by nondestructive examinations. In-service monitoring can also be used to measure the rate of degradation and to detect changes in operating conditions that can adversely affect structural capacity or leak-tight integrity. 
Table 2.8 Accessible containment surface areas and pressure-retaining weld that require visual examination.

- Structures that are parts of reinforcing structure, such as stiffening rings, manhole frames, and reinforcement around openings

- Wetted surfaces of submerged areas (required to satisfy minimum surface area inspection requirements)

- Portions of insulated surface areas (required to satisfy minimum surface area inspection requirements)

- $\quad$ Flow channeling devices within containment vessels

- Attachment welds between structural attachments and the pressure-retaining boundary or reinforcing structure

- Containment penetration welds subject to cyclic loads and thermal stress during normal plant operation

- $\quad$ Longitudinal welds

- $\quad$ Circumferential welds

- $\quad$ Flued head and bellows seal circumferential welds joined to the penetration

- $\quad$ Flange welds

- $\quad$ Nozzle-to-shell welds

Source: Refs. 2.6 and 2.24 
Table 2.9 Containment surface areas that could experience accelerated degradation and aging.

\begin{tabular}{|c|c|c|}
\hline $\begin{array}{c}\text { Environmental or Operating } \\
\text { Conditions }\end{array}$ & Typical Areas & Likely Locations \\
\hline $\begin{array}{l}\text { Areas subject to accelerated } \\
\text { corrosion with no or minimal } \\
\text { corrosion allowance } \\
\text { or } \\
\text { Areas where the absence or } \\
\text { repeated loss of protective } \\
\text { coatings has resulted in } \\
\text { substantial corrosion or pitting }\end{array}$ & $\begin{array}{l}\text { Areas exposed to standing water } \\
\text { Areas exposed to repeated wetting } \\
\text { and drying } \\
\text { Areas where persistent leakage has } \\
\text { occurred } \\
\text { Areas subject to microbiological } \\
\text { attack } \\
\text { Areas with geometries that permit } \\
\text { water accumulation }\end{array}$ & $\begin{array}{l}\text { Penetration sleeves and bellows } \\
\text { Surfaces wetted during refueling } \\
\text { Concrete-to-steel shell or liner } \\
\text { interface } \\
\text { Shell regions embedded in concrete } \\
\text { including areas shielded by } \\
\text { diaphragm floors } \\
\text { Leak-chase channels } \\
\text { Drain areas including sand pocket } \\
\text { regions } \\
\text { Sump liners } \\
\text { Interior surfaces of BWR Mark I } \\
\text { and II suppression pools } \\
\text { Exterior surfaces of BWR Mark I } \\
\text { and II drywells } \\
\text { Emergency core cooling system } \\
\text { suction intake at the bottom of BWR } \\
\text { suppression pool } \\
\text { Dissimilar metal welds }\end{array}$ \\
\hline $\begin{array}{l}\text { Areas subject to excessive wear } \\
\text { from abrasion or erosion }\end{array}$ & $\begin{array}{l}\text { Areas where mechanical wear, } \\
\text { abrasion, or erosion cause a loss of } \\
\text { protective coatings, deformations, or } \\
\text { material loss } \\
\text { Areas that experience frequent } \\
\text { vibration }\end{array}$ & $\begin{array}{l}\text { Surfaces subject to substantial } \\
\text { traffic } \\
\text { Sliding pads or supports (baseplates } \\
\text { of BWR Mark I suppression } \\
\text { chamber support columns) } \\
\text { Pins or clevises } \\
\text { Shear lugs } \\
\text { Seismic restraints } \\
\text { Surfaces exposed to water jets from } \\
\text { testing operations } \\
\text { Safety relief valve discharge areas } \\
\text { BWR drywell head, vent system } \\
\text { supports, and downcomers and } \\
\text { bracing } \\
\text { Personnel airlocks, equipment } \\
\text { hatches, and control rod drive } \\
\text { (CRD) hatches }\end{array}$ \\
\hline
\end{tabular}

Source: Refs. 2.6, 2.33-3.35, and 2.36 
Table 2.10 Degradation mechanisms that can potentially cause material damage to containment steels.

\section{Degradation} Mechanism
Low-Temperature Exposure

High-Temperature Exposure

Intergranular Corrosion

Dealloying Corrosion

Hydrogen Embrittlement

Neutron Irradiation

\section{Likelihood of Causing Material Damage to Containment Steels}

Effects of low-temperatures on the properties of containment steels are not considered to be a significant containment issue because low-temperature exposure and fracture toughness are addressed during containment design and because exposure to temperatures low enough to cause brittle fracture is not expected.

Temperature-dependent property values for containment steels are provided in Section II, Part D of the Code (2.15). Material damage to containment steels due to high-temperature exposure is not expected because temperatures high enough to affect mechanical properties are not likely to occur except in the unlikely event of a severe accident.

Intergranular corrosion is a metallurgically-influenced corrosion process that takes place when the corrosion rate of the grain-boundary areas of an alloy exceeds that of the grain interiors. Metals that experience intergranular corrosion exhibit time-dependent weight loss that can accelerate with time. Intergranular corrosion of austenitic and ferritic stainless steels and nickel-based alloys used to make containment pressure boundary components is not considered likely. These materials are normally not exposed to solutions such as ferric sulfate, cupric sulfate, and acids that are required to cause this type of degradation.

Dealloying is a metallurgically influenced corrosion process in which one constituent of an alloy is preferentially removed leaving behind an altered residual structure that is less tolerant to flaws and applied loads (2.40). Material damage to containment steels due to dealloying corrosion is not considered likely because containment steels are not exposed to molten salts, and because oxidizing atmospheres and sufficient hydrogen gas are not generally present inside BWR and PWR containment vessels.

Hydrogen influences the behavior and properties of nearly all ferrous alloys, particularly steels in which the yield strength is close to the ultimate strength. During normal plant operations, hydrogen embrittlement of containment steels is not expected to be a serious problem because sufficient hydrogen gas is not generally present inside BWR and PWR containment vessels.

Metals exposed to neutron irradiation can be damaged when neutrons displace metal atoms from their normal lattice positions to form interstitials and vacancies. Irradiation damage to containment steels is not very likely because biological shielding effectively limits exposure of the materials to levels that are considered safe for occupational workers, and end-of-life fluence of containment components is anticipated to be quite small (2.27). Even in the unlikely event of a severe accident, irradiation damage to containment steel components is not expected to be significant. 
Table 2.11 Types of general corrosion that can potentially cause physical damage to containment pressure boundary components.

\begin{tabular}{|c|c|}
\hline $\begin{array}{l}\text { Type of } \\
\text { General Corrosion }\end{array}$ & $\begin{array}{l}\text { Likelihood of Causing Physical Damage } \\
\text { to Containment Pressure Boundary Components }\end{array}$ \\
\hline $\begin{array}{l}\text { Atmospheric } \\
\text { Corrosion }\end{array}$ & $\begin{array}{l}\text { Atmospheric corrosion is the gradual degradation or alteration of a material by } \\
\text { contact with substances such as oxygen, carbon dioxide, water vapor, and sulfur and } \\
\text { chlorine compounds that are present in the atmosphere }(2.40) \text {. In buildings, } \\
\text { corrosion of uncoated structural steel elements often occurs when warm, moist air } \\
\text { from inside the building permeates through the walls and ceilings and condenses on } \\
\text { the surfaces of colder steel beams, columns, and fasteners. In nuclear power plants, } \\
\text { atmospheric corrosion can be suspected whenever uncoated carbon and low-alloy } \\
\text { steel components are exposed to air with a relative humidity that exceeds about } \\
70 \text { percent. }\end{array}$ \\
\hline $\begin{array}{l}\text { Aqueous } \\
\text { Corrosion }\end{array}$ & $\begin{array}{l}\text { Corrosion of metals in aqueous environments occurs when two or more } \\
\text { electrochemical reactions take place on the surface causing the metal or alloy to } \\
\text { change from a metallic state to a nonmetallic state }(2.40) \text {. A common example of } \\
\text { this phenomenon is rusting in which metal (iron) is converted to a nonmetallic } \\
\text { corrosion product (rust). Aqueous corrosion of the external surface of a BWR } \\
\text { Mark I metal containment shell in the sand-cushion region of the drywell has } \\
\text { occurred due to water that leaked from the refueling pool }(2.26) \text {. Physical damage to } \\
\text { carbon and low-alloy steel fasteners and pressure-retaining components of the pri- } \\
\text { mary system has also occurred at a number of PWR plants due to boric acid } \\
\text { (H3BO3) attack ( } 2.41,2.42) \text {. Similar types of physical damage caused by aqueous } \\
\text { corrosion is possible whenever carbon and low-alloy steel components are in contact } \\
\text { with pure, treated, contaminated, or seawater. }\end{array}$ \\
\hline $\begin{array}{l}\text { Galvanic } \\
\text { Corrosion }\end{array}$ & $\begin{array}{l}\text { Galvanic corrosion is accelerated degradation that occurs when a metal or alloy is } \\
\text { electrically coupled to a more noble metal in the same electrolyte }(2.40) \text {. The three } \\
\text { requirements for galvanic corrosion are (1) materials possessing different surface } \\
\text { potentials, ( } 2 \text { ) a common electrolyte, and (3) a common electrical path. Galvanic } \\
\text { corrosion has been known to occur in dissimilar-metal, butt-welded piping systems } \\
\text { that carry an electrolytic solution. The most severe corrosion occurs adjacent to the } \\
\text { weld on the anodic member. Destruction of weld metal in carbon steel piping } \\
\text { systems has also occurred because the welds were anodic to the base metal ( } 2.40) \text {. } \\
\text { Physical damage to welds and base metal in nuclear power plants caused by galvanic } \\
\text { corrosion can occur in locations where dissimilar metals are in contact and an } \\
\text { electrolytic solution is present. }\end{array}$ \\
\hline
\end{tabular}


Table 2.11 (Cont'd) Types of general corrosion that can potentially cause physical damage to containment pressure boundary components.

\section{Type of General Corrosion}

\section{Likelihood of Causing Physical Damage to Containment Pressure Boundary Components}

\section{Stray-Current Corrosion}

General Biological Corrosion

Molten-Salt Corrosion

Liquid-Metal Corrosion

High-Temperature Corrosion
Stray-current corrosion is degradation resulting from direct current flow through paths other than the intended circuit (2.40). There are many sources of stray electrical current, but cathodic protection systems, high voltage direct current systems, and direct current welding operations are potentially the most significant for nuclear power plant structures (2.29). Damage caused by alternating current is less than that caused by direct current and decreases in severity as the frequency increases.

General biological corrosion, or microbiological-induced corrosion (MIC) as it is sometimes called, is deterioration of metal as a result of the metabolic activity of microorganisms (3.39). A continuous film of bacteria, algae, or slime can contribute to general biological corrosion, but the formation of a continuous film over a large area is rare. Consequently, biological corrosion is usually localized because microorganisms tend to settle in discrete colonies rather than uniformly over the surface of a material.

Molten-salt corrosion is the oxidation of metals in contact with molten salts (2.40). Degradation of containment pressure boundary components by molten-salt corrosion is not considered likely because light-water reactors are cooled with water not molten fluorides, nitrates, sulfates, or chloride salts.

Liquid-metal corrosion is the deterioration of materials in contact with liquid metals such as sodium, potassium, and lithium (2.40). Degradation of containment pressure boundary components by liquid-metal corrosion is not considered likely because light-water reactors are cooled with water not liquid metals like reactors for fast breeder, fusion, and space nuclear power applications.

High-temperature corrosion occurs when metal is exposed to an oxidizing gas at elevated temperature causing the metal to react directly with the gas without the presence of a liquid electrolyte (2.40). Because temperatures in excess of those associated with containment operations are required to cause high-temperature corrosion, degradation of containment pressure boundary component by this mechanism is not considered likely. 
Table 2.12 Types of localized corrosion that can potentially cause physical damage to containment pressure boundary components.

\section{Type of Localized Corrosion}

\section{Likelihood of Causing Physical Damage to Containment Pressure Boundary Components}

Filiform

Corrosion

Crevice

Corrosion

Pitting

Corrosion

Localized Biological Corrosion
Filiform corrosion occurs under thin organic coatings in the form of randomly distributed threadlike filaments that appear as worm-like blemishes (2.40). The source of initiation is usually a cut, nick, pore, scratch, or disruption in the coating. Because filiform corrosion produces very localized distress on metal surfaces, its effects on containment integrity is not expected to be significant. However, coating damage may become a maintenance concern.

Crevice corrosion is localized attack of a metal surface adjacent to an area that is shielded from full exposure to the environment because of close proximity between the metal and the surface of another material (2.40). Narrow openings or spaces between metal-to-metal or nonmetal-to-metal components, cracks, seams, or other surface flaws can serve as sites for corrosion initiation. Stainless steels are more prone to crevice corrosion than carbon steels particularly in the presence of chloride solutions, but containment pressure boundary components made from all types of steels can experience this type of localized damage when exposed to aqueous environments.

Pitting corrosion is degradation of a metal surface confined to a point or small area that takes the form of cavities (2.40). Pitting is one of the most common types of localized corrosion encountered in aqueous environments. The propagation of pits is thought to involve the dissolution of metal and the maintenance of a high degree of acidity at the bottom of the pit by the hydrolysis of the dissolved metal ions making the rate at which pitting corrosion progresses very unpredictable. Pitting corrosion of containment pressure boundary components made from all types of steels is possible whenever they are exposed to aqueous environments.

Localized biological corrosion, like general biological corrosion, is deterioration of metal as a result of the metabolic activity of microorganisms (2.40). Because microorganisms tend to settle in discrete colonies rather than uniformly over the surface of a material, most biologically induced corrosion tends to be localized. Localized damage to carbon, lowalloy, and even stainless steel components caused by biological corrosion is possible when environmental conditions are favorable for microorganisms. 
Table 2.13 Mechanically-assisted degradation that can potentially cause physical damage to containment pressure boundary components.

\section{Type of Mechanically- Assisted Degradation}

\author{
Likelihood of Causing Physical Damage \\ to Containment Pressure Boundary Components
}

Erosion

Fretting

Cavitation

Corrosion

Fatigue

Surface

Flaws

Arc Strikes

Overload

Conditions
Erosion is the destruction and removal of a material by the abrasive action of moving fluids. Material loss can be accelerated by the presence of solid particles or matter in suspension. Except in the torus region of BWR Mark I metal containments, moving water is not usually present inside containment vessels. Therefore, erosion of pressureretaining components is not expected to be a generic concern (2.26).

Fretting is wear that occurs between tight-fitting surfaces subjected to cyclic motion of extremely small amplitude. Steels used to construct containment pressure boundary components are not routinely subjected to wear caused by fretting because these components generally remain static.

Cavitation is loss of material caused by a liquid that experiences rapid and intense pressure changes. This action is generally associated with pumps and piping systems and is therefore not considered to be a significant containment degradation mechanism.

Corrosion fatigue is the process in which a metal fractures prematurely under conditions of simultaneous corrosion and repeated cyclic loading at lower stress levels or fewer cycles than would be required in the absence of the corrosive environment (2.40). Corrosion fatigue of pressure-retaining components is not expected to be a generic concern (2.26).

Surface flaws such as notches, cracks, gouges, grooves, dents, and tool marks can be created during routine operations, in-service maintenance, repair activities, or equipment failures that generate missiles or pipe whips. Stress concentrations caused by these types of flaws located in critical regions of the containment, can affect performance by contributing to premature structural failure at loads well below those permitted in design or loss of leak-tight integrity. Surface flaws located in aqueous environments can also serve as initiation sites for filiform and crevice corrosion.

Arc strikes are another type of surface flaw that can cause loss of ductility in mild and low-alloy steels, hardening of higher carbon and alloy steels, or localized cracking in higher strength, hardenable grades of steel (2.43). Arc strikes represent any localized heat-affected zone or change in the surface contour of the finished weld or base metal caused by an arc produced by the passage of electrical current from welding electrodes, magnetic particle inspection electrodes, electrical shorts, or other sources.

Equipment failures, excessive piping loads, and movements caused by thermal expansion or contraction due to extreme-temperature exposure are examples of over-load conditions that can permanently deform, bulge, stretch, bend, buckle, or neck pressure-retaining components. These changes in component geometry can be attributed to plastic deformation of the metal or brittle fracture of the component. The damage caused by overload conditions can have a detrimental effect on containment structural capacity and leak-tight integrity and adversely affect its ability to perform its intended function. 
Table 2.14 Environmentally-induced and fatigue degradation mechanisms that potentially can cause cracking of containment metallic pressure boundary components.

\section{Degradation} Mechanism

Stress-Corrosion
Cracking

Hydrogen Damage

Fatigue

\section{Likelihood of Causing Physical Damage to Containment Pressure Boundary Components}

Stress-corrosion cracking is a material degradation process that requires the simultaneous action of a corrodent and sustained tensile stress to initiate and propagate cracks in metals and alloys. Carbon, low-alloy, and stainless steels exposed to various aqueous environments are susceptible to stress-corrosion cracking. Aqueous solutions that may be present at nuclear power plants and could contribute to stress-corrosion cracking include ground water containing chlorides and sulfates, borated water in PWRs, sodium pentaborate in BWRs, and certain types of decontamination fluids (2.26).

Hydrogen damage most often results from the combined action of hydrogen and residual or applied tensile stress (2.40). It manifests itself in many ways, such as cracking, blistering, hydride formation, and loss of tensile ductility. Physical damage to pressure-retaining steels by hydrogen is not expected to be a serious problem because neither hydrogen at high pressures nor hydrogen at high temperatures are found inside the containment vessel.

Fatigue is the progressive, localized, and permanent structural change that occurs in a material subjected to repeated or fluctuating strains at normal stresses that have maximum values less than the tensile strength of the material (2.9). Guidance for performing fatigue evaluations is provided in Section III, Division 1 of the ASME Code (2.13). Although design rules for fatigue of steels used to construct containment pressure boundary components are included in the ASME Code, fatigue resulting from cyclic loads such as the ones listed in Table 2.15 is not expected to be a generic concern for either liners of reinforced concrete containments or the shells of metal containments (2.26).

Table 2.15 Possible cyclic loads on containment pressure boundary components.

Startup and shutdown cycles (temperature transients)

Pipe reactions (at penetrations)

Crane loads

Leakage-rate test pressures

Safety relief valve discharge tests

Refueling loads

Loads resulting from repair and replacement activities 


\section{DAMAGE ASSESSMENT}

Aging degradation can affect the ability of metallic pressure boundary components of LWR containment systems to perform satisfactorily in the event of an accident by reducing its structural capacity or leak-tight integrity. Of the degradation factors noted in Section 1.2.2, loss of section due to either general or pitting corrosion was considered to represent the greatest potential threat. The aging problems of the containment differ from most other mechanical components because service loads primarily result from periodic pressure or leakage-rate testing. Mechanical loads due to the reaction forces of the penetrating systems also are normally low, so fatigue, with the possible exception of the bellows of high-energy systems, is a limited (or isolated) problem. The most severe fatigue loads result from blowdown of the safety or relief valves that produces vibrations of the pipes and pressure pulsations in the suppression pool. The most critical areas are related to inaccessible surfaces and in the suppression pool, because of difficulties associated with performing inspections.

One of the significant problems associated with containment aging is the inaccessible areas of the steel structures where the detection and assessment of possible degradation (primarily corrosion) is very difficult. Nonmetallic seals and gaskets represent another aging concern relative to containment leak-tightness as these items can degrade under the influence of time and temperature. However, these items are periodically evaluated under well-defined inspection programs, and can be or are routinely replaced. Some penetration constructions can be susceptible to stress corrosion cracking due to high stresses that can be present in stainless steel bellows. Bellows and penetration assemblies are evaluated through visual inspections and leakage-rate testing. Bellows are also subject to fatigue analysis. Coatings provided on many metal components to minimize corrosion occurrence also may degrade under the influence of the plant service environment (e.g., chemical attack, abrasion, and temperature). Coating systems need to be maintained so that they can continue to provide protection. Coating life is directly related to maintenance. The economic life of a coating is determined by comparing maintenance costs with recoating costs. Based on the high cost of recoating (e.g., surface preparation, application, and cleanup), the personnel dose, and outage-related costs, maintenance can be extensive before its costs exceed those of recoating. Inspection of coatings is generally done through visual inspections, but the condition of in-place coatings also can be assessed (e.g., thickness and bond to substrate).

\subsection{IN-SERVICE INSPECTION TECHNIQUES AND METHODOLOGIES}

The primary goal of inspection is to identify the location, type, and magnitude of structural imperfections or flaws. The ASME Code (3.1) requires that when defect flaws or evidence of degradation exist that require evaluation in accordance with ASME Code acceptance criteria, either surface or volumetric examinations are to be conducted. Nondestructive examination is the primary method used to evaluate the presence and significance of indications of degradation of the containment pressure boundary. Selection of the appropriate method depends on the type and nature of the degradation, the component geometry, and the type and circumstances of inspection. Cost and availability are also factors.

Nondestructive examination methods for metallic materials principally involve surface and volumetric inspections to detect the presence of degradation (i.e., loss of section due to corrosion or presence of cracking). The surface examination techniques primarily involve visual, liquid penetrant, and magnetic particle methods. Volumetric methods include ultrasonic, eddy current, and radiographic. Rules for surface and volumetric examinations of containment pressure boundary components are also provided in Subsection IWA of the ASME Code. Alternative techniques, combinations of techniques, and newly developed techniques are permitted provided the results are considered to be equivalent or superior to those of the specified technique. Acceptance standards are defined in Article IWE-3000 of the ASME Code. In order to obtain repeatable and reproducible nondestructive examination results using any of the methods described below, several factors must be understood and controlled: material evaluated, evaluation procedure utilized, environment, calibration/baseline reference, acceptance criteria, and human factors. Table 3.1 presents a summary of the application by flaw type and important material characteristics for the techniques discussed below. Table 3.2 presents the dominant sources of variance for these techniques.

\subsubsection{Visual Inspection}

Visual inspection is one of the most common and least expensive methods for evaluating the condition of a weld or component (e.g., presence of surface flaws, discontinuities, or corrosion). It is generally the first inspection that is performed as part of an evaluation process and is beneficial for performing gross defect detection and in identifying areas for more detailed examination. Interior and exterior containment surface areas that could experience accelerated degradation and aging were identified in Table 2.9 and Table 2.6 provided several indicators of damage to pressureretaining steel components. Visual inspections can identify where a failure is most likely to occur, and when failure has 
commenced (e.g., rust staining or coating cracks). Once a suspect area is identified, all surface debris and protective coatings are removed so that the area can be inspected in more detail.

Visual examinations can be performed either with the unaided eye or optical magnifiers. Three classifications of visual examinations are specified in the ASME Code: (1) VT-1 (detect discontinuities and imperfections on the surfaces of components such as cracks and corrosion), (2) VT-2 (detect evidence of leakage from pressure-retaining components), and (3) VT-3 (determine general mechanical and structural condition of components and their supports). Without material or component removal, visual inspections are limited to accessible areas. In situations where access is limited or normal visual acuity is not sufficient, examination may require the use of visual aids such as the equipment listed in Table 3.3. Subsection IWA of the ASME Code (3.2) provides rules for remote visual examination and examinations using surface replication methods. To examine underwater portions of the suppression chamber, either the chamber must be drained or underwater examination techniques must be used. Drainage of the chamber relieves the hydrostatic pressure on the coating surfaces and may cause additional blistering or bursting of existing coating blisters. Underwater techniques have been developed that include desludging, ultrasonic mapping of critical areas, coating adhesion tests, dryfilm thickness determinations, and repair of localized areas (3.3). Since crevice corrosion is possible at hatch locations, and under bolts, nuts, and gaskets, proper maintenance, use of grease and lubricants, and routine visual inspections are used to address and inspect for corrosion. The effectiveness of a visual inspection is dependent on the experience and competence of the person performing the inspections.

\subsubsection{Liquid Penetrant Testing}

Liquid penetrant testing can be used to detect, define and verify surface flaws in solid or essentially nonporus components (e.g., cracks, porosity, laminations or other types of discontinuities that have a capillary opening to the surface) of virtually any size and shape. Indications of a wide spectrum of flaw sizes can be found with little capital expenditure regardless of the configuration of the test article or the flaw orientation. The procedure consists of thoroughly cleaning and drying the surface to be examined followed by application of a liquid penetrant. Surface defects or cracks absorb the penetrant through capillary action. After a dwell period, excess penetrant is removed from the surface and a developer is applied that acts as a blotter to draw penetrant from the defects to reveal their presence. Colored or fluorescent penetrants may be utilized, with white light or black light, respectively, used for viewing. Effectiveness of the method is dependent on the properties of the penetrant and the developer. Limitations of the technique are that operator skill requirements are fairly high, only surface flaw defects can be detected, area inspected must be clean since scale or paint film may hide flaws, results are affected by surface roughness and porosity, and no permanent record of inspection is provided.

\subsubsection{Eddy Current Inspection}

Eddy current inspection methods are based on electromagnetic induction and can be applied to electrically-conductive materials for detection of cracks, porosity, and inclusions, and to measure the thickness of nonconductive coatings on a conductive metal. In the flaw detection mode eddy current can detect surface connected or near surface anomalies. It is based on the principle that alternating current flow in a coil proximate to an electrical conductor will induce current flow in the conductor. The current flow (i.e., eddy current) creates a magnetic field that opposes the primary field created by the alternating current flow in the coil. The presence of a surface or near-surface discontinuity in the conductor will alter the magnetic field (i.e., magnitude and phase) which can be sensed as a change in the flow of current in a secondary coil in the probe or change of inductance of the probe. The output signal from the detection circuit is fed to an output device, typically a meter, oscilloscope, or chart recorder. Flaw size is indicated by extent of response change as the probe is scanned along the test object. Eddy current techniques do not require direct contact with the test piece, and paint or coatings do not have to be removed prior to its application. For discontinuities of a given size, the sensitivity of eddy current decreases with distance below the surface. Best results are obtained when the magnetic field is in a direction that will intercept the principal plane of the discontinuity. Also, the technique requires calibration, is sensitive to geometry of the test piece, results may be affected by material variations, no permanent record is provided, and demagnification may be necessary following inspection.

\subsubsection{Magnetic Particle Testing}

Magnetic particle testing is used to detect surface and shallow subsurface discontinuities in ferromagnetic materials. A magnetic field is induced into the ferromagnetic material by using permanent magnets, electromagnets, or by passing high currents through or around the component. The surface is dusted with iron particles that may be dry, suspended in a liquid, colored, or fluorescent. The magnetic lines of force (flux) will be disrupted locally by the presence of the flaw 
with its presence indicated by the iron particles that are attracted by leakage of the magnetic field at the discontinuity. The resulting magnetically-held collection of particles forms a pattern that indicates the size, shape, and location of the flaw. Effectiveness of the method quickly diminishes depending on flaw depth and type, and scratches and surface irregularities can give misleading results. Special equipment, procedures, and process controls are required to induce the required magnetic fields (e.g., use of proper voltage, amperage, and mode of induction). Factors that can affect sensitivity include orientation of the discontinuity with respect to the induced magnetic field; strength of the magnetic field; shape of component; and size, shape, and general characteristics of the magnetic particles as well as the fluid carrying the particles. Also, linear discontinuities that are oriented parallel to the direction of the magnetic flux will not be detected. Under ideal conditions, it is possible to detect cracks with a width as little as $10^{-3} \mathrm{~mm}$, and when magnetization by DC current is used subsurface defects may be detected at depths on the order of 3 to $7 \mathrm{~mm}$ (3.4).

\subsubsection{Ultrasonic Testing}

Ultrasonic testing uses sound waves of short wavelength and high frequency (e.g., 0.5 to $20 \mathrm{MHz}$ ) to detect surface and subsurface flaws, and measure material thickness. Piezoelectric materials, which dilate or strain when a voltage is applied across the crystal faces, form the basis for electromechanical transducers.* The expansion and contraction produced by alternating voltage generates a compression wave in the surrounding medium. The compression wave can be transmitted at right angles to the component surface, or a coupling wedge can be used to transmit shear or Rayleigh waves into the object. The ultrasound is transmitted as a series of pulses of extremely short duration and during the time interval between transmissions the transducer can detect reflected signals. A sound wave propagating through a material continually loses a part of its energy because of scattering and internal friction effects within the material. Attenuation losses, together with beam divergence, account for the major limitation on the depth of penetration that can be achieved for component inspection. The extent of attenuation increases with an increase in frequency.

Either one transducer, which acts as both transmitter and receiver, or two transducers, where one transducer transmits the signal and a second receives the signal, have been used. The most commonly used technique is pulse echo in which sound is introduced into the test object and travels through the material examined with some attendant loss of energy. Reflections (echoes) are returned to the receiver from internal imperfections or the component's surfaces. The returning pulse is displayed on a screen that gives the amplitude of the pulse and the time taken to return to the transducer. Inclusions or other imperfections are detected by partial reflection or scattering of the ultrasonic waves, time of transit of the wave through the test object, and features of the spectral response for either a transmitted or reflected signal. Operator interpretation is made by pattern recognition, signal magnitude, timing, and probe positioning. Flaw size, distance, and reflectivity can be interpreted. The technique has good penetration capability, high sensitivity to permit detection of very small flaws, good accuracy relative to other nondestructive examination methods, only one surface has to be accessible, and rapid results are provided. For thickness measurements digital meters are commonly used. In the pulse-echo mode an ultrasonic transducer transmits waves normal to the component surfaces, signals are reflected from the front and back surfaces, and the difference in arrival times of the two signals is used to indicate the thickness. Crosssection loss is then calculated by taking the difference between the as-built thickness and the thickness measured. Components can also be scanned to detect subsurface abnormalities such as cracks or voids. Information obtained during a test can be displayed as either an " $\mathrm{A}$ " scan (displays initial pulse, any defect echoes, and backwall echo), "B" scan (initial signal, defect echoes, and backwall echoes recorded as a function of probe position), or "C" scan (provides plan view of specimen). "A" scans are most commonly used. Ultrasonic testing is commonly used in nuclear plants to monitor wall thinning of the containment vessel caused by corrosion. Rough surface conditions such as could be present on metallic components of containment pressure boundary systems present problems relative to signal scattering. Focused transducers provide the best results where rough surfaces are present. Because of its complexity, ultrasonic testing requires considerable technician training and skill. One major disadvantage of this approach is the requirement of a coupling medium. The contact wedge-type transducers are sensitive to the plate surface condition and the coupling state and, therefore, inspection results may not be satisfactory. A coupling medium consisting of a column of water appears to be the most suitable for this approach $(3.5,3.6)$. Since conventional piezoelectric transducers operate at frequencies higher than $500 \mathrm{kHz}$, the corresponding inspection range is relatively short (a few meters) because of a relatively high wave attenuation in that frequency range. Also, defects just below the surface may not be detected, and reference standards are required.

* Conversely, if the crystal is subjected to a mechanical strain, an electrical field will be created in which the voltage produced is proportional to the amount of strain (3.4). 
Instead of using the typical approach described above, dry-coupled piezoelectric transducers employed for guided-wave inspection of piping (3.7) may also be used for plates. Compared to the thickness vibration of a conventional transducer, the piezoelectric transducer in this case expands or contracts lengthwise. When pressed against the surface of a material under inspection, the lengthwise motion of the transducer imparts the force to the material through friction and generates the guided wave. Detection of the guided wave is achieved by the reverse process. The operating frequency of the drycoupled transducer is low (100 kHz or less) and, therefore, it is well suited for long-range inspection (tens of meters) because of a correspondingly low wave attenuation. The requirement of direct physical contact to the plate surface may be a disadvantage of this approach.

Noncontact ultrasonic pulses can be generated through focusing a series of light impulses from a laser onto the surface of the object inspected (3.4). The remotely positioned laser sends out a series of very short high-energy light impulses that are converted by thermomechanical effects into sound impulses. The laser pulse at the point of incidence on the object surface produces rapid heating (without damage) resulting in a localized temperature rise that generates ultrasonic waves. The emission from a second laser illuminates the surface of the test object and ultrasonic echoes returning to the test object surface cause deflections that produce modulation of the reflected light from the illuminating laser. An interferometer analyzes the modulated reflected light signal and converts it into a signal that can be presented on a cathode-ray tube. The main advantages of laser-induced ultrasonics is that no mechanical coupling is required and the acquisition of results is rapid, however, sensitivity is not as good as more conventional ultrasonic systems.

Another ultrasonic testing technique is the time of flight diffraction (TOFD) method that relies on the diffraction of ultrasonic waves from cracks or defect tips, rather than reflection such as in pulse-echo methods. Usually two probes (transmitter and receiver) are used, with the probes aligned geometrically on either side of the object being inspected (e.g., crack or weld). The transmitter produces a relatively wide beam spread in order to maximize the extent of a scan. A scan (" $\mathrm{A}$ " scan) is taken in sequential positions along the length of interest. The wave propagation times are used to indicate and locate the diffraction source. If both tips of a defect can be resolved, then the actual depth and "throughwall" thickness of the flaw can be accurately calculated. Interpretation of results can be difficult, however, because it is hard to achieve clear signals in the "A" scans due to the nature of the weak diffracted signals coupled with noise, and interference derived from very small pores or material nonuniformity (particularly for welds). Data enhancing algorithms such as the synthetic aperture focusing technique can be used to improve defect characterization by eliminating beam spread effects. One of the best applications of this method has been to on-line weld inspection since it can inspect the full weld with rejection of unwanted signals, and scans are continuous and contain all data from individual "A" scans.

\subsubsection{Radiographic Techniques}

Radiographic techniques involve the use of penetrating $\gamma$ - (decay process of radioactive substances) or X-radiation (bombarding a metal target with a beam of high-velocity electrons) and are based on differential absorption of the radiation. X-radiographic inspection is applied to the detection of surface connected and internal anomalies as well as the internal configuration of a test object. Radiation is capable of detecting any feature in a component or structure provided that there are sufficient differences in thickness or density within the test article. The source is placed close to the material to be inspected and the radiation passes through the material and is captured on film placed on the opposite side of the test article from the source. Sensitized paper (paper radiography), fluorescent screen viewing (fluoroscopy), and detection and monitoring by electronic sensing equipment (xeroradiography) can also be used to monitor the intensity of radiation passing through a material. A two-dimensional projection of the area being inspected is displayed on the film (permanent record). The thickness, density, and absorption characteristics of the material affect the intensity of radiation passing through an object. Possible imperfections are indicated on the film as density changes (i.e., series of gray shades between black and white). The choice of type of source is dependent on the thickness of material to be tested. Gamma rays have the advantage of portability. Gamma radiometry systems consist of a source that emits gamma rays through the specimen and a radiation detector and counter. Direct transmission or backscattering modes can be used to make measurements. The count or count rate is used to measure the specimen dimensions or physical characteristics (e.g., density and composition). Primary limitations of radiography are that radiation protection has to be observed while applying the method, personnel must be licensed or certified, results are not immediately available, the structure must be accessible from both sides, detection of crack-like anomalies is highly dependent on the exposure geometry and orientation of the crack with respect to incident irradiation, and it tends to be expensive relative to many other nondestructive examination methods. Best results are generally obtained when the defect has an appreciable thickness in the direction parallel to the radiation beam. 
Neutron radiography involves the transmission of neutrons through a component with the associated production of a radiograph on film. Sources of neutron beams include a radioactive isotope, a particle accelerator, or a nuclear reactor. Neutron emissions are classified according to their kinetic energies as cold (slow neutrons), thermal (medium speed), or fast (3.4). Generally the thermal neutrons are used in neutron radiography. As a neutron beam passes through a medium it will be attenuated due to neutron scatter (collisions with atom nuclei) and capture (absorption of neutron into nucleus creating an isotope of the atom). With neutron beam radiography there is a greater tendency for the thermal neutron beam attenuation to increase as the atomic mass number of the element increases. The general principles of beam attenuation with increasing thickness, shadow formation, and other geometrical effects are similar to those of $\gamma$ - or Xradiography, however, recording of results differs. Either direct-exposure or transfer screens are used. In the directexposure method the screen is placed in direct contact with the film and neutrons falling on the screen are absorbed and a secondary emission, to which the film emulsion is sensitive, is released. Transfer screens are positioned behind the object to be radiographed, a neutron exposure made, and the transfer screen used to expose the film. Neutron radiation is a highly specialized and costly process, but has been used for a number of applications including inspection of nuclear fuel elements.

A special form of radiograpy, neutron tomography, merges standard neutron radiography with the computed tomography techniques common to most of today's medical scanners to enable two- and three-dimensional external and internal visualizations of objects. The object to be scanned is located in front of the neutron beam port and activation film used to record the results. The activation film is then used to expose photographic film. The object is then rotated a precise amount and the procedure repeated until images have been taken over $180^{\circ}$. After processing the film, the images are digitized on a scanning microdensitometer and stored for computer processing. Data from each of the stored images is aligned and normalized to the same exposure and used to reconstruct images of cross sections of a scanned object. Density variations can be indicated using colors. As neutron tomography is particularly effective in detecting hydrogenbased substances, it is useful in identifying corrosion products since they absorb the neutrons, however, since results are averaged, pitting corrosion may not be detectable. Computed tomography also can be used in conjunction with $\gamma$ - and Xradiography beam measurements.

\subsubsection{Acoustic Emission Inspection}

Acoustic emission inspection is based on monitoring and interpretation of stress waves generated by a structure under load. Acoustic emissions are small amplitude stress waves (50 kHz to $10 \mathrm{MHz}$ frequency) resulting from release of kinetic energy as a material is strained beyond its elastic limit (e.g., crack growth and plastic deformation). Material stress can come from mechanical or thermal loading, as well as from a variety of other means. There are basically two types of acoustic emissions from materials - a continuous type of low amplitude associated with plastic deformation and movement of dislocations within a material, and a burst type of high amplitude and short duration resulting from development and growth of cracks. The stress waves propagate throughout the specimen and may be detected as small displacements by piezoelectric transducers positioned on the surface of the material. A typical acoustic emission system consists of a number of sensors, preamplifiers, signal filters, amplifier, and a recording system. Signal measurement parameters most commonly used to interpret results include ringdown counts (threshold-crossing pulses), energy counts (area under rectified signal envelope), duration (elapsed time for ringdown counts), amplitude (highest peak voltage), and rise time (time from first threshold crossing to signal peak). Primary applications of acoustic emission inspection include continuous monitoring or proof testing of critical structures, monitoring of production processes, and experimental research related to material behavior. Advantages of acoustic emission are that it is extremely sensitive, the entire structure can be monitored, it is relatively unobtrusive, onset of failure can be identified, and triangulation can be used to identify source location. Acoustic emission can detect growing cracks of a much smaller size than is detectable by conventional techniques, and since there is a marked increase in activity when a crack or discontinuity approaches critical size, it can warn of impendent instability and catastrophic conditions. Certain aspects of the corrosion process are detectable by acoustic emission (e.g., stress-corrosion cracking, hydrogen cracking, corrosion fatigue, and gas evolution) (3.4,3.8). Disadvantages are that it requires considerable technical experience to conduct the test and interpret results, background noise can interfere with signals, and a material may not emit until the stress level exceeds a prior applied level (i.e., Kaiser effect).

\subsubsection{Thermographic Inspection}

Thermographic inspection methods are applied to measure a variety of material characteristics and conditions. In the flaw detection mode they are used for detection of interfaces and/or variation of properties of interfaces within layered systems. The test object must be thermally conductive and reasonably uniform in color and texture. The procedure 
involves inputting a pulse of thermal energy that is diffused within the test object according to thermal conductivity, thermal mass, inherent temperature differentials, and time of observation. The thermal state of the test object is monitored by a thermographic scanner camera that has infrared energy spectrum detection capability. Interpretation of results is done through visual monitoring of the relative surface temperature as a function of time and relating the timedependent temperature differences to the internal condition of the test object. Irregularities in temperature contours can be related to defects as flaws or irregularities that will affect the amount of heat conduction in their vicinity. Results are recorded as a function of time and the process is relatively rapid. Specialized equipment is required and since the method is a volume inspection process, resolution is lost near the edges and at locations of nonuniform geometry change.

Thermal inspection becomes less effective in the detection of subsurface flaws as the thickness of the object increases. Pulsed infrared techniques have been developed that can perform inspections through the thickness of test objects. The process basically entails providing heat through a high-intensity thermal pulse or step heating, and dynamically collecting infrared images of the material surface using an infrared thermal imager tied to a video recording system. Digitized image processing can be used to enhance the images received. To be successful, the heat applied at the top surface must penetrate to the bottom surface with a temperature differential of several degrees for good infrared contrast.

\subsubsection{Electrochemical Corrosion Monitoring}

Electrochemical corrosion monitoring techniques are available to make measurements directly related to corrosion rate rather than indirectly in terms of the flaws produced by corrosion. Potential surveys, linear polarization, and AC impedance are techniques that have been utilized. Electrochemical potential measurements using a standard half-cell (e.g., copper-copper sulfate) can be used to locate anodic portions of a structure (i.e., potential gradients indicate possibility of corrosion). The more negative the value of the standard half-cell potential, the greater the tendency of the metal to lose its electrons (i.e., corrode). The linear polarization resistance method impresses DC current from a counter electrode onto the working electrode (e.g., steel structure). Current is passed through the counter electrode to change the measured potential difference by a known amount with the working electrode being polarized. An electronic meter measures the potential difference between the reference electrode and the working electrode. Measurements as a function of DC voltage applied across the cell provide an indirect measure of the corrosion current. The AC impedancepolarizing technique utilizes an alternating applied voltage with the data analyzed as a function of frequency. The AC technique provides polarization resistance as well as information on polarization mechanisms at the anode and cathode which is important for interpretation of the $\mathrm{AC}$ impedance data. The technique requires rather sophisticated equipment (e.g., AC frequency generator and analyzer system) and the Tafel slopes must be known to convert AC impedance data into corrosion rate information (3.9). Each of these methods requires contact with the part of the structure monitored and, where corrosion rates are provided, the rates are only since equipment installation and monitoring.

\subsection{INSPECTION OF INACCESSIBLE PORTIONS OF METALLIC PRESSURE BOUNDARIES}

Inspection of inaccessible portions of metallic pressure boundary components of nuclear power plant containments (e.g., fully embedded or inaccessible containment shell or liner portions, the sand pocket region in Mark I and II drywells, and portions of the shell obscured by obstacles such as platforms or floors) requires special attention. Embedded metallic portions of the containment pressure boundary may be subjected to corrosion resulting from ground water permeation through the concrete; a breakdown of the sealant at the concrete-containment shell interface that permits entry of corrosive fluids from spills, leakage, or condensation; or in areas adjacent to floors where the gap contains a filler material that can retain fluids. Examples of some of the problems that have occurred at nuclear power plants include corrosion of the steel containment shell in the drywell sand cushion region, shell corrosion in ice condenser plants, corrosion of the torus of the steel containment shell, and concrete containment liner corrosion. In addition there have been a number of metallic pressure boundary corrosion incidents that have been identified in Europe (e.g., corrosion of the liner in several of the French $900 \mathrm{MW}$ (e) plants and metal containment corrosion in Germany). Corrosion incidences such as these may challenge the containment structural integrity and, if through-wall, can provide a leak path to the outside environment. Although no completely suitable techniques for inspection of inaccessible portions of containment pressure boundaries have been demonstrated to date, several techniques have been proposed (i.e., ultrasonic inspection, electromagnetic acoustic transducers, half-cell potential measurements, magnetostrictive sensors, and multimode guide waves. Provided below is a summary of prior research and candidate techniques evaluated under this program. 


\subsubsection{Prior Research}

Prior research studies have investigated use of ultrasonics and electromagnetic acoustic transducers.

\subsubsection{Ultrasonic testing}

Guided (or Lamb) wave generation and detection using a conventional piezoelectric transducer, Fig. 3.1, is based on Snell's law $(3.5,3.6)$. The transmitting transducer generates plane acoustic waves in the coupling medium between the transducer and the plate. The medium may be either fluid, such as water, or a wedge material such as plexiglass (for the latter case, an additional thin layer of couplant is required to couple the generated wave into and out of the plate). When the longitudinal (or compressional) wave in the coupling medium arrives at the plate surface, a mode conversion takes place according to Snell's law, and the guided wave is subsequently produced and propagated in the plate. The guidedwave mode produced in the plate satisfies the following equation for Snell's law:

$$
\operatorname{Sin} \theta=V / V p
$$

where $\theta$ is the incident angle, $\mathrm{V}$ is the longitudinal wave velocity in the coupling medium, and $\mathrm{Vp}$ is the phase velocity of the guided-wave mode in the plate. Detection of the guided waves in the plate is achieved when the guided wave is mode-converted back to the longitudinal wave in the coupling medium.

Ultrasonic testing is commonly used to monitor wall thinning and can be used to detect and monitor corrosion if at least one side of the structure is accessible. In the pulse-echo mode an ultrasonic transducer transmits waves toward the metal surfaces, signals are reflected from the front and back surfaces, and the difference in arrival times of the two signals is used to indicate the component thickness. Metal loss is then calculated by taking the difference between the as-built thickness and the thickness measured.

In Germany, an extensive evaluation was conducted by Technical Inspection Service (Munich) to evaluate the feasibility of using ultrasonic methods to detect corrosion damage of the containments of PWRs or liners of BWRs in areas that are inaccessible ( i.e., embedded bottom portion of containments of PWRs, areas of containments of PWRs adjoining platforms, penetrations through the containments of PWRs, and steel liners of BWRs inside pressure-suppression chamber) (3.10). In order to establish suitable search units (favorable signal-to-noise ratio) for detection of metal containment corrosion, a calibration block with simulated corrosion was prepared. A sharp-edged and a cambered shallow pit were machined to a depth of $2.5 \mathrm{~mm}$ into a $39-\mathrm{mm}$-thick calibration block. The sharp-edged pit was used to qualify the search units considered. Corrosion-inhibiting paint was applied to one surface of the block.

Several angle beam search units were used to examine the calibration block $\left(45^{\circ} .60_{. .}^{\circ} 70^{\circ}\right.$ and $\left.90^{\circ}\right)$. In setting up the qualification tests, experience has shown that locations of corrosion in containments can occur at distances to approximately $100 \mathrm{~mm}$ below the interface where the containment shell becomes embedded in concrete. This results in long beam paths with correspondingly large projection distances for the ultrasonic examinations. A pulse-echo unit was used in the tests with sensitivity adjusted based on signal-to-noise ratio (average method). Results obtained showed that the sharp-edged pit was detectable (signal-to-noise ratio $>12$, input angles from $45^{\circ}$.to $90^{\circ}$ ), but the rounded pit (input angles from $35^{\circ}$ to $80^{\circ}$ ) could not be detected. Supplemental testing was then performed on a PWR containment and corroded calibration blocks.

During repair to the containment of a PWR at a German nuclear power it was possible to perform ultrasonic examinations and to establish the extent to which such examinations were suitable for detecting corrosion damage. To facilitate detection of surface corrosion on the inside of the containment, which later became visible when the concrete was removed, angle beam search units were used to scan zones with different coupling conditions. When selecting search units for examination of containment corrosion several aspects were taken into account: (1) surface conditions of the calibration block and the containment differed, (2) the containment was coated internally and externally while the corrosion block was coated only with a corrosion-inhibiting paint, and (3) reflection characteristics of corrosion points in the containment differ from those of the sharp-edged or cambered shallow pits in the corrosion block. Supplemental examinations were carried out to characterize the corrosion and to qualify the testing technique. The tests involved coated surfaces and surfaces machined until they were bright metal. With the $45^{\circ}$ search unit it was found that the influence of the coating could be disregarded and locations of corrosion could be separated from the interference level of the detection zone $(\sim 6 \mathrm{~dB})$ in single to triple skips. For the $60^{\circ}$ and $70^{\circ}$ search units, because of the long paths and surface roughness of the component, the indications of corrosion were masked by interference. With coating present, 
signals from the $90^{\circ}$ search units were highly damped so wave propagation distance was inadequate. When the coating was removed by grinding, the noise level from surface roughness was too high to use the $90^{\circ}$ search units. With this as background, ultrasonic tests were performed from the inside and outside of the containment with varying beam paths (single to triple skip distances).

Measurements on the inside containment surface were performed at four locations. The locations included those with and without corrosion. Coupling conditions were such that the surface was either coated or bright metal (e.g., ground). Indications of corrosion pits were obtained from each of the locations where corrosion pits were present. For measurements from the outside of the containment, the coupling area was coated and slightly smoothed. Echo heights indicative of corrosion were obtained from the outside surface of the containment for only one of the four corrosion locations. Removal of the concrete adjacent to this area revealed corrosion that was about $100 \mathrm{~mm}$ below the interface. Wall thickness measurements were then performed on the containment at this same location. The initial wall thickness at coated locations ranged from 31.2 to $31.4 \mathrm{~mm}$. The smallest measured wall thickness at this location was $29.3 \mathrm{~mm}$ indicating an approximate wall thinning of $2 \mathrm{~mm}$, or a loss in thickness of $6.4 \%$. General corrosion was found to be difficult to detect.

Further examinations were carried out on calibration blocks with artificial corrosion induced. These examinations were performed to verify whether and under which test conditions corrosion could be safely detected with $45^{\circ}$ angle beam search units. The previous calibration block and another calibration block containing a 2-mm-deep pit, sharp-edged on one side and flattened on the other, were artificially corroded for a period of seven months using $1 \% \mathrm{NaCl}$ solution at $20^{\circ} \mathrm{C}$ to produce corrosion pits up to 2.4-mm deep. The corrosion pits were detectable in both calibration blocks with adequate signal-to-noise ratio.

The study concluded that corrosion pits could be adequately detected by ultrasonic testing with $45^{\circ}$ angle beam search units if the corroded surfaces were sufficiently pitted (e.g., $\geq 2.4-\mathrm{mm}$ deep). In this case sufficient sound intensity is transmitted back to the search unit as a result of adequate reflectivity. The ultrasonic wave length is a measure of reflectivity and it must be on the order of magnitude of the extent of the corrosion pits. Signal-to-noise ratio should be on the order of $12 \mathrm{~dB}$ for detectability. Results of this study indicated that it was possible to detect well-developed corrosion pits (pit depth of same order of magnitude as ultrasonic wave length) with $45^{\circ}$ angle beam $2 \mathrm{MHz}$ search units within a distance of up to $130 \mathrm{~mm}$ below the interface between the concrete and metal containment.

\subsubsection{Electromagnetic acoustic transducers}

An electromagnetic acoustic transducer (EMAT) is a device that generates and detects ultrasonic waves in metal based on the Lorentz force (3.11) which is a force that acts on a moving charge in a static magnetic field. The EMAT consists of a transmitter and receiver, both of which contain a permanent magnet or electromagnet and a coil (Fig. 3.2). The transmitter coil is excited by high radio-frequency current to induce an eddy current into the surface of the metal examined. The eddy current interacts with the magnetic field generated by the transmitter coil to produce a Lorentz force that interacts with alternating current (supplied by the EMAT coil) and an externally supplied magnetic flux to generate guided plate waves in the metal (i.e., pulse-echo and through-transmission modes generate low frequency horizontal shear (SH) plate or Lamb waves). Detection of elastic waves is accomplished by the reverse process in which the wave in the presence of a static magnetic field gives rise to eddy currents in the metal that induces a voltage to the EMAT coil. EMATs have been applied to long-range inspections of tubes (3.12) and steel sheets (3.13). EMATs have advantages for detection of corrosion because: a couplant is not needed, the ultrasound is generated directly in the metal rather than in the transducer, the high-energy waves can travel relatively long distances parallel to the plate surface, the wave velocity is independent of plate thickness, and the ultrasound can be generated through a surface coating up to about 1.5-mm-thick. Disadvantages of EMATs are that their efficiency is low and thus the signal-to-noise ratio may be poor, and they lose sensitivity when the gap to the surface of the component inspected is increased.

The capability of adapting EMATs to detect corrosion in Mark I containment vessels and correlating EMAT signals with corrosion damage to make quantitative evaluations were evaluated in the laboratory (3.14). Since it had been shown that the $\mathrm{SH}_{0}$ mode had less attenuation than the $\mathrm{SH}_{1}$ mode, the $\mathrm{SH}_{0}$ mode was primarily used for the experiments. Simulated corrosion-like defects ( $13-\mathrm{mm}$ wide by $102-\mathrm{mm}$ long by $11-\mathrm{mm}$ deep) were milled into a $2.1-\mathrm{m}$-wide by $4.9-\mathrm{m}$-long by 25.4-mm-thick plate at a distance of $0.6 \mathrm{~m}$ from one end. Pulse-echo and through-transmission modes were evaluated. In the pulse-echo mode the transmitter generates a wave in the plate parallel to its surface. The signal, which is scattered by a defect such as a crack or corrosion, is detected by a receiver located near the transmitter. In the throughtransmission mode, the transmitter also generates a wave that travels parallel to the plate surface, however, the signal is 
detected by a receiver that is located at the opposite end of the plate. Experimental results show that SH waves scattered from planar slots (also for planar cracks and similar boundaries) produce signals that are measurable at substantial distances ( $3 \mathrm{~m}$ or more) from a small (two wavelength) scatterer that extends halfway through the plate. In the pulseecho geometry, a flaw at least half-way through the plate thickness and two wave lengths long $(\sim 127 \mathrm{~mm})$ provided strong scattering signals that could be detected at distances to $4.6 \mathrm{~m}$. Rounding of the flaw causes the signal to become weaker and spreads it more over a larger angle (i.e., scattered energy from planar slot is primarily $\mathrm{SH}_{0}$ mode while semicircular slot scatters a great deal of energy into other modes). Although the through-transmission mode was not as sensitive (lower relative detectability), it was felt that deep corrosion damage (i.e., $>75 \%$ of the plate thickness) could be detected at a distance to $15 \mathrm{~m}$ or more, but defect sizing would be difficult. The significant amount of coherent elastic wave energy present in the plate indicates that discrimination of any type of scattering anomaly will be improved dramatically using synthetic aperture signal processing.

\subsubsection{Assessment of Candidate Techniques}

Several techniques have been identified having potential application to inspection of inaccessible regions of NPP containment metallic pressure boundaries. Analytical and experimental studies have been conducted to assess the capability of high-frequency acoustic imaging, magnetostrictive sensors, and multimode guided waves.

\subsubsection{High-frequency acoustic imaging.}

Exploratory analytical and experimental simulations have been conducted by the Engineering Technology Center (Mystic, CT) to investigate the feasibility of applying high-frequency acoustic imaging techniques to the detection and localization of thickness reductions in the metallic pressure boundaries of nuclear power plant containments $(3.15,3.16)$.

\subsection{Numerical simulations}

The analytical study used an elastic layered-media code (OASES Code, Massachusetts Institute of Technology) to perform a series of numerical simulations to determine the fundamental two-dimensional propagation physics (3.17, 3.18). Results from the two-dimensional studies were used to address three-dimensional issues related to defect classification.

Range-independent results. Initial evaluations utilized the range-independent version of the OASES Code. The code was developed and validated for the evaluation of the acoustic field in a system of stratified fluid and/or elastic layers. The propagation scenario must be horizontally layered with the material parameters of each layer fully specified in terms of sound speed, density, and absorption. An arbitrary number of fluid or solid elastic layers can be interleaved, though the outer layers are modeled as halfspaces. The received field due to an arbitrary source array can be calculated at arbitrary depth and range positions. The response is determined for a single frequency by means of an exact fully-elastic calculation by wavenumber integration. Table 3.4 presents the material properties used in the numerical models. Figure 3.3 presents the approximate model of the containment scenario that was created. The model represents a portion of the problem addressed either above or below the interface, but does not represent the interface. A nominal 25-mm-long source array represents the ultrasonic sensor and the array is steered down at an angle to couple to a particular shear wave angle in the steel. The model was run for angles $\left(35\right.$ to $\left.70^{\circ}\right)$ and frequencies $(0.5$ to $5 \mathrm{MHz})$ of currently available commercial sensors. Normal stress was calculated over a grid at a spacing of $1 \mathrm{~cm}$ in range and depth with the field calculated to a depth extending from $25 \mathrm{~mm}$ above to $25 \mathrm{~mm}$ below the steel layer. Degradation of the steel layer was represented by spatially uncorrelated surface roughness on the bottom of the steel layer. Although it was demonstrated that the code could model the basic scenario, clear modal structural dependence on frequency was seen. After several runs of the model utilizing a wide range of parameters, it became clear that the range-independent version of the code was inadequate to capture the important processes of propagation. The levels of roughness on the interface used to represent degradation were essentially meaningless. Roughness was modeled simply as an attenuation of a forwardpropagating wave with no backscatter wave generated by the roughness. As a result, the approach was changed to use of the range-dependent version of OASES in which the full interface scenario could be modeled.

Range-dependent results. The range-dependent version of OASES also applies to evaluation of the acoustic field in a system of stratified fluid and/or elastic layers. This version of the code permitted modeling of the full scenario, which includes the air/concrete interface, a finite-length source, and discrete degradation regions. The field in one sector is propagated to the next sector by a virtual array of sources located on the sector boundary. A single scatter model is used (i.e., the field is calculated once forward through the sectors and then once backward). 
The two-dimensional numerical model for the embedded steel containment scenario is presented in Fig. 3.4. Degradation of the steel is represented by a $10-\mathrm{cm}$-long notch cut from both surfaces. The degradation thickness, T, and its distance from the interface, $\mathrm{dx}$, are parameters used in the simulation. A nominal 25-mm-long source array in a "wedge" material represents the ultrasonic sensor with the wedge material modeled as a fluid and thus only supports compressional waves. The array is steered down at an angle to couple to a particular shear wave angle in the steel. Results for simulation of a $0.5 \mathrm{MHz}$ source which excites a $45^{\circ}$ shear wave in the steel surrounded only by air are presented in Fig. 3.5. Degradation is present on both sides of the steel, $\mathrm{T}=4 \mathrm{~mm}$, located at a distance of $55 \mathrm{~cm}$ from the source. The top plot shows the normal stress in $\mathrm{dB}$ as a function of range and depth for the forward-propagating field. Attenuation due to absorption by the steel is fairly low. The middle plot shows the same information for the backward-propagating field and indicates significant reflection of energy by the presence of degradation. The bottom plot shows line plots of the forward- and backward-propagating fields at the top of the steel layer. For this scenario, the degradation gives a signal level of $-17 \mathrm{~dB}$, which includes the scattering strength of the degradation and the attenuation of the steel. This return is significant and easily measurable. Results when concrete is added to the model are presented in Fig. 3.6. For the same degradation parameters as before, significant loss of energy occurs to the concrete as noted by high field levels above and below the steel layer to the right of the interface in both the forward and backscatter plots. The mechanism is phase-speed matching, shear waves in the steel leak off via Snell's Law into compressional waves in the concrete. Also, an additional $20 \mathrm{~dB}(37-17 \mathrm{~dB})$ of energy, normally seen by the sensor, has been lost due to leakage into the concrete. This will limit penetration ability.

In order to determine the dependence of the field on frequency and depth of degradation, the model in Fig. 3.4 was run for frequencies from 0.1 to $1 \mathrm{MHz}$ and two-sided degradation depth from 0.5 to $10 \mathrm{~mm}$. Figure 3.7 presents plots of signal level in $\mathrm{dB}$ versus degradation depth in $\mathrm{mm}$. Results indicate that the system will be able to distinguish between relatively small surface imperfections (e.g., $\leq 1 \mathrm{~mm}$ ) and more serious degradation (e.g., $>2 \mathrm{~mm}$ ). However, as the change in signal level $(<10 \mathrm{~dB})$ for defects in the range of 4 to $10 \mathrm{~mm}$ is relatively small, quantification of defect size in this range will require careful calibration. In order to evaluate the signal penetration capabilities, the model in Fig. 3.4 was rerun for frequencies from 0.1 to $1 \mathrm{MHz}$ and a two-sided, 4-mm-deep degradation located at interface distances from 5 to $20 \mathrm{~cm}$. Results in Fig. 3.8 show a high attenuation of received signal with distance. The concrete adds $3-4 \mathrm{~dB}$ of two-way signal loss per $\mathrm{cm}$ of concrete penetrated. The range of depths that can be penetrated will depend on the capabilities of the transducer used.

The two-dimensional numerical model for the steel-lined concrete containment scenario is presented in Fig. 3.9. Since the purpose is to detect degradation in the liner, which is thin compared to the concrete section, the field was limited to the steel liner (i.e., the containment was modeled as a pure halfspace). Normal stress in $\mathrm{dB}$ as a function of depth and range for the forward-and backward-propagating fields resulting from a $0.5 \mathrm{MHz}, 25-\mathrm{mm}$-long source array coupled with a wedge to excite a $45^{\circ}$ shear wave in the steel are presented in Fig. 3.10. In this scenario a 2-mm-deep, two-sided degradation, located $5 \mathrm{~cm}$ from the air/concrete interface was used. The figure shows that most of the forward energy from the source is injected through the plate directly into the concrete and lost so that the returned signal levels are very low. This will limit the ability of a practical system to excite waves in the liner. Signal levels are $40 \mathrm{~dB}$ (factor of 100 ) lower than the comparable values for the steel containment scenario. Also, if there are scatterers in the concrete, such as reinforcement, studs, or voids, they will tend to scatter energy back to the plate that may interfere with the desired measurements. Degradation depth (degradation depths from 0.5 to $3 \mathrm{~mm}$ located $5 \mathrm{~cm}$ from the interface, and frequencies from 0.1 to $1 \mathrm{MHz}$ ), and penetration (2-mm-deep degradation, located from 5 to $20 \mathrm{~cm}$ from interface, and frequencies from 0.1 to $1 \mathrm{MHz}$ ) studies indicate that for this scenario unacceptably high loss to the concrete occurs (e.g., on order of $100 \mathrm{~dB}$ ) for a small degradation close to the interface. Due to this magnitude of loss, it appears unlikely that acoustic imaging technology can be applied to this scenario.

Three-dimensional issues. Having established the basic restrictions imposed by important parameters of the twodimensional scenario as well as by the sensors themselves, the feasibility of designing an array of sensors that can scan the surface of the containment to localize and map thickness reductions was investigated.

Localization and mapping are similar operations from the point of view of a sensor system. Generally, a sensor system searches an area or volume by scanning in two or three dimensions. The search can be active, where the sensor sends out pulses of energy and listens for returns, or passive, where the sensor just listens for energy from an active source. The system under consideration here is an active system, since there are no active sources in our scenario. For an active system, sufficient energy must be input into the medium so that a signal reflected back from the target is of sufficient magnitude that it is measurable at the receiver. The search area or volume is divided into bins in some coordinate system

(e.g., rectangular, cylindrical or spherical). The results of a sensor sweep in which the transmitter is sequentially moved 
from bin to bin are recorded for each bin. If the record is a "target/no target" decision, this is known as localization and locates the target. If the record is a received level, either in the form of raw data or interpreted via some transform, this is known as mapping. The problem at hand is a mapping problem, as the desired output is a spatial map of the degree of degradation over the entire surface of the containment.

Array processing is used to do either localization or mapping. Localization is a bit easier to describe. From there, mapping is a simple generalization. In order to localize a point scatterer, several directional views of it must be obtained and correlated. A classical (3.19) way to do this in two dimensions is with an array of sensors using a "range-bearing" type of algorithm (Fig. 3.11). Typically, a line array of $\mathrm{N}$ individual, omni-directional sensors is used in a coherent fashion. In a narrow-band frequency sense, the sensors are electronically phased to transmit and receive a tight angular beam of propagating energy. As shown on the left of the figure, this beam can be steered in a particular direction, $\theta$. By sweeping the beam over this angle and identifying which angle gives the strongest return, the bearing of the target relative to the array can be found. Once bearing is known, the range is determined by using time-of-flight information. The range of the target is given by multiplying the two-way travel time, $2 \tau$, by half the medium sound speed, $\mathrm{c} / 2$. Range and bearing information then uniquely locate the target in cylindrical coordinate space (although a line array does have an up-down ambiguity). The localization accuracy is dictated by the resolution of the array in the angular direction, and the bandwidth of the pulse in the range direction. These constraints give the minimum bin size in the two directions.

Figure 3.12 provides a simple illustration of the important parameters that govern the resolution of line arrays. In order to avoid spatial aliasing of the array, the elements must have a spacing, $d x$, smaller than $\lambda / 2$, where $\lambda$ is the wavelength of the signal, $\lambda=\mathrm{c} / \mathrm{f}, \mathrm{c}$ is the sound speed of the material and $\mathrm{f}$ is the frequency of the signal. This is similar to the Nyquist condition of signal processing and must be met to prevent bearing ambiguity. In the far-field, the beam pattern of the array is a sine function whose main lobe width is dictated by the length of the array, L. The angular resolution, $\theta_{3 \mathrm{~dB}}$, of the array in radians is simply the wavelength, $\lambda$, divided by the length of the array, $\mathrm{L}$. The resolution, $\mathrm{D}$, at a particular range, $\mathrm{R}$, is this angular resolution multiplied by that range. This is only true in the far-field of the array which starts at a range equal to $2 \mathrm{r}_{\mathrm{T}}=2 \mathrm{~L}^{2} / \lambda$. The strength of the array side lobes is a function of the amplitude taper applied across the array. For a Hamming taper, a target in the side lobe will have a level more than $40 \mathrm{~dB}$ below the level of a target in the main lobe. Since the range bin size is proportional to the duration of the pulse sent out by the source (Fig. 3.11), a good estimate of this pulse duration is: $\tau=1 / \mathrm{BW}$, where $\mathrm{BW}$ is the bandwidth of the signal.

Using the characteristics of typical ultrasonic sensors noted in Table 3.5, bin sizes can be calculated. The range bin width is computed from the bandwidth of the sensor. With a $\mathrm{Q}=\Delta \mathrm{f} / \mathrm{f}_{\mathrm{c}}=0.6$, a $1 \mathrm{MHz}$ sensor has a $\tau=1.7 \mu \mathrm{s}$, or $\Delta \mathrm{R}=$ $5 \mathrm{~mm}$. Thus, the range bin size is $0.5 \mathrm{~cm}$. The total range of primary interest for the containment inspection scenario is on the order of $30 \mathrm{~cm}$, which is equal to about 60 bins. This is not a very taxing burden for a system to measure and calculate. If one would like to localize down to about $3 \mathrm{~cm}$, a $0.5 \mathrm{~cm}$ range bin size more than meets the criterion and is a good practical range resolution.

Angular resolution presents more of a problem with available sensors. A typical sensor is in the form of a piston that is large compared to a wavelength. Also the typical sensor is not an omni-directional source, as is required for the formation of an array. To understand the high directionality of this sensor, one can model it as a dense array of finite length $\mathrm{L}$, phased coherently in one direction. At $1 \mathrm{MHz}$, a $25-\mathrm{mm}$ shear sensor has a main lobe width of only $\theta_{3 \mathrm{~dB}}=7^{\circ}$. To understand the severity of this limitation, note that at $25 \mathrm{~cm}$ from the sensor location the diameter of the spot the sensor interrogates is $\mathrm{D}$, where $\mathrm{D}$ is $3 \mathrm{~cm}$ wide. These ultrasonic sensors cannot be used together in a scanning array, as each sensor beam pattern would make looking in any direction other than the intrinsic sensor direction impossible. Thus, the current sensor technology can only be used in spot detection and mapping scenarios. If there were suspected degradation in an area of the containment, the sensor could be physically moved along at 3 to $5 \mathrm{~cm}$ intervals to sweep out a small area. This is a labor-intensive process that would be warranted if degradation was suspected, but would not be practical to interrogate a large area.

Scannable sensor technology, such as used for medical ultrasound, should be capable of being developed. The medical ultrasound sensors are manufactured by bonding many signal wires to a solid piezoelectric block on a substrate, and then cutting the block into individual sensors, leaving a line array of $\mathrm{N}$ sensors in the substrate (Fig. 3.13). For example, at 1 $\mathrm{MHz}$, the spacing on this array would have to be on the order of $1.5 \mathrm{~mm}$ to avoid aliasing and $2.54 \mathrm{~cm}$ in total length for an angular resolution of $\theta_{3 \mathrm{~dB}}=7^{\circ}$. This would require a 17-element array, that would be very reasonable in terms of cost and complexity to drive electronically. The finite size of the individual sensors would allow a total scan sector width of $120^{\circ}$, or about 18 angular bins. Experiments with the wedge material would have to be made to demonstrate that the directionality of the sensor would not interfere with the coupling characteristics of the wedge, and vice versa. Given the 
fixed scan sector size of $120^{\circ}$, the maximum penetration ability of the sensor and the required depth of coverage will limit the array offset, as shown in Fig. 3.14. Array offset is the separation between scanning stations so that the scan cones overlap, as shown in the figure, to provide complete coverage. Using parameters provided, it is estimated that the array offset will be on the order of $1.5 \mathrm{~m}$, or 75 stations (scan locations) would be required to interrogate a $36-\mathrm{m}$ diameter containment.

Conclusions from numerical simulations. The range-dependent version of the OASES Code successfully modeled the steel containment and steel-lined concrete containment scenarios using the discrete notch approach. For the steel containment scenario, significant degradations $(>2 \mathrm{~mm})$ located below the concrete/air interface give reasonable intrinsic backscatter levels $(-15 \mathrm{~dB})$ that are $10-15 \mathrm{~dB}$ above the expected noise level due to surface imperfections. Dependence of degradation depth is small, but measurable. The embedding concrete introduces large losses that will limit penetration ability. Backscatter strength was not very sensitive to frequency or angle of the transducer $(<5 \mathrm{~dB})$ for the sharp-edge degradations examined. Results indicate that acoustic imaging technology can be applied to this scenario. For the steel-lined reinforced concrete containment scenario, the thin steel liner in conjunction with the concrete produce unacceptably high signal losses to concrete $(\sim 100 \mathrm{~dB})$. Application of acoustic imaging technology to this scenario seems unlikely. Currently available sensors cannot be used in array configurations to interrogate a large area (global inspection) due to their intrinsic narrow beam pattern, which does not allow steering. This limits these sensors to spot detection and mapping scenarios, where degradation is already suspected; however, scannable sensor technology, such as used for medical ultrasound, should be capable of being developed.

\subsection{Experimental simulations}

Based on the prior numerical simulations, the proposed solution is to propagate ultrasonic waves (either shear or compressional), whose wavelengths are a fraction of the plate thickness, from accessible regions of a free-standing steel containment vessel (or liner of reinforced concrete containments) laterally to detect degradations located below the airconcrete interface (Fig. 3.15). Ideally, the reflected returns from material defects can be processed to generate an image of the degradation. The proposed technique is known as an angle-beam inspection, where instead of placing an ultrasonic transducer in direct contact with a test specimen, a plastic wedge is used to couple the transducer to a test structure (Fig. 3.16). The transducer generates compressional waves in the wedge that are refracted in the test structure, usually as shear waves. Shear waves are used because for a given inspection frequency they have shorter wavelengths than compressional waves and therefore can resolve smaller defects. These refracted waves "skip" laterally away from the source through the structure. When the waves encounter discontinuities, acoustic reflections occur. This technique is often used to inspect welded joints and to determine the presence of cracks or other structural flaws. The incident waves for this type of inspection are not typically required to propagate over considerable distances or to propagate in constrained or embedded regions of the test structure, as required to do in order to demonstrate success in the proposed test scenarios. Moreover, the significance of the embedding concrete on propagation of ultrasonic waves in the steel and how well corrosive type degradations act as acoustic reflectors are unknown.

The feasibility of employing the technique under the proposed scenario therefore centers on determining if a measurable and decipherable signal is returned from an area exhibiting degradation (e.g., wall thinning due to corrosion). In an effort to not only provide a basis for improving the numerical models, but also to continue the feasibility study in a more practical forum, a series of controlled laboratory experiments was designed. The experiments attempt to limit conditions to two-dimensional scenarios where only degradation variations in the direction of the incident wave are considered, and flat plates can be used as propagating media. The physics side of the problem was addressed by investigating the energy lost from the interrogating signals into the surrounding concrete, as well as characterizing acoustic scatter arising from different defect geometries. Also of primary importance was the practical issue of determining the performance limits exhibited by a commercially available angle-beam inspection system. The ability to discern and extract the degradation characteristics using acoustic signals that include information about both the corrosive damage and the propagation path are important, but at this early stage of development, a secondary concern.

Testing equipment. A completely integrated laboratory testing package (pulser-receiver electronics, acquisition software and hardware, transducers and wedges) was provided by a commercial vendor. The testing equipment consisted of a pulser/receiver card, a high frequency analog-to-digital acquisition board (both of which were attached to a standard PC ISA bus), controlling software, piezoelement contact transducers, coupling wedges, and industrial grade ultrasonic gel couplant. The transducers had a $25-\mathrm{mm}$-diameter circular radiating face that produced an estimated halfangle beam width of just over six degrees. The transducers were tuned to $0.5 \mathrm{MHz}$, which is a relatively low frequency for ultrasonic testing (shear wave length in steel at $0.5 \mathrm{MHz}$ is about $6 \mathrm{~mm}$ ), but allows for additional penetration. The equipment can be utilized in either the through-transmission mode, where separate transducers act as source and receiver 
(bistatic), or the pulse-echo mode, in which a single transducer injects a wave and then passively listens for a return (monostatic). When operated in the through-transmission mode, the source and receiver transducers are attached to coupling wedges having the same angle. The coupling wedges are specified by the refracted shear-wave angle (measured from the surface normal) introduced into the test structure. All the wedge angles used $\left(45^{\circ}, 60^{\circ}\right.$, and $\left.70^{\circ}\right)$ were past the compressional wave critical angle for steel (i.e., compressional waves will not be excited in the steel plate). As the transducer does not generate a planar incident field, the energy is injected in all directions. Therefore, the main lobe of the incident sound field does not excite compressional waves in a steel test structure, but the side lobes below the main lobe may excite compressional waves.

The input-voltage waveform was a toneburst, with the signal length, level (in percent of maximum), and center frequency specified by the user. The signal length used in the experiments was 4 microseconds, and the frequency was $0.5 \mathrm{MHz}$. The maximum input voltage that the pulser could generate was $300 \mathrm{~V}$. Because the transducers were uncalibrated, the relationship between input voltage and mechanical force was unknown.* The acquisition board range was \pm 0.5 volts with a precision of 8 bits. The receiver gain ranged from $0-70 \mathrm{~dB}$.

System performance and operability. The initial experimental activity consisted of verifying operability of the equipment through conduct of a conventional ultrasonic thickness test. Figure 3.17 shows a sketch of the experiment and the measured return. The transducer was placed in direct contact (i.e., no coupling wedge) with the longest edge of a 25 $\mathrm{mm}$ thick by $203-\mathrm{mm}$ wide by $914-\mathrm{mm}$ long mild steel plate, for the purpose of injecting compressional waves across the plate's width. The plate thickness was chosen to approximate that used for fabrication of steel containment vessels. Plate width was selected so that no side interactions would take place when waves were directed down the length of the test platform and the width-centered source and receiver were not more than $178 \mathrm{~mm}$ apart $\left(124 \mathrm{~mm}\right.$ for a $45^{\circ}$ propagation angle, $168 \mathrm{~mm}$ for a $70^{\circ}$ propagation angle). Thus, where propagation distances were less than $89 \mathrm{~mm}$, the plate width was rendered effectively infinite.

When operating in a monostatic configuration as shown in Fig. 3.17, the transducer also acted as the receiver (i.e., input and free-vibration ringdown of the piezoelectric element were both measured). This is shown as the clipped portion of the signal before 40 microseconds (receiver gain was set to record the reflected signal from the plate's opposite edge, which displayed significantly lower levels than signals listed above). The first returns after the source had died down were from the direct path to the opposite edge of the plate, and they occurred at 75 microseconds. When half of this delay (time of flight for one-way travel) was multiplied by the assumed compressional wave speed in steel $(0.55 \mathrm{~cm} / \mathrm{s})$, the $203-\mathrm{mm}$ width was estimated to be $206 \mathrm{~mm}$. Although the transducer used was not specifically designed for this type of test, the results demonstrate a properly operating system.

The system's input/output dynamic range was experimentally determined by measuring the maximum signal that the system could inject and the minimum signal that the system could read. Two transducers (both attached to $45^{\circ}$ coupling wedges) were placed adjacent to one another on the 25 -mm-thick steel plate. With the receiver gain set to the allowed minimum $(0 \mathrm{~dB})$ and the input level set to the allowed maximum $(100 \%)$, the signal transmitted from one transducer to the other was monitored. The receiver position was slowly moved away from the source until the received signal obtained its first maximum (i.e., the receiver fell on the first "hot spot"). This was assumed to be the maximum signal level that could be injected. The maximum measurable signal, with no receiver gain, coincidentally, just filled the acquisition board range. The maximum measurable signal was $-6 \mathrm{~dB}$ re. 1 volt. The source was then removed from the plate, receiver gain maximized $(70 \mathrm{~dB})$, and average signal levels determined for one hundred background signal measurements on the plate and then averaged to obtain a minimum measurable signal level (to suppress uncorrelated sensor noise). Figure 3.18 presents the power spectral densities for the maximum and minimum signals. At $0.5 \mathrm{MHz}$, where the source signal is concentrated, a $125 \mathrm{~dB}$ difference can be seen. This difference represents the system's input/output dynamic range.

In order to attribute differences in measured signals to physical effects, measurement repeatability was quantified. The tests were performed on vertically oriented plates to incorporate any problems associated with fixing the transducers in this orientation. The tests involved measuring the transmitted signal from one transducer to another for several different relative separation distances. Transmitted signals were recorded over a three-day period on three plates, with a total of nine measured signals obtained at each separation distance. Of the nine measured signals at each separation distance, the ratios of the maximum to minimum received signal levels were determined and the results are presented in Fig. 3.19 for five different source/receiver separation distances. The plot indicates a maximum variability of $2 \mathrm{~dB}$, thus indicating that

* More expensive pulser/receiver cards that can generate inputs of $1000 \mathrm{~V}$ are commercially available. 
measured differences greater than $2 \mathrm{~dB}$ could be attributed to effects outside of pure chance.

Source and waveguide characterization. In order to accurately image the location and shape of a degradation, the distortion caused by wave guide propagation of unfocused incident waves must be considered. For this purpose, numerical modeling can be an invaluable tool, however, the modeling assumptions are critical. Therefore, as a basis for refining the numerical modeling assumptions, wave guide effects on signal propagation were addressed by a series of tests.

Using one transducer as a source and a second as a roving receiver (both transducers fixed to a $45^{\circ}$ coupling wedge), a bistatic array was simulated. By doing so, the incident wave interactions with the plate's edges could be effectively monitored as the wave propagated down the plate. The experimental setup for monitoring forward-travelling waves in a plate is shown in Fig. 3.20. Combined envelopes of received signals at several locations relative to a fixed source are presented in Fig. 3.21. Image brightness is proportional to the envelope of the received signal level. Several results that can be derived from this experiment are:

- $\quad$ "Hot spots", seen as bright features, correspond to structural wave interactions with the measured surface. These features appear with regular spatial periodicity corresponding to the "skip length" of a $45^{\circ}$ incident signal.

- $\quad$ The magnitudes of the hot spots diminish as the receiver is moved further from the source. Table 3.6 summarizes spreading loss values. Spreading losses at $254 \mathrm{~mm}$ are about $8 \mathrm{~dB}$ (this accounts for incident coupling losses as well) and for every additional $254 \mathrm{~mm}$ of propagation distance, $6 \mathrm{~dB}$ of spreading loss occurs (note that these propagation distances are measured along the plate and are based on injection through a $45^{\circ}$ coupling wedge, for the $70^{\circ}$ wedge the spreading losses must be scaled by $\sin 70^{\circ} / \sin 45^{\circ}=$ 1.33). Because there is no strong evidence of scattering to non-specular waves due to surface interactions, the edge reflections must be "specular" (i.e., similar to a pool ball bouncing off the edge of a pool table). Consequently, the measurement noise floor due to spurious reflections from surface imperfections should be low.

Figure 3.22 shows the results of a similar series of tests measuring the backward-travelling wave signal reflected from the plate's opposite edge. The "packets" of signal comprising the reflected returns have now been spread over time due to geometric spreading and multi-bounce interference. Although even in the ideal case of an edge reflector it is difficult to determine the exact position of the reflector in any given time signal, the signal "packets" plotted together "point" to the reflector.

Assessment of signal loss components. Figure 3.23 presents a schematic of the test setup used to study the signal levels returned from "artificial" degradations of various shapes. The artificial "degradations" are uniform cross-section slots, either rectangular, rounded, or "V" shaped, cut across the plate's 203-mm width. Because side interactions are intentionally avoided, the degradations are rendered effectively two-dimensional. All of the degradations were 4-mm deep by $10-\mathrm{mm}$ wide. Monostatic returns were measured at several distances from each slot's leading edge. Figure 3.24 shows a sample return signal from a rectangular slot. The reflected signal "level" is defined as the maximum value in the signal packet that is assumed, by simple time gating procedures, to have emanated from the slot.

Figure 3.25 presents reflected signal levels at several source locations relative to the slot geometry. For the $45^{\circ}$ coupling wedge, the returns from the rectangular slot were, averaged over source location, around $1 \mathrm{~dB}$ higher than those from the rounded slot and $4 \mathrm{~dB}$ higher than those from the "V" shaped slot (Fig. 3.25a). For the $70^{\circ}$ coupling wedge, the differences were 5 and $9 \mathrm{~dB}$, respectively (Fig. 3.25b). When an increase in received signal level was obtained at a position located a greater distance from the notch leading edge this was due to the location's proximity to a hot spot. These results include the effects of geometric spreading, which are greater for the $45^{\circ}$ coupling wedge than for the $70^{\circ}$ wedge because the path to and from the slot is longer for the deeper angle. A more thorough analysis of the measured differences would incorporate advanced acoustic scattering theories that were beyond the scope of this study.

It is useful to develop an average "reflection coefficient" for the rectangular notch, where the reflection coefficient is the ratio of incident to reflected signal level minus geometric spreading. For sources located in a continuous threedimensional medium, the spreading loss is inversely proportional to the distance from the source and is termed spherical spreading. For sources located in a continuous two-dimensional medium, the spreading loss is inversely proportional to the square root of the distance from the source and is termed cylindrical spreading. Because the geometric spreading estimates account for incident coupling losses, removal of the spreading loss from the measured signal levels generates a useful result based on the maximum measurable signal. The average reflection coefficient for the rectangular notch 
using the $45^{\circ}$ coupling wedge is about $-23 \mathrm{~dB}$ and for the $70^{\circ}$ coupling wedge about $-23.5 \mathrm{~dB}$. By comparing the reflected returns from notches of various cross-sections to those from the rectangular cross-section, this result can be used as a basis for estimating reflection coefficients for other notch shapes. Figure 3.26 presents examples of the timewindowed returns reflected from the three different notch geometries. A comparison of these returns reveals that the arrival times of the reflected signals are very nearly equal despite the fact that the reflected fields from each notch geometry are theoretically markedly different. The implication here is that the component of the reflected signal propagating at $45^{\circ}$ is biasly received, while other propagation angles are filtered out to varying degrees. Consequently, the scattered field is measured at very nearly a single angle. Without measuring the entire field it will be difficult to make statements on the character of the reflector. Phased array receivers can be used to effectively sample the scattered field over a much wider band of angles (3.15).

Reflected signal levels were also used to investigate the effect of degradation depth. Figure 3.27 shows a sketch of the notches were used in this test. All notches were rectangular in shape, 10-mm wide, and had notch depths of either 4, 8, or $12 \mathrm{~mm}$. Differences in reflected signal at several source locations relative to the notch for both $45^{\circ}$ and $70^{\circ}$ coupling wedge pair are presented in Fig. 3.28. For the $45^{\circ}$ coupling pair (Fig. 3.28a), the returns from the 4-mm-deep notch are, averaged over source location, around $3 \mathrm{~dB}$ lower than those from the 8 -mm-deep notch and about $6 \mathrm{~dB}$ lower than those from the 12-mm-deep notch. This trend is as expected, as deeper notches project a greater area of acoustic impedance. Figure $3.28 \mathrm{~b}$ shows the reflected signal levels from the three different notches using a $70^{\circ}$ coupling wedge pair. The resulting trend for this case is not as expected. For some source-receiver separation distances the reflected returns from the shallowest notch are actually greater than those received from the deepest notch. The odd trend was qualitatively observed over a broad range of separation distances, eliminating skipping effects as a possible explanation. The explanation for these results may, again, only be realized after incorporating advanced scattering theories, which was beyond the scope of this study.

Concrete effects. The final series of tests to assess the individual components of signal loss involved measuring the effect that concrete has on waves travelling in an embedded plate. Figure 3.29 shows the wooden molds that were built to allow the midsection of steel plates to be embedded in concrete. To determine the effect that bond quality had on induced losses, one of the plates was wrapped with a single layer of 4-mil-thick plastic sheet prior to casting to prevent bonding between the concrete and plate ("unbonded"). Two other plates were cast without the plastic sheet to permit bond development between the concrete and plates ("bonded").

Figure 3.30 presents a simplified schematic of the test setup for the concrete effects tests. The source transducer location, $\mathrm{s}$, was varied from $6.3 \mathrm{~cm}$ to $11.4 \mathrm{~cm}$ in $1.27-\mathrm{cm}$ steps in order to sufficiently sample one half of a skip length for a $45^{\circ}$ coupling wedge. A receiving transducer maintained at a fixed position was used to monitor the signal that propagated through the plate. The received signal level was defined as the maximum value in the incident signal packet that arrived at the receiver. Figure 3.31 a presents the maximum value in received signal level for the three free-standing plates prior to their embedment in concrete using an input source positioned at several locations. As expected, there was only minimal variation from plate to plate and the plastic wrap had no noticeable effect. Figure $3.31 \mathrm{~b}$ presents results after embedding the midsections of the three plates in concrete. The two "bonded" plates display a significant loss in signal level ( $30 \mathrm{~dB}$, or $1.6 \mathrm{~dB}$ per centimeter of two-way travel), while the "unbonded" plate signal level remained relatively high, incurring virtually no losses. Note that the results for the "bonded" plates are very similar, with the differences being attributable to a combination of measurement and concrete bond variations. These results show that the interface, or bond, between the concrete and steel plays a critical role in determining the proportion of energy lost from waves travelling in the steel.

Figure 3.32 presents the effect of wedge coupling angle on received signal levels for a plate after it was embedded in concrete (bonded). The $70^{\circ}$ coupling wedge shows transmitted signal levels that are roughly $4-5 \mathrm{~dB}$ higher than those received using the $45^{\circ}$ coupling wedge. Assuming that both wedges couple equally well to the test structure, this result is to be expected because the incident wave injected by the $70^{\circ}$ coupling wedge experiences fewer interactions with the concrete-steel interface due to the longer skip distances.

Results of the concrete-effects tests show that characterizing degradation based on reflected returns may be difficult, even if its position can be determined. The propagation path plays a prominent role in determining the level of the returned signal. Path conditions cannot be well known without destructive testing. Also, the overall level of the reflected returns cannot be used (for the system and procedure employed here) to confidently characterize degradation located below the air/concrete interface. 
Implications of masking signals. To determine the role that competing signals may play in dictating the technique's feasibility, a simulated field condition was tested. Figure 3.33 shows the test setup. Signals reflected from a 4-mm deep rectangular notch located $127 \mathrm{~mm}$ from the air-concrete interface were measured and compared to those obtained with no concrete present.

Previous tests indicated that the source "self-noise" tended to mask low-level returns. Mechanisms of source "self-noise" are illustrated schematically in Fig. 3.34. As noted in the figure, the incident signal:

- couples to an injected shear wave,

- reverberates inside the wedge due to the surface reflection from the wedge-test structure interface and the side lobes "spraying" the sides of the wedge,

- bounces repeatedly across the thickness of the test structure directly under the wedge, and

- couples to other wave types, such as surface and compressional waves.

By altering the test setup to that shown in Fig. 3.35, where a second transducer is used to receive the reflected returns (bistatic condition), the inner wedge reverberant field and the through-thickness standing echoes are eliminated. This is illustrated in Fig. 3.36 which shows the reflected signals received for the $70^{\circ}$ coupling wedge located $203 \mathrm{~mm}$ from the notch's leading edge for three cases: monostatic measurements with no concrete; monostatic measurements with concrete; bistatic measurements with concrete. As shown by the middle plot, the additional receiver gain needed to monostatically measure the return reflected from the notch embedded in concrete causes the previously low-level source self-noise to now completely mask the return. When the returns are measured bistatically (bottom plot), the source selfnoise is suppressed and the returns from the notch are apparent. Without this simple procedural alteration, the inspection technique would not be able to clearly detect returns from the notch. Based on results from the signal loss component experiments, the reflected signal for the embedded case should be about $-51 \mathrm{~dB}(9.4 \mathrm{~dB}$ of spreading loss, $-23.5 \mathrm{~dB}$ reflection coefficient, $18 \mathrm{~dB}$ of loss to concrete) down from the maximum measurable signal (-6 dB). It was measured at $50.5 \mathrm{~dB}$, thus supporting the signal loss estimation technique.

Figure 3.37 shows in greater detail the bistatically-measured return from the rectangular notch in the plate embedded in concrete. Although the return from the notch is evident, there are still competing return signals (occurring between 50 and 130 microseconds) that have not been eliminated by using a bistatic approach. These returns would normally be considered secondary, but because the peak in the reflected signal packet from the notch is suppressed by the effect of the concrete, they are now down only 6-10 dB (linear factor of about 2-3). It is interesting to note that the reflected signal builds somewhat sharply at around 60 microseconds. This time delay corresponds very nearly to the time it would theoretically take a compressional wave propagating directly down the plate's axis to traverse to and from the notch's leading edge. Thus, it appears as though an incident side lobe has coupled to a compressional wave in the steel plate. These signals could be considered a localizing aid as opposed to competing signals, as the compressional signal returns are down by a linear factor of 3 ( or $9.5 \mathrm{~dB}$ ) relative to the reflected shear wave field. An important point is that if a competing signal can be identified, then it in all likelihood can be removed from the return signal during post-processing.

In light of this observation, the through-transmission tests to determine the effect of the embedding concrete were rescrutinized. Figure 3.38 shows (from top to bottom): the transmitted signal through a free plate without concrete, an unbonded plate embedded in cured concrete, and a bonded plate embedded in cured concrete. As shown by Fig. 3.38's top and middle plots, the effect of the plastic wrap was to virtually eliminate additional losses imposed by the embedding concrete. Also, the character of the transmitted signal for these two conditions was not altered significantly. However, as noted in the bottom plot in this figure, the character and overall level of the transmitted signal through the bonded embedded plate does change. Thus it appears as though the transmitted shear wave, which skips down the plate and therefore interacts repeatedly with the concrete interface, is affected by the concrete to a much greater degree than waves propagating directly down the axis of the plate. As the degradation distance below the air/concrete interface increases, effects of the concrete will act to suppress the returned shear wave field, which propagates at an angle to the plate surface, to levels below the returned compressional wave field, which propagates parallel to the plate surface. By using signals that are directed down the axis of the plate at angles deeper than $70^{\circ}$, the return signal level's strong dependence on path conditions may be suppressed.

Conclusions from experimental simulations. The experiments performed were designed to assess the performance of a commercially available fully integrated angle-beam inspection system, and to investigate the propagation physics that govern the use of angle-beam inspections. The measurement system displayed an input/output dynamic range of $125 \mathrm{~dB}$. Therefore, in the absence of competing signals, $105 \mathrm{~dB}$ of losses can be incurred while still maintaining a $20 \mathrm{~dB}$ signal- 
to-noise ratio. The mild steel plates used in the experiments propagated signals as if they were effectively free of surface imperfections, which would otherwise act as random scatterers. Under similar conditions, the surface generated noise baseline due to surface flaws should be minimal. Results obtained from rectangular, rounded, and "V" shaped notches provide a preliminary basis for estimating reflected signal levels from a vast array of two-dimensional degradations. Results for the steel plates embedded in concrete indicate that an additional $1.6 \mathrm{~dB}$ and $1.4 \mathrm{~dB}$ of signal loss is incurred for each centimeter of two-way signal travel when using $45^{\circ}$ and $70^{\circ}$ coupling wedges, respectively. Thus, waves directed at shallow angles are least affected by the concrete, regardless of coupling condition, and may be of more value for the inspection scenario of interest. Steel plates that are not bonded to concrete show virtually no additional losses compared to free plate signal losses; however, if fluids are present at the interface between the concrete and steel plate, increased signal losses will occur. Results from the signal-loss component experiments provide a basis for estimating the total loss induced on an incident signal for many scenarios (e.g., in the absence of competing signals, a 4-mm-deep rounded degradation located $30 \mathrm{~cm}$ below the air/concrete interface for the steel containment scenario should be detectable using a $70^{\circ}$ coupling wedge because $50 \mathrm{~dB}$ of signal-to-noise ratio remains after estimated losses of $73 \mathrm{~dB}$ ). Competing signal environments (e.g., compressional wave field) may mask the signal return to make defect detection difficult; however, use of bistatic measurements and discrimination techniques can minimize or eliminate competing signals.

\subsubsection{Magnetostrictive sensors}

Magnetostrictive sensors (MsS) are devices that launch guided waves and detect elastic waves in ferromagnetic materials electromagnetically to determine the location and severity of a defect based on timing and signal amplitude. The magnetostrictive force refers to the force that acts in ferromagnetic material due to strains associated with magnetic domain motion (3.20). Figure 3.39 presents a schematic diagram of MsS used for generation and detection of guided waves in a pipe (3.21). With MsS, the magnetostrictive force is produced directly in the part under inspection by setting the magnetic domains in the material into a vibrational motion by applying alternating magnetic fields to the material. For piping, the magnetic fields are applied by supplying an alternating electric current to the MsS coil that encircles the pipe. This magnetostrictive force generates the guided waves. Detection of the guided waves is achieved by the reverse process where the guided waves cause domains to vibrate and, consequently, cause the magnetic induction of the material to change with time. The changing magnetic induction induces an electric voltage in the MsS coil. The magnetostrictive force is independent of the sign of the applied magnetic field and is in the direction of the applied field. Therefore, in the absence of a static bias magnetic field, the alternating magnetic field results in generation of guided waves of twice the frequency of the applied magnetic field (3.11). To produce the wave of the same frequency and to enhance the efficiency of the sensor (which is proportional to the magnetostriction coefficient), a static magnetic field is also applied to the material $(3.21,3.22)$. The technique is noncontact, couplant free, and requires minimum surface preparation. In addition, the technique has a sensing or inspection range from a single sensor location that can exceed several hundred feet on bare metals, the sensor can detect defects on the inside and outside diameters of pipe surfaces, and it can inspect structures whose surfaces are not directly accessible due to the presence of paint or insulation. For noncontact applications, the technique is limited to ferromagnetic materials. Its primary application has been to piping systems.

A preliminary study has been conducted by Southwest Research Institute (San Antonio, TX) to investigate the feasibility of applying magnetostrictive sensor technology to inspection of plate-type materials and evaluate its potential for detecting and locating thickness reductions in the containment metallic pressure boundary resulting from corrosion (3.23). This study has involved both modeling and experimental studies. Also preliminary MsS system requirements for containment inspection have been developed.*

* Since completion of this study, a follow-on study was funded by the Electric Power Research Institute at Southwest Research Institute. Possible limitations of the MsS inspection technique caused by the presence of concrete were investigated in the laboratory by testing samples of a $1.22 \mathrm{~m}$ by $6.1 \mathrm{~m}$ by $6.4-\mathrm{mm}$-thick steel plate embedded in concrete. It was found that the concrete significantly increased the guided wave attenuation. In the A0 wave mode at relatively low frequency (e.g., below $25 \mathrm{KHz}$ ) relatively large defects could be detected at distances to a few feet. If the concrete was not bonded to the plate there were no measurable effects of the concrete on wave attenuation. More detailed results of this investigation are available in EPRI Report 1000105, "Experimental Validation of Concrete Effects on Guided Waves in Plates," published 19 December 2000. Since completion of the EPRI-funded study, the MsS technology has advanced significantly. For long-range plate inspection the technology now primarily uses shear horizontal (SH) waves because they provide better inspection results than Lamb waves (due to dispersion and extraneous wave mode 


\subsection{Modeling studies}

Dispersion properties of Lamb waves, which refer to longitudinal guided waves in plates, were investigated theoretically using a general-purpose software package called DISPERSE $(3.24,3.25)$ (Imperial College, University of London). Using this software package, dispersion curves of Lamb waves were calculated for three different boundary conditionsfree boundary, one side in contact with concrete, and both sides in contact with concrete. Table 3.7 presents the material property values used in the calculations (3.25). In the modeling studies the plate was assumed to be $12.7 \mathrm{~mm}$ thick, and the concrete was assumed to be infinitely thick and perfectly bonded to the plate.

Modeling results. Figure 3.40 presents calculated dispersion curves of longitudinal guided waves for a plate that is free, backed by concrete on one side, and backed by concrete on both sides. The vertical axis represents the group velocity of the wave expressed in units of $\mathrm{mm} / \mu \mathrm{sec}$, where $1 \mathrm{~mm} / \mu \mathrm{sec}$ is equivalent to $10^{5} \mathrm{~cm} / \mathrm{sec}$. The horizontal axis represents the product of the wave frequency and the plate thickness expressed in units of MHz-mm. The use of the frequencythickness product in the horizontal axis normalizes the effects of plate thickness on the dispersion curves and makes the plots valid for plates of arbitrary thickness (e.g., the $1 \mathrm{MHz}-\mathrm{mm}$ point in the horizontal axis corresponds to $1 \mathrm{MHz}$ of frequency in a 1-mm-thick plate, or $100 \mathrm{kHz}$ of frequency in a 10-mm-thick plate). Curves indicated by S0, S1, and S2 are those for the first three symmetric (S) wave modes. Curves indicated by A0, A1, and A2 are those for the first three antisymmetric (A) wave modes. With respect to the median line of the plate thickness, the displacement of S wave modes has a symmetric distribution, whereas that of A wave modes has an antisymmetric distribution, as illustrated in Fig. 3.41.

For cases where the plate is backed on one or both sides by concrete, the DISPERSE program became somewhat unstable, so the calculation was performed for only S0, A0, and A1 modes. Comparing the plots in Fig. 3.40 for the three plate conditions, the minimum velocity of the $\mathrm{S} 0$ mode increased from approximately $1.8 \mathrm{~mm} / \mu \mathrm{sec}$ in (a) to 2.05 $\mathrm{mm} / \mu \mathrm{sec}$ in (b), and then to $2.4 \mathrm{~mm} / \mu \mathrm{sec}$ in (c). Also, comparing the A0 mode velocities for the free plate and plates backed by concrete, there was only a slight decrease (i.e., no more than $0.3 \mathrm{~mm} / \mu \mathrm{sec}$ ) in the low-frequency range (i.e., below $1 \mathrm{MHz}-\mathrm{mm}$ ). Overall, the effect of concrete on the group velocity appears to be relatively small.

In addition to dispersion curves, the DISPERSE program calculates wave attenuation. Results for a plate backed by concrete on one side and on both sides are shown in Figs. 3.42(a) and 3.42(b), respectively. It was assumed that the attenuation in the plate material was negligible and, thus, the free plate had zero wave attenuation. The attenuation plots in Fig. 3.42 therefore represent the energy loss into the surrounding concrete. In these plots, only A0 and S0 modes are shown. Attenuation of other modes was much higher and out of range of the plot. The plots show a large increase in attenuation when the concrete was placed on one side of a plate. As might be expected, the effect of concrete on attenuation increased by a factor of two or more when the concrete was placed on both sides of the plate. The plots also show that attenuation was significantly less for the A0 mode than for the S0 mode. Interestingly, the plots show negligible attenuation for the $\mathrm{A} 0$ mode when the frequency-thickness was less than about $0.55 \mathrm{MHz}-\mathrm{mm}$. According to these results, the $\mathrm{A} 0$ mode would be better than the S0 mode for long-range inspection of plates backed by concrete on one or both sides. Particularly, if the frequency of the A0 mode is less than $0.55 \mathrm{MHz}-\mathrm{mm}$, no reduction in the inspection range due to concrete-induced attenuation is expected to occur (e.g., in a 12.7-mm-thick plate, this frequency corresponds to less than about $43 \mathrm{kHz}$ ).

The guided wave loses its energy into the surrounding concrete by generating both shear and compressional waves at the plate and concrete interface that propagate away in the concrete medium. The propagation angle, $\theta$, of these waves is governed by Snell's law

$$
\theta=\sin ^{-1}\left(\mathrm{~V}_{\mathrm{c}} / \mathrm{V}_{\mathrm{p}}\right)
$$

where $\mathrm{V}_{\mathrm{c}}$ is the velocity of a bulk (shear or compressional) wave in the concrete, and $\mathrm{V}_{\mathrm{p}}$ is the phase velocity of the guided wave in the plate. If $V_{p}$ is less than $V_{c}$, then $\theta$ would be imaginary. This means that the bulk wave in the concrete cannot be generated, and consequently the energy of the guided wave would not be leaked away and there would be no increase in guided-wave attenuation. Below $0.55 \mathrm{MHz}-\mathrm{mm}$, the phase velocity of the A0 mode is smaller than the velocity of the shear (and compressional) wave in concrete. This explains why the attenuation of the A0 mode is negligible in that frequency region, even if the plate is backed by concrete on both sides.

generation). Also, a thin-strip-shaped MsS probe has been developed that can be permanently bonded to a structure's surface for active structural health monitoring of large structures (e.g., a steel containment). 
Conclusions from modeling studies. The validity of the DISPERSE program calculations for simple geometries such as pipes and plates has been well confirmed experimentally. Although its validity for complicated geometries such as a plate backed by concrete on both sides has yet to be confirmed, it appears possible to achieve long-range inspection under this scenario using a low-frequency A0 wave mode.

\subsection{Experimental studies}

For generation and detection of guided waves in plates, the MsS design shown schematically in Fig. 3.43 was used (3.26). The probe consisted of a stack of U-shaped cores (e.g., made of ferrite) and a coil wound on the core. When an alternating electric current was supplied to the probe, an alternating magnetic field was applied to the plate underneath in the widthwise direction. The applied magnetic field generated guided waves in the plate that propagated in the same direction. Guided wave detection was achieved by the reverse process in which the alternating magnetic induction of the plate caused by the guided waves was electromagnetically coupled to the core material and a voltage signal induced in the coil. In addition to the MsS probe, a device was added (i.e., permanent magnets) to apply the required static bias magnetic field to the plate.

Experimental arrangement and procedures. The overall experimental setup is shown in Fig. 3.44. A carbon steel plate (ASTM A-36), approximately $6.35-\mathrm{mm}$-thick by 1.23 -m-wide by $6.11-\mathrm{m}$ long placed on two wooden supports, was used as the test article. Due to its weight, the plate arched somewhat toward the floor. The transmitting and receiving MsS probes were approximately $30 \mathrm{~cm}$ long and $2.5 \mathrm{~cm}$ wide. The length of the probe was aligned parallel to the width of the plate so that the wave was launched in the lengthwise direction of the plate. Static magnetic fields were applied in the lengthwise direction of the plate using permanent magnetic circuits. Excitation and detection of guided waves were accomplished using an instrument called the "magnetostrictive sensor reflectometer (MsSR)," that had been developed by SwRI for piping inspections. A photograph of the overall experimental arrangement is shown in Fig.3.45.

Initial activities addressed the capability of the MsS to generate and detect guided waves. Both the pitch-catch and pulse-echo techniques were employed for data acquisition. For the pitch-catch technique, the transmitting MsS probe was placed near one end of the plate and the receiving probe near the mid-length location of the plate. For the pulseecho technique, both probes were placed near one end of the plates (Fig. 3.44). After investigating guided-wave generation and detection capability using the pitch-catch technique, the feasibility of detecting defects in the plate was investigated using the pulse-echo technique. For this purpose, a notch was machined into the plate at a position corresponding to approximately $2 / 3$ the plate length (Fig. 3.44). The notch was approximately $3-\mathrm{mm}$ deep by 6 -mm wide, and a length that was changed from 10 to $30 \mathrm{~cm}$ in $10-\mathrm{cm}$ increments to evaluate the relationship between notch length and signal amplitude. A photograph of the 30-cm-long notch is shown in Fig. 3.46.

Experimental results. As noted, the experimental studies addressed the generation and detection of guided waves in plates, and the capability to detect defects in a plate.

Guided wave generation and detection. An example of data obtained from the plate sample using the pitchcatch technique is shown in Fig. 3.47. The data were taken with the transmitting and receiving probes placed at approximately $5 \mathrm{~cm}$ and 2.73 meters from one end of the plate, respectively. The transmitting probe was excited with a 3 -cycle-long, $60 \mathrm{kHz}$ sinusoidal pulse. The detected signals after the initial pulse were relatively complex. To identify each of the detected signals by observing their dispersion characteristics (3.18), the short-time Fourier transform (STFT) was performed on the time-amplitude data in Fig. 3.47, and the results are presented in Fig. 3.48. In this figure the logarithms of the absolute values of the STFT are shown as gray-scale images (the brighter image, the larger the amplitude of the spectral component). The time evolution of each frequency component comprising the detected signals can be observed and used to study wave dispersion (3.27).

From the data in Fig. 3.48, the highest frequency component contained in the signals in Fig. 3.47 was no more than about $120 \mathrm{kHz}$. Referring to the dispersion curves for a free plate given in Fig. 3.40(a), the above frequency corresponds to about the $0.76 \mathrm{MHz}-\mathrm{mm}$ point in the frequency-thickness axis. Over that frequency range, there are only two possible longitudinal guided waves - the lowest order symmetric wave mode (S0) and the lowest order antisymmetric wave mode (A0). According to the dispersion curves in Fig. 3.40(a), the group velocity of the $\mathrm{S} 0$ mode over that frequency range is approximately constant (e.g., $5.44 \times 10^{5} \mathrm{~cm} / \mathrm{sec}$ at $20 \mathrm{kHz}, 5.42 \times 10^{5} \mathrm{~cm} / \mathrm{sec}$ at $60 \mathrm{kHz}$, and $5.38 \times 10^{5} \mathrm{~cm} / \mathrm{sec}$ at 100 $\mathrm{kHz}$ ), whereas that of the A0 mode increases rapidly with frequency (e.g., $1.98 \times 10^{5} \mathrm{~cm} / \mathrm{sec}$ at $20 \mathrm{kHz}, 2.81 \times 10^{5}$ $\mathrm{cm} / \mathrm{sec}$ at $60 \mathrm{kHz}$, and $3.10 \times 10^{5} \mathrm{~cm} / \mathrm{sec}$ at $100 \mathrm{kHz}$ ). 
Based on the expected behavior of the $\mathrm{S} 0$ and A0 modes, the curved lines in Fig. 3.48 are easily identified as the A0 mode. They are curved to the right because the lower frequency components have a slower group velocity and thus arrive at the receiving MsS probe later in time than the higher frequency components. The second signal after the initial pulse in Fig. 3.47 is then identified as the A0 mode that was detected when the wave reached the receiving probe while traveling toward the far end of the plate. The subsequent A0 mode signals are those that were detected after the wave was reflected from the far end of the plate sample and was traveling back and forth between the two ends. The pulse length of the $\mathrm{A} 0$ mode signals gets longer with time because of the dispersion. Using the first and third $\mathrm{A} 0$ mode signals in Fig. 3.48, the round-trip time of the wave was measured at $6.150 \mathrm{msec}$ at $20 \mathrm{kHz}$ and $4.305 \mathrm{msec}$ at $60 \mathrm{kHz}$. The corresponding group velocity is then $1.99 \times 10^{5} \mathrm{~cm} / \mathrm{sec}$ at $20 \mathrm{kHz}$ and $2.84 \times 10^{5} \mathrm{~cm} / \mathrm{sec}$ at $60 \mathrm{kHz}$, respectively, which agrees well with the calculated values given earlier.

The straight lines in Fig. 3.48 are identified as those produced by the S0 mode. The lines are straight because the S0 mode has an approximately constant velocity and thus is nearly dispersionless over the frequency range investigated. The signal after the initial pulse in Fig. 3.47 was identified as the S0 mode, detected when the wave reached the receiving probe while traveling toward the far end of the plate. Excluding those identified as A0 signals, all subsequent signals in Fig. 3.47 should therefore be S0 mode signals.

Unlike the A0 mode signals, however, there were more S0 mode signals than the number that would be normally expected when the wave travels back and forth between the two ends of the plate sample. Based on the calculated group velocity of the $\mathrm{S} 0$ mode and the position of the receiving MsS probe, the signals that occur at normally expected arrival times are identified and indicated as $\mathrm{S} 0$ in both Figs. 3.47 and 3.48. The other signals that occur at abnormal arrival times were unexpected. These signals first appeared after approximately $0.31 \mathrm{msec}$ from the second normal S0 signal (that was detected while the wave was traveling back after reflection from the far end of the plate sample). With increasing travel time, the occurrence of the abnormal signals became more frequent. They also occurred at a regular interval of approximately $0.31 \mathrm{msec}$.

An investigation of the possible cause of the abnormal S0 signals led to the following conclusions: (1) the phenomenon is exactly analogous to the generation of multiple secondary echoes that trail the backwall echo with a regular interval when an ultrasonic beam is propagated along the length of a narrow test piece (3.28), and (2) it is a result of mode conversion at the lateral boundaries of the plate sample. Figure 3.49 illustrates the mechanism that produced the abnormal S0 signals. Assume that the longitudinal (L) wave generated by the MsS probe is propagated in the lengthwise direction of a finite size (a $\mathrm{xd}$ ) plate. Since the probe is finite in length, the L wave beam spreads laterally as it propagates along the lengthwise direction of the plate. Some of the wave on the outskirts of the beam will eventually hit the lateral boundary of the plate at an angle $\theta_{\mathrm{L}}$. A portion of the $\mathrm{L}$ wave is then mode-converted to a shear-horizontal (SH) wave (3.29) and travels across the width of the plate at an angle $\theta_{\mathrm{SH}}$ following Snell's law:

$$
\sin \theta_{\mathrm{SH}} / \sin \theta_{\mathrm{L}}=\mathrm{V}_{\mathrm{SH}} / \mathrm{V}_{\mathrm{L}}
$$

where $\mathrm{V}_{\mathrm{SH}}$ and $\mathrm{V}_{\mathrm{L}}$ are the phase velocities of the $\mathrm{SH}$ and the $\mathrm{L}$ wave modes, respectively. When the $\mathrm{SH}$ wave arrives at the other side of the plate, a portion of it converts back to the $\mathrm{L}$ wave mode while the remaining portion of the wave is reflected back toward the other side of the plate. The portion of the beam that has gone through this mode-conversion process arrives at the probe later than the other portion of the beam that has traveled to the other end of the plate and returned without going through the mode conversion. In the case of grazing incidence, where $\theta_{\mathrm{L}}$ is approximately equal to $90^{\circ}$, the time separation $\Delta \mathrm{t}$ between the two is given approximately as (3.28),

$$
\Delta \mathrm{t}=\mathrm{d} \sqrt{\left(\left(\frac{\mathrm{V}_{\mathrm{L}}}{\mathrm{V}_{\mathrm{SH}}}\right)^{2}-1\right)} / \mathrm{V}_{\mathrm{L}}
$$

where $\mathrm{v}_{\mathrm{L}}$ is the group velocity of the $\mathrm{L}$ wave mode. For $\mathrm{V}_{\mathrm{SH}}=3.26 \times 10^{5} \mathrm{~cm} / \mathrm{sec}, \mathrm{V}_{\mathrm{L}}=5.43 \times 10^{5} \mathrm{~cm} / \mathrm{sec}$, and $\mathrm{v}_{\mathrm{L}}=5.42$ $\mathrm{x} 10^{5} \mathrm{~cm} / \mathrm{sec}$ for the $\mathrm{S} 0$ wave at $60 \mathrm{kHz}$, and $\mathrm{d}=1.23 \mathrm{~m}$ for the plate sample, $\Delta \mathrm{t}=0.30 \mathrm{msec}$, which compares well with approximately $0.31 \mathrm{msec}$ separation observed experimentally. A portion of the SH wave that is reflected back toward the other side of the plate is again mode-converted to the $\mathrm{L}$ wave and returns to the probe. Since this wave has traversed the plate width twice, its arrival time is delayed by another $\Delta \mathrm{t}$. By repeating the process, a series of abnormal signals is thus produced. 
In summary, the data in Fig. 3.47 show that both the $\mathrm{S} 0$ and the $\mathrm{A} 0$ wave modes can be generated and detected using the MsS probe. Since the first A0 signal is larger in amplitude than the first S0 signal, the probe design used in this experiment appears to be more effective in generating the $\mathrm{A} 0$ wave mode than the $\mathrm{S} 0$ wave mode. The tendency of the probe to simultaneously produce both modes is not a significant concern because the primary wave mode generated and detected can be controlled by applying a phased-array principle using multiple probes.

Defect detection. Before inducing a notch in the plate sample, data were acquired from one end of the test article using the pulse-echo technique while controlling the MsS probes to generate and detect either the S0 or the A0 wave mode. Mode control was achieved using a total of three MsS probes (one for transmitting and two for differential receiving) whose relative positions from each other and from the probe end of the plate sample were adjusted to maximize the signal amplitudes of the desired wave mode. Figure 3.50 presents the resulting data for the $\mathrm{S} 0$ mode and the A0 mode waves. The data in Fig. 3.50(a) were obtained by exciting the transmitting MsS probe with a 5-cycle, 40$\mathrm{kHz}$ sinusoidal pulse. The data in Fig. 3.50(b), on the other hand, were obtained by exciting the transmitting MsS probe with a 2-cycle, 20-kHz sinusoidal pulse. The S0 mode data in Fig. 3.50(a) show the secondary signals after each endreflected signal. These secondary signals, produced by mode conversion at the lateral boundaries of the plate sampled together with the unsuppressed A0 mode signals, make the signal pattern complicated. For long-range inspection of a large welded-plate structure (e.g., nuclear power plant concrete containment liner) using the S0 mode wave, secondary signals produced from the welds may interfere with defect detection. Because of the mode-converted secondary signals and the presence of unsuppressed A0 mode signals, the attenuation of the S0 mode wave in the plate material is difficult to determine from the data in Fig. 3.50(a). However, the apparent wave attenuation (which includes the loss due to beam divergence) may be determined by using the amplitudes of the first arriving signals of the end-reflected signals. The first arriving signals represent the waves that traveled along the straight path normal to the MsS probe. Secondary signals represent the waves that diverged from the straight path and, thus would be lost. Using the amplitudes of the first arriving signal of the first and second end-reflected signals, the apparent attenuation is determined to be approximately $0.33 \mathrm{~dB} / \mathrm{m}$.

The A0 mode data in Fig. 3.50(b), unlike the data in Fig. 3.50(a), show a relatively simple signal pattern. The data also exhibit low-amplitude S0 mode signals that were not completely suppressed. The unsuppressed S0 mode signals form most of the background noise signals. Due to the dispersion of the A0 mode, the pulse length of the A0 signals is elongated with time and it is interesting to observe that the second end-reflected signal is larger in amplitude than the first signal. The same behavior is also observed with the A0 mode signals in Fig. 3.50(a). The cause of this erratic behavior is presently uncertain. Using the first and the third end-reflected signals, the attenuation coefficient of the 20$\mathrm{kHz} \mathrm{A} 0$ wave was determined to be approximately $0.086 \mathrm{~dB} / \mathrm{m}$.

Operating the MsS probes to generate and detect one of the S0 and A0 mode waves, data were acquired after inducing a $10-\mathrm{cm}$-long notch at 4.06 meters from the probe end of the plate. This process was then repeated after increasing the notch length to $20 \mathrm{~cm}$ and then to $30 \mathrm{~cm}$. Notch depth was kept at approximately 50 percent of the plate thickness. Results are shown in Figs. 3.51 and 3.52 for the $40-\mathrm{kHz}$ S0 mode wave and the $20-\mathrm{kHz}$ A0 mode wave, respectively. In both cases, the signals from all three notches were observable, indicating that long-range guided-wave inspection of plates using the MsS technique is feasible. Figure 3.53 presents plots of defect signal amplitude versus the notch length. As in the case of guided-wave inspection of piping (3.30), the amplitudes of the defect signals increase approximately linearly with notch length, also indicating the feasibility of determining the severity of a defect from the defect signal. The amplitude of a signal from a reflector, such as a notch or corrosion, is proportional to the cross-sectional area of the defect (in the plane normal to the guided wave beam propagation) relative to the total beam width of the interrogating guided wave. Therefore, the product of both length and depth of a defect influences the defect signal amplitude. Consequently, separate determination of both length and depth of a defect from a single data trace is not generally feasible. However, since the relative area of a given-size defect to the total beam width of the guided wave will vary with the mode and frequency of the guided wave employed for inspection, the signal amplitude from the same defect will also vary. The marked difference in the amplitude of the $30-\mathrm{cm}$-long notch relative to the end-reflected signal amplitude in Figs 3.51 and 3.52, for example, confirms the variation of the defect signal with the guided wave mode and frequency used for detection (in this case, $40-\mathrm{kHz} \mathrm{S} 0$ mode and $20-\mathrm{kHz}$ A0 mode). Taking advantage of this variation, it appears feasible to separately determine both the depth and the length of a defect by combining two or more sets of data taken using different guided wave modes and frequency.

Assuming that the signal-to-noise ratio required for detection is $6 \mathrm{~dB}$ and that the defect signal amplitude is linearly proportional to the notch length, the minimum detectable length of a 50-percent wall notch can be estimated using the data in Fig. 3.53 and a simple linear interpolation. For example, assume that the defect is located approximately 4 meters from the MsS probe, as in the test setup used in this investigation. In order for a defect to be detectable, its signal 
amplitude is required to be at least twice (i.e., $6 \mathrm{~dB}$ ) that of the background noise level. Based on the background noise level and the notch signal amplitude plots in Fig. 3.53, the minimum detectable length of a 50 percent through-wall notch is estimated to be about $10 \mathrm{~cm}$ for the $40-\mathrm{kHz} \mathrm{S} 0$ wave and about $1.5 \mathrm{~cm}$ for the $20-\mathrm{kHz}$ A0 wave. If the defect is located at a distance of 15 meters from the MsS probe, the defect signal amplitude would be further reduced by the wave attenuation over that distance, which is equal to $0.33 \mathrm{~dB} / \mathrm{m} \times 2 \times 15 \mathrm{~m}=10 \mathrm{~dB}$ for the $40-\mathrm{kHz}$ S0 wave and $0.086 \mathrm{~dB} / \mathrm{m}$ $\mathrm{x} 2 \times 15 \mathrm{~m}=2.58 \mathrm{~dB}$ for the $20-\mathrm{kHz}$ A0 wave. The minimum detectable notch length at the $15-\mathrm{m}$ distance is then about $4.4 \mathrm{~cm}$ for the $40-\mathrm{kHz}$ S0 wave and about $1.8 \mathrm{~cm}$ for the $20-\mathrm{kHz}$ A0 wave. Although the data in Fig. 3.53 show that the $\mathrm{A} 0$ wave is much better than the $\mathrm{S} 0$ mode for defect detection, this may not be true since the background noise level can be reduced, particularly for the S0 mode, by improving the MsS probe. For the same cross-sectional area of defect, the signal amplitude from a corrosion pit is generally equal to or larger than the signal amplitude from a notch (3.30). Therefore, the results obtained with the $20-\mathrm{kHz}$ A0 wave suggest that a 50-percent through-wall, 1.8 -cm-diameter corrosion pit located within a 15-meter distance could be detectable using the MsS technique.

Referring to the 40-kHz S0 wave data in Fig. 3.51, there was also a secondary notch signal that was produced by mode conversion at the lateral boundaries of the plate sample. The presence of the notch did not seem to affect the endreflected signal significantly; but it produced a noticeable reduction in the amplitude of the secondary end-reflected signals, indicating that the notch reflects a substantial portion of the mode-converted SH wave while the wave traverses the plate.

The effect of the notch on the end-reflected signal of the $20-\mathrm{kHz}$ A0 wave data in Fig. 3.52 is dramatic as its peak-topeak amplitude is reduced from approximately 0.27 volts with a $10-\mathrm{cm}$-long notch to 0.12 volts with a 30 -cm-long notch. The influence of the notch on the end-reflected signal is understandable since the beam divergence angle of the A0 mode is relatively small. Therefore, when a notch becomes significantly long relative to the width of the outgoing beam, a significant portion of the outgoing beam is reflected from the notch, which substantially reduces the amount of beam reaching the far end of the plate.

Conclusions from experimental studies. Results indicate that (1) guided waves have potential for performing global, long-range inspections of plates and plate-like structures such as the metallic pressure boundary of nuclear power plant containments, and (2) guided waves are expected to work well for inspection of plates backed by concrete on either one or both sides. For a given MsS probe size, the beam-divergence angle is significantly smaller for the A0 mode wave than the S0 mode wave. Because of the smaller beam divergence and associated benefits such as a higher spatial resolution, a smaller energy loss through beam spreading and less probability of extraneous signal generation from interaction with welded boundaries, the A0 mode wave would be better for use in plate inspection than the S0 mode wave. One disadvantage of good beam collimation of the A0 mode is that a large defect can shadow the area behind it and, as a result, may create a blind spot.

\subsubsection{MsS system and time requirements for containment inspection}

Figure 3.54 presents a conceptual drawing of how a MsS system may be deployed for liner inspection. The MsS instrument, scanner-control box, and portable computer are set up on a cart. The scanner, which contains the MsS probes, is attached on the liner wall. The probe and scanner are connected to the instruments via a relatively long (15 to 30 meters) cable. At a given scan position, the wave is launched in one direction (e.g., upward in the figure) and the resulting data are acquired. The wave is then launched in the opposite direction (e.g., downward in the figure) and the data are acquired. This achieves inspection of both sides of the scanner up to the respective inspection range. The scanner is then moved to the next scan position and measurements repeated. The scan interval will be dependent on the size of the beam produced by the probe. In this manner, inspection of a large area of the liner, including areas backed on both sides by concrete (i.e., embedded), can be cost-effectively achieved.

The existing MsS system developed for pipe inspection consists of three main components: (1) MsS instrument containing transmitter and receiver electronics, (2) field-portable computer for data acquisition and analyses, and (3) $\mathrm{MsS}$ probes for pipe inspection including devices for providing a static bias magnetic field. In order to implement the MsS technique for practical inspection of the containment metallic pressure boundary, the MsS system requires additional development in the following three areas: (1) MsS probes, (2) probe scanner, and (3) data acquisition and analysis system with custom software for examination control and data analysis. The present MsS instrument that contains transmitter and receiver electronics is suitable for plate inspection except for possible minor modifications.

The probe is the key to successful system performance. The preliminary probe design used in this feasibility study demonstrated the ability to launch and detect guided waves in a relatively thin $(6.35-\mathrm{mm})$ steel plate. For practical 
implementation, additional work on the probe design is required in several areas:

(1) Applicability to a range of plate thickness since the containment pressure boundary thickness can range from about $6.35 \mathrm{~mm}$ (liner of reinforced concrete containment) to greater than $25.4 \mathrm{~mm}$ (steel containment vessel).

(2) Multiple probe design for control of wave directionality and wave mode. This is necessary to simplify signal pattern and subsequent data analyses.

(3) Device for providing static bias magnetic field necessary for MsS probe operation. A tradeoff study is required between the permanent magnet-based device and the electromagnet-based device considering the relative merits and demerits of each, such as handling ease, electric power requirement, weight, size, and cost.

Automated movement of the MsS probes along the containment wall surface will be needed for high examination productivity. A magnetically held wall crawler that can support the MsS probes and provide a static bias magnetic field required for MsS operation is envisioned. The magnetic wall crawler approach could conceivably serve the dual purpose of supporting the crawler on the wall as well as static magnetic field generation for the probes. An automated crawler will also increase inspection coverage due to its ability for remote guidance into small annuli between the wall and objects positioned near the wall, where manual repositioning of a probe carriage assembly would be precluded. Integrated control of the scanner can be accomplished by commercial single- or dual-axis motor control instrumentation in communication with the MsS system computer. In a typical examination, the scanner would be manually driven or positioned to a reference location. During data acquisition, it would step to each successive location along a linear path (horizontal or vertical), stopping at each step location to acquire data. Step increments of $30 \mathrm{~cm}$ are currently anticipated. Functional requirements of the scanner include the following:

(1) Ability to attach to and crawl on the vertical wall surface of containment while carrying the MsS probes and cables.

(2) Ability to progress in the forward or reverse direction along a single linear axis of motion as a minimum, with the ability to redirect to an orthogonal direction desirable.

(3) Ability to track its position relative to a reference point. The device should tolerate typical wall surface roughness or small step discontinuities without stalling.

(4) Ability to easily change MsS probes for increased productivity. The device, including attached cables and connectors, should also be designed for easy radioactive decontamination.

MsS data acquisition involves (1) a pulsed excitation of the transmitting MsS probes to launch guided waves into the containment metallic pressure boundary, (2) detection of signals reflected from defects or geometric discontinuities such as welds and metallic attachments (e.g., studs, angles, or I-sections) in the receiving MsS probes, and (3) digitization of the detected signals, data processing and analysis, and data filing and storage. The existing MsS instrument developed for pipe inspection can perform steps (1) and (2) for plate inspection. Step (3) is performed in the rugged field-portable computer, and the majority of the system hardware and operating software is directly applicable for plate inspection. However, since plate inspection requires different inspection procedures and different manner of data presentation and analyses, some of the system software will need to be tailored to plate inspection. Additional developments needed in the system software for plate inspection include:

(1) The ability to control scanner motion both automatically and manually, retrieve scanner positional coordinates, and provide graphical displays of the data for analysis, as well as archival and hardcopy of all data and displays.

(2) Data analysis procedures for identification of anomalies and their locations as well as for differentiation of defects from geometric features such as welds and other attachments.

Since nuclear power plant containments vary in size and physical makeup, and numerous obstacles within the containment may prevent or delay access to the containment metallic pressure boundary when performing an inspection, it is difficult to determine inspection time accurately. Therefore, a more idealized estimate will be given based on the assumption of a horizontal linear scan. Additional assumptions include no obstacles in the scan path requiring avoidance or manual repositioning, and a maximum scan distance of 15 meters without instrumentation relocation. As indicated earlier, MsS data are acquired at each step increment along the scan axis. The step size is currently estimated at $30 \mathrm{~cm}$. The coverage area for the guided waves will approximate a rectangular area extending above and below the scan axis up to a distance of at least 15 meters for a steel containment in a region that is not backed by concrete. The time to step to the next scan axis position and stop to acquire and average waveforms successively in both vertical directions is 
estimated at less than 4 minutes. This is based on the assumption that the pulse repetition rate is 10 and that 1000 waveforms are averaged for each of two directions plus position increment time. Therefore, actual scanning time for 15 meters of linear scan is 200 minutes ( 3.3 hours). Initial equipment setup time should be no more than 30 minutes, yielding a total time of less than 4 hours for a total coverage area of $450 \mathrm{~m}^{2}$.

Previous information indicated that the concrete backing on the containment metallic pressure boundary would not increase wave attenuation significantly for the low-frequency A0 mode. This suggests that when a low-frequency A0 mode wave is used for inspection, the coverage area per unit time would not be significantly reduced, even if the portion of the containment metallic pressure boundary backed on both sides by concrete is included in the inspection. For inspection of only the portion of the pressure boundary backed on both sides by concrete, data acquisition is needed in only one direction, reducing the scanning time by half. Opportunities to increase inspection time include being able to operate at higher pulse repetition rates and not requiring as much waveform averaging. Without actual experience of MsS inspection of a containment metallic pressure boundary backed by concrete, conservative estimates for these parameters were used. In each of these cases, the time required for data analysis was excluded since it is highly dependent on the average number of indications present and the quality of the data. There is currently no experience on which to base an estimate. Also, data analysis could be performed simultaneously with data acquisition, providing a second computer is available for running the analysis software. As data become available from a scan, they could easily be transferred via a communication linkage for real-time analysis to a separate location, that does not need to be located in containment.

\subsubsection{Multimode guided wave techniques}

Ultrasonic waves can be generated by either an oblique angle-beam or normal-beam technique. In the oblique anglebeam technique a longitudinal-wave transducer mounted on an acrylic angle-beam shoe generates guided waves in a pipe or plate structure. This approach is similar to that used for finding anomalies in a "V"-joint weld and has been investigated as a technique for inspection of inaccessible regions of nuclear power plant containment metallic pressure boundaries $(3.15,3.16)$. The ultrasonic beam, having large side lobes, spreads out as it is reflected from the boundaries to somewhat limit the inspection resolution of this technique for the scenario of interest. This potential limitation however can be overcome through use of an array of sensors. Another potential limitation of this technique results from mode conversion, where both longitudinal and shear waves result after reflections from the boundary, regardless of the kind of incident wave being used. The multi-reflected waves influence the signal-to-noise ratio and make the echoes from an anomaly difficult to interpret. Use of bistatic acoustic imaging has been demonstrated to reduce the inner wedge reverberant field and to eliminate the through-thickness standing echoes. Thus, if a competing signal can be identified, it in all likelihood can be removed from the return signal during post-processing, increasing the probability of detecting the presence of an anomaly.

As an alternative, the guided wave technique exhibits promise since guided waves can propagate in embedded plates for a long distance. Much work has been reported recently on ultrasonic guided waves for inspection of free plates, pipes, and various structures (3.31-3.34). Magnetostrictive sensors (MsS) have been employed to generate guided waves in plates (3.35). As the MsS technique does not have mode control ability, all possible guided wave modes are generated. Based on a short-time Fourier transform (STFT), dispersion curves in a low frequency range were obtained for the A0 and S0 modes experimentally (3.35). However, in a practical inspection, single-mode generation is desirable in order to simplify signal interpretation. A MsS array however can be used to implement mode control by suppressing the undesired modes. As the frequency associated with the currently used MsS technique is generally less than $200 \mathrm{kHz}$, anomaly detection sensitivity and resolution is reduced relative to higher frequency methods.

\subsection{Multimode guided waves}

The multimode guided wave technique is more sensitive than techniques which utilize shear waves (e.g., electromagnetic acoustic transducers), provides a global inspection technique for characterizing corrosion damage, follows the contour of the structure, can travel long distances (e.g., $100 \mathrm{~m}$ depending on frequency and mode characteristics), and can interrogate different regions or cross sections (i.e., depths) of the component inspected (3.313.37). The guided plate waves can be excited at one point on the structure, propagate over considerable distances, and be received at a remote point on the structure. Although this technique has been used with success to detect defects in piping materials, until recently its applicability to plate-type materials has not been demonstrated.

A countless number of guided wave modes at specific frequencies could be selected for a particular non-destructive evaluation problem, each point producing special sensitivities by way of wave structure across the thickness of the 
component being studied, and also specific penetration powers as a result of interface and surface displacement values and subsequent energy leakage into neighboring media (3.38). The mode and frequency choice has a strong influence on non-destructive evaluation and flaw detection, classification, and sizing potential as well as the ability to propagate guided waves over long distances, despite the presence of coatings and other surrounding media. Phase velocity dispersion curves serve as the guide to controlling and selecting various guided wave modes (3.33). From a guided wave mode generation point of view the phase velocity curve is necessary to determine an entry angle of the wave excitation since the phase velocity of a mode is related to the entry angle via Snell's law. Dispersion curves for a particular structure are generated numerically. Corresponding group velocity curves describe the velocity at which the mode propagates and allows for localization of a defect. With a variable angle shoe, modes can be generated along a horizontal line (i.e., constant velocity which depends on the angle of incidence of the normal beam into the wedge) on the phase velocity dispersion curves. Varying the angle and frequency allows for the possible generation of modes with a phase velocity greater than the phase velocity in the shoe (3.33).

Controlling and selecting the guided wave mode/frequency combination is critical in obtaining optimal performance of the guided wave technique. First, a dominant single mode should be generated to simplify interpretation of echoes. Second, the sensitivity of a guided wave depends significantly on both the mode number and frequency at which it is excited. One mode/frequency combination may reflect strongly from a certain type of defect. Hence, the ability to generate guided wave modes at a variety of points on the dispersion curve is key to achieving optimal performance of the guided wave technique. The approach to mode and frequency selection is therefore crucial, which can ultimately be based on theoretical and/or experimental means. One aspect of a theoretical approach beyond dispersion curve analysis includes theory of elasticity computations of displacement distributions across a structure. The focus can be on achieving in-plane or out-of-plane optimal values on a surface or at a specific location inside a structure in an attempt at flaw analysis or improved penetration power. From an experimental point of view, an angle-beam transducer at a specific angle can be used to achieve a particular phase velocity value. Unfortunately, the presence of a phase velocity spectrum due to a transducer source influence, size and velocity pattern, as well as the frequency spectrum itself, often limits the ability to specifically achieve the particular mode and frequency of choice. Multiple modes can be obtained.

A preliminary investigation has been conducted by The Pennsylvania State University (University Park) to investigate the feasibility of applying multimode guided waves to inspection of containment metallic pressure boundary materials $(3.39,3.40)$. The investigation involved experimental studies as well as defect sizing.

\subsection{Theoretical background}

Figure 3.55 presents a coordinate system that could be used for SH wave propagation. For Lamb wave propagation, consider the particle velocity to be in the $\mathrm{x}_{1}-\mathrm{x}_{2}$ plane direction rather than in the $\mathrm{x}_{3}$ direction shown. Phase velocity and group velocity dispersion curves can be generated for each (3.41). A sample Lamb wave dispersion curve for a steel plate is shown in Fig. 3.56a and an example of a SH phase velocity dispersion curve is illustrated in Fig. 3.56b. Note that some SH modes are dispersive, but for $\mathrm{n}=0$ the mode is non-dispersive. Wave structure is identical along a particular SH mode but changes drastically along a Lamb wave mode. When using guided waves to penetrate a steel plate embedded in concrete, it becomes necessary to consider wave structure at the surfaces of the plate and subsequent energy leakage into the concrete. Rather than study this phenomenon theoretically, a variety of different Lamb wave modes and SH mode situations were studied. It is know that phase velocity and frequency tuning would be useful in this Lamb wave case in order to modify wave structure and, hence, energy leakage into the concrete. For the SH case, only the $\mathrm{n}=0$ mode was considered, but excellent results were obtained.

At a frequency of $565 \mathrm{kHz}$ used for the Lamb wave experiments, there are several modes propagating in the 25.4-mmthick steel plate. Two modes are studied with emphasis on pseudo-surface (combined A0 and S0 modes) waves and the A3 mode. The wave structures of both modes are shown in Fig. 3.57. Both Figs. 3.57a and 3.57b show the in-plane and out-of-plane displacements, each with a different distribution pattern. From Fig. 3.57a, it can be seen that the energy focuses close to the plate boundary area on the same side of the transducer. Therefore, it can detect anomalies on one side only. In order to find anomalies close to the other side using the pseudo-surface mode, the transducer needs to be moved to the other side. Although more tedious for experimentation, this wave mode can determine which side the anomalies are close to, and thus provide more information about anomalies. Compared with pseudo-surface waves, A3 modes have the energy distribution across the entire plate thickness and can detect anomalies on the both sides of the plate. 


\subsection{Experimental studies}

A limited experimental investigation has been conducted to demonstrate the feasibility of using the guided wave technique for identification and location of thickness reductions in the metallic pressure boundary of nuclear power plant containments. The specimens studied are shown in Fig. 3.58, and include a free plate (no concrete) with two anomalies (plate 1), a plate embedded in concrete with one anomaly (plate 2), and a plate embedded in concrete but having no anomalies (plate 3). All three plates are 25.4-mm thick by $203-\mathrm{mm}$ wide by $914-\mathrm{mm}$ long. For practical purposes, the thickness of the concrete, when present, is large enough that it can be considered a "half space." The plate specimens provide a benchmark for studying various aspects of guided wave inspection, including sensitivity, transmission ability across anomalies, inspection reliability, and penetration ability.

SH waves. SH guided waves have particle displacements in the shear horizontal direction, which is perpendicular to the propagation direction. SH waves are sensitive to the transverse boundary conditions. Therefore, a transducer couplant for SH waves should be a highly viscous material such as honey. Although coupling requirements once limited applications of SH waves, advancements of electromagnetic acoustic transducers (EMATs) have resulted in SH waves once again receiving a lot of attention because of the couplant-free advantage of EMATs. Figure 3.59a presents a schematic of a typical EMAT application system and Fig. 3.59b shows a picture of the EMAT's used in the experiments. The grid spacing of the EMAT's is $17.7 \mathrm{~mm}$, which determines the corresponding frequency for generating the nondispersive SH wave mode (i.e., 200-250 kHz). The non-dispersive SH wave mode has the same phase velocity as the SH bulk wave velocity $(3200 \mathrm{~m} / \mathrm{s})$, and a uniform displacement distribution across the plate thickness.

The waveforms obtained from testing the three plate specimens are shown in Fig. 3.60. Figure 3.60a presents the reflected echoes for the free plate with two anomalies (plate 1) and shows that both anomalies can be detected by using the SH waves. Because the non-dispersive SH wave mode has a uniform particle displacement distribution, some energy can pass the first anomaly to be reflected by the second anomaly. The backwall echo (BWE) shows good penetration ability of the SH wave mode. Figures $3.60 \mathrm{~b}$ and $3.60 \mathrm{c}$ present the anomaly echoes for the plate containing an anomaly embedded in concrete (plate 2). The echoes are obtained by putting the transducer at end A on the top and bottom surfaces of the plate, respectively. From Figs. 3.60b and 3.60c it can be seen that the SH guided waves have the same sensitivity to the anomaly whether the transducer is located on the top or bottom plate surface, even though the anomaly is just on the top surface. The signal for transducer placed at end B of plate 2 is shown in Fig. 3.60d. The signal for the plate specimen embedded in concrete but without an anomaly (plate 3) is shown in Fig. 3.60e and demonstrates insensitivity to the concrete edge and the plate-concrete interface. The strong backwall echo demonstrates the excellent penetration power of the SH guided waves across the steel-concrete interface.

Lamb waves. Unlike SH waves, Lamb waves have particle displacement distribution in both parallel and perpendicular directions to the propagation direction. Lamb waves are sensitive to both transverse and normal boundary conditions. Common couplants can be used for generating Lamb waves. A transducer mounted on a wedge for Lamb wave generation is shown in Fig. 3.61. The frequency and wedge angle determines the generated Lamb wave mode. Two wedge angles were considered at the frequency of $565 \mathrm{kHz}$. When the wedge was set to 62 degrees, it generated the A0 and S0 modes simultaneously, both having the same phase velocity $(3030 \mathrm{~m} / \mathrm{s})$ at the working frequency, which degenerates into pseudo-surface waves. As the pseudo-surface wave has energy distribution close to the plate boundary, it is very sensitive to an anomaly close to the boundary. However, it is not sensitive to the anomalies on the other side of the plate. Figure 3.62a is the pulse-echo signal for the transducer placed at the opposite surface (bottom) to anomalies on the free plate (plate 1). It can be seen that both anomalies are ignored and only a backwall echo is received. If the transducer is placed on the same surface (top) as the anomalies, however, only the first anomaly echo can be received, as shown in Fig. 3.62b, which means that most energy close to the plate boundary is reflected back by the first anomaly. This is a different case than occurred for the SH waves due to the uniform energy distribution feature of the SH wave mode.

In order to obtain a fairly uniform energy distribution across the plate thickness for Lamb waves, the wedge angle was changed to 38 degrees. Once again, the tone burst frequency was $565 \mathrm{kHz}$. The phase velocity and group velocity of the generated Lamb waves were $4385 \mathrm{~m} / \mathrm{s}$ and $2220 \mathrm{~m} / \mathrm{s}$, respectively. As a result, the A3 Lamb wave mode was generated (Fig. 3.57b). Figures 3.63a and 3.63b present the pulse-echo signals for the free plate (plate 1) with the transducer on the top and bottom surfaces, respectively. The signals shown in Figs. 3.63a and 3.63b indicate that by generating the A3 Lamb wave mode, the transducer can detect anomalies from either the top or bottom surfaces of the plate. The Lamb wave mode also shows a great sensitivity to anomalies. Figures $3.63 \mathrm{c}$ and $3.63 \mathrm{~d}$ provide the signals for the plate containing an anomaly embedded in concrete (plate 2) when the transducers were placed at ends A and B, respectively. 
Compared with SH waves, Lamb waves show a higher signal to noise ratio in Figs. 3.63c and 3.63d. Figure 3.63e is the pulse-echo signal for the plate embedded in concrete without an anomaly (plate 3 ). Multiple echoes were received from the plate-concrete interface before the backwall echo, indicating a disadvantage of the Lamb wave mode. This problem could be overcome by setting a threshold for an anomaly call. Most anomalies of major concern would probably be more than $20 \%$ the plate thickness and reflect stronger echoes than those from the plate-concrete interface. Use of multimode Lamb wave signals can also be considered for an anomaly call.

\subsection{Elements of defect sizing in a wave guide using SH guided waves}

The Boundary Element Method (BEM) is being developed to study the interaction of various guided wave packets of energy with various corrosion boundaries in a structure. This study was carried out on elliptical-shaped scatterers with a variation in defect depth and length values as shown in Fig 3.64. This type of reflection could model items of interest such as corrosion boundaries and pitting. Corrosion and surface breaking defects, of course, will be more complex than the nice geometrical figures used in the BEM studies. The BEM program is being developed, though, to handle greater variations in the geometrical shaped reflectors compared to elliptical pitting. Frequency spectrums for the amplitudes of the scattered modes in both-pulse echo and through-transmission modes are discussed. Characterization of the defect depth and length is implemented for some special situations based on features of the BEM results. For initial experiments reported in this section, artificial corrosion and crack type defects were fabricated with different depths and lengths in 10-mm-thick steel plates. Theoretical and experimental data on the scattering of SH waves is obtained, demonstrating potential for solving this difficult classification problem. The goal of the modeling efforts is therefore to establish guidelines so that the best modes and frequencies could be considered for impingement to provide the best chance of success in determining the defect shape and size characteristics. An electromagnetic-acoustic transducer (EMAT) technique for $\mathrm{SH}$ wave excitation is used.

Ultrasonic guided waves are being used extensively for defect and materials characterization; some theoretical and experimental results using BEM are available (3.41-3.45). The finite-element method (FEM) for the Lamb and SH wave scattering problem has been analyzed elsewhere (3.46-3.49). The electromagnetic-acoustic transducer (EMAT) technique for $\mathrm{SH}$ wave excitation has also been described elsewhere (3.50).

Problem statement and solution. The boundary value problem for an elastic isotropic plate presented in Fig. 3.64 is considered. The incident time harmonic wave is propagating in the positive $\mathrm{X}_{1}$ direction. The mode incident on the crack results in both reflected and transmitted waves of all orders of the propagation modes that could exist in the plate for a given frequency. The crack considered has an elliptical shape, with horizontal axis $2 \mathrm{a}$ and vertical axis $\mathrm{b}$.

For any frequency, scattering from a crack generates a finite number of propagating and countable numbers of nonpropagating modes. For the SH modes the particle displacement vector has only an $\mathrm{X}_{3}$ component. Displacement and stress for the friction-free boundary conditions can be presented in a form (3.51):

\section{$\underline{\text { Displacement }}$}

$u_{3}^{n}\left(x_{1}, x_{2}, t\right)=U^{n}\left(x_{1}, x_{2}\right) e^{-i \omega t}=\left\{\begin{array}{cc}B_{n} \cos \left(n \pi x_{2} / d\right) e^{i\left(k_{n} x_{1}-\omega t\right)} & \text { (symmetric modes) } \\ A_{n} \sin \left(n \pi x_{2} / d\right) e^{i\left(k_{n} x_{1}-\omega t\right)} & \text { (antisymmetric modes) }\end{array}\right.$

\section{$\underline{\text { Stress }}$}

$\tau_{23}^{n}\left(x_{1}, x_{2}, t\right)=T_{23}^{n}\left(x_{1}, x_{2}\right) e^{-i \omega t}=\left\{\begin{array}{cc}-B_{n} \mu q_{n} \sin \left(n \pi x_{2} / d\right) e^{i\left(k_{n} x_{1}-\omega t\right)} & \text { (symmetric modes) } \\ A_{n} \mu q_{n} \cos \left(n \pi x_{2} / d\right) e^{i\left(k_{n} x_{1}-\omega t\right)} & \text { (antisymmetric modes) }\end{array}\right.$

$\tau_{13}^{n}\left(x_{1}, x_{2}, t\right)=T_{13}^{n}\left(x_{1}, x_{2}\right) e^{-i \omega t}=\left\{\begin{array}{cc}i k_{n} B_{n} \mu \cos \left(n \pi x_{2} / d\right) e^{i\left(k_{n} x_{1}-\omega t\right)} & \text { (symmetric modes) } \\ i k_{n} A_{n} \mu \sin \left(n \pi x_{2} / d\right) e^{i\left(k_{n} x_{1}-\omega t\right)} & \text { (antisymmetric modes) }\end{array}\right.$

$k_{n}^{2}=\left(\frac{\omega}{c_{T}}\right)^{2}-\left(\frac{\pi n}{d}\right)^{2} ; \ldots q_{n}^{2}=\left(\frac{\omega}{c_{T}}\right)^{2}-k_{n}^{2} \ldots(n=0,1,2, \ldots)$

where $A_{n}$ and $B_{n}$ are unknown coefficients and $d=2 h$. Note that the amplitudes of the SH modes (Eqn. 3.5) are 
independent of frequency and wave number. Hence wave structure of the SH mode does not vary along the entire dispersion curve. This is in contrast to Lamb wave behavior, where the wave field is a function of the position on the dispersion curve. The total displacement field is the superposition of the incident and scattered wave fields. The time dependent term $e^{-i \omega t}$ is omitted elsewhere.

$$
U\left(x_{1}, x_{2}\right)=A_{p}^{I N} U^{p}\left(x_{2}\right) e^{i k_{p} x_{1}}+\sum_{n=0}^{\infty} A_{n}^{ \pm} U^{n}\left(x_{2}\right) e^{ \pm i k_{n} x_{1}}
$$

where, $A_{p}^{I N}$ is the known amplitude of the incident $p_{\text {th }}$ mode, and $A_{n}^{ \pm}$denotes the unknown amplitudes of the scattered waves traveling in the positive and negative $\mathrm{x}_{1}$ directions respectively. $U^{n}\left(x_{2}\right)$ denotes the known amplitude of the $n_{\text {th }}$ mode for the traction free plate, and $k_{n}$ represents wave numbers of SH waves. The summation in Eqn. (3.7) is over all propagating and evanescent modes that can exist in a plate for a particular frequency of interest.

Far away from a defect only the amplitudes of the propagating modes are significant. This is expressed by keeping only the real roots $k_{n}$, according to the phase velocity dispersion curves as shown in Fig. 3.65. The solution of the problem can be obtained by coupling the BEM solution for the rectangular area and a far-scattered field on the boundaries $\Gamma_{ \pm}$ (Fig. 3.64a). This approach is effective for a rectangular area with a large enough length L. Therefore the far-field displacement and stress on the boundaries $\Gamma_{ \pm}$can be expressed only by using propagating modes.

The boundary-value problem for modeling the rectangular area leads to the following boundary integral equation (3.41,3.42).

$$
C(\xi) U(\xi)+\int_{\Gamma} \frac{\partial U^{*}(\xi, x)}{\partial n} U(x) d \Gamma(x)=\int_{\Gamma} U^{*}(\xi, x) \frac{\partial U(x)}{\partial n} d \Gamma(x)
$$

where $\Gamma$ is the total boundary of the modeling area, the value of $C(\xi)$ depends on the boundary smoothness and $\partial U / \partial n$ is the derivative of $U$ with respect to the outward normal to the boundary $\Gamma$. The terms $U(x)$ and $\partial U(x) / \partial n$ are the boundary values of the displacements and tractions. $U^{*}(r)$ is the fundamental solutions in the frequency domain expressed through a Hankel function of the first kind (3.36)

$$
U^{*}(r)=\frac{i}{4} H_{0}^{1}\left(\frac{\omega}{c_{T}} r\right) .
$$

The procedure to obtain a numerical solution of Eqn. (3.8) by using coupling conditions on the boundaries $\Gamma_{ \pm}$and finding the reflection and transmission coefficients is discussed elsewhere $(3.41,3.42)$.

The results presented here are used for a sizing study of elliptical defects with 2 a equal to $0.3,6.35$, and $12.7 \mathrm{~mm}$. Reflection and transmission coefficients versus frequency are shown in Fig. 3.66 for an $\mathrm{n}=0$ incident mode, $\mathrm{n}=0$ reflected and transmitted mode from the $0.3 \mathrm{~mm}$ notch defect. There is an excellent monotonic change in amplitude versus percent through-wall depth for all frequencies. A sample result is shown in Fig. 3.67 for $0.5 \mathrm{MHz}$. Sample results are illustrated in Figs. 3.68 and 3.69 for grooves of 6.35 and $12.7 \mathrm{~mm}$ compared to the $0.3 \mathrm{~mm}$ elliptical defect. There is sometimes a monotonic change of amplitude with defect depth, but not at all frequencies.

Generally, many BEM computer runs could be conducted to seek a reflection characteristic such that there would be a monotonic increase with depth of a reflector. At this time, sizing is only possible if the reflector type is known. Therefore the focus will be on the 0.3-mm-wide notch-type defect. Theoretical results were shown in Figs. 3.66 and 3.77 with a monotonic change of amplitude with through-wall size. Future work should focus on both defect detection and quantification. BEM tools are now available to assist in this study.

Experimental studies. Experiments were conducted on nine steel plates, each of which had either a groove or notch in one surface. The size of a defect was either $0.3-, 6.35-$, or $12.7-\mathrm{mm}$ wide with a depth equal to either $10 \%, 30 \%$ or $50 \%$ the through-plate thickness. Two electromagnetic SH wave transducers (SH EMATs) were used to generate and receive 
horizontal shear waves in the steel plate using a tone burst signal generator and oscilloscope system. Both throughtransmission and pulse-echo modes were used. On each plate, a reference signal was obtained by separating the two EMATs $76.2 \mathrm{~mm}$. The non-defect signal amplitude was then recorded. For through transmission, the two EMATs were $76.2 \mathrm{~mm}$ apart with each transducer $38.1 \mathrm{~mm}$ from the centerline of the defect (see Fig. 3.70a). A sample throughtransmission signal is shown in Fig. 3.71. A sample pulse-echo waveform for the setup shown in Fig. 3.70b is shown in Fig. 3.72. The envelope peak-to-peak value of the signal was measured and the transmission coefficient calculated by dividing it by that of the reference signal. For the pulse-echo mode, the two EMATs were put side by side and on the same side of the defect to simulate the pulse-echo mode. They were located $38.1 \mathrm{~mm}$ away from the center of the defect. Similar calculations to above can provide the reflection coefficient. A through-transmission result is shown in Fig. 3.73. It can be seen that the trend of the curve for the theoretical and experimental results is consistent. Let's now focus on the 0.3 -mm-wide-notch-type defect to see if a linear relationship with size can be obtained. Excellent results are shown for both the through-transmission mode in Fig. 3.74 and for the pulse-echo mode in Fig. 3.75.

Concluding remarks. Both SH and Lamb wave modes can be used for the inspection of steel containment structures, both somewhat insensitive to the concrete boundary for specific velocity and frequency values. On the other hand, strong benefits of the SH wave mode via an EMAT transducer was demonstrated with overall improved signal-to-noise ratio with practically no interference from the concrete interface and the non-contact testing potential.

Preliminary results presented here show that defect quantification analysis can be carried out for SH guided wave impingement onto a defect in a wave guide. Both pulse-echo and through-transmission methods were considered. In particular, the possibility of a monotonic increase in amplitude change with size is noted. Potential advantages of shearhorizontal waves compared to "Lamb" type waves include less mode conversion, constant wave structure for a particular mode for all frequencies, and less sensitivity to boundary conditions because of the lateral particle velocity. Presented BEM results can be used to establish data acquisition and analysis guidelines for development of a test protocol and quantification algorithm development program. Besides modeling and BEM analysis, feature extraction possibilities could also be obtained from experimental or calibration standards using guidelines established in this study.

\subsection{COMMENTARY}

Inspection of inaccessible portions of metallic pressure boundary components of NPP containments (e.g., fully embedded or inaccessible conJainment shell or liner portions, the sand pocket region in Mark I and II drywells, and portions of the shell obscured by obstacles such as platforms or floors) requires special attention. Embedded metallic portions of the containment pressure boundary may be subjected to corrosion resulting from ground water permeation through the concrete; a breakdown of the sealant at the concrete-containment shell interface that permits entry of corrosive fluids from spills, leakage, or condensation; or corrosion may occur in areas adjacent to floors where the gap contains a filler material that can retain fluids. Corrosion, should it occur, may challenge the containment structural integrity and, if through-wall, can provide a leak path to the outside environment. At present nondestructive evaluation techniques for use in determining the condition of the containment pressure boundary are time-consuming and costly because they tend to examine only a small area at a time. A nondestructive technique is required that can be used remotely to examine inaccessible regions of the containment metallic pressure boundary. Such a technique ideally should also be capable of performing global inspections so that determination of the overall condition of the containment metallic pressure boundary can be achieved in a cost- and performance-effective manner. Identification and/or development of such technique(s) becomes increasingly important as the median age of the NPPs now exceeds 20 years, and in the not-too-distant future several of these plants will be nearing the end of their initial operating license period.

The performance of a commercially available fully-integrated angle-beam inspection system was evaluated through both numerical and experimental studies. The numerical studies indicated that for the embedded steel-lined concrete containment scenario, the thin steel liner with concrete backing combine to give unacceptably high signal loss to the concrete for small degradations close to the interface. However, for the embedded steel containment scenario, significant degradations (i.e., $2 \mathrm{~mm}$ ) below the concrete-air interface give a reasonable intrinsic backscatter level that is sufficiently above the expected noise level to be detectable. Experimental results using 25-mm-thick steel plates show that notches contained in the plates were detectable using high-frequency acoustic-imaging technology. When the plates were embedded in concrete, the concrete caused additional signal loss, but defects such as a 4-mm-deep rounded degradation located up to $30 \mathrm{~cm}$ below the air-concrete interface should be detectable. The losses to the concrete were strongly dependent on the coupling conditions between the steel and concrete, and ultrasonic waves directed at shallow angles were least affected by the concrete, regardless of coupling condition. 
Magnetostrictive sensor-generated guided waves that had been used for inspection of long lengths of piping and tubing has been successfully adapted for application to guided wave inspection of plate-type materials. Modeling studies suggest that a low frequency AO mode wave (e.g., $20 \mathrm{kHz}$ in a 25.4-mm-thick steel plate) is best suited for inspection of containment boundaries backed on one or both sides by concrete. Experimental results demonstrated that the magnetostrictive sensor technique can generate and detect guided waves in plates and detect a defect over a long range, including defects contained in areas difficult to access because of equipment or attachments. The amplitude of signals reflected from notches machined in a steel plate was affected by the product of defect length and depth in the plate normal to the guided wave beam propagation. The effect of a defect embedded in concrete was not evaluated experimentally using magnetostrictive sensors.

Lower frequency methods appear to be best for inspection of plates bounded by concrete because of reduced attenuation, but sensitivity to defects and defect resolution are reduced relative to higher frequency methods. Horizontal shear and Lamb wave modes can be used for inspection of steel containment structures, both somewhat insensitive to the concrete boundary for specific velocity and frequency values. Strong benefits of the horizontal wave mode via an electromagnetic acoustic transducer were demonstrated with overall improved signal-to-noise ratio, practically no interference from the concrete interface, and the non-contact testing potential. Although preliminary, results show that defect quantification analysis can be carried out for horizontal shear guided wave impingement onto a defect in a wave guide. Both pulse-echo and through-transmission methods were considered. In particular, the possibility of a monotonic increase in amplitude change with size was noted. Potential advantages of horizontal shear waves compared to "Lamb" type waves includes less mode conversion, constant wave structure for a particular mode for all frequencies, and less sensitivity to boundary conditions because of the lateral particle velocity. The Boundary Element Method (BEM) can be used to establish data acquisition and analysis guidelines for development of a test protocol and quantification algorithm development program. Besides modeling and BEM analysis, feature extraction possibilities could also be obtained from experiment or calibration standards using guidelines established in this study.

Conventional ultrasonic inspection techniques generate ultrasonic beams that tend to spread out as the beam is reflected from the component boundaries to limit the technique's inspection resolution. Also, mode conversion occurs where both longitudinal and shear waves are present after reflections from component boundaries to potentially influence the signalto-noise ratio and make the defect echoes difficult to interpret. Furthermore, multiple echoes can be received from the plate-concrete interface and, unless the correct combination of frequency and wedge-input angle is selected, only the first of a series of defects will be detected, or defects may not be detectable at all from the opposite surface of a plate containing a surface defect. Therefore, techniques utilizing guided waves that interrogate the specimen cross section (i.e., provide energy distribution across component cross section) should be investigated in more detail (e.g., electromagnetic acoustic transducers, magnetostrictive sensors, and multimode guided wave methods).

A series of laboratory experiments should be conducted to evaluate candidate systems under more prototypical conditions. Specimens should be fabricated and tested that would evaluate effects such as flaw geometry (e.g., notch, flat-bottom holes, and thinned areas), size (e.g., width, length, and depth), orientation, and location relative to the plateconcrete interface; three-dimensional effects (e.g., plate curvature); structural discontinuities (e.g., welds, anchor, or studs); and the presence of concrete as well as the quality of the bond between the concrete and steel. As a part of these investigations instrumentation systems should be optimized to control wave direction and mode, establish operable plate thicknesses, inspection range, and defect detectability data generated (e.g., probability of defect detection curves). Signal processing should be investigated as a method to discriminate between defects of potential significance and other scatterers (e.g., welds, concrete voids, and anchor studs). In addition to being able to detect defects, work needs to be done on sizing and classifying the severity of a particular defect. Development of the BEM approach should continue to establish guidelines so that the most effective wave modes and frequencies can be considered for impingement to provide the optimum probability for determining a defect shape and size characteristics. Work should also be conducted on developing a system that can perform global inspections through use of comb transducers or transducer arrays. Once these experiments have been completed, the most promising of the three potential candidate systems should be evaluated under representative field conditions and optimized.

\subsection{REFERENCES}

3.1 ASME Boiler and Pressure Vessel Code, American Society of Mechanical Engineers, New York, New York, 1988. 
3.2 "Rules for Inservice Inspection of Nuclear Power Plant Components," ASME Boiler and Pressure Vessel Code, Section XI, Division 1, Subsection IWA, Greneral Requirements, American Society of Mechanical Engineers, New York, New York, July 1, 1995.

3.3 Stuart, C.O., "Underwater Coating Repair Cuts Nuclear Maintenance Costs," Power Engineering, Vol. 97, No. 7, pp. 31-34, July 1993.

3.4 Hull, B. and John, V., Non-Destructive Testing, MacMillan Press Ltd., London, England, 1994.

3.5 Alleyne, D.N. and Cawley, P., "Optimizations of Lamb Wave Inspection Techniques, NDT\&E Intenational 25, pp. 11-22, 1992.

3.6 Ghosh, T., Kundu, T. and Karpur, P., "Efficient Use of Lamb Modes for Detecting Defects in Large Plates," Ultrasonics 36, pp. 791-801, 1998.

3.7 Alleyne D.N. and Cawley, P., "The Excitation of Lamb Waves in Pipes Using Dry-Coupled Piezoelectric Transducers," J. NDE 15, pp. 11-20, 1996.

3.8 Beissner, R.E. and Birring, A.S., Nondestructive Evaluation Methods for Characterization of Corrosion, NTIAC-88-1, Nondestructive Testing Information Analysis Center, San Antonio, Texas, December 1988.

3.9 ASM Inernational, “Corrosion,” ASM Handbook, Vol. 13, Materials Park, Ohio, 1992.

3.10 Pocock D.C., Worthington J.C, Oberpichler, R, Van Exel, H., Beukelmann D., Huth, R., and Rose, B., LongTerm Performance of Structures Comprising Nuclear Power Plants, Report EUR 12758 EN, DirectorateGeneral Science, Research and Development, Commission of European Communities, Luxembourg, 1990.

3.11 Krautkramer, J. and Krautkramer, H., Ultrasonic Testing of Materials, Chapter 8, $4^{\text {th }}$ Ed., Springer Verlag, New York, New York, 1990.

3.12 Mohr, W. and Holler, P., "On Inspection of Thin-Walled Tubes for Transverse and Longitudinal Flaws by Guided Ultrasonic Waves," IEEE Transactions on Sonics and Ultrasonics SU-23, pp. 369-374, New York, New York, 1976.

3.13 Latham, W.M., Latimer, P.J., and MacLauchlan, E.T., "EMAT-Generated Lamb Waves for Volumetric Inspection of Strip Steel," Process Control and Sensors for Manufacturing, Editors Boss, R. H. and Pepper, D. M., SPIE 3399, pp. 139-150, Bellingham, WA., 1998.

3.14 Electric Power Research Institute, The Feasibility of Using Electromagnetic Acoustic Transducers to Detect Corrosion in Mark I Containment Vessels, EPRI NP-6090, Palo Alto, California (November 1988).

3.15 Bondaryk, J.E., Corrado, C.N., and Godino, V., Feasibility of High Frequency Acoustic Imaging for Inspection of Containments, NUREG/CR-6614, U. S. Nuclear Regulatory Commission, Washington, D.C. (August 1998).

3.16 Rudzinsky, J., Bondaryk, J. and Conti, M., Feasibility of High Frequency Acoustic Imaging for Inspection of Containments: Phase II, ORNL/NRC/LTR-99/1, Lockheed Martin Energy Systems, Inc., Oak Ridge National Laboratory, Oak Ridge, Tennessee, July 1999.

3.17 Schmidt, H., SAFARI: Seismo-Acoustic Fast-Field Algorithm for Range Independent Environments, User's Guide, SACLANT ASW Research Centre I-19100 La Spezia, Italy, May 1987.

3.18 Schmidt, H., OASES User Guide and Reference Manual, Version 2.1, Massachusetts Institute of Technology, Cambridge, Massachusetts, 1997.

3.19 Johnson, D.H. and Dudgeon, D.E., Array Signal Processing, Prentice-Hall, Inc., Englewood Cliffs, New Jersey, 1993.

3.20 Kittel, C., "Physical Theory of Ferromagnetic Domains," Rev. Modern Phys 21, pp. 541-583, 1949. 
3.21 Kwun, H. and Bartels, K.A., "Magnetostrictive Sensor Technology and Its Applications," Ultrasonics 36, pp. $171-178,1998$.

3.22 Williams, R.C., "Theory of Magnetostrictive Delay Lines for Pulse and Continuous Wave Transmission," IEEE Trans. on Ultrasonics Engineering UE-7, pp. 16-38, New York, New York, 1959.

3.23 Kwun, H., Feasibility of Magnetostrictive Sensor Inspection of Containments, NUREG/CR-5724 (ORNL/SUB/98-SZ272V), U. S. Nuclear Regulatory Commission, Washington, D. C., March 1999.

3.24 Pavlakovic, B., Lowe, M., Alleyne, D. and Cawley, P., "DISPERSE: A General-Purpose Program for Creating Dispersion Curves," Review of Progress in Quantitative Nondestructive Evaluation16, (Edited by D. O. Thompson and D. E. Chimenti), Plenum Press, New York, New York, pp. 185-192, 1997.

3.25 Pavlakovic, B. and Lowe, M., DISPERSE User's Manual, Version 1.0, Imperial College, University of London, London, England,1997.

3.26 Development of Magnetostrictive Sensor for Plate Inspection (ongoing), Southwest Research Institute Project 17-9077, Southwest Research Institute, San Antonio, Texas.

3.27 Kwun, H. and Bartels, K.A. "Experimental Observation of Elastic-Wave Dispersion in Bounded Solids of Various Configurations," J. Acoust. Soc. Am. 99, pp. 962-96, 1996.

3.28 Krautkramer, J. and Krautkramer, H., Ultrasonic Testing of Materials, Chapter 16, Section 2, $4^{\text {th }}$ Ed., Springer Verlag, New York, New York, 1990.

3.29 Kittel, C., "Physical Theory of Ferromagnetic Domains," Rev. Modern Phys 21, Section 6, 1949.

3.30 Kwun, H. and Dynes, C. "Long-Range Guided-Wave Inspection of Pipe Using the Magnetostrictive Sensor Technology - Feasibility of Defect Characterization," Nondestructive Evaluation of Utilities and Pipelines II, Edited by W. G. Reuter, SPIE Vol. 3398, pp. 28-34, Bellingham, WA., 1998.

3.31 Cho, Y. and Rose, J.L., "Guided Waves in a Water Loaded Hollow Cylinder," Nondestructive Testing \& Evaluation 12, pp. 323-339, 1996.

3.32 Rose, J.L., Jiao, D. and Spanner, J. Jr., "Ultrasonic Guided Wave NDE for Piping," Materials Evaluation 54(11), pp. 1310-1313, November 1996.

3.33 Quarry, M.J. and Rose, J.L., "Multimode Guided Wave Inspection of Piping Using Comb Transducers," Materials Evaluation 57(10), pp. 1089-1090, October 1999.

3.34 Alleyne, D.N. and Cawley, P., "Long Range Propagation of Lamb Wave in Chemical Plant Pipework," Materials Evaluation 45(4), pp. 504-508, April 1997.

3.35 Kwun, H. and K.A. Bartels, "Experimental Observation of Elastic-Wave Dispersion in Bounded Solids of Various Configurations," J. Acoustical Society of America 99(2), pp. 962-968, February 1996.

3.36 Alleyne, D.N. and Cawley, P., "The Interaction of Lamb Waves With Defects," IEEE Transactions on Ultrasonics, Ferro Electrics, and Frequency Control 39(3), pp. 381-397, 1992.

3.37 Alleyne, D. N. and Cawley, P. “The Long-Range Detection of Corrosion in Pipes Using Lamb Waves," Review of Progress in Quantitative NDE, Plenum Press, New York, NY, pp. 2075-2080, 1995.

3.38 Rose, J.L. Pelts, S.P. and Quarry, M.J., “A Comb Transducer Model for Guided Wave NDE,” Ultrasonics 36, Elsevier Publishers, New York, NY, pp. 163-169, 1998.

3.39 Li, J. and Rose, J.L., "Guided Wave Inspection of Containment Structures," Materials Evaluation 59(6), pp. 783-787, June 2001. 
3.40 Rose, J.L. and Zhao, X., "Anomaly Throughwall Depth Measurement Potential with Shear Horizontal Guided Waves," Materials Evaluation 59(10), pp. 1234-1238, October 2001.

3.41 Rose, J.L., Ultrasonic Waves in Solid Media, Cambridge University Press, New York, NY,1999.

3.42 Cho, Y. and Rose, J.L., J. Acoustical Society of America 99(4), pp. 2097-2109, 1996.

3.43 Rose, J.L., Pelts, S.P. and Cho, Y., Journal of Nondestructive Evaluation, 19(2), pp. 55-66, 2000.

3.44 Pelts, S.P., Cysyk, J.P. and Rose, J.L., Review of Progress in Quantitative Nondestructive Evaluation 16, pp. 137-143, 1996.

3.45 Cho, Y., Hongerholt, D.D., and Rose, J.L., IEEE Transactions on Ultrasonics, Ferro Electrics, and Frequency Control 44(1), pp. 44-52, 1997.

3.46 Abduljabbar, A. and Datta, S.K., J. Applied Physics 54(2), pp. 461—472, 1983.

3.47 Datta, S.K., Al-Nassar, Y. and Shah, A.H., Review of Progress in Quantitative Nondestructive Evaluation 10, pp. 97-104, 1991.

3.48 Koshiba, M., Karakida, S. and Suzuki, M., IEEE Trans. Sonics Ultrasonics, SU-31, pp. 18-25, 1984.

3.49 Koshiba, M. Hasegawa, K. and Suzuki, M., IEEE Trans. Ultrasonics, Ferro Electrics, and Frequency Control 34(4), pp. 461-466, (1987).

3.50 Fortunko, C.M., King, R.B. and Tan, M. J. Applied Phys., 53, 3450-3458, 1982.

3.51 Kobayashi, S., "Chapter 4, Elastodynamics," Boundary Element Methods in Mechanics, North-Holland Publishers, Amsterdam, The Netherlands, pp.192-255, 1987.

3.52 "Volume 17 - Nondestructive Evaluation and Quality Control," ASM Handbook (formerly ninth edition, Metals Handbook), ASM International, Materials Park, Ohil, 1989. 


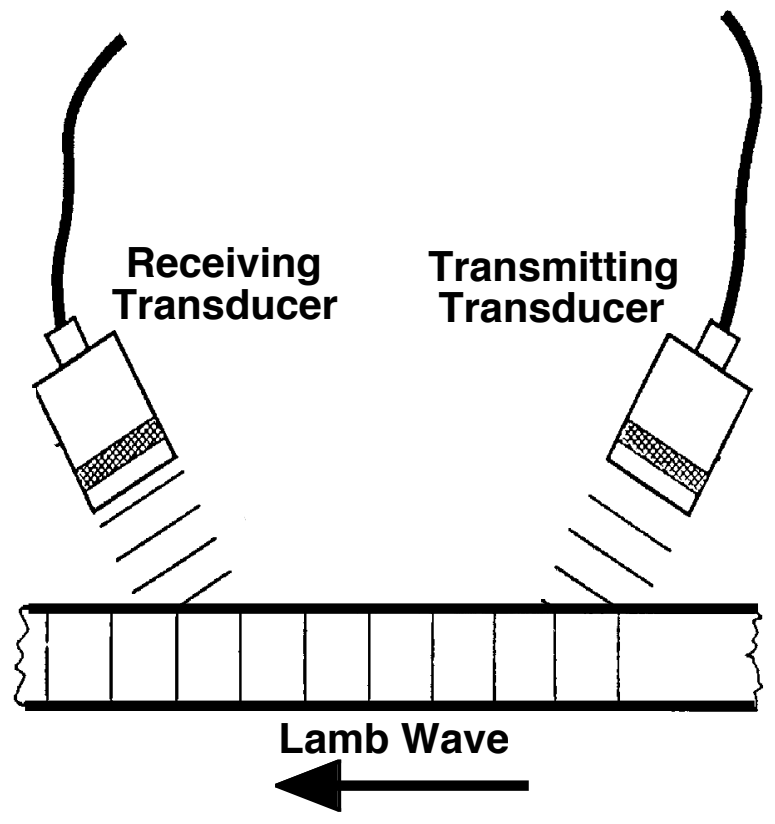

Fig. 3.1 Guided wave generation and detection in a plate using piezoelectric transducers.

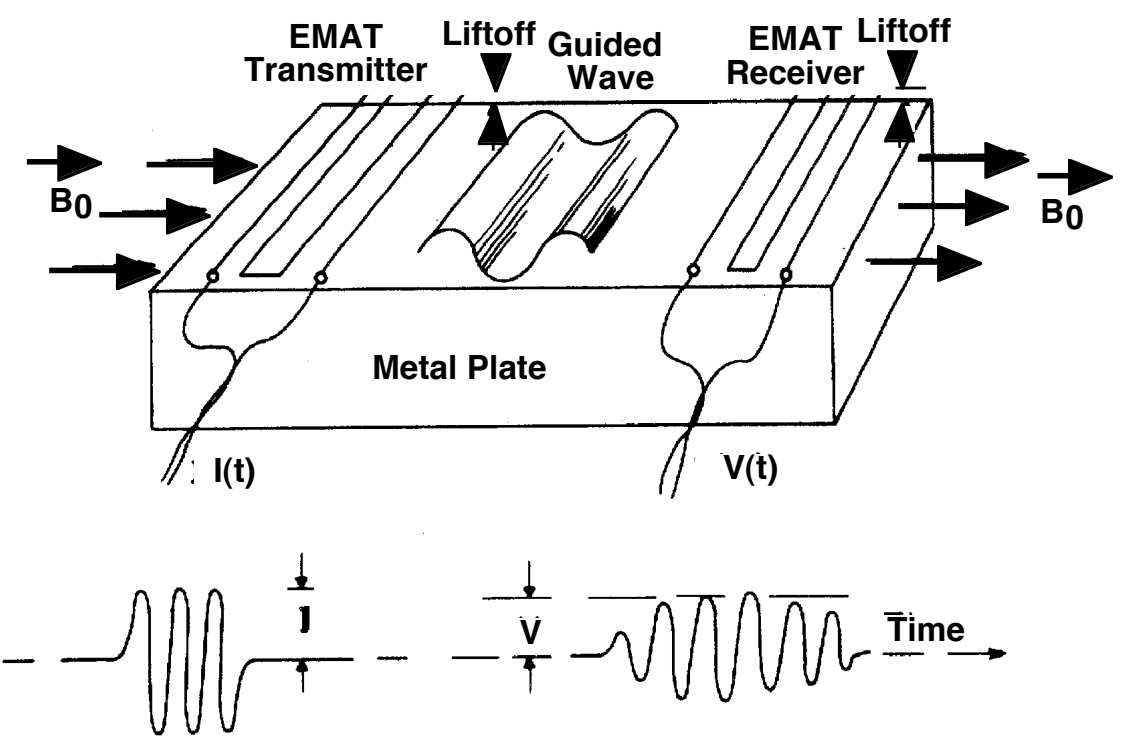

Fig. 3.2 Common EMAT setup for guided waves. 


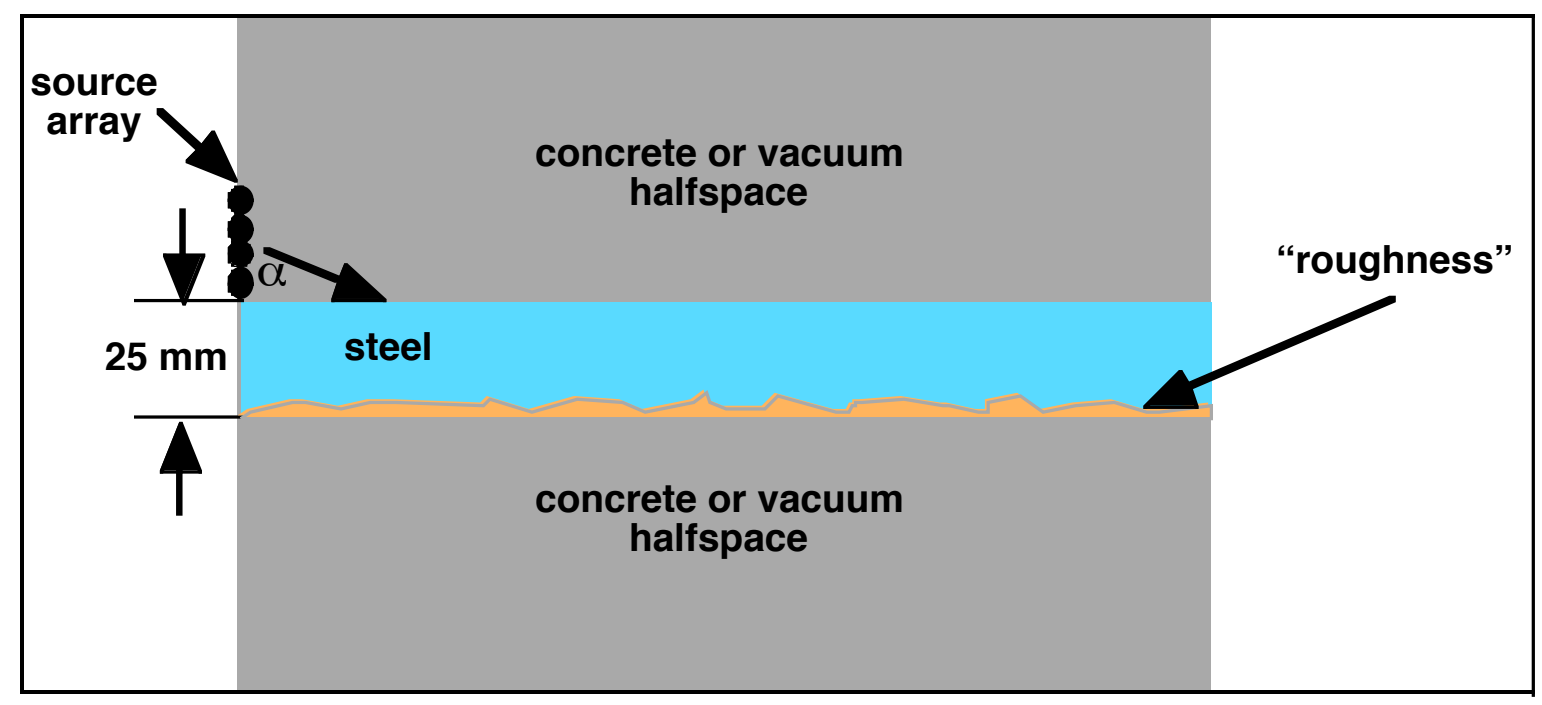

Fig. 3.3 Range-independent OASES simulation scenario for steel containment scenario.

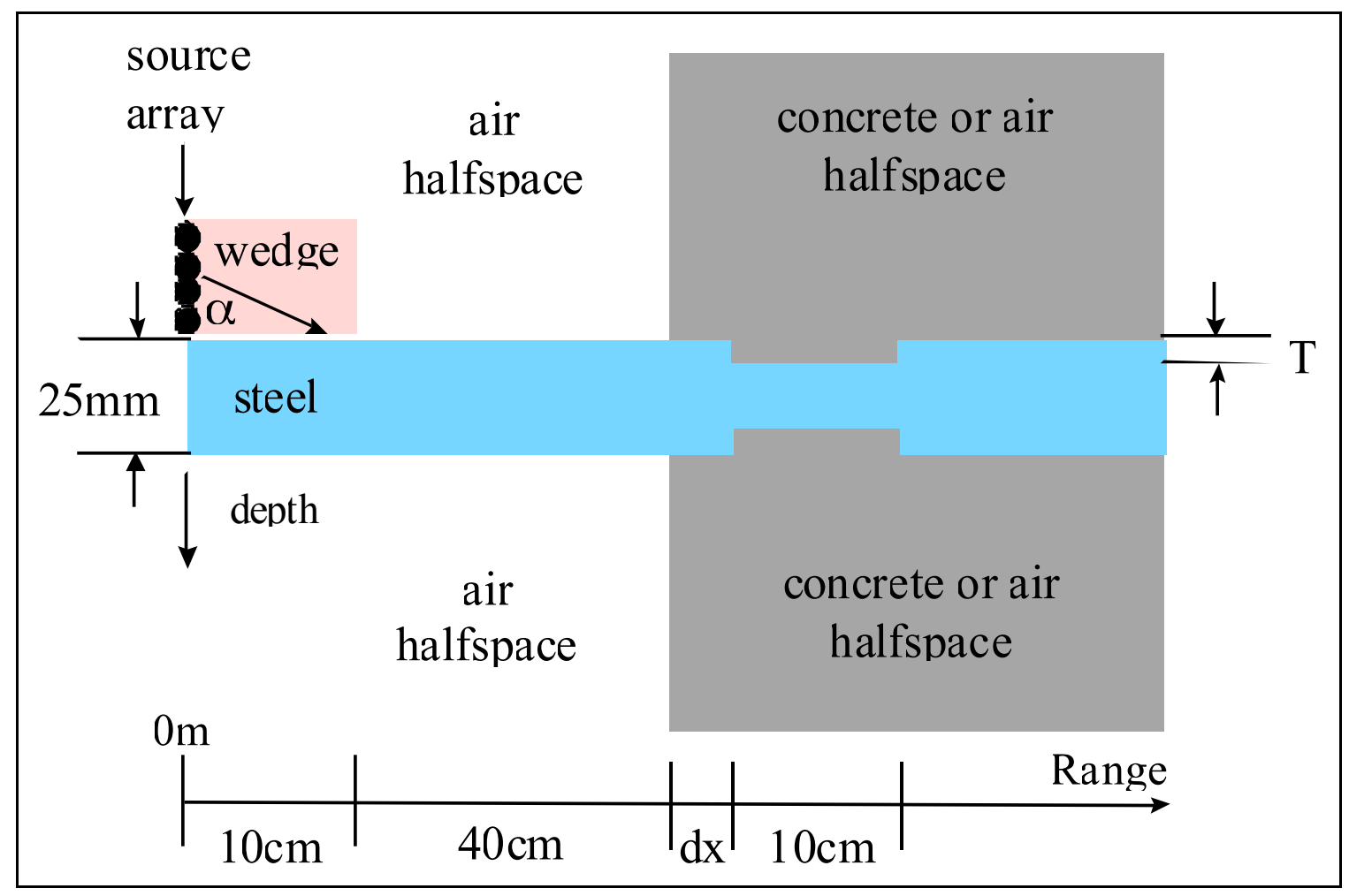

Fig. 3.4 Range-dependent numerical simulation scenario for steel containment scenario. 


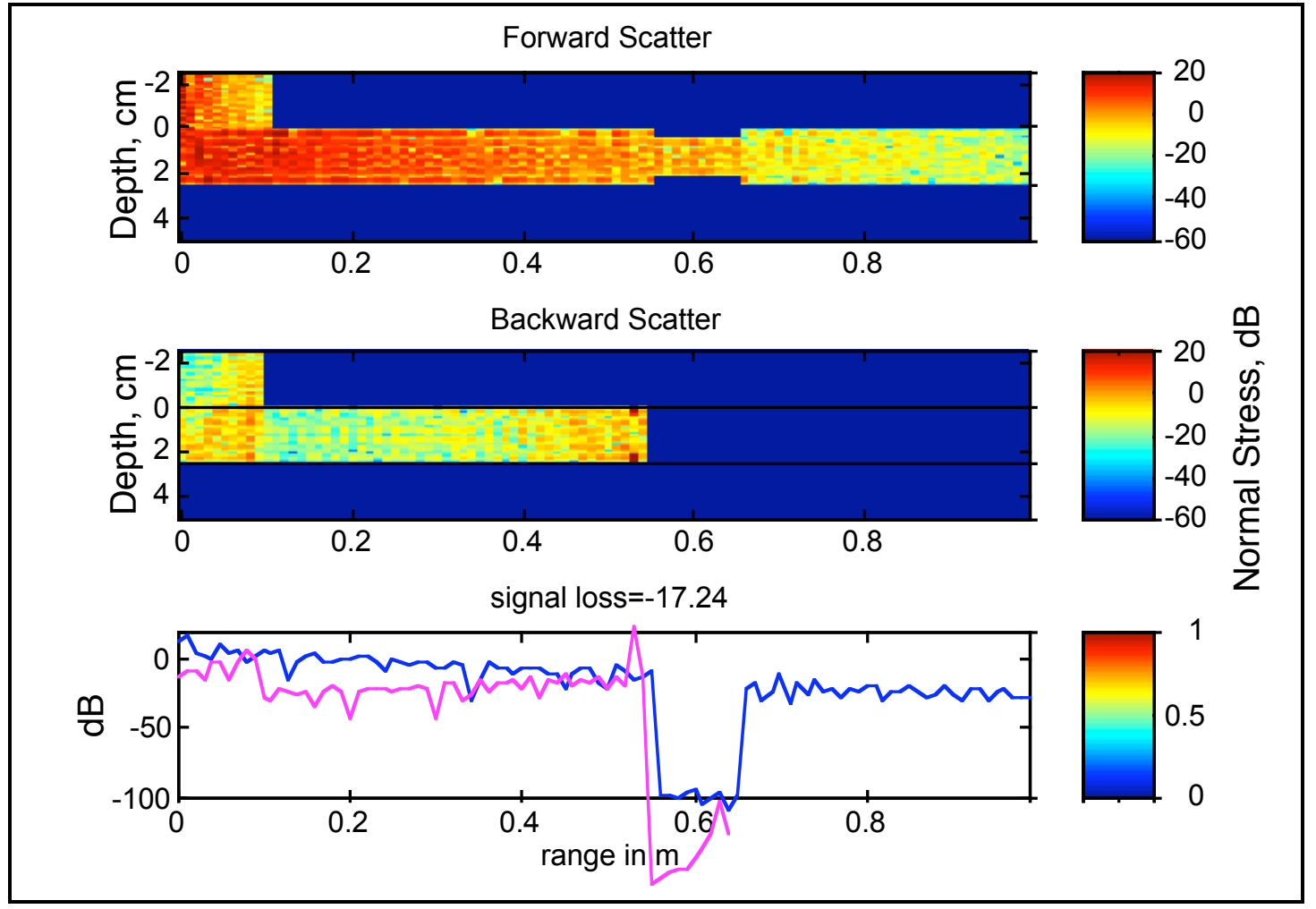

Fig. 3.5 Results of simulation scenario for a steel layer surrounded by air only.

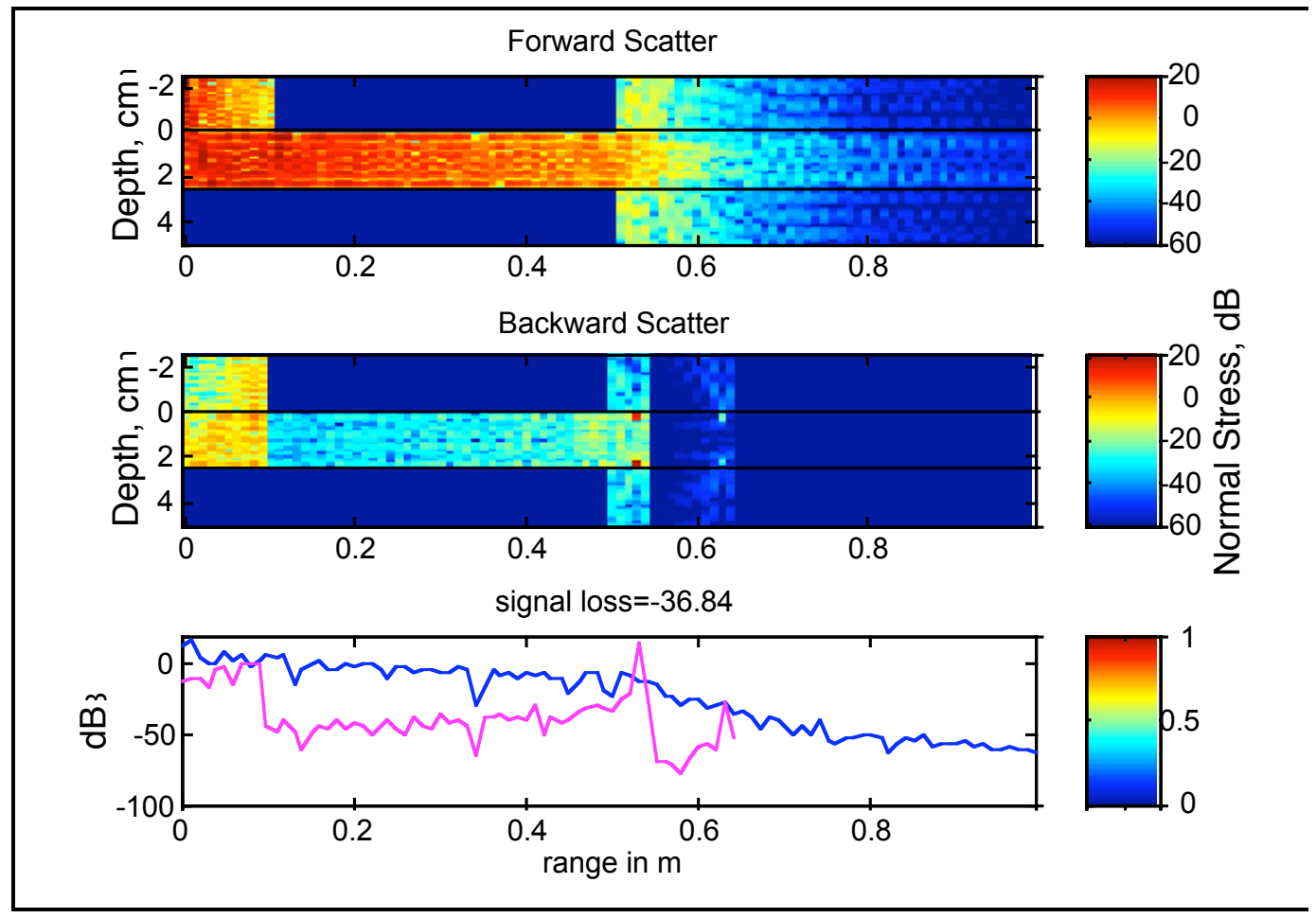

Fig. 3.6 Results of simulation scenario for embedded steel containment. 


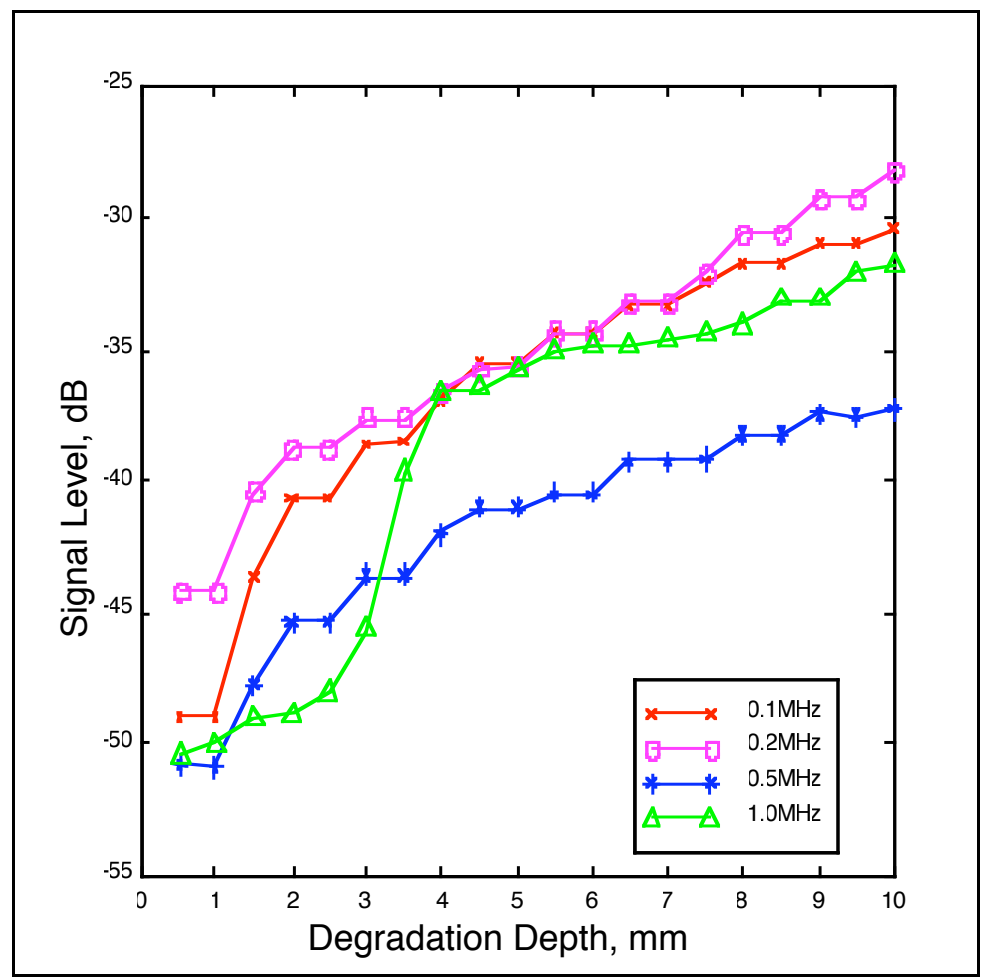

Fig. 3.7 Signal level from a degradation located $5 \mathrm{~cm}$ below air/concrete interface as a function of degradation depth and frequency.

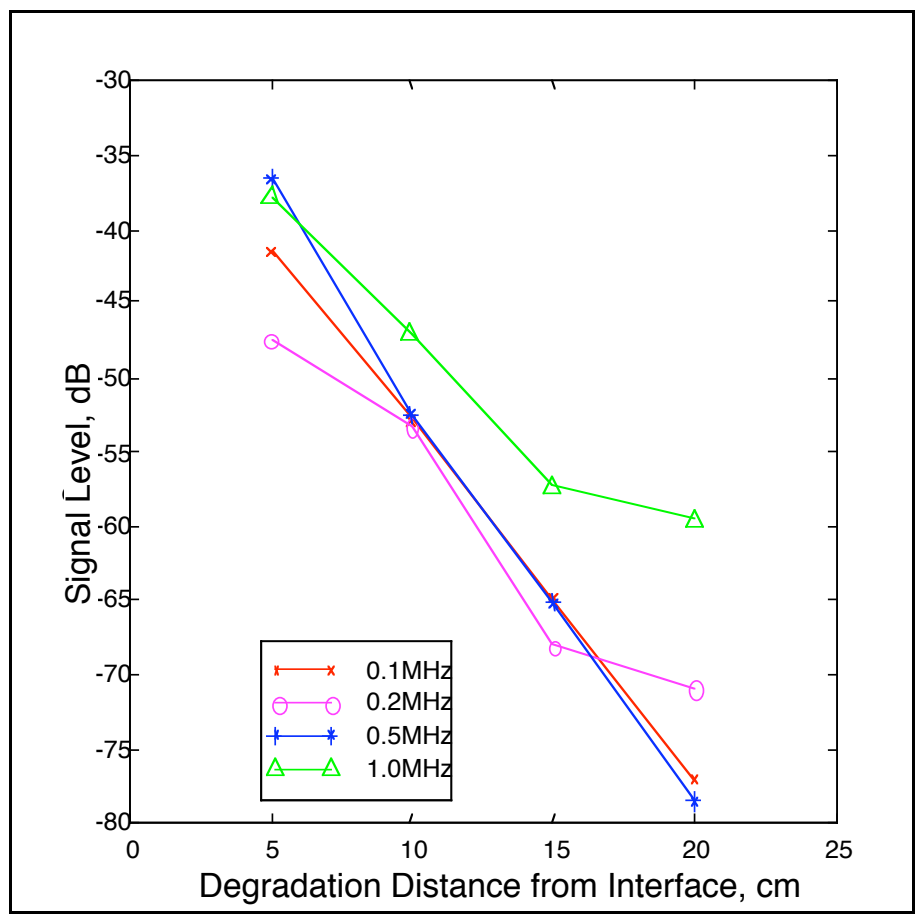

Fig. 3.8 Signal level from a 4-mm-deep degradation as a function of degradation distance from interface and frequency. 


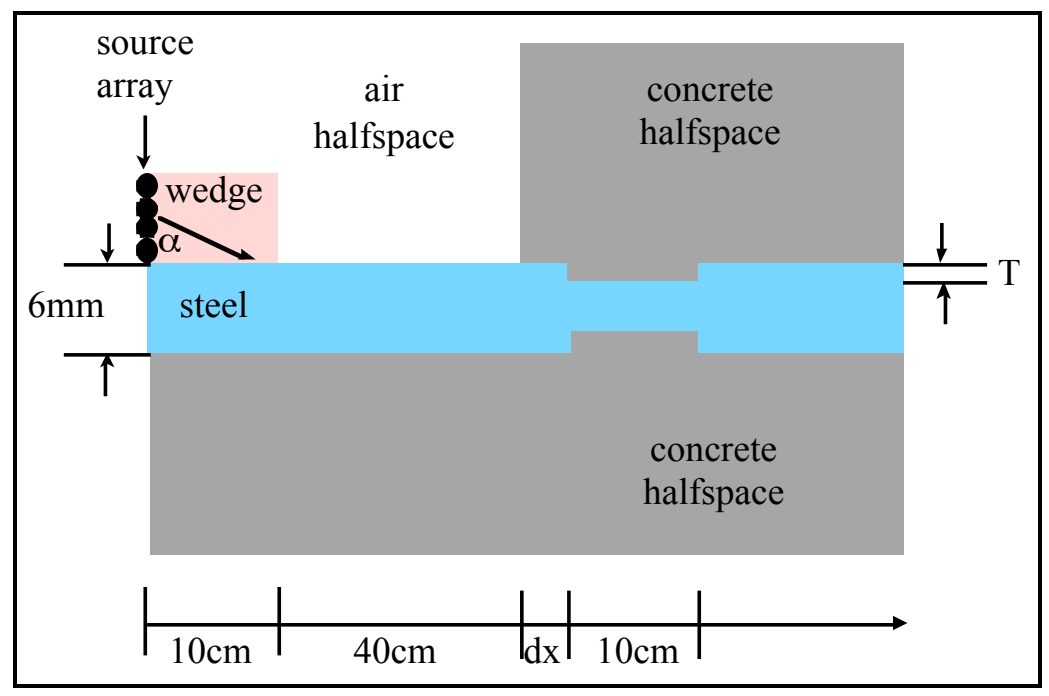

Fig. 3.9 Simulation scenario for steel-lined concrete containment with 6-mm-thick steel layer backed by a concrete halfspace below.

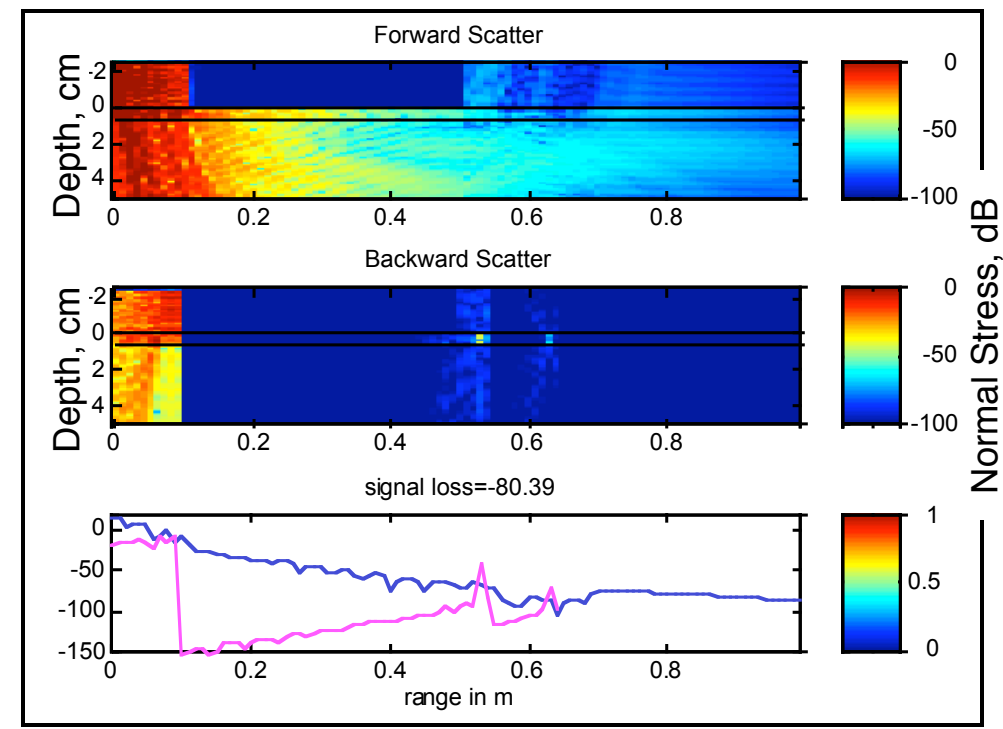

Fig. 3.10 Results of simulation scenario for steel-lined concrete containment . 


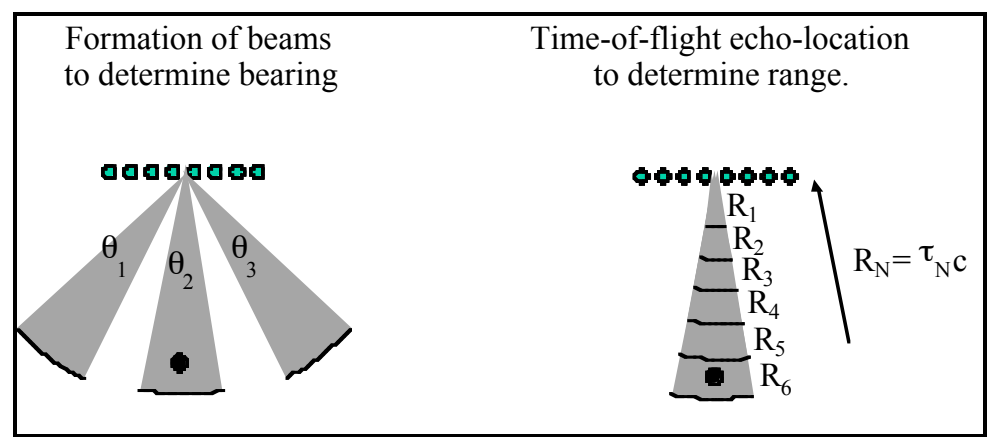

Fig. 3.11 Illustration of localization by means of beam steering for bearing determination and range gating for distance determination.

Beamforming constraints:

- aliasing

$d x \leq \lambda / 2$

- near/far field $\quad R \geq \mathbf{2} r_{T}=\mathbf{2} L^{2} / \lambda$

- main lobe width $\boldsymbol{\theta}_{3 d B}=\lambda / \boldsymbol{L}$

- array length $L=N d x$

- resolution $\quad \boldsymbol{D}=\boldsymbol{R} \boldsymbol{\theta}_{3 d \boldsymbol{B}}$

- side lobe level f(array taper)

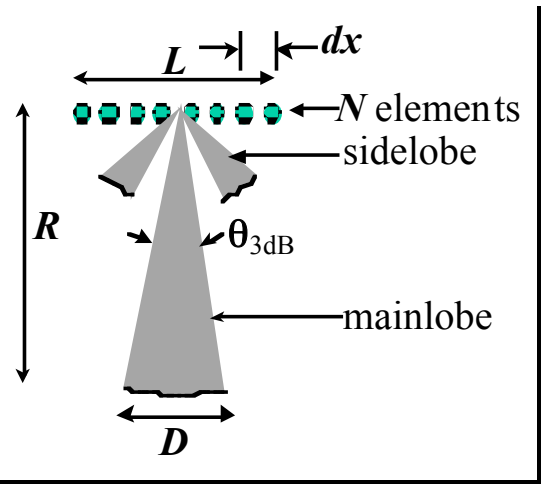

Fig. 3.12 Illustration of beam-forming parameters and their effect on beam shape.

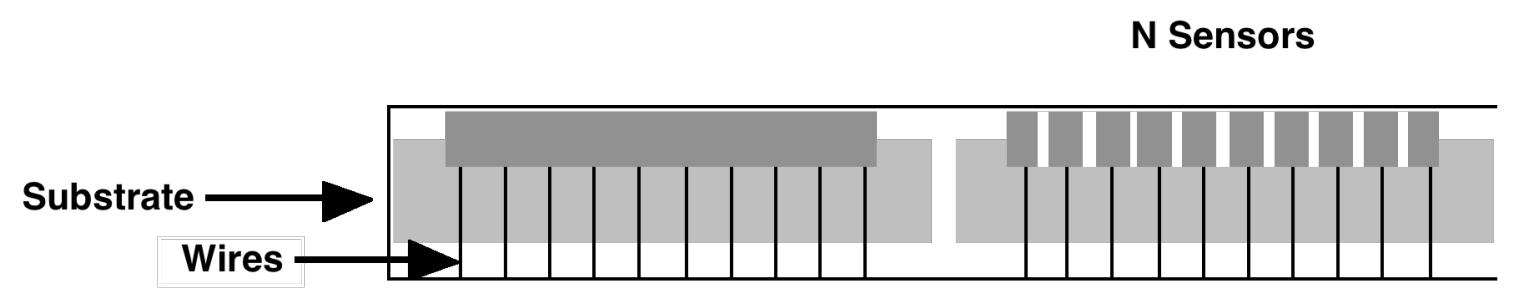

Fig. 3.13 Sensor array cut from a single piezoelectric block, with left side showing initial bonding of piezoelectric material to wires and substrate, and right side the array cut into individual elements prior to potting. 


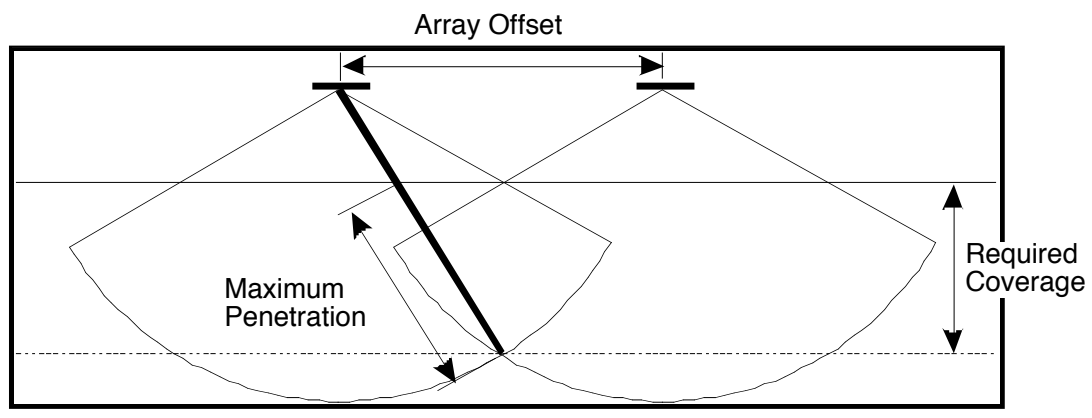

Fig. 3.14 Array spacing and beam overlap for a scannable array system with maximum penetration dictated by propagation physics.

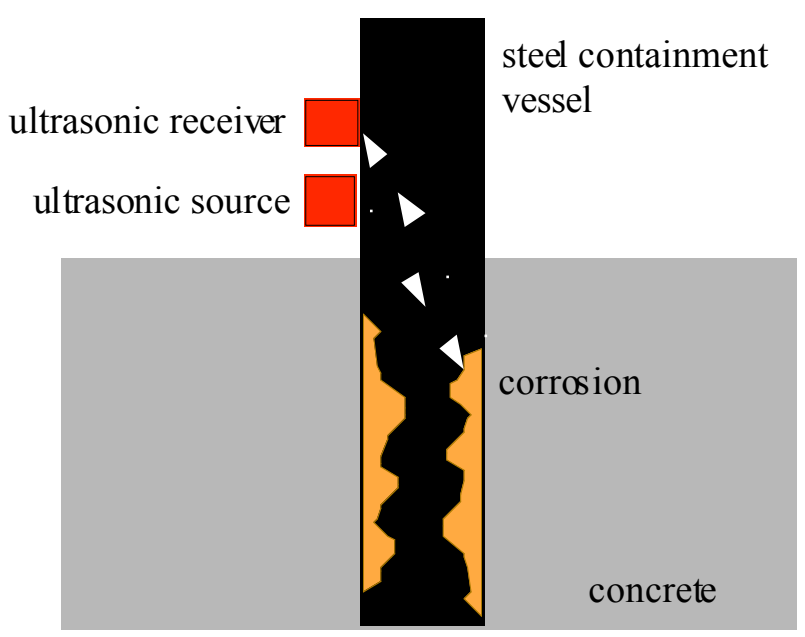

Fig. 3.15 Proposed approach for detection of degradation below air/concrete interface.

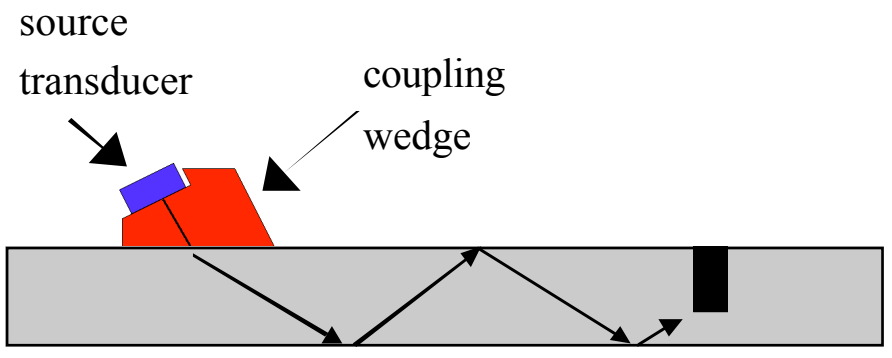

Fig. 3.16 Procedure used for angle-beam inspections. 


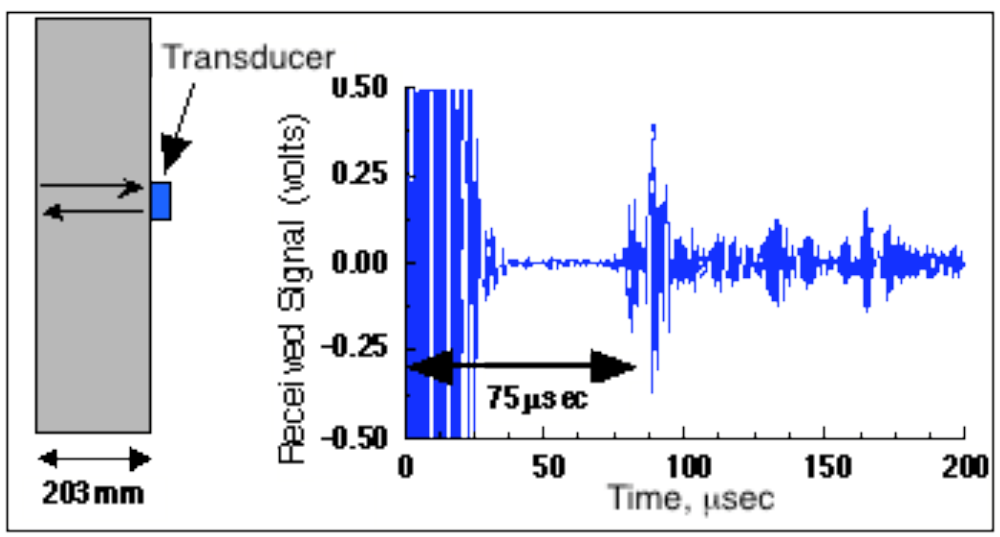

Fig. 3.17 Test setup and measured return for thickness measurement.

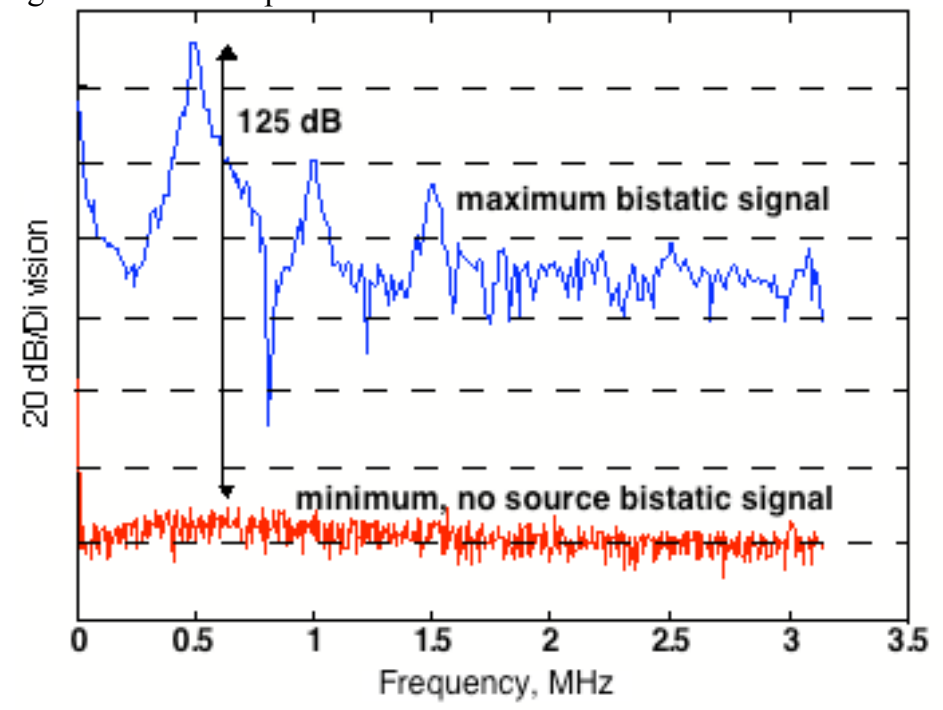

Fig. 3.18 Power spectral densities of maximum and minimum signals. 


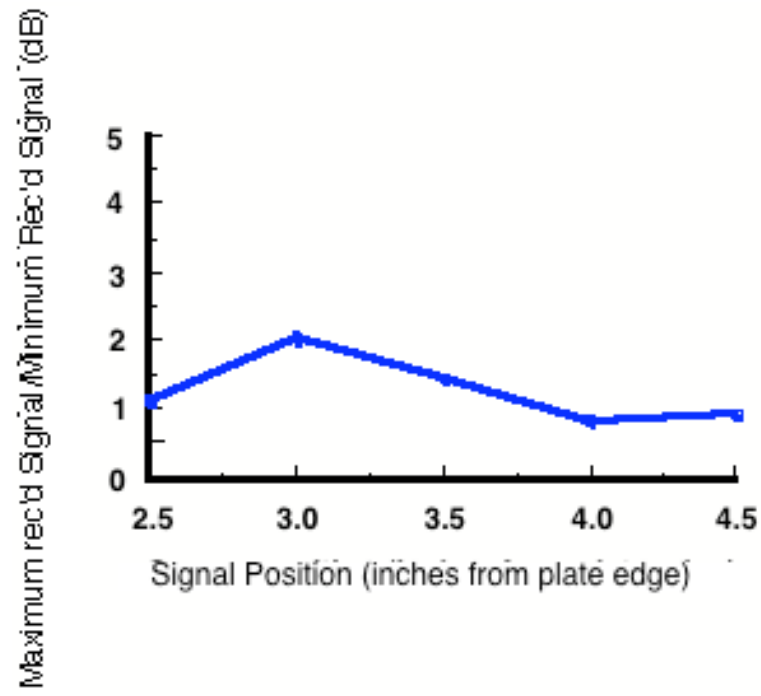

Fig. 3.19 Received signal ratios for different source/receiver separation distances.

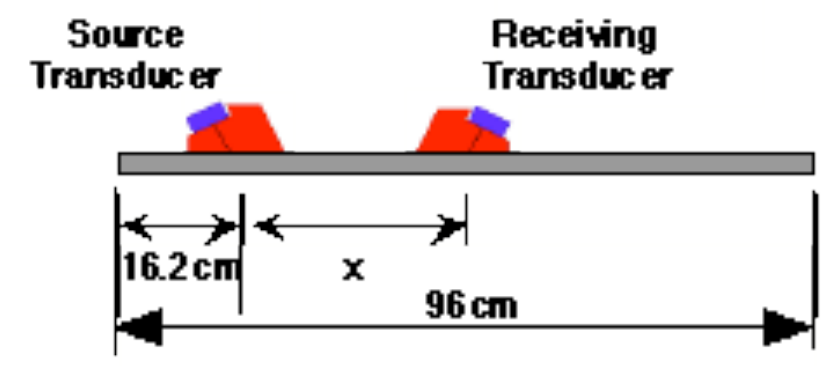

Fig. 3.20 Test setup for monitoring forward-travelling waves in free plate.

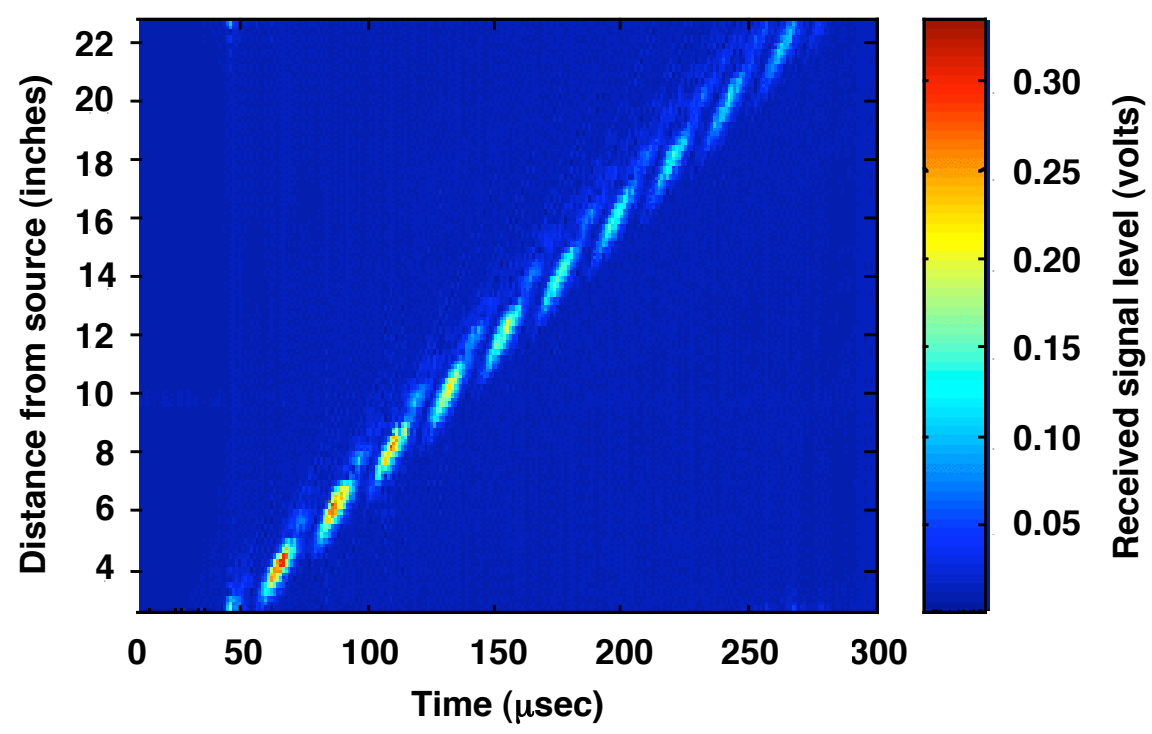

Fig. 3.21 Combined envelopes of received signals at several locations relative to a fixed source (forward-travelling waves). 


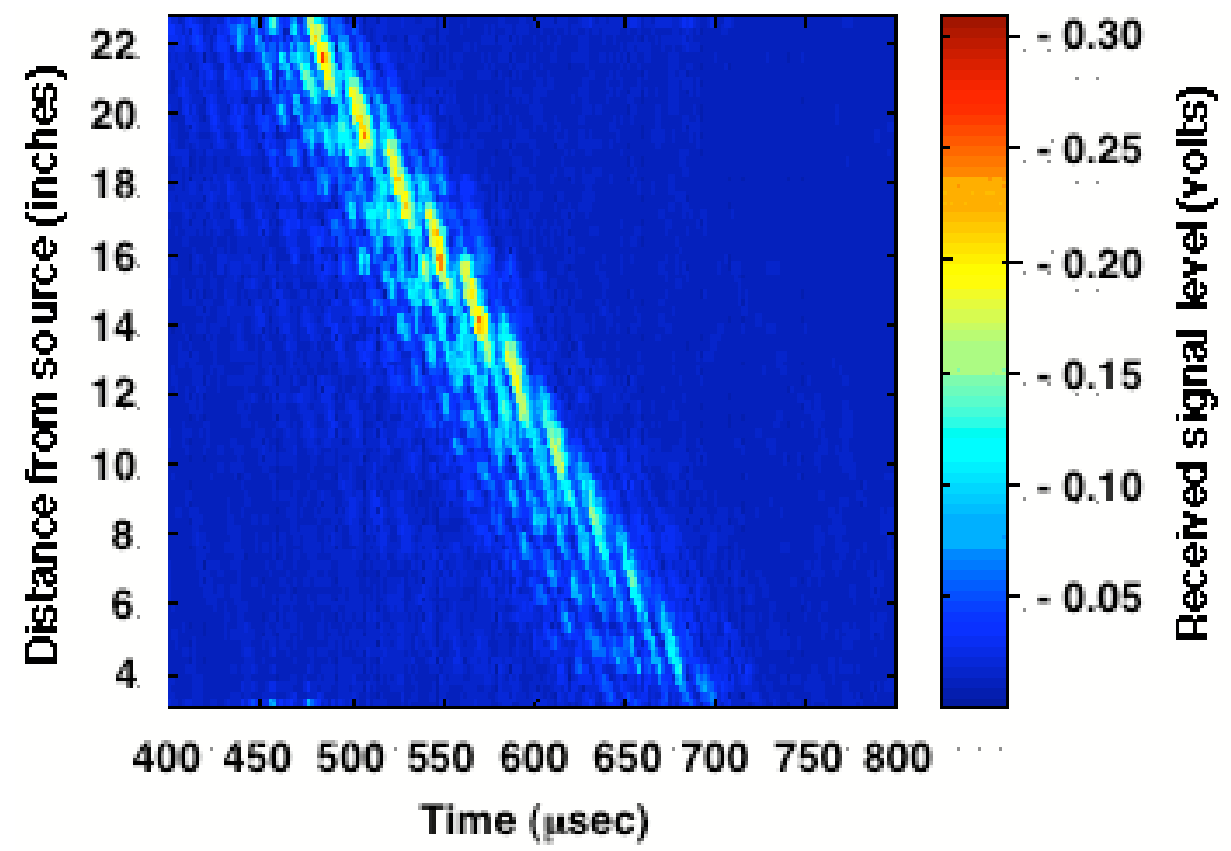

Fig. 3.22 Combined envelopes of received signals at several locations relative to a fixed source (backward-travelling reflected waves).

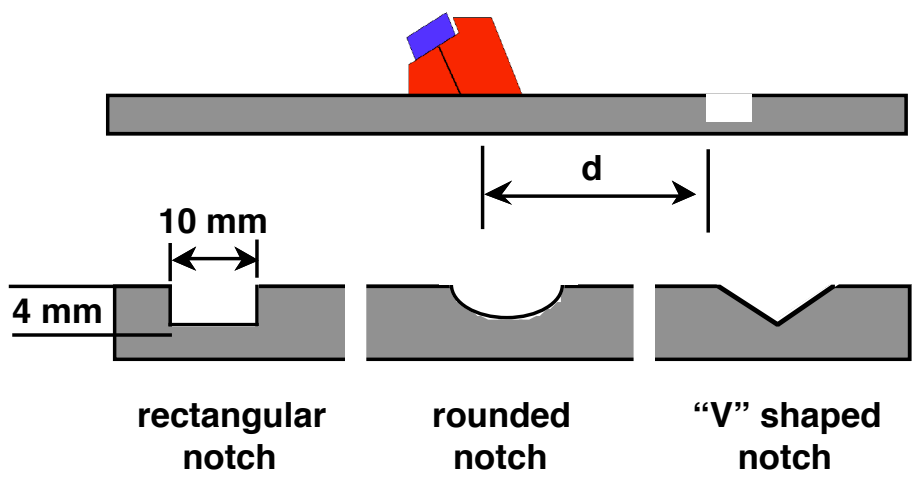

Fig. 3.23 Schematic of test setup for degradation shape study. 


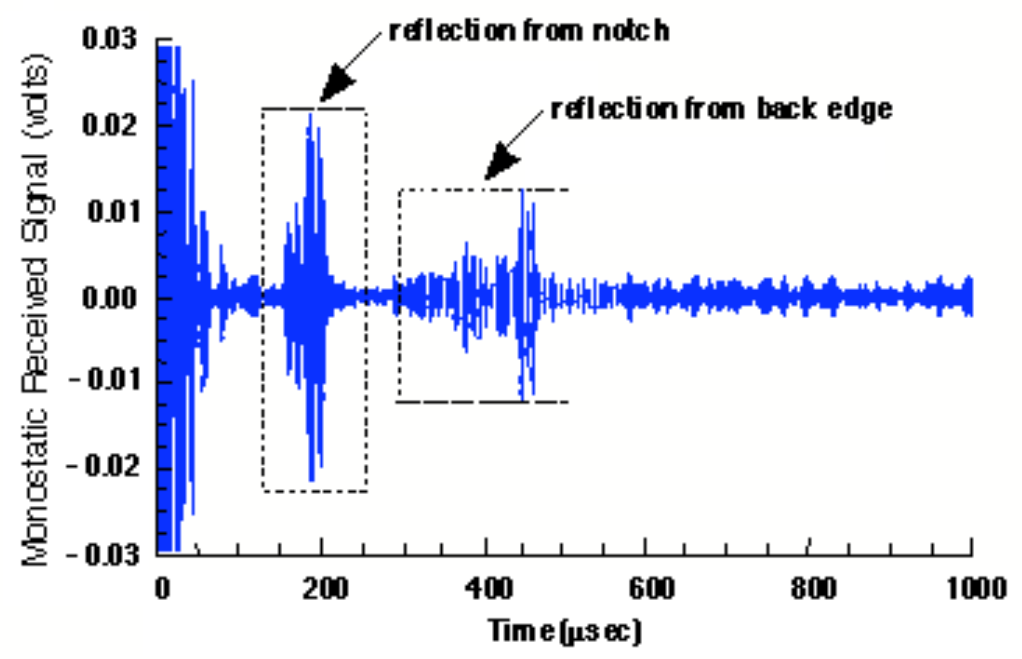

Fig. 3.24 Sample reflected return signal from rectangular notch.
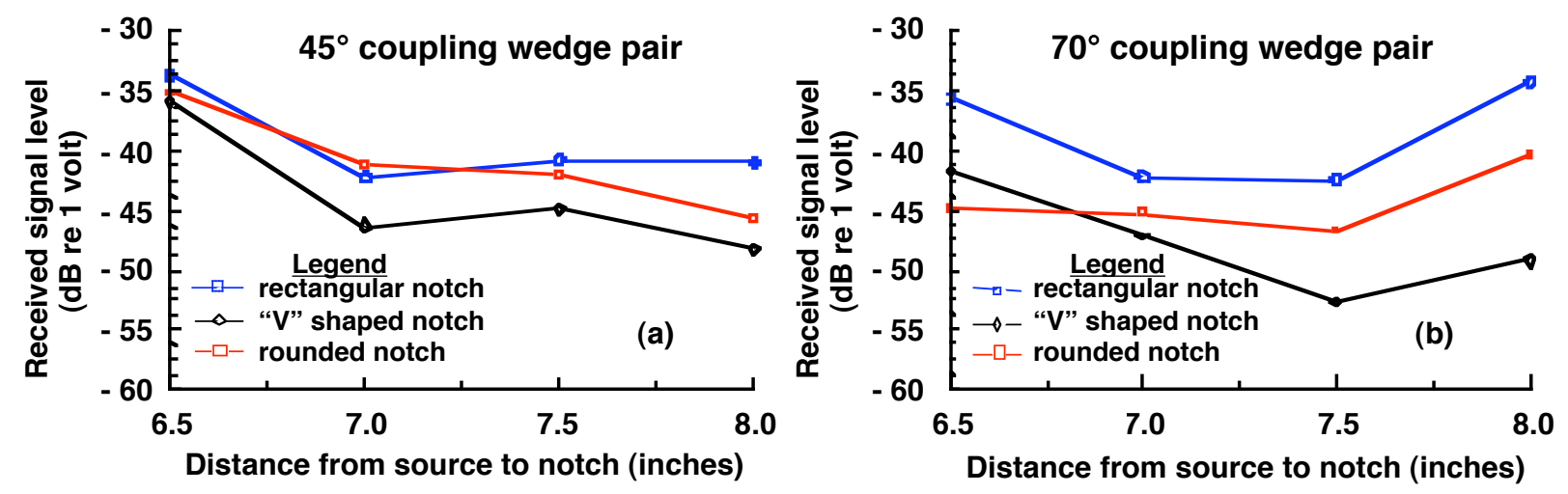

Fig. 3.25 Results of degradation shape study.

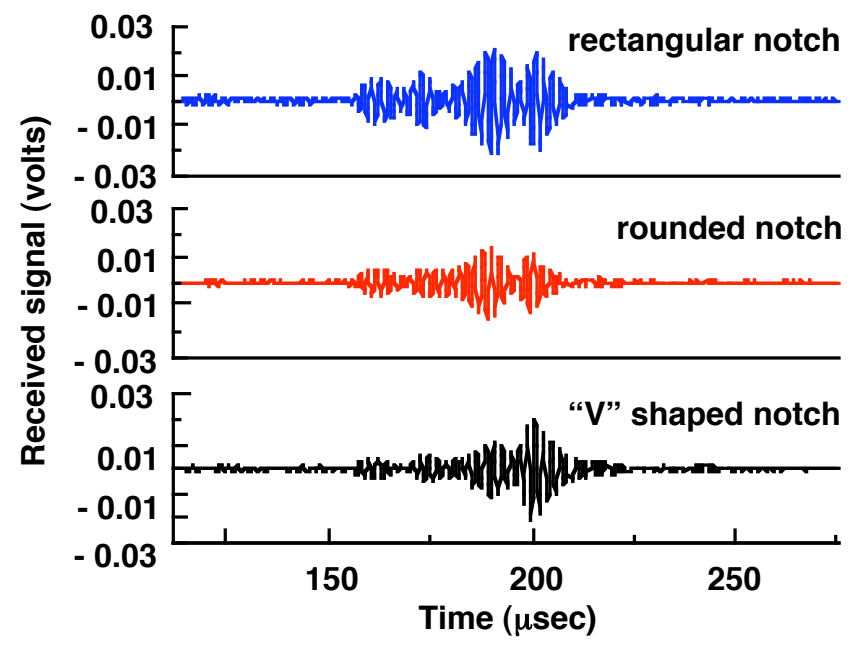

Fig. 3.26 Time-windowed returns from different notch geometries. 


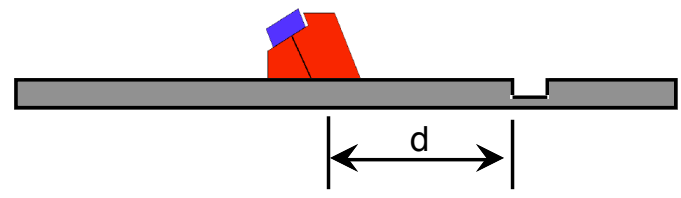

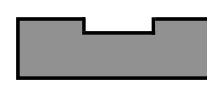

notch 1

$(4 \mathrm{~mm})$

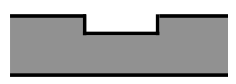

notch 2

$(8 \mathrm{~mm})$

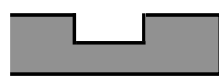

notch 3

$(12 \mathrm{~mm})$

Fig. 3.27 Test setup for degradation depth study
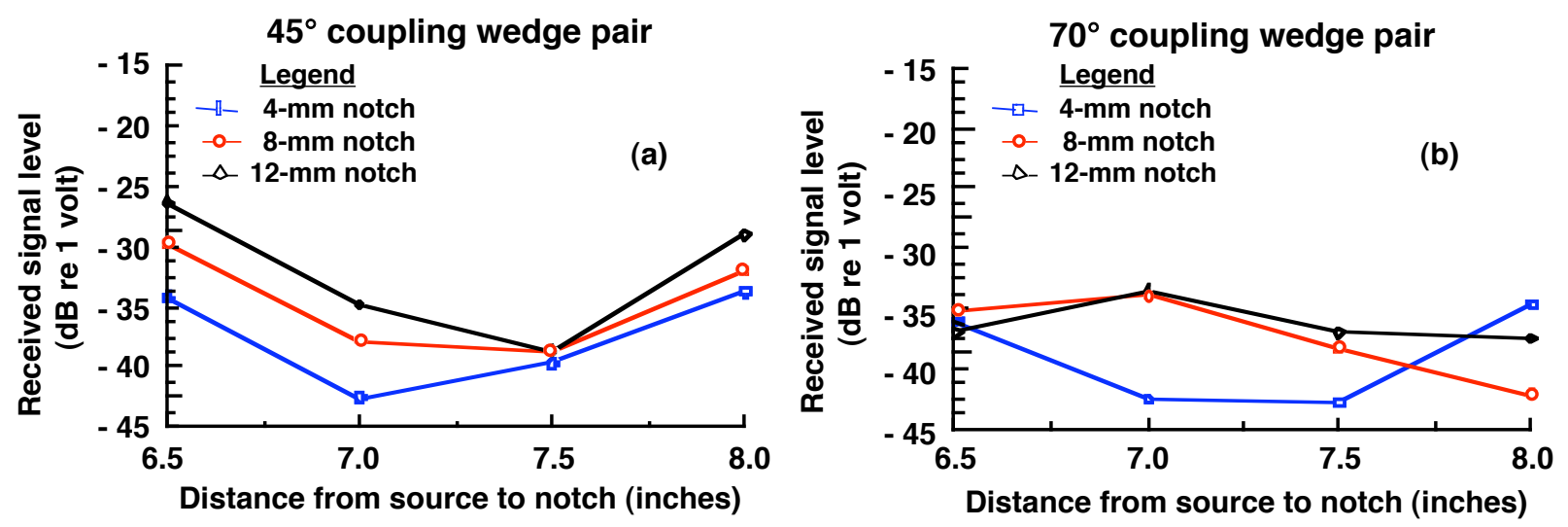

Fig. 3.28 Results of degradation depth study.

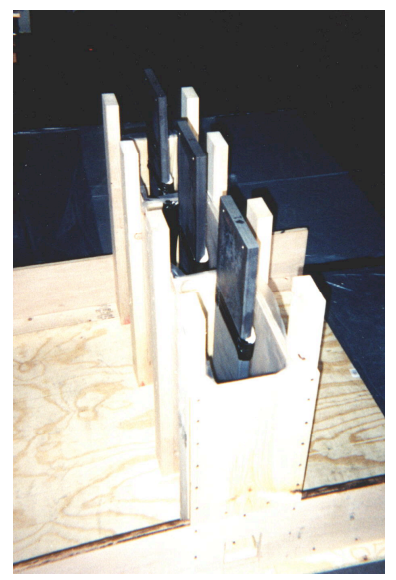

Fig. 3.29 Molds for embedding portions of steel plates in concrete. 


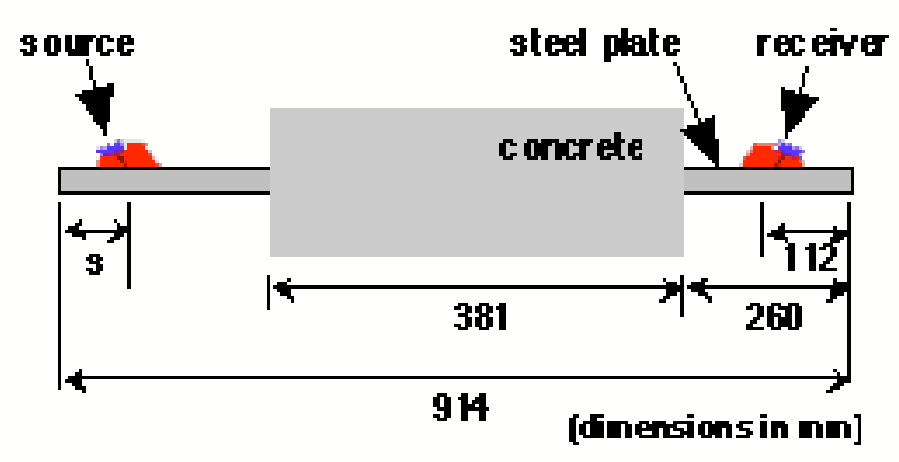

Fig. 3.30 Test setup for concrete effects tests.
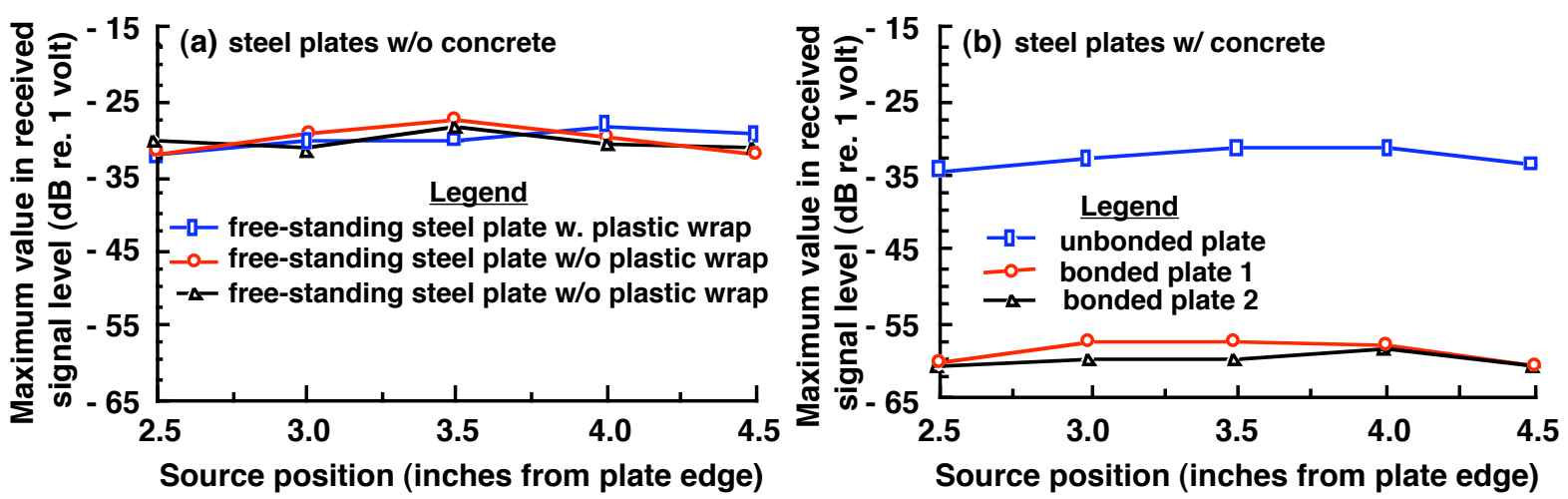

Fig. 3.31 Transmitted signal level: (a) free-standing steel plates and

(b) steel plates embedded in concrete over part of their length.

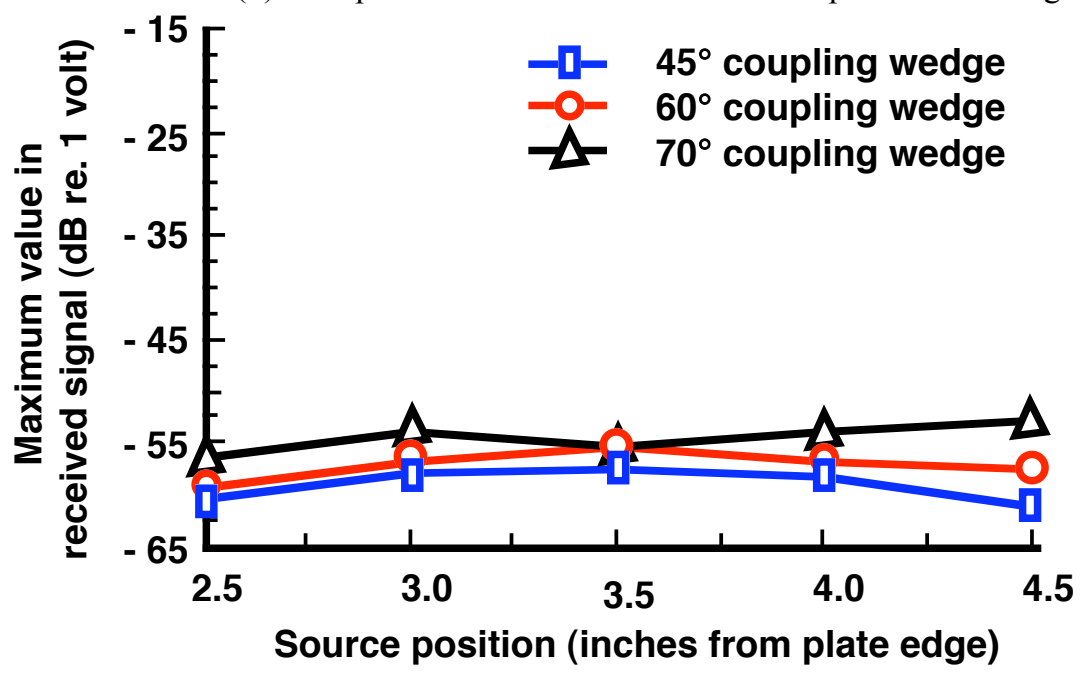

Fig. 3.32 Effect of coupling wedge angle on transmitted signal levels for a bonded steel plate embedded in concrete over part of its length. 


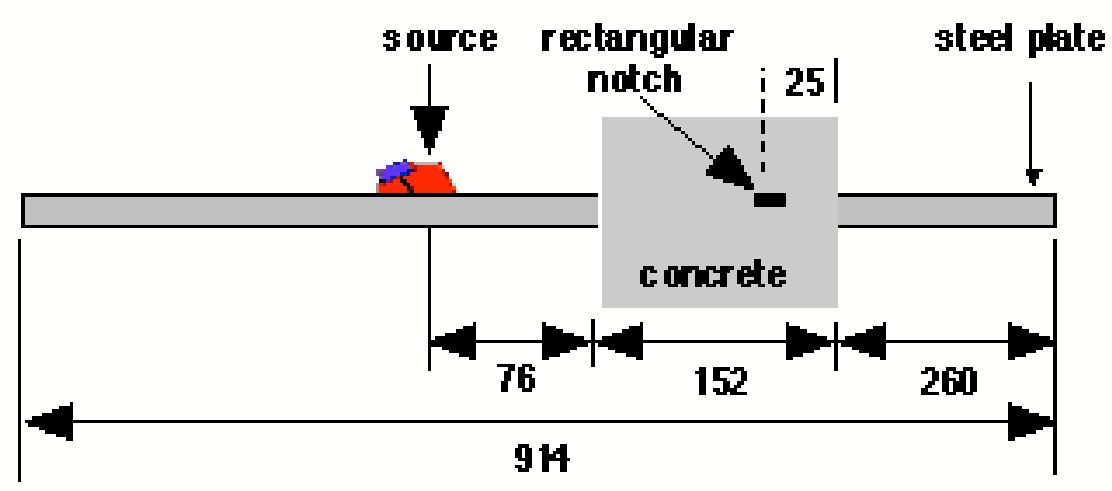

Fig. 3.33 Test setup for simulated field conditions to investigate role of competing signals.

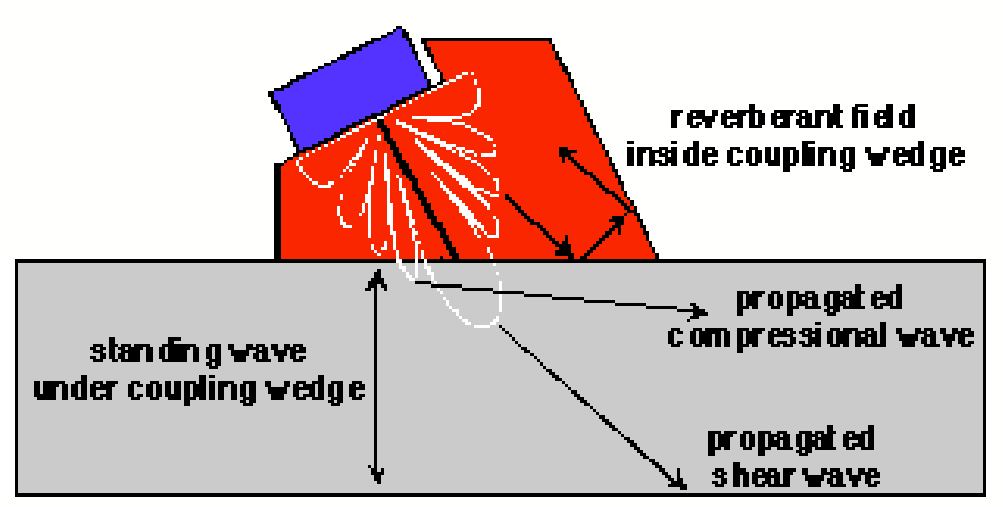

Fig. 3.34 Mechanisms of source "self noise."

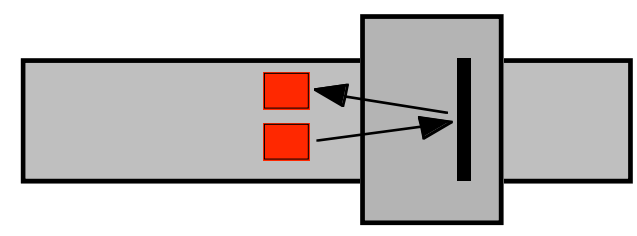

Fig. 3.35 Test setup for bistatic measurements to eliminate "self noise." 


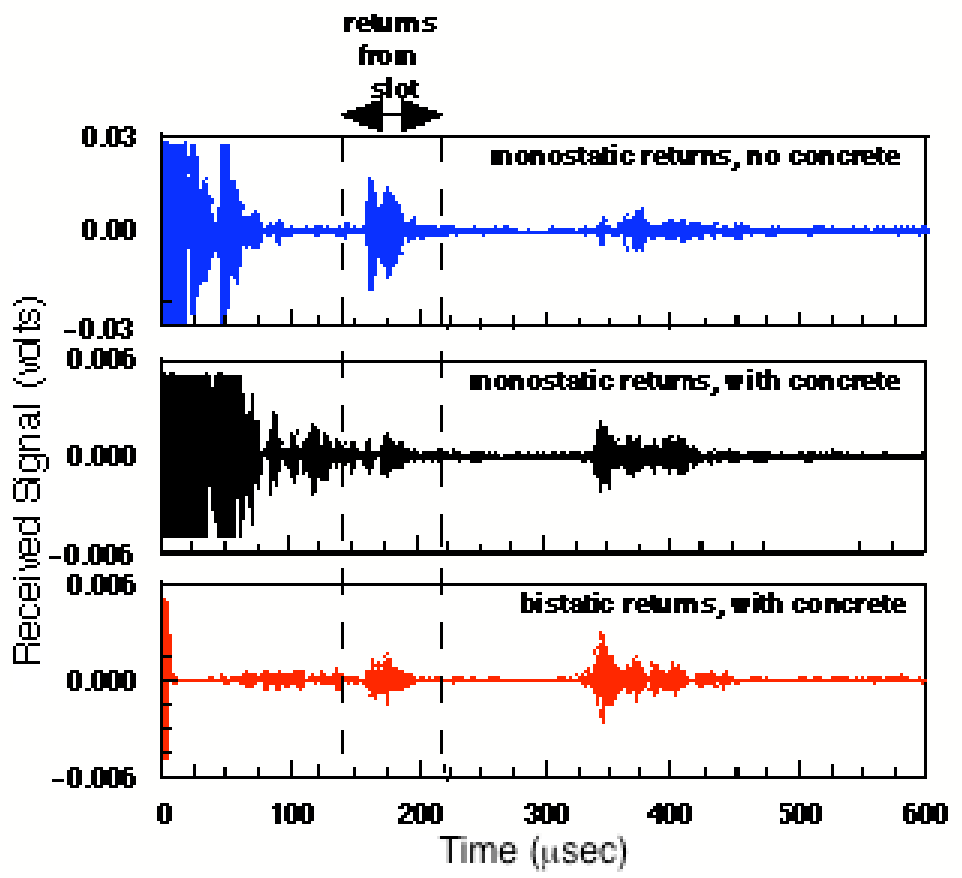

Fig. 3.36 Time histories of reflected signals from rectangular notch for three different conditions.

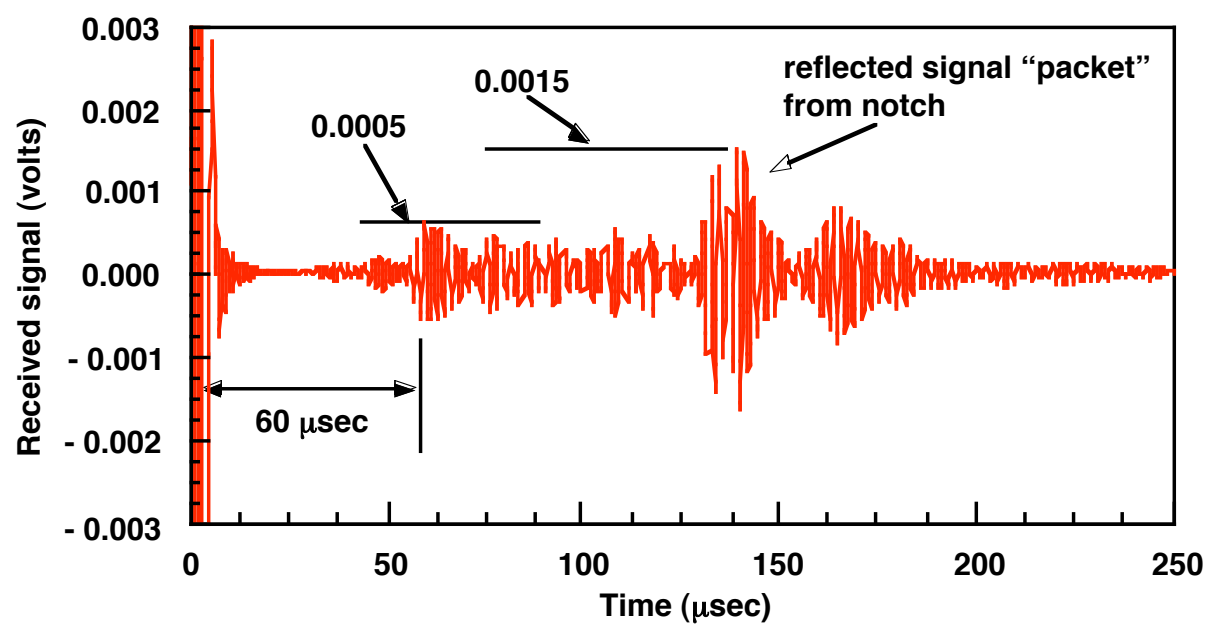

Fig. 3.37 Bistatic measured return from rectangular notch in a bonded steel plate embedded in concrete over part of its length. 


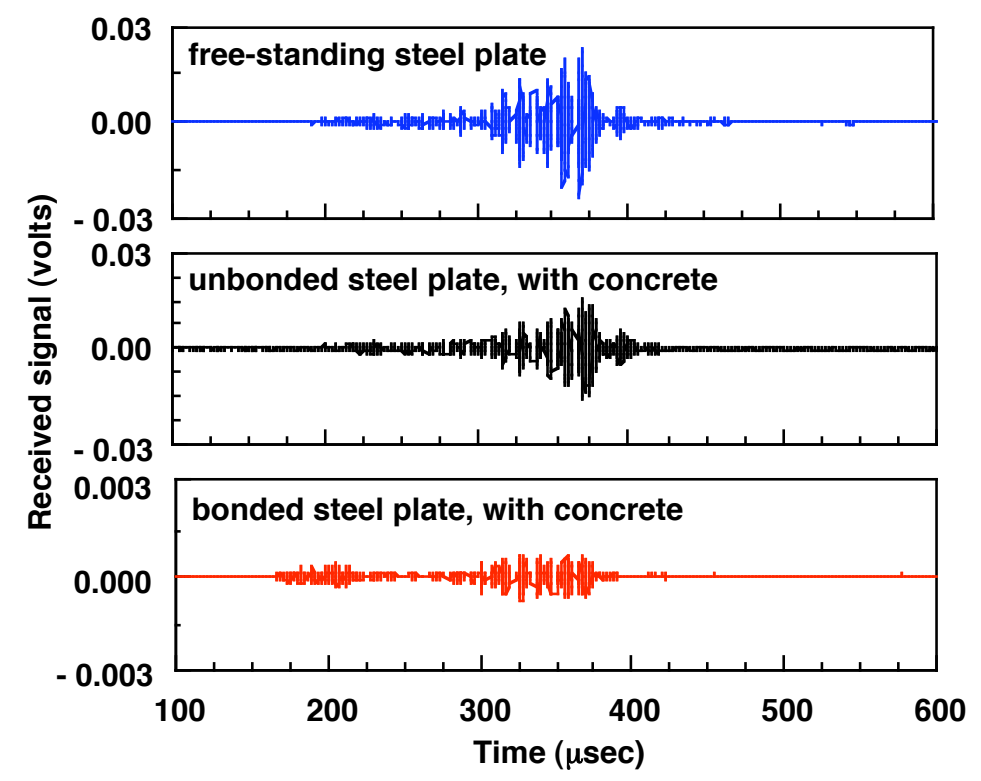

Fig. 3.38 Time histories of signals transmitted through free-standing steel plate, unbonded steel plate with concrete, and bonded steel plate with concrete.

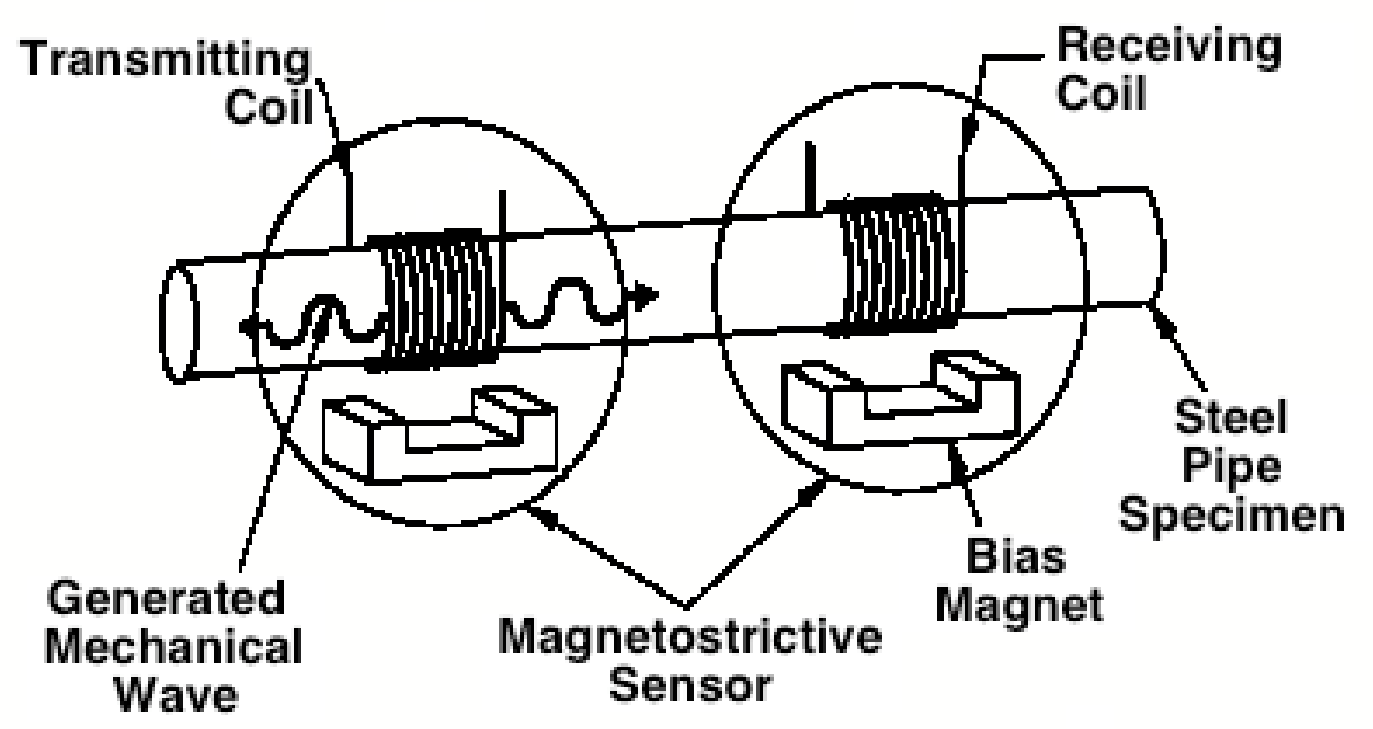

Fig. 3.39 Schematic of magnetostrictive sensor setup for generation and detection of guided waves in pipes. 

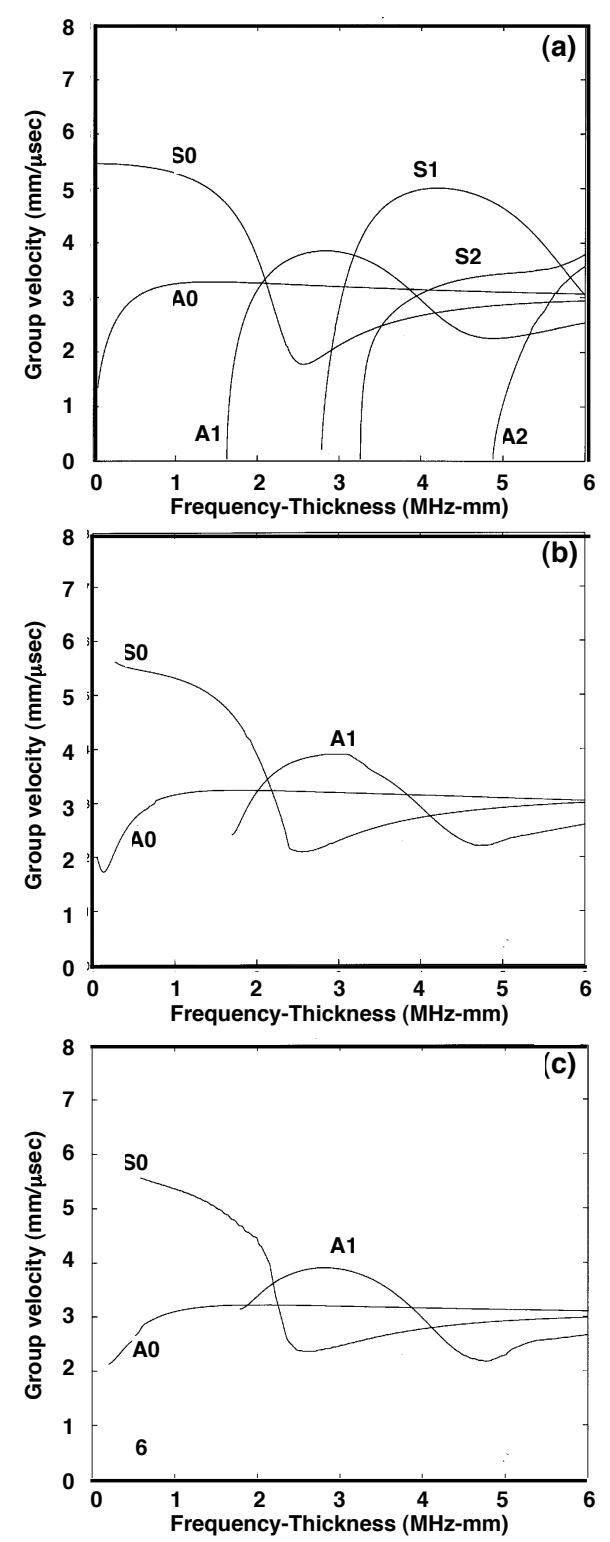

Fig. 3.40 Calculated dispersion curves for longitudinal guided waves in a plate for three conditions: (a) plate is free, (b) plate is backed by concrete on one side, (c) plate is backed by concrete on both sides.

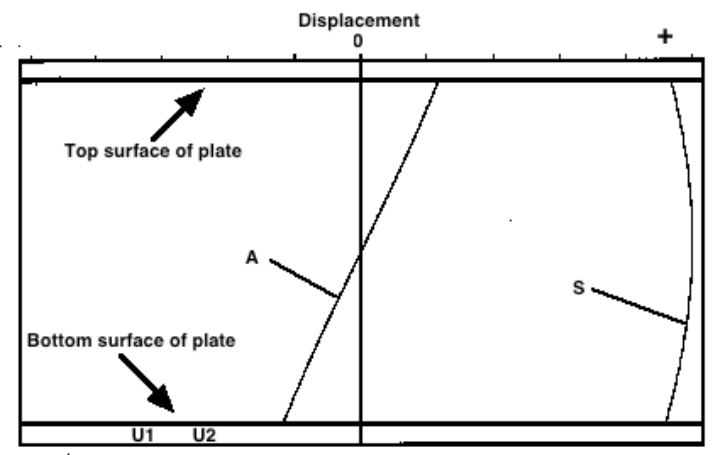

Fig. 3.41 Displacements of antisymmetric (A) and symmetric (s) wave modes across plate thickness. 

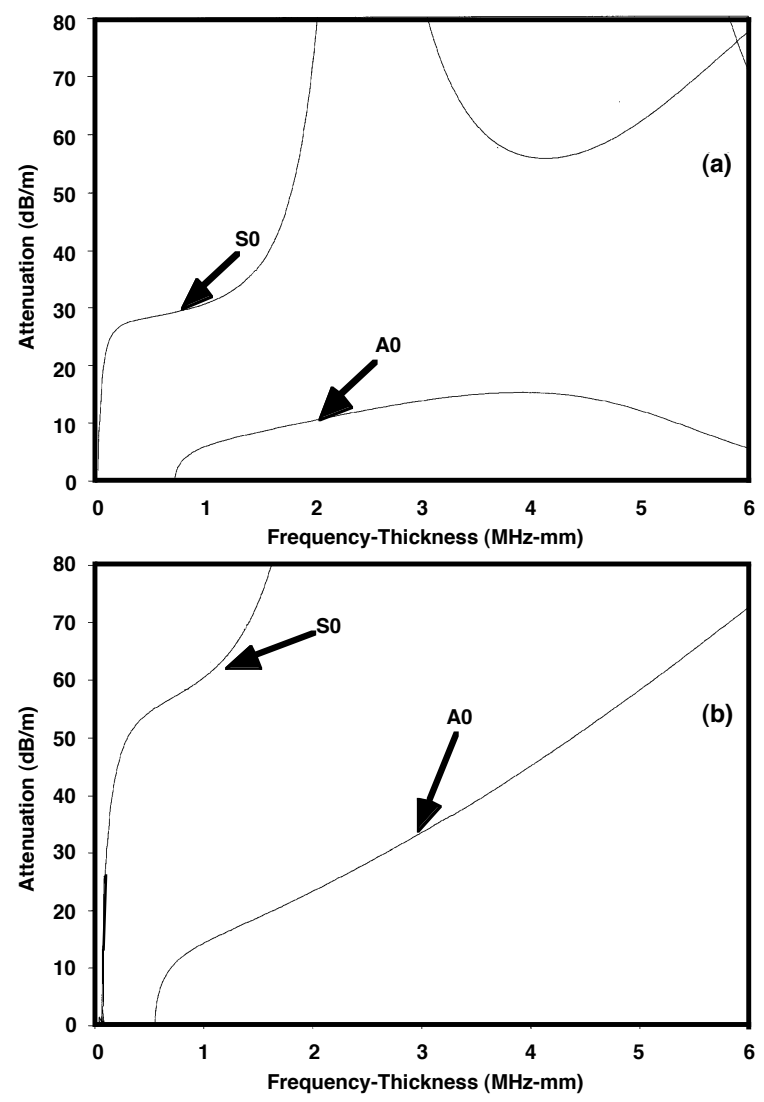

Fig. 3.42 Calculated wave attenuation for: (a) plate backed by concrete on one side and (b) plate backed by concrete on both sides.

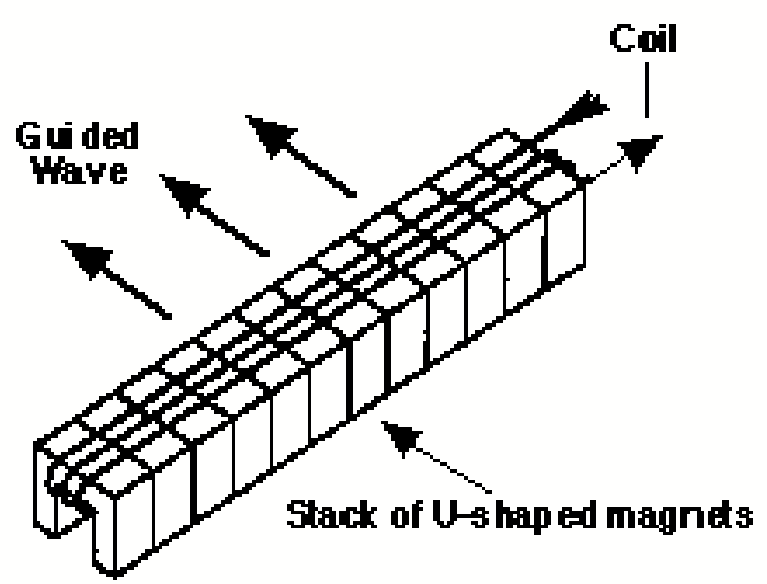

Fig. 3.43 Schematic of a coil wound around a stack of U-shaped magnets. 


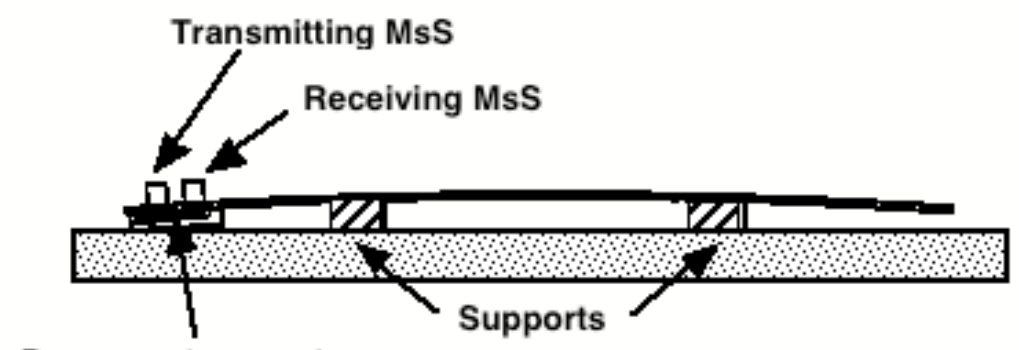

Permanent magnets

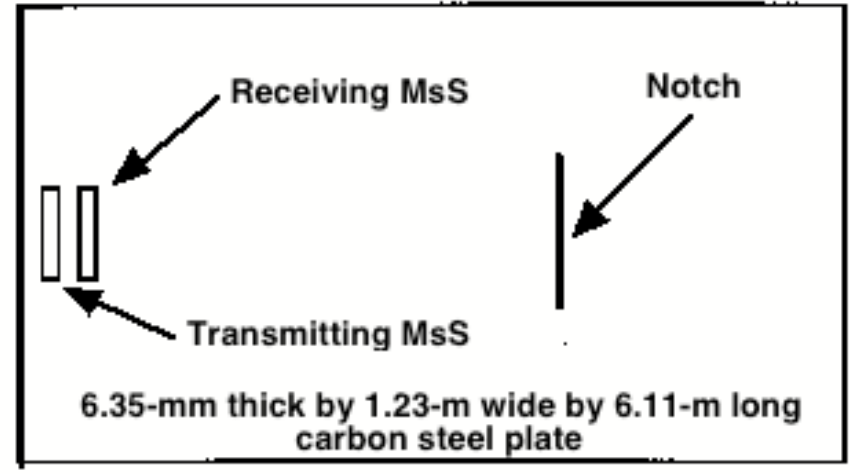

Fig. 3.44 Schematic of plate test article with setup for MsS probes. (Permanent magnets are arranged on bottom of plate for convenience).

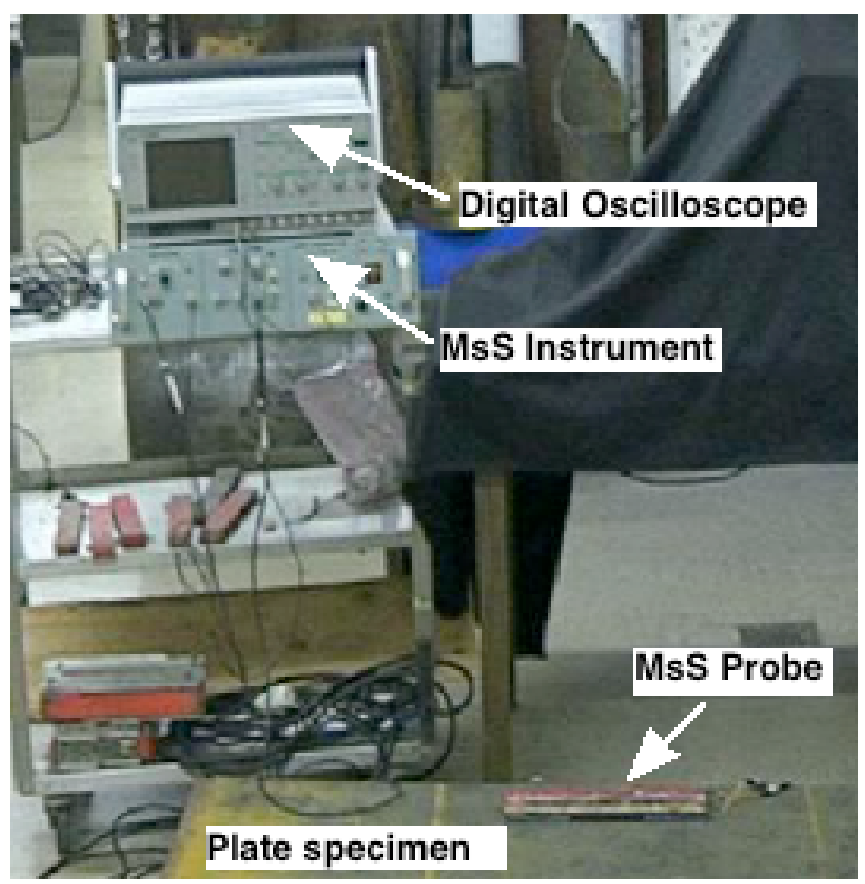

Fig. 3.45 Photograph of the overall experimental arrangement 


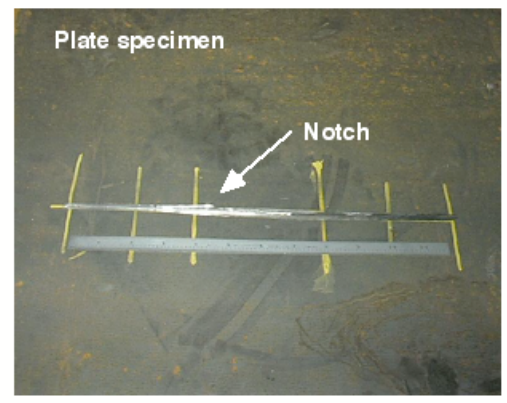

Fig. 3.46 Photograph of the 30-cm-long notch in plate specimen.

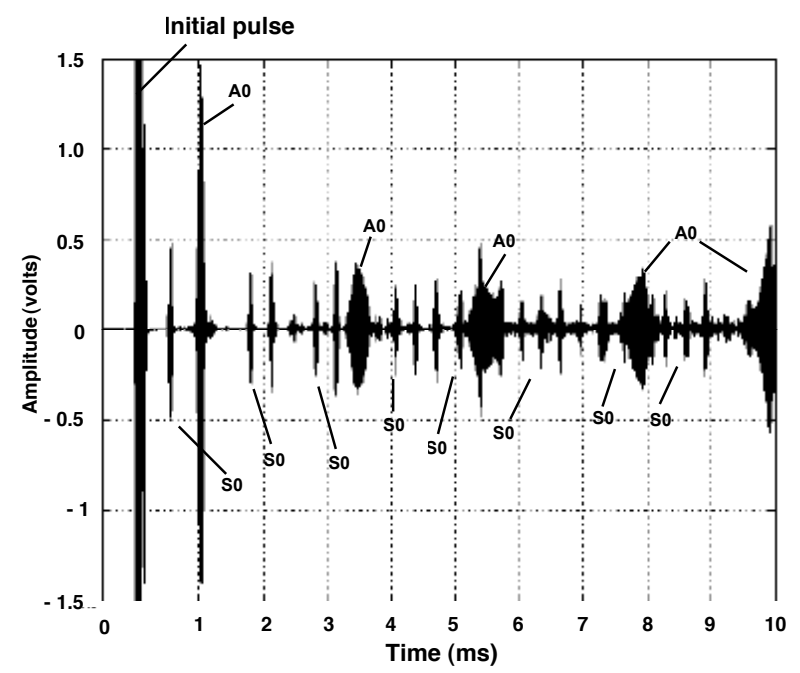

Fig. 3.47 MsS data from plate specimen using pitch-catch technique.

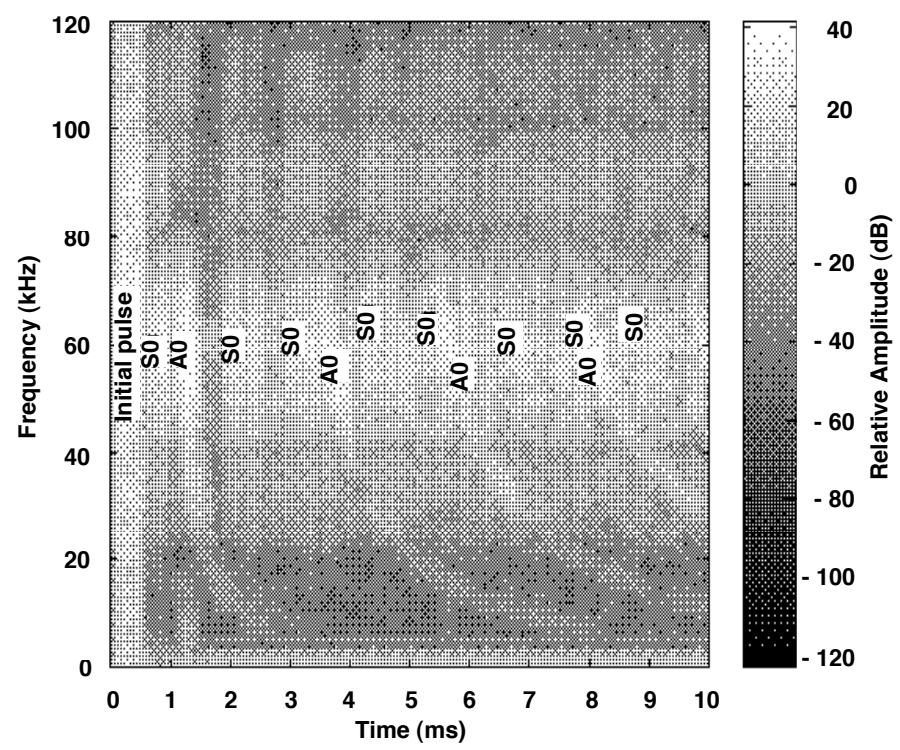

Fig. 3.48 Time-frequency representation of data in Fig. 3.47 obtained by using short-time fourier transform (STFT). 


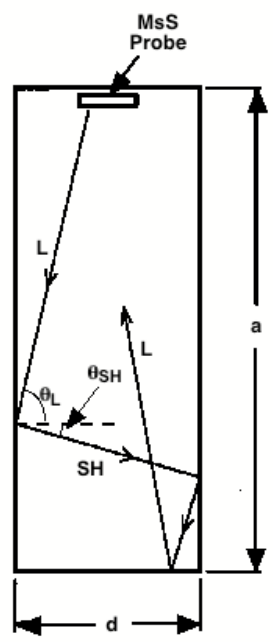

Fig. 3.49 Illustration of mode conversion at the lateral boundaries of a finite-sized plate.
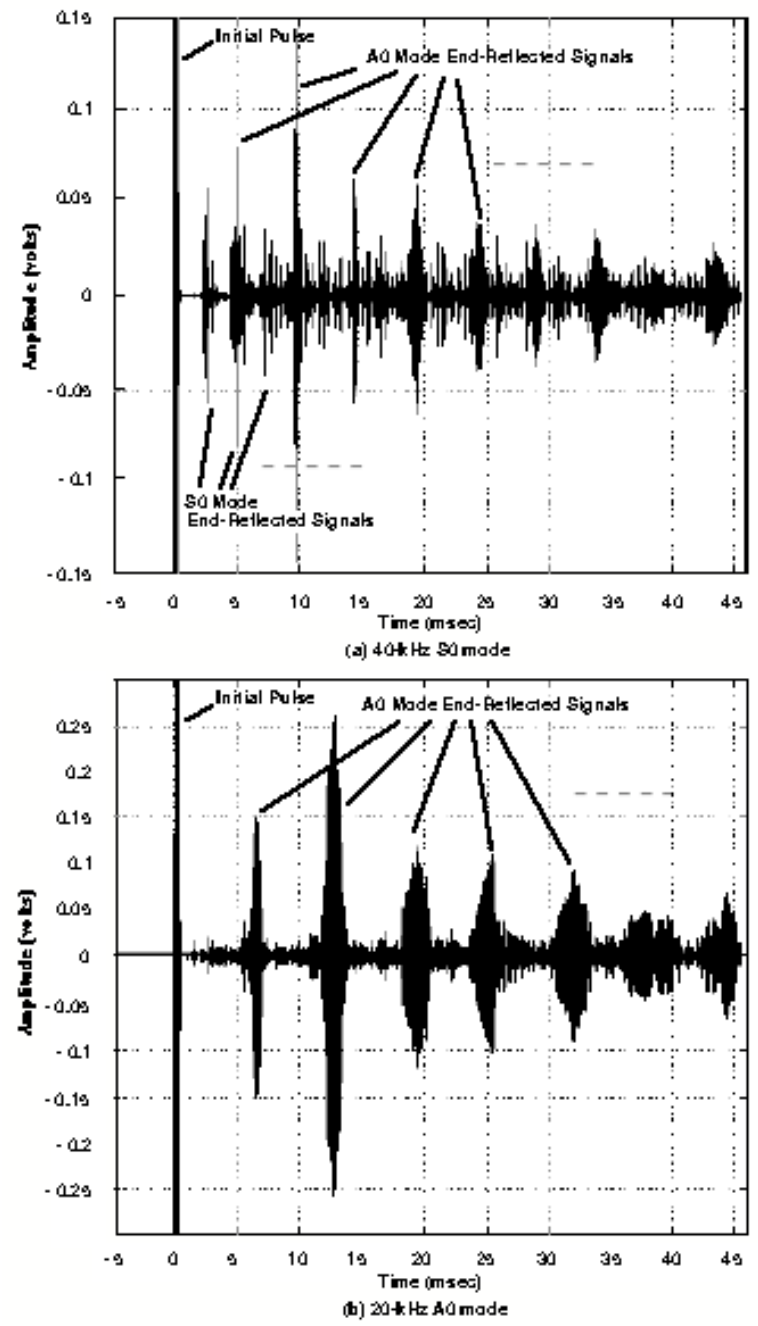

Fig. 3.50 MsS data using pulse-echo mode for steel plate prior to introducing a defect. Dotted lines indicate that signals continue to occur. 


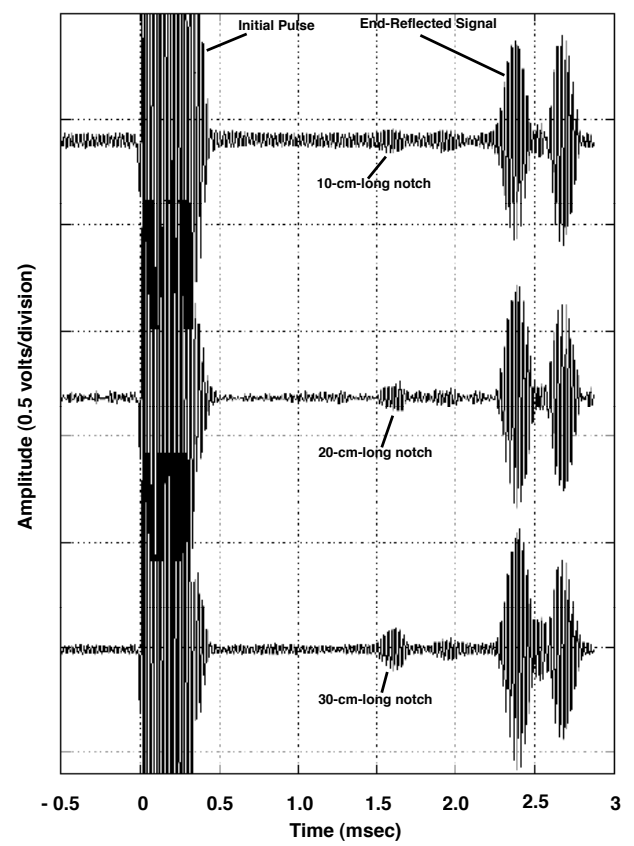

Fig. 3.51 Pulse-echo data for 40-kHz S0 mode obtained from plate containing different length notches.

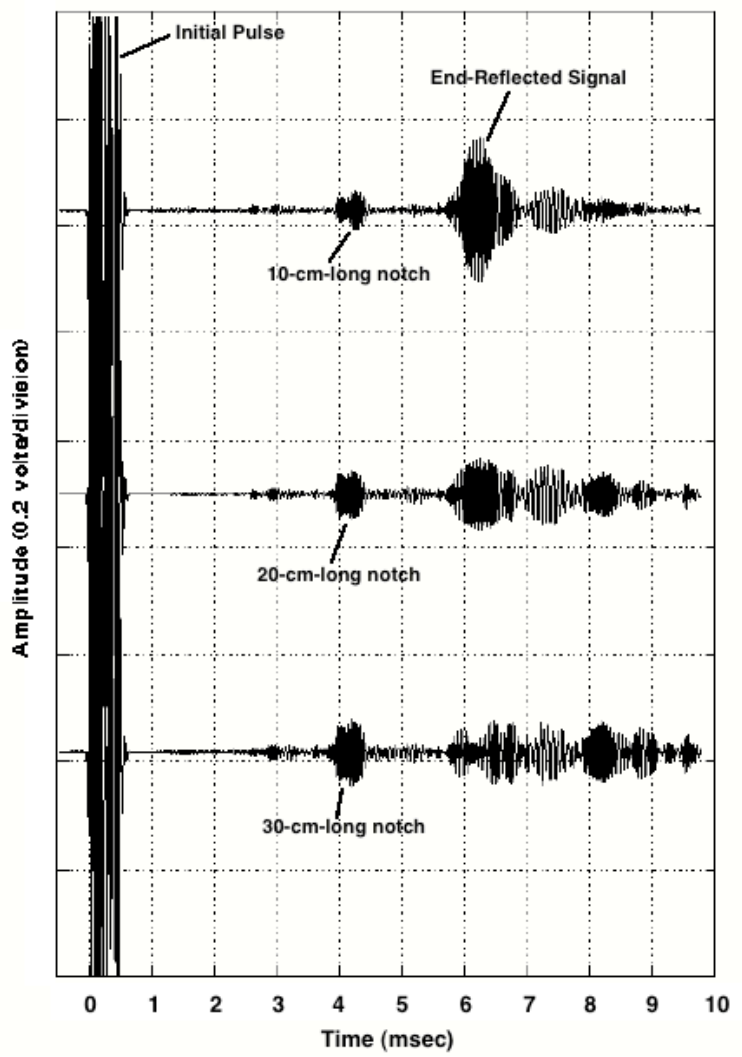

Fig. 3.52 Pulse-echo data for 20-kHz A0 mode obtained from plate containing different length notches. 

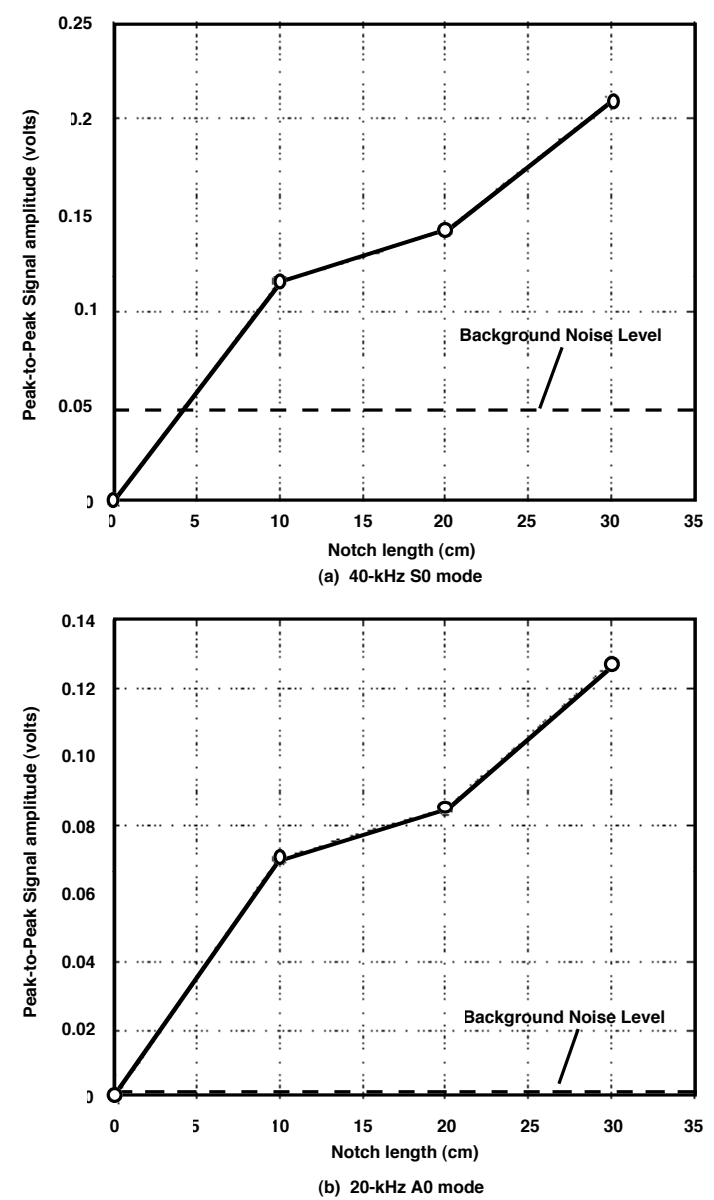

Fig. 3.53 Plots of signal amplitude versus notch length.

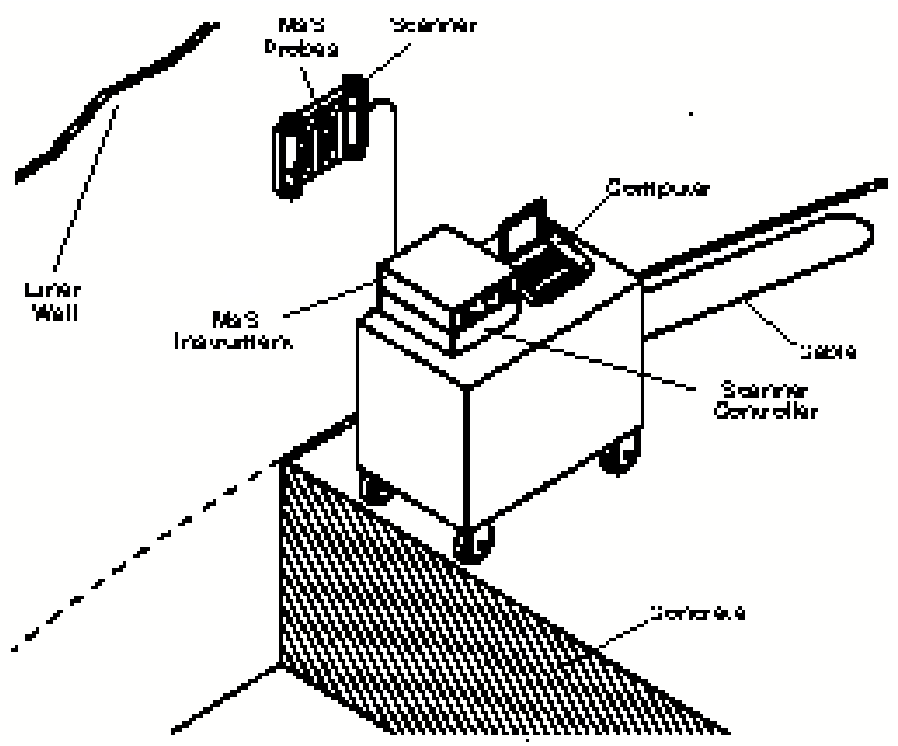

Fig. 3.54 Conceptual drawing of MsS system deployed for liner inspections. 


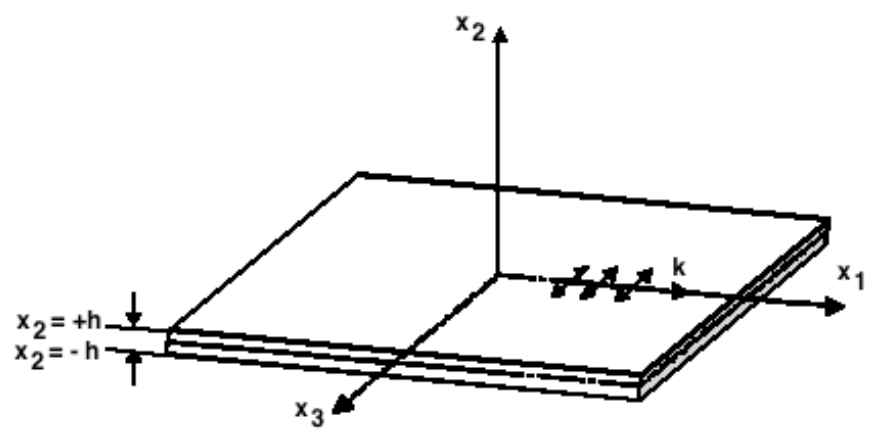

Fig. 3.55 SH wave propagation mode where propagation is along $\mathrm{x}_{1}$ and particle displacements are along $\mathrm{x}_{3}$.

(Particle displacements for Lamb wave propagation mode are in $\mathrm{x}_{1}-\mathrm{x}_{2}$ plane.)

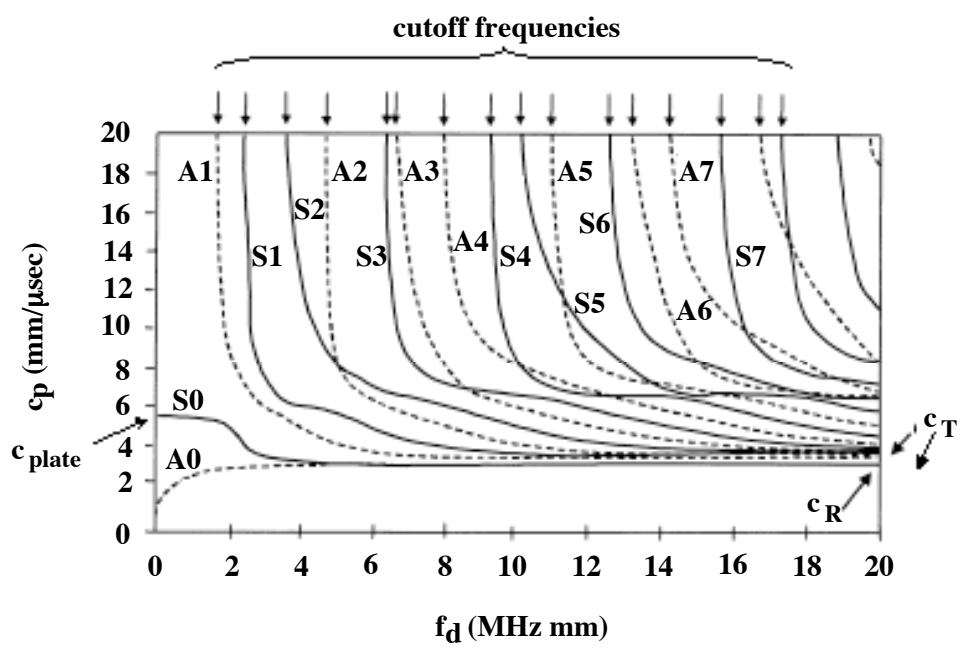

(a) Sample Lamb wave phase velocity dispersion curves

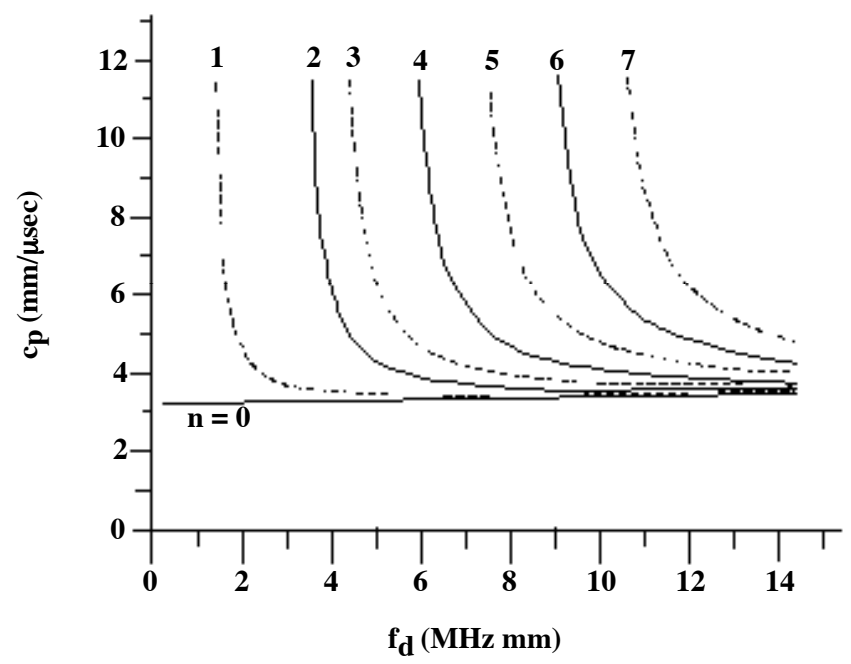

(b) Sample SH mode phase velocity dispersion curves: solid curves denote symmetric modes and dashed curves antisymmetric mode

Fig. 3.56 Simple dispersion curves for steel plate $\left(\mathrm{c}_{\mathrm{T}}=3.1 \mathrm{~m} / \mathrm{msec}\right)$. 


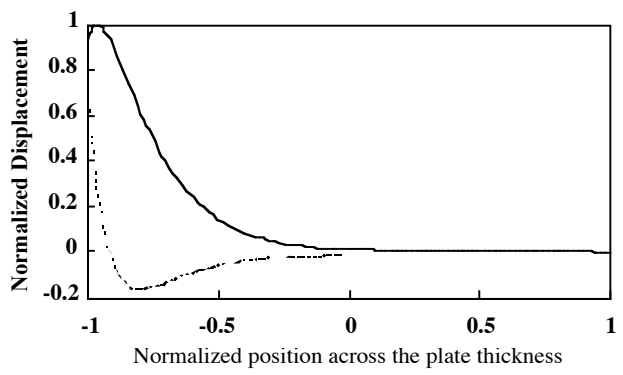

(a) Wave structure for the pseudo-surface wave mode

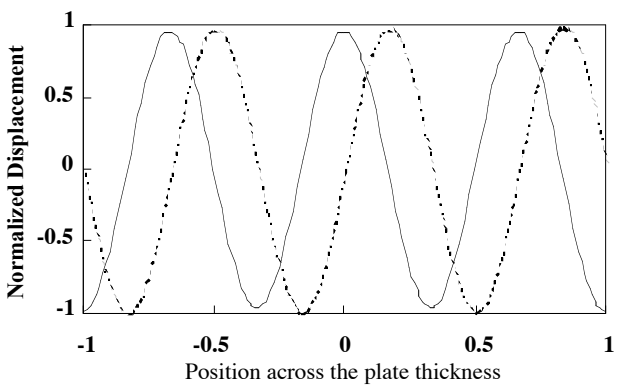

(b) Wave structure for the $\mathrm{A} 3$ mode

Fig. 3.57 Wave structure for the pseudo-surface mode and A3 mode at frequency of $565 \mathrm{kHz}$. (The plate thickness is $25.4 \mathrm{~mm}$. Solid line is out-of-plane displacement and dashed line is in-plane displacement.)

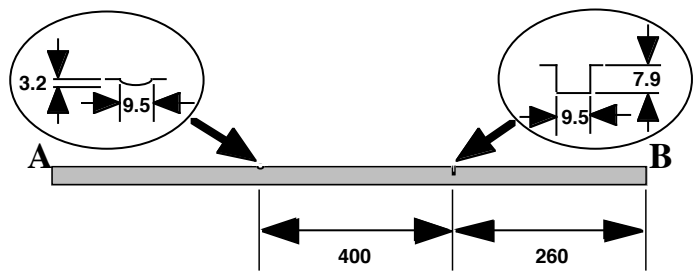

(a) Plate 1

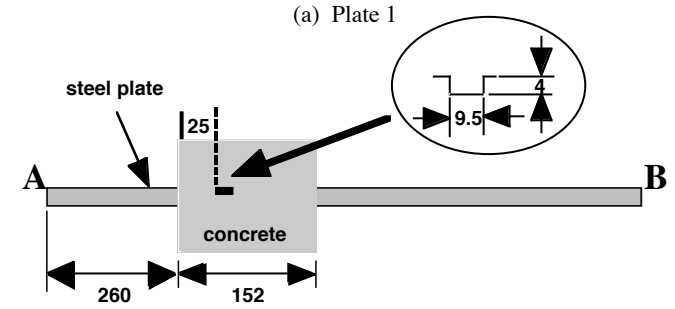

(b) Plate 2

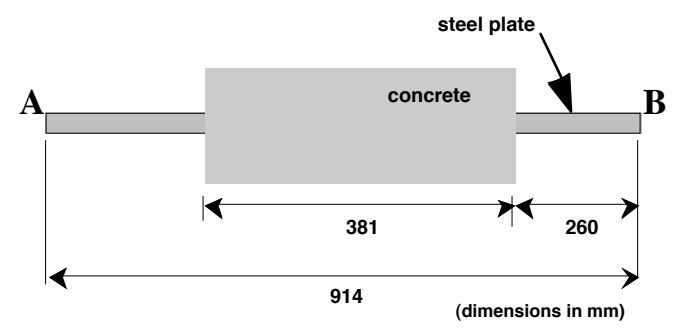

(c) Plate 3

Fig. 3.58 Schematics of plate specimens. 


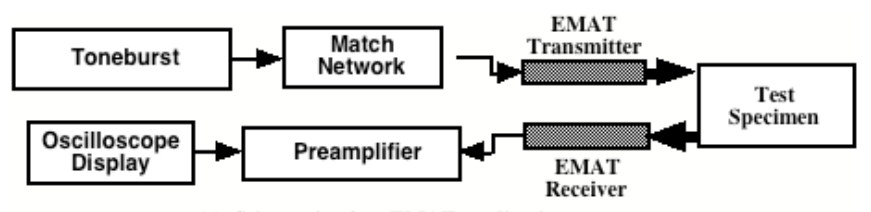

(a) Schematic of an EMAT application system.

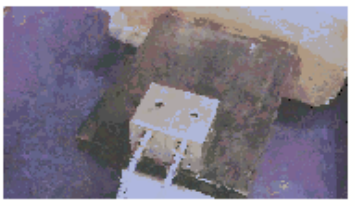

(b) An EMAT system for concrete inspection.

Fig. 3.59 Typical EMAT system and application.

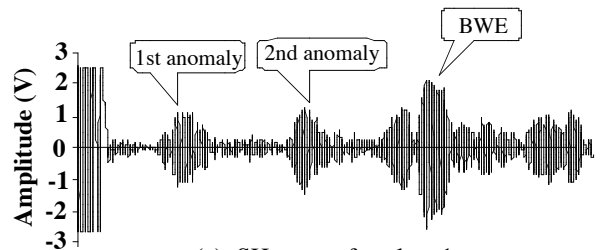

(a) $\mathrm{SH}$ waves for plate 1

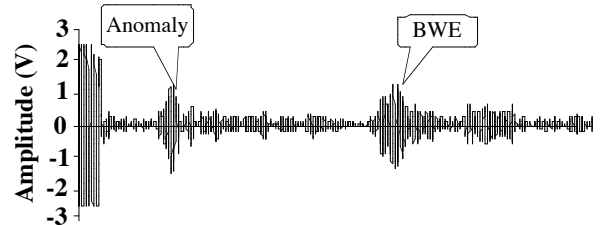

(b) $\mathrm{SH}$ waves for plate 2: transducer at position A top surface

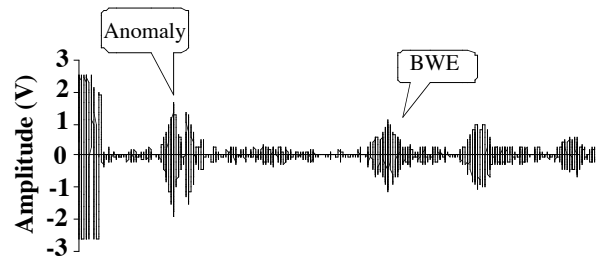

(c) $\mathrm{SH}$ waves for plate 2: transducer at position A bottom surface

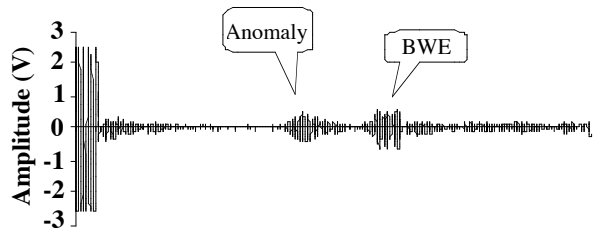

(d) $\mathrm{SH}$ waves for plate 2: transducer at position B top surface

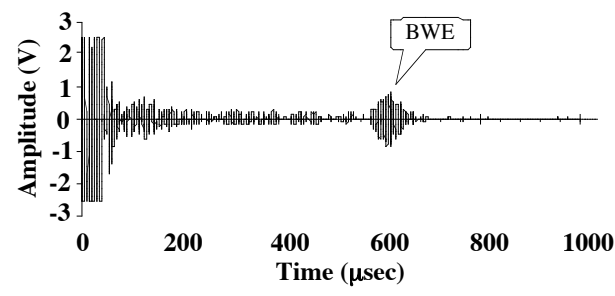

(e) $\mathrm{SH}$ waves for plate 3: transducer at position A top surface

Fig. 3.60 SH guided wave experimental results with EMAT SH system.

(Frequency $=240 \mathrm{kHz}$, nondispersive $\mathrm{SH}$ wave mode.) 


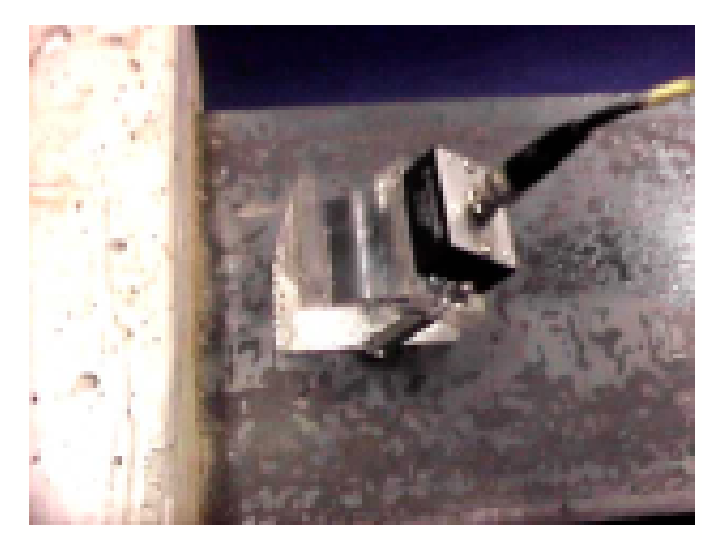

Fig. 3.61 Transducer mounted on wedge for Lamb wave excitation.

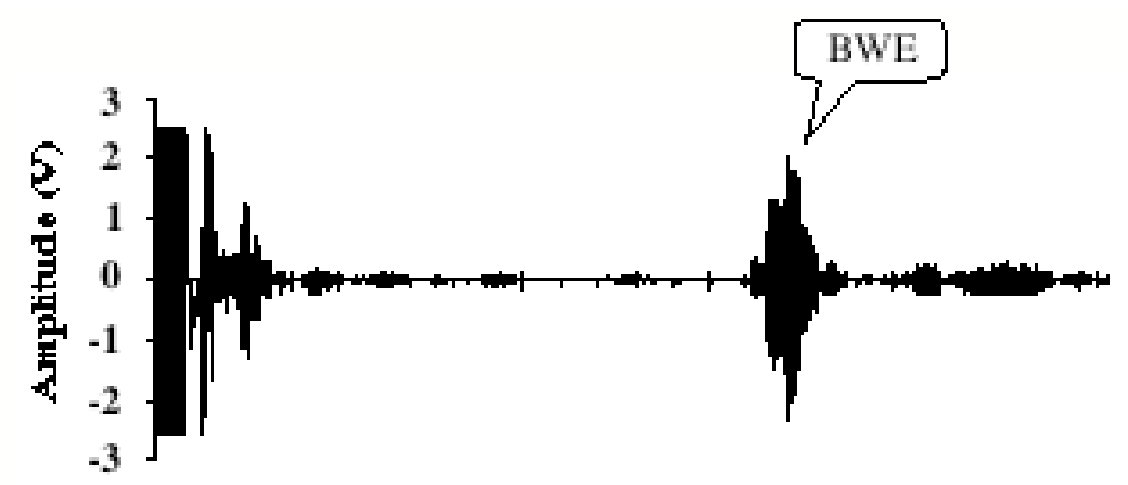

(a) Pulse echo signal plate 1: transducer at position A bottom surface

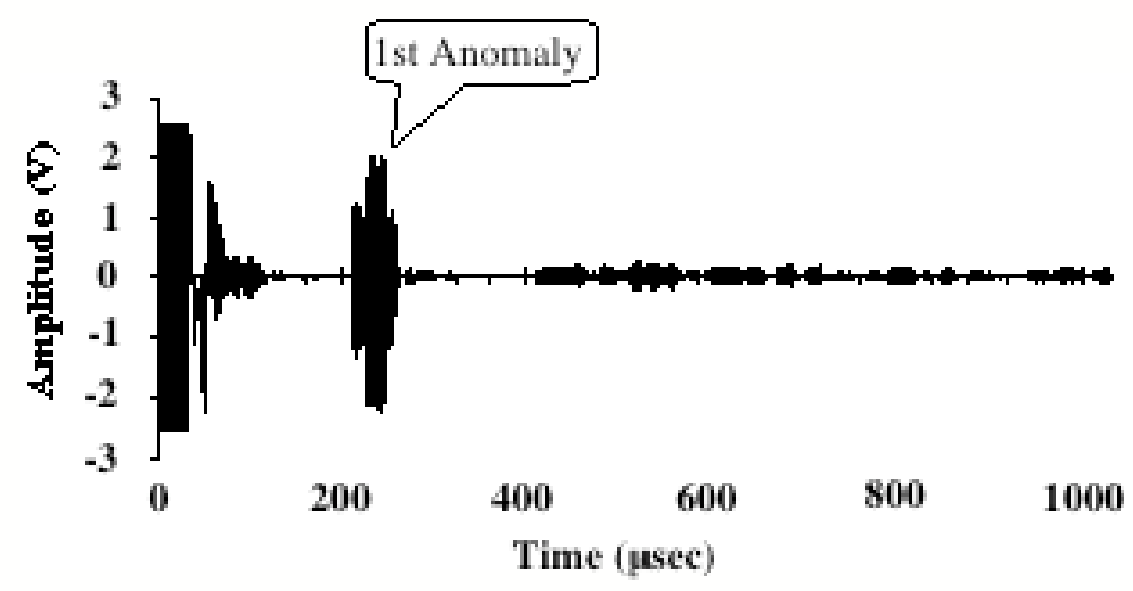

(b) Pulse echo signal plate 1: transducer at position A top surface

Fig. 3.62 Pseudo-surface Lamb wave mode for plate inspections. (Frequency $=565 \mathrm{kHz}$; wedge angle $=62^{\circ}$ ). 


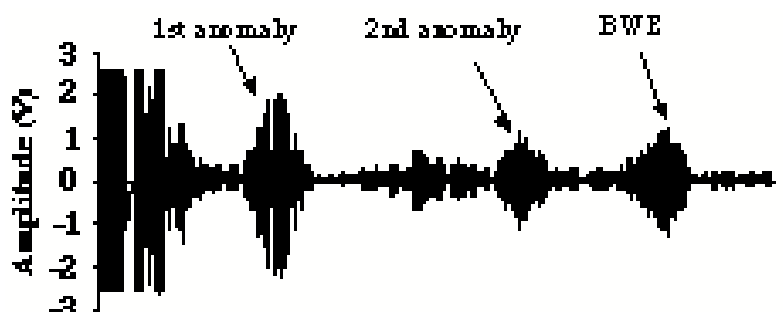

(a) Pu ke echosingl of A3 lambwav mole tor fote 1 banedu cer at pocition a bop as rtac

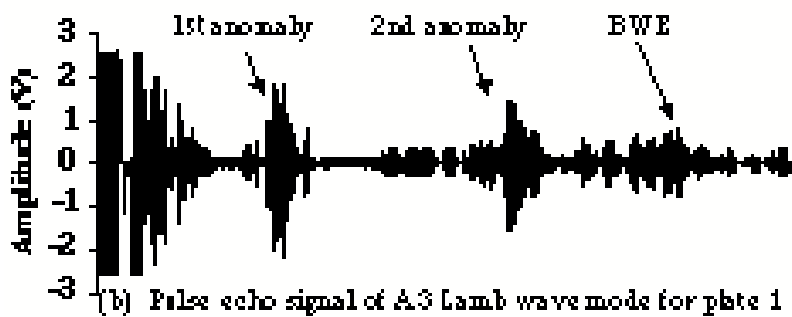
banedu cer al position A bottom surtac

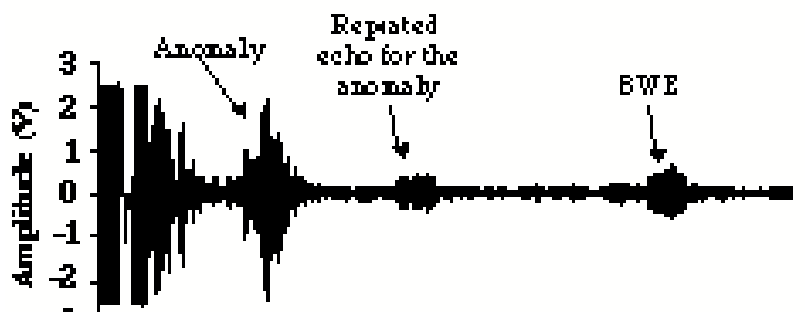

(c) Puke echosingl of A3 lambwave mole tor fore 2 banedu cer at position a top ou rtac

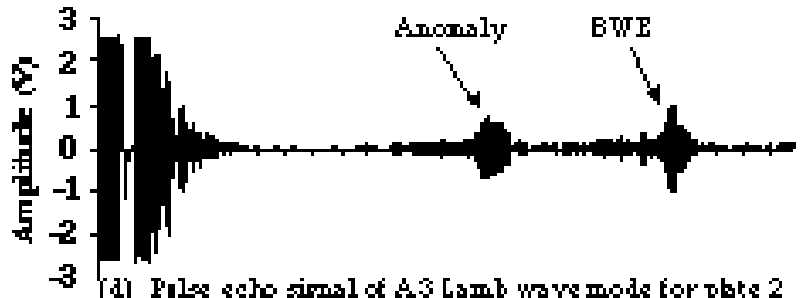
bansdu eer at position B top surtac

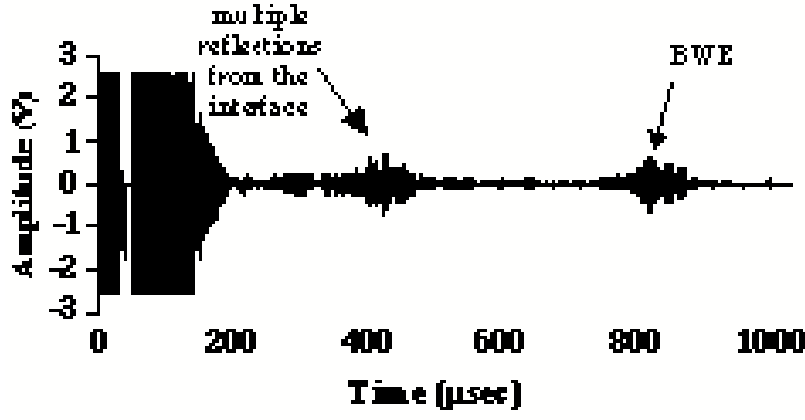

(e) Pube echosignol of A3 lamb wave mole tor fore 3 banedu cer at position $A$ top ou rtac

Fig. 3.63 Pulse-echo signal of A3 Lamb wave mode for plate 3: transducer at position A top surface.

$\left(\right.$ Frequency $=565 \mathrm{kHz}$, wedge angle $=38^{\circ}$.) 


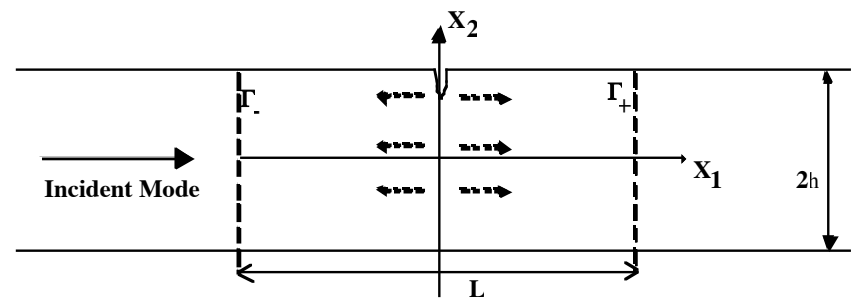

(a) Plate model, solid and dashed arrows show incident and scattering modes, respectively. (Area contained between $\Gamma \pm$ lines is used for BEM modeling)

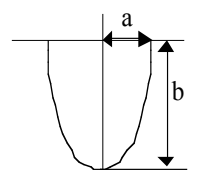

(b) Prameters for an elliptical-shaped flaw

Fig. 3.64 Boundary Element Method (BEM) wave scattering model.

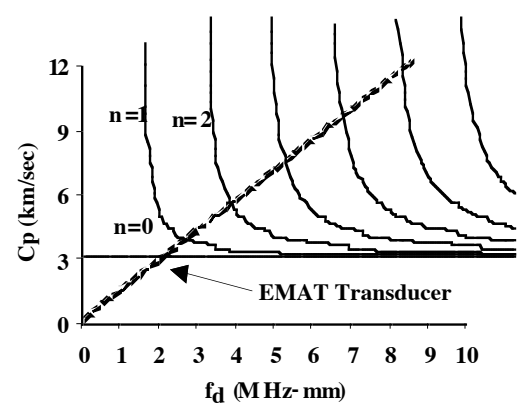

(a) Phase velocity dispersion curves

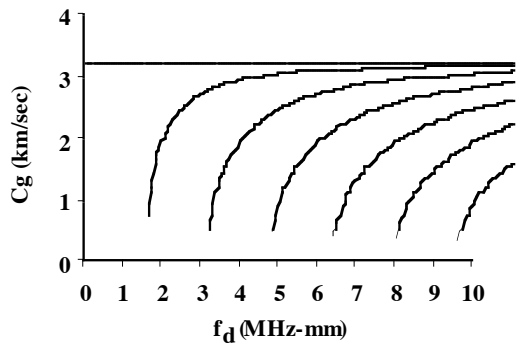

(b) Group velocity dispersion curves

Fig. 3.65 SH phase and group velocity dispersion curves for 10-mm-thick steel plate.

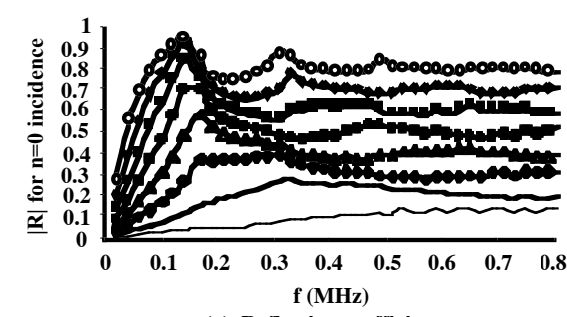

(a) Reflection coefficients

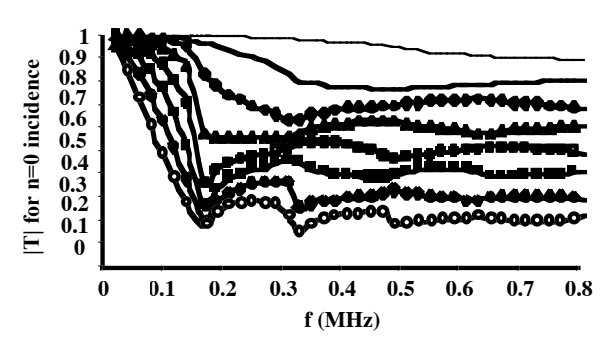

(b) Transmission coefficients

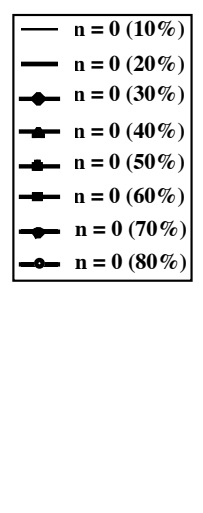

Fig. 3.66 Reflection and transmission coefficients. ( $N=0$ mode under $\mathrm{n}=0$ incident mode for 0.3 -mm elliptical notch width and 10 to 80 percent through-plate thickness depth.) 


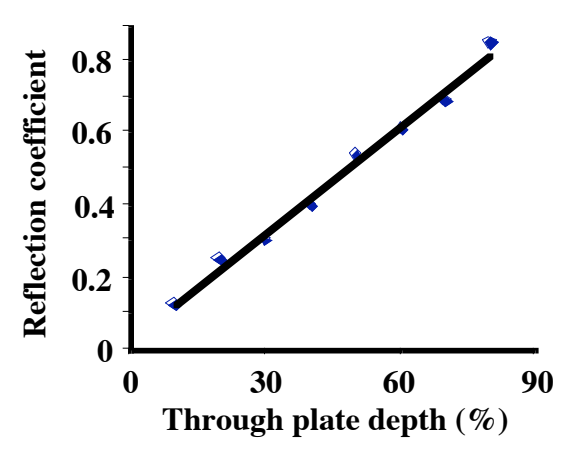

(a) Reflection

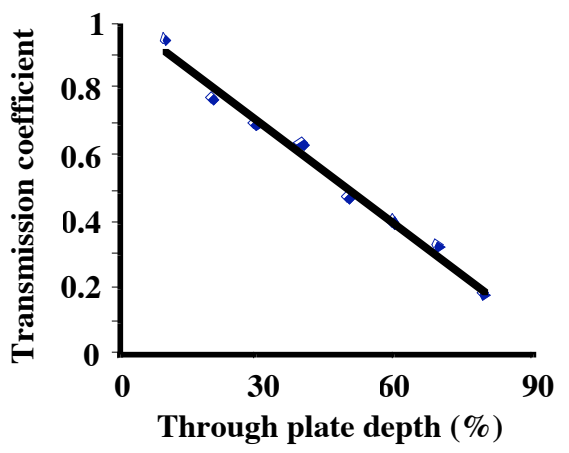

(b) Transmission

Fig. 3.67 Reflection and transmission coefficients showing linear increase in amplitude with percent through-wall depth. $(\mathrm{n}=0$ mode under $\mathrm{n}=0$ incident mode at frequency of $0.5 \mathrm{MHz}$.)

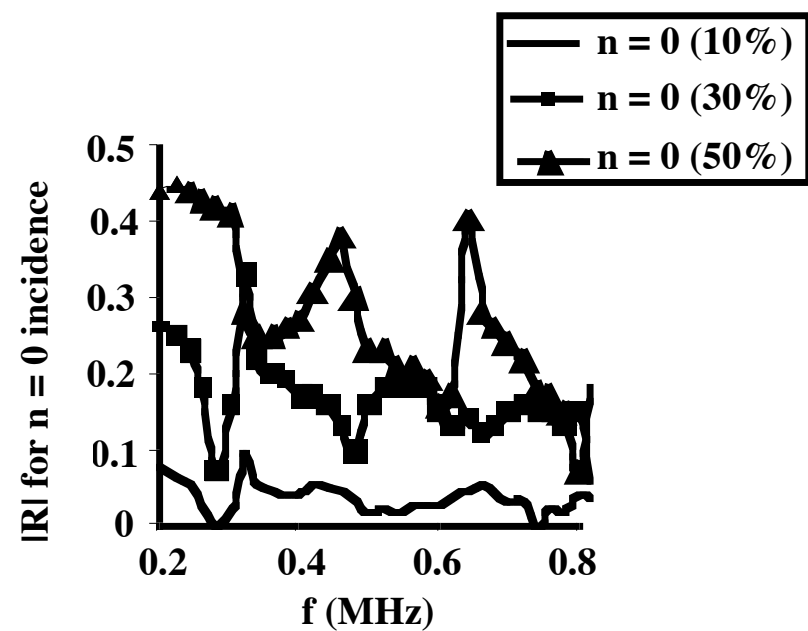

(a) Reflection

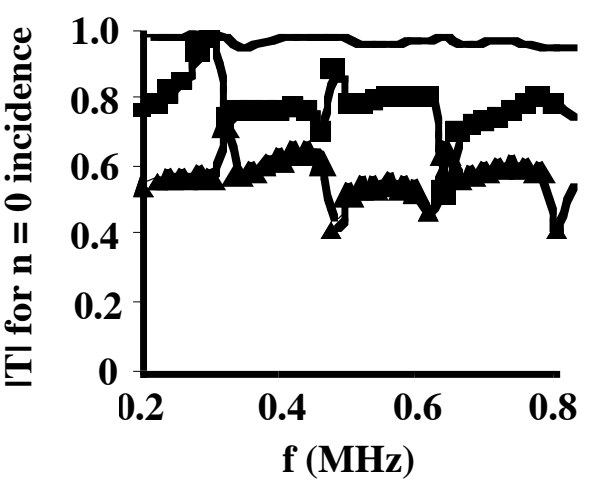

(b) Transmission

Fig. 3.68 Reflection and transmission coefficients for 6.35 -mm elliptical defect width and either 10,30 or 50 percent through-plate thickness depth. $(\mathrm{n}=0$ mode under $\mathrm{n}=0$ incident mode.)

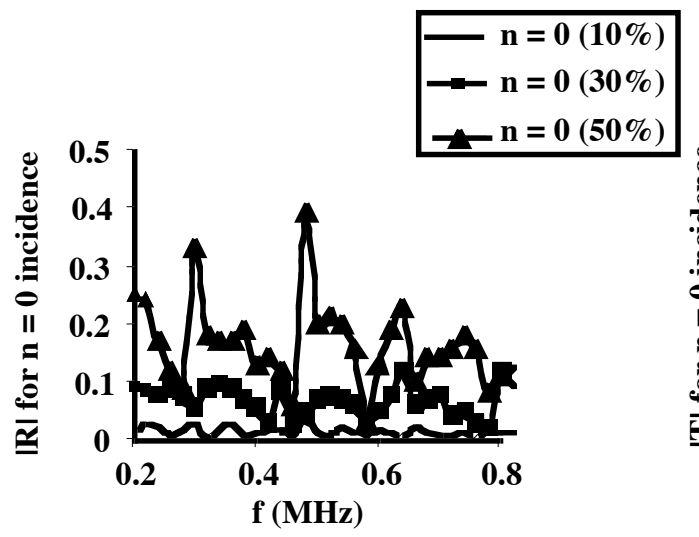

(a) Reflection

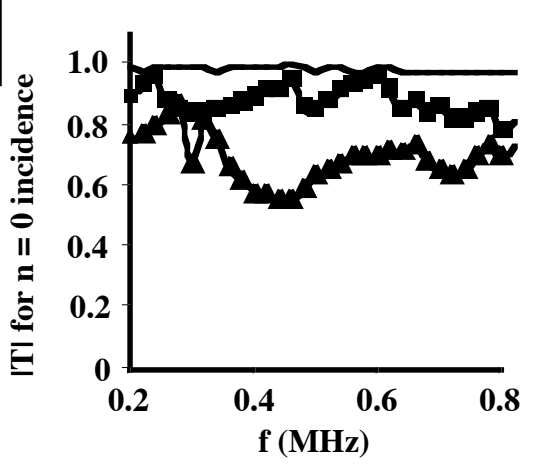

(b) Transmission

Fig. 3.69 Reflection and transmission coefficients for 12.7-mm elliptical defect width and either 10,30 or 50 percent through-plate thickness depth. $(\mathrm{N}=0$ mode under $\mathrm{n}=0$ incident mode.) 


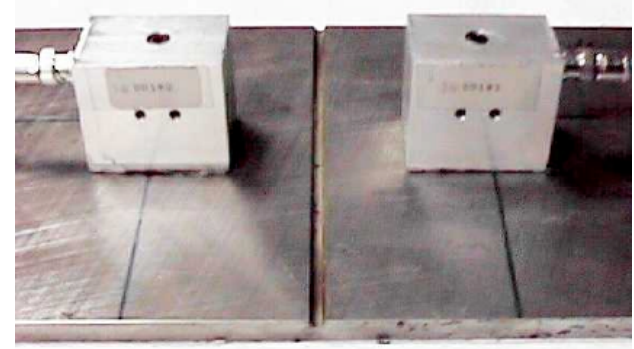

(a) Through transmission mode; EMATs are 3 in. away from each other and $1.5 \mathrm{in}$. from center groove.

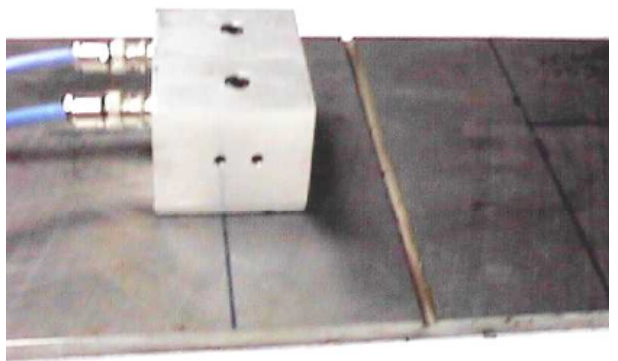

(b) Pulse-echo mode; EMATs are 1.5 in. away from center groove.

Fig. 3.70 Experimental setup.

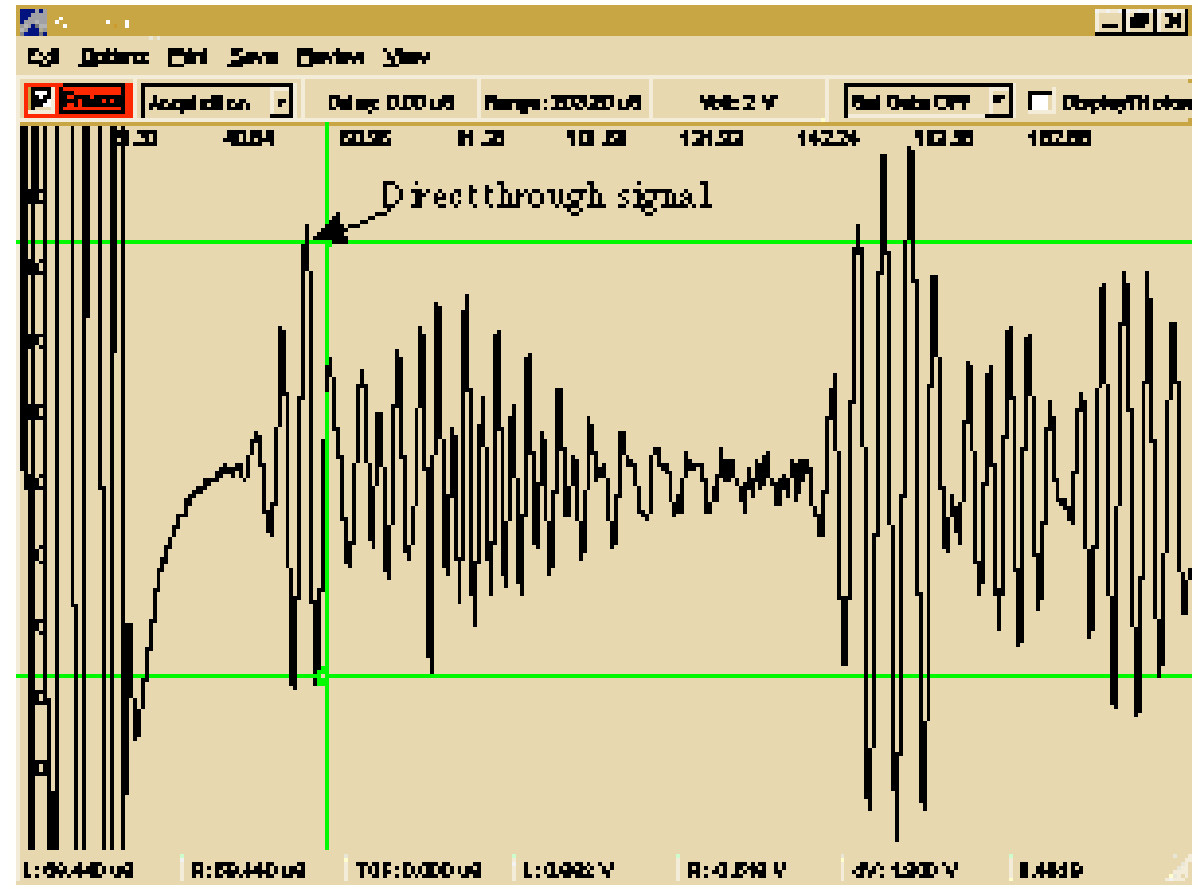

Fig. 3.71 Through-transmission signal from $0.3-\mathrm{mm}$-wide notch 10 percent through depth of $10-\mathrm{mm}$-thick plate. 


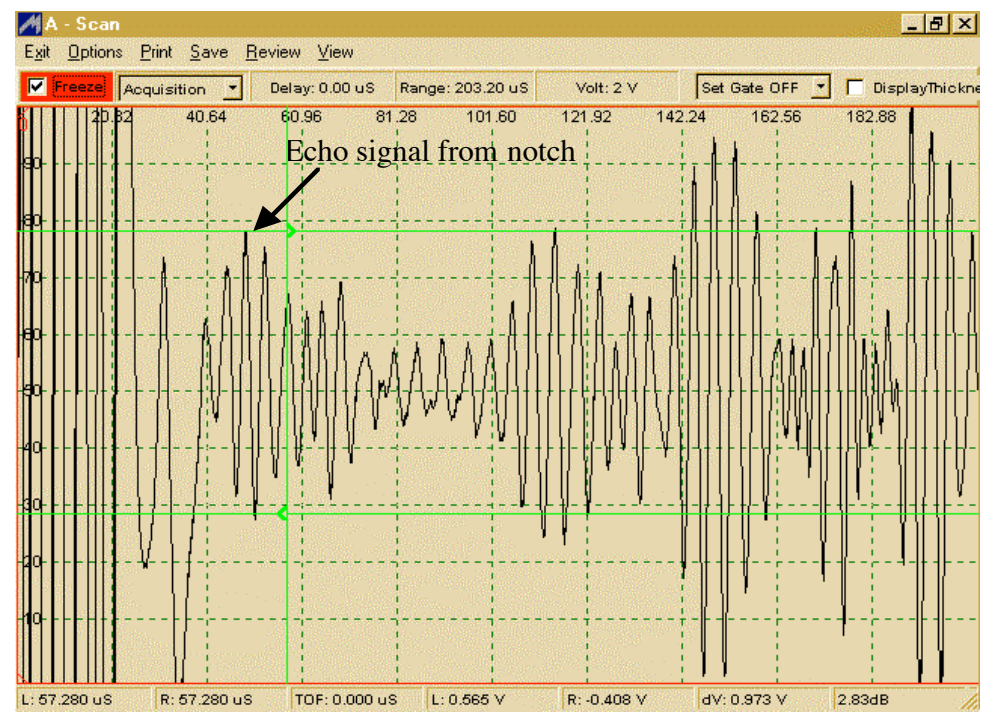

Fig. 3.72 Pulse-echo signal from 0.3 -mm-wide notch

30 percent through depth of 10 -mm-thick plate. (SH wave of mode 0 .)

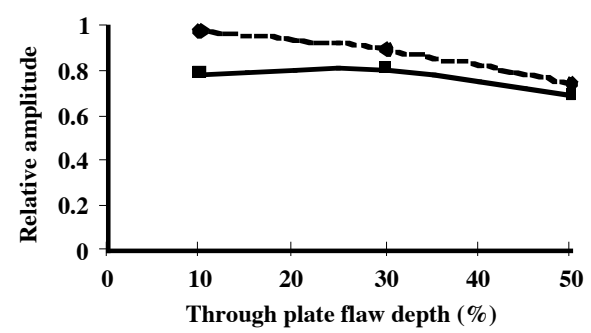

(a) 0.5 in. notch defect

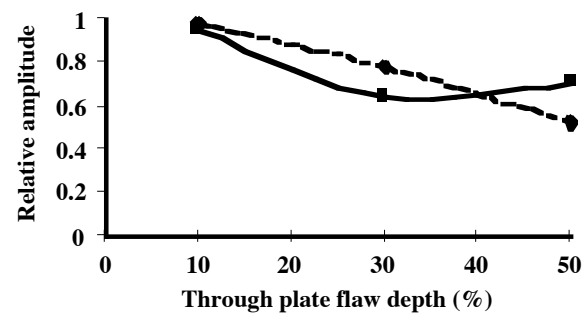

(b) 0.25 in. notch defect

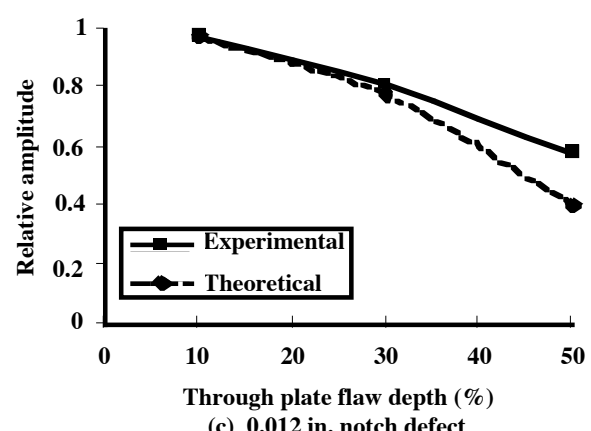

(c) 0.012 in. notch defect

Fig. 3.73 Theoretical and experimental relative amplitude results for $12.7-\mathrm{mm}, 6.35-\mathrm{mm}$, and $0.3-\mathrm{mm}$-wide notches of different dept in a 10-mm-thick plate.(76.2-mm transducer separation, $205 \mathrm{kHz}, \mathrm{n}=0$ mode) 


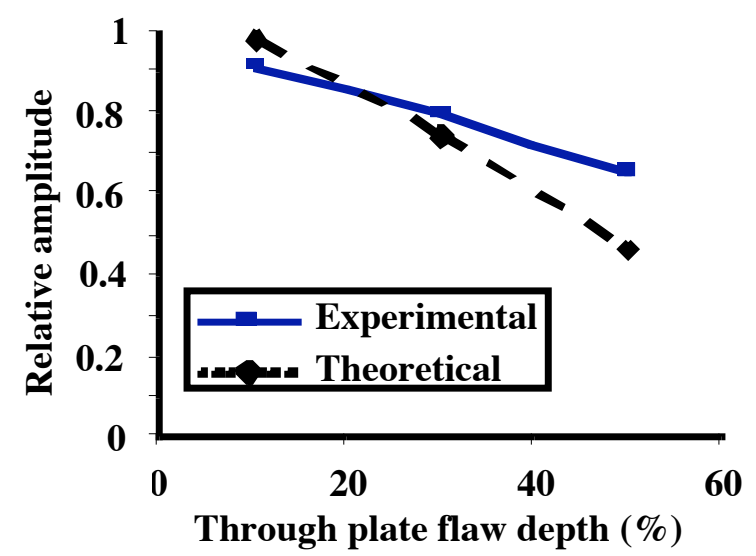

Fig. 3.74 Theoretical and experimental through-transmission signal amplitude versus through-plate flaw depth for $0.3-\mathrm{mm}$-wide notch. $(\mathrm{n}=0$ mode at $205 \mathrm{kHz})$

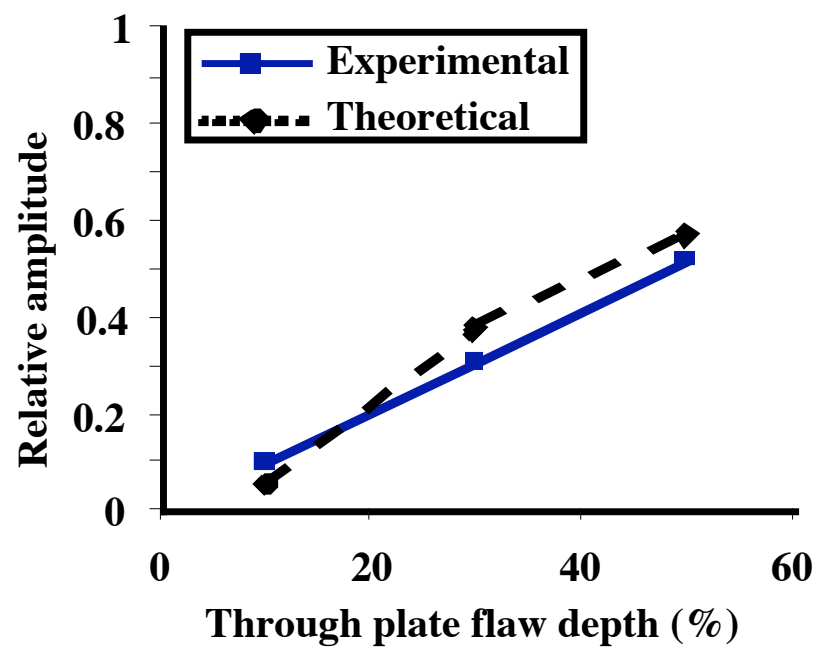

Fig. 3.75 Theoretical and experimental pulse-echo signal amplitude versus through-plate flaw depth for $0.3-\mathrm{mm}$-wide notch. $(\mathrm{n}=0$ mode at $205 \mathrm{kHz})$ 
Table 3.1 Applicability and important material characteristics of selected metallic materials NDE methods.*

\begin{tabular}{|l|c|c|c|c|l|}
\hline \multirow{2}{*}{ Technique } & \multicolumn{4}{|c|}{ Applicability by Flaw Type } & \multirow{2}{*}{ Important Material Characteristic } \\
\cline { 2 - 5 } & Surface & Planar** & Interior & Volumetric & \\
\hline Visual & $\mathrm{X}$ & $\mathrm{X}$ & & $\mathrm{X}^{3}$ & None \\
\hline Liquid penetrant & $\mathrm{X}$ & & & $\mathrm{X}^{3}$ & Flaw must intercept surface \\
\hline Magnetic particle & $\mathrm{X}$ & $\mathrm{X}$ & $\mathrm{X}^{1}$ & $\mathrm{X}^{3,4}$ & Material must be magnetic \\
\hline Ultrasonic & $\mathrm{X}$ & $\mathrm{X}$ & $\mathrm{X}$ & $\mathrm{X}$ & Acoustic properties \\
\hline Eddy current & $\mathrm{X}$ & $\mathrm{X}$ & $\mathrm{X}$ & $\mathrm{X}$ & $\begin{array}{l}\text { Material must be } \\
\text { electrically/magnetically conductive }\end{array}$ \\
\hline Radiography & & $\mathrm{X}$ & $\mathrm{X}$ & $\mathrm{X}$ & Changes in thickness and density \\
\hline Acoustic emission & $\mathrm{X}$ & $\mathrm{X}$ & $\mathrm{X}$ & & Material sensitive since it is AE source \\
\hline Thermography & $\mathrm{X}$ & $\mathrm{X}$ & $\mathrm{X}$ & $\mathrm{X}$ & Material heat transfer characteristics \\
\hline
\end{tabular}

*Adaptation of: J. D. Wood, "Guide to Nondstructive Evaluation Techniques," ASM Handbook, Vol. 17, pp. 49-51, ASM International, Materials Park, Ohio, 1992.

**Thin in one direction.

$1=$ limited application, $2=$ possible application, $3=$ surface, $4=$ subsurface.

Table 3.2 Dominant sources of variance of selected metallic materials NDE methods.*

\begin{tabular}{|l|c|c|c|c|c|c|}
\hline \multirow{2}{*}{ Technique } & \multicolumn{5}{|c|}{ Variance Sources } \\
\cline { 2 - 7 } & Materials & Equipment & Procedure & Calibration & Criteria & $\begin{array}{c}\text { Human } \\
\text { Factors }\end{array}$ \\
\hline Visual & & & $\mathrm{X}$ & & $\mathrm{X}$ & $\mathrm{X}$ \\
\hline Liquid penetrant & $\mathrm{X}$ & & $\mathrm{X}$ & & & $\mathrm{X}$ \\
\hline Magnetic particle & $\mathrm{X}$ & $\mathrm{X}$ & $\mathrm{X}$ & & $\mathrm{X}$ & $\mathrm{X}$ \\
\hline Ultrasonic & & $\mathrm{X}$ & $\mathrm{X}$ & $\mathrm{X}$ & $\mathrm{X}$ & $\mathrm{X}$ \\
\hline Eddy current & & $\mathrm{X}$ & $\mathrm{X}$ & $\mathrm{X}$ & $\mathrm{X}$ & $\mathrm{X}$ \\
\hline Radiography & & $\mathrm{X}$ & $\mathrm{X}$ & & $\mathrm{X}$ & $\mathrm{X}$ \\
\hline Acoustic emission & $\mathrm{X}$ & $\mathrm{X}$ & $\mathrm{X}$ & $\mathrm{X}$ & $\mathrm{X}$ & $\mathrm{X}$ \\
\hline Thermography & & $\mathrm{X}$ & $\mathrm{X}$ & $\mathrm{X}$ & & \\
\hline
\end{tabular}

*Adaptation of Table 7-1 in "Nondestructive Evaluation (NDE) Capabilities Data Book," prepared by W.D.

Rummel et al., Nondestructive Testing Information Analysis Center, Texas Research Institute, Inc., Austin, Texas, May 1996. 
Table 3.3 Equipment used to aid visual inspection.

- $\quad$ Flexible or rigid borescopes for illuminating and observing internal closed or inaccessible areas

- Image sensors for remote sensing or for the development of permanent visual records in the form of photographs, video tapes, or computer-enhanced images

- Magnifying systems for evaluating surface finish, surface shape, and surface microstructure

- Dye and fluorescent penetrants and magnetic particles for enhancing the observation of cracks

Source: Ref. 3.52 .

Table 3.4. Material properties used in OASES models.

\begin{tabular}{|l|c|c|c|c|c|c|c|c|}
\hline Material & $\begin{array}{c}\text { Modulus } \\
\mathrm{E} \\
(\mathrm{GPa})\end{array}$ & $\begin{array}{c}\text { Shear } \\
\text { Modulus } \\
\mathrm{G} \\
(\mathrm{GPa})\end{array}$ & $\begin{array}{c}\text { Density } \\
\left(\mathrm{kg} / \mathrm{m}^{3}\right)\end{array}$ & $\begin{array}{c}\text { Comp. } \\
\text { speed } \\
\mathrm{c}_{\mathrm{p}} \\
(\mathrm{m} / \mathrm{s})\end{array}$ & $\begin{array}{c}\text { Shear } \\
\text { speed } \\
\mathrm{c}_{\mathrm{s}} \\
(\mathrm{m} / \mathrm{s})\end{array}$ & $\begin{array}{c}\text { Lamb } \\
\text { speed } \\
\mathrm{c}_{\mathrm{r}} \\
(\mathrm{m} / \mathrm{s})\end{array}$ & $\begin{array}{c}\text { Loss } \\
\text { Factor } \\
\eta\end{array}$ & $\begin{array}{c}\text { Poisson } \\
\text { ratio } \\
v\end{array}$ \\
\hline Steel & 200 & 77 & 7850 & 5048 & 3132 & 2896 & $1 \times \mathrm{xE}-4$ & 0.28 \\
\hline Concrete & 24 & 9 & 2569 & 3056 & 1872 & 1747 & $2 \times \mathrm{E}-2$ & 0.34 \\
\hline Air & & & 1.2 & 345 & & & $3.5 \mathrm{xE}-3$ & \\
\hline
\end{tabular}

Table 3.5 Piezoelectric sensor characteristics.

\begin{tabular}{|l|l|}
\hline Frequencies & $0.5,1.0,2.25,3.5,5.0 \mathrm{MHz}$ \\
\hline $\mathrm{Q}=\Delta \mathrm{f} / \mathrm{fc}$ & 0.6 \\
\hline Size & $0.25 ”, 0.5 ”, 1.0 ”$ in diameter \\
\hline Shear Angles in Steel & $30,45,60,70$ degrees \\
\hline Typical Cost & pulser/receiver $-\$ 7 \mathrm{~K}$, sensors $-\$ 400$ \\
\hline
\end{tabular}

Table 3.6 Measured spreading loss values.

\begin{tabular}{|c|c|c|}
\hline $\begin{array}{c}\text { Distance along plate, } \\
45^{\circ} \text { coupling wedge }(\mathrm{cm})\end{array}$ & $\begin{array}{c}\text { Distance along plate, } \\
70^{\circ} \text { coupling wedge }(\mathrm{cm})\end{array}$ & Loss $(\mathrm{dB})$ \\
\hline 10.5 & 13.9 & 11.4 \\
\hline 20.6 & 27.4 & 13.0 \\
\hline 30.8 & 40.9 & 15.4 \\
\hline 41.0 & 54.4 & 17.8 \\
\hline 51.1 & 67.9 & 19.5 \\
\hline
\end{tabular}

Table 3.7 Material properties used for DISPERSE calculations.

\begin{tabular}{|c|c|c|}
\hline Property & Steel Plate & Concrete \\
\hline Density $\left(\mathrm{g} / \mathrm{cm}^{3}\right)$ & 7.93 & 2.2 \\
\hline $\begin{array}{c}\text { Compressional wave velocity } \\
(\mathrm{cm} / \mathrm{sec})\end{array}$ & $5.96 \times 10^{5}$ & $4.30 \times 10^{5}$ \\
\hline $\begin{array}{c}\text { Shear wave velocity } \\
(\mathrm{cm} / \mathrm{sec})\end{array}$ & $3.26 \times 10^{5}$ & $2.30 \times 10^{5}$ \\
\hline
\end{tabular}




\section{MITIGATION AND REPAIR}

Structures almost from the time of construction will start to deteriorate in one form or another due to exposure to the environment (e.g., temperature, moisture, and loadings) (4.1). The rate of deterioration is dependent on factors such as the component's structural design, materials selection, quality of construction, and aggressiveness of environmental exposure. Termination of a component's service life occurs when it no longer can meet its functional and performance requirements, which often occurs prior to reaching the desired service life.

In the previous section it was noted that in-service inspection techniques are available that can indicate the occurrence and extent of environmental-related degradation. Periodic application of these techniques as part of a condition assessment program can monitor the progress of deterioration. Results obtained from these programs can be used to develop and implement a remedial action prior to the structure achieving an unacceptable level of performance. Depending on the degree of deterioration and the residual strength of the structure, the function of a remedial measures activity may be structural, cosmetic, protective, or any combination of these three functions. Basic components of a remedial measures program include diagnosis (damage evaluation), prognosis (can the repair be made and is it economical), scheduling (priority assignments), method selection (depends on nature of distress, adaptability of proposed method, environment, and costs), preparation (function of extent and type of distress), and application (4.2). Figure 4.1 indicates the basic steps of a typical repair strategy (4.3).

Maintenance and repair activities are usually performed to offset the effects of aging and deterioration. These activities are occasionally required to correct deficiencies that were not anticipated in the original design, but mostly they are performed to mitigate the effects of degradation or to prevent future failures. Based on past operating experience, maintenance activities typically involve repair or replacement of seals, gaskets, coatings, and bellows expansion joints, but grinding and welding are occasionally required to repair surface defects or corrosion damage.

Caulking, sealants, elastomeric seals, and gaskets are used in containment applications to make fluid-tight joints between components. Over time, these materials become brittle or resinous and lose their elastic properties. This effect is timedependent and irreversible. Environmental conditions and material formulation influence the deterioration rate, but periodic replacement is usually required to assure continuous leak-tight integrity. Occasionally, seals or gaskets fail in service. These failures can disrupt operations and often require corrective actions to restore leak-tight integrity. Fluids that leak from faulty joints can create additional maintenance problems, particularly when the fluids are corrosive to pressure boundary components.

Several penetrations and airlock doors use mechanically tightened nonmetallic seal material. Exposure of these nonmetallic materials to modest temperatures and relativly low radiation doses for long periods of time can cause embrittlement and seal failure. Leak testing after each opening and periodic replacement of the seals is generally used to address potential aging of these components.

Nonmetallic seals (e.g., moisture barriers) between concrete and steel are used at several places in most containments to prevent ingress of moisture. High temperatures can cause embrittlement of this material to such an extent that it may not be able to accommodate the differential expansions that occur during normal operation or pressure testing. Also, abrasion or impact may damage the seals. Visual examination of these seals can verify their condition and the necessity for repair or replacement.

Paints and other protective coatings are applied to carbon steel surfaces to enhance their corrosion resistance and to facilitate decontamination by providing a physical barrier between the steel and the surrounding environment. Most operating nuclear power plants have similar types of coatings (e.g., primer coating of inorganic zinc and intermediate and finish coatings of polyamide epoxy; or primer, intermediate, and finish coatings of phenolic epoxy enamel). These coatings have been applied according to manufacturer's recommendations, with available industry standards used in the coating selection process (4.4). The integrity of the coating influences its ability to protect steel from corrosion. In order to assure satisfactory long-term performance, periodic in-service inspection and maintenance of coated surfaces is required to detect coating degradation and to repair physical damage. Coating degradation can occur as a result of exposure to high-temperature and high-humidity environments, radiation, condensation, and immersion in water or other chemical solutions. Chipping, flaking, gouging, abrasion, cracking, pin holes, and wear can also influence coating performance in localized areas and lead to corrosion of the base metal. Although aging effects of qualified metal coatings have not been quantified, data on coating life is available for plants having ages in excess of 20 years. The coating life for wet or submerged service has been found to range from a minimum of 7 years to an upper limit of 15 
years or more, depending on how the coating was applied and which product was utilized (4.5). It is expected that in a relatively dry environment coatings on interior containment surfaces will last a minimum of 40 years, if sufficient maintenance is performed. Many of the degradation modes noted above depend strongly on the quality of the initial coating application and the possibility of maintenance. In-service inspection is an important part of coating maintenance because aging effects have not yet been quantified (4.5). Unfortunately, not all surfaces of the containment are accessible for coating inspection and maintenance, but underwater inspection and repair of deteriorated coatings and base metal is feasible (4.6).

Bellows expansion joints are intended to be maintenance-free components, but occasionally maintenance is required when in-service inspection reveals physical damage or when leaks are detected by a pressure test. Surface defects such as cracks, dents, and gouges that can affect bellows performance are repaired whenever possible, but defective bellows may require replacement.

Maintenance activities that involve repair or replacement of containment pressure boundary components must comply with requirements in Section XI, Division 1, Subsection IWA of the Code (4.7). These rules address examination, inspection, and pressure testing of weld repairs, defect removal, and installation of replacements.

Information summarized below addresses repairs versus replacements, containment pressure boundary restoration, special restoration practices, case histories of containment pressure boundary restoration, and conclusions and recommendations. More detailed information on each of these topics is available elsewhere (4.8).

\subsection{REPAIR VERSUS REPLACEMENT}

A repair is the process of restoring a nonconforming component by welding, brazing, or metal removal such that existing design requirements are met (4.7). The nonconformance may be the result of material damage caused when the microstructure of a material was modified by exposure to a hostile environment, or physical damage caused when the geometry of a component was altered. Potential causes for these two damage categories were identified previously in Fig. 2.5. Examples of repair activities include:

- removing weld or material defects,

- reducing the size of defects to a size acceptable to the applicable flaw evaluation criteria, and

- addition of weld or braze material.

Defects are flaws, discontinuities, or groups of discontinuities whose indications do not meet specified acceptance criteria (4.9). Components found to contain defects that do not meet acceptance standards may be acceptable for continued service without the removal or repair of the defect or replacement if an engineering evaluation indicates that the defect is nonstructural in nature or has no effect on the structural integrity of the containment. Components containing defects that are not acceptable based on an engineering evaluation may not be returned to service until the defect either has been removed by mechanical methods or repaired, or the component or portion of the component containing the defect is replaced (4.10). Replacement includes the addition of components (e.g.,valves), and system changes (e.g., rerouting of piping). Possible reasons for replacing nuclear power plant components are listed in Table 4.1.

Current rules and requirements for repair of pressure-retaining components by welding, brazing, or metal removal; specification and construction of items to be used for replacement; and installation of replacement items are provided in Section XI, Division 1, Article IWA-4000 (4.7) of the Code and in Code Case N-236-1 (4.11). Additional requirements that have been adopted by the NRC pertaining to applicable codes and standards are provided in Title 10, Part 50 of the Code of Federal Regulations. Regulations in paragraph 50.55a impose limitations on specific editions and addenda of Section XI, Division 1 of the Code dealing with Class MC and Class CC components. These regulations adopt requirements in Subsections IWE and IWL of the Code $(4.10,4.12)$ with modifications that address examination of concrete containments and examination of metal containment and liners of concrete containments.

Guidelines for determining whether an activity is considered a repair or a replacement are provided in Section XI, Division 1, Nonmandatory Appendix J of the Code (4.13) in the form of a decision tree. The decision tree is also useful for distinguishing repair and replacement activities (including modifications) from maintenance which is considered a separate activity. Examples of maintenance activities include: 
- adjustment of packing, removal of bonnet, stem, or actuator, or disconnecting hydraulic or electrical lines on valves;

- $\quad$ changing oil, flushing the cooling system, adding packing rings or mechanical seal maintenance on pumps;

- $\quad$ grinding or machining on valve disk seating surfaces;

- removing arc strikes or weld spatter in the area of previous preservice or inservice surface examinations; and

- $\quad$ preparing welds for nondestructive examinations (4.13).

\subsection{CONTAINMENT PRESSURE BOUNDARY RESTORATION}

\subsubsection{Conditions for Continued Service}

According to requirements provided in 10 CFR 50, Appendix J, evidence of structural deterioration that could affect the structural integrity or leaktightness of metal and concrete containments must be corrected before the containment can be returned to service. Corrective actions that are taken must be performed in accordance with the repair procedures, nondestructive examinations, and testing specified in applicable Codes including those editions and addenda of Section XI that have been adopted by the NRC. The Owner is responsible for preparing Repair/Replacement Plans that list all editions, addenda, and Code cases that are applicable to a particular repair or replacement.

Requirements contained in Section XI, Subsection IWA-4000 (4.7) of the Code state that containment pressure boundary components with flaws, discontinuities, or areas of degradation that do not meet acceptance standards may not be returned to service unless:

- the unacceptable flaws, discontinuities, or areas of degradation are removed to the extent necessary to meet the acceptance standards,

- a repair involving welding is performed such that existing design requirements are met, or

- the component or portion of the component containing the unacceptable flaws or areas of degradation is replaced.

These three conditions are intended to ensure that metal and concrete containment pressure boundary components remain free from defects during their entire service life. A less prescriptive condition for continued service has been developed and included in requirements provided in Section XI, Subsection IWE-3000 (4.10) of the Code. These requirements state that containments with pressure boundary components that contain flaws, discontinuities, or areas of degradation that do not meet acceptance standards may be permitted to remain in service provided an engineering evaluation reveals that the flaws, discontinuities, or areas of degradation have no affect on structural capacity or leak-tight integrity.

\subsubsection{Defect removal}

According to requirements provided in Section XI, Subsection IWA-4300 (4.7) and Subsection IWE-3000 (4.10) of the Code, containment pressure boundary components that contain defects may be returned to service provided the unacceptable flaw or discontinuity is removed or reduced to an acceptable size and the resultant section thickness created by the removal process is equal to or greater than the minimum design thickness. If the affected component has been reduced below the minimum design thickness, the component either must be repaired, replaced, or evaluated before being returned to service. Defects may be removed or reduced to an acceptable size using a mechanical removal process.

\subsubsection{Welding repairs}

Containment pressure boundary components that have been reduced below the minimum design thickness either by degradation or defect removal may be repaired by welding and returned to service. Requirements for welding repairs of similar materials, cladding, and dissimilar materials are provided in Section XI, Subsection IWA-4500 (4.7) of the Code. All welding repairs must be completed and documented in accordance with the requirements of the Repair/Replacement Program.

\subsubsection{Replacements}

As an alternative to defect removal or repair, items or portions of containment pressure boundary components that contain flaws, discontinuities, or areas of degradation may be replaced with items that meet the acceptance standards. 
Items used as replacements must be constructed, installed, and documented in accordance with the requirements of the Repair/Replacement Program.

\subsubsection{Engineering evaluation}

Engineering evaluations are performed on a case-by-case basis by qualified engineers and authorized personnel who determine the adequacy of damaged or degraded components for their intended use. Acceptance criteria are generally established so that components with flaws, discontinuities, or areas of degradation that adversely affects the structural capacity, leaktight integrity, or remaining service life of the containment are not considered acceptable for continued service.

According to requirements provided in Section XI, Subsection IWE-3122 (4.10) of the Code, containments that contain pressure boundary components with flaws, discontinuities, or areas of degradation that are found by engineering evaluation to have no effect on structural capacity or leaktight integrity may be returned to service without removing the defect or repairing or replacing the defective component. Damaged components are considered acceptable for continued service if either the thickness of the base material is reduced by no more than 10 percent of the nominal thickness or it can be demonstrated by analysis that the reduced thickness satisfies the requirements of the design specification.

\subsubsection{Materials}

The leaktightness of BWR and PWR containment vessels is ensured by a continuous pressure boundary consisting of nonmetallic seals and gaskets and metallic components that are either welded or bolted together. Nonmetallic components are used to prevent leakage from pumps, pipes, valves, personnel airlocks, equipment hatches, manways, and mechanical and electrical penetration assemblies. The remaining pressure boundary consists primarily of steel components such as metal containment shells, concrete containment liners, penetration liners, heads, nozzles, structural and nonstructural attachments, embedment anchors, pipes, tubes, fittings, fasteners, and bolting items that are used to join other pressure-retaining components. Material specifications permitted for construction of metal and concrete containment pressure boundary components are listed in Section III, Division 1, Subsection NE (4.14) and Section III, Division 2, Subsection CC of the ASME Code (4.15).

\subsubsection{Base materials}

Ferrous materials permitted for use as base materials in containment pressure boundary component construction, repairs, and replacements must conform to the material specifications provided in Section II, Part A (4.16) of the Code. The lists of permitted material specifications often change from one edition or addenda of the Code to another as a result of actions taken by ASME and ASTM committees to delete, merge, edit, or modify existing material specifications and to adopt new ones. Section II, Part D (4.17) of the Code contains tabulated maximum allowable stress values, design stress intensity values, and thermal properties for all ferrous materials cited in the Code. The tables are organized so that materials with similar compositions and characteristics are grouped together.

\subsubsection{Welding materials}

Material specifications for welding rods, electrodes, and filler metals permitted for use in repair welding of containment pressure boundary components are provided in Section II, Part C (4.18) of the Code. The American Welding Society (AWS) has established a system for identifying and classifying welding rods and electrodes. The AWS classifications for carbon steel electrodes for shielded metal-arc welding are provided in ASME specification SFA-5.1 (4.18).

\subsubsection{Welding Methods.}

Repairs to containment pressure boundary component base material and welds can be categorized as those involving welding of similar materials, dissimilar materials, or austenitic stainless steel and nickel-base cladding. According to the repair and replacement requirements found in Section XI, Subsection IWA-4000 (4.7) of the Code, these three categories of repairs may only be performed using either the shielded metal-arc welding (SMAW) or the gas tungsten-arc welding (GTAW) process. Requirements for welding procedure and welding performance qualifications using these methods are provided in Section IX (4.19) of the Code. Exceptions and modifications to these requirements as well as repair welding requirements are provided in the construction codes and in Section XI, Subsection IWA-4000 (4.7) of the Code. 


\subsubsection{Shielded metal-arc welding (SMAW)}

Shielded metal-arc welding is a manual welding process that uses heat generated by an arc between a covered metal electrode and the work to produce a coalescence of metals. Gas (normally carbon dioxide) that shields the arc and weld zone from the atmosphere is produced by the decomposition of the electrode covering. Filler metal that becomes part of the weld is obtained from the consumable electrode.

Prior to welding, items being joined by the SMAW process are placed beside or in contact with each other. Holding or clamping pressure is normally not required. Welding begins when the welder momentarily touches the electrode on the base material to initiate an arc. The arc melts both the base material and the tip of the welding electrode creating a molten pool of metal. As the welder manipulates the electrode, molten electrode metal is continuously transferred to the base material until the electrode metal is consumed or the arc is extinguished. The resulting weld is covered by a slag layer produced by the decomposition of the electrode covering. Removal of this slag layer and any spatter that may be present is essential to the production of high-quality welds. The quality of welds deposited by the SMAW process depends on the design of the joint, selection of the electrode, technique and accessibility, and skill level of the welder. Despite the need for skilled welders, SMAW is the most widely used welding process for the following reasons:

- SMAW can be used in all positions (flat, vertical, horizontal, and overhead),

- SMAW can be used with virtually all base-metal thickness of $1.6 \mathrm{~mm}$ and greater,

- SMAW can be used in areas of limited accessibility,

- Welding electrodes are readily available for almost all manufacturing, construction, and maintenance and repair applications involving low-carbon, mild, low-alloy, high-strength, quenched and tempered, high-alloy, and stainless steels,

- SMAW requires a relatively small investment in rather simple equipment, and

- Cladding and hard surfacing layers can be applied using the SMAW process.

\subsubsection{Gas tungsten-arc welding (GTAW)}

Gas tungsten-arc welding is a high-temperature metal-joining process that uses heat generated by an arc between a nonconsumable tungsten alloy electrode and the work. Weld pool temperatures can approach $2,500^{\circ} \mathrm{C}$. An inert gas (normally argon, helium, or a mixture of argon and helium) sustains the arc and protects the molten metal from atmospheric contamination. Gas tungsten-arc welds can be made with or without filler metal depending on the thickness of the materials being joined. When required, filler metal can be added manually in straight lengths or automatically from rolls or coils (4.19).

The GTAW process can be used to weld almost all types of metals ranging in thickness from a few thousandths of a millimeter to many millimeters. Although carbon and low-alloy steels can be welded using this process, it is used primarily for joining dissimilar metals, stainless steels, aluminum, magnesium, and reactive materials and for root-pass welding of carbon and low-alloy steels. Welds produced using this process are generally high-quality, low-distortion welds that are free of spatter. During the welding operation, the welder can maintain precise control of heat input, and vision is not impaired because fumes and smoke are not produced as in certain other arc welding processes. However, welders who use the GTAW process must have a relatively high level of skill and slightly more dexterity and coordination than welders who use the SMAW process.

\subsubsection{Defect Removal.}

Indications of flaws, discontinuities, or areas of degradation that are detected in containment pressure boundary components can be removed or reduced to an acceptable size by mechanical methods such as grinding. Requirements for defect removal are provided in Section XI, Subsection IWA-4300 (4.7) of the Code. According to these requirements, in areas where repair welding is not required, the affected area must be faired into the surrounding area so that all sharp notches and severe discontinuities are eliminated. When repair welding is required, the cavity produced by the defect removal process must be finished smooth with beveled sides and rounded edges so that suitable access for welding is provided. To ensure that the indications have been removed or reduced to an acceptable size by the defect removal procedure, the affected surfaces must be examined using either magnetic particle or liquid penetrant methods. In those instances when repair welding of similar materials is to be performed or when repair welding of cladding or dissimilar materials is required and the defect penetrates the base material, the original defect must be completely removed. 


\subsubsection{Repair Welding}

Requirements for repair welding are provided in the original construction code or Section III, Division 1, Subsection NE (4.14) of the Code. With certain exceptions, all welds in P-No. 1 materials, including repair welds, must be post-weld heat treated. In new construction, where fabrication activities can be staged and properly sequenced, post-weld heat treatment (PWHT) is normally not a problem. However, PWHT of repair welds in existing containment pressure boundary components is not always feasible, especially when the size and configuration of the repair leads to highly restrained weld joints and when factors such as water backing make preheat and PWHT impractical. For these reasons, alternative repair welding methods are provided in Section XI, Subsection IWA-4500 (4.7) of the Code. These requirements permit repairs to base material and welds of similar materials, cladding, and dissimilar materials without the required PWHT where:

- the neutron fluence in the repair area is taken into account when weld metal composition limits are established,

- the welding procedure and the welders are qualified in accordance with the requirements of Section IX (4.19) of the Code and the additional requirements provided in Subsection IWA-4500, and

- the welding procedure includes weld preparation and specified preheat provisions.

Additional alternative repair welding method requirements for repairs to similar materials, cladding, and dissimilar materials are summarized below. Also included are requirements for butter bead-temper bead repairs of metal and concrete containment pressure boundary components.

\subsubsection{Similar metals}

Repairs to P-Nos. 1, 3, 12A, 12B, and 12C* base materials and associated welds may be made without the specified PWHT based on requirements provided in Section XI, Subsection IWA-4510 (4.7) of the Code. These requirements only apply to repairs that have a maximum finished surface area of $64,500 \mathrm{sq}$. $\mathrm{mm}$ and a depth of repair that is no greater than one-half the base material thickness. For these repairs, peening may be used except on the initial and final weld layers. In addition, the test assembly base material, weld metal, and heat affected zone (HAZ) for the welding procedure qualification test must meet the impact test requirements for the construction code and Owner's requirements. The completed repair area must be nondestructively examined after the weld has been at ambient temperature for at least 48 hours. The examination must include a surface examination and a volumetric examination unless each layer was examined by the magnetic particle method.

An experimental effort to evaluate the technical acceptability of making welding repairs to thick-section P-No. 1 steels without PWHT has been undertaken (3.138). In this study, four test assemblies were prepared using steel plates that conformed to ASTM A 516, Grade 70 requirements and E7018 covered electrodes. The assemblies were welded in the flat position using the SMAW process. Each assembly was prepared using a different set of preheat and interpass temperatures. Charpy data, metallographic examination results from broken Charpy specimens, tensile data, microhardness data, and microstructure examination results from the weldments were compared to those obtained from companion test specimens that had been subjected to PWHT. Based on this comparison, the optimum preheat/interpass temperature range for weld repairs in ASTM A 516, Grade 70 steel is $93-149^{\circ} \mathrm{C}$.

\subsubsection{Cladding}

When the ferritic material is within $3.18 \mathrm{~mm}$ of being exposed, repairs to austenitic stainless steel and nickel-base cladding on P-Nos. 1, 3, 12A, 12B, and 12C base materials can be made without PWHT based on requirements provided in Section XI, Subsection IWA-4520 (4.7) of the Code. After the completed weld has been at ambient temperature for at least 48 hours, the weld repair and the adjacent preheated band must be examined by the liquid penetrant method and deposited weld metal and HAZ must be examined by the ultrasonic method.

\subsubsection{Dissimilar metals}

Repairs to welds that join P-No. 8 or P-No. 43 material to P-Nos. 1, 3, 12A, 12B, and 12C base material can be made without the specified PWHT based on requirements provided in Section XI, Subsection IWA-4530 (4.7) of the Code.

*P-Nos. 12A, 12B, and 12C are material classifications originally identified in Section III and later reclassified and included in Section IX. 
These requirements are only applicable to repairs made along the fusion line of a nonferritic weld to ferritic base material where $3.18 \mathrm{~mm}$ or less of nonferritic weld deposit exists above the original fusion line after defect removal. If the defect penetrates into the ferritic base material, repair of the base material may be performed provided the depth of the repair in the base material does not exceed $9.53 \mathrm{~mm}$. Repairs to a completed joint must not exceed one-half the joint thickness, and the surface of the completed repair may not exceed 64,500 sq. mm. After the completed weld has been at ambient temperature for at least 48 hours, the weld repair and the adjacent preheated band must be examined by the liquid penetrant method, the radiographic method, and, if practical, the ultrasonic method.

\subsubsection{Butter bead-temper bead}

An alternative welding technique that is intended for use in the repair of metal and concrete containment pressure boundary components where preheat and PWHT are impractical has been developed. This technique is known as butter bead - temper bead welding. Butter bead - temper bead welding is suitable for use when the size or configuration of the repair leads to highly restrained weld joints or the repair area is backed by water. Requirements for this technique are provided in Section XI, Subsection IWA-4540 (4.7) of the Code. Butter bead-temper bead welding involves application of a butter layer of surfacing weld metal followed by the application of temper beads or a temper bead layer. This welding sequence eliminates the need for PWHT.

Prior to butter bead - temper bead welding of the production test or the actual work, areas to be welded must be examined by magnetic particle or liquid penetrant methods, and all surrounding surface areas must be clean and free of scale, rust, moisture, or other surface contaminants. The minimum preheat temperature specified in the welding procedure specification and the production test must be maintained during tack welding and until completion of the weld. However, the maximum interpass temperature may not exceed $260^{\circ} \mathrm{C}$. As the welding progresses, the welder must apply a butter bead layer followed by temper beads or a temper bead layer. Improper application of the temper bead or defects in the butter bead or temper bead must be repaired by application of a new butter bead and temper bead. After the welding is completed, no post-weld heat treatment is required.

\subsubsection{Replacements}

Replacement items that involve installation by welding are required to be installed using appropriate welding requirements noted earlier. Repaired areas and welded joints made for installation of replacement items must be examined in accordance with the requirements of the construction code identified by the Owner in the Repair/Replacement Plan.

\subsubsection{Pressure tests}

According to the special testing requirements for containment modifications provided in 10 CFR 50, Appendix J (3.1), repairs or major modifications to containment pressure boundary components or replacement of these components must be followed by a Type A, Type B, or Type C leakage-rate test, as applicable to the affected area.

\subsubsection{Documentation}

The Owner is responsible for the preparation and maintenance of the reports and records that are required for all repairs and replacements. The types of documents that may be involved include:

- Certified Design Specification

- $\quad$ Certified Design Report

- Design Report

- Overpressure Protection Report

- Manufacturer's Data Report

- Material Certification

- Evaluation Report (required by Section XI, Subsection IWA-4150)

The Owner is also responsible for the preparation of the Owner's Report for Repairs or Replacements, Form NIS-2, as required in Section XI, Subsections IWA-4910 and IWA-6210 (4.7) of the Code. 
Alternative documentation requirements to those just described are provided in Code Case N-532 (4.21). This code case permits the use of a Repair/Replacement Certification Record, Form NIS-2A, which references a unique Repair/Replacement Plan identification number that is assigned by the Owner. Certification of the repair or replacement is achieved when Form NIS-2A is signed and dated by the Authorized Nuclear Inservice Inspector.

\subsection{SPECIAL RESTORATION PRACTICES}

Repair or mitigtion practices have been developed for specialized conditions. These conditions include: underwater welding, welding with concrete backing, inaccessible areas, temporary non-Code reapairs, protective coatings, damaged bellows, and cathodic protection.

\subsubsection{Underwater Welding}

Underwater welding has been used for many years for special salvage operations or for making temporary structural repairs. Practical difficulties encountered in underwater welding include rapid quenching of the weldment by the surrounding water and susceptibility of the weldment to hydrogen embrittlement. Both tensile strength and ductility have been found to be drastically reduced compared with similar joints welded in air (4.22). As its name implies, underwater welding is performed below the water surface, but underwater welding can be performed in either a wet or a dry environment.

Dry underwater welding is performed in a dry habitat and often requires construction of a customized high-pressure chamber around the welding zone. The dry environment allows production of high-quality welds. Shielded metal-arc, gas metal-arc, and gas tungsten-arc welding processes can be used for dry underwater welding applications, but the large amounts of smoke and fumes produced by the shielded metal-arc welding often make it the least desirable option. Because an underwater chamber can be very expensive and time consuming to design, fabricate, and setup, dry underwater welding may not be the most desirable option except in special or unique situations.

Wet underwater welding is performed at ambient pressure with the welder/diver in the water without any mechanical barrier between the water and the welding arc. Wet welding has been demonstrated to produce acceptable welds at depths much greater than those encountered in containment pressure boundary component repairs. Wet welding, however, produces welds that are of relatively poor quality due primarily to problems of heat transfer, welder visibility, and the presence of hydrogen in the arc atmosphere during the welding operation (4.23).

Although both dry and wet underwater welding environments experience increased pressure with depth, the wet environment also increases the cooling rate during welding. Depending on the heat input and the plate thickness, a shielded metal-arc weld produced above water takes between 8 and 16 seconds to cool from 800 to $500^{\circ} \mathrm{C}$ compared to the same weld produced underwater which takes between 1 and 6 seconds to cool the same amount (4.23). The structure of steel after the welding procedure is completed depends on the cooling rate and the temperature from which it cools (4.24). It can vary from soft, ductile pearlitic structure to hard, less-ductile martensitic structure. Rapid cooling of the weld metal produces a quenching effect that influences the weld metal phase transformation characteristics and produces a weld solidification structure with reduced toughness and ductility. Enhanced cooling also produces significant amounts of martensite in the heat affected zone (HAZ) in nearly all low-carbon steels. This effect can be a concern because as the martensite content increases, the HAZ become more susceptible to hydrogen cracking. Additional technical information related to underwater welding is contained in an AWS specification prepared specifically for this condition (4.25).

Supplementary rules for dry and wet underwater welding repairs or replacements of P-No. 8 (austenitic stainless steel) and P-No. 4X (low-alloy steel) materials are provided in Code Case N-516 (4.26). When applicable, these methods can be used in lieu of the alternative welding methods permitted in Section XI, Subsection IWA-4500 (4.7) of the Code provided all other applicable requirements of Section XI are met. Welding processes permitted by Code Case N-516 for

underwater repairs and replacements are listed in Table 4.2. Similar code cases for underwater welding of other materials such as carbon steels permitted for construction of containment pressure boundary components have not been approved by ASME. 


\subsubsection{Underwater welding qualification}

According to Code Case N-516 (4.26), the Welding Procedure Specification for dry and wet underwater welding qualification must conform to the requirements of Section IX (4.19) of the Code for groove welds. Welders and welding operators for dry and wet underwater welding must be qualified in accordance with requirements provided in Section IX (4.19) of the Code and the additional variables listed in this code case.

\subsubsection{Filler metal qualification}

Code Case N-516 (4.26) requires that the filler metal be qualified. Filler metal qualification is achieved by preparing an all-weld-metal coupon in accordance with ASME welding rod, electrode, and filler metals specification SFA-5.4 using the production welding process at an acceptable depth that is approximately the same as the depth of the production weld. Testing requirements and acceptance criteria for the all-weld-metal coupon are provided as part of the Code case.

\subsubsection{Confirmation weld}

Before underwater production welding can be initiated, Code Case N-516 (4.26) requires that a confirmation weld be produced at the welding location to demonstrate that the welding system is functioning properly. This confirmation weld must be made using the qualified welding procedure with each production welding system. In lieu of a confirmation weld, this code case permits the substitution of procedure qualification at the underwater location.

\subsubsection{Examination}

When the underwater environment makes it impractical to conduct the required examinations, Code Case N-516 (4.26) requires that the following examinations be performed.

- $\quad$ After the defect has been removed, the cavity must be visually examined remotely at a minimum of $5 \mathrm{x}$ and evaluated using surface examination acceptance criteria.

- $\quad$ The weld must be visually examined remotely at a minimum of $5 \mathrm{x}$ and evaluated using surface examination acceptance criteria.

- The weld can be examined by ultrasonic testing techniques using a procedure qualified for the underwater environment in lieu of any other required volumetric examination.

Acceptance criteria for these examinations must be based on applicable requirements of Section XI (4.7) of the Code or the applicable construction code.

\subsubsection{Welding with Concrete Backing}

During welding operations, base material immediately adjacent to the welding arc can reach temperatures as high as $1,370^{\circ} \mathrm{C}$ for a short period of time (4.24). Because metal is a good heat conductor and air is very poor, the thermal gradient near the welding arc depends primarily on the thickness of the base material being welded. For thick sections, where heat disperses rapidly through the base material by conduction, the thermal gradient is generally quite pronounced especially when the base material is not preheated. By comparison, a narrow band of red-hot base material may be visible for a short distance behind the welding arc in relatively thin sections such as liners of reinforced concrete containments. Table 4.3 points out the difference that base material thickness can have on the instantaneous cooling rate for bead-on-plate surface welds backed by air. These values reflect instantanous cooling rates for base material at a nominal temperature of $760^{\circ} \mathrm{C}$. The effects of welding induced high-temperature exposure on the properties and qualities of the weld metal, HAZ, and base material can be significant. Consequently, measures necessary for assuring predictable weldment behavior are reflected in the prescriptive rules and requirements provided in the ASME Code for welding procedure specification and welder/welding operator performance qualification. For example, preheat, interpass temperature limits, and PWHT requirements are often specified to help ensure that high-quality weldments are produced.

Although the ASME Code rules and requirements are considered comprehensive and complete for most routine welding activities, they do not adequately address the impacts that repair welding operations can have on other containment components and materials such as embedment anchors that are attached to the concrete containment liner and concrete that has been cast against the liner. Figures 4.2 and 4.3 illustrate situations in which high temperatures produced by repair or replacement welding of a containment pressure boundary component could affect adjacent concrete and 
metallic components including embedment anchors and reinforcing bars embedded in the concrete. Ways in which high temperatures from repair welding operations can adversely affect concrete and metallic items embedded in concrete are summarized in Table 4.4.

\subsubsection{Concrete temperature limits}

Recognizing that concrete strength tends to decrease with increasing temperature (4.27), building and construction codes for concrete provide temperature limits for the concrete to assure predictable behavior and performance. Table 4.5 identifies the rules and requirements pertaining to high-temperature exposure of concrete and metallic embedments that appear in selected codes $(4.15,4.7,4.28,4.29)$. Absent from the table are rules and requirements written specifically for welding of base materials backed by concrete. Building codes and guidance documents prepared by organizations such as the American Concrete Institute (ACI) and The International Union of Laboratories and Experts in Construction Mtaterials, Systems, and Structures (RILEM) do not adequately address this issue because very little quantifiable data about rapid, localized heating of concrete are available (4.30,4.31).

\subsubsection{Welding qualification issues}

To minimize or eliminate potential high-temperature effects of repair welding operations on concrete and metallic embedments, the issues listed in Table 4.6 need to be considered when plans for welding repairs of containment pressure boundary components backed by concrete are being prepared.

\subsubsection{Welding Repair Alternatives for Inaccessible Areas}

Innovative welding solutions are being considered for the repair of degraded carbon and low-alloy steel components because welding provides an effective means for making the types of high-quality repairs that are required by utility owners, jurisdictional authorities, and regulatory agencies. One innovative solution under development involves an outside surface weld overlay repair to remedy inside surface erosion-corrosion damage to carbon steel piping (4.32). If adequately developed and thoroughly tested, this solution could be submitted for ASME consideration as a code case. Once approved, use of this technique would eliminate the need for repair of the inside pipe surface by providing sufficient replacement metal on the outside of the pipe to restore structural integrity.

Besides pipe repairs, this innovative solution might also be applicable to repairs of inaccessible areas of metal containments and liners of concrete containments damaged by corrosion. Figure 4.4 shows a situation in which an inaccessible area of a metal containment shell has corroded to the point that its structural capacity is no longer considered adequate and a repair is required. In this case, repair welding is only feasible from one side due to the narrow gap between the metal shell and the biological shield wall. Four possible welding repair techniques for this situation are shown in Figs. 4.5-4.8 and described below.

\subsubsection{Replacement plate welding}

Figure 4.5 shows a conventional replacement plate welding repair. In this repair technique, the structural integrity of the containment is restored to its preservice condition by removing the defective area, replacing it with new plate material, performing the necessary repair welding and PWHT, and conducting the required nondestructive evaluations and leakage-rate tests.

\subsubsection{Doubler plate welding}

A doubler plate welding repair is shown in Fig. 4.6. Structural capacity and leaktight integrity are provided in this repair technique by removing the damaged portion of the metal shell, fitting a larger plate over the hole, performing the necessary repair welding and PWHT, and conducting the required nondestructive evaluations and leakage-rate tests.

\subsubsection{Stiffener plate welding}

Installation of stiffener plates as shown in Fig 4.7 is another repair technique that could be used to strengthen the remaining shell without affecting the leaktightness of the containment. Use of stiffener plates eliminates the need for repair of the corroded surface by providing additional structural elements to restore structural integrity. Because this 
repair technique does not involve repair of the corroded surface, it has no effect on the leaktight integrity of the containment.

\subsubsection{Overlay welding}

Surface overlay welding as shown in Fig. 4.8 might be considered the most desirable alternative repair technique. Use of surface overlay welding eliminates the need for repair of the corroded surface by providing sufficient replacement metal to restore structural integrity. This repair technique is also desirable because it has no effect on the leaktightness of the containment.

\subsubsection{Temporary Non-Code Repairs}

Whenever leakage from an ASME Code Class 1,2, or 3 component pressure boundary (e.g., pipe wall, valve body, and pump casing,) is discovered, the component must be declared inoperable (4.33). If the flaw is detected while the plant is in operation, the plant may need to be shut down before the flawed component can be repaired or replaced and the plant returned to a safe operating condition. Rules for repairing flawed components are provided in Section XI, Subsection IWA (4.7) of the Code. Repairs completed in accordance with these requirements ensure that the structural integrity of the component has been restored.

Repairs not in compliance with rules provided in Section XI (4.7) of the Code are considered non-code repairs. Techniques that could be used to make temporary non-code repairs to flawed piping include clamps with rubber gaskets, encapsulation of leaking pipes in cans using liquid sealants, and certain types of weld overlays. However, temporary non-code repairs of ASME Code Class 1,2, and 3 piping are considered unacceptable unless they are first approved in writing by the NRC. Guidance from the NRC for performing non-code repairs to flawed piping is provided in Generic Letter 90-05 (4.34). For Class 1, 2, and 3 piping, a licensee is required to perform code repairs or request the NRC to grant relief for temporary non-code repairs on a case-by-case basis regardless of pipe size. Relief requests are usually made by licensees to avoid unscheduled plant shutdowns.

\subsubsection{Class 1 and 2 piping}

To be considered acceptable, temporary non-code repairs of Class 1 and 2 piping must have load-bearing capability similar to that provided by engineered weld overlays or engineered mechanical clamps. Relief requests based on repairs such as encapsulation of leaking pipes in cans using liquid sealants, clamps with rubber gasketing, or non-engineered weld overlays (patches) will not be granted because these repair techniques are considered unacceptable. However, engineered weld overlays or engineered mechanical clamps that are designed to meet the load-bearing requirements of the piping may be acceptable under certain conditions (4.34). Use of engineered weld overlays and engineered mechanical clamps in BWR plants is discussed in Generic Letter 88-01 $(4.35,4.36)$.

\subsubsection{Class 3 piping}

Because of the rather frequent instances of small leaks in some Class 3 piping systems, such as service water systems, relief requests for temporary non-code repairs of Class 3 piping will be considered by the NRC. Guidance for such a request consists of assessing the structural integrity of the flawed piping by a flaw evaluation and the overall degradation of the system by an augmented inspection. In addition, the licensee evaluation should consider system interactions such as flooding, spraying water on equipment, and loss of flow. Furthermore, temporary non-code repairs should be evaluated for design loading conditions.

Temporary non-code repairs of Class 3 piping in high-energy systems where the maximum operating temperature exceeds $93^{\circ} \mathrm{C}$ or the maximum operating pressure exceeds $1.9 \mathrm{MPa}$, must have load-bearing capability similar to that provided by engineered weld overlays or engineered mechanical clamps. Licensee requests for high-energy Class 3 piping repairs based on techniques such as encapsulation of leaking pipes in cans using liquid sealants, clamps with rubber gasketing, or non-engineered weld overlays (patches) are not considered acceptable. For temporary non-code repairs of Class 3 piping in moderate-energy systems, that is, other than high-energy systems, the licensee may consider non-welded repairs. To ensure acceptable in-service performance, the structural integrity of the temporary non-code repair of Class 3 piping should be assessed periodically. 
For Class 3 piping, two specific flaw evaluation approaches should be considered, namely, the "through-wall flaw" and the "wall thinning" approaches. If the flaw is found acceptable by the "through-wall flaw" approach, a temporary noncode repair may be proposed. If the flaw is found acceptable by the "wall thinning" approach, immediate repair is not required but the licensee should comply with the guideline for repair and monitoring. An augmented inspection is a part of the relief acceptance criteria. The extent of the augmented inspection is more stringent for high-energy lines than for moderate-energy lines because of the potential for more severe failure consequences.

A request for relief from requirements of Section XI (4.7) of the Code was submitted to the NRC on January 16, 1991 (4.37). The request was prepared in accordance with guidance provided in Generic Letter 90-05 (4.34) to cover temporary non-code repairs of Class 3 stainless steel piping located inside the containment. During the latter stages of a scheduled refueling outage, nondestructive examinations of service water system supply and return piping for a containment fan cooler and service water containment penetrations produced indications of degradation resulting from microbiologically-induced corrosion (MIC). Although the defects were within ASME Code allowable limits, flaw growth rates in the presence of MIC are not predictable making continued use of the service water system during the next operating cycle unjustified. Relief was requested to allow the installation of welded stainless steel sleeves over susceptible welds in the service water piping and over welds at containment penetrations that indicated MIC damage. Figures 4.9 and 4.10 show the proposed repair configurations. According to the request, the sleeves constituted an engineering repair, restored the piping to its full structural and pressure-retaining capability, and complied with Section XI repair requirements with the single exception that existing flaws were not removed.

\subsubsection{Containment pressure boundary components}

Containment pressure boundary component degradation is usually discovered during a general inspection of accessible interior and exterior surface areas. General inspections are performed in accordance with 10 CFR 50 requirements. Flaws discovered as a result of these inspections and tests that do not meet acceptance criteria (defects) must be repaired before the plant is allowed to return to service. Consequently, there is no need for submitting a relief request to the NRC for a temporary non-code repair of the containment aimed at keeping the plant in operation until the next scheduled outage.

\subsubsection{Protective Coating Repairs}

Organic coating systems, or paints as they are more commonly known, are used in nuclear power plant containments to protect ferrous metal surfaces from corrosion and to facilitate decontamination of metal and concrete surfaces. Corrosion protection is needed for all exposed carbon steel items including surfaces of metal containment shells, concrete containment liners, structural steel elements, uninsulated mechanical equipment, piping system components and related hardware, and electrical-mechanical machinery. Protective coatings also play an important role in achieving and maintaining radiological control by providing surfaces that can be readily decontaminated. Although reasons for using protective coatings are based primarily on economic considerations, factors that could influence their use include material compatibility, heat transfer characteristics, and the consequences of failure during a design basis accident.

\subsubsection{Regulatory overview}

Application of protective coatings on structures, equipment, and components in nuclear power plants is not required by the NRC because coatings provide no specific safety-related function to mitigate the consequences of postulated accidents. However, quality assurance requirements provided in 10 CFR 50, Appendix B (4.38) are applicable to protective coatings because failure and disbonding during operating and emergency conditions could interfere with engineered safety systems required for safe shutdown and cooling of the reactor vessel. Potential consequences of protective coating failure are identified below (4.39).

- Massive delaminations or peeling of coatings during a loss-of-coolant accident could block containment sumps used to recirculate cooling water.

- Plugging of flow passages by paint chips or debris could block water flow to containment spray nozzles, emergency pumps, or the reactor core.

- Chemical- or mechanical-induced damage to the reactor coolant system such as intergranular stresscorrosion cracking and abrasion could be caused by the decomposition of coating materials and their subsequent chemical interaction with reactor safety system components (e.g., hydrogen generation due to radiolytic decomposition). 
Acceptance criteria for protective coating systems (including coating repairs) are provided in Sect. 6.1.2 of the NRC Standard Review Plan (4.40). According to these criteria, coating systems applied to the insides of containments are acceptable if they meet the regulatory positions of Regulatory Guide 1.54 (4.41) and the standards of ANSI N101.2 (4.42). Regulatory Guide 1.54 describes an acceptable method for complying with NRC quality assurance requirements with regard to protective coatings applied to ferritic steels, aluminum, stainless steel, zinc-coated (galvanized) steel, concrete, or masonry surfaces of water-cooled nuclear power plants. The requirements and guidelines included in ANSI N101.4 (4.43) are generally acceptable, subject to the four exceptions listed in Regulatory Guide 1.54, because they provide an adequate basis for complying with the pertinent quality assurance requirements of 10 CFR 50, Appendix B (4.38). In addition, the containment coating system is acceptable if it has been evaluated as to its suitability to withstand a postulated design basis accident and qualified under conditions that take into account the postulated design basis accident.

Since ANSI N101.2, N101.4, and 5.12 (4.42-4.44) were issued in the early 1970s, responsibility for updating, rewriting, and issuing appropriate ANSI replacement standards has been transferred to ASTM, specifically ASTM Committee D33, on Protective Coating and Lining Work for Power Generation Facilities (4.45). After 25 years of inservice experience and performance data on protective coatings have been developed, a very restrictive set of guides, standard practices, specifications, test methods, and quality assurance requirements for coatings for use in nuclear power plants have been prepared and issued (4.45 to 4.62). Requirements for monitoring the effectiveness of maintenance of nuclear power plants are provided in 10 CFR 50.65 (4.63).

Technical guidance for NRC inspections of filled organic coatings used in maintenance of safety related-equipment is provided in the NRC Inspection Manual (4.64). According to this document, filled organic coatings including epoxy, polyester, urethane, and phenolic materials are appropriate for use over eroded or corroded areas provided the ASME Code minimum thickness has not been violated. Coatings are not ASME Code materials and thus cannot be used to perform structural repairs. Areas where the ASME Code minimums are not met must be replaced or restored by weld build-up in the location of the wall loss prior to application of the coating. Inspectors are instructed to ensure that the licensee has considered the following items:

- Is the selected coating appropriate for the system temperature, immersion service, chemical environment (pure water, sea water, borated water), and intended purpose (corrosion barrier versus erosion resistance)?

- Was ultrasonic testing performed prior to application of the coating to verify that minimum wall thickness requirements were satisfied?

- Have the consequences of a coating failure been analyzed?

- Were coating application procedures in place and followed?

- Were the coating manufacturer's specified time and temperature for adequate cure followed prior to returning equipment to service?

- Following coating applications to pumps, examine what performance testing was performed to verify pump acceptance.

\subsubsection{Potential degradation mechanisms and failure criteria}

Selection of an appropriate repair coating system for containment surfaces should include consideration of the expected service environment. The five major stressors that can potentially cause coating degradation are temperature, condensation and immersion, radiation, physical damage, and corrosion of base metal (4.65). Ways in which coatings can fail include checking, cracking, blistering, flaking, peeling, delamination, and scaling.

Checking is the phenomenon manifested in coating films by slight breaks in the film that do not penetrate through the last applied coating. Where precision is necessary in evaluating a coating film, checking may be described as visible (as seen with the naked eye) or as microscopic (as observed under a magnification up to 10x). Although checking is not easily recognized, a standard test method for evaluating the degree of checking has been established (4.66).

Cracking is a break or a split in the coating system extending through the film or to the substrate. Where this phenomenon is difficult to determine, the break should be called a crack only if the underlying surface is visible. The use of a magnification of $10 \mathrm{x}$ is recommended in cases where it is difficult to differentiate between cracking and checking. A standard method for evaluating the degree of cracking has been established. This method is based on comparison to pictorial standards (4.67). 
Blistering is the formation of bubbles in a coating film resulting from some weakness in the coating system. A standard procedure has been established for describing the size and density of blisters so that comparisons of severity can be made (4.68).

Flaking is a phenomenon manifested in coating films by the actual detachment of pieces of the film itself either from its substrate or from coating previously applied. Peeling, delamination, and scaling may also be used to describe this phenomenon which is generally preceded by cracking, checking, or blistering. Flaking is the result of loss of adhesion and is usually due to stress-strain factors coming into play. A standard method for evaluating the degree of failure has been established. This method is based on comparison to pictorial standards (4.69).

\subsubsection{Underwater coating repairs}

Protective coatings located in immersion areas of nuclear power plants have experienced premature failure while in service. Where the coating degradation and resulting pitting corrosion are localized, cleaning and coating repairs have been performed to halt the corrosion process and prevent additional coating degradation (4.70). In BWR plants, coating degradation has occurred in the suppression chambers where demineralized cooling water for the reactors is stored. The suppression chambers, which are part of the containment pressure boundary, are constructed of carbon-steel components that are, in most cases, coated. Materials located below the water line are exposed to aggressive environmental conditions including exposure to ionizing radiation and radiological contamination, high-pressure steam releases, decontamination operations, demineralized water immersion, and abrasive action from sludge (4.71). In PWR plants, premature coating failures can occur in immersion areas of condensate storage tanks.

Successful protective coating system performance depends on periodic inspections aimed at early detection of defects and failures, identification of repair alternatives, and timely execution of repairs. Options for coating inspection in immersion areas involve either draining to allow access for inspection personnel or underwater inspection by qualified divers.

Pitting corrosion is localized degradation that can be detected most effectively by draining the affected area and inspecting under dry conditions (4.72). Problems associated with draining the suppression chamber in a BWR plant include treatment of radiologically contaminated water, decontamination of all internal surfaces, and installation of rigging or scaffolding to provide the required access. Decontamination is a labor-intensive effort that may subject workers to increased risk of radiation exposure. In addition, mobilization and demobilization of equipment and personnel for decontamination, repair, and inspection can severely damage or destroy the original coating. Other activities related to suppression chamber draining include reactor vessel defueling, drain pump installation and operation, high-pressure water decontamination of all internal components, and packaging and disposal of radioactive waste.

The preferred alternative to draining the suppression chamber in a BWR plant is underwater inspection and repair. Potential advantages include reduced radiation exposure of personnel and elimination of the need for draining. Desludging, coating inspection, and underwater coating repair are the fundamental elements of this alternative (4.73). Desludging reduces radiological exposure and increases visibility. Sludge and debris accumulation is due primarily to corrosion products from uncoated piping systems. Removal is accomplished by divers using brushes that loosen the debris and high-volume vacuum systems that draw the debris through large-capacity, high-efficiency filters. Debris that is collected by the filters is treated as radioactive waste. After desludging operations are completed, a qualitative visual inspection of the entire surface area is performed to determine the overall condition of the coating and to identify areas where cracking, blistering, flaking, and corrosion have occurred. For those areas where general corrosion has occurred, sufficient nondestructive thickness measurement are obtained so that the wall thickness of the degraded component can be precisely established. In areas where localized or pitting corrosion has occurred, pit shape, density, and depth are established (4.74). Results of the nondestructive examinations should then be recorded and used to assess the current condition of the degraded component (4.75). The data may also be used as a baseline for trending future performance or for comparison with companion data to establish an instantaneous corrosion rate. Areas where the wall thickness is below the minimum acceptable level must be either repaired or replaced prior to coating.

Damaged coatings in areas without significant metal loss should be repaired using a 100 percent solids underwater-cured epoxy coating. Use of this type of epoxy should be considered because it is formulated to displace water in contact with the surface of the metal and it cures in 24 to 36 hours depending on the temperature. To maximize the quality of the epoxy coating repair, the spot should be cleaned with power grinding tools, the edges of the coating should be feathered, 
and adjacent areas should be roughened to provide good adhesion for the replacement coating. After cleaning, the epoxy coating should be applied to the bare metal and overlapped onto the existing coating. Although this underwater repair process is suitable for spot coating repairs, it is not recommended for major recoating work (4.73). As with any coating system used to protect containment pressure boundary components, the quality assurance requirements provided in 10 CFR 50, Appendix B (4.38) are applicable to underwater coating repairs.

\subsubsection{Options for Restoring Damaged Bellows}

Stainless steel bellows expansion joints are used in nuclear power plants as flexible seals between process piping and the containment vessel wall. The piping, which may carry steam or other liquids at high pressures and temperatures, moves under the influence of temperature changes and applied forces. As the pipe moves relative to the containment wall, the bellows expands and contracts to accommodate the differential movement while maintaining the leaktight integrity of the containment. When properly installed, the bellows is not part of the process piping. It is intended to serve as a pressure boundary between the inside of the containment vessel and the surrounding atmosphere. In order to serve its intended function, bellows expansion joints cannot withstand significant mechanical abuse. However, despite efforts to protect the bellows, inadvertent damage such as mechanical denting, arc strikes, tool gouges, and scratches have occurred making remedial action necessary.

During the early years of nuclear power plant construction, there were few successful attempts to repair bellows that had been damaged after installation. Manufacturers of stainless steel bellows discouraged attempts at repairs, and the ASME Code prohibited welding repairs on bellows. Eventually, advancements in welding capabilities and development of specially designed copper back-up dies permitted successful repairs to damaged bellows (4.76). Finally, after testing programs were conducted to develop data needed to understand the performance of repaired bellows, action was taken by ASME to approve a code case detailing rules under which repairs to bellows could be performed. Code Case N-315 (4.77) was approved on February 14, 1984. This code case addresses repair of bellows elements for Section III, Division 1, Class 2, 3, and MC construction (4.78).

Options for restoring the leaktightness and structural integrity of bellows that have been damaged while in service are described below $(4.76,4.79)$. However, restoration activities that produce discontinuities in the welds or base metal, changes in wall thickness resulting from the addition of welded patches or removal of metal by blending (grinding), or unevenness or irregularities in the bellows contour may affect the useful service life of the bellows.

\subsubsection{Replacement of penetration assembly}

Replacement of an entire penetration assembly that contains a damaged bellows is an option that could be taken, but this approach is generally not considered. Removal of walls and equipment to provide access necessary for the replacement would be expensive and time consuming, especially, if a plant shutdown is required to complete the replacement.

\subsubsection{Replacement of damaged bellows}

Removal of damaged bellows with one or more plies and replacement with a new one is a feasible option provided there is sufficient access for a crew of skilled craftsmen and their equipment. In this procedure, a new bellows element is cut in half using longitudinal saw cuts. After removal of the damaged bellows, the new bellows parts are reassembled around the penetration. Reconnection is a two-step process. The first step involves completion of the longitudinal seam welds that follow the contour of the convolutions. After these welds are completed, the circumferential attachment welds are completed joining the ends of the bellows to the pipe and the containment shell. Due to site-specific conditions, it may be necessary for the craftsmen to wear life-support equipment. Depending on the conditions, there may even be special restrictions on access frequency and time available at the work site because of radiation levels. For bellows replacement to be successful, thorough preparation, qualification, execution, and quality control are essential.

\subsubsection{Installation of new enveloping bellows}

When the outer ply of a two-ply bellows is damaged and its removal could damage an otherwise sound inner ply, a larger enveloping bellows can be installed around the damaged outer ply. Installation is similar to that described previously addressing replacement of damaged bellows except thick plate rings that extend outward from the existing bellows support pipe to the new bellows diameter are used to connect the new bellows to the pipe. The monitoring function that was lost when the outer ply of the original bellows was damaged now takes place in the annular space between the 
enveloping bellows and the inner ply of the original bellows. Although functional, the redesigned penetration assembly may need to be analyzed and evaluated to ensure that affected components can accommodate the change in spring constants resulting from the addition of the enveloping bellows.

\subsubsection{In-place welding repairs to damaged bellows}

In-place welding repairs have been successful in restoring the leaktight integrity of single-ply bellows and the outer ply of two-ply bellows. Holes as large as $25 \mathrm{~mm}$ in diameter have been effectively repaired with both insert plug patches and lapped patches. Slots up to $0.8 \mathrm{~mm}$ wide by $12.7 \mathrm{~mm}$ long have been sealed by groove welding and others have been sealed with fillet-welded lap patches.

According to requirements provided in Code Case N-315 (4.77), welding repairs of bellows elements may be made by an $\mathrm{N}$ Certificate Holder (4.14), but the size of the repair is limited to 2,580 sq. mm. Requirements for N Certificate Holders involved in Code Case N-315 bellows repair are provided elsewhere (4.77).

\subsubsection{Removal of severe dents}

When access permits, a small contoured anvil can be pushed into position inside a dented or mashed convolution to force the damaged surface to return essentially to its original shape. External cosmetic work such as blending is usually required while the anvil is in place.

\subsubsection{Blending the surface}

When bellows are found damaged with dents or gouges that are not considered severe, the stress intensifying characteristics of the abrupt change in contour can be lessened by surface blending. If some surface metal was removed when the damage occurred, an appraisal of the loss must be made with respect to pressure requirements. Obviously, it is desirable that little or no additional metal be removed at the deepest point during blending.

\subsubsection{Cathodic Protection}

Anodes are metallic surfaces where electrical current leaves the metal and enters the electrolyte. Locations where this occurs exhibit corrosion as metal ions form and electrons are released. Cathodes are metallic surfaces where electrical current enters the metal from the electrolyte. Anodes and cathodes can be two separate pieces of metal or different areas on the same piece of metal. Solutions ranging from fresh to salt water or the strongest alkalis to the strongest acids can serve as electrolytes provided they are capable of conducting electricity. Electrical connection between anodes and cathodes can be any metallic path that allows electrons to flow. Connection between anodic and cathodic areas on the same piece of metal is provided by the metal itself.

Corrosion of carbon steel in water occurs when iron losses electrons creating ferrous ions. These ions combine with water and oxygen to produce various compounds such as ferrous hydroxide and ferric oxide (rust) depending on the temperature and other environmental conditions. Corrosion protection for carbon-steel components exposed to air or water is often accomplished by applying a thin coating such as paint or zinc (galvanizing) to the surface. The coating keeps water from contacting the underlying metal thereby interrupting the electrical circuit between anodic and cathodic areas. An effective but less practical method is to keep the relative humidity of the surrounding air lower than a critical level below which water will not form on exposed surfaces. For iron, the critical relative humidity level is about 60 percent (4.80).

An alternative corrosion prevention technique that is quite effective under certain conditions is cathodic protection. Cathodic protection is defined as the reduction or elimination of corrosion by making the metal a cathode. This condition can be achieved either by attachment to a sacrificial anode or by means of an impressed direct current (4.80). In applying cathodic protection to a metal structure, the objective is to force the entire surface of the structure exposed to the environment to collect current from the environment making the exposed surface a cathode. When this condition is achieved, corrosion is successfully mitigated (4.81).

Cathodic protection can be used to maintain structures in their present service condition without allowing additional corrosion damage to occur (4.82). It can also be used to enhance the effectiveness of other corrosion mitigation techniques. Although cathodic protection may not necessarily be the only acceptable method for controlling corrosion at 
a specific location, it is the only technique capable of totally reversing those chemical and electrical phenomena causing corrosion. Long-term effective corrosion control is now possible with minimum routine monitoring and periodic system evaluation using automated data acquisition and control. However, cathodic protection should only be considered when there is an aging-management commitment to monitor and maintain the system. Advantages and disadvantages of cathodic protection systems are summarized in Table 4.7.

Although potentially useful in corrosion mitigation, cathodic protection should not be considered under the following conditions:

- For atmospherically exposed metallic components that extend from the concrete such as steel anchors and embedments, metal containment shells, and liners of reinforced concrete structures. These conditions are not suitable because an electrolyte such as concrete, soil, or water must exist between the steel and the anode.

- When a cathodic protection anode cannot be installed in an electrically continuous electrolyte with the steel. If the steel to be protected and the anode are separated by air or completely shielded by dielectric materials such as plastics or epoxy coatings, protection current cannot flow. In addition, if another metal, whether electrically continuous or discontinuous, partially shields the steel being protected, cathodic protection may not be applicable.

- If there is insufficient or no electrical continuity within the majority of the affected steel. Electrical continuity of reinforcing bars, steel embedments, and other metallic components can be measured and verified. When electrically discontinuous steel components are identified, electrical continuity between these components can be established by means of wire attachments or welding to another electrically continuous component. However, if the majority of reinforcing bars and steel embedments in a structure are not electrically continuous, this technique may not be practical.

- When the cathodic protection system cannot be designed to avoid hydrogen generation that could result in hydrogen embrittlement of posttensioning steel tendon or high-strength bolting materials.

\subsubsection{Sacrificial anode cathodic protection systems}

Sacrificial anode cathodic protection systems rely on a metal that is naturally anodic to the structure being protected in the environment of interest. Three metals - magnesium, zinc, and aluminum - are commonly used as sacrificial anodes (4.80). Magnesium is used routinely in buried soil applications, zinc is used in both fresh and marine water environments, and aluminum is used most often in offshore structures where lighter weight is important. These particular metals are well suited for use as sacrificial anodes because they exhibit well defined corrosion processes and are naturally anodic to carbon steels in most environments.

Basic components of a sacrificial anode cathodic protection system are identified in Table 4.8. Because these components generally require no routine maintenance during their useful service life, sacrificial anode cathodic protection systems are considered passive. The voltage difference between sacrificial anodes and cathodes is limited to about one volt or less depending on the anode material and the specific environment (4.80). This limitation reduces the current distribution pattern along the cathode and makes sacrificial anode cathodic protection systems less suited for use in freshwater applications and low-conductivity environments such as concrete.

Initial efforts to stop corrosion of the drywell at the Oyster Creek nuclear power plant included installation of a sacrificial anode cathodic protection system (4.83). This system relied on anodes that were inserted into the sandbed through small-diameter existing holes through the concrete biological shield wall. This scheme was only effective for a short period of time because, as the sand around the anodes dried out, the electrical circuit between the cathode (drywell shell) and the anodes was broken thereby rendering the system ineffective. Additional information about the Oyster Creek drywell corrosion problem is provided in Sect. 4.4.1.1.

\subsubsection{Impressed current cathodic protection systems}

Impressed current cathodic protection systems rely on an external electrical power source to provide the required direct current (DC). Batteries, engine generator sets, thermoelectric generators, fuel cells, and solar cells may be used to power this type of cathodic protection system, but rectifiers attached to alternating current (AC) utility power lines are frequently used. These systems, with their necessary array of electrical components, are more complex than sacrificial anode cathodic protection systems making them potentially less reliable.

Basic components of an impressed current cathodic protection system are identified in Table 4.9. To function properly, the positive terminal of the power source must be connected to the anodes and the negative terminal must be connected to the structure (cathode). Reversal of these connections will cause accelerated corrosion of the structure. 
Major differences in the application of impressed current cathodic protection to either atmospherically exposed, buried, or submerged structures are related to the type and the position of the anodes. For atmospherically exposed portions of chloride-ion contaminated reinforced concrete intake structures, the anodes must be distributed over the surface of the structure which is relatively close to the metal being protected. Anodes for underground or submerged structures are remotely placed in soil or water away from the structure and electrically connected to the structure being protected. Uniform protection current then flows for some distance through the electrolyte from the anodes to the structure. To ensure a long service life, anodes for impressed current cathodic protection systems are usually made from nonconsumable materials that are naturally cathodic to steel. High-silicon cast iron or graphite anodes are often used to protect buried or submerged structures while conductive polymeric materials and precious metals (platinized titanium or tantalum) are used to mitigate corrosion of steel embedded in concrete (4.81).

\subsubsection{Stray electrical current}

Unlike natural corrosion that is influenced by environmental factors such as oxygen concentration or $\mathrm{pH}$, stray-current corrosion is induced by errant electrical currents from an external source. Stray electrical current is defined as current that follows a path other than the intended circuit (4.82). For example, current that leaves its intended path because of insufficient electrical connections within the intended circuit or poor insulation around the intended conductive material and finds its way through an electrolyte to an alternate low-resistance metal conductor such as a buried pipeline is considered stray current. Accelerated corrosion occurs at locations along the surface of the alternate conductor where the stray current reenters the electrolyte. Fortunately, most electrical currents flow along an intended circuit and are therefore not classified as stray currents.

Stray electrical currents can originate from both AC and DC sources. Damage caused by stray AC is less common than that caused by DC because periodic reversal of current flow is not as detrimental as flow in only one direction. When stray AC causes corrosion, it usually decreases in severity as the frequency increases (4.82). Stray current can be either dynamic or static in nature. Static or steady-state stray currents exhibit little or no time-dependent variation whereas dynamic stray currents that vary in amplitude may change locations as a function of time as they pass to and from the electrolyte. Potential sources of stray electrical currents at nuclear power plants are identified in Table 4.10 (4.82).

It is often difficult to detect static stray current due to its non-changing nature. Time-dependent variations associated with dynamic stray currents are usually much easier to detect because of amplitude or frequency changes. Techniques most commonly used to detect stray electrical currents include half-cell potential measurements and cooperative testing. Reference electrodes such as copper-copper sulfate and silver-silver chloride are routinely used to make half-cell potential measurements. Each half cell consists of a pure metal in contact with a solution of known concentration of its own ions. When two half cells are coupled together to form a reference electrode, they create characteristic and reproducible electrical potentials that can be measured with a volt meter. Cooperative testing requires involvement with another party to determine the source of the stray current. Application of these techniques varies depending on whether the stray current is static or dynamic. In areas where dynamic stray current is suspected, electrical potential measurements acquired at prescribed time intervals can provide indications that the stray current fluctuates with time or is related to a periodic event. These indications can help identify the source(s) of the stray current. Data that exhibit constant response, such as no change in electrical potential with time, can be used to eliminate dynamic stray current from consideration.

When static stray current is suspected, time-dependent electrical potential measurements do not provide sufficient information to identify the source and other techniques must be used. One such technique involves acquiring half-cell potential measurements as a function of distance. High potential values may indicate locations where stray current is being picked up from the electrolyte. Areas where low potential values are measured may indicate locations where the stray current is reentering the electrolyte and accelerated corrosion is occurring. Another means available for determining static stray current is to identify the probable sources of DC and then ask the operators of the other sources to sequentially participate in cooperative testing. During cooperative testing, or interference testing as it is sometimes called, the other operators in turn cycle the current from their source "on" and "off." The owner of the structure experiencing the stray current then records half-cell potential measurements while the current sources are interrupted. After the source of stray current has been confirmed, potential solutions to the problem can be identified. In some applications, it may not be practical or advisable to interrupt the suspected current source. In these instances, it may be possible for the other party to simply vary the current so that intended fluctuations can be detected. If the cause of stray current corrosion cannot be modified or eliminated, it may be possible to use impressed current cathodic protection as a means to mitigate the effects of stray currents. 


\subsection{CASE HISTORIES}

Several incidences of corrosion of steel containments or liners of reinforced concrete containment have occurred. An overview of several is provided below.

\subsubsection{Metal Containment Corrosion}

Two well-documented incidences of metal containment corrosion occurred at Oyster Creek and Nine Mile Point Unit 1 Nuclear Power Stations. Metal containment corrosion has also been observed at two nuclear power plants in Germany.

\subsubsection{Drywell corrosion at Oyster Creek}

GPU Nuclear Corporation's Oyster Creek nuclear power plant is located near Forked River, New Jersey. This plant includes a BWR nuclear steam supply system with a Mark I pressure-suppression containment. The containment pressure boundary consists of a steel drywell that surrounds the reactor pressure vessel and much of the primary coolant piping, and a torus that is connected to the bottom of the drywell by ten vent pipes. In the unlikely event of an accident, the drywell and torus are designed to safely contain the heat, steam, and radioactive materials preventing their release into the surrounding environment. The containment is a code stamped pressure vessel that was constructed in the 1960s in accordance with requirements provided in Section VIII (4.84) of the Code.

The drywell is essentially a free-standing pressure vessel that is surrounded by a concrete biological shield wall. Support for the drywell, reactor pressure vessel, and other steam supply system components is provided by a concrete pedestal that extends upward from the bottom of the drywell shell. The bottom of the drywell shell rests on concrete that is part of the basemat foundation for the plant. There is a nominal 2.54- to 7.62-mm-thick air gap between the drywell shell and the concrete biological shield wall. This gap, which is filled with compressible insulation, allows the drywell to expand and contract in response to thermal and pressure loads during normal plant operations. A sandbed approximately $1.52 \mathrm{~m}$ tall by $0.38 \mathrm{~m}$ wide is provided at the base of the air gap where the outside of the drywell shell intersects with the concrete biological shield wall. This feature was required in the original design to provide transitional radial support for the drywell thereby reducing local stresses in the drywell shell.

In the early 1980s, water was discovered leaking out the top of the sandbed through an annulus around the torus vent line. Inspection of this area during a refueling outage revealed that water from the reactor cavity was leaking down and around the outside of the drywell, through the insulation in the air gap, and into the sandbed (4.85). During subsequent investigations, it was discovered that the five $102-\mathrm{mm}$ diameter drains that had been installed in the sandbed during the original construction of the plant to remove water from the sandbed were clogged allowing water to saturate the sand and corrode the outside surface of the exposed carbon steel drywell shell. After compacted sand was removed from the drain lines during the twelfth refueling outage in 1988, hundreds of liters (several hundred gallons) of water drained from the sandbed.

Because corrosion of the outside surface of the drywell shell was suspected, extensive ultrasonic testing (UT) was performed from inside the containment to determine the extent and severity of the degradation. These measurements revealed that thinning was most severe in the sandbed region where the original plate thickness was $29.3 \mathrm{~mm}$ and that shell thicknesses in some local areas were as low as $20.3 \mathrm{~mm}$. These findings were particularly alarming because the minimum acceptable drywell shell thickness in the sandbed region was $18.8 \mathrm{~mm}$. Verification of the UT measurements was achieved by removing 51-mm diameter cores from the drywell shell and physically measuring their thickness. Holes produced by the core drilling operation were replaced with machined plugs that were seal welded to the drywell shell from inside the containment. Figure 4.11 shows the repair technique used to replace the drywell shell material removed during the coring operation. Welding was performed in accordance with the rules and requirements of the original construction code and approved by an Authorized Nuclear Inspector. Once completed, inspected, tested, and accepted, the leak-tight integrity of the Oyster Creek containment was restored to its original condition.

Initial efforts to stop the corrosion process involved fixing leaks in the drywell-to-refueling-cavity seal and installing a cathodic protection system. Table 4.11 identifies potential water sources that were investigated at Oyster Creek and describes remedial actions that were taken to eliminate water from the sandbed. In 1988, anodes were inserted into the sandbed through small-diameter holes that penetrated the concrete biological shield wall. This scheme for arresting the corrosion process by controlling the flow of current between anodic and cathodic surfaces was only effective for a short period of time. As the sand around the anodes dried out, the electrical circuit between the cathode (drywell shell) and the 
anodes was broken thereby rendering the system ineffective. The ineffectiveness of the cathodic protection system was verified by UT measurements. Analysis of time-dependent UT data revealed that the rate of corrosion before and after installation of the cathodic protection system was the same.

After attempts to stop the corrosion process by application of cathodic protection failed, aggressive efforts were undertaken to remove the sand and apply a protective coating of epoxy paint to accessible areas of the drywell shell in the sandbed region. Access to the sandbed was provided by drilling $508-\mathrm{mm}$ diameter holes through the concrete biological shield wall about $305 \mathrm{~mm}$ away from the ten vent lines. These holes, which were completed in November 1992, were large enough to allow workers to crawl from the torus region into the sandbed. About one week into the fourteenth refueling outage that started on November 28, 1992, workers entered the sandbed and began vacuuming out the sand and cleaning the drywell shell surface in preparation for painting. The workers discovered that the corrosion was relatively uniform and that it could be easily removed with scrapers and hand-held equipment. By the end of January 1993, the drywell shell had been cleaned and painted with a two-part, self-curing epoxy coating allowing the plant to return to service at the end of the refueling outage in early February. Application of the protective coating on the outside of the drywell shell was not required by the NRC because coatings provide no specific safety-related function to mitigate the consequences of postulated accidents. Quality assurance requirements provided in 10 CFR 50, Appendix B (4.38) also were not applicable in this situation because failure and disbonding during operating and emergency conditions would not interfere with engineered safety system required for safe shutdown and cooling of the reactor vessel.

As the sand was being removed, workers discovered other problems.

- The floor of the sandbed was rough and irregular (large voids were found in some parts of the sandbed floor).

- Segments of reinforcing bars were not embedded in concrete.

- The drain pipes were protruding about 76 to $102 \mathrm{~mm}$ above the rough concrete floor surface.

According to the original design documents, a smooth concrete floor with troughs leading to the five drains was to have been constructed to serve as the floor for the sandbed. Because this work was never performed, some standing water always remained at the bottom of the sandbed to sustain the corrosion process even when the drains were functioning properly. In order to solve this problem, a new sandbed floor was installed using an epoxy-based system to fill in the voids, cover the exposed reinforcing bars, and pour a new floor up to the level of the top of the five drain pipes.

Even though the original design called for sand to be installed in the sandbed to provide transitional radial support for the drywell shell, sand was not reinstalled after the floor was repaired and the walls were painted. This consensus decision between GPU Nuclear, General Electric, and NRC personnel was based on results of detailed analytical studies performed to resolve this issue. Results of the entire Oyster Creek investigation also provided the basis for reducing the containment peak pressure from $427 \mathrm{kPa}$ to $303 \mathrm{kPa}$ and for establishing a new minimum drywell shell thickness in the sandbed region of $13.7 \mathrm{~mm}$.

Monitoring of the long-term performance of the drywell shell continues as part of the overall aging management strategy. Monitoring activities include:

- periodic visual examinations of the epoxy paint,

- UT measurements of the drywell shell above the sandbed, and

- inspections for leakage from the reactor cavity.

So far, no additional thinning of the drywell shell has been detected, the epoxy paint appears to be in excellent condition, and efforts to eliminate water from the sandbed region have been effective.

In the event that remedial actions are required in the future, contingency plans have been prepared for repairing the drywell shell to restore its structural integrity. The four repair welding techniques that are addressed in the plan include:

- replacement plate repair welding,

- doubler plate repair welding,

- $\quad$ stiffener plate repair welding, and

- $\quad$ surface overlay repair welding. 
These techniques were discussed in the previous section on welding repair alternatives for inaccessible areas and illustrated in Figs. 4.5 to 4.8 .

\subsubsection{Torus corrosion at Nine Mile Point Unit 1}

Nine Mile Point Unit 1 nuclear power plant is located near Lycoming, New York on the southeastern shore of Lake Ontario. This plant includes a BWR nuclear steam supply system that produces 1,850 MWt and a Mark I pressure suppression containment. The torus is a free-standing carbon steel pressure vessel that was fabricated in 1965 by Chicago Bridge and Iron, Co. (4.86) and consists of 20 pipe-shaped segments or bays that are mitered and welded together. The diameter of the pipe-shaped segments is $8.23 \mathrm{~m}$ and the total length of the torus is $112 \mathrm{~m}$. Structural support is provided by a series of steel columns that are welded to the torus shell and rest on a concrete floor slab. Four columns are provided in every other bay; two on the outer side and two on the inner side of the torus. The bottom surface of the torus is about $450 \mathrm{~mm}$ above the concrete floor. A concrete biological shield wall surrounds the torus creating an enclosure called the torus room. Carbon steel plates that conformed to ASTM A 201*, Grade B requirements were used to fabricate the torus shell (4.87). The nominal thickness of these plates was $11.7 \mathrm{~mm}$ which included a $1.6 \mathrm{~mm}$ corrosion allowance. Most areas on the outside surface of the torus are accessible for visual inspection, but the surface is coated to prevent corrosion. The inside of the torus is partially filled with water, and all surfaces above and below the water line are not coated. Consequently, thinning of the torus shell due to corrosion has slowly occurred.

The thickness of the torus shell has been monitored since 1975 because of its degradation potential and significance to containment integrity. Periodic UT was performed to quantify the amount of wall thinning that had occurred and to estimate the rate of corrosion. Based on visual inspections performed inside the torus, nondestructive examination results, and laboratory analyses of water samples, it was concluded that the observed wall thinning was being caused by general corrosion and that local attack (pitting, crevice, and biological corrosion) was not occurring. In about 1980, the torus was reanalyzed to address new load combinations and ASME Code allowable stresses. These analyses were based on the minimum nominal wall thickness of $11.7 \mathrm{~mm}$ and took full credit for the $1.6 \mathrm{~mm}$ corrosion allowance provided in the original design calculations. After NRC inspections in March 1988 revealed that the torus wall was very near its minimum allowable thickness, additional calculations were performed establishing a worst case minimum wall thickness of $11.4 \mathrm{~mm}$. These calculations reflected a reduction in condensation oscillation loads and indicated that the most critical location was at the bottom of the torus shell.

Following the engineering evaluation, a new corrosion monitoring program was initiated in August 1989 to measure the thickness of all 40 mid-bay plates on the bottom surface of the torus. Part of the program included suspending metal samples in the torus water so that the thickness of these samples could also be periodically measured. The samples were fabricated from carbon steel that conformed to ASTM A 516, Gr. 70 requirements (4.88). Prior to installation, the samples were preconditioned in the same way that laboratory corrosion test specimens are preconditioned prior to exposure testing (4.98). This particular steel was used because steel conforming to ASTM A 201, Gr. B requirements was no longer manufactured, and its chemistry was similar to that used in construction of the torus shell. Since the monitoring program began, UT measurements have been performed at six-month intervals. Every effort is made to use the same personnel and equipment to examine the same locations during each inspection. Results of these UT measurements are used to update the thickness of the plates and to estimate remaining service life of the torus. At the current rate of corrosion, It was estimated that the torus shell will be at its minimum acceptable thickness in about the year 2007, which is very near the end of its 40-year operating license. Additional background information about the corrosion at Nine Mile Point, Unit 1 and analyses performed by Brookhaven National Laboratory to address this type of Mark I torus problem are presented in a reported issued by the NRC (4.90).

Over the years, a number of options to mitigate the effects of corrosion were explored by Niagara Mohawk. These options included:

- $\quad$ using a corrosion inhibitor in the torus water,

- $\quad$ inerting the torus with nitrogen during outages,

- $\quad$ coating the inside surface of the torus,

- $\quad$ installing a cathodic protection system, and

- modifying the torus to improve its structural capacity.

*Material specification ASTM A 201 was discontinued in 1966 and replaced by ASTM A 515. 
So far, no actions have been taken to implement any of these options. A brief discussion of these options and reasons for rejecting or further considering each option are provided below.

\subsection{Corrosion inhibitors}

Addition of chemicals to the torus water was rejected for the following reasons. Chemicals to scavenge oxygen, such as hydrazine, would require removal prior to startup; could produce undesirable gases, such as ammonia; could cause $\mathrm{pH}$ problems; and could be a safety risk (i.e., carcinogenic). In addition, the possible gains in terms of reducing corrosion were estimated to be minimal.

\subsection{Inerting the torus}

Maintaining a nitrogen purge on the torus during outages was rejected because of safety concerns. Nitrogen could escape or leak from the torus into the drywell resulting in pockets of low oxygen concentrations. Atmospheric conditions like this could create a potential suffocation hazard for workers.

\subsection{Coatings}

Despite the potential benefits of an effective coating system, application of either an organic or a metal spray protective coating on the inside surface of the torus was rejected. Reasons for rejection include outage critical path impacts, the relatively short service life of a coating in this service environment, the need for extensive long-term maintenance, and as-low-as-reasonably-achievable considerations. Application of a coating system would require removing the water, sludge, and debris from the torus and thoroughly cleaning all exposed surfaces in preparation for the coating. Of the two coating systems considered, application of a metal spray, such as zinc, zinc-aluminum, or aluminum, would provide at least one distinct advantage over an organic coating. The metal spray coating could be classified as non-safety related. Unlike organic paints and epoxies that fail by producing loose flakes or sheets that could potentially clog the emergency core cooling system (ECCS), consequences of metal spray coating failure would likely not affect plant safety. A catastrophic metal spray failure would result in sheets of metal falling from the surface and sinking to the bottom of the torus without affecting the performance of the ECCS. Compared to organic coatings, metal spray coatings take somewhat longer to apply. However, the time difference is not considered significant.

\subsection{Cathodic protection}

Installation of sacrificial anodes and an impressed current cathodic protection system were considered to stop the corrosion process. In the sacrificial anode concept, either zinc anodes would be placed in the water and electrically connected to the torus shell, or zinc screens would be welded to the torus shell surface. After installation, the zinc would create a passive protection system requiring no periodic maintenance. However, use of sacrificial anodes was not considered feasible due to low conductivity of the water. An alternative approach based on an impressed current cathodic protection system for this application would be more complex than the sacrificial anodes system just described. This active system would require installation of an electrical conductor 360 degrees around the torus with direct current applied between the cable and the torus shell. Direct current would be supplied by a rectifier powered by an alternating current source. For the system to function properly and provide the required corrosion protection, the conductor would need to be installed under water and supported by structures attached to the torus shell. Due to concerns about loads imposed on the conductor and its support structure during a loss of coolant accident, and the impracticality of installing a suitable system, installation of an impressed current cathodic protection system also was not considered feasible.

\subsection{Structural modifications}

Based on available information, the most viable option involved structural modifications to the torus shell to enhance its ability to resist applied loads. In this concept, eight stiffener rings would be fillet welded to the outside surface of the torus shell on each of the 20 bays. The stiffener rings would be fabricated from 457-mm wide by $12.7-\mathrm{mm}$ thick carbon steel plates rolled through the thickness to conform to the outside surface of the torus shell. All eight stiffener rings for each bay would be spaced longitudinally at $305-\mathrm{mm}$ intervals. The four center stiffener rings would extend 210 degrees around the shell and be centered about the bottom of the torus. Figure 4.12 shows a conceptual view of how these four stiffener rings would be installed on each of the 20 bays. Two adjacent stiffener rings would extend 15 degrees above the horizontal centerline on the outer part of the torus and terminate at the inner column wing plates. The final two stiffener rings would be coped between the outer column wing plates and the miter joint between bays on the inner part 
of the torus. To accommodate obstructions such as penetrations and reinforcing pads, the stiffener rings would be coped around or bridged to adjacent rings to provide an acceptable load path. The configuration of the stiffener rings to accommodate these obstructions would be developed to allow sufficient access for inspection of the stiffener plate to torus shell fillet welds.

Each ring would be prefabricated in sections that would be approximately 4-m long. This dimension was selected to facilitate movement into the torus room. Once inside, the ring sections would be assembled on the floor, welded together, and then turned and lifted into position. Inherent flexibility of the thin stiffener rings would allow spreading to fit a curvature greater than 180 degrees. In order to minimize the impact on plant operations, it was desired that these stiffener rings be installed while the plant was in operation. Under these conditions, the torus would contain water making it necessary to weld some parts of each stiffener ring with water backing. The feasibility of performing such welding has not been fully investigated and may not be permitted based on rules provided in applicable sections of the ASME Code. The structural modifications would be performed in phases with work starting first on selected bays. Presuming installation during operations is feasible, initial considerations suggest that the work could proceed on one or more bays at a time without affecting operations or jeopardizing the integrity of the remaining bays. However, analyses of an asymmetric torus configuration has not been completed. If this option would be selected, installation of the stiffener rings would reestablish an adequate corrosion allowance for the projected remaining plant life plus a 20 -year extension.

\subsubsection{Metal containment corrosion in Germany}

There are 20 operating nuclear power plants in Germany. The majority of these plants are of the PWR type with spherical-steel containments that range in diameter from 44 to $56 \mathrm{~m}$. Older containments have a $30-\mathrm{mm}$-thick metal shell with a $1-\mathrm{mm}$ corrosion allowance. Newer designs use a $38-\mathrm{mm}$-thick metal shell with a 2-mm corrosion allowance. Except for the lower portion of the metal containment shell embedded in concrete, all areas of the shell are coated. A reinforced concrete shield building about 1.5 to $1.8 \mathrm{~m}$ in thickness surrounds each metal containment primarily to provide protection from aircraft impact. The metal containment shell and the shield building are isolated from each other except for a common foundation.

Instances of metal containment corrosion have occurred at the Obrigheim (KWO) and Neckar I (GKN-1) nuclear power plants (4.91). These plants are PWRs that started commercial operation in March 1969 and December 1976, respectively. Corrosion was detected during an inspection of the KWO plant on the inside surface of the containment in the transition area where the metal shell becomes embedded in the concrete floor slab. Thermal insulation was installed at this location during construction to protect the metal shell from high-temperature exposure during a loss-of-coolant accident. Corrosion of the metal shell occurred when high humidity levels inside the containment penetrated the thermal insulation and reached the inside surface of the metal shell. The average depth of corrosion adjacent to the moist insulation was about $1 \mathrm{~mm}$ with local areas to $6 \mathrm{~mm}$. In addition to corrosion of the metal shell, galvanized sheet metal covers installed over the insulation were also heavily corroded. During inspection of the KWO plant, a portion of the concrete adjacent to the outside surface of the metal shell was removed to a depth of about $100 \mathrm{~mm}$ to provide access for visual examination of this suspect area. This examination revealed no corrosion.

Using information obtained from the condition assessments, an evaluation of the degradation was performed indicating that the corrosion was limited, it was not significant enough to present a safety problem, and the metal shell did not need to be restored to its original thickness. Based on these conclusions, a repair program designed to halt the corrosion process and thereby stop further degradation was developed and implemented. Inside the containment, corroded areas of the metal shell were cleaned and reconditioned, a coating was applied to affected areas, and a new seal design (silicone plus metal covers) was installed at the interface between the metal shell and the concrete floor slab. The thermal insulation was not reinstalled because the evaluation revealed that it was not needed. Outside the containment, areas of concern were coated and the thermal insulation was reinstalled at the interface between the metal shell and concrete.

Inspection of the GKN-1 containment revealed corrosion on the inside surface of the metal shell in a transition region similar to that in the KWO plant. Based on this finding, the same repair procedure used at the KWO plant was implemented. Damage observed at the GKN-1 plant provided the basis for recommending that all plants having a transition region of similar design be inspected to determine if the thermal insulation is moist and the metal shell has corroded. 
A similar investigation at BWR plants was also performed. Suspect areas such as the transition region where the metal shell penetrates the concrete and locations where platforms are in close proximity to the metal shell were inspected, but no corrosion was detected.

\subsubsection{Liner plate corrosion in concrete containments}

Liners of reinforced and post-tensioned concrete containments are typically constructed using relatively thin [about 6.4-mm thick] carbon steel plates that are welded together to create a leak-tight barrier against the uncontrolled release of radioactivity to the surrounding environment. Although liner plates are not designed to carry loads, corrosion could have a detrimental effect on containment reliability and availability under design basis accidents and beyond design basis events. Any liner plate thinning can create geometrical transitions that influence strain concentration. This influence could change the failure threshold under challenging environmental or accident conditions and may reduce the design margin of safety. Corrosion that results in thinning, pitting, or cracking is of particular concern when the entire thickness of the liner plate is affected. Holes, pits, and cracks that penetrate completely through the liner plate disrupt the pressure boundary and may create pathways to the surrounding environment. Instances of liner plate corrosion have been reported at nuclear power plants in the United States and France.

\subsubsection{U.S. experience}

Potential locations for containment liner plate corrosion in nuclear power plants in the United States include:

- $\quad$ the junction of the containment cylinder and intermediate floors and basemat concrete for PWR and BWR Mark III containments,

- the junction of the drywell and the base or intermediate concrete floors for BWR Mark I and II containments,

- $\quad$ surfaces adjacent to crane rail girders and supports attached to the liner plate,

- $\quad$ water-soaked areas where carbon steel liner plate is used in BWR Mark I and II containments, and

- $\quad$ surfaces behind insulation and ice condenser baskets.

Inspections of containment liners have shown various degrees of corrosion at six nuclear power plants (4.92). The types of corrosion that were detected are described below.

- Corrosion of the drywell liner was detected at Brunswick, Units 1 and 2 at various locations near the junction of the concrete floor and the drywell liner. $\bullet$

- $\quad$ Peeled coatings and spots of liner corrosion were identified at Trojan and Beaver Valley, Unit 1.

- Minor corrosion of the containment liner at Salem Unit 2 was detected prior to an integrated leakage-rate test.

- Discoloration of the vertical portion of the containment liner was observed at an insulation joint at Robinson Unit 2.

From a safety viewpoint, the only corrosion that was considered significant occurred inside the two Mark I concrete containments at the Brunswick nuclear power plant located approximately $3 \mathrm{~km}$ north of Southport, North Carolina (4.93-4.100). General and pitting corrosion affecting as much as 50 percent of the nominal 8-mm thick liner was detected at several locations along a narrow band around the inside circumference of both drywells. The corrosion was caused by an accumulation of water at the junction of the drywell liner and the concrete floor surface (Elev. 4'-6") at the bottom of the containment. Degradation of sealing materials applied around the inside circumference of the containments at this junction allowed the water to enter and accumulate in this region. Procedures used by the licensee to quantify the extent and depth of the corrosion damage involved:

- $\quad$ removing concrete adjacent to the liner to provide access for inspection (Unit 1 only),

- $\quad$ cleaning (sandblasting and wire brushing) the liner plates,

- $\quad$ selecting designated inspection zones,

- $\quad$ measuring the base metal plate thickness using ultrasonic testing methods, and

- determining the depth of pitting and general corrosion using dental molding compound.

- Corrosion of the liner ranging from clusters of surface pitting to a 2-mm-diameter hole has also been observed at Brunswick Unit 2 (4.93). Corrosion has also formed a 6-mm-diameter hole in the liner at North Anna 2 (4.94). 
Metal loss and pitting depth measurements revealed that there were locations of the liners that were below the minimum acceptable thickness of $5 \mathrm{~mm}$. Five such sections were identified in Unit 2, but the damage in Unit 1 was more severe. Corrosion was observed around virtually the entire circumference of the Unit 1 drywell. The damage even extended below the level of the concrete floor surface making removal of concrete adjacent to the liner necessary. Although corrosion of the drywell liner for Unit 1 was more severe than the corrosion for Unit 2, the leaktight integrity of both Brunswick containments was never jeopardized because the thinning and pitting did not penetrate completely through the liner plates.

In order to restore damaged liner plates to the required minimum thickness and thereby allow the units to be returned to service, the licensee performed a series of construction activities. Details of these activities are described below. Figure 4.13 shows a cross section of the drywell liner repair for the Unit 1 containment.

- Areas with significant metal loss or pitting were repaired by overlay welding in which weld metal was deposited on the damaged liner plates to supplement the existing thickness. During welding, efforts were taken to limit the interpass temperature of the liner plates to $79^{\circ} \mathrm{C}$.

- Following welding, each area was examined using the liquid penetrant test method. Results of this test were used to determine the acceptability of the welding repairs. All damaged and repaired areas were recoated.

- Mortar was placed in Unit 1 to return the concrete floor to its original elevation and configuration.

- Intersections of the concrete floors and drywell liners were sealed with an elastomeric sealant.

\subsubsection{French experience}

Electricite de France discovered liner plate corrosion near the bottom of several of its thirty-four 900-MW PWR posttensioned concrete containments (4.101). Corrosion of the 6-mm-thick carbon steel liner plates occurred in two separate areas. Both areas were inside the containments and involved liner plates located between the basemat and the 1-m-thick concrete floor slab.

Liner plate corrosion was first detected at a plant that had been in service for about 10-15 years. Corrosion occurred in the conical-shaped portion of the liner in an inaccessible area located beneath the concrete floor slab. The corrosion started near the joint sealant at the intersection of the concrete floor and the steel liner and extended downward about $200 \mathrm{~mm}$. At some locations the corrosion produced holes through the liner plates that were up to $10 \mathrm{~mm}$ in diameter. The cause for the corrosion was attributed to a breakdown in the joint sealant in conjunction with the presence of high humidity during construction and operation. Examination of construction details in this area also revealed that water containing corrosive substances was stagnating in some of the pressurization channels that were welded to the outer surface of the liner. These channels were installed during construction and used to inspect the welds that joined the liner plate sections. After the concrete was placed and construction completed, access to the space between the channels and the liner plates was restricted making inspection impossible.

Thinning of liner plates was also observed in some plants at the bottom of the joint in the concrete floor slab. The corrosion reduced the thickness of the liner plates to $3 \mathrm{~mm}$ in some locations. This damage was attributed to decomposition of the joint sealant and the presence of acidic water $(\mathrm{pH}=5)$ at the liner-concrete interface.

In order to halt the corrosion process and stop further damage, the French developed a repair technique. Steps taken to repair pits and holes through the liner plates involved removing portions of the concrete floor slab at selected locations, sandblasting the corroded liner plates, inspecting the damaged areas, welding cover plates over the pits and holes, coating (painting) the repaired areas, and replacing the concrete to restore the floor to its original configuration. In addition, the pressurization channels were filled with cement grout, the cavity between the liner and the floor slab was filled with a corrosion inhibitor (wax), and a new joint sealant was installed. The new joint sealant consisted of a composite elastomeric material that was shielded by a series of metallic sheets attached by bolts. This method of attachment was selected so that the sheets could be periodically removed to provide access for inspection of the elastomeric material.

Even though corrosion produced pits and holes through the liner plates at some plants, air that escaped from the containments through these holes during periodic integrated leakage-rate tests did not adversely affect the test results. The measured leakage from the containment was less than the allowable leakage limit. 


\subsection{COMMENTARY}

Welding provides an effective means for making the types of high-quality repairs that are required by utility owners, jurisdictional authorities, and regulatory agencies. Rules for routine welding are available in codes and standards for repair situations where the area to be repaired is readily accessible by a skilled workman equipped with the necessary tools. Although intended for routine welding activities, these rules contain numerous exceptions and limitations that must be considered by the Owner as plans for the repair or replacement are being developed. Addressed in the next two sections are: (1) identification and description of major topics addressed by these rules along with some of the more significant exceptions and limitations for repair and replacement of degraded containment pressure boundary components and (2) special restoration practices for containment pressure boundary component repair or replacement situations not specifically covered by rules provided in the ASME Code. In addition, candidate research topics as identified.

\subsubsection{Routine Welding Repair and Replacement Topics}

The following topics present important rules, exceptions, and limitations for routine welding activities. These topics will likely be addressed in plans submitted by an Owner to the $\mathrm{NRC}$ for consideration for performing a containment pressure boundary component repair or replacement.

- Ferrous material specifications permitted for repairs and construction of replacements for metal containments and liners of concrete containments are provided in Section II, Part A (4.16) of the Code.

- Welding material specifications permitted for repairs and construction of replacements for metal containments and liners of concrete containments are provided in Section II, Part C (4.18) of the Code.

- According to the repair and replacement requirements provided in Section XI, Subsection IWA-4000 (4.7) of the Code, welding repairs to similar materials, dissimilar materials, or austenitic stainless steel and nickel-base cladding may only be performed using either the shielded metal-arc welding (SMAW) or the gas tungsten-arc welding (GTAW) process. The following exceptions and limitations for these categories of repair welding may apply, however.

- Butter bead - temper bead welding is intended for use in the repair of metal and concrete containment pressure boundary components where preheat and post-weld heat treatment are impractical. Requirements for this technique are provided in Section XI, Subsection IWA-4540 (4.7) of the Code.

- Requirements for welding procedure and welding performance qualifications using the SMAW and GTAW processes are provided in Section IX (4.19) of the Code. Exceptions and modifications to these requirements as well as repair welding requirements are provided in the construction codes and in Section XI, Subsection IWA-4000 (4.7) of the Code.

- Before containment pressure boundary components can be repair welded, a welding procedure specification must be developed and qualified. Its purpose is to determine whether the proposed weldment is capable of providing the required properties for the intended application.

- After a suitable welding procedure specification has been qualified, tests to qualify the performance of the welders and welding operators that actually perform the required welding must be conducted. Performance qualification requirements are provided in Section IX (4.19) of the Code.

\subsubsection{Special Welding Repair and Replacement Topics}

The following topics present special rules and technical issues that pertain to containment pressure boundary component repair and replacement situations not specifically covered by rules provided in the ASME Code.

- Supplementary rules for dry and wet underwater welding repairs or replacements of P-No. 8 (austenitic stainless steel) and P-No. 4X (low-alloy steel) materials are provided in Code Case N-516 (4.26). When applicable, these methods can be used in lieu of the alternative welding methods permitted in Section XI, Subsection IWA-4500 (4.7) of the Code provided all other applicable requirements of Section XI are met. Similar code cases for underwater welding of other materials such as carbon steels permitted for construction of containment pressure boundary components have not been approved by ASME.

- When welding is performed on a metal containment shell or a concrete containment liner backed by concrete, the rate of heat dissipation can affect the quality of the deposited weld metal. Consequently, measures necessary for assuring predictable weldment behavior should be factored into the development of a suitable welding procedure specification and welder/welding operator performance qualification. Although the ASME Code rules and 
requirements are considered comprehensive and complete for most routine welding activities, they do not adequately address the impacts that repair welding operations and the resulting high temperatures can have on adjacent concrete and metallic components including embedment anchors and reinforcing bars embedded in the concrete.

- Innovative welding solutions are being considered for the repair of degraded carbon and low-alloy steel components located in inaccessible areas. One innovative solution under development involves an outside surface weld overlay repair to remedy inside surface erosion-corrosion damage to carbon steel piping (4.32). Use of this technique would eliminate the need for repair of the inside pipe surface by providing sufficient replacement metal on the outside of the pipe to restore structural integrity.

- Welding repair alternatives are being considered for the restoration of structural integrity to degraded metal containments and liners of concrete containments located in inaccessible areas. Before such alternatives can be implemented, they must first be adequately developed and thoroughly tested and then submitted for ASME consideration as a code case.

- Repairs not in compliance with rules provided in Section XI (4.7) of the Code are considered non-code repairs. Techniques that could be used to make temporary non-code repairs to flawed piping include clamps with rubber gaskets, encapsulation of leaking pipes in cans using liquid sealants, and certain types of weld overlays. Temporary non-code repairs of ASME Code Class 1,2, and 3 piping are considered unacceptable unless they are first approved in writing by the NRC. Guidance from the NRC for performing non-code repairs to flawed piping is provided in Generic Letter 90-05 (4.34). For Class 1, 2, and 3 piping, a licensee is required to perform code repairs or request the NRC to grant relief for temporary non-code repairs on a case-by-case basis regardless of pipe size. Relief requests are usually made by licensees to avoid unscheduled plant shutdowns.

- Containment pressure boundary component degradation is usually discovered during a visual examination of accessible interior and exterior surface areas. Flaws discovered as a result of these inspections and tests that do not meet acceptance criteria (defects) must be repaired before the plant is allowed to return to service. Consequently, there is no need for submitting a relief request to the NRC for a temporary non-code repair of the containment aimed at keeping the plant in operation until the next scheduled outage.

- Application of protective coatings on structures, equipment, and components in nuclear power plants is not required by the NRC because coatings provide no specific safety-related function to mitigate the consequences of postulated accidents. However, quality assurance requirements provided in 10 CFR 50, Appendix B (4.38) are applicable to protective coatings because failure and disbonding during operating and emergency conditions could interfere with engineered safety systems required for safe shutdown and cooling of the reactor vessel. Although reasons for using protective coatings are based primarily on economic considerations, factors that could influence their use include material compatibility, heat transfer characteristics, and the consequences of failure during a design basis accident.

- Options for restoring the leaktightness and structural integrity of bellows that have been damaged while in service include replacement of the penetration assembly that contains the damaged bellows, replacement of the damaged bellows, installation of a new enveloping bellows, in-place welding repairs to damaged bellows, removal of severe dents, and blending the surface. Restoration activities that produce discontinuities in the welds or base metal, changes in wall thickness resulting from the addition of welded patches or removal of metal by blending (grinding), or unevenness or irregularities in the bellows contour may affect the useful service life of the bellows.

Under certain conditions, cathodic protection can be quite effective in preventing corrosion. Corrosion prevention can be achieved either by means of an impressed direct current or attachment to a sacrificial anode. In applying cathodic protection to a metal structure, the objective is to force the entire surface of the structure exposed to the environment to collect current from the environment making the exposed surface a cathode. When this condition is achieved, corrosion is successfully mitigated.

\subsubsection{Research Topics}

Effects of high-temperature exposure on concrete resulting from welding repairs to steel liner plates backed by concrete are not well quantified. Very little test data about rapid, localized heating of concrete are available. Questions about concrete behavior under these short-term, but severe, service conditions can be effectively answered by performing a carefully controlled experimental investigation in which a representative portion of a containment cross section is constructed, repair welded, and methodically disassembled for examination and testing. Results of this investigation would provide valuable information about the following uncertainties:

- temperature distribution patterns in the vicinity of a liner plate welding repair; 
- depth and extent of concrete affected by welding repair activities;

- extent of concrete cracking and spalling, if any;

- changes in mechanical properties of the affected liner plate, reinforcing bars, anchor studs, and embedment anchors; and

- magnitude of concrete surface irregularities, if any, adjacent to the liner plate repair area.

As a minimum, the experimental investigation should involve the construction of at least two types of test sections. To be representative, each test section should include concrete, reinforcing bars, and liner plate that is attached to the concrete either by anchor studs or embedment anchors. Configurations of two candidate test sections are shown in Figs. 4.14 and 4.15 .

During liner plate fabrication, simulated corrosion damage could be produced by machining 50 percent of the metal from the liner surface at selected locations to create thinned areas. Overall dimensions of the thinned areas could also be varied so that the effects of damage size and location are examined as test variables. Although grinding could be used to produce the thinned areas, machining provides a more precise means for controlling the location and dimensions of the simulated corrosion damage. At least five thinned areas requiring repair welding could be machined in each liner plate as shown in Fig. 4.16. Prior to concrete placement, thermocouples should be installed at selected locations for use in monitoring concrete and steel temperatures before, during, and after welding. Prior to the welding repair, the test sections could be utilized as part of an evaluation of candidate nondestructive evaluation methods for detection of metallic pressure boundary wall thinning.

Two types of welding repairs involving either an overlay welding repair technique or a doubler-plate welding repair technique should be performed to provide the basis for meaningful comparison. Knowledge gained from this comparison would be useful in selecting the more desirable welding repair technique and in understanding which technique produces the least damage to the concrete, reinforcing bars, and liner anchorage system. Cross-sectional views of both welding repair techniques are shown in Fig. 4.17. The four recommended test section configurations for the experimental investigation are identified in Table 4.12.

\subsection{REFERENCES}

4.1 Browne, R.D., "Durability of Reinforced Concrete Structures," New Zealand Concrete Construction, Parts 1 and 2, September and October 1989.

4.2 Waddell, J.J., "Basic Steps of a Concrete Repair Program, pp. 30-33 in Concrete International 2(9), American Concrete Institute, Farmington Hills, MI, September 1980.

4.3 Technical Committee 124-SRC, "Draft Recommendation for Repair Strategies for Concrete Structures Damaged by Reinforcement Corrosion," pp. 415-436 in Materials and Structures 27(171), International Union of Testing and Research Laboratories for Materials and Structures (RILEM), Cachan, France, 1984.

4.4 Guidelines on Nuclear Safety-Related Coatings, EPRI TR-109937, Electric Power Research Institute, Palo Alto, California, April 1998.

4.5 Shah, V.N., Smith, S.K., and Sinha, U.P., Insights for Aging Management of Light Water Reactor Components, NUREG/CR 5314, Vol. 5, U.S. Nuclear Regulatory Commission, Washington, DC, March 1994.

4.6 Stuart, C.O., "Underwater Coating Repair Cuts Nuclear Maintenance Costs," Power Engineering, Vol. 97, No. 7, July 1993, pp. 31-34.

4.7 "Rules for Inservice Inspection of Nuclear Power Plant Components," ASME Boiler and Pressure Vessel Code, Section XI, Division 1, Subsection IWA, General Requirements American Society of Mechanical Engineers, New York, New York, July 1, 1995.

4.8 Oland, C.B., and Naus, D.J., A Survey of Repair Practices for Nuclear Power Plant Containment Metallic Pressure Boundaries, NUREG/CR-6615 (ORNL/TM-13601), U.S. Nuclear Regulatory commission, Washington, D.C., May 1998. 

for Testing and Materials, West Conshohocken, Pennsylvania, 1991.

4.10 "Rules for Inservice Inspection of Nuclear Power Plant Components, "ASME Boiler and Pressure Vessel Code," Section XI, Subsection IWE, Requirements for Class MC and Metallic Liners of Class CC Components of Light-Water Cooled Plants, American society of Mechanical Engineers, New York, New York, July 1, 1995.

4.11 "Repair and Replacement of Class MC," Code Case N-236-1, ASME Boiler and Pressure Vessel Code, Code Cases, Nuclear Components, American Society of Mechanical Engineers, New York, New York, 1995.

4.12 "Rules for Inservice Inspection of Nuclear Power Plant Components," ASME Boiler and Pressure Vessel Code, Section XI, Division 1, Subsection IWL, Requirements for Class CC Components of Light-Water Cooled Plants, American Society of Mechanical Engineers, New York, New York, July 1, 1992.

4.13 "Rules for Inservice Inspection of Nuclear Power Plant Components," ASME Boiler and Pressure Vessel Code, Section XI, Division 1, Nonmandatory Appendix J, Guide to Plant Maintenance Activities and Section XI Repair/Replacements, American Society of Mechanical Engineers, New York, New York, July 1, 1995.

4.14 "Rules for Construction of Nuclear Power Plant Components," ASME Boiler and Pressure Vessel Code, Section III, Division 1, Subsection NE, Class MC Components, American Society of Mechanical Engineers, New York, New York, July 1, 1995.

4.15 "Rules for Inservice Inspection of Nuclear Power Plant Components," ASME Boiler and Pressure Vessel Code, Section XI, Division 1, Subsection IWL, Requirements for Class CC Components of Light-Water Cooled Plants, American Society of Mechanical Engineers, New York, New York, July 1, 1992.

4.16 "Materials," ASME Boiler and Pressure Vessel Code, Section II, Part A - Ferrous Materials Specifications, American Society of Mechanical Engineers, New York, New York, July 1, 1992.

4.17 "Materials," ASME Boiler and Pressure Vessel Code, Section II, Part D - Properties, American Society of Mechanical Engineers, New York, New York, July 1, 1995.

4.18 "Materials," ASME Boiler and Pressure Vessel Code, Section II, Part C, Specifications for Welding Rods, Electrodes, and Filler Metals, American Society of Mechanical Engineers, New York, New York, July 1, 1995.

4.19 "Qualification Standards for Welding and Brazing Procedures, Welders, Brazers, and Welding and Brazing Operators," ASME Boiler and Pressure Vessel Code, Section IX, American Society of Mechanical Engineers, New York, New York, July 1, 1995.

4.20 Friedman, L.M., Weld Repair Without Postweld Heat Treatment of Thick-Section Carbon Steel Components, EWI-MR9402, Edison Welding Institute, Columbus, Ohio, February 1994.

4.21 "Alternative Requirements to Repair and Replacement Documentation Requirements and Inservice Summary Report Preparation and Submission as Required by IWA-4000 and IWA-6000," Case N-532, ASME Boiler and Pressure Vessel Code, 1995 Code Cases, Nuclear Components, American Society of Mechanical Engineers, New York, New York, July 1, 1995.

4.22 Tsai, C.L. and Masubuchi, K., Interpretive Report on Underwater Welding, Bulletin 224, Welding Research Council, New York, New York, 1977.

4.23 "Volume 6 - Welding, Brazing, and Soldering," ASM Handbook, ASM International, Materials Park, Ohio, 1993. 
4.24 Linnert, G.E., Welding Metallurgy, Volume 1, Third Edition, American Welding Society, New York, New York, 1965.

4.25 Specification for Underwater Welding, ANSI/AWS D3.6-93, American Welding Society, Miami, Florida, 1993.

4.26 "Underwater Welding," Case N-516, ASME Boiler and Pressure Vessel Code, 1995 Code Cases, Nuclear Components, American Society of Mechanical Engineers, New York, New York, July 1, 1995.

4.27 Naus, D.J., A Review of the Effects of Elevated Temperature on Concrete Materials and Components with Particular Reference to the Modular High-Temperature Gas-Cooled Reactor(MHTGR), ORNL/NRC/LTR88/2, Oak Ridge National Laboratory, Oak Ridge, Tennessee, March 1988.

4.28 Structural Welding Code-Reinforcing Steel, ANSI/AWS D1.4-92, American Welding Society, Miami, Florida, 1992.

4.29 Code Requirements for Nuclear Safety Related Concrete Structures, ACI 349-90, American Concrete Institute, Farmington Hills, Michigan, 1990.

4.30 Kilic, A.N., "A Transient Analysis of Decomposition and Erosion of Concrete Exposed to a Surface Heat Flux," Nuclear Technology, Vol. 108, No. 3, American Nuclear Society, Inc., La Grange Park, Illinois, December 1994.

4.31 Powers, D.A. and Arellano F.E., Large-Scale, Transient Tests of the Interaction of Molten Steel with Concrete, NUREG/CR-2282, U.S. Nuclear Regulatory Commission, Washington, D.C., January 1982.

4.32 Markovits, C.C. and Giannuzzi, A.J., EPRI Weld-Related Research Activities, EPRI TR-104307, Electric Power Research Institute, Palo Alto, California, July 1994.

4.33 Generic Letter 91-18, U.S. Nuclear Regulatory Commission, To: All Nuclear Power Plant Licensees and Applicants, Subject: Information to Licensees Regarding Two NRC Inspection Manual Sections on Regulation of Degraded and Nonconforming Conditions and on Operability, November 7, 1991.

4.34 Generic Letter 90-05, U.S. Nuclear Regulatory Commission, To: All Holders of Operating Licenses for Nuclear Power Plants, Subject: Guidance for Performing Temporary Non-Code Repair of ASME Code Class 1, 2, and 3 Piping, June 15, 1990.

4.35 Generic Letter 88-01, U.S. Nuclear Regulatory Commission, To: All Licensees of Operating Boiling Water Reactors (BWRs) and Holders of Construction Permits for BWRs, Subject: NRC Position on IGSCC in BWR Austenitic Stainless Steel Piping, January 25, 1988.

4.36 Generic Letter 88-01, Supplement 1 U.S. Nuclear Regulatory Commission, To: All Licensees of Operating Boiling Water Reactors (BWRs) and Holders of Construction Permits for BWRs, Subject: NRC Position on Intergranular Stress Corrosion Cracking (IGSCC) in BWR Austenitic Stainless Steel Piping, January 25, 1988.

4.37 ASME Code Relief Request - Service Water, letter dated January 16, 1991, from G. E. Vaughn, Carolina Power and Light Company, Raleigh, North Carolina, to the United States Nuclear Regulatory Commission, Washington, D.C., NRC Public Documents Room, Washington, D.C., Fiche 56472, Frames 317-326.

4.38 “Quality Assurance Criteria for Nuclear Power Plants and Fuel Reprocessing Plants,” Appendix B, Code of Federal Regulations, Title 10, Part 50, January 1, 1997.

4.39 Schwartztrauber, K.E., Contamination and Decontamination Experience with Protective Coatings at TMI-2, EPRI NP-5206, Electric Power Research Institute, Palo Alto, California, May 1987. 

1981.

4.41 Quality Assurance Requirements for Protective Coatings Applied to Water-Cooled Nuclear Power Plants, Regulatory Guide 1.54, U.S. Nuclear Regulatory Commission, Washington, D.C., June 1973.

4.42 Protective Coatings (Paints) for Light Water Nuclear Reactor Containment Facilities, ANSI N101.2, American National Standards Institute, New York, New York, 1972.

4.43 Quality Assurance for Protective Coatings Applied to Nuclear Facilities, ANSI N101.4, American National Standards Institute, New York, New York, 1972.

4.44 Protective Coatings (Paints) for the Nuclear Industry, ANSI 5.12, American National Standards Institute, New York, New York, 1974.

4.45 "Standard Guide for Use of Protective Coatings in Nuclear Power Plants," ASTM Designation: D 5144-91, 1991 Annual Book of ASTM Standards, West Conshohocken, Pennsylvania, 1991.

4.46 "Standard Guide for Selection of Test Methods for Coatings for Use in Light-Water Nuclear Power Plants," ASTM Designation: D 3842-86 (Reapproved 1991), 1986 Annual Book of ASTM Standards, West Conshohocken, Pennsylvania, 1986.

4.47 "Standard Practice for Quality Assurance for Protective Coatings Applied to Nuclear Facilities," ASTM Designation: D 3843-93, 1993 Annual Book of ASTM Standards, West Conshohocken, Pennsylvania, 1993.

4.48 "Standard Test Method for Evaluating Coatings Used in Light-Water Nuclear Power Plants at Simulated Design Basis Accident (DBA) Conditions," ASTM Designation: D 3911-95, 1995 Annual Book of ASTM Standards, West Conshohocken, Pennsylvania, 1995.

4.49 "Standard Test Method for Chemical Resistance of Coatings Used in Light-Water Nuclear Power Plants," ASTM Designation: D 3912-95, 1995 Annual Book of ASTM Standards, West Conshohocken, Pennsylvania, 1995.

4.50 "Standard Test Method for Effects of Radiation of Coatings Used in Light-Water Nuclear Power Plants," ASTM Designation: D 4082-95, 1995 Annual Book of ASTM Standards, West Conshohocken, Pennsylvania, 1995.

4.51 "Standard Test Method for Measurement of Dry Film Thickness of Protective Coating Systems by Destructive Means," ASTM Designation: D 4138-94, 1994 Annual Book of ASTM Standards, Philadelphia, Pennsylvania, 1994.

4.52 "Standard Practice for Qualification of Coating Applicators for Application of Coatings to Concrete Surfaces," ASTM Designation: D 4227-95, 1995 Annual Book of ASTM Standards, West Conshohocken, Pennsylvania, 1995.

4.53 "Standard Practice for Qualification of Coating Applicators for Application of Coatings to Steel Surfaces," ASTM Designation: D 4228-95, 1995 Annual Book of ASTM Standards, West Conshohocken, Pennsylvania, 1995.

4.54 "Standard Test Method for Determination of the Decontaminability of Coatings Used in Light-Water Nuclear Power Plants," ASTM Designation: D 4256-89 (Reapproved 1994), 1989 Annual Book of ASTM Standards, West Conshohocken, Pennsylvania, 1989.

4.55 "Standard Practice for Surface Cleaning Concrete for Coating," ASTM Designation: D 4258-83 (Reapproved 1993), 1993 Annual Book of ASTM Standards, West Conshohocken, Pennsylvania, 1983.

4.56 "Standard Practice for Surface Cleaning Concrete Unit Masonry for Coating," ASTM Designation: D 4261-83 (Reapproved 1993), 1993 Annual Book of ASTM Standards, West Conshohocken, Pennsylvania, 1983. 
4.57 "Standard Practice for Determining Coating Contractor Qualifications for Nuclear Powered Electric Generation Facilities," ASTM Designation: D 4286-90, 1990 Annual Book of ASTM Standards, West Conshohocken, Pennsylvania, 1990.

4.58 "Standard Guide for Establishing Procedures to Qualify and Certify Inspection Personnel for Coating Work in Nuclear Facilities," ASTM Designation: D 4537-91, 1991 Annual Book of ASTM Standards, West Conshohocken, Pennsylvania, 1991.

4.59 "Standard Specification for Sample Preparation for Qualification Testing of Coatings to be Used in Nuclear Power Plants," ASTM Designation: D 5139-90, 1990 Annual Book of ASTM Standards, West Conshohocken, Pennsylvania, 1990.

4.60 "Standard Guide for Establishing Procedures to Monitor the Performance of Safety Related Coatings in an Operating Nuclear Power Plants," ASTM Designation: D 5163-91, 1991 Annual Book of ASTM Standards, West Conshohocken, Pennsylvania, 1991.

4.61 "Standard Guide for Developing a Training Program for Coating Work Inspectors in Nuclear Facilities," ASTM Designation: D 5498-94, 1994 Annual Book of ASTM Standards, West Conshohocken, Pennsylvania, 1994.

4.62 "Standard Guide for Maintaining Unqualified Coatings (Paints) Within Level I Areas of a Nuclear Power Facilities," ASTM Designation: D 5962-96, 1996 Annual Book of ASTM Standards, West Conshohocken, Pennsylvania, 1996.

4.63 "Domestic Licensing of Production and Utilization Facilities," Code of Federal Regulations, Title 10, Part 50, paragraph 50.65, January 1, 1997.

4.64 Maintenance - Filled Organic Coatings Used in Maintenance of Safety Related Equipment, NRC Inspection Manual, Chapter Part 9900 Technical Guidance, U.S. Nuclear Regulatory Commission, Washington, D.C., October 1, 1994.

4.65 Shah, V.N., Smith, S.K., and Sinha, U.P., Insights for Aging Management of Light Water Reactor Components, NUREG/CR 5314, Vol. 5, U.S. Nuclear Regulatory Commission, Washington, DC, March 1994.

4.66 "Standard Test Method for Evaluating Degree of Checking of Exterior Paints," ASTM Designation: D 660-93, 1993 Annual Book of ASTM Standards, West Conshohocken, Pennsylvania, 1993.

4.67 Standard Test Method for Evaluating Degree of Cracking of Exterior Paints," ASTM Designation: D 661-93, 1993 Annual Book of ASTM Standards, West Conshohocken, Pennsylvania, 1993.

4.68 "Standard Test Method for Evaluating Degree of Blistering of Paints," ASTM Designation: D 714-87 (Reapproved 1994), 1994 Annual Book of ASTM Standards, West Conshohocken, Pennsylvania, 1987.

4.69 "Standard Test Method for Evaluating Degree of Flaking (Scaling) of Exterior Paints," ASTM Designation: D 772-86, 1986 Annual Book of ASTM Standards, West Conshohocken, Pennsylvania, 1986.

4.70 Torus Shells with Corrosion and Degraded Coatings in BWR Containments, IE Information Notice No. 88-82, Office of Inspection and Enforcement, U.S. Nuclear Regulatory Commission, Washington, DC, October 14, 1988, pp. 1-2.

4.71 Stuart, C.O., "Underwater Coating Inspections Cut BWR Maintenance Costs," Power Engineering, Vol. 91, No. 8, August 1987, pp. 20-23.

4.72 Torus Shells with Corrosion and Degraded Coatings in BWR Containments, IE Information Notice No. 88-82, Supplement 1, Office of Inspection and Enforcement, U.S. Nuclear Regulatory Commission, Washington, DC, May 2, 1989, pp. 1-2. 
4.73 Stuart, C.O., "Underwater Coating Repair Cuts Nuclear Maintenance Costs,” Power Engineering, Vol. 97, No. 7, July 1993, pp. 31-34.

4.74 "Standard Practice for Examination and Evaluation of Pitting Corrosion," ASTM Designation: G 46-94, 1994 Annual Book of ASTM Standards, West Conshohocken, Pennsylvania, 1994.

4.75 Oland, C.B. and Naus, D.J., Degradation Assessment Methodology for Application to Steel Containments and Liners of Reinforced Concrete Structures in Nuclear Power Plants, ORNL/NRC/LTR-95/29, Oak Ridge National Laboratory, Oak Ridge, Tennessee, February 1996.

4.76 Merrick, E.A., Reimus, W.S., O’Toole, Jr., W.G., and Bressler, M.N., "Replacement Options for Damaged Bellows," Metallic Bellows and Expansion Joints: Part II, PVP-Vol. 83, S. J. Brown, editor, presented at the 1984 Pressure Vessels and Piping Conference and Exhibition, San Antonio, Texas, June 17-21, 1984, American Society of Mechanical Engineers, New York, New York, pp. 85-133.

4.77 "Repair of Bellows, Section III, Division 1," Case N-315, ASME Boiler and Pressure Vessel Code, 1995 Code Cases, Nuclear Components, American Society of Mechanical Engineers, New York, New York, July $1,1995$.

4.78 "Rules for Construction of Nuclear Power Plant Components," ASME Boiler and Pressure Vessel Code, Section III, Division 1, Subsection NE, Class MC Components, American Society of Mechanical Engineers, New York, New York, July 1, 1995.

4.79 Merrick, E.A., O’Toole, W.G. and Malkmus, M., "Repair of Bellows Expansion Joints," Metallic Bellows and Expansion Joints, PVP-Vol. 51, R. I. Jetter, S. J. Brown, and M. R. Pamidi, editors, presented at the 1981 Joint Conference of the Pressure Vessels and Piping, Materials, Nuclear Engineering, Solar Energy Divisions, Denver, Colorado, June 21-25, 1981, American Society of Mechanical Engineers, New York, New York, pp. 61-73.

4.80 Corrosion Basics - An Introduction, National Association of Corrosion Engineers, Houston, Texas, 1984.

4.81 "Volume 13 - Corrosion," ASM Handbook, formerly ninth edition, Metals Handbook, ASM International, Materials Park, Ohio, September 1987.

4.82 Swiat, W., Young, W., Pajak, J., Funahashi, M., Burke, D., and Wagner, J., State-of-the-Art-Report Corrosion of Steel in Concrete, ORNL/NRC/LTR-93/2, Oak Ridge National Laboratory, Oak Ridge, Tennessee, May 1993.

4.83 Lipford, B.L. and Flynn, J.C., "Drywell Corrosion Stopped at Oyster Creek,” Power Engineering, Vol. 97, No. 11, November 1993, pp. 47-50.

4.84 "Rules for Construction of Pressure Vessels," ASME Boiler and Pressure Vessel Code, Section VIII, American Society of Mechanical Engineers, New York, New York, June 30, 1968.

4.85 Lipford, B.L. and Flynn, J.C., "Drywell Corrosion Stopped at Oyster Creek,” Power Engineering, Vol. 97, No. 11, November 1993, pp. 47-50.

4.86 Manufacturers Data Report for Nuclear Vessels, Form N-1, Vessel No. G-1293, Chicago Bridge and Iron Company, Greenville, Pennsylvania, 1965.

4.87 "Tentative Specification for Carbon-Silicon Steel Plates of Intermediate Tensile Ranges for Fusion-Welded Boilers and Other Pressure Vessels," ASTM Designation: A 201-61T, American Society for Testing and Materials, Philadelphia, Pennsylvania, 1961.

4.88 Standard Specification for Pressure Vessel Plates, Carbon Steel, for Moderate- and Lower-Temperature Service," ASTM Designation: A 516-90, 1990 Annual Book of ASTM Standards, West Conshohocken, Pennsylvania, 1990. 
4.89 "Standard Practice for Preparing, Cleaning, and Evaluating Corrosion Test Specimens," ASTM Designation: G 1-90 (Reapproved 1994), 1994 Annual Book of ASTM Standards, West Conshohocken, Pennsylvania, 1990.

4.90 Tan, C.P. and Bagchi, G., BWR Steel Containment Corrosion, NUREG-1540, U.S. Nuclear Regulatory Commission, Washington, DC, April 1996.

4.91 Naus, D.J., Report of Foreign Travel of D. J. Naus, Engineering Technology Division, ORNL/FTR-4924, Oak Ridge National Laboratory, Oak Ridge, Tennessee, March 31, 1994.

4.92 Liner Plate Corrosion in Concrete Containments, IE Information Notice No. 97-10, Office of Inspection and Enforcement, U.S. Nuclear Regulatory Commission, Washington, DC, March 13, 1997, pp. 1-3.

4.93 Docket No. 50-324, Brunswick-2, Carolina Power \& Light Co., Raleigh, North Carolina, April, $27,1999$.

4.94 Docket No. 50-330, North Anna-2, Virginia Power, Richmond, Virginia, 1999.

4.95 Inspection Report Nos.: 50-325/93-02 and 50-324/93-025, Brunswick 1 and 2, U.S. Nuclear Regulatory Commission, Region II, Atlanta, Georgia, March 4, 1993, NRC Public Document Room, Washington, DC, Docket Nos.: 50-324 and 50-325, Fiche 74228:193-225.

4.96 Inspection Report Nos.: 50-325/93-15 and 50-324/93-15, Brunswick 1 and 2, U.S. Nuclear Regulatory Commission, Region II, Atlanta, Georgia, April 23, 1993, NRC Public Document Room, Washington, DC, Docket Nos.: 50-324 and 50-325, Fiche 74770:006-039.

4.97 Inspection Report Nos.: 50-325/93-25 and 50-324/93-25, Brunswick 1 and 2, U.S. Nuclear Regulatory Commission, Region II, Atlanta, Georgia, June 18, 1993, NRC Public Document Room, Washington, DC, Docket Nos.: 50-324 and 50-325, Fiche 75542:283-302.

4.98 Inspection Report Nos.: 50-325/93-31 and 50-324/93-31, Brunswick 1 and 2, U.S. Nuclear Regulatory Commission, Region II, Atlanta, Georgia, October 1, 1993, NRC Public Document Room, Washington, DC, Docket Nos.: 50-324 and 50-325, Fiche 76732:086-110.

4.99 Errata Letter for Inspection Report Nos.: 50-325/93-31 and 50-324/93-31, Brunswick 1 and 2, U.S. Nuclear Regulatory Commission, Region II, Atlanta, Georgia, November 10, 1993, NRC Public Document Room, Washington, DC, Docket Nos.: 50-324 and 50-325, Fiche 77189: 126-130.

4.100 Inspection Report Nos.: 50-325/93-45 and 50-324/93-45, Brunswick 1 and 2, U.S. Nuclear Regulatory Commission, Region II, Atlanta, Georgia, October 1, 1993, NRC Public Document Room, Washington, DC, Docket Nos.: 50-324 and 50-325, Fiche 77004:222-239.

4.101 MacLachlan, A., "Containment Liners Found Corroded at Some EDF 900-MW Reactors," Nucleonics Week, Vol. 33, No. 19, May 7, 1992, pp. 5-6. 


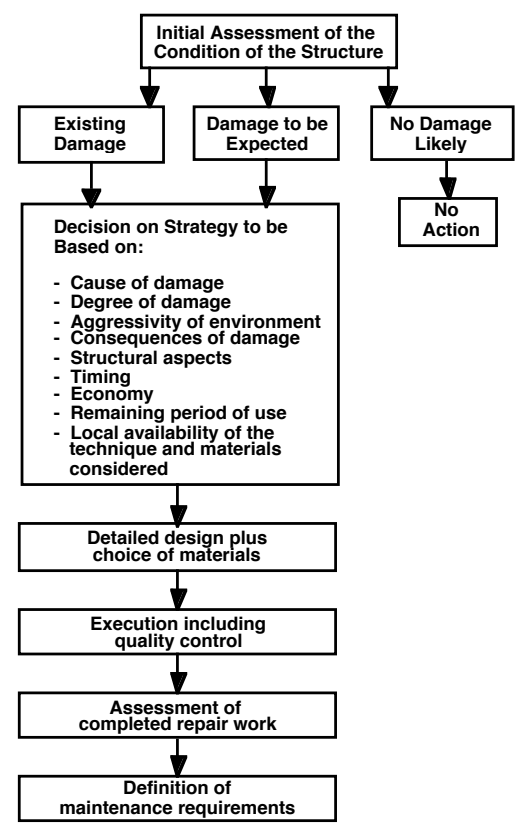

Fig. 4.1 Steps to be taken in a repair process.

Source: TC 124-SRC, "Draft Recommendation for Repair Strategies for Concrete Structures Damaged by Reinforcement Corrosion,” pp. 415-436 in Materials and Structures 27(171) RILEM, Cachan, France, 1984.

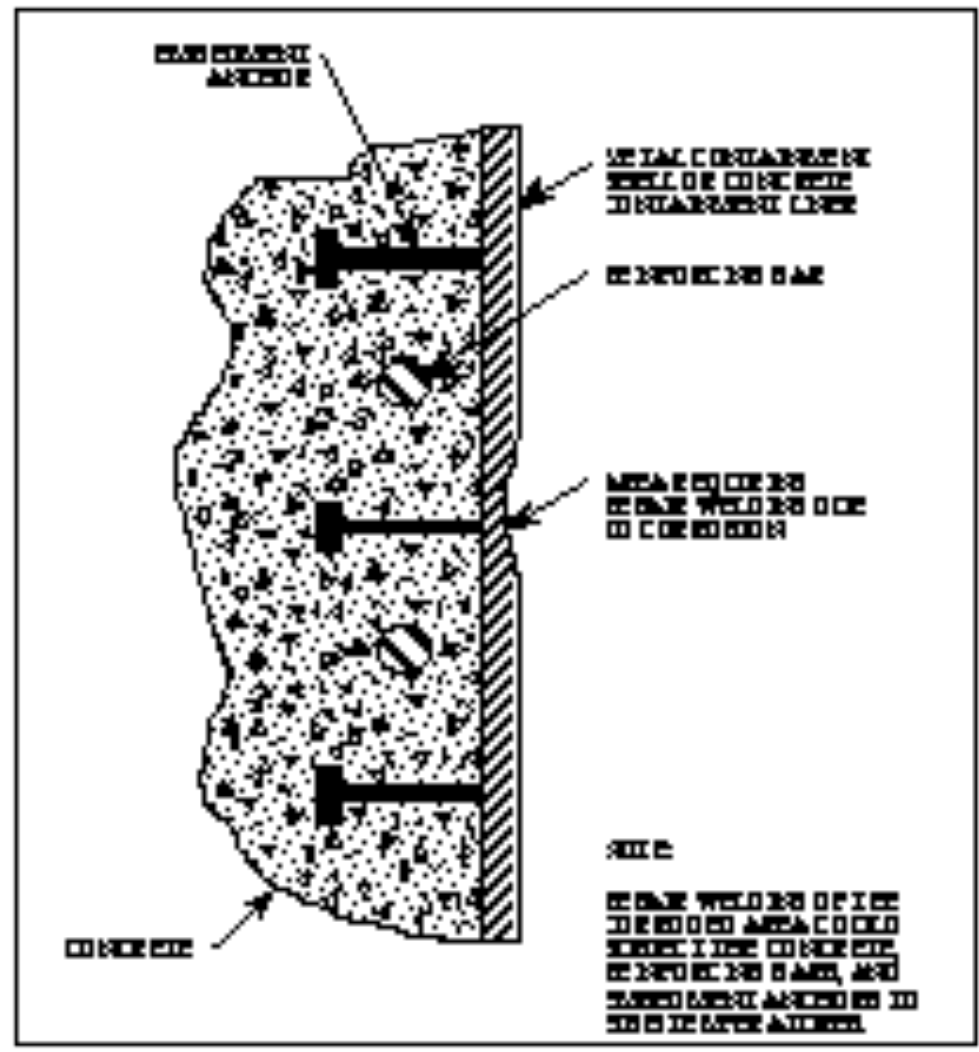

Fig. 4.2 Metal containment shell or concrete containment liner requiring welding repair due to corrosion. 


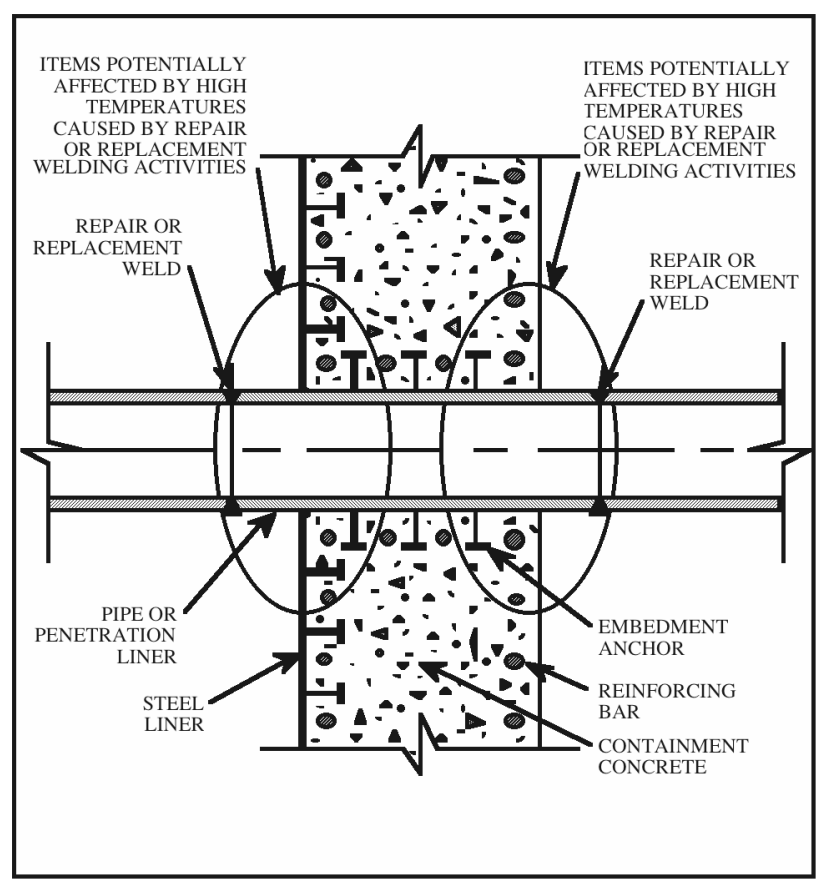

Fig. 4.3 Items potentially affected by high-temperatures produced by repair or replacement welding.

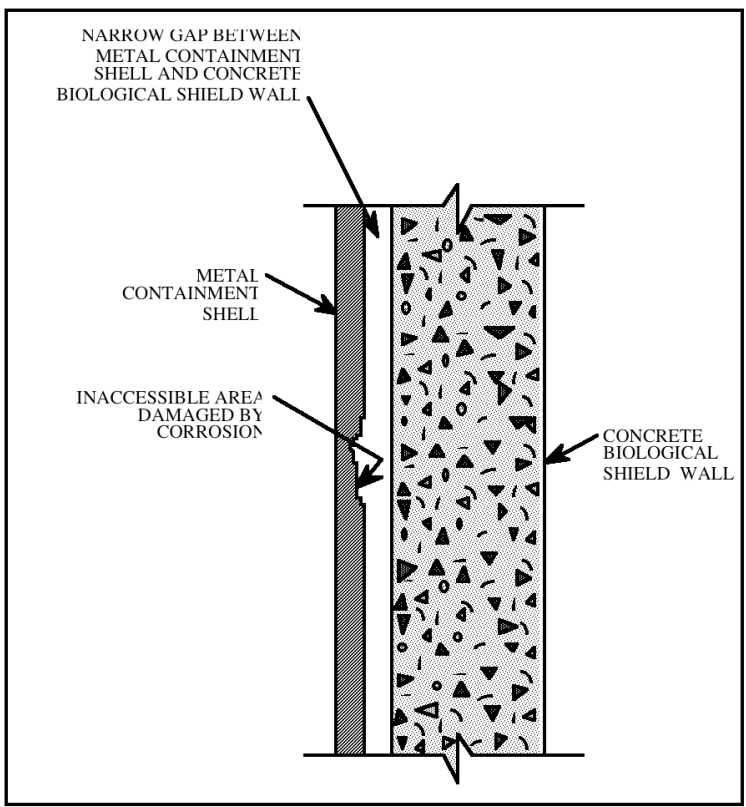

Fig. 4.4 Inaccessible area of a metal containment shell corroded to point that its structural capacity is no longer considered adequate and a repair is required. 


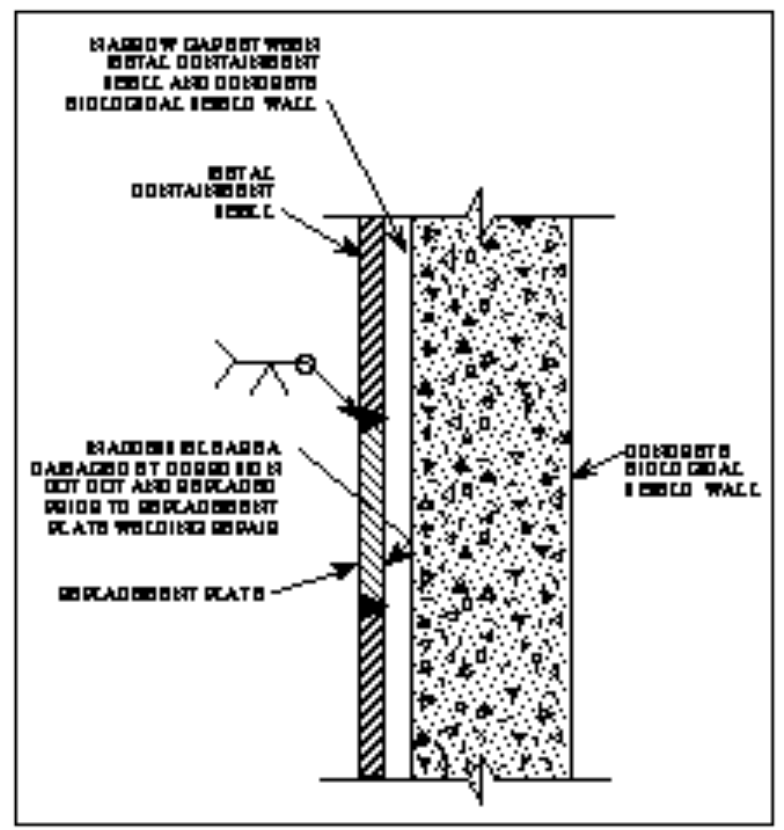

Fig. 4.5 Replacement plate repair welding technique.

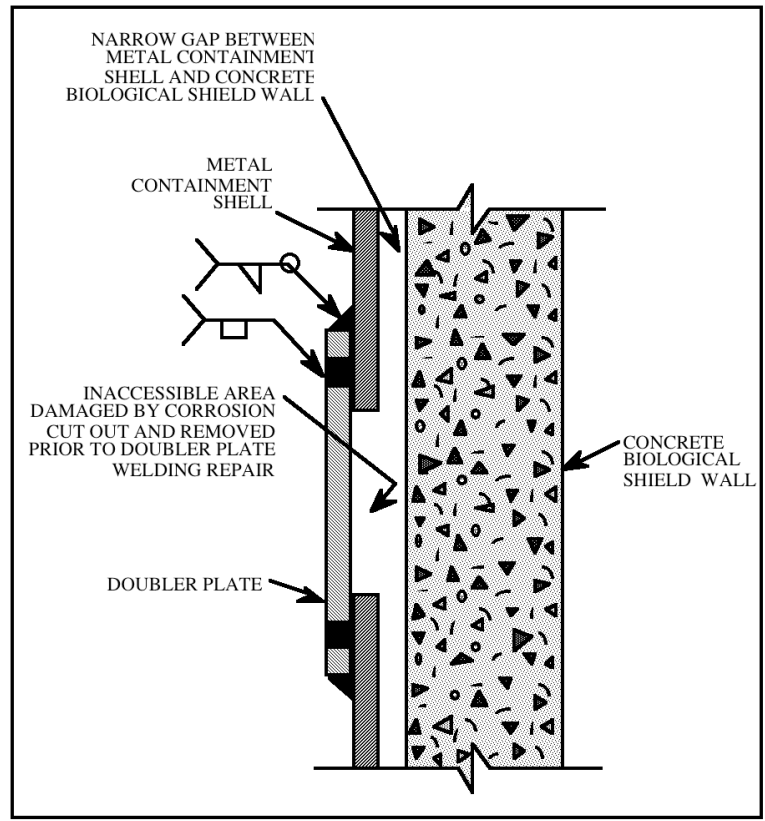

Fig. 4.6 Doubler plate repair welding technique. 


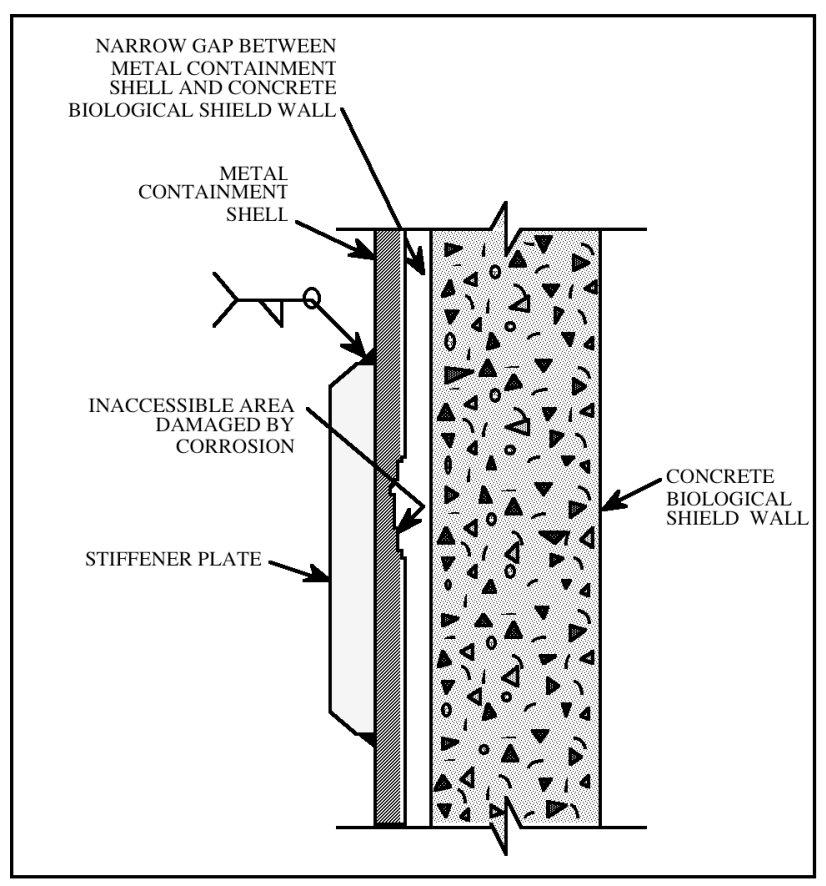

Fig. 4.7 Stiffener plate repair welding procedure.

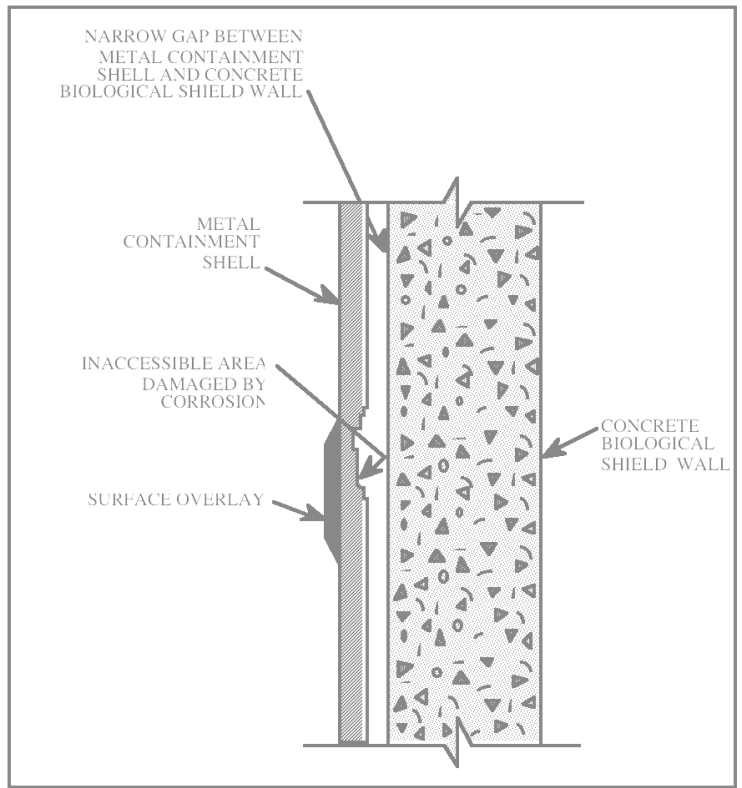

Fig. 4.8 Surface overlay repair welding technique. 


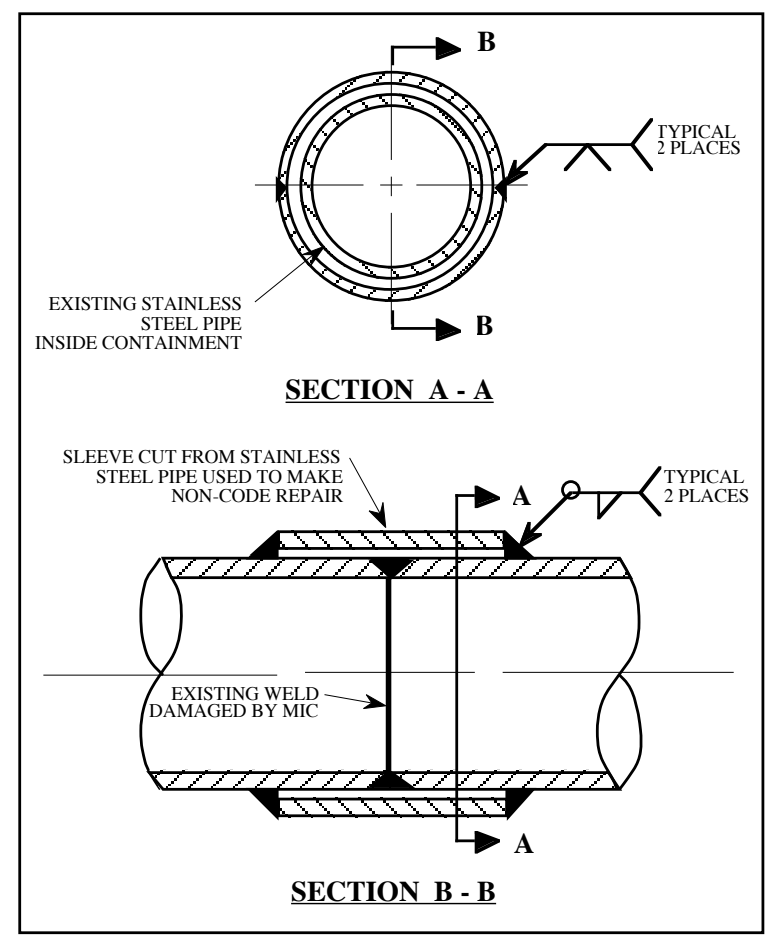

Fig. 4.9 Proposed non-code repairs for welds in ASME Class 3 stainless steel piping damaged by microbiologically-induced corrosion.

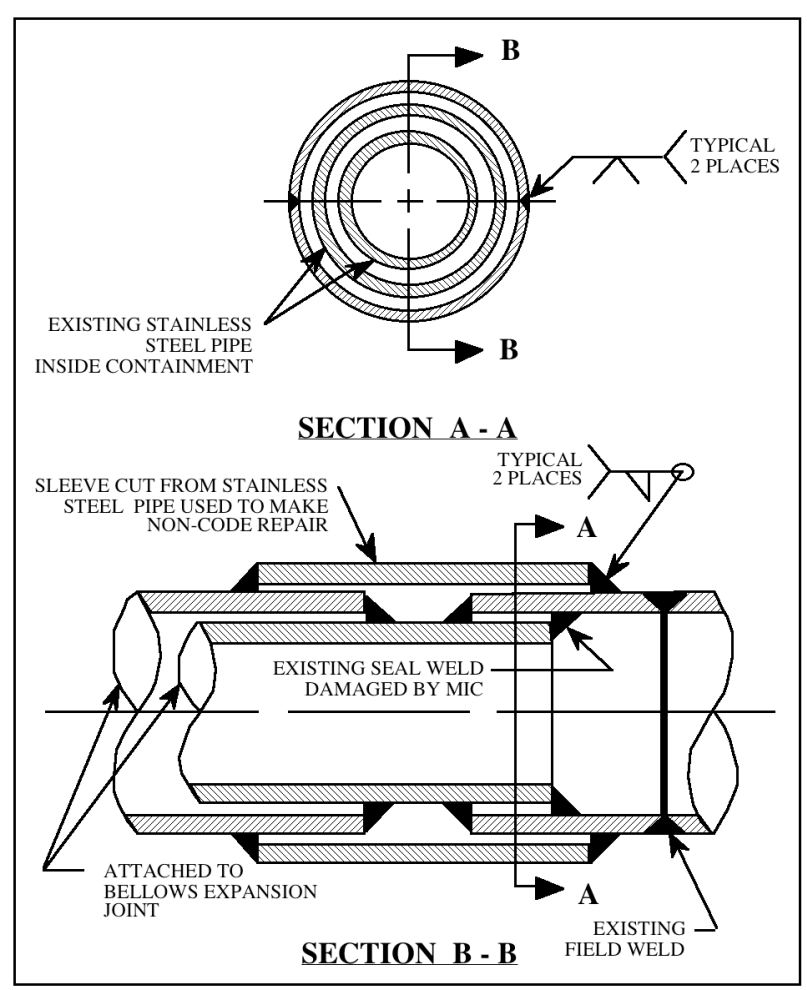

Fig. 4.10 Proposed non-code repair for welds at containment penetrations in ASME Class 3 stainless steel piping damaged by microbiologically-induced corrosion. 


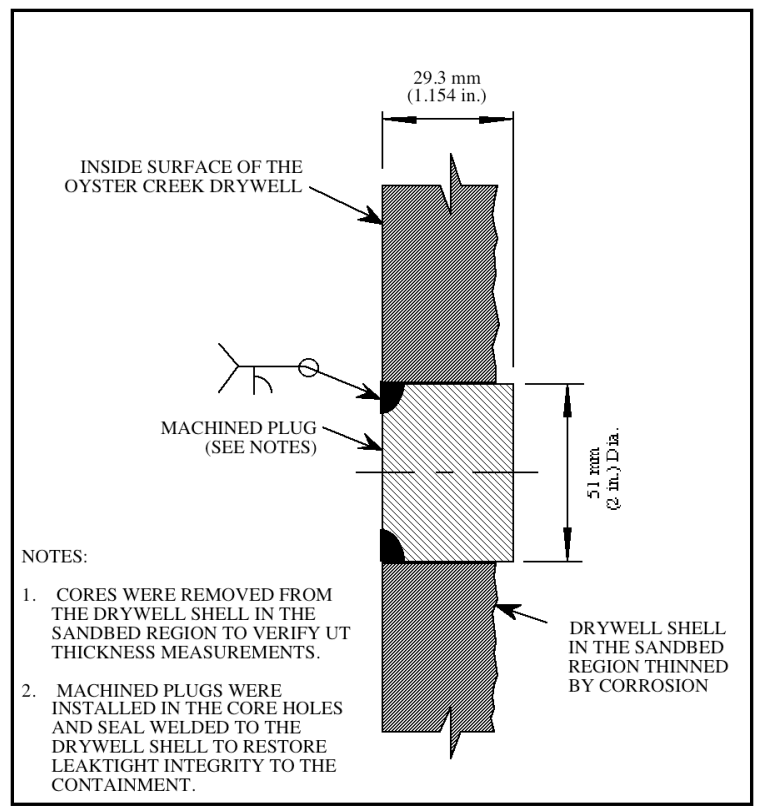

Fig. 4.11 Repair technique used to replace drywell shell material removed by coring and restore leaktight integrity to the Oyster Creek containment.

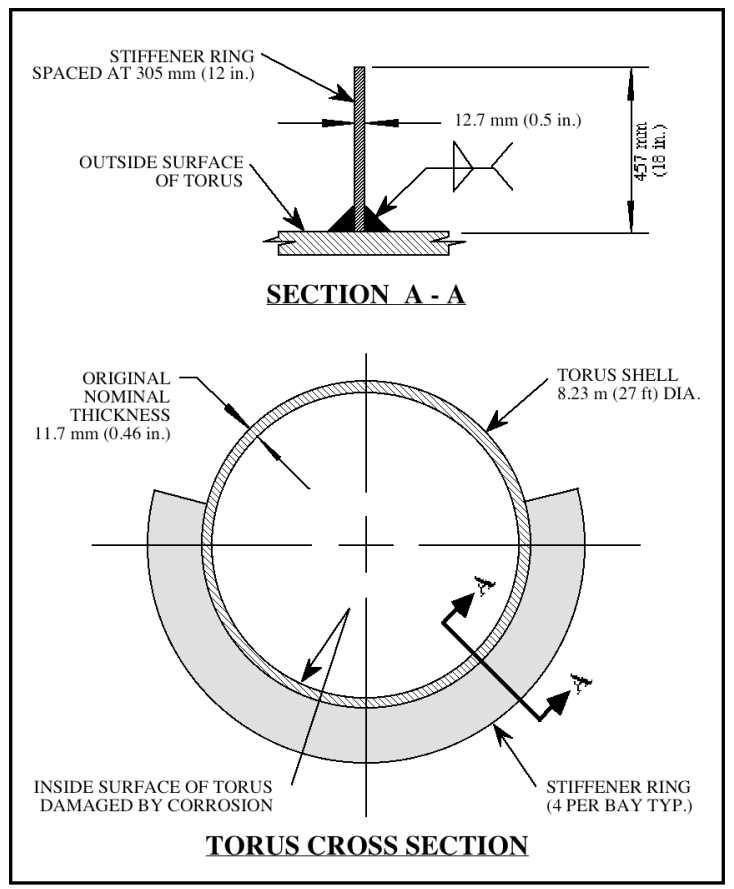

Fig. 4.12 Conceptual view showing how four of eight stiffener rings would be installed on the outside surface of each bay of the Nine Mile Point, Unit 1 torus. 


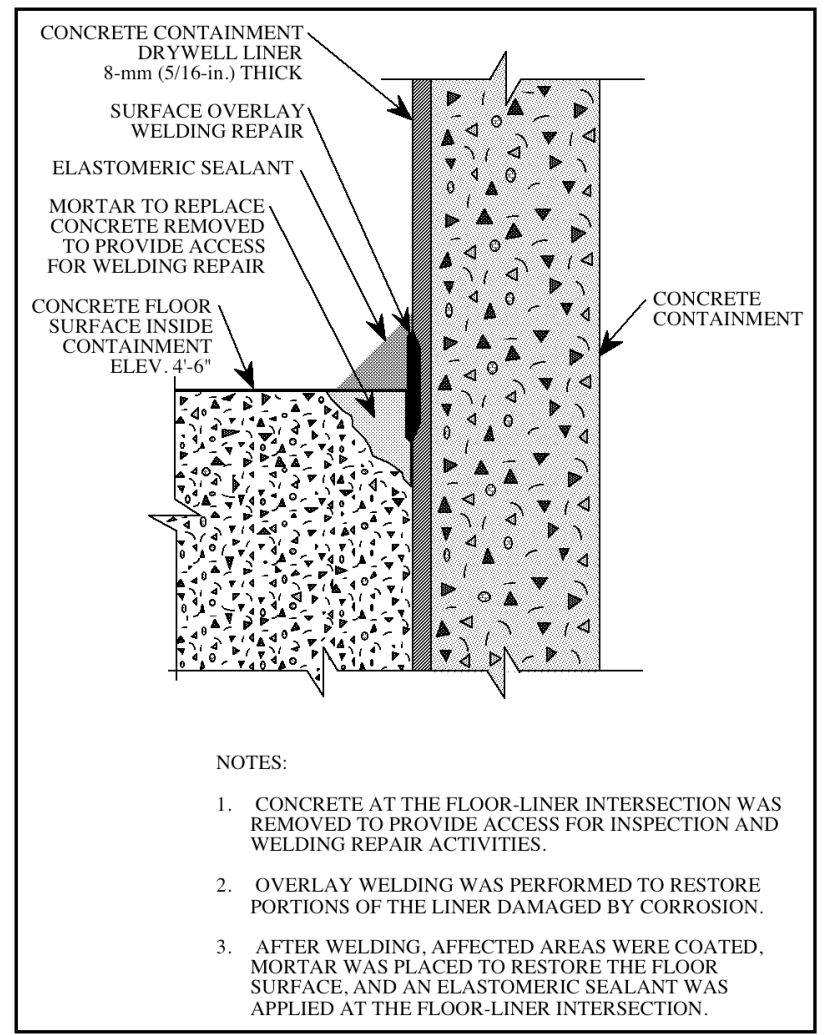

Fig. 4.13 Cross-sectional view of the drywell liner repair performed inside the Brunswick, Unit 1 concrete containment.

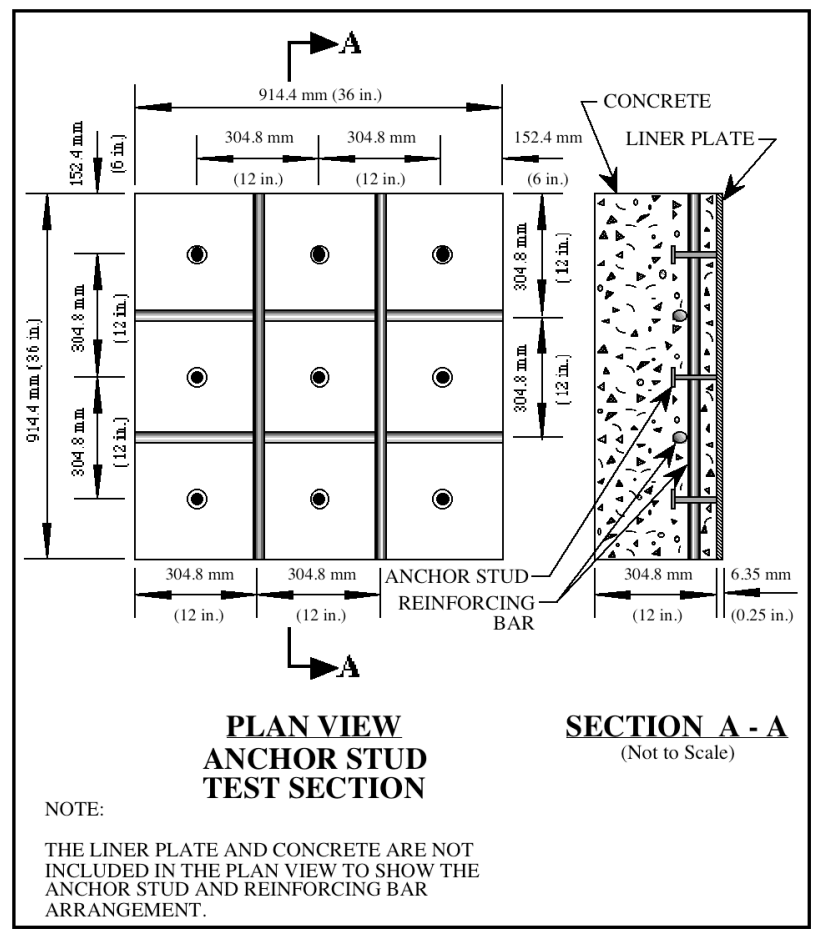

Fig. 4.14 Recommended anchor stud test section configuration. 


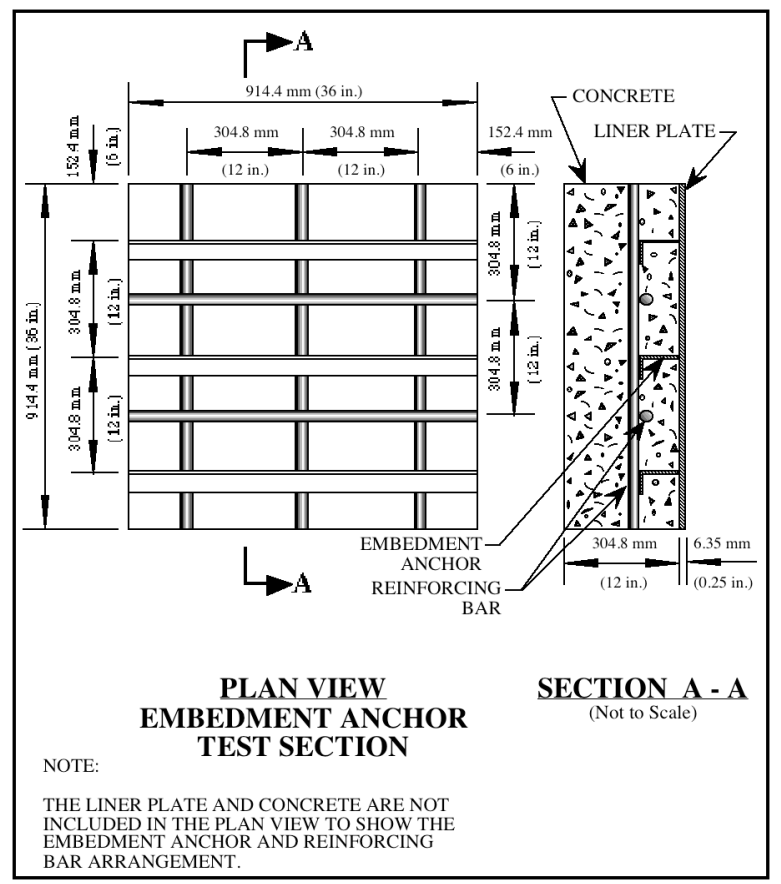

Fig. 4.15 Recommended embedment anchor test section configuration.

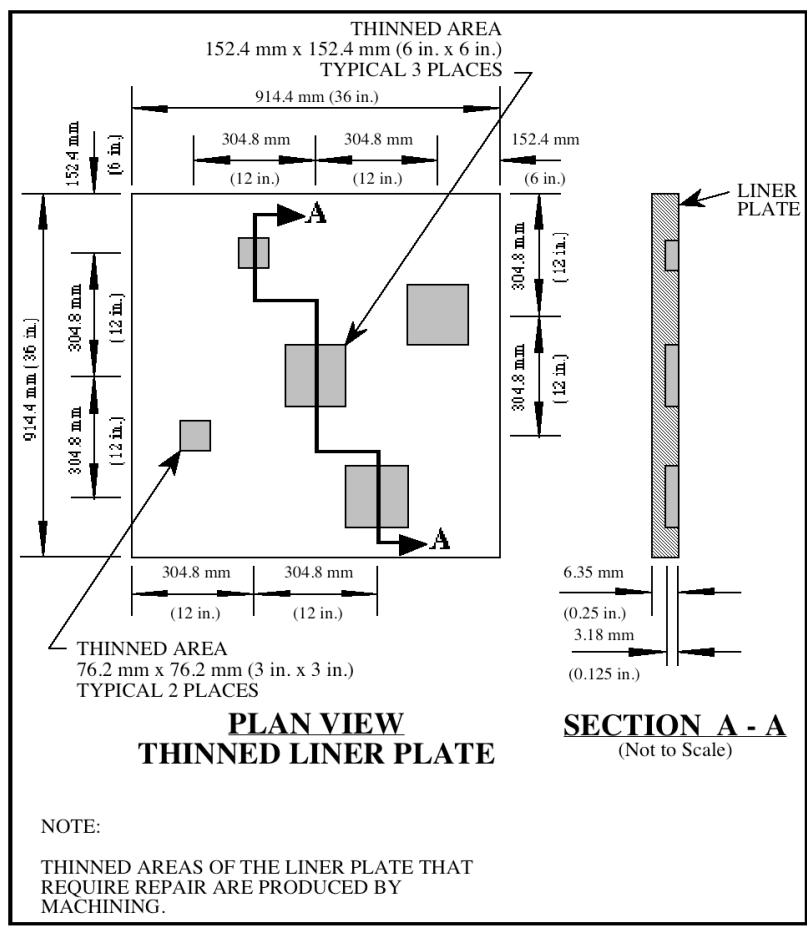

Fig. 4.16 Recommended liner plate configuration. 


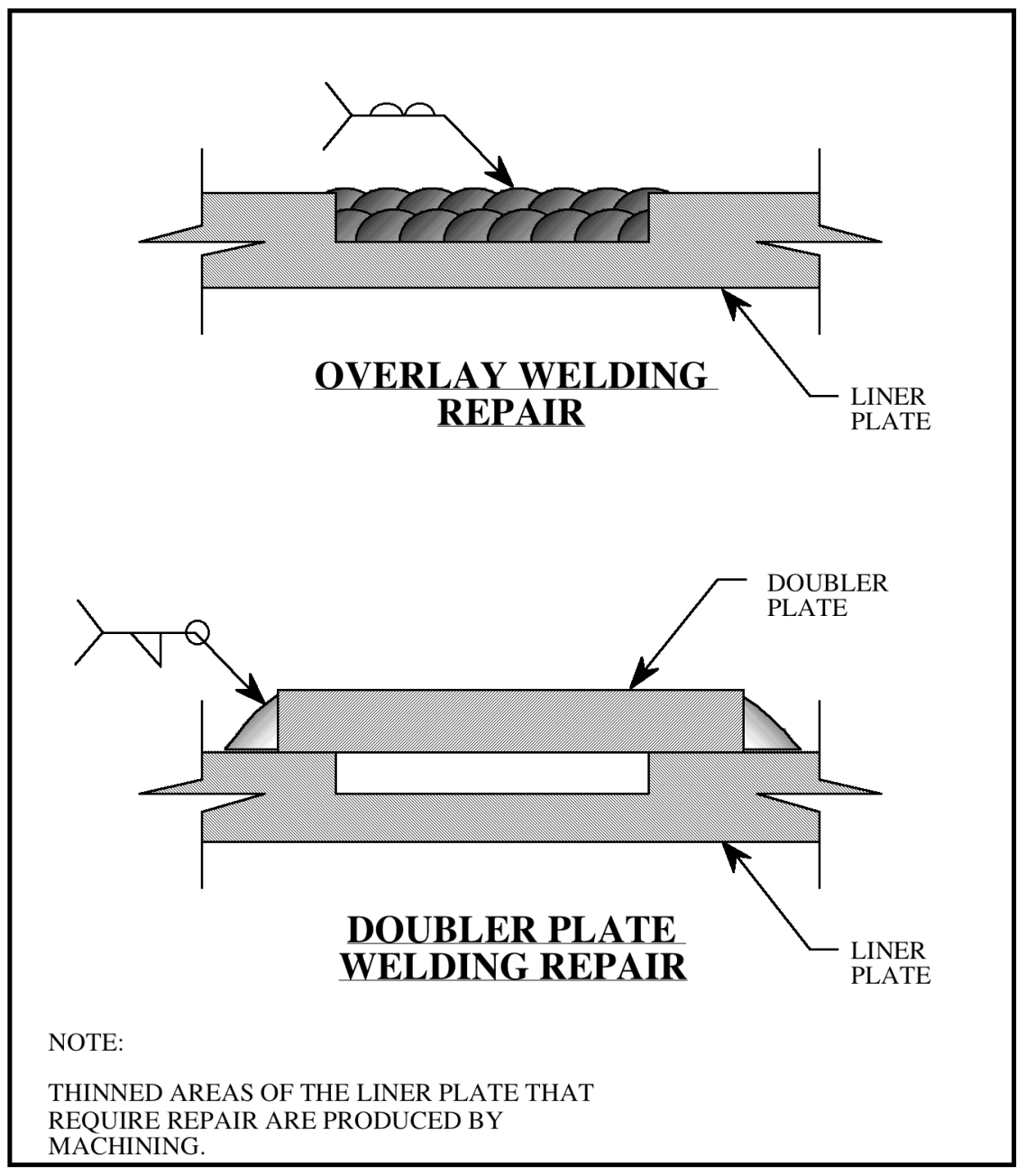

Fig. 4.17 Recommended liner plate weld repair technique. 
Table 4.1 Reasons for replacement of nuclear power plant components.

- Discrepancies detected during in-service inspection

- Regulatory requirements change

- Design changes to improve equipment service

- Changes to improve reliability

- Damage

- Failure during service

- Personnel exposure

- Economics

- End of service life

- Discrepancies detected during maintenance

Table 4.2 Welding processes permitted by Code Case N-516 for underwater repairs and replacements of P-No. 8 and P-No. 4X materials.

\begin{tabular}{|lcc|}
\hline \multicolumn{1}{|c}{$\begin{array}{c}\text { Welding } \\
\text { process }^{(1)}\end{array}$} & $\begin{array}{c}\text { Dry } \\
\text { welding }\end{array}$ & $\begin{array}{c}\text { Wet } \\
\text { welding }\end{array}$ \\
\hline \hline Shielded Metal-Arc Welding (SMAW) & Yes & Yes \\
Plasma-Arc Welding (PAW) & Yes & No \\
Gas Tungsten-Arc Welding (GTAW) & Yes & No \\
Gas Metal-Arc Welding (GMAW) & Yes & Yes ${ }^{(2)}$ \\
\hline (1) Combinations of applicable processes are also permitted & & \\
(2) Flux Cored Arc Welding (FCAW)-type only & & \\
\hline
\end{tabular}

Table 4.3 Instantaneous cooling rates for bead-on-plate surface welds at a nominal base material temperature of $760^{\circ} \mathrm{C}$.

\begin{tabular}{|cc|}
\hline $\begin{array}{c}\text { Base material thickness, } \\
\mathbf{m m}\end{array}$ & $\begin{array}{c}\text { Instantaneous cooling rate, } \\
{ }^{\circ} \mathbf{C} / \mathbf{s e c} .\end{array}$ \\
\hline \hline 6.44 & 23 \\
12.7 & 60 \\
25.4 & 100 \\
\hline
\end{tabular}


Table 4.4 Ways in which welding induced high-temperature exposure can adversely affect concrete and concrete embedments.

\begin{tabular}{|c|c|c|}
\hline Material or component & $\begin{array}{l}\text { Adverse } \\
\text { affect }\end{array}$ & $\begin{array}{c}\text { Potential } \\
\text { significance }\end{array}$ \\
\hline \multirow[t]{3}{*}{$\begin{array}{l}\text { Portland Cement } \\
\text { Concrete } \\
\text { (Ref. 4.27) }\end{array}$} & Explosive spalling & $\begin{array}{l}\text { Rapid and localized heating of concrete can pro- } \\
\text { duce explosive spalling due to forces resulting } \\
\text { from thermal expansion of the heated materials or } \\
\text { very high steam pressures in the concrete pores } \\
\text { that cause tensile stresses that are larger than the } \\
\text { tensile strength of the concrete. Explosive } \\
\text { spalling can occur when the temperature of the } \\
\text { concrete reaches about } 315^{\circ} \mathrm{C} \text {. }\end{array}$ \\
\hline & $\begin{array}{l}\text { Volume change leading to } \\
\text { shrinkage, expansion, or } \\
\text { cracking }\end{array}$ & $\begin{array}{l}\text { Absorbed water and chemically combined water } \\
\text { are gradually lost from the hydrates in Portland } \\
\text { cement paste up to about } 850^{\circ} \mathrm{C} \text {. Dehydration of } \\
\text { the calcium hydroxide in the cement paste begins } \\
\text { about } 400^{\circ} \mathrm{C} \text { and is essentially complete at } 600^{\circ} \mathrm{C} \text {. } \\
\text { Some conventional aggregates undergo crystal } \\
\text { transformation when exposed to high } \\
\text { temperatures over about } 370^{\circ} \mathrm{C} \text {. }\end{array}$ \\
\hline & $\begin{array}{l}\text { Strength and stiffness } \\
\text { reduction }\end{array}$ & $\begin{array}{l}\text { On heating, strength and stiffness of concrete } \\
\text { decrease due to loss of bonds (dehydration } \\
\text { effects) and microcracking resulting from } \\
\text { differences in thermal expansion between the } \\
\text { aggregates and the cement paste matrix. The } \\
\text { decrease in compressive strength becomes very } \\
\text { significant at temperatures above } 450^{\circ} \mathrm{C} \text {. }\end{array}$ \\
\hline \multirow[t]{2}{*}{$\begin{array}{l}\text { Metallic Items } \\
\text { Embedded in Concrete }\end{array}$} & Concrete cracking or spalling & $\begin{array}{l}\text { Heating of metallic embedments such as anchor } \\
\text { studs attached to concrete containment liners can } \\
\text { produce concrete cracking or spalling as the em- } \\
\text { bedments expand and lengthen relative to the } \\
\text { surrounding concrete. }\end{array}$ \\
\hline & Loss of bond with concrete & $\begin{array}{l}\text { Cracking and spalling of concrete caused by high- } \\
\text { temperature exposure can significantly degrade } \\
\text { the bond between embedments and the } \\
\text { surrounding concrete. }\end{array}$ \\
\hline
\end{tabular}


Table 4.5 Rules and requirements pertaining to high-temperature exposure of concrete and metallic embedments.

\begin{tabular}{|c|c|c|}
\hline Source & Issue & Rule or requirement \\
\hline $\begin{array}{l}\text { ASME Code Section III, } \\
\text { Division 2, Subsection } \\
\text { CB-3430, } 1995 \text { Edition } \\
\text { (Ref. 4.15) }\end{array}$ & $\begin{array}{l}\text { Temperature limits for } \\
\text { concrete reactor vessels }\end{array}$ & $\begin{array}{l}\text { Temperature limits are provided for construction, } \\
\text { normal, abnormal and severe environmental, ex- } \\
\text { treme environmental, and failure loading condi- } \\
\text { tions. The maximum allowable effective liner } \\
\text { temperature is limited to } 149^{\circ} \mathrm{C} \text { at the liner- } \\
\text { concrete interface and } 204^{\circ} \mathrm{C} \text { between cooling } \\
\text { tubes. }\end{array}$ \\
\hline $\begin{array}{l}\text { ASME Code Section III, } \\
\text { Division 2, Subsection } \\
\text { CC-3440, 1995 Edition } \\
\text { (Ref. 4.15) }\end{array}$ & $\begin{array}{l}\text { Temperature limits for } \\
\text { concrete containments }\end{array}$ & $\begin{array}{l}\text { The temperature of concrete is limited under nor- } \\
\text { mal conditions to } 66^{\circ} \mathrm{C} \text { except for local areas, } \\
\text { such as around penetrations, where the maximum } \\
\text { temperature is limited to } 93^{\circ} \mathrm{C} \text {. During an } \\
\text { accident or any other short-term period, the } \\
\text { maximum concrete temperature is limited to } \\
177^{\circ} \mathrm{C} \text {. Higher temperatures are permitted } \\
\text { provided strength tests are performed and there is } \\
\text { evidence that the increased temperatures do not } \\
\text { cause deterioration of the concrete with or } \\
\text { without load. }\end{array}$ \\
\hline $\begin{array}{l}\text { ASME Code Section III, } \\
\text { Division } 1 \text {, Subsection } \\
\text { CB-4300 and } \\
\text { Division 2, Subsection } \\
\text { CC-4300, } 1995 \text { Edition } \\
\text { (Ref. 4.1) }\end{array}$ & $\begin{array}{l}\text { Preheating prior to bending or } \\
\text { straightening of reinforcing } \\
\text { bars }\end{array}$ & $\begin{array}{l}\text { The temperature of the bar at the concrete surface } \\
\text { is limited to } 260^{\circ} \mathrm{C} \text {. Any method of applying } \\
\text { preheat that does not harm the bar material or the } \\
\text { concrete may be used. }\end{array}$ \\
\hline $\begin{array}{l}\text { ASME Code Section XI, } \\
\text { Division 1, Subsection } \\
\text { IWA-4540, } 1995 \\
\text { Edition } \\
\text { (Ref. } 4.7 \text { ) }\end{array}$ & $\begin{array}{l}\text { Alternative repair welding } \\
\text { method involving butter } \\
\text { bead-temper bead repairs of } \\
\text { metal containments and liners } \\
\text { of concrete containments }\end{array}$ & $\begin{array}{l}\text { Requirements are provided for repair welding } \\
\text { when factors such as water backing make preheat } \\
\text { and PWHT impractical. A production test is } \\
\text { required as part of the qualification process prior } \\
\text { to any repair welding. No temperature limits are } \\
\text { provided. }\end{array}$ \\
\hline $\begin{array}{l}\text { AWS Structural } \\
\text { Welding Code-- } \\
\text { Reinforcing Steel } \\
\text { ANSI/AWS D1.4-92 } \\
\text { Subsection } 4.3 \\
\text { (Ref. 4.28) }\end{array}$ & $\begin{array}{l}\text { Control of distortion, } \\
\text { shrinkage, and heat }\end{array}$ & $\begin{array}{l}\text { When welding is performed on bars or other } \\
\text { structural components embedded in concrete, } \\
\text { allowance shall be made for thermal expansion of } \\
\text { the steel to prevent spalling or cracking of the } \\
\text { concrete or significant destruction of the bond } \\
\text { between concrete and the steel reinforcing bar. } \\
\text { No temperature limits for concrete or steel are } \\
\text { provided. }\end{array}$ \\
\hline $\begin{array}{l}\text { Code Requirements for } \\
\text { Nuclear Safety Related } \\
\text { Concrete Structures ACI } \\
349-90 \\
\text { (Ref. 4.29) }\end{array}$ & $\begin{array}{l}\text { Welding of attachments to } \\
\text { large concrete embedments }\end{array}$ & $\begin{array}{l}\text { Welding of attachments to large concrete embed- } \\
\text { ments is permitted provided the welding is per- } \\
\text { formed in accordance with good practice to avoid } \\
\text { excessive expansion of the embedment which } \\
\text { could result in spalling or cracking of the concrete } \\
\text { or excessive stress in the embedment. }\end{array}$ \\
\hline
\end{tabular}


Table 4.6 Issues that need to be considered in a Repair/Replacement Plan for welding repairs of containment pressure boundary components backed by concrete.

\begin{tabular}{|ll|}
\hline \multicolumn{1}{|c|}{ Issue } & \multicolumn{1}{c|}{ Consideration } \\
\hline \hline $\begin{array}{l}\text { Concrete removal prior } \\
\text { to repair welding }\end{array}$ & $\begin{array}{l}\text { Whenever repair welding of a containment pressure boundary component backed by } \\
\text { concrete is being planned, consideration should be given to removing the concrete } \\
\text { prior to repair welding. This approach will ensure that a high-quality weld is } \\
\text { produced and that the concrete is not exposed to high temperatures. } \\
\text { concrete temperature }\end{array}$ \\
$\begin{array}{l}\text { If removal of concrete prior to repair welding is not feasible, a maximum allowable } \\
\text { temperature limit for the affected concrete should be specified. Based on limited } \\
\text { quantifiable test data about the effects of rapid, localized heating on concrete and no } \\
\text { established guidance from applicable codes and standards, a maximum allowable } \\
\text { concrete temperature of } 260^{\circ} \mathrm{C} \text { is suggested. Short-term exposure of concrete to this } \\
\text { temperature is not expected to cause significant concrete strength reduction, and } \\
\text { explosive spalling of the concrete should not be a serious concern. However, } \\
\text { ensuring that the specified temperature limit is not exceeded during the welding repair } \\
\text { may be difficult or impossible due to the inaccessibility of the exposed concrete } \\
\text { surface and problems associated with making precise concrete surface temperature } \\
\text { measurements. } \\
\text { When heat generated by repair welding will affect items such as steel anchor studs } \\
\text { and structural or nonstructural attachments that are embedded in the concrete, a } \\
\text { maximum allowable temperature limit for the embedment at the embedment-concrete } \\
\text { interface should be specified. Using requirements presented in the AWS Structural } \\
\text { Welding Code for Reinforcing Steel (Ref. 4.28), a maximum allowable embedment } \\
\text { temperature of } 260^{\circ} \mathrm{C} \text { at the embedment-concrete interface is suggested. Short-term } \\
\text { exposure of metallic embedments to this temperature is not expected to produce ther- } \\
\text { mal expansion that would cause significant spalling or cracking of the concrete or } \\
\text { significant destruction of the bond between concrete and the embedment. }\end{array}$ \\
\hline
\end{tabular}


Table 4.7 Advantages and disadvantages of cathodic protection systems.

\section{Advantages}

- Cathodic protection can be nondestructively evaluated using sensors or monitors placed on or near the affected structure. These devices can be used to assess the extent of corrosion and to collect data for evaluating the time-dependent degradation of the structure.

- Sacrificial anode cathodic protection systems are relatively simple passive systems that function as long as an anode and a cathode are electrically connected while immersed in an electrolyte.

- Cathodic protection systems for nuclear power plant containment pressure boundary components can usually be installed for less than the cost of replacement. However, cathodic protection may not be suitable for all situations.

- Cathodic protection can be used to mitigate effects of stray currents.

- Properly installed and activated cathodic protection systems can halt corrosion of steel embedded in chloride-ion contaminated reinforced concrete structures. Even underpowered impressed current cathodic protection systems can extend the remaining useful life of these structures.

\section{Disadvantages}

- For cathodic protection to be effective, electrical continuity between all metallic components to be protected must be provided. Reinforcing bars in concrete structures are typically interconnected by wire ties, steel supports, and other metallic connections. When suitable electrical connections between reinforcing bars and other major steel components do not exist, wiring can be installed and welding performed to ensure continuity.

- Undesirable hydrogen can be generated at the cathode of an electrochemical cell when the potential of the cathode reaches the hydrogen evolution potential. The value of this potential depends on the chemical reactions associated with the cell.

- Due to potential hydrogen generation, application of impressed current cathodic protection to high-strength and highly stressed steel used in certain bolting applications and in posttensioned concrete containment construction may result in hydrogen embrittlement of the affected metals.

- All impressed current cathodic protection systems have the potential to cause stray electrical current corrosion of other metals. Stray current leakage from impressed current cathodic protection systems is generally associated with underground or submerged environments, where the distance between anodes and the protected structure is relatively long. On the other hand, stray current leakage to other structures caused by impressed current cathodic protection of atmospherically exposed structures is less likely because the anodes are very close to the structure being protected.

- Impressed current cathodic protection systems are considered active systems because they require an external source of DC power. These power sources often require periodic maintenance and therefore may not always be reliable. 
Table 4.8 Basic components of a sacrificial anode cathodic protection system.

- Current distribution hardware and related wiring (anode)

- Protected metal structure such as a metal containment shell, liner of reinforced concrete structure, concrete reinforcing bars, metallic components immersed in water, etc. (cathode)

- Concrete, soil, or water capable of conducting electricity (electrolyte)

- Evaluation devices, reference electrodes, wiring, etc. (electrical connection)

Table 4.9 Basic components of an impressed current cathodic protection system.

- Current distribution hardware and related wiring (anode)

- Protected metal structure such as a metal containment shell, liner of reinforced concrete structure, concrete reinforcing bars, metallic components immersed in water, etc. (cathode)

- Concrete, soil, or water capable of conducting electricity (electrolyte)

- Evaluation and control devices, reference electrodes, controller, rectifier, wiring, etc. (external DC power source and electrical connection)

Table 4.10 Potential sources of stray electrical current at nuclear power plants.

\begin{tabular}{|ll|}
\hline \multicolumn{1}{|c|}{ Potential Source } & Type of Stray Current \\
\hline \hline Electrical railway and mass transit systems & Dynamic \\
High voltage direct current (HVDC) systems & Dynamic/Static \\
Impressed current cathodic protection systems & Static \\
DC welding operations & Dynamic \\
Electrical grounding systems & Dynamic/Static \\
Battery power supplies and battery recharging stations & Dynamic \\
DC motors such as elevators, cranes, remote & Dynamic \\
controlled valves, etc. & \\
Industrial machinery & Dynamic \\
Electroplating operations & Dynamic \\
Telephone systems with very old technology & Dynamic \\
Electronic and instrumentation and control equipment & Dynamic \\
Railroad train switch signals & Dynamic \\
Geophysical effects such as lightning strikes, sun & Dynamic \\
spots, related electromagnetic interferences, and & \\
telluric currents & \\
\hline
\end{tabular}


Table 4.11 Potential water sources and remedial actions taken to eliminate water from the sandbed at the Oyster Creek nuclear power plant.

\begin{tabular}{|c|c|c|}
\hline $\begin{array}{l}\text { Potential water } \\
\text { source }\end{array}$ & $\begin{array}{l}\text { Detection } \\
\text { method }\end{array}$ & $\begin{array}{l}\text { Remedial } \\
\text { action }\end{array}$ \\
\hline Spent Fuel Pool & Vacuum Box Testing & Repaired by underwater welding. \\
\hline $\begin{array}{l}\text { Reactor Cavity Seal } \\
\text { Bellows }\end{array}$ & Pressure Testing & No leaks detected. \\
\hline $\begin{array}{l}\text { Reactor Cavity Seal } \\
\text { Drain Line }\end{array}$ & Pressure Testing & Gasket repaired. \\
\hline $\begin{array}{l}\text { Reactor Cavity Seal } \\
\text { Under Drain }\end{array}$ & Video Surveillance & Modified concrete trough contour. \\
\hline Reactor Cavity Liner & $\begin{array}{l}\text { Visual Inspection, Dye } \\
\text { Penetrant Testing, and } \\
\text { Vacuum Box Testing }\end{array}$ & $\begin{array}{l}\text { Extensive leaks identified. Temporary coating } \\
\text { during refueling outage, stainless steel tape and } \\
\text { elastomeric coating applied. }\end{array}$ \\
\hline Skimmer System Piping & Helium Leakage Testing & System was isolated. \\
\hline Equipment Storage Pool & $\begin{array}{l}\text { Visual Inspection, Dye } \\
\text { Penetrant Testing, and } \\
\text { Vacuum Box Testing }\end{array}$ & Repaired by welding. \\
\hline Sandbed Drains & Examination of Drain Lines & $\begin{array}{l}\text { Drains were unclogged allowing water to drain } \\
\text { from the sandbed. }\end{array}$ \\
\hline
\end{tabular}

Table 4.12 Recommended test section configurations for the liner plate welding repair experimental investigation.

\begin{tabular}{|ccc|}
\hline Test section designation & Test section type & Repair welding technique \\
\hline \hline 1 & Anchor Stud & Overlay \\
2 & Anchor Stud & Doubler Plate \\
3 & Embedment Anchor & Overlay \\
4 & Embedment Anchor & Doubler Plate \\
\hline
\end{tabular}




\section{RELIABILITY-BASED CONDITION ASSESSMENT}

Nuclear power plants are designed to withstand operating conditions, extreme environmental events, and postulated design-basis accidents. Many mechanical, electrical, and structural components and systems in a nuclear power plant are susceptible during their service lives to a phenomenon known as aging. Aging may lead to time-dependent changes in engineering properties that may impact the ability of such systems to withstand various challenges from plant operation, the environment, and accidents. The Nuclear Plant Aging Research (NPAR) Program addressed these concerns for components and systems that may affect plant operation (5.1).

Much of the research on the impact of aging and deterioration in nuclear power plants has focused on mechanical and electrical components (5.2-5.6). Mechanical and electrical components and systems play an active role in mitigating accident sequences that arise from internal or external challenges to the safety-related systems in the plant. Relative to structural components and systems, mechanical and electrical components are easily and often frequently tested in service, and they can, if necessary, be replaced during normal scheduled maintenance with a minimum disruption of facility operation. Moreover, many such components are nominally identical and, as a result, test data often are available for modeling their failure rates.

In contrast, structures are passive under normal operating conditions but play an essential role in mitigating extreme events initiated by earthquake, wind, or other external influences. Moreover, failure of major structural components may impact the operation of mechanical and electrical systems as well (so-called common cause failures). Unlike mechanical and electrical components, structural components and systems are plant-specific and unique, and only limited data are available to judge their performance in service. Structures may be difficult to inspect with any regularity, key components may be inaccessible, and significant structural degradation may not be noticeable until failure is impending. Moreover, structural components usually cannot be replaced. Thus aging of structural components and systems may be more significant in terms of overall plant risk than may be evident from a cursory examination of their role in accident mitigation. Instead, quantitative analysis procedures are required to evaluate margins of safety of existing steel structures and to support decisions regarding whether to continue service. Such condition assessments must account for material degradation that may occur as a result of a hostile service environment, the stochastic nature of past and future loads due to operating conditions and the environment, and the uncertainty in nondestructive evaluation techniques.

Time-dependent changes in structural properties, as well as challenges to nuclear power plant structural components and systems, are random in nature. Safety evaluations of new and existing structures can be conducted rationally within a probabilistic framework $(5.7,5.8)$. A methodology has been developed as part of the ORNL/NRC Structural Aging Program that provides a reliability-based framework for condition assessment and probability-based life predictions of concrete structures in nuclear power plants (5.9). In this methodology, structural condition assessment and service life predictions focus on a few critical structural components and systems within the plant. These critical structural components can be identified by considering the impact of their degradation on plant risk in explicit probabilistic terms through the mathematical formalism of a probabilistic risk assessment (PRA) or a probabilistic margin assessment. A seismic PRA is divided conceptually into hazard, fragility (capacity), and plant logic components. The following steps generally are followed: (1) identify seismic hazard from potential seismogenic sources, seismicity in the vicinity of the plant, and attenuation of ground motion to the site; (2) develop plant logic to explain the interrelation of various plant components and systems in mitigating the effect of initiating events; (3) develop building response and fragility models to determine demand on plant components and systems and their capacities; and (4) measure risk by calculating core damage probability, plant damage states, and offsite consequences to public health and safety.

\subsection{STRUCTURAL DETERIORATION AND ITS EVALUATION}

The major mechanism of deterioration affecting nuclear power plant steel structures is corrosion, with fatigue or corrosion/fatigue possible, but less likely. Other deterioration mechanisms are discussed briefly for completeness.

\subsubsection{Corrosion}

Corrosion is an electrochemical reaction between a metal and its environment. Corrosion is the most damaging mechanism affecting metal containments and liners. Mechanisms that are of particular significance in carbon steels used for nuclear power plant containments, liners and other Category I steel structures are uniform corrosion, localized pitting and crevice corrosion. Intergranular or transgranular stress-corrosion may also occur, and may be important in stainless 
steels. Corrosion impacts one structural limit state and one performance-related limit state. At design load conditions, shell thinning from general corrosion may lead to gross inelastic deformations in regions of tensile stress or instability in regions of compressive stress. Penetration of the shell by localized corrosion may lead to the development of a leak path and diminished pressure retention.

The electrochemistry of the corrosion process is reasonably well understood, and mathematical models of the electrochemical processes underlying corrosion are available (5.10). Here, we emphasize those aspects of the corrosion process that impact structural performance.

\subsubsection{Uniform corrosion}

Uniform corrosion occurs over a large area of the surface of the component and is characterized by an essentially uniform thinning of the section. Excessive thinning due to uniform corrosion may lead to gross inelastic deformations or instability of the shell. The depth of corrosion in steel is modeled by,

$$
x(t)=C\left(t-t_{i}\right)^{\alpha}
$$

in which $\mathrm{t}=$ time, $\mathrm{t}_{\mathrm{i}}=$ induction or initiation time required to activate the process, $\mathrm{C}=$ rate parameter, and $\alpha=$ time-order parameter. It should be noted that Eqn 5.1 is empirical in nature. The associated corrosion rate (for purposes of comparison with experimental data) is,

$$
\mathrm{dx} / \mathrm{dt}=\alpha \mathrm{C}\left(\mathrm{t}-\mathrm{t}_{\mathrm{i}}\right)^{(\alpha-1)} .
$$

The parameters $\mathrm{C}$ and $\alpha$ must be determined from experimental data, supplemented by knowledge of the physics of the underlying mechanism of attack. In time-dependent reliability analysis, $\mathrm{C}, \alpha$ and $\mathrm{t}_{\mathrm{i}}$ are modeled as random variables, as described subsequently. Once active corrosion initiates, the corrosion rate is related to the corrosion current density, $\mathrm{i}_{\text {corr }}$.

An alternate expression for corrosion is (5.11),

$$
x(t)=a \ln (t)
$$

in which a is an experimental constant and the induction time has been ignored. The implied corrosion rate is proportional to $1 / \mathrm{t}$.

Two general methods are recognized for estimating atmospheric corrosion-resistance of low-alloy steels (5.12) from test data. The first utilizes linear regression analysis of short-term data to predict long-term performance by extrapolation. The second determines a corrosion resistance index based on chemical composition of the steel. The regression analysis presumes a log-linear relation between loss and time, leading to Eqn 5.1. The idea of extrapolating beyond the realm of observed data violates one of the basic tenets of regression analysis as a predictor. No convincing answer is provided to the question of long-term extrapolation or similitude of accelerated aging testing.

Corrosion testing is conducted mainly in the laboratory under carefully controlled conditions with small specimens. Corrosion progression normally is measured by weighing and measuring material loss. Laboratory experiments often involve accelerated testing, or attempts to simulate a multi-year service life by a test of a few weeks or months. One must be cautious in using the results of such accelerated aging tests to determine $\mathrm{C}$ and $\alpha$, as the aging mechanisms may not scale properly from the laboratory to the service environment (5.13-5.15). Physical factors that govern the corrosion process include temperature, residual stress, and cyclic loading rate, if cyclic loads are present. Temperature affects oxygen solubility, $\mathrm{pH}$, and corrosion product formation. In the presence of a moving fluid, the corrosion rate may increase as fluid velocity increases. Degree of exposure - total, partial, or intermittent - also may change rate and mode of corrosion. On the other hand, the induction period normally is ignored in an accelerated laboratory test. Failure to include this (random) induction time has been shown to lead to a conservative estimate of remaining service life or residual strength (5.16).

Corrosion testing occasionally may be conducted in the field. Field tests may involve either small specimens or structural components. While environmental similitude is easier to maintain, accurate measurements of the corrosion process may be difficult to obtain under field conditions. Table 5.1 summarizes average uniform corrosion parameters for carbon and 
weathering steels, some of which are similar to the low-carbon ferritic steels used for containments and liners, in several environments $(5.17,5.18)$. These values were determined from tests of small specimens, and some error may result from extrapolating these data to structural members. The constants $C$ and $\alpha$ are such that $\mathrm{x}(\mathrm{t})$ is measured in $\mu$-m when $\mathrm{t}$ is measured in years. Since no information or data were provided on the corrosion induction period, it was assumed that corrosion initiated immediately and that $t_{i}=0$; this is a conservative assumption. Some of the parameters provided by (5.17) have been used in reliability-based evaluation of bridge deterioration (5.19) and to devise bridge inspection strategies (5.20). Uniform corrosion rates are dependent on the environment and ambient temperature. The uncertainty in the corrosion rate is quite large; one reference reported a coeff'cient of variation of 0.7 for uniform corrosion in stainless steel containers (5.11). A more typical coefficient of variation in $\mathrm{C}$ would be 0.3 .

The time order parameter for uniform corrosion, $\alpha$, is less than unity, indicating a decrease in corrosion rate with time. The initial corrosion rate in mild steels exposed to fresh or seawater is of the order $200 \mu-\mathrm{m} / \mathrm{yr}$, decreasing parabolically to $100 \mu-\mathrm{m} / \mathrm{yr}$ after one year (5.21) as corrosion product film provides a protective barri er against further oxidation. The time-order parameter can be treated as deterministic; the fact that it is close to 0.5 suggests that corrosion might be modeled as a diffusion-type process.

In nuclear power plants, estimated general corrosion rates from field surveys are (5.22): 0.52 - $1.4 \mathrm{~mm} / \mathrm{yr}$ (Oyster Creek exterior drywell shell); $0.08 \mathrm{~mm} / \mathrm{yr}$ (Nine Mile Point torus interior above waterline); $1.15 \mathrm{~mm} / \mathrm{yr}$ (McGuire 2, exterior of the containment); $0.33 \mathrm{~mm} / \mathrm{yr}$ (McGuire 1 interior of containment). One must be cautious about extrapolating such measurements to service life prediction since the corrosion rate decreases with time (cf Eqns 4.2 and 4.3), and corrosion measured early in a service period may not be indicative of subsequent performance. Coating degradation from temperature, condensation and immersion, radiation and impact allows corrosion to initiate and spread, lifting the coating and accelerating deterioration.

Possible structural degradation from uniform corrosion often is addressed in ordinary structural design by providing an extra thickness or "corrosion allowance" to the material. This allowance typically is on the order of 1-3 mm when no protective coating is provided. The maximum penetration of corrosion is a random variable and can be modeled by a Type I distribution of largest values or Gumbel distribution (5.21). Parameters of the extreme value distribution can be related empirically to the mean corrosion penetration; this then can be used to determine the 99-percentile value of loss of section due to corrosion and thus a corrosion allowance (in $\mathrm{mm}$ ) to ensure satisfactory performance during a service period.

The corrosion allowance approach has also been suggested for designing containers for long-term waste storage (5.23). Problems with long-term extrapolation of data (out to 1000 years or more) necessitates very conservative assumptions regarding corrosion mechanisms. Making such assumptions, steady-state corrosion rate in low-carbon steel at $90 \mathrm{C}$ is predicted to be $209 \mu-\mathrm{m} / \mathrm{yr}$. Experimental data (short term) invariably fall below this level.

The presence of aggressive chemicals (e.g., boric acid, sodium pentaborate) can accelerate the rate of metallic corrosion (5.24). Components known to have been affected by corrosive attack by borated water leaking through seals and valves include threaded fasteners, reactor coolant piping, pumps and valves. Corrosion reported at the Catawba and McGuire plants was due to borated water leaking from an instrumentation line that pooled against the metal shell. Corrosion rates up to $43 \mathrm{~mm} / \mathrm{yr}$ may occur in carbon or low-alloy steels exposed to borated water at $92 \mathrm{C}$; because of the high rate, such components cannot be designed using the corrosion allowance approach, and instead must be protected from such aggressive attack.

\subsubsection{Localized corrosion - pitting and crevice}

Pitting and crevice corrosion are highly localized. Pits can be hidden under a surface of corrosion products, making detection difficult. Many nondestructive methods can locate relatively large pits but cannot distinguish between pits and other surficial defects (5.25). Pitting corrosion is often identified by the presence of surface nodulation. Problem areas usually represent only a small percentage of total surface area, and the local pitting usually is not accompanied by significant loss of material. However, evaluation of the depths of pitting corrosion is necessary to ensure the integrity of the pressure boundary. A single through-the-thickness crack is sufficient to cause leakage.

Pitting and crevice corrosion are similar in their mechanisms and descriptive mathematical models (5.25,5.26). The pitting process appears to be initiated by an electrochemical breakdown of the passive film from local acidity, 
inhomogeneities in the material, or other phenomena causing local disruption of the passive layer. Cyclic loading also can disrupt the passive layer, forming anodic areas at points of rupture and giving rise to corrosion-fatigue.

The initiation and growth of pits are not readily measured by methods that are used to evaluate uniform corrosion. In fact, pits frequently become dormant following an initial period of growth and subsequently reinitiate (so-called pit birth and death (5.27)). However, mathematical modeling of growth of individual pits follows the same semi-empirical formulas as used for uniform corrosion (Eqns 5.1 - 5.3). In aluminum, it has been observed that pit depth is proportional to $t^{1 / 3}$ (5.25). In steels, it has been observed (5.28) that pit volume increases linearly with time. Assuming a hemispherical pit of radius $r$ and constant bulk dissolution rate $B$, pit volume $(2 / 3) \pi r 3=B t$, again implying that $r$ is proportional to $t^{1 / 3}$. This seems to agree well with experimental results. On the other hand, at least one study (5.11) suggests that in stainless steels, pit growth is a linear function of time. A pitting rate proportional to $\mathrm{t}^{-0.6}$ has been proposed (5.29). The pitting corrosion rate can be $3 \times 10^{5}$ to $10^{6}$ times higher than general corrosion (5.30). One researcher reports an exponent of 3.42 in Eqn 5.1 (5.31).

Local pitting corrosion penetration is related to anodic current density (5.23). Maximum pit depths were measured over an area of approx $3 \mathrm{~m}^{2}$ in carbon steel specimens tested in $\mathrm{NaHCO}_{3}+\mathrm{Cl}^{-}$for periods of up to 1.1 years. These data were analyzed at different exposure times using statistics of extremes. Results indicated that maximum pitting depth was related to time by $\mathrm{x}_{\max }=8.35 \mathrm{t}^{046}$, where $\mathrm{t}$ is in $\mathrm{yr}$ and $\mathrm{x}_{\max }$ in $\mathrm{mm}$. Extrapolation of these data to a $1000-\mathrm{yr}$ life yielded a pit depth of $200 \mathrm{~mm}$; however, the validity of this extrapolation clearly is questionable and without doubt conservative.

Table 5.2 summarizes data on pitting corrosion identified by a literature search. Although only limited data were identified, it is clear that the rate of pit growth is potentially much higher than that of uniform corrosion.

Limited statistical studies have been performed for pitting corrosion depth. When several pits are present, the maximum pit depth $\mathrm{x}_{\max }$ within an area is of more interest than the distribution of individual pit depths. $\mathrm{x}_{\max }$ has been reported to be a linear function of the log of exposed area $(5.30,5.32)$. The distribution of maximum pit size can be determined from the individual pit depths using extreme value statistics $(5.25,5.28)$, assuming that the pit depths are statistically independent $(5.30,5.31,5.33)$.

A stochastic model for pitting corrosion has been developed (5.34). It was assumed that the number, $\mathrm{N}(\mathrm{t})$, of pits at time, $\mathrm{t}$, is a Poisson process, dependent on the mean surface area and random initiation time. The growth in pit surface area is described by a stochastic finite-difference equation. Others have modeled the growth in maximum pit depth as a discrete-space, continuous-time Markov process (5.35). The evolution of the probability density of pit depth in time was described by a Kolmogorov forward differential equation. A laboratory program conducted as part of this study found that the mean and variance of maximum pit depth were proportional to $\mathrm{t}^{\mathrm{a}}$ and $\mathrm{t}^{\mathrm{b}}$, respectively, where $0<\mathrm{a}, \mathrm{b}<1$. The probability distribution of maximum pit depth was found to be Type I extreme value at different exposure periods, with mode and scale parameters that increase linearly with time (5.36).

In a electrochemical rather than structural engineering approach (5.37), changes in current during corrosion were measured and analyzed statistically. The "survival probability" was the probability that the electrode remained unpitted. The probability of survival was found to be,

$$
L(t)=\exp (-A(t) t)
$$

in which $\mathrm{A}(\mathrm{t})=$ time-dependent pit generation rate. If the surface area is divided into small elementary areas, pitting in each area can be treated as statistically independent events. The maximum pit depth was described by a Type I distribution of largest values. If depth increases by $x=b \log t+c$, then $d x / d t=b / t$ and time at which the maximum pit penetrates the thickness of the component is described by a Weibull probability distribution. This time-dependent model does not take into account birth and death processes of pits. Moreover, pit initiation cannot be modeled as a Poisson process with stationary increments, since the intervals are not independent and occurrences have a tendency to cluster.

\subsubsection{Fatigue and Fracture}

Metals contain voids and inclusions at the microscopic level. In addition, a structural component may contain surficial geometric discontinuities (e.g., weld undercuts, reentrant corners, and holes) or local damage (e.g., cracks and corrosion loss) that cause stress concentrations. In the presence of cyclic loads, these subcritical defects may grow, eventually leading to failure at loads much smaller than the statically applied monotonic load causing failure. 
The loads applied to a nuclear power plant structure may be cyclic in nature. Examples of operational cyclic, thermal and mechanical loads in a containment include startup/shutdown thermal transients, pipe reactions, safety relief valve (SRV) discharge tests, cranes, and refueling operations. Although extreme environmental events such as earthquakes may also include cycling, the rate of occurrence and duration of such events is sufficiently small that they would not cause fatigue damage to accumulate.

Early nuclear power plant steel structures and components were designed with little consideration for fatigue. Since the late 1960's, however, design requirements for reactor pressure vessels and Class 1 piping have included fatigue considerations (5.38). Current fatigue design analyses are aimed at demonstrating that a component has a cumulative use factor (computed from a Palmgren-Miner analysis) of less than 1.0 at the end of a 40-year design life. The analysis is made with conservative assumptions regarding the number and magnitude of operating transients. Several fatiguemonitoring programs are under development in the U. S., aimed at determining increases in the cumulative usage factor on-line as a function of operating transients.

Fatigue is not believed to be a significant problem in steel containments and liners except at points of structural discontinuities (e.g., weld undercuts), or heavy weldments where residual stresses may approach yield. Ductile carbon steels of the type used in containments and liners are not susceptible to low-cycle fatigue, and can withstand numerous reversals of moderate inelastic strain without failure. However, general corrosion may cause the surface of the shell to become rough, resulting in local stress concentrations, and corrosion pits also may serve as sites for fatigue crack initiation and growth. Crack initiation time can be reduced by a factor of as much as three when pitting is present. An exception to the general fatigue insensitivity of the containment is the stainless steel bellows at Mark I containment penetrations, which have high residual stresses from cold-rolling and are susceptible to low-cycle fatigue and stresscorrosion cracking.

It is convenient to envision three stages in the fatigue process: (1) crack initiation; (2) stable (subcritical) crack growth; and (3) unstable crack growth or fast fracture. The third stage occurs so rapidly in comparison with the first two that it can be ignored in service life predictions. Crack initiation and growth processes are driven by different factors. The initiation phase reflects interactions of the metal with the bulk environment. Dislocations due to slip lead to highly localized stresses that nucleate a macroscopic crack that then propagates. In the crack growth phase, the local crack tip environment, which may be different from bulk environment, determines the process. The relative contributions of these phases depend on the load spectrum, material characteristics, and initial condition of the component. If the structure is essentially defect-free and the stress range is low, most of the life of the structure is consumed in initiating a detectable flaw. On the other hand, many welded components contain initial flaws (e.g., lack of fusion and penetration), and in such components, there is essentially no initiation phase. A facility for analyzing both phases of fatigue is required in condition assessment. Fatigue often is thought of as having two domains: (1) low-cycle fatigue, with service life of 100,000 cycles or less, and (2) high-cycle fatigue, with service life of more than 100,000 cycles. In the latter, the metal initially is essentially defect-free and cyclic stresses remain in the elastic range.

During a service load history involving time-varying or cyclic loads, failure can occur by single overload or by accumulation of damage (5.39). In failure analysis, "damage" is an aggregated parameter describing the macroscopic appearance or manifestation of functional impairment. There may be no immediate relation between damage and measurable physical quantities (this is the case prior to visible crack initiation, where microstructural changes cannot be detected by the usual field inspection methods), or the relation may be quite obvious (i.e., crack propagation). Timedependent reliability methods and condition assessment procedures must be tailored to these realities. Sources of uncertainty in fatigue modeling include random load and material properties, system modeling, damage accumulation law, and defect size. The state of the art of probabilistic fatigue analysis has been reviewed in a series of four papers (5.40).

\subsubsection{Low-Cycle Fatigue}

All models used to analyze fatigue are empirical to a degree, with parameters that are dependent on the metal and its service environment, and are determined by testing small specimens under cyclic load. The primary load parameter affecting fatigue is the stress (or strain) range, $\Delta \mathrm{S}=\mathrm{S}_{\max }-\mathrm{S}_{\min }$. Other factors that may be important in varying degrees include mean stress (or stress ratio, $\mathrm{R}=\mathrm{S}_{\min } / \mathrm{S}_{\max }$ ), load sequence, and cyclic frequency. Fatigue life to "failure" is defined in a number of ways: as time (or number of cycles) to complete fracture of the specimen; as time required for a specified increase in specimen compliance; or as time to initiation of detectable (and presumably repairable) cracking. When utilizing experimental data to develop fatigue assessment procedures, it is essential to understand the relation 
between "failure" as it relates to the performance of the structure in service and "failure" as it is defined in the experimental fatigue database.

The most common way of expressing the fatigue life of a component in terms of the number of cycles to "failure," $\mathrm{N}$, is through the well-known S-N relation between stress and cycles,

$$
\mathrm{N}(\Delta \mathrm{S})^{\mathrm{m}}=\mathrm{C}
$$

in which $\Delta \mathrm{S}=$ applied stress range and $\mathrm{m}$ and $\mathrm{C}$ are experimental constants. When fatigue testing is deformationcontrolled, rather than load-controlled, stress range is often replaced with total strain range or plastic strain range. Equation (5.5) is sometimes referred to as the Basquin equation. A more general model is the Coffin-Manson equation (5.40)

$$
\Delta \varepsilon / 2=\left(\sigma_{\mathrm{f}} / \mathrm{E}\right)(2 \mathrm{~N})^{\mathrm{b}}+\varepsilon_{\mathrm{f}}(2 \mathrm{~N})^{\mathrm{c}}
$$

in which $\Delta \varepsilon=$ strain range, $\mathrm{E}=$ modulus of elasticity, and $\sigma_{\mathrm{f}}, \varepsilon_{\mathrm{f}}, \mathrm{b}$ and $\mathrm{c}=$ experimental constants. The first term is equivalent to Eqn 5.5, expressed in terms of elastic strain; the second term dominates in the low-cycle regime, where the cycling is inelastic.

Fatigue test data presented in the form of S-N curves indicate a substantial inherent variability about the median curve; coefficients of variation in fatigue life at a given stress commonly are on the order of $0.30-0.60(5.40)$. This inherent variability can be displayed by presenting the S-N curves as a family of curves at different cumulative probabilities, or P$\mathrm{S}-\mathrm{N}$ curves (4.43). In developing fatigue curves for design purposes, one might select a 5-percentile or 10-percentile curve. However, in developing fatigue curves for design purposes from experimental data, it has been customary to divide the stress and/or corresponding median life by deterministic factors of safety. For example, in ASME Code Section III, median low-cycle (controlled strain) fatigue curves were lowered by factors of 2 on stress and 20 on cycles to obtain design fatigue curves. These adjustments are intended to account for scatter in data, size effects, surface finish, and environmental effects. More recent studies indicate that the ASME curves may not address environmental effects in the low-cycle (strain greater than $0.1 \%$ ) range (5.42). Data from several samples of smooth specimens tested under fully reversed strain cycling $(\mathrm{R}=-1)$ were analyzed. Temperature (in air), percentage dissolved oxygen and strain rate (in aqueous solution) had the most significant impact. Strain rate in air or characteristics of load vs time had little effect on fatigue life.

Because of economic limitations, most fatigue data are determined by testing small, smooth specimens under carefully controlled conditions. Most structural components that are susceptible to fatigue damage are neither small and smooth nor subject to constant amplitude cycling. Fatigue damage is most likely to initiate and develop at weld undercuts and other stress raisers (notches) where the local stress (or strain) is amplified by a significant factor above the "far-field stress" (or strain) computed from a finite-element analysis. Such local effects are not included within the normal factors of safety on smooth-specimen fatigue curves alluded to above. The question arises as to how to deal with such local effects.

One approach is to conduct fatigue tests of larger specimens containing representations of the fatigue critical structural details. This has, in fact, been done for civil structures; over a period of three decades from the 1950's to the 1980's, numerous fatigue tests of representative bolted and welded details, mainly representative for bridge structures, were conducted at Lehigh University, the University of Illinois, and other institutions (5.43). The test results were collected in six main categories of details, and allowable cyclic stresses for four main load conditions were determined with an appropriate factor of safety. The results can be seen in Appendix K of the current LRFD Specification (5.44). Such an approach, while acceptable for routine design of civil structures where details are repetitive, may be unduly conservative when applied to a specific fatigue-critical detail. Thus, its use in condition assessment of a set of specific details in a structural system may not provide uniform or consistent reliability among these details. Moreover, in light of recent advances in computational ability to analyze complex nonlinear stress-strain histories accurately, it is a highly inefficient method for condition assessment.

Smooth-specimen fatigue curves can be used to determine fatigue behavior of structural components with stress raisers, provided that the local stress-strain history at the notch can be analyzed. If the material remains entirely elastic, the local maximum stress (or strain) at a notch is the product of the far-field stress and a stress concentration factor, K, However, when the material local to the notch is stressed beyond the elastic range, the local stresses and strains can no longer be 
determined from K. Studies (5.45) have shown that Neuber's rule (5.46) can be used in this case to determine the local stress-strain history at the notch needed to utilize smooth-specimen fatigue data. Neuber's rule postulates that the product of local stress and strain range is proportional to the product of far-field elastic stress and strain range, or,

$$
\Delta \sigma \Delta \varepsilon=\mathrm{k}_{\mathrm{f}}^{2} \Delta \mathrm{S} \Delta
$$

in which $\mathrm{k}_{\mathrm{f}}$ is an effective stress concentration factor and the far-field elastic stress and strain ranges, $\Delta \mathrm{S}$ and $\Delta \mathrm{e}$, can be determined by finite-element analysis or other conventional structural analysis procedure. The second condition needed for determining $\Delta \sigma$ and $\Delta \varepsilon$ is given by the constitutive model for the material. Assuming, for example, a RambergOsgood law,

$$
\varepsilon=K(\sigma)^{\mathrm{n}}
$$

in which $\mathrm{K}=$ compliance and $\mathrm{n}$ = strain-hardening exponent, one would obtain

$$
\Delta \sigma=\left[\left(\mathrm{k}_{\mathrm{f}} \Delta \mathrm{S}\right)^{2} / \mathrm{KE}\right]^{1 /(1+\mathrm{n})}
$$

Entering the S-N curve at this value of $\Delta \sigma$ would give the fatigue life of the detail.

When the load amplitudes vary in time, the number of cycles to failure (or time to failure) must be determined from a cumulative damage law. Such laws relate fatigue behavior under variable amplitude loading to the known behavior under constant amplitude cycling, which can be determined from experiments. The most commonly used of these laws is the Palmgren-Miner hypothesis, which postulates that damage accumulates linearly simply as a function of the number of cycles at a particular stress (or strain) level. Under variable amplitude loading, then, damage accumulation, D, is described by,

$$
\mathrm{D}=\sum_{\mathrm{i}} \Delta \mathrm{D}_{\mathrm{i}}=\sum_{\mathrm{i}}^{\mathrm{N}} \mathrm{C}^{-1}\left(\Delta \mathrm{S}_{\mathrm{i}}\right)^{\mathrm{m}}
$$

in which $\mathrm{N}=$ number of load cycles and, $\Delta \mathrm{D}_{\mathrm{i}}=$ increment of damage in cycle $\mathrm{i}$. If the load history consists of $\mathrm{k}$ discrete load amplitudes, Eqn 4.10 takes the more familiar form,

$$
\mathrm{D}=\sum_{\mathrm{i}}^{\mathrm{k}} \mathrm{n}_{\mathrm{i}} / \mathrm{N}\left(\Delta \mathrm{S}_{\mathrm{i}}\right)
$$

in which $\mathrm{n}_{\mathrm{i}}=$ number of cycles in the load history at stress level $\Delta \mathrm{S}_{\mathrm{i}}, \mathrm{N}\left(\Delta \mathrm{S}_{\mathrm{i}}\right)=$ number of cycles to failure under constant amplitude loading $\Delta \mathrm{S}_{\mathrm{i}}$, determined from Eqns (4.5) or (4.6), and $\Sigma \mathrm{n}_{\mathrm{i}}=\mathrm{N}$. When the cycles are not clearly defined, as is sometimes the case in broad-band excitation, rainflow cycle counting can be used to determine $n_{i}(5.47)$. (This necessitates a time-domain rather than frequency-domain analysis.) The Palmgren-Miner hypothesis asserts that failure occurs when $\mathrm{D}>1.0$. The Palmgren-Miner damage hypothesis does not account for stress sequence effects on fatigue life. However, a review of other damage accumulation theories indicate that other, more complex, rules do not provide consistently better results (5.40).

\subsubsection{Crack Propagation and Fracture}

Growth of an existing crack, once initiated, can be predicted by fracture mechanics analysis (5.48). Under the domain of applicability of linear elastic fracture mechanics (LEFM), unstable crack growth leading to fracture initiates when,

$$
\mathrm{K}>\mathrm{K}_{\mathrm{Ic}}
$$

in which $\mathrm{K}_{\mathrm{Ic}}=$ (plane strain) fracture toughness and $\mathrm{K}=$ stress intensity. The plane strain fracture toughness is a material parameter dependent on temperature, rate of loading, and the environment. For mild steel at ambient conditions, $\mathrm{K}_{\mathrm{Ic}}$ typically is about $140 \mathrm{MNm}^{-3 / 2}$ and its coefficient of variation typically is about 0.15 . The stress intensity is,

$$
\mathrm{K}=\mathrm{Y}(\mathrm{a}) \sigma \sqrt{\pi \mathrm{a}}
$$


in which $\sigma=$ far-field stress, $a=$ characteristic crack size, and $\mathrm{Y}(\mathrm{a})=$ correction factor based on relative crack size and shape and far-field loading. For a large plate in tension with a center crack (through the plate thickness) of length 2a, $\mathrm{Y}(\mathrm{a})=1.0$; for a penny-shaped crack within the plate with radius $\mathrm{a}, \mathrm{Y}(\mathrm{a})=2 / \pi$; and for an edge crack loaded in tension or flexural tension with depth a less than half the thickness, $\mathrm{Y}(\mathrm{a})=1.12$. Procedures are also available for modeling nonlinear behavior; the J-integral and crack-opening displacement approaches are two such procedures.

Fatigue crack growth (leading to increases in $\mathrm{K}$ up to $\mathrm{K}_{\mathrm{Ic}}$ ) is most commonly modeled using the Paris equation (5.47),

$$
\mathrm{da} / \mathrm{dN}=\mathrm{C}(\Delta \mathrm{K})^{\mathrm{m}}
$$

in which $\Delta \mathrm{K}=$ range of fluctuating stress intensity factor, obtained by replacing $\sigma$ by $\Delta \sigma$ in Eqn (4.13), and $\mathrm{C}$ and $\mathrm{m}$ are experimental constants (unrelated to the $\mathrm{C}$ and $\mathrm{m}$ in Eqn 5.5). With the stress history known, Eqn 4.14 can be integrated to determine the crack size as a function of elapsed cycles, $N$. Refinements to Eqn 4.14 for incorporating the mean stress or stress ratio, $\mathrm{S}_{\min } / \mathrm{S}_{\max }$, the threshold for crack growth, $\mathrm{K}_{\mathrm{th}}$, and other factors known to affect crack growth rate, are available (5.49). These effects generally have a second-order effect on predicted defect growth.

The crack growth analysis becomes difficult when several cracks grow simultaneously and interaction for cracks in close proximity may occur. In this case, the rate at which fractured area is produced may be more meaningful than crack growth rate. This suggests a "damage mechanics" approach, where multiple flaws are smeared (5.50).

Current analysis and design procedures do not consider possible synergistic effects of corrosion from an aggressive environment and fatigue from mechanical or thermal loads. The corrosion-fatigue process consists of several stages: pit formation and growth, crack formation from the pit (assuming corrosion pit can be modeled as a sharp crack), coalescence and corrosion-fatigue crack propagation (5.28). Post-failure fractographic investigations have revealed that a pit (or pits) is often the origin of the fracture surface, meaning that pit initiation and coalescence is the trigger for fatigue crack initiation. The transition of a pit into a crack occurs at a stress intensity of about $\mathrm{K}=1.2 \mathrm{MPam}^{1 / 2}$ for lowalloy steel; this is below the threshold for a long planar surface flaw (5.28).

\subsubsection{Stress Corrosion Cracking}

Stress-corrosion cracking (SCC) and fatigue damage may occur in the bellows, which are subjected to reversals in deformations due to heating and cooling during normal operation, pressure loads during leakage-rate tests, and high residual stresses. Maximum bellows deformations are $13-50 \mathrm{~mm}$ due to thermal expansion; such cycles may occur on the order of $1000-5000$ times during a 40 -year service life.

The initiation of SCC on a surface appears to be primarily dependent on mechanically- or chemically-induced rupture of the protective film (depassivation). This gives rise to acidity in occluded areas and development of local pitting or crevice corrosion at sites where cracking subsequently may initiate (5.23,5.51). Stress-corrosion cracking can also initiate at sites within the interior of a component, even in the presence of an aggressive external environment. Interior microcrack formation appears to occur first where intergranular features are smooth rather than coarse, regardless of where such sites occur. The metal must be stressed in tension above a threshold stress or stress intensity level for SCC to initiate and progress. Once initiated, stress-corrosion crack growth occurs at a much higher rate than either general or pitting corrosion, and even the minimum rate is too great for a corrosion allowance approach to design.

SCC is troublesome for time-dependent reliability analysis. It is difficult to analyze mathematically and to detect or repair prior to component failure. There is no unique definition of when localized corrosion changes into a stresscorrosion crack. Several cracks may initiate and repassivate prior to the time at which a dominant crack forms and propagates. Unexpected SCC problems in nuclear power plant s are costly to repair and raise additional safety concerns that are difficult to resolve. There are no satisfactory accelerated test methods for SCC (5.51).

\subsubsection{Elevated Temperature and Irradiation Effects}

Temperatures required for permanent degradation in strength or stiffness of carbon steel must be on the order of $500 \mathrm{C}$. Similarly, embrittlement of reactor pressure vessel steels has been noted for neutron radiation with fluence greater than $10^{19} \mathrm{n} / \mathrm{cm}^{2}$ (5.52). Since the containment is unlikely to see such levels of exposure, strength reduction due to prolonged elevated temperatures or radiation embrittlement of the metal containment shell is not generally a concern. Such effects are of more concern for the reactor pressure vessel and certain piping within the nuclear power plant. Neutron fluence of 
$10^{19} \mathrm{n} / \mathrm{cm}^{2}$ causes plane strain fracture toughness $\mathrm{K}_{\mathrm{Ic}}$ in the reactor pressure vessel material to reduce by about $20 \%$ after 40 years (5.53). Such fluences do not occur in the containment. On the other hand, creep can occur at elevated temperatures, introducing residual stresses or deformations (5.54).

\subsubsection{Deterioration of Coatings}

Coatings protect the structure from corrosion and facilitate decontamination. Coating degradation can occur due to elevated temperatures, excessive moisture, radiation, and mechanical abrasion and chipping. Localized problems occur before general failure of the coating system. Once corrosion initiates, however, failure of the coating system accelerates.

Many plant owners already have found it necessary to perform local repairs of coating systems, and it seems likely that such repairs will continue to be needed at regular intervals during an extended service life. Fortunately, coating maintenance usually can be performed along with other required maintenance activities. Underwater-cured epoxy is a common solution for spot repairs of coatings in tanks and suppression chambers. Coating performance thus does not appear to be a significant consideration in developing reliability-based condition assessment methodologies.

\subsubsection{Deterioration Summary}

There is substantial uncertainty, both inherent variability and modeling error, in modeling fatigue, corrosion, and their combinations, and in drawing inferences regarding their current and future impact on structural behavior. Fatigue analysis methodology for predicting service life and margins of safety must rely heavily on small specimen testing coupled with advanced (nonlinear) computational procedures. There seems to be little prospect of using inservice data to develop models for predicting damage accumulation, other than in a qualitative sense. Failure rates in properly designed and fabricated structures are very small. Observations of inservice data to infer actual failure rates either involve extreme censoring of data or accelerated life testing. In an accelerated test, failure mechanisms may not scale as in the prototype. Extrapolation of such data is highly questionable. Moreover, early failures in service may occur as a result of defects at assembly, or errors in fabrication. It has been suggested that an "acceleration function" could be developed to make the time-dependent reliabilities the same under service and accelerated conditions (5.55). The acceleration function must be assumed; several have been proposed in which limited data have been used to estimate the empirical constants in the model statistically. However, this approach is empirical rather than mechanistic, as the scaling is done to preserve equal probabilities.

In modeling damage accumulation due to structural aging, it is important to measure microstructural parameters that correlate with an engineering property useful for structural evaluation. A review of the literature reveals that this often is not done, making much of the literature on material aging of limited use for structural evaluation purposes. Damage parameters in structural condition assessment must be defined to be consistent with detection parameters in common nondestructive evaluation methods. This is one difficulty in using the traditional S-N/Palmgren-Miner approach to analyzing fatigue. "Damage" in this approach evolves with cycles (or with time) in a way that cannot be measured by conventional nondestructive evaluation methods. As a result, the residual strength of a structure or component at some intermediate stage of damage evolution cannot be evaluated. Another example of this is the use of half-cell potential measurements to evaluate corrosion; this method can detect likely corrosion zones but cannot determine loss of section needed for structural calculations. In contrast, the detectability of a particular crack size can be related to the nondestructive evaluation method selected, however, ignoring the crack initiation phase may lead to an overly pessimistic appraisal of residual strength or remaining service life.

For accurate condition assessment and service life prediction, there is a need to track the evolution of microstructural damage prior to the state where there is some detectable manifestation of deterioration. The relatively new field of continuum damage mechanics $(5.50,5.46,5.47)$ provides one possible approach. A second approach is to take advantage of the apparently close correlation of magnetic and mechanical properties of ferromagnetic materials (5.58). It has been found that magnetic hysteresis measurements during cyclic loading could be used to track the evolution of fatigue damage (5.59). For A533 Gr B steel (softening material) tension specimens cycled under both constant amplitude strain (low-cycle) and load (high-cycle) controlled, measurements of magnetic hysteresis during cycling indicated that the magnetic properties remained quite stable over 80 - 90 percent of the fatigue life, but changed dramatically as macrocracks formed. 


\subsection{TIME-DEPENDENT RELIABILITY ANALYSIS AND FRAGILITY MODELING}

The evaluation of steel structures for continued service should provide quantitative evidence that their strength is sufficient to withstand future demands within the proposed service period with a level of reliability sufficient for public safety. Structural loads, engineering material properties, and strength degradation mechanisms are random in nature. Uncertainties that complicate the evaluation of aging effects arise from a number of sources: (1) inherent randomness in structural loads, initial strength, and degradation mechanisms; (2) lack of in-service measurements and records; (3) limitations in available models for quantifying time-dependent material changes and their contribution to containment strength; (4) inadequacies in nondestructive evaluation; and (5) shortcomings in existing methods to account for repair. Time-dependent reliability analysis methods provide the framework for dealing with uncertainties in performing condition assessments of existing and aging structures and for determining whether in-service inspection and maintenance is required to maintain their performance at the desired level. This information can be utilized on several levels: to identify a review level event to be used in a subsequent structural analysis; to identify a high-confidence, low probability of failure capacity; to determine an instantaneous probability of component or system failure; and to determine the probability of failure during any service period. A well-formulated system reliability analysis also can be used to establish priorities for in-service inspection and maintenance. Existing internal events probabilistic risk assessments (PRAs) of operating plants have been used to establish priorities for inspection of the reactor pressure vessel and piping (5.60). Inspection priorities were established by ranking importance measures based on the contribution of component failures to core damage probability. While the information necessary to perform such an importance analysis is a product of the structural reliability analysis, such an evaluation has not yet been attempted for steel containments and liners.

\subsubsection{Probabilistic Models of Loads}

Structural loads occur randomly in time and are random in their intensity. Structural load models and descriptive load statistics have been gathered in previous research to develop probability-based limit states design and condition assessment procedures for nuclear power plant structures $(5.61,5.62)$.

\subsubsection{Discrete load models.}

The duration of structural loads that arise from rare operating or environmental events, such as accidental impact, earthquakes and tornadoes, is short and such events occupy a negligible fraction of the service life of a structure. Such loads can be modeled as a sequence of short-duration load pulses occurring randomly in time. One of the simplest pulse process models is illustrated by the sample function in Figure 5.1a. The occurrence in time of the loads (impulses) is described by a Poisson process, with mean (stationary) rate of occurrence, $\lambda$, random intensity $S_{j}$ and duration $\tau$ (5.63). The number of events, $\mathrm{N}(\mathrm{t})$, to occur during service life, $\mathrm{t}$, is described by the probability mass function,

$$
P[N(t)=n]=(\lambda t)^{n} \exp (-\lambda t) / n ! \quad n=0,1,2, . .
$$

The intensity of each load is a random variable, described by cumulative distribution function (CDF) $F_{i}(x)$. One can generalize this process to one in which the load process is intermittent (Figure 5.1b) and the duration of each load pulse has an exponential distribution,

$$
\mathrm{F}_{\mathrm{T}_{\mathrm{d}}}(\mathrm{t})=1-\exp [-\mathrm{t} / \tau] ; \mathrm{t} \geq 0
$$

in which $\tau=$ average duration of load pulse. The probability that the load process is nonzero at any arbitrary time is $p=$ $\lambda \tau$.

\subsubsection{Continuous load models.}

Loads due to normal facility operation or climatic variations can be modeled by continuous load processes. A Poisson process with rate $\lambda$ may be used to model changes in load intensity if the loads are relatively constant for extended periods of time, as illustrated by the sample function in Figure 45.1c. Here, the duration of each load is exponential, with average duration $\tau=1 / \lambda$. Finally, loads that fluctuate with sufficient rapidity in time that they cannot be modeled by a sequence of discrete pulses can be modeled as continuously parametered stochastic processes, a sample function of which is shown in Figure 5.ld. 
Many of the loads for which nuclear power plant structures are designed can be modeled by such processes (5.64, 5.65). A summary of load statistics obtained from prior research is presented in Table 5.3. The operating load statistics were obtained from a consensus estimation survey (Delphi) of nuclear power plant loads (5.65). The subset of normal operating loads presented - dead, pressure, pipe reaction, restraint of thermal expansion - are typical for a variety of nuclear power plants. The load statistics presented in Table 5.3 are believed to be sufficient for developing and testing reliability-based condition assessment methods for nuclear power plants. However, it is known that many plant operating loads are plant dependent; moreover, environmental loads may well depend on the plant site. When plantspecific load statistics are available from in-service monitoring programs or site-specific hazard analyses, they should be used in lieu of those in Table 5.3.

\subsubsection{Probabilistic Models of Resistance}

\subsubsection{Initial resistance}

The properties of steel that are required in reliability analysis of steel structures include yield strength, tensile strength, Young's modulus of elasticity, and Poisson's ratio. The existing literature on this subject for common grades of structural steel was reviewed in depth as part of the effort to develop load and resistance factor design procedures $(5.66,5.44)$. These data are summarized in the top portion of Table 5.4. A number of ASTM designations and grades of steel are represented in these data, but they all were construction grades and are designated simply as "carbon." A lognormal CDF

$$
\mathrm{F}_{\mathrm{X}}(\mathrm{X})=\Phi\left(\frac{\ln (\mathrm{x} / \mathrm{m})}{\beta}\right)
$$

in which $\mathrm{m}$ and $\beta=$ median and logarithmic standard deviation of random variable, $\mathrm{X}$, and $\Phi(\mathrm{)}=\mathrm{CDF}$ of a standard normal variate fits all data in Table 5.4 reasonably well.

Additional data were located on the strength of various grades of carbon steel plate used as containments or liners in nuclear power plants. Statistical data for yield and ultimate tensile strengths for specific designations of plate are presented in the lower part of Table 5.4 (5.67). In comparison with the grades of carbon steel used for rolled shapes and plates that are common to civil construction, the mean strengths are somewhat more conservative with respect to the nominal strengths while the coefficients of variation (COV) are smaller, indicating a higher standard of quality control in fabrication. There is a tendency in these data for the mean strength to decrease with increasing plate thickness, a tendency that has been observed elsewhere.

The resistance of a steel component depends on other factors besides the material strength. A simple model of resistance to a particular limit state is given by (5.66),

$$
\mathrm{R}=\mathrm{R}_{\mathrm{n}} \mathrm{MFP}
$$

in which $\mathrm{R}_{\mathrm{n}}=$ nominal strength computed using material strengths, dimensions and analytical procedures prescribed by the code; $\mathrm{M}=$ material factor; $\mathrm{F}=$ fabrication factor; and $\mathrm{P}=$ professional factor. $\mathrm{M}, \mathrm{F}$, and $\mathrm{P}$, are random variables that, as a group, model the different sources of uncertainty in the resistance. To take a specific example, one might model flexural strength as,

$$
\mathrm{R}=\mathrm{BF}_{\mathrm{y}} \mathrm{Z}_{\mathrm{x}}
$$

in which $\mathrm{F}_{\mathrm{y}}=$ random yield strength (see Table 5.4), $\mathrm{Z}_{\mathrm{x}}=$ plastic section modulus, and $\mathrm{B}=$ bias factor. If the Code were to require the use of elastic analysis, the nominal strength would be,

$$
\mathrm{R}_{\mathrm{n}}=\mathrm{F}_{\mathrm{yn}} \mathrm{S}_{\mathrm{xn}}
$$

in which $\mathrm{F}_{\mathrm{yn}}=$ specified yield strength and $\mathrm{S}_{\mathrm{xn}}=$ handbook elastic section modulus. With the notations in Eqns. (45.18) and (5.19), the random resistance would be,

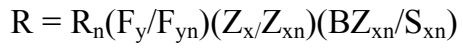


in which, using the notation in Eqn (5.17),

$$
\begin{aligned}
& \mathrm{M}=\mathrm{F}_{\mathrm{y}} / \mathrm{F}_{\mathrm{yn}} \\
& \mathrm{F}=\mathrm{Z}_{\mathrm{x}} / \mathrm{Z}_{\mathrm{xn}} \\
& \mathrm{P}=\mathrm{BZ}_{\mathrm{xn}} / \mathrm{S}_{\mathrm{xn}} .
\end{aligned}
$$

With a good quality control program, the mean of $\mathrm{F}$ is typically close to 1.0 , and its $\mathrm{COV}$ is 0.05 or less. The mean and $\mathrm{COV}$ of $\mathrm{P}$ depend on the fundamental assumptions underlying the analysis - use of simple flexural theory, neglect of strain hardening, etc. - and its rigor in modeling the behavior of interest. Since such assumptions usually are on the conservative side, the mean of $\mathrm{P}$ is usually greater than 1.0 , while the COV typically is on the order of $0.05-0.10$.

\subsubsection{Time-dependent deterioration in resistance}

Reliability assessments of existing steel structures that may age in time require time-dependent statistical models and descriptions of the structural resistance. Since aging has not been considered previously in probability-based design work, the available resistance statistics in Table 5.4 apply to new construction. In the absence of full-scale monitoring of structural performance, time-dependent resistance must be obtained from mathematical models of degradation mechanisms described in Section 4.4.1, along with a knowledge of the initial resistance.

The structural resistance is modeled as a time-dependent function (5.62),

$$
\mathrm{R}(\mathrm{t})=\mathrm{R}_{0} \mathrm{G}(\mathrm{t})
$$

in which $\mathrm{R}_{0}=\mathrm{R}(0)$, the initial resistance, and $\mathrm{G}(\mathrm{t})$ is a time-dependent degradation function defining the fraction of initial strength remaining at time, t. Due to uncertainties in the structural impact on damage initiation and growth from aggressive environmental attack, $\mathrm{G}(\mathrm{t})$ for a steel component will be a non-increasing random process unless there is some intervention in the form of in-service replacement or repair.

Conceptually, a degradation function for predicting time-dependent resistance can be associated with each degradation mechanism. In the case of corrosion, for example, it has been shown that severely corroded material has virtually no strength, whereas uncorroded material retains its original strength properties. The reduction in structural strength from corrosion comes primarily from loss of section, but also is affected by stress or strain concentrations that arise from general roughness of the corroded surface. Tests of simple tension specimens that have been uniformly corroded prior to testing have shown that their tensile strengths based on nominal area (in units of force) are proportional to the loss of section due to corrosion; however, their strains at fracture are reduced by approximately a factor of 2 (5.68), apparently due to the strain concentrations from local nonuniformities of the corroded surface.

As an example, consider a situation in which uniform corrosion penetrates to depth, $\mathrm{x}(\mathrm{t})$, in a plate of thickness, $\mathrm{W}$. Assuming that strength rather than ductility governs, when $\mathrm{x}(\mathrm{t})$ reaches the thickness $\mathrm{W}$, the plate loses all capacity to carry load. The impact of this degradation depends on the nature of the behavioral limit state. If the plate is in a state of simple tension,

$$
R(t)=F_{y} W(1-x(t) / W)
$$

and sample function $\mathrm{g}(\mathrm{t})$ is simply $1-\mathrm{x}(\mathrm{t}) / \mathrm{W}$. On the other hand, if the plate is stressed in flexure, the bending strength per unit width is,

$$
\mathrm{R}(\mathrm{t})=\mathrm{F}_{\mathrm{y}} \mathrm{W}^{2}(1-\mathrm{x}(\mathrm{t}) / \mathrm{W})^{2} / 6
$$

and $g(t)=(1-x(t) / W)^{2}$. Thus, small errors in estimating $x(t)$ would have a more significant impact on flexural strength than on tensile strength. Moreover, as damage progresses and $x(t)$ increases, the governing limit state may change during the service life of the component, creating an unanticipated and potentially dangerous situation. Since $\mathrm{x}(\mathrm{t})$ actually is modeled as a random process, $\mathrm{X}(\mathrm{t})$ (e.g., penetration of corrosion, modeled in Section 5.4.1), the probability distribution of $\mathrm{X}(\mathrm{t})$ plays a key role in the condition assessment. 


\subsubsection{Time-Dependent Reliability Analysis of Degrading Structures}

In this section, a time-dependent reliability analysis is considered, fully coupled in the sense that knowledge of both stochastic loading and resistance are required. The areas of damage mechanics, stochastic characterization of the plant environment, service load history, and current strength are integrated to determine probability distributions of future structural safety margins or additional useable life associated with a minimum required structural capacity.

A schematic representation of time-dependent reliability analysis of a deteriorating structure is presented in Figure 5.2 (5.16). Sample functions of time-dependent resistance and discrete and continuous load processes are shown in Figures 5.2a and 5.2b; the scheme in Figure 5.2a was used to evaluate concrete safety-related structures in nuclear power plants in previous work $(5 \cdot 16,5.69-5.73)$.

\subsubsection{Degradation independent of service loads}

The failure probability of a structural component can be evaluated as a function of (or an interval of) time if the stochastic processes defining the residual strength and the probabilistic characteristics of the loads at any time are known. The strength, $\mathrm{R}(\mathrm{t})$, of the structure and applied loads, $\mathrm{S}(\mathrm{t})$, are both random functions of time. Assuming that degradation is independent of load history, at any time, $t$, the margin of safety, $M(t)$, is

$$
M(t)=R(t)-S(t)
$$

Making the customary assumption that $\mathrm{R}$ and $\mathrm{S}$ are statistically independent random variables, the (instantaneous) probability of failure is,

$$
P_{f}(t)=P[M(t)<0]=\int_{0}^{\infty} F_{R}(x) f_{S}(x) d x
$$

in which $F_{R}(x)$ and $f_{S}(x)$ are the cumulative distribution function of $R$ and probability density function (PDF) of $S$ (5.7). Equation (4.25) provides an instantaneous quantitative measure of structural reliability, provided that $P_{\mathrm{f}}(\mathrm{t})$ can be estimated and/or validated (5.16). It does not convey information on how $\mathrm{P}_{\mathrm{f}}$ is evolving with $\mathrm{t}$ as degradation occurs, or on what information future performance can be inferred from past performance.

For service life prediction and reliability assessment, one is more interested in the probability of satisfactory performance over some period of time, say $(0, \mathrm{t})$, than in the snapshot of the reliability of the structure at a particular time provided by Eqn. (5.25). Indeed, it is difficult to use reliability analysis for engineering decision analysis without having some time period (e.g., an in-service maintenance interval) in mind. The probability that a structure survives during interval of time $(0, t)$ is defined by a reliability function, $L(0, t)$. If, for example, $n$ discrete loads $S_{1}, S_{2}, \ldots, S_{n}$ occur at times $t_{1}, t_{2}, \ldots, t_{n}$ during $(0, t)$, the reliability function becomes

$$
\mathrm{L}(\mathrm{t})=\mathrm{P}\left[\mathrm{R}\left(\mathrm{t}_{1}\right)>\mathrm{S}_{1}, \ldots, \mathrm{R}\left(\mathrm{t}_{\mathrm{n}}\right)>\mathrm{S}_{\mathrm{n}}\right]
$$

in which $R\left(t_{i}\right)=$ strength at time of loading $S_{i}$.

Taking into account the randomness in the number of loads and the times at which they occur [cf Eqn. (5.15)] as well as initial strength, the reliability function becomes (5.69)

$$
\mathrm{L}(\mathrm{t})=\int_{0}^{\infty} \exp \left(-\lambda \mathrm{t}\left[1-\mathrm{t}^{-1} \int_{0}^{\mathrm{t}} \mathrm{F}_{\mathrm{s}}\left(\mathrm{g}_{\mathrm{i}} \mathrm{r}\right) \mathrm{dt}\right]\right) \mathrm{f}_{\mathrm{R}_{0}}(\mathrm{r}) \mathrm{dt}
$$

in which $\mathrm{f}_{\mathrm{R}_{0}}=\mathrm{PDF}$ of the initial strength $\mathrm{R}_{0}$ and $\mathrm{g}_{\mathrm{i}}=$ fraction of initial strength remaining at time of load $\mathrm{S}_{\mathrm{i}}$. The probability of failure during $(0, t)$ is

$$
F(t)=1-L(t)
$$


The conditional probability of failure within time interval $(t, t+\Delta t)$, given that the component has survived up to $t$, is defined by the hazard function,

$$
h(t)=-d \ln L(t) / d t
$$

The reliability and hazard functions are integrally related

$$
L(t)=\exp \left[-\int_{0}^{t} h(x) d x\right]
$$

The hazard function is especially useful in analyzing structural failures due to aging or deterioration. For example, if the structure has survived during the interval $\left(0, \mathrm{t}_{1}\right)$, it may be of interest in scheduling in-service inspections to determine the probability that it will fail before $t_{2}$. Such an assessment can be performed if $h(t)$ is known. If the time-to-failure is $\mathrm{T}_{\mathrm{f}}$, this probability can be expressed as

$$
\mathrm{P}\left[\mathrm{T}_{\mathrm{f}}<\mathrm{t}_{2} \mid \mathrm{T}_{\mathrm{f}}>\mathrm{t}_{1}\right]=1-\exp \left(-\int_{\mathrm{t}_{1}}^{\mathrm{t}_{2}} \mathrm{~h}(\mathrm{x}) \mathrm{dx}\right)
$$

The hazard function for pure chance failures is constant with time. When structural aging occurs and strength deteriorates, $h(t)$ characteristically increases with time. Reliability assessments of nondegrading and degrading structural components can be distinguished by their hazard functions. Much of the challenge in structural reliability analysis of deteriorating structures lies in relating $\mathrm{h}(\mathrm{t})$ to specific degradation mechanisms, such as corrosion. The common assumption in some time-dependent reliability studies that the failure rate increases linearly has been shown to be invalid for aging structures in nuclear plants (5.69). When degradation mechanisms are synergistic, $\mathrm{h}(\mathrm{t})$ generally is unknown at the current state-of-the-art. In-service inspection and maintenance impact the hazard function, causing it to change discontinuously at the time it is performed.

The methods summarized above have been extended to structures subjected to combinations of structural load processes and to structural systems (5.16). The reliability function has a similar appearance to that of Eqn. (5.27), but the outer integral on resistance increases in dimension in accordance with the number of components in the system. The system reliability then is evaluated by Monte Carlo simulation, using an adaptive importance sampling technique to enhance the efficiency of the simulation $(5.71,5.72)$.

\subsubsection{Illustration of time-dependent reliability - corrosion}

The effect of degradation in component strength due to corrosion is illustrated for a steel cylindrical shell. The sensitivity study herein identifies some of the more important parameters for condition assessment purposes. Each reliability analysis is carried out for a period of 60 years, the sum of the initial service period of 40 years and a tentative 20 -year period of continued service. The cylindrical steel shell has a radius of $17 \mathrm{~m}$ and a uniform wall thickness $\mathrm{h}_{0}$ and is subjected to accidental pressure whose nominal value, $\mathrm{P}_{\mathrm{a}}$ is $276 \mathrm{kPa}$. The shell is fabricated from pressure vessel grade carbon steel whose nominal yield stress, $\mathrm{F}_{\mathrm{yn}}$, is $262 \mathrm{MPa}$ and ultimate strength is $483 \mathrm{MPa}$. The design basis is

$$
\mathrm{S}_{\mathrm{mc}} \geq \mathrm{D}+\mathrm{L}+\mathrm{P}_{\mathrm{a}}
$$

where $\mathrm{S}_{\mathrm{mc}}=134 \mathrm{MPa}$ for ASTM A516/GR 70 steel, and D, L, $\mathrm{P}_{\mathrm{a}}$ denote the stresses caused by the dead load, live load, and pressure build-up, respectively.

According to elastic analysis, the maximum stress caused by the internal pressure inside the shell is $\mathrm{P}_{\mathrm{a}} \mathrm{r} / \mathrm{h}_{0} \mathrm{which}$ gives the required shell thickness as $h_{o}=34 \mathrm{~mm}$. The shell wall is subject to general corrosion. The thickness at time $t$ is

$$
\begin{array}{ll}
\mathrm{H}(\mathrm{t})=\mathrm{h}_{\mathrm{o}} ; & \mathrm{t} \leq \mathrm{T}_{\mathrm{I}} \\
\mathrm{H}(\mathrm{t})=\mathrm{h}_{\mathrm{o}}-\mathrm{C}\left(\mathrm{t}-\mathrm{T}_{\mathrm{I}}\right)^{\mathrm{m}} ; & \mathrm{t}>\mathrm{T}_{\mathrm{I}}
\end{array}
$$

where $T_{I}$ is the initiation time prior to which corrosion loss is zero. The limit state for tensile yielding under accidental pressurization is 


$$
\mathrm{p}_{\mathrm{y}}(\mathrm{t})-\mathrm{P}(\mathrm{t})=0
$$

where $p_{y}(t)$ is the pressure corresponding to first yield and $\mathrm{P}(\mathrm{t})$ is the magnitude of the accidental pressure at time $\mathrm{t}$. This limit state is conservative, since after its first yield the cylindrical shell does not lose all its ability to resist further pressure build-up.

Normalizing this limit state with the above design equation, we obtain,

$$
1.95 X \frac{\mathrm{H}(\mathrm{t})}{\mathrm{h}_{0}}-\mathrm{Y}=0 .
$$

where $\mathrm{X}$ is the random yield stress and $\mathrm{Y}$ is the random accidental pressure magnitude, both normalized by their respective nominal values. $\mathrm{X}$ is lognormal with mean 1.1 and COV 0.07. The arrival of the (normalized) accidental pressure $Y$ takes place according to a stationary Poisson pulse process, with an assumed mean rate of 0.0017 per year. The CDF of $\mathrm{Y}$ is Type I with mean 0.8 and COV 0.20 . Rate parameter $\mathrm{C}$ is assumed to be either deterministic or lognormal, with mean $231 \mathrm{~m}$ and COV of 0.30 , to illustrate the sensitivity of the reliability to randomness in $\mathrm{C}$. The initiation time $\mathrm{T}_{\mathrm{I}}$ is assumed to be a lognormal random variable with a mean of 10 year and COV 0.30 . Time order parameter $\mathrm{m}$ is deterministic and equal to 0.7 .

Figure 5.3(a) shows the hazard function $\mathrm{h}(\mathrm{t})$ and the failure probability $\mathrm{F}(\mathrm{t})=1-\mathrm{L}(\mathrm{t})$ (probability that life $\mathrm{T}$ of the structure is less than $t$ ) of the structure for periods of up to 60 years when $C$ is deterministic. It can be seen that if the corrosion loss is neglected, $\mathrm{h}(\mathrm{t})$ remains constant, implying that the instantaneous failure probability does not increase with time. On the other hand, by taking corrosion into account, the effect of aging can be seen clearly. Figure 5.3(b) compares reliability estimates for the two cases when corrosion rate parameter, $\mathrm{C}$, is modeled as random or deterministic. Provided that $\mathrm{C}$, as a fraction of component thickness, or the mean rate of occurrence of the significant load are small, the results are practically the same. When $\mathrm{C}=500 \mu \mathrm{m} / \mathrm{yr}$, randomness in $\mathrm{C}$ has less than an order-of-magnitude effect after 60 years. The failure probabilities in all these examples are estimated by Monte-Carlo simulation with sufficient samples to keep the standard error in the estimates below $0.5 \%$.

Figure 5.4 shows the effect of making the occurrences of $\mathrm{P}_{\mathrm{a}}$ less frequent. By lowering the mean rate to 0.0001 per year, both $\mathrm{h}(\mathrm{t})$ and $\mathrm{F}(\mathrm{t})$ decrease by more than one order of magnitude from the above case. Figure 5.5 compares the failure probabilities completed with and without an induction period prior to corrosion initiation. The hazard functions in Figs. $5.3-5.5$ clearly are nonlinear. The assumption of a linear failure rate may be conservative for structural components subjected to corrosion.

The above tensile limit state is a linear function of the thickness $\mathrm{H}(\mathrm{t})$. By considering a flexural limit state, which is a quadratic function of $\mathrm{H}(\mathrm{t})$, there is a more pronounced effect of section loss. Consider a plate of unit width made of the same material as described above, subject to the same corrosion mechanism, and having the same initial thickness of 34 $\mathrm{mm}$. If the plate is subjected to live load (assume dead load is negligible), the design basis then is,

$$
06 \mathrm{~F}_{\mathrm{yn}} \mathrm{S}_{\mathrm{xn}} \geq \mathrm{L}
$$

where $\mathrm{S}_{\mathrm{xn}}$ is the nominal value of the elastic section modulus. The limit state is

$$
\mathrm{F}_{\mathrm{y}} \mathrm{S}_{\mathrm{X}}-\mathrm{L}=0
$$

Upon normalization as before, this becomes

$$
1.67 X\left(\frac{\mathrm{H}(\mathrm{t})}{\mathrm{h}_{0}}\right)^{2}-\mathrm{Y}=0 .
$$

In this example, strength $\mathrm{X}$ is assumed to be a lognormal random variable with mean 1.1 and COV 0.11. Y is a Type I random variable with mean 0.3 and COV 0.50 , which occurs as a stationary Poisson pulse process with mean rate of 0.5 per year. 
Figure 5.6 shows the effect of general corrosion is more pronounced on the flexural limit state than on the tensile limit state. Hazard function $\mathrm{h}(\mathrm{t})$ at 60 years is more than one order magnitude lower if corrosion is not taken into account. Figure 5.7 shows the level of conservation in the reliability prediction if the time to initiate corrosion is neglected.

\subsubsection{Degradation dependent on service loads}

Damage accumulation due to fatigue depends on the load history. Despite advances in fatigue and fracture analysis, the use of $\mathrm{S} / \mathrm{N}$ diagrams for constant amplitude cycling, coupled with the Palmgren-Miner rule for dealing with variable amplitude cycling, still is state-of-the-art for predicting fatigue crack initiation or service life $(5.74,5.75)$.

If degradation occurs due to fatigue damage accumulation under variable amplitude loading during interval $(0, t)$, we have from Eqn 4.10,

$$
D(t)=\sum_{i=1}^{N(t)} C^{-1} S_{i}^{m}
$$

in which $\mathrm{N}(\mathrm{t})=$ random number of load cycles. Failure is assumed to occur when $\mathrm{D}(\mathrm{t})>\Delta$, in which $\Delta=$ random variable that accounts for uncertainty in Miner's rule at failure. Parameter $\Delta$ often is assumed to be lognormal, with median $\mathrm{m}_{\Delta}=$ 1.0 and $\mathrm{SD}(\ln \Delta)=0.30$ to $0.60(4.42,4.78,4.79)$. If the damage increments are small, $\mathrm{N}(\mathrm{t})$ is large, and the load (stress) process is stationary and narrow band, the expected value of $\mathrm{D}(\mathrm{t})$ is,

$$
\begin{aligned}
& E[D(t)]=E[N(t)] E\left[C^{-1} S^{m}\right] \\
& =(v t) C^{-1} E\left[S^{m}\right]
\end{aligned}
$$

in which $\mathrm{E}[\mathrm{N}(\mathrm{t})]=v \mathrm{t}, v=$ mean cycling rate, and $\mathrm{E}\left[\mathrm{S}^{\mathrm{m}}\right]$ is the mth moment of stress range $\Delta \mathrm{S}$. The latter is determined from,

$$
\mathrm{E}\left[\mathrm{S}^{\mathrm{m}}\right]=\int_{0}^{\infty} \mathrm{S}^{\mathrm{m}} \mathrm{f}_{\mathrm{s}}(\mathrm{s}) \mathrm{ds}
$$

in which $f_{s}(s)=$ PDF of stress range, which must be determined from the operating load history. The variance of $D(t)$ is more difficult to obtain, but is proportional to $1 / \mathrm{t}$. Thus, assuming that $\mathrm{t}$ is large, the fatigue life can be defined at the point where $\mathrm{E}[\mathrm{D}(\mathrm{t})]=1.0(5.78)$. This assumption leads to the relation,

$$
\left(v \mathrm{~T}_{\mathrm{f}}\right) \mathrm{E}\left[\mathrm{S}^{\mathrm{m}}\right]=\mathrm{C}
$$

which resembles the traditional Basquin equation, in which the deterministic parameters are replaced by mathematical expectations, and $\mathrm{T}_{\mathrm{f}}=$ time to failure.

If the excitation $\mathrm{S}(\mathrm{t})$ is modeled as a narrow-band Gaussian process with zero mean and variance $\sigma \mathrm{s}^{2}$, the peak amplitudes can be described by a Rayleigh distribution:

$$
F_{s}(x)=1-\exp \left(-x^{2} / 2 \sigma s^{2}\right) ; x \geq 0
$$

Under these conditions, $\mathrm{E}\left[\mathrm{S}^{\mathrm{m}}\right]$ in Eqns 4.41 and 4.42 is,

$$
\mathrm{E}\left[\mathrm{S}^{\mathrm{m}}\right]=\left(\sqrt{2} \sigma_{\mathrm{s}}\right)^{\mathrm{m}} \Gamma\left(\frac{\mathrm{m}+2}{2}\right)
$$

Recent extensions of the Palmgren-Miner cumulative damage hypothesis have been made for both broad-band and narrow-band stochastic excitation (5.79). Several power spectral density functions (PSDs) have been suggested to model 
Gaussian excitations in the frequency domain; sample functions, $s(t)$, in the time domain then can be determined by simulation. When the excitation is broad band, cycles are defined by the "rainflow" cycle-counting procedure. A damage correction factor for broad-band (rainflow, time domain analysis) damage accumulation was developed by simulation to enable the simpler Rayleigh closed-form approximation in Eqs 5.37 and 5.38 to be used (5.80).

Equations 5.39 - 5.44 can be used to predict time to initiate a detectable defect (say, $6 \mathrm{~mm}$ in size) or to predict overall fatigue life. However, the residual strength at an arbitrary time, $\mathrm{t}$, in the interval $0 \leq \mathrm{t} \leq \mathrm{T}_{\mathrm{f}}$ cannot be determined. Fracture mechanics can be used to determine residual strength or time to failure after initiation of a crack.

Crack growth can be predicted from

$$
\mathrm{da} / \mathrm{dN}=\mathrm{C}(\mathrm{Y} \Delta \mathrm{S} \sqrt{\pi \mathrm{a}})^{\mathrm{n}}
$$

in which a $=$ crack size, $\Delta \mathrm{S}=$ stress amplitude, and $\mathrm{Y}=$ geometric correction factor. Assuming that the loading can be modeled as a sequence of random loads, $\mathrm{S}_{\mathrm{i}}(5.81)$,

$$
\int_{a_{0}}^{a_{f}}(Y \sqrt{\pi a})^{-m} d a=C \sum_{i=1}^{N(t)} S_{i}^{m}
$$

in which $\mathrm{a}_{0}=$ initial crack size, and $\mathrm{a}_{\mathrm{f}}=$ final crack size. It can be shown that if the load history is stationary and narrowband,

$$
\lim _{t \rightarrow \infty} C \sum_{i=1}^{N(t)} S_{i}^{m}=(v t) C E\left[S^{m}\right]
$$

The similarities of the right hand side of Eqn 5.47 to Eqn 5.42 should be noted. Other, more involved equations for predicting crack growth are available. However, it is arguable whether they are any more useful in time-dependent reliability analysis than this relatively simple approach because of the numerous uncertainties in the crack growth process and the ability of any equation to model it.

Statistical models of $\mathrm{a}_{0}$ and $\mathrm{a}_{\mathrm{f}}$ must be known for Eqn 4.46 to be useful in life prediction. The initial flaw size might be assumed to be the minimum detectable flaw size. This would depend on the NDE technology, since resolution of the different methods is different and, what is more important, depend on field conditions. Or, $\mathrm{a}_{0}$ might be the maximum size of flaw allowed to remain unrepaired in the structure if, following inspection, a decision is made to repair only those flaws larger than some "critical" size. The final flaw size, $\mathrm{a}_{\mathrm{f}}$, might be the size at the onset of unstable crack propagation, the component thickness (recommended in analyzing and ranking pipe welds for leakage probabilities using the PRAISE code (5.82) or for "leak-before-break" analysis), the crack size corresponding to an unacceptable increase in component compliance, or other performance-related definition. With $\mathrm{a}_{0}$ or $\mathrm{a}_{\mathrm{f}}$ defined, the probability of unacceptable defect growth can be determined from Eqn 5.46 (see, e.g., 5.83,5.84).

Fatigue crack growth is a random process. In applying the Paris-Erdogan law in fatigue reliability analysis, some researchers have assumed either $\mathrm{m}$ or $\mathrm{C}$ to be the random variable or the random process (the other being deterministic), and some have taken them to be jointly distributed (e.g., 5.84). Others found $\mathrm{m}$ and $\log \mathrm{C}$ to be linearly dependent for high tensile steel (5.85) or assumed $\mathrm{C}$ to be a non-stationary Gaussian process (5.86).

Deterministic models like Eqn. 5.14 also have been rendered stochastic by multiplying the right hand side with a nonnegative random process $(5.87,5.88)$ as in the following:

$$
\frac{\mathrm{dA}(\mathrm{t})}{\mathrm{dt}}=\mathrm{C}(\Delta \mathrm{K})^{\mathrm{m}} \mathrm{x}(\mathrm{t})
$$

where $\mathrm{A}(\mathrm{t})$ is the random crack size and $\mathrm{X}(\mathrm{t})$ is the random process. Alternately, arguing that uncertainty in crack growth rate arises out of inhomogeneity and randomness of material properties at or near the crack-tip, others (eg, 
5.84,5.89,5.90) have introduced a multiplicative random function of the crack-tip position, a, rather than of $t$, in their stochastic models:

$$
\frac{\mathrm{dA}}{\mathrm{dn}}=\mathrm{C}(\Delta \mathrm{K})^{\mathrm{m}} \mathrm{x}(\mathrm{a}) .
$$

Fatigue crack growth has often been idealized as a Markov process. In such an approach, probabilistic fracture mechanics has been utilized to ascertain the transition probabilities (5.83,5.91). A diffusive Markov process has been adopted to obtain the first passage time to reach the critical crack size (5.87). Others started with crack-growth as a general stochastic process, but subsequently approximated the process to be Markovian (continuous-time and continuous-state) assuming that the correlation function vanishes at time intervals of practical interest (5.92). Crack growth has been modeled with a two-dimensional Markov vector process $[A(t), Z(t)]^{\mathrm{T}}$ where $A(t)$ is the crack size as in Eqn. 5.48 and $Z(t)$ is a stationary Gaussian process. $Z(t)$ is related to $X(t)$ of Eqn. 4.48 by the transformation $Z(t)=\sigma_{Z}$ $\Phi^{-1}\left(\mathrm{~F}_{\mathrm{x}}\{\mathrm{X}(\mathrm{t})\}\right]$ where $\sigma_{\mathrm{Z}}$ is the stationary standard deviation of the process $\mathrm{Z}(\mathrm{t})$ and $\Phi(\bullet)$ is the standard normal distribution function. A Petrov-Galerkin finite-element formulation has been used to obtain a numerical solution for the time required to reach a critical crack-size (5.88). Others have used the Fokker-Planck equation to determine the pdf of crack-size as a function of time $(5.87,5.93)$. A discrete space and discrete time uni-directional unit-jump Markov model has been used for damage growth (5.94). Work has also been conducted to improve the cumulative damage model (5.95).

\subsubsection{Illustration of time-dependent reliability - fatigue}

To illustrate how the fatigue analysis might be performed, we consider cycling due to system-relief valve (SRV) loads. The SRV loads are unique to BWR plants. The SRVs are provided for protection against overpressure of the reactor pressure vessel during operating transients and for rapid depressurization during postulated accidents. During a SRV discharge, the suppression pool is subjected to oscillating dynamic pressures, which the containment and drywell must be able to withstand. It should be emphasized that actual SRV loads are very complex, especially when several valves participate. Accordingly, the following analysis is for illustrative purposes only.

The SRV loads are specified by the vendor. In this illustration, we will consider SRV loads from a Mark III containment that were evaluated as part of a consensus estimation survey of loads in nuclear power plants (5.65). The total estimated number of SRV occurrences in 40 years was 1620 , implying a rate of $40.5 / \mathrm{yr}$. The pressure fluctuations depend on the arrangement of the SRV lines; a typical frequency would be $8 \mathrm{~Hz}$. The duration of each event is approximately $0.75 \mathrm{sec}$, implying an average of 6 pressure (or stress) cycles per event. The peak design pressure is approximately $207 \mathrm{kPa}$. The $\mathrm{A} / \mathrm{E}$ 's surveyed believed that the design values provided by the vendor were conservative; the mean of the actual peak pressure was thought to be approximately 0.8 times the design value, or $165 \mathrm{kPa}$, and its coefficient of variation about 0.14 . Unfortunately, the stresses induced by these SRV pressures could not be determined from the information presented in the consensus estimation survey (5.65). Based on typical design capacities of containments, however, it is assumed for illustrative purposes that the cyclic stress range induced by the SRV load has a mean of less than $83 \mathrm{MPa}$.

We assume a median S-N curve consistent with a Fatigue Category B detail:

$$
\mathrm{NS}^{3.1}=3.532 \times 10^{10}
$$

with a coefficient of variation of 0.60 in $\mathrm{N}$ for given $\mathrm{S}$. Assuming that the damage is a lognormal random variable, the median damage accumulation to occur in periods of 30 to 60 years (from Eqn. 5.40b) and the probability of fatigue failure, are shown below:

\begin{tabular}{|ccc|}
\hline Time & Median Damage & Probability of Fatigue Failure \\
\hline 30 & $4.57 \times 10^{-4}$ & 0 \\
40 & $6.10 \times 10^{-4}$ & 0 \\
50 & $7.62 \times 10^{-4}$ & 0 \\
60 & $9.15 \times 10^{-4}$ & $\Phi(-10) \sim 10^{-24}$ \\
\hline
\end{tabular}


It is obvious that the probability of fatigue failure is negligible. Taking the randomness of the stress range into account has a negligible impact on this probability. Similar analysis of other details indicate that the fatigue limit state generally would not play a significant role in condition assessment of steel containments and liners.

\subsubsection{Fragility Modeling of Steel Containments and Liners}

Probabilistic models of resistance of steel containments and liners are integrated with stochastic load models to develop fully-coupled time-dependent reliability assessment tools. An intermediate step in the development of fully-coupled reliability analysis procedures is the fragility modeling of the containment. Fragility analysis is a relatively simple but powerful technique for assessing the capability of a structural system to withstand specified (sometimes referred to as screening or review-level) events in excess of the design-basis event. This process sometimes is referred to as a "safety margin analysis." During the last decade, it has been used to determine the capability of nuclear power plant structural components and systems to withstand, with high confidence, review-level earthquakes of a prescribed level in excess of the safe-shutdown earthquake (SSE). For example, the review earthquake might be set at $0.30 \mathrm{~g}$ if the design-basis SSE were $0.17 \mathrm{~g}$. The basic idea is that if the system can be shown to perform safely at the review level, it is judged sufficient for public safety regardless of what the actual (unknown) hazard might be. With respect to a steel containment or liner, the fragility is defined as its probability of "failure," conditioned on a level of demand (from ground motion, wind velocity, internal pressure, etc.). Failure in this case is assumed to occur when (generally inelastic) deformations are large enough to interfere with the operation of attached equipment, when pressure retention is lost, or leakage above a tolerable level occurs.

\subsubsection{Role of fragility in probabilistic safety assessment}

With the limit states identified, the limit state probability can be expressed as,

$$
\mathrm{P}[\mathrm{LS}]=\sum_{\mathrm{x}} \mathrm{P}[\mathrm{LS} \mid \mathrm{D}=\mathrm{x}][\mathrm{D}=\mathrm{x}]
$$

in which $\mathrm{D}$ is a random variable (or random vector) describing the intensity of demand on the system, and $\mathrm{P}[\mathrm{LS} \mid \mathrm{D}=\mathrm{x}]$ is the conditional limit state probability, given that $\mathrm{D}=\mathrm{x}$. The probability $\mathrm{P}[\mathrm{D}=\mathrm{x}]$ is sometimes denoted the hazard, and variable $x$ is the "control" or "interface" variable. The conditional probability, $P[L S \mid D=x]=F_{R}(X)$, is the fragility.

It is clear that a fragility analysis is an essential ingredient of the fully coupled risk analysis embodied in Eqn. (5.51). It also can be used to determine probabilistic safety margins against specific identified events for decision and regulatory purposes. Identification of probabilistic safety margins is central to modern facility risk management. Although providing a less informative measure of safety than that obtained from a fully coupled risk analysis, risk-informed decision-making based on the results of a structural fragility assessment has several advantages:

(1) The probabilistic system analysis is effectively uncoupled from the hazard analysis. Thus, while knowledge of the hazard is useful in identifying appropriate review-level events (e.g., a 2,500-yr mean recurrence interval earthquake), such knowledge is not essential. Absent credible data on review-level events, one might simply inquire as to the fragility were the design-basis event to be exceeded by some arbitrary margin, say 50 percent.

(2) The need to interpret and defend very small limit state probabilities (on the order of $10^{-5} / \mathrm{yr}$ or less) is avoided. There are limited data to support probabilities of this level, and such estimates are highly dependent on the probabilistic models selected. At the current state-of-the-art, (conditional) fragilities are more robust than unconditional limit state probabilities.

(3) A properly conducted fragility analysis is less complex, less costly, and involves fewer disciplines than a fully coupled risk analysis. Accordingly, there is less likelihood of miscommunication among members of the risk analysis team and the results are more easily understood by a nonspecialist decision-maker or regulator.

\subsubsection{Fragility modeling concepts}

Fragility analysis is a technique for assessing and displaying, in probabilistic terms, the capability of an engineered component or system to withstand a specified event (sometimes referred to as a review-level event), one that often is 
well in excess of the design-basis event. Fragility modeling requires a focus on the behavior of the system as a whole and, specifically, on things that can go wrong with the system. The fragility modeling process leads to a mediancentered estimate of system performance, coupled with an estimate of the uncertainty in performance. This focus is different from typical deterministic analysis, where conservative estimates of structural parameters are used, and the conservatism propagates through the safety analysis in an unpredictable manner. The fragility concept has found widespread usage in the nuclear industry, where it has been used in seismic probabilistic safety and/or margin assessments of safety-related plant systems (5.96). In a seismic margins study, the control variable usually is the effective peak ground acceleration or spectral acceleration at the fundamental period of the structure.

The fragility of a structure commonly is modeled by a lognormal cumulative distribution function (CDF). If the structural capacity can be described as the product of numerous statistically independent random variables, the central limit theorem provides some justification for this choice of CDF. The lognormal CDF is described by,

$$
\mathrm{F}_{\mathrm{R}}(\mathrm{x})=\Phi\left[\ln \left(\mathrm{x} / \mathrm{m}_{\mathrm{R}}\right) / \beta_{\mathrm{R}}\right]
$$

in which $\Phi[\bullet]=$ standard normal probability integral, $\mathrm{m}_{\mathrm{R}}=$ median capacity (expressed in units that are dimensionally consistent with the demand parameter, $\mathrm{x}$, in Eqn. (5.51), and $\beta_{\mathrm{R}}=$ logarithmic standard deviation, approximately equal to the coefficient of variation $(\mathrm{COV}), \mathrm{V}_{\mathrm{R}}$, when $\mathrm{V}_{\mathrm{R}}<0.3$.

Equation (5.52) depicts the conditional limit state probability of the system when the state of knowledge is essentially perfect (within the bounds of normal engineering mechanics). In this case, parameters $m_{R}$ and $\beta_{R}$ measure inherent randomness (or aleatory uncertainty). Such uncertainties are essentially irreducible under current engineering analysis procedures. As an example, the yield strength of ASTM A615/60 reinforcing bars tested in accordance with standard American Society for Testing and Materials (ASTM) procedures is a random variable that can be modeled by a lognormal distribution, with a mean of $490 \mathrm{MPa}$ and $\mathrm{COV}$ of 0.10 . These statistical estimates are relatively stable from dataset to dataset, assuming that the sample size is not too small. Sampling from a different lot of A615/60 bars (or different bar sizes) will yield essentially the same statistics. This is characteristic of aleatory uncertainty; additional data or other information does not change the probabilistic models in any significant way. Similarly, compressive or tensile strength of concrete and dimensions of structural components fabricated and inspected according to American Concrete Institute (ACI) standards are inherently random. Thus, if the state of knowledge is essentially perfect, the 5-percent exclusion limit for capacity, defined as,

$$
\mathrm{R}_{0.05}=\mathrm{m}_{\mathrm{R}} \exp \left(-1.645 \beta_{\mathrm{R}}\right)
$$

might be selected as a basis for checking safety. If the review-level demand selected were less than $\mathrm{R}_{0.05}$, then the probability of acceptable performance of that structural component at that level would be at least $95 \%$.

However, additional sources of uncertainty in capacity arise from assumptions made in the analysis of the system and from limitations in the supporting databases. In contrast to aleatory uncertainties, these knowledge-based (or epistemic) uncertainties depend on the quality of the analysis and supporting databases, and generally can be reduced, at the expense of more comprehensive (and costly) analysis. Sources of epistemic uncertainty in reinforced concrete structures would include two-dimensional models of three-dimensional structures, support conditions that are neither fully rigid nor simple, neglect of shear deformations in structural analysis, treatment of cracking by "smeared" models, and limitations in the supporting databases. The presence of epistemic uncertainty means that the fragility actually is described by a family of curves, reflecting incomplete knowledge regarding the parameters used to model the structural fragility: in the median, COV, and the CDF itself. To first order, these uncertainties can be assumed to be vested in the estimate of the median capacity, $\mathrm{m}_{\mathrm{R}}$, in Eqns. (5.52) and (5.53). Under this assumption, $\mathrm{m}_{\mathrm{R}}$ is replaced by a random variable, $\mathrm{M}_{\mathrm{R}}$, which is assumed to be modeled by a lognormal distribution with median $m_{R}$ and logarithmic standard deviation $\beta_{U}$. Then, the family of lognormal CDFs, defined by parameters $\left(\mathrm{m}_{\mathrm{R}}, \beta_{\mathrm{R}}, \beta_{\mathrm{U}}\right)$, displays the overall uncertainty in capacity. The 5 percent exclusion limit in Eqn. (4.53) thus becomes a random variable as a result of the uncertainty in $\mathrm{M}_{R}$, modeled by $\beta_{\mathrm{U}}$. The lower 5 -percent confidence interval on $\mathrm{R}_{0.05}$ is defined by,

$$
\mathrm{R}_{\mathrm{k}}=\mathrm{m}_{\mathrm{R}} \exp \left[-1.645\left(\beta_{\mathrm{R}}+\beta_{\mathrm{U}}\right)\right] .
$$

One might say (with a Bayesian interpretation) that the probability of surviving an event with intensity $R_{k}$ is $95 \%$ with $95 \%$ confidence. In some previous seismic margin studies, $\mathrm{R}_{\mathrm{k}}$ has been called the HCLPF, or "highconfidence, low probability of failure" capacity. 
In many applications, it is desirable to have one overall estimate of fragility for review purposes that reflects both aleatory and epistemic uncertainty. Such an estimate is provided by the mean fragility, defined as (5.97)

$$
\mathrm{E}\left[\mathrm{F}_{\mathrm{R}}(\mathrm{x})\right]=\left[\ln \left(\mathrm{x} / \mathrm{m}_{\mathrm{R}}\right) / \beta_{\mathrm{c}}\right]
$$

in which

$$
\beta_{\mathrm{C}}=\left(\beta_{\mathrm{R}}^{2}+\beta_{\mathrm{U}}^{2}\right)^{1 / 2} .
$$

At the usual levels of aleatory and epistemic uncertainty found in the assessment of reinforced concrete structures, $R_{k}$ in Eqn. (5.54) corresponds to approximately the 1 to 2-percentile of $E\left[F_{R}(x)\right]$.

At the present state-of-the-art, median component fragilities, variabilities and uncertainties are obtained by scaling up from the original design analyses and by expert judgement and familiarity with the manner in which similar buildings and other structures have responded in earthquakes $(5.96,5.98)$. When the demand and capacity of the system are specified in terms of EPA, the structural response calculations and associated uncertainties must be reflected in the fragility curve along with the strength of materials energy dissipation. Accordingly, the capacity of a structural component (in units of EPA) is given as

$$
\mathrm{R}=\mathrm{F}_{\mathrm{sc}} \mathrm{F}_{\mathrm{br}} \mathrm{SSE}
$$

in which $\mathrm{F}_{\mathrm{sc}}=$ strength capacity safety factor, $\mathrm{F}_{\mathrm{br}}=$ building response safety factor (which reflects differences between design-basis and site-specific response spectra, dynamic properties, and soil-structure interaction), and SSE = ground acceleration due to the safe-shutdown earthquake. $F_{s c}$ is expressed, in turn, as the product, $F_{s} F$, in which $F_{s}$ is an overstrength factor, reflecting the difference between elastic design level and ultimate strength, and $F$ is an energy dissipation factor, modeling the additional toughness provided by ductility. Numerous sources of conservatism and uncertainty are introduced by this simplified analysis (5.99).

It should be noted that fragilities can be constructed for a range of performance requirements and/or limit states shy of loss of integrity. One could, for example, envision a collection of fragilities describing progressively more severe limit states: onset of nonlinear action, attaining a maximum deformation greater than some fraction of shell radius or shell thickness, onset of slow leakage, and finally incipient instability, depressurization and loss of integrity. A collection of such fragilities might appear as in Figure 5.8. At a given level of demand, $x$, such a depiction conveys a sense of the additional margin of safety and reliability that remains at each stage. If the structure is properly designed, detailed and fabricated, the fragilities should be well spaced out, as in Figure 5.8(a). Clustering of the curves, as in Figure 5.8(b), may indicate little additional margins of safety once a threshold demand is reached.

It should be noted that probability distributions other than the lognormal CDF can be used for structural fragility analysis (5.97). The central limit theorem of probability theory provides some theoretical justification for the lognormal distibution if one views structural capacity as being modeled as the product of independent factors. On the other hand, the weakest link hypothesis, which often is used in modeling material failure, suggests that the Weibull distribution also might be appropriate. At the current state of the art, however, in which supporting data are limited, neither model has a compelling advantage over the other. Moreover, the well-known tail sensitivity problem in structural reliability becomes a factor. A fragility normally is constructed from a knowledge of the median (or most likely value) and an estimate of the total uncertainty. With this construction, the lower tail of the CDF (at or below the 1-percent exclusion limit), which is used to evaluate the safety margin, is sensitive to the choice of CDF. For a (typical) $\beta_{\mathrm{c}}=0.20$, the lognormal HCLPF $=$ $0.63 \mathrm{~m}_{\mathrm{R}}$ and the Weibull HCLPF $=0.48 \mathrm{~m}_{R}$, a difference of over $20 \%$. Such a lack of robustness suggests that one fragility model must be postulated for consistency in making comparative risk or margin evaluations in the regulatory process.

Any structural component has a minimum strength. Some studies have proposed that the fragility be truncated at and below some value, say three logarithmic standard deviations below the logarithimic median. This practice should strongly be discouraged for at least two reasons. First, it is not clear what the minimum strength should be; the available data are not sufficient to determine it, and the tail sensitivity problem becomes a factor, as above. Furthermore, focusing on identifying the minimum strength causes the analyst to focus on the wrong issue; instead, the emphasis in the fragility modeling should be on depicting as accurately as possible the most likely behavior of the system and its attendant 
uncertainties.

\subsubsection{Example fragility of structural component - steel containment with localized corrosion}

\subsection{Present design criteria}

Typical steel containments range in diameter from $18 \mathrm{~m}$ (BWR Mark I) to $43 \mathrm{~m}$ (PWR large dry). With shell thicknesses that are on the order of 25 to $51 \mathrm{~mm}$, their radius-to-thickness $(\mathrm{R} / \mathrm{t})$ ratios are on the order of 350 to 1,750 , making them thin shells of revolution for purposes of structural analysis.

Steel containments are designed by allowable stress methods in accordance with the NRC Standard Review Plan (5.100), Section 3.8.2, and the American Society of Mechanical Engineers (ASME) Boiler and Pressure Vessel Code, Section III, Division 1, Subsection NE (5.101). In-service inspection and repair are governed by ASME Code Section XI, Division 1, Subsections IWE and IWA, respectively. Present containment design procedures date from the 1960's. The design load combinations that usually govern containment design are:

$$
\begin{aligned}
& \text { Normal loads: } \mathrm{D}+\mathrm{L}+\mathrm{P}_{0}+\mathrm{T}_{\mathrm{o}}+\mathrm{R}_{\mathrm{o}} \\
& \text { Abnormal loads: } \mathrm{D}+\mathrm{L}+\mathrm{P}_{\mathrm{a}}+\mathrm{T}_{\mathrm{a}}+\mathrm{R}_{\mathrm{a}}
\end{aligned}
$$

in which $\mathrm{D}$ and $\mathrm{L}$ are dead and live (mainly equipment, including crane) loads, $\mathrm{P}_{0}=$ normal pressure, $\mathrm{T}_{\mathrm{o}}=$ normal temperature, and $\mathrm{R}_{\mathrm{o}}=$ normal pipe reactions; $\mathrm{P}_{\mathrm{a}}$ and $\mathrm{T}_{\mathrm{a}}$ are the pressure and temperature arising from the design basis LOCA. Primary membrane stresses from these loads are checked against allowable stress $\mathrm{S}_{\mathrm{mc}}=1.1 \mathrm{~F}_{\mathrm{u}} / 4$, in which $\mathrm{F}_{\mathrm{u}}=$ tensile strength. The LOCA pressure, $\mathrm{P}_{\mathrm{a}}$, generally is the most important load for the design of the containment. In addition, buckling may also be important in free-standing vessels under dead load combined with lateral forces.

ASME Code design procedures for both steel and reinforced concrete containments are based on elastic structural analysis using specified allowable stresses and loads. The design procedures incorporate numerous conservatisms: in addition to the allowable stress factors, the nominal strengths and loads are specified subjectively and usually very conservatively. The inelastic load-carrying capacity and ductility of the steel are ignored.

Numerous analyses and tests of scaled models over the past decade have confirmed that this reserve capacity is well in excess of the design basis intemal pressure (5.102-5.104). For example, the calculated ultimate capacities, $\mathrm{P}_{\mathrm{u}}$, of six reinforced concrete containments designed in the 1960's to 1980's have been summarized (5.105). With "failure" defined as yielding of all circumferential reinforcement, the factor of safety $\mathrm{P}_{\mathrm{U}} / \mathrm{P}_{\mathrm{a}}$ ranged from 2.5 to 6.3. Studies for steel containments (5.106) indicated a range of $\mathrm{P}_{\mathrm{U}} / \mathrm{P}_{\mathrm{a}}$ from 2.2 to 5.6 based on a limiting hoop strain equal to twice the yield strain; membrane action of the containment wall was the limiting factor in all cases. The higher factors of safety are for ice-condenser containments, which typically are designed for lower pressures (on the order of $\mathrm{P}_{\mathrm{a}}=83 \mathrm{kPa}$ ). Later studies (5.107) led to similar results and conclusions: median values of $\mathrm{P}_{\mathrm{U}} / \mathrm{P}_{\mathrm{a}}$, reported were 3.0 for reinforced concrete containments and 3.4 for steel containments.

When a containment is designed for $\mathrm{P}_{\mathrm{a}}$ by allowable stress methods, there is an inherent presumption that, with the usual conservatism provided by the safety factors and other assumptions, it will survive an event that is in excess of $\mathrm{P}_{\mathrm{a}}$. The question is: by how much? Allowable stress methods of analysis provide no quantitative basis for answering this question; indeed, the usual design process does not address it. The level of conservatism is substantial but unpredictable. The fragility modeling process removes these unpredictable and nonuniform levels of conservatism, and identifies a median-centered measure of structural capacity. Moreover, the uncertainties in capacity in excess of the design basis are taken into account explicitly.

\subsection{Structural limit states, analysis, and performance requirements.}

A clear relation between performance limits and structural response must be established for the system fragility to be useful as a structural evaluation tool.

Containment limit states. In a conventional building structural system, the relations between safe performance and structural limit states are clear: fracture in tension or buckling in compression leads to failure in a determinate system or immediate visible distress and redistribution of forces in an indeterminate system. In a containment, different authors 
have suggested different failure definitions (5.108). The function of a containment is to confine radioactive material in the event of an accident, so the performance limit is loss of integrity or ability to perform this essential function. Thus, a commonly agreed-upon definition of failure involves loss of pressure boundary. This performance limit must be related to structural limit states that can be identified from the finite-element analysis, along with local or general structure or material failure criteria.

Demands on the containment resulting from an accident include overpressurization in combination with elevated temperatures, dynamic pressurization, internal missiles, and attack by degraded core materials. The scope of this study is limited to the structural actions due to static pressurization in combination with elevated temperatures. Containment structural response to these challenges includes loss of integrity from leakage (due to cracks) or deformations or rupture (5.109). Consequences of these failure modes may differ. Leakage involves depressurization over a period of $2 \mathrm{hr}$ or greater, while rupture may result in depressurization within $2 \mathrm{hr}$; at the extreme, catastrophic rupture would lead to depressurization on the order of seconds. Containment failure modes and times to containment failure affect the source term, contingency planning, and notification systems (5.110). In terms of offsite risk, failures involving early release of radionuclides are most significant. This investigation is limited to structural failure of the containment; structural failures giving rise to early release are of particular interest.

Scaled model containment tests conducted over the past decade at Sandia National Laboratory (SNL) have provided insights into the nature of failure mechanisms in metallic pressure boundaries. For example, SNL tests of 1:32 and 1:8 scale models of steel containments indicated that pressure at general yielding could be determined accurately by a simple limit equilibrium analysis using the von Mises yield criterion (5.109). Effects of penetrations were localized and did not affect the overall response. In general, the SNL tests indicated that structural failure occurred when the maximum local strains exceeded the fracture ductility of the material (on the order of $25 \%$ to $30 \%$ ). Locally, strain concentrations adjacent to points of transition in shell thickness around penetrations could be as high as 2 to 4 times the average farfield strains. Leakage at penetrations was caused by a combination of failure of the seals and structural failure of the penetration assembly. Shell deformations can cause rotation of penetration sleeves, which lead to leakage (5.111). Leakage at hatches was related to the average membrane strain values ranging from 0.025 to 0.073 at the elevation of the hatch (5.109). Leakage generally did not occur prior to general yielding. The scaled model tests that included ring stiffness and penetrations generally failed when the far-field membrane strain was on the order of 0.02 to 0.03 .

A test of a 1:6 scale model of a concrete containment with steel liner at SNL resulted in failure by excessive leakage at several tears in the liner in the vicinity of penetrations where the liner was thickened (5.112). These liner tears initiated under studs adjacent to the thickened insert plate, and were caused by local stress concentrations that the studs imposed on the liner when the vessel was pressurized. At this point, far-field hoop strains in the liner were approximately 0.02 . The most critical failure mode under prirnary internal pressurization was found to be tensile failure of the perimeter wall in the hoop direction, followed by tensile failure in the dome away from joints (5.113). A more recent evaluation of a prestressed concrete PWR containment (5.114) confirmed that thermal loads are self-limiting and concrete experiences significant cracking near ultimate; thus, temperature effects on ultimate strength are small. Moreover, thermal buckling of the steel liner relieves the stresses. Thus, temperature affects only material properties. Hoop membrane strains controlled failure at a pressure about 3.3 times the design pressure.

Excessive general shell deformations causing malfunction of appurtenant equipment also violate the containment performance requirement. Large displacement-related issues include potential interactions with the polar crane bridge, piping, and adjacent structures (5.105). In a BWR Mark I containment, radial expansion of the shell may cause axial deformation of the bellows: a $152-\mathrm{mm}$ compression would cause compression of adjacent bellows convolutions, while a $305-\mathrm{mm}$ compression would crush the bellows assembly. It has been asserted that it would be conservative to assume leakage at $75 \%$ of the deformation required for full bellows compression (5.115). Structural deformations also are important in the vicinity of mechanical/electrical penetrations, where they may lead to seal failure. However, leakage seldom occurs prior to membrane yielding.

To summarize, structural failure may occur in the containment shell due to general membrane stresses, at the point where the containment shell interfaces with the basemat due to excessive bending strain, or at points of strain concentration where the shell changes thickness. Such failures generally can be associated with reaching maximum local strains on the order of 0.2 (membrane) or 0.3 (bending). Failure generally does not occur at the penetrations themselves, which are well reinforced, but very large shell strains are found adjacent to reinforced areas. Excessive local strains cause tensile failure (tensile instability) as well as ovalization of sleeves at penetrations leading to leakage at penetration seals. 
Analysis of Structural Behavior. Early evaluations of containment integrity were based on simple limit equilibrium analysis (e.g., 5.106), and involved relatively simple failure definitions (e.g., general yielding, maximum hoop strain equal to twice the yield strain, etc). Limit analyses often provide an accurate estimate of overall ultimate pressure capacity, since the ductility of the steel causes the pressure-deformation relation to be nearly flat at conditions approaching ultimate. They are less effective for predicting behavior in the stages beyond first yield but prior to overall instability, particularly at penetrations, stiffeners and points of transition of shell thickness. At the level of complexity associated with real containment behavior, the relation between internal pressure and deformation or strain can best be described using finite-element analysis. To trace the containment behavior over the entire loading range and to replicate experimental observations, the finite-element analysis must have the capability of modeling nonlinear material constitutive behavior, geometric nonlinearities due to large deformations, and the dependence of strength and stiffness on elevated temperature.

The commercially available finite-element code, ABAQUS, has the necessary features for containment analysis. The capabilities of ABAQUS are well-known in the structural engineering community. The finite-element analysis is conducted for a specified pressure-temperature-time history well into the large-deformation range. The loading can be considered to be static. Eventually, the code may fail to converge; however, the useful limit of the containment usually is reached prior to this point. The occurrence of various structural limit states is determined by post-processing the strains (or deformation) determined from the finite-element analysis, and comparing them to the limit states identified in the next section.

Limit States of Structural Performance. The preceding review of containment behavior has shown a consensus that general shell rupture is the most important structural limit state, and that ductile failure leading to leakage or rupture can be related to a maximum strain criterion involving either general hoop strain or local strain at points of strain concentration. Numerous approaches have been proposed for identifying such structural limits; three are identified below. Because of the large-deformation behavior that precedes failure, all are expressed in terms of true stress-strain, rather than engineering stress-strain. These can be related to engineering stress-strain without difficulty.

One simple description of the limit state is,

$$
\varepsilon_{\mathrm{p}}>\varepsilon_{\mathrm{f}}
$$

in which $\varepsilon_{\mathrm{f}}=\ln \left(\mathrm{A}_{0} / \mathrm{A}_{\mathrm{r}}\right)=2 \ln \left(\mathrm{d}_{0} / \mathrm{d}_{\mathrm{f}}\right)=$ true strain at failure (fracture ductility), measured in a uniaxial tensile test, and $\varepsilon_{\mathrm{p}}=$ effective plastic strain, determined as,

$$
\varepsilon_{\mathrm{p}}=\sqrt{2}\left[\left(\varepsilon_{1}-\varepsilon_{2}\right)^{2}+\left(\varepsilon_{2}-\varepsilon_{3}\right)^{2}+\left(\varepsilon_{3}-\varepsilon_{1}\right)^{2}\right]^{1 / 2} / 3
$$

in which $\varepsilon_{i}, i=1,2,3=$ principal components of plastic strain. This definition does not account for the effects of stress triaxiality, but in cases where stressing is similar to that in a simple tension test, Eqn. (5.63) provides a good estimate of the failure point.

The presence of a triaxial stress state may significantly alter the effective plastic strain in a material at failure and alter its apparent ductility. The triaxial stress state can be described by the ratio of the von Mises effective stress, m, and mean stress, m:

$$
\begin{aligned}
& \sigma_{v \mathrm{~m}}\left[\left(\sigma_{1}-\sigma_{2}\right)^{2}+\left(\sigma_{2}-\sigma_{3}\right)^{2}+\left(\sigma_{3}-\sigma_{1}\right)^{2}\right]^{1 / 2} / \sqrt{2} \\
& \sigma_{\mathrm{m}}=\left(\sigma_{1}+\sigma_{2}+\sigma_{3}\right) / 3
\end{aligned}
$$

in which $\sigma, i=1,2,3$, are principal stresses. Two alternate limit states then are defined, respectively, as (5.116,5.117):

$$
\varepsilon_{\mathrm{p}}>\varepsilon_{\mathrm{f}} \alpha 2^{1-3\left(\sigma \mathrm{m} / \sigma_{\mathrm{v}} \mathrm{m}\right)}
$$




$$
\varepsilon_{\mathrm{p}}>\varepsilon_{\mathrm{f}} \alpha \exp \left[-3 \sigma_{\mathrm{m}} / 2 \sigma_{\mathrm{m}}\right] .
$$

In both cases, $\alpha=$ experimental constant determined by considering the uniaxial stress state. Finally, a simple stressbased (rather than strain-based) limit state has been proposed (5.118):

$$
\sigma_{\mathrm{vm}}=\eta \mathrm{F}_{\mathrm{y}}
$$

in which $F_{y}=$ uniaxial yield strength and $\eta=$ "derating" factor, assumed to equal approximately 0.7 .

The above strain limits do not reflect the effects of corrosion. The impact of corrosion on the structural properties (strength or stiffness) of a corroded component or system has not received as much attention in the literature. Corrosion models developed for structural condition assessment have tended to be empirical in nature (5.119). It is reasonable to assume that corroded material has no load-carrying capacity; however, uncorroded material remaining in a structural component retains its initial strength. A series of tests on corroded SA516/70 steel specimens has confirmed this assumption, but also has shown that the limit strain of the undamaged portion of the corroded specimen decreases by a factor of approximately 2 due to local concentrations of strain (5.120). Similar results have been observed for carbon steels used in bridges (5.121). An adjustment for this loss of ductility in corroded steel must be made in the failure criteria.

The strain-based limit states above model ductile failure for simple structural components subjected to highly idealized test conditions. When used with the results of the finite-element analysis of containment behavior, they must be adjusted for more realistic conditions using a series of "knockdown" factors $(5.120,5.122,5.123)$. These factors account for the relative level of sophistication of the finite-element analysis, local imperfections and concentrations of strain that the finite-element analysis cannot capture, differences between containment design and construction, relative effects of membrane action versus bending at points of maximum strain, increases in ductility of steel at elevated temperatures, and so forth. Accordingly, the limit state for containment fragility analysis is defined by,

$$
\varepsilon_{\mathrm{p}}>\varepsilon_{\mathrm{f}} \mathrm{f}_{1} \mathrm{f}_{2} \mathrm{f}_{4}
$$

in which $\mathrm{f}_{1}=$ factor to correct uniaxial limit strain for triaxiality (the multiplier of $\varepsilon_{\mathrm{f}}$ in Eqns. (5.63) or (5.64), $\mathrm{f}_{2}=$ factor that accounts for bias and uncertainty in the finite-element analysis itself, and $f_{4}=$ factor to account for the reduction in ductility in corroded steel.

Loss of containment integrity can arise from any one of several failure modes; the system limit state is defined by the Boolean equation,

$$
\mathrm{LS}=\bigcup_{\mathrm{i}=1}^{\mathrm{m}} \mathrm{F}_{\mathrm{i}}
$$

in which $F_{i}=$ failure associated with mode $i, i=1,2, \ldots, m$. It is assumed that each $F_{i}$ can be related to a local effective plastic strain determined from Eqn. (5.61), which can be identified in due course by finite-element post-processing. If it can be shown through a sensitivity analysis that only one of the modes dominates (e.g., effective local strain at a point of transition in shell thickness), the Boolean in Eqn. (5.67) becomes a simple event, and the fragility analysis can be simplified.

It is assumed in the sequel that failure occurs by tensile instability (limiting strain) in the uncorroded material. Excessive displacements in the containment shell may lead to failure of appurtenant safety-related systems. In contrast to failures related to effective plastic strains, however, displacement limits are containment-dependent. Moreover, local deformations can be related to global or local strains, which are determined from the finite-element analysis. Accordingly, limit states related to excessive shell displacements are subsumed in the strain-based limit states identified above, and are not considered further. Similarly, fracture mechanics criteria for containment failure (5.124) are not pursued, absent evidence from the SNL test programs that unstable propagating cracks are relevant failure mechanisms in ductile carbon steels typical in containments. Moreover, sharp flaws have not been observed in corroded sections of containments. Finally, there are other potential failure modes that are not accounted for in the present structural analysis, such as leakage at seals and penetrations. 


\subsection{Statistical databases and experimental design}

A fragility assessment requires median-centered estimates of system capacity. The material strengths specified for design by the American Society for Testing and Materials (ASTM) and other standardizing organizations usually are substantially less than the actual strengths. These specified strengths rarely correspond to a particular fractile of the CDF of strength. Recent studies of carbon steels suggests that the mean or median strength may be as much as $30 \%$ higher than the specified strength. Most modes of failure of interest in fragility analysis are only credible at pressures and temperatures well beyond the design basis. Accordingly, for a median centered estimate of system capacity to withstand such demands, this source of conservatism must be removed. Moreover, the estimated capacity of the containment is affected by numerous sources of uncertainty, which must be clearly identified as part of the fragility modeling exercise. These uncertainties are both aleatory and epistemic in nature.

Inherent randomness. The main sources of uncertainty affecting strength of steel structures are variability in the yield strength, tensile strength, and fracture ductility. Other parameters, such as Poisson's ratio and modulus of elasticity exhibit lesser variability. Variation in the thickness of the plate due to the rolling process is negligible in comparison and can be ignored. These sources of uncertainty are essentially irreducible at the current state-of-the-art. Data collected in research to develop probability-based design codes (5.66,5.67); and condition assessment procedures for steel structures in nuclear plants (5.119) can be used for this purpose.

A summary of strength data for steel at ambient temperature conditions $\left(20^{\circ} \mathrm{C}\right)$ is presented in Table 5.4. Strength parameters are described by lognormal CDFs, while the constitutive properties (modulus, Poisson's ratio) are described by normal distributions. The test conditions for these data are unknown, but it is believed that most were mill tests conducted by standard ASTM procedures. The strength of carbon steel under slow rates of load (approx $1 \mathrm{hr}$ to failure) is known to be about $28 \mathrm{MPa}$ less than the reported mill test results. Accordingly, the mean strengths in Table 5.4 should be reduced by this amount in the experimental design.

During the course of internal pressurization, the temperature in the steel also increases. Changes in the behavior of steel at elevated temperature should be taken into account. A review of available data on performance of structural steels at elevated temperatures (5.125) indicates that the variability in strength and stiffness at elevated temperatures is approximately the same as at ambient. Thus, while the mean strength (or stiffness) is temperature-dependent, the variability is assumed to be the same as at ambient.

The failure strain or fracture ductility, $\varepsilon_{f}$, of SA 516/60 and 516/70 steels (cf Eqn. (5.60) also is a random variable. However, less data are available to describe it, since this parameter has not been of interest in previous structural reliability studies. The fracture ductility of steel decreases slightly as the tensile strength increases. Limited information (summarized in Table 5.4) indicates that $\varepsilon_{\mathrm{f}}$ can be described by a normal distribution.

In a reinforced or prestressed concrete containment with a steel liner, the structural capacity to withstand intemal pressurization and temperature is provided mainly by the concrete and reinforcement. The liner also contributes to capacity, provided that it can act in a composite fashion with the containment structure. A summary of strength data for reinforced or prestressed concrete structures is provided in Table 5.5. Much of these data were collected as part of continuing research to develop probability-based design criteria for buildings and other structures (5.126). Additional information was collected in a program to develop probability-based design criteria for nuclear plant structures $(5.60,5.67)$. In some cases, concrete and reinforcement properties for specific nuclear power plants are available.

The corrosion patterns in the fragility analyses to be performed subsequently are assumed to be known in location, but random in depth. Uncertainties in this depth must be included in the analysis. Previous studies have modeled the progression of corrosion as a random process to forecast time-dependent reliability of degrading structures (5.119):

$$
\mathrm{C}(\mathrm{t})=\mathrm{C}_{\mathrm{O}}\left(\mathrm{t}-\mathrm{t}_{\mathrm{i}}\right)^{\mathrm{m}}
$$

in which $\mathrm{C}_{0}$ and $\mathrm{m}$ equal the rate and time order parameters that are obtained from experimental data, and $\mathrm{t}_{\mathrm{i}}=$ period required to initiate corrosion. The rate parameter, $\mathrm{C}_{0}$, can be assumed to be a lognormal random variable. The timeorder parameter, $\mathrm{m}$. is constant at 0.7 . With a median of $\mathrm{C}_{0}$ approximately equal to $200 \mu \mathrm{m}$ for containment environments, the corrosion loss would be approximately $2.6 \mathrm{~mm}$ in $40 \mathrm{yr}$., assuming $\mathrm{t}_{\mathrm{i}}=0$. The COV can be as high as 0.50 . The uncertainty in $t_{i}$ can be neglected, in first approximation (5.70). 
When an in-service condition assessment is performed, the presence of corrosion often can be detected (e.g., by visual inspection, half-cell potential or ultrasonic measurement), but the extent of the corrosion may remain unknown if its location is inaccessible to measurement. In such cases, an estimate for sensitivity analysis purposes may be obtained from Eqn. (4.68), taking $t$ as the present age of the containment. If corrosion measurements are available, of course, these should be used. In the sequel, it will be assumed that the latter is the case, and that the median corrosion penetration is known. However, the actual penetration is randomly distributed about the median. This randomness must be described by a bounded distribution; otherwise, there is a non-negligible probability that the penetration will exceed the plate thickness.

Knowledge-based uncertainty. Three sources of uncertainty are attributable to lack of knowledge. The first arises due to the finite-element modeling of the containment for structural analysis purposes: the refinement of the model, treatment of boundary conditions, etc. The second arises from the definition of the failure criteria against which the finite-element results are checked. The third is due to fitting supporting experimental data with probability models and extrapolating well beyond the realm of observation to identify design levels.

Uncertainty from the finite-element modeling arises from the selection of mesh size, element types (continuum versus shell), idealized loading and boundary conditions, execution parameters and postprocessing. A measure of this uncertainty would be given by a comparison of finite-element predictions to experimental data obtained under carefully controlled conditions. Such data is very difficult to come by. The ABAQUS code has been widely tested in the structural engineering community for a variety of applications and, assuming no human error, is believed to yield accurate results. In the circumstances, it is assumed that the uncertainty in structural response computed from ABAQUS can be described by a normal distribution. With the further assumption that the estimated effective strain in the containment is an unbiased estimate of the true strain, and can be computed to within plus/minus $20 \%$ of the true value with $95 \%$ confidence, the COV of $\mathrm{f}_{2}$ is 0.10 . On the other hand, structural failure may occur as a result of local strains at a scale that the finite-element analysis cannot capture without costly refinement of the mesh. To account for this effect, the mean of $\mathrm{f}_{2}$ is taken as 0.5 for membrane action and 0.75 for bending action.

Uncertainties in the limit state definition (Eqn. (5.66) arise from two sources: the true strain at fracture under multiaxial state of stress (measured by the product $\varepsilon_{\mathrm{f}} \mathrm{f}_{1}$ ), and the loss of ductility due to corrosion, measured by $\mathrm{f}_{4}$. Some data are available to describe $\varepsilon_{\mathrm{f}}$ under uniaxial load conditions (cf Table 5.4). Although test replicates are limited for multiaxial stress conditions, there is some evidence that the variability is approximately the same as for uniaxial conditions. Accordingly, all uncertainty in $\varepsilon_{\mathrm{f}} \mathrm{f}_{1}$ is assumed to be vested in $\varepsilon_{\mathrm{f}}$. For similar reasons, uncertainty in the reduction in $\varepsilon_{\mathrm{f}}$ due to corrosion is assumed to be included in the uncertainty in $\varepsilon_{\mathrm{f}}$.

Experimental design and sampling plan. Structural response by finite-element analysis can be idealized by the (implicit) function, $\mathrm{G}$,

$$
\varepsilon_{\mathrm{p}}=\mathrm{G}\left(\mathrm{F}_{\mathrm{y}}, \mathrm{F}_{\mathrm{u}}, \mathrm{E}, \mathrm{v}, \mathrm{C} ; \mathrm{p}, \mathrm{T}\right)
$$

in which $\varepsilon_{\mathrm{p}}=$ effective plastic strain. Parameters $\mathrm{F}_{\mathrm{y}}, \mathrm{F}_{\mathrm{u}}, \mathrm{E}$ and $v$ (noted in Table 5.4), and $\mathrm{C}$ are modeled as random variables; internal pressure, $\mathrm{p}$, is the control variable, and $\mathrm{T}=$ temperature. The structural limit state is reached if the response exceeds the failure limit (Eqn. (5.66)) at any point in the containment.

Closed-form solutions of containment response in terms of the basic random variables cannot be obtained from finiteelement analysis. Accordingly, the fragility must be constructed by a numerical experiment that couples the finiteelement analysis with Monte Carlo simulation. Each experiment (i.e., finite-element analysis of the containment) will result in a different relation between $\varepsilon_{\mathrm{p}}$ and $\mathrm{p}$, which must be checked against a random failure limit in Eqn. (5.66); postprocessing these data and rank-ordering results in the fragility sought. As with any experiment, there is sampling error associated with the size of the sample. This sampling error generally is inversely proportional to the square root of the sample size. Small samples may result in large error (reproducibility among experiments), while samples large enough to reduce this error may be costly to obtain. Clearly, there is a tradeoff between accuracy and cost.

If the fragility curves were to be developed from a classical Monte Carlo approach, a large number of simulations would be required to define the fragility with an acceptably small sampling error at the lower exclusion limits $(0.01-0.10)$ of significance in safety margin analysis. Since each sample requires a complete finite-element analysis of the containment, such an approach would be costly in terms of computational effort. Variance reduction techniques can be used to enhance the efficiency of the numerical experiment (5.127). 
A particular variance reduction technique involves a stratified sampling plan known as "Latin Hypercube Sampling" (5.128). Latin Hypercube Sampling is a generalization of the notion "sampling without replacement." One divides the range of each variable into $\mathrm{N}$ equiprobable intervals, and associates a value, $\mathrm{x}_{\mathrm{i}}$, with the midpoint of each interval. These values are randomly matched without replacement in constructing $\mathrm{N}$ random samples used in the numerical experiment (finite-element analysis) until each value of each variable has been selected exactly once. The resulting $\mathrm{N}$ finite-element analyses result in $\mathrm{N}$ containment pressure-strain relations that are post-processed. Estimators of structural response or fragility that are obtained from this sampling procedure can be shown to be unbiased; moreover, the variance of such estimators, which is a measure of sampling error, generally is less than that for classical Monte Carlo simulation. In nonstatistical terms, this is because stratified sampling, in effect, forces the entire range of each random variable to be represented in the numerical experiment. The cost of finite-element analysis must be considered in selecting sample size, $\mathrm{N}$; once this is done, however, there is some assurance that the sampling error is near-minimum for the sample size selected.

If the aleatory and epistemic uncertainties are considered together (as in Eqn. (5.56)), the set of numerical experiments need be performed only once. If the epistemic uncertainty is to be displayed explicitly, however, the entire procedure must be repeated a sufficient number of times to capture the effect of the uncertainty in the medians. One would generate a set of parameter medians by LHS; construct the fragility as described in the preceding paragraph; and repeat the process a suffficient number of times to display the epistemic uncertainty explicitly. The first approach is followed in the next section to keep the number of finite-element analyses to a manageable number.

\subsection{Fragility analysis of steel containment}

The fragility analysis procedure for a steel containment is illustrated in this section using the containment for an ice condenser plant. The specific plant utilized in the analysis was selected because it was one of the reference plants in the NUREG-1150 risk study (5.129) and there have been several independent assessments of its capacity that could be used as a check on the finite-element analysis. We first consider the containment fragility in the undegraded (uncorroded) condition to establish a benchmark. This analysis is compared with the results obtained in previous containment analyses (5.120,5.122) and in the Individual Plant Examination (5.134). Subsequently, corrosion patterns that are consistent with field inspection findings in similar containments are postulated, and the fragilities are reassessed. For both analyses, the uncertainties are propagated using a Latin Hypercube sampling plan, and points of failure are identified through post-processing the structural response data calculated by ABAQUS. The aleatory and epistemic uncertainties are lumped together in the analysis, leading to a mean fragility (cf Eqn. (5.55)).

The PWR ice-condenser containment was designed for an internal pressure $74 \mathrm{kPa}$. The internal diameter is $35 \mathrm{~m}$; the springline height is $35 \mathrm{~m}$; and the apex of the spherical dome is $53 \mathrm{~m}$. The steel is A516/Grade 60 plate, varying in thickness from $35 \mathrm{~mm}$ at the basemat to $12 \mathrm{~mm}$ at the springline. Vertical and circumferential stringers are welded to the exterior of the shell at spacings of approximately $1.2 \mathrm{~m}$ vertical and $3 \mathrm{~m}$ circumferential.

The statistics used to construct the Latin Hypercube samples and perform the fragility analysis are summarized in Table 5.6. Fourteen Latin Hypercube samples are summarized in Table 5.7. All parameters were assumed to be statistically independent. Column (5) in Table 5.7 models uncertainty in corrosion penetration as a fraction of plate thickness. The parameter "Model" in column (6) accounts for uncertainty in the ABAQUS finite-element code, and also is dependent on whether failure occurs by membrane or bending action. To account for these effects, $\mathrm{f}_{2}$ is defined as the product of the value in column (6) and the mean of $\mathrm{f}_{2}$ in Table 5.6, depending on the nature of the structural action that governs. Fourteen Latin Hypercube samples were selected so that the minimum and maximum of the samples would plot at approximately the 5-percentile and 95-percentile cumulative probabilities using the plotting positions $\mathrm{p}_{\mathrm{i}}=(\mathrm{i}-0.3) /(\mathrm{n}+$ $0.4)$, which approximate the rank-medians.

Benchmark fragilities of undegraded containment. The results of the 14 benchmark containment analyses were postprocessed, rank-ordered, and plotted on probability paper. Typical relations between internal pressure and effective plastic strain in the ice basket region and near the interface between the steel shell and the basemat are shown in Figures 5.9(a) and 5.9(b). For Sample No. I shown in Figure 5.9(a) for the ice basket region, pressure at first yield, 2\% effective plastic strain, and containment failure were, respectively, $310 \mathrm{kPa}, 386 \mathrm{kPa}$ and $455 \mathrm{kPa}$, the latter occurring at a failure strain of 0.075 . The rank-ordered failure pressures for the 14 containment samples are plotted on lognormal probability paper in Figure 5.10. The mean (and median) containment capacity is $455 \mathrm{kPa}$, and the logarithmic standard deviation, $\beta_{\mathrm{c}}$ (approximating the COV in capacity), is 0.04 . The 5-percent exclusion limit is estimated at $427 \mathrm{kPa}$. 
Two previous deterministic studies for this containment have been conducted by SNL. In the first study (5.122), shell rupture was analyzed with two sectional finite-element models, one that modeled general shell behavior and the second that modeled effects of penetrations. The MARC finite-element code was used to perform the containment analysis. Using the second model, the pressures at progressive limit states of first yield, $2 \%$ hoop strain, and mean failure pressure at a limit strain of 0.11 at temperatures of approximately $154^{\circ} \mathrm{C}$ were, respectively, $276 \mathrm{kPa}, 400 \mathrm{kPa}$, and $531 \mathrm{kPa}$. It was found that the reduction in capacity at elevated temperature was proportional to the reduction in steel tensile strength at the same temperature. In the second study (5.120), containment failure was analyzed using the ABAQUS code. The "best estimate" of failure pressure using a strain-based failure criterion similar to Eqn. (5.63) was $469 \mathrm{kPa}$.

Although neither of these studies considered the randomness in the structural parameters explicitly, their findings clearly are consistent (in the mean or median) with the value in the present study. In passing, a simple limit analysis of the containment cylinder with an average shell thickness of $19 \mathrm{~mm}$, ignoring the effect of the stiffeners, leads to a computed failure pressure of $489 \mathrm{kPa}$; apparently, limit analysis is sufficient to provide an independent check to the finite-element analysis in this particular case.

Fragility analyses of all containments have been conducted as part of the Individual Plant Examinations (IPEs) and the results have been summarized (5.130). The licensee efforts and the quality of the fragility analyses presented varied considerably. In some cases, several failure modes were considered and a composite CDF of failure pressure at elevated temperature was developed. In other cases, only an estimated median and error bounds were provided at ambient temperature, or previously published fragilities were adjusted judgmentally to model the plant in question. The plantspecific analysis (as part of the IPE) of the ice condenser containment considered in this study was performed by EQE, Inc. and is comprehensive in nature. A total of seven failure modes were considered at various temperatures, and a composite lognormal fragility model corresponding to a temperature of $93^{\circ} \mathrm{C}$ was developed. The estimated median failure pressure was $469 \mathrm{kPa}$. If the fragility is lognormal, $\beta_{\mathrm{c}}$ can be estimated from the tabulated 5-percentile, median, and 95-percentile values as,

$$
\beta_{\mathrm{c}}=-\ln \left(\mathrm{R}_{.05} / \mathrm{m}_{\mathrm{R}}\right) / 1.645
$$

or

$$
\beta_{\mathrm{c}}=\ln \left(\mathrm{R}_{0.95} / \mathrm{R}_{.05}\right) / 3.29
$$

with $\mathrm{R}_{.05}=59 \mathrm{psi}(407 \mathrm{kPa})$ (cf Table 5.8), the COV is 0.08 .

A review of Individual Plant Examination fragilities for steel PWR containments and other containments (5.130) is summarized in Tables 5.8(a) and 5.8(b). The fragilities presented for the NUREG-1150 plants were checked against the results presented in that study (5.129). The two studies of steel containments that are most complete (Sequoyah and Watts Bar) provide lower and upper bounds on the logarithmic standard deviation (COV) of 0.08 and 0.17. Compared to these results, the COV 0.04 determined herein is low. The reason for this is unclear; the fact that the earlier studies may have attempted to account for nonstructural failure modes as well as structural failure may be a contributing factor. On the other hand, all $\beta_{\mathrm{c}}$ 's reported in Table 5.8 are substantially less than the $\beta_{\mathrm{c}}=0.27$ reported (5.131). Finally, we note that while the medians in Table 5.8 exceed the design basis by a factor typically, 2.5 to 6.0 , the COVs in Table 5.8 are lower, in all cases, than those determined in seismic fragility analyses of nuclear power plant structural components and systems $(5.96,5.97)$.

Fragility of corroded containment. Corrosion of containments has been found to be highly localized in regions where water or chemicals accumulate (5.132). In the following, therefore, we consider the impact of postulated corrosion patterns in the steel containment behind the ice basket, at the level of the upper floor, and at the point where the shell penetrates the basemat. Postulating corrosion damage based on what has been observed by location, areal extent, and the mean loss of shell thickness, and determining the impact of such damage on strength closely models the condition assessment process as it is likely to be implemented in practice following an in-service inspection. The assumption of deterministic areal extent also facilitates the finite-element analysis, since irregular elements are not needed to model the corroded regions. However, such an in-situ inspection generally would not determine the variability in loss of thickness. In addition, there would be measurement uncertainties associated with such a determination. Thus, these sources of uncertainty in corrosion penetration are modeled by a uniform distribution, with median and COV $\beta_{R}$ as shown in 
Column (3) of Table 5.6. The median penetration is varied to determine the sensitivity of the fragility to this important degradation parameter.

The ice condenser containment fragility analyses from the present study are summarized in Table 5.9 for postulated mean corrosion losses of $10 \%$ and $25 \%$ of the shell thickness behind the ice basket; losses of $50 \%$ at the upper floor level; and loss of $50 \%$ in the basemat region. The fragilities also are illustrated for these postulated corrosion conditions on lognormal probability plots in Figure 5.11 . For example, for $25 \%$ loss of section (approximately $4 \mathrm{~mm}$ ), the mean pressure at containment failure by tensile instability was $386 \mathrm{kPa}$ at an effective limiting plastic strain of 0.048 ; the estimated $5 \%$ and $95 \%$ values of capacity are $352 \mathrm{kPa}$ and $427 \mathrm{kPa}$. The COV in capacity has increased to 0.06 over the benchmark case. The first three lines of Table 5.9 and Figure 5.11 show that the reduction in fragility at all fractiles is nonlinearly proportional to the median percentage loss in thickness, with a larger decrease occurring between the undegraded condition and $10 \%$ loss than between the 10 and $25 \%$ losses. This reduction occurs because the fracture ductility of a corroded section decreases by a factor of 2 , regardless of corrosion penetration. The variability in section loss is relatively more significant for moderate corrosion penetration, and its effects on overall containment strength are highly localized.

For the damage state identified as "50\% loss at basemat," five of the containments analyzed failed in the basemat region, while nine failed in the uncorroded ice basket region prior to reaching the limit strain in the basemat. This limit state thus involves the union of two failure events, as in Eqn. (4.67); as a result, the probability plot is highly nonlinear on lognormal probability paper, and the 5-, 10- and 95-percent values cannot be estimated accurately from a Latin Hypercube sample of this size.

Other containment limit states. The containment limit state identified in Section 5.2.4.3.2 is based on (generally localized) limiting effective plastic strain, and models ductile tearing of the steel shell leading to leakage or rupture. As internal pressure is increased, the containment structure transitions through several increasingly severe states of damage, reaching first the point of first yielding in the shell, followed by a general hoop strain of, say, 0.02 . These lesser limit states, in themselves, may not affect containment function. However, they can be estimated through a relatively simple limit analysis of the shell rather than by nonlinear finite-element analysis (5.106). Thus, it is of interest to compare the fragilities associated with these precursor limit states with the fragilities presented in the previous two sections. The spacing of the fragility curves for progressively increasing damage severity, when plotted in the same figure, conveys an idea of the robustness and additional margin of safety of the containment structure during the development of a designbasis accident. Closely spaced fragilities would indicate little margin to failure beyond the first indications of damage, whereas widely spaced fragilities indicate that significant local damage may occur prior to failure or loss of function.

The results of this comparative analysis in the form of containment fragilities based on first yield, plastic strain, and tensile instability for the undegraded ice condenser containment are presented in Figure 5.12. The values plotted are obtained from the finite-element analysis results (cf Figure 5.9). The mean fragilities at the limit states of first yield and circumferential strain of 0.02 were, respectively, $290 \mathrm{kPa}$ and $365 \mathrm{kPa}$. These mean values compare well to the results of the earlier MARC analysis values of $276 \mathrm{kPa}$ and $400 \mathrm{kPa}(5.122)$. The spacing of the curves in this illustration shows that a substantial additional margin exists following first yielding for inelastic load redistribution.

\subsection{COMMENTARY}

\subsubsection{Structural Reliability}

The previous sections have illustrated some of the applications of probabilistic risk analysis and fragility modeling procedures in assessing the safety of aging reinforced concrete or steel structural components and systems in nuclear power plants during events at or beyond the design basis. In this section, an attempt is made to summarize what has been learned from these analyses, and make observations about their use in condition assessment and decision-making regarding possible service life extensions.

\subsubsection{Appraisal of structural reliability methods}

Structural reliability analysis provides the framework for analyzing uncertainties in structural loads, operational demands on a structural component or system, and structural capacity to withstand demands. This information can be utilized on several levels: to identify a review level event to be used in a subsequent structural analysis; to identify a structural capacity in which there is a high-confidence of a low probability of failure; to determine a probability of component or 
system failure at any time; and to determine the probability of failure during any service period.

In theory, component or system reliabilities can be computed from first-order reliability methods (FORM) or fulldistribution methods $(5.7,5.133)$. In practice, this may not be as easy as it sounds. The determination of $\mathrm{P}_{\mathrm{f}}(\mathrm{t})$ in Eqn. (5.25) requires statistical data on material strengths, dimensions and other basic random variables, modeling errors, and a verifiable structural model of behavior based on principles of mechanics to identify the limit condition (excessive inelastic deformation, instability, etc). There also is the numerical problem in evaluating the probability integral for realistic systems.

In classical reliability analysis, there is a presumption that the limit state function (viz Eqn. (5.24)) is available in closed form, and therefore that the domain of integration in Eqn. (5.25) is well-defined. However, modern structural analysis often is performed using finite-element methods. In contrast to classical mechanics, finite-element analysis is algorithmic in nature, yielding structural responses (forces, displacements) at discrete points, but not a general closed-form expression for the limit state function. One can, however, use finite-element analysis to develop a "response surface" approximation to the limit state surface that is sufficiently accurate to be used in reliability analysis $(5.134,5.135)$. One first performs the finite-element analysis at a set of carefully selected experimental points in the domain of random variables. Next, a relatively simple function or response surface - commonly a second-order polynomial - is fitted to the finite-element analysis results by regression or interpolation analysis. Once an adequate representation of the actual limit state has been achieved (and this may involve some iteration in order to minimize statistical error), the reliability analysis can be performed using the response surface.

The computation of the probability integrals in Eqn. (5.25) is numerically difficult when more than a few random variables are involved. Monte Carlo methods can be used to perform these computations in approximate form (5.127). The Monte Carlo approach has a number of practical advantages, particularly in a structural system reliability analysis [e.g., (5.136]: complex structural behavior can be accommodated; stochastic dependency can be modeled; the possible introduction of new random variables due to inspection and repair can be dealt with; and several failure modes can be included, e.g., fracture from overload as opposed to fracture from crack growth. Perhaps one of the most useful features of Monte Carlo simulation is the way in which it facilities visualization of the damage evolution process.

The main disadvantage of Monte Carlo methods is their lack of numerical efficiency in structural reliability analysis which involves small probabilities. If the event probabilities of interest are on the order of $10^{-\mathrm{N}}$, an unmodified random sampling procedure requires approximately $10^{\mathrm{N}+1}$ samples for the failure probability estimate to be stable. The number of samples required to achieve a given sampling error, expressed by the standard deviation, $\operatorname{SD}\left(\mathrm{P}_{\mathrm{f}}\right)$, can be reduced by modifying the random sampling process. In structural reliability analysis "importance sampling" often has been used for this purpose (5.70,5.137-5.139). They can be categorized by: direct, updating, adaptive schemes, or spherical schemes/directional sampling. The efficiency of these approaches depends on the number of times the structural limit state must be calculated if the $\mathrm{SD}\left(\mathrm{P}_{\mathrm{f}}\right)<\varepsilon$; the efficiency thus is related more to the structural analysis than to the uncertainty analysis. In all methods except adaptive sampling, the positioning of the importance sampling PDF must have been achieved with a suitable algorithm, often FORM. None of the methods is optimal under all circumstances, and some experimentation is required to determine the best approach for the particular problem at hand.

\subsubsection{Challenges in structural reliability}

The gap between research and practice remains large in component versus system performance, and the difficulty in testing large structural systems directly makes this a difficult issue to resolve. System reliability depends on the limit state, redundancy (to an unpredictable degree), post-elastic behavior, and other factors. Current fragility models are based on rather simple models. Advances in system reliability analysis methods should enable the fragility models to be vastly improved. Along with this, better definitions of limit states that are tied to the performance requirements of the facility are required to improve fragility modeling. Structural behavior models must include nonlinear response explicitly - not through the simple multiplicative factors - and the strength, inelastic deformation and energy dissipation limit states must be better related to the performance requirements of the facility as a whole.

Acceptable risk targets for design and evaluation remain an issue, notwithstanding the fact that a number of regulatory agencies already have set such targets. Regulatory goals now are often given in terms of annual probability of occurrence or exceedence. Target reliabilities used in developing probability-based codes for buildings and bridges were based on a calibration procedure that imposed a degree of continuity with existing practice (a necessary condition to facilitate professional acceptance in the short term). Unfortunately, the database underlying structural reliability analysis 
is limited, especially so for nuclear power plant structures. Different researchers use different databases and thus arrive at different risk estimates and conclusions. The calculated risk or reliability level is a surrogate for the actual risk. The true risk is unknown; nor do we know at what level structural failure risk is with respect to other competing risks. Advances in computational reliability analysis have made it easy to obtain answers, but it is still difficult to obtain good answers. Thus, there is a need for validation of reliability analysis methods as more regulatory agencies introduce regulations that include quantitative risk targets. The comparison of probabilities computed in a Probabilistic Risk Assessment to such a goal must be meaningful. Better quantification of reliability targets or acceptable risks - and the supporting database - also are required. Improvements in risk communication also will be necessary for such methods to reach their full potential for implementation.

\subsubsection{Fragility Analyses}

Code provisions evolve and change over time as a result of new research and experience. Some provisions become less conservative, as confidence builds; others become more conservative as a result of problems that develop in service. Some design challenges may be newly identified; others may have been revised upward during the service life as a result of additional research. It is reasonable to ask, for an existing containment or seismic Category I structure (one that very likely has performed well for a service life of 30 - 40 years): Should this structure meet the safety requirements of the code(s) under which it was designed or the most recent edition(s), bearing in mind that the design provisions may not be exactly the same? Has degradation encroached unduly on the margin of safety?

Such questions are not trivial. Structural repair and maintenance invariably are costly and disruptive, and in some instances may not be feasible. Quantitative evidence that a nominally degraded containment structure still can perform its functions and should be allowed to continue in service has major economic implications and presents a regulatory issue requiring interpretation, judgment and decision. It is unlikely that this issue can be addressed by the type of analysis normally performed in support of structural design, namely, an elastic analysis of response to one design-basis event using nominal material strengths. Such an analysis does not give an accurate picture of structural performance under a spectrum of possible (however unlikely) events. Instead, the analysis should use the material properties as they are in the structure (i.e., mean or median-centered values). The actual behavior of the structure should be modeled, including nonlinear action. Moreover, a range of challenges at and beyond the design basis should be considered to model the inevitable uncertainties (aleatory and epistemic) that are present. Addressing these issues focuses the attention of plant managers, engineers and regulatory authorities on the major safety issues. It does not require them to micromanage safety through assuring satisfaction of prescriptive design formulae, something that may happen when the evaluation process is tied too closely to a prescriptive code.

The fragility analysis provides a structured framework for identifying aging factors that are important to safety; for identifying areas where the potential for degradation to impact safety is significant; for focusing in-service inspection, maintenance and repair; for guiding the acquisition of additional data; and for arriving at risk-informed decisions regarding the suitability of an existing containment for continued service. In contrast to the typical design analysis, the fragility depicts how the containment may perform under a spectrum of possible events. A properly conducted fragility analysis must be based on rational structural mechanics and structural reliability principles, and requires a supporting database to describe the various uncertainties that are likely to affect containment performance. The relation between performance requirements and structural limits must be clear and defensible. The state-of-the-art has advanced during the past 20 years to the point that such an analysis now is feasible.

The starting point must be the benchmark fragility of the containment structure in the undegraded condition, which should be part of the documentation of every operating plant. This fragility should be developed using methods similar to those described in this study and at the same level of technical rigor. That fragility should be peer reviewed because of the technical and economic implications of the decision process. Once all stakeholders agree on the benchmark, subsequent changes to the containment fragility as a result of operating conditions, corrosion or deterioration from other environmental stressors can be clearly identified. Such an evaluation might take any one of several forms. For one, the utility might observe deterioration in the course of routine inspection and wish to evaluate whether such deterioration is structurally significant. For another, the regulatory authority may wish to evaluate the impact on the integrity of a particular containment of postulated deterioration similar to that observed in another plant. In any event, the fragility of the containment is revised based on deterioration that has been observed or postulated for comparison to the benchmark fragility. 
In this study, fragilities were obtained for an ice condenser containment subjected to accidental internal pressurization. A nonlinear finite-element analysis program (ABAQUS) coupled to a Latin Hypercube sampling plan was used to propagate uncertainties. While such an approach provides the most comprehensive picture of containment performance, simpler reliability tools such as those presented in Appendix $\mathrm{C}$ might be sufficient for establishing a general relation between uncertainty and safety; certainly, an approximate analysis could be used for preliminary decision-making or determining whether to invest in a more comprehensive study. In support of this approximate analysis, it is recommended that at least one nonlinear finite-element analysis be performed to "anchor" the fragility curve at its median. In this analysis, all parameters should be set equal to their median values. Parameter $\beta_{\mathrm{c}}$ (Eqn. (5.56)), which defines the slope of the fragility, can be estimated from the results presented in Table 5.8. For most containments in the undegraded condition, this value is between 0.10 and 0.20 . [It is possible that $\beta_{\mathrm{c}}$ could be related to a specific containment type, e.g., Mark III, PWR subatmospheric, etc; this was not examined in this study, however]. For degraded containments, $\beta_{\mathrm{c}}$ should be increased by 50 percent. With $\mathrm{m}_{\mathrm{R}}$ and $\beta_{\mathrm{c}}$ determined, the mean fragility is defined by the lognormal distribution in Eqn. (4.55). The 5- or 10-percentile values then could be compared to the review event.

This revised fragility provides a major source of quantitative support to the decision process, but the results must be interpreted with care. In particular, the epistemic uncertainties in the analysis are sufficiently high that acceptance/rejection criteria should not be predicated on this basis alone. The absolute numbers themselves are less important than how sensitive they are to various assumptions and uncertainties in the analysis. At the current state-ofthe-art, it is difficult to attach any statistical significance to small differences in the 5 or 10-percentile values. On the other hand, the rate of change in the 5 or 10-percentile values from the benchmarks due to aging may be more informative. Decreases in these fractiles of a factor of two or more during 30 years might be cause for concem, regardless of the initial condition. More particularly, an increase in the rate of change would indicate accelerating degradation; such a finding would suggest that a comprehensive in-service examination of structural integrity be initiated. The sources of all uncertainties should be investigated carefully, and a sensitivity study should be performed to identify those uncertainties that most affect the fragility. Such a sensitivity study provides guidance on where to request additional information. Not all uncertainties are equally significant for risk.

The fragility assessment presented for the ice condenser plant took into account failure by tensile instability in the containment shell, and thus models containment fragility with respect only to structural failure. There are a number of other potential failure modes that were not accounted for in this analysis. For example, leaks have been detected during integrated leakage-rate tests at seals (organic gaskets needing replacement), electrical penetrations (degradation of organic portions or cracking of ceramics), equipment or personnel hatches, at bellows (due to transgranular stress corrosion cracking), and so forth. Many of these "leak modes" are unrelated to structural issues. Nonetheless, if included, they may cause the fragility curve to shift leftward and lower the estimated margin, particularly at the lower fractiles of the fragility; at the same time, the logarithmic standard deviation may increase by an unknown margin. Comparing structural fragilities for postulated degradation to an undegraded benchmark fragility is useful for understanding how corrosion (or other structural damage) might impact the safety margin. On the other hand, for a more complete understanding of the contribution of the containment to overall risk, nonstructural failure modes should be included, as indicated by Eqn. (5.67).

In a containment fragility analysis, the structural performance and hazard issues are uncoupled, so the problem of identifying acceptably small limit state probabilities for decision analysis purposes (acceptable risks) is circumvented to a degree. However, this problem is replaced with another: that of determining appropriate "review level" events and fractiles of the fragility to check against those review level events. Some understanding of the nature of the interaction between hazard and fragility is necessary to arrive at (set of) sensible review-level events (4.99). It is well-known that the major contributions to plant risk often come from a relatively small range of hazards. In seismic Probabilistic Risk Assessment, for example, earthquake ground motions with intensities two to four times the SSE contribute the major portion of seismic risk. In a similar vein, one should attempt to identify the magnitude of challenge that contributes most to containment failure probability, and use the associated event as the basis for the safety margins assessment. In this way, fruitless consideration of challenges that have negligible contribution to risk would be minimized, and the containment margins assessment might be made highly efficient. Since the events considered are, by definition, extremely rare, a Delphi may be necessary to assist in this identification.

\subsection{REFERENCES}

5.1 Vora, J.P. et al. (1990). "Nuclear plant aging research (NPAR) program plan," NUREG-1144, U.S. Nuclear Regulatory Commission, Washington, DC. 
5.2 McDonald, P.E. (editors) (1989). "Residual life assessment of major light water reactor components," NUREG/CR-4731, Vols. 1 \&\& 2, U.S. Nuclear Regulatory Commission, Washington, D.C..

5.3 Meale, B.M. and Satterwhite, D.G (1988). "An aging failure survey of light water reactor safety systems and components," NUREG/CR-4747, U.S. Nuclear Regulatory Commission, Washington, D.C..

5.4 Vesely, W.E., Kurth, R.E., and Scalzo, S.M. (1990). "Evaluations of core melt frequency effects due to component aging and maintenance," NUREG/CR-5510, U.S. Nuclear Regulatory Commission, Washington, DC.

5.5 Vesely, W.E. (1992). "Approaches for age-dependent probabilistic safety assessments with emphasis on prioritization and Sensitivity studies," NUREG/CR-5587, U.S. Nuclear Regulatory Commission, Washington, D.C.

5.6 Vo, T.V. et al. (1994). "Feasibility of developing risk-based rankings of pressure boundary systems for inservice inspection," NUREG/CR-6161, U.S. Nuclear Regulatory Commission, Washington, D.C.

5.7 Shinozuka, M. (1983). "Basic analysis of structural safety," J. Struct. Eng. 109(3), pp. 721-740, American Society of Civil Engineers, New York, New York.

5.8 Melchers, R.E. (1987). "Structural reliability - analysis and prediction," Chichester, Ellis Horwood Publishing, Herts, United Kingdom.

5.9 Naus, D.J., Oland, C.B., and Ellingwood, B.R. (1996). Report on aging of nuclear power plant reinforced concrete structures, NUREG/CR-6424, Oak Ridge National Laboratory, Oak Ridge, Tennessee.

5.10 Berger, D.M. (1983). "Fundamentals and prevention of metallic corrosion." Corrosion and Corrosion Protection Handbook, Marcel Dekker, New York.

5.11 Porter, F.M., Naish, C.C. and Sharland, S.M. (1994). "A probabilistic approach to assessing radioactive waste container lifetimes." Proc. ANS Conf. on High-level Waste, Las Vegas, NV, May.

5.12 ASTM G 101-89. "Standard guide for estimating atmospheric corrosion resistance of low-alloy steels." Am. Soc. For Testing and Materials, West Conchohocken, Pennsylvania.

5.13 Jaske, C. E. (1987). "Benefits of remaining life assessment." Chemical Engrg. Progress:37-46.

5.14 Natalie, C.A. (1987). "Evaluation of uniform corrosion." ASM Handbook. Volume 13 - Corrosion, ASM International, pp. 229-230.

5.15 Clifton, J.R. (1993). "Predicting Service life of concrete." J. Materials 90(6):611-617, American Concrete Institute, Farmington Hills, Michigan.

5.16 Ellingwood, B. and Mori, Y. (1992). "Condition assessment and reliability-based life prediction of concrete structures in nuclear plants." ORNLJNRC/LTR-92/4, Oak Ridge National Laboratory, Oak Ridge, TN, 147 pp.

5.17 Komp, M.E. (1987). "Atmospheric corrosion ratings of weathering steels - calculation and significance." Materials Performance 26(7):4244.

5.18 Structural Alloys Handbook Volume 3 (1989). Metals and Ceramics Information Center, Battelle, Columbus, $\mathrm{OH}$.

5.19 Kayser, J.R. and Nowak, A.S. (1989). "Reliability of corroded steel girder bridges." Struct. Safety 6(1):53-63.

5.20 Sommer, A., Nowak, A.S. and Thoft-Christensen, P. (1993). "Probabilisty-based bridge inspection strategy." J. Struct. Engrg., 119(12):3520-3536, American Society of Civil Engineers, New York, New York. 
5.21 Akashi, M., Fukuda T. and Yoneyama, H. (1990). "A corrosion localization assessment of the mild steel used for nuclear waste package." Mat. Res. Soc. Symp. Proc. vol. 176.

5.22 Shah, V.N., Smith, S.K. and Sinha, U.P. (1994). "Insights for aging management of light water reactor components - steel containments." NUREG/CR-5314, Vol. 5, U.S., Washington, DC.

5.23 Marsh, G.P., et al (1985). "Evaluation of localised corrosion of carbon steel overpacks for nuclear waste disposal in granite environments." Symposium on Scientific Basis for Nuclear Waste Management, Materials Research Society Symposium Proceedings Vol. 50, Pittsburgh, PA. pp. 421-428.

5.24 Czajkowski, C.J. (1990). "Survey of botic acid corrosion of carbon steel components in nuclear plants." NUREG/CR-5576, U.S. Nuclear Regulatory Commission, Washington, DC.

5.25 Sprowls, D.O. (1987). "Evaluation of pitting corrosion." ASM Handbook. Volume 13 - Corrosion, ASM International, pp. 231-233.

5.26 Sharland, S.M., et al (1991). "The assessment of localised corrosion of carbon and stainless steel containers for intermediate- and low-level radioactive waste under repository conditions." ANS Conf. on Nuclear Waste Packaging, Las Vegas, NV, Sept.

5.27 Williams, D.E., Westcott, C. and Fleishmann, M. (1985). "Stochastic models of pitting corrosion of stainless steels." J. Electrochem. Soc. 132(8): 1796-1804.

5.28 Kondo, Y. (1989). "Prediction of fatigue crack initiation life based on pit growth." Corrosion Science 45(1):711.

5.29 Ahammed, M. and Melchers, R.E. (1995). "Probabilistic analysis of pipelines subjected to pitting corrosion leaks." Engineering Structures, vol 17, no. 2, pp. 74-80.

5.30 Joshi, N.R. (1994). "Statistical analysis of UT corrosion data from floor plates of a crude oil aboveground storage tank." Materials Evaluation, vol 52, pp 846-9.

5.31 Shibata, T. (1994). "Application of extreme value statistics to corrosion." J. of Research, vol. 99, no 4, pp 32736, National Institute of Standards and Technology, Gaithersburg, Maryland.

5.32 Aziz, P.M. (1956). "Application of the statistical theory of extreme values to the analysis of maximum pit depth data for aluminum." Corrosion, NACE, 12, (10), pp 495t-506t.

5.33 Scarf, P.A. and Laycock, P.J. (1994). "Application of extreme value theory in corrosion engineering", J. of Research, vol 99, no 4, pp 313-20, National Institute of Standards and Technology, Gaithersburg, Maryland.

5.34 Mola, E.E., Mellein, B., Rodriguez, E.M., Vicente, J.L., Salvarezza, R.C. and Arvia, A.J. (1990). "Stochastic approach for pitting corrosion modeling I - The case of quasi-hemispherical pits." J. Electrochem. Soc. 137(5): 1384-1390.

5.35 Provan, J.W. and Rodriguez, E.S. (1989). "Part I: Development of a Markovian description of pitting corrosion." Corrosion 45(3): 178-192.

5.36 Strutt, J.E., Nichells, J.R. and Barbier, M.E. (1985), "The prediction of corrosion by statisitical analysis of corrosion profiles." Corrosion Sci. 25(5).

5.37 Gabrielli, C., et al (1990). "A review of the probabilistic aspects of localized corrosion." Corrosion Science 46(4):266-278.

5.38 Ware, A.G., Morton, D.K. and Mtzel, M.E. (1995). "Application of NUREG/CR-5999 interim fatigue curves to selected nuclear power plant components." NUREG/CR-6260, Washington, DC. 
5.39 Madsen, H.O. (1982). "Deterministic and probabilistic models for damage accumulation due to time varying loads." Dialog 5-82, Danish Engineering Academy, Lyngby.

5.40 Committee on Fatigue and Fracture Reliability (1982). "Fatigue reliability, I - IV." J. Struct. Div. 108(1):1 - 88, American Society of Civil Engineers, New York, New York.

5.41 Provan, J.W. (1987). "Probabilistic approaches to the material-related reliability of fracture-sensitive stuctures." in Probabilistic Fracture Mechanics and Reliablity, (Dordrecht; Boston) Martinus Nijhoff Publishers, The Netherlands.

5.42 Keisler, J., Chopra, O.K. and Shack, W.J. (1994). "Statistical analysis of fatigue strain-life data for carbon and low-alloy steels.” NUREG/CR-6237, U.S. Nuclear Regulatory Commission, Washington, DC.

5.43 Keating, and Fisher, J.W. (1986). "Evaluation of fatigue tests and design criteria on welded details." NCHRP Report 286, Transportation Research Board, Washington, DC.

5.44 LRFD specification for structural steel buildings (1993). American Institute of Steel Construction, Chicago, IL.

5.45 Ellingwood, B.R. (1976). "Probabilistic assessment of low-cycle fatigue behavior of structural welds." $J$. Pressure Vessel Tech. 98(1):26-32, American Society of Mechanical Engineers, New York, New York.

5.46 Topper, T.H., et al (1969). "Neuber's rule applied to fatigue of notched specimens." J. Materials JMLSA, 4(1):200-209.

5.47 Barsom, J. and Rolfe, S. (1987). Fatigue and fracture control in structures. Prentice-Hall, Englewood Cliffs, NJ.

5.48 Broek, D. (1988). The practical use of fracture mechanics. Dortrecht; Kluwer Academic Publishers, The Netherlands.

5.49 Dowling, N.E. (1993). Mechanical behavior of materials. Prentice-Hall, Englewood Cliffs, NJ.

5.50 Kachanov, L.M. (1986). Itroduction to continuum damage mechanics. Martinus Nijhoff, Dordrecht, the Netherlands.

5.51 Kobayashi, T., Shockey, D.A. and Jones, R.L. (1991). "Deriving SCC initiation times and growth rates from posttest fractographic analysis." Corrosion Science 47(7):528-535.

5.52 Chopra, O.K., Shack, W.J. and Rosinski, S.T. (1991). "Radiation embrittlement of the neutron shield tank from the Shippingport Reactor." NUREG/CR-5748, Washington, DC.

5.53 Yoshimura, S., Zhang, M.-Y., and Yagawa, G. (1993). "Life extension simulation of aged RPV material using probabilistic fracture mechanics analysis on massively parallel computer." Trans.. 12th Int Conf. on Struct. Mech. in Reactor Tech. Vol. M, Elsevier, Amsterdam, the Netherlands, pp. 165 - 176.

5.54 Murakami, S. and Mizuno, M. (1991). "Elaborated constitutive equations for structural analysis for creep, swelling and damage under irradiation." Nuclear Technology 95:219-227 (August 1991).

5.55 Strelec, H. (1993). "A model for accelerated life testing." Struct. Safety 12(2):129-136.

5.56 Chaboche, J.L. (1988). "Continuum damage mechanics, Parts I and II." J. Appl. Mech. 55(3):59-71, American society of Mechanical Enginers, New York, New York.

5.57 Lemaitre, Jean (1992). A course on damage mechanics. Springer-Verlag, Berlin, Germany.

5.58 Jiles, D.C., Biner, S.B., Govindaraju, M.R. and Chen, Z.J. (1994). "Applications of a new magnetic monitoring technique to in situ evaluation of fatigue damage in ferrous components." NUREG/GR-0013, Washington, DC. 
5.59 Jiles, D.C., Habermehl, S. and Atherton, S.L. (1984). "Application of hysteresis modeling to non-destructive inspection of stress," Proc. ${ }^{\text {st }}$ Nat'l Seminar on N.D.I. of ferromagnetic materials, Houston, Texas.

5.60 Doctor, S. R., et al (1993). "Nondestructive examination (NDE) reliability for inservice inspection of light water reactors." NUREG/CR4469 (15 Volumes), Washington, DC.

5.61 Hwang, H., Ellingwood, B., Shinozuka, M. and Reich, M. (1987). "Probability-based design criteria for nuclear plant structures." J. of Struct. Engrg. 113(5):925-942, American Society of Civil Engineers, New York, New York.

5.62 Ellingwood, B. and Mori, Y. (1993). "Probabilistic methods for condition assessment and life prediction of concrete structures in nuclear power plants." Nuc. Engrg. and Des. 142:155-166.

5.63 Pearce, T.H. and Wen, Y.K. (1985). "Stochastic combinations of load effects." J. Struct. Engrg. 110(7):16131629, American Society of Civil Engineers, New York, New York.

5.64 Ellingwood, B. (1983). "Probability based safety checking of nuclear plant structures." NUREG/CR-3628, U.S. Nuclear Regulatory Commission, Washington, DC.

5.65 Hwang, H., et al (1983). "A consensus estimation study of nuclear power plant structural loads." NUREG/CR3315, U.S. Nuclear Regulatory Commission, Washington, DC.

5.66 Galambos, T.V. and Ravindra, M.K. (1978). "Properties of steel for use in LRFD." J. Struct. Div. ASCE 104(9):1459-1468, American Society of Civil Engineers, New York, New York.

5.67 Ellingwood, B. and Hwang, H.(1985). "Probabilistic descriptions of resistance of safety-related structures in nuclear plants." Nuc. Engrg. and Des. 88(1):169-178.

5.68 Cherry, J. L. (1995). "Interim report on capacity of degraded containments." Sandia National Laboratories, Albuquerque, NM.

5.69 Mori,Y. and Ellingwood, B. (1993). "Reliability-based service life assessment of aging concrete structures. " $J$. Struct. Engrg. ASCE 119(5):1600-1621, American Society of Civil Engineers, New York, New York.

5.70 Mori, Y and Ellingwood, B. (1993). "Methodology for reliability-based condition assessment - Application to concrete structures in nuclear plants." NUREG/CR-6052, U.S. Nuclear Regulatory Commission, Washington, DC, $145 \mathrm{pp}$.

5.71 Mori, Y. and Ellingwood, B. (1994a). "Maintaining reliability of concrete structures I: role of inspection/repair." J. Struct. Engrg. 120(3):824-845, American Society of Civil Engineers, New York, New York.

5.72 Mori, Y. and Ellingwood, B. (1994b). "Maintaining reliability of concrete structures II: optimum inspection and repair." J. Struct. Engrg. 120(3):846-867, American Society of Civil Engineers, New York, New York.

5.73 Mori, Y. and Ellingwood, b.R. (1994). "Reliability assessment of degrading concrete shear walls." ORNL/NRC/LTR-94/6, Oak Ridge National Laboratory, Oak Ridge, Tennessee.

5.74 Banon, H., et al (1994a). "Assessing fitness for purpose of offshore platforms. I: Analytical methods and inspections." J. Struct. Engrg. ASCE 120(12):3595-3612.

5.75 Kung, C.J. and Wirsching, P.H. (1993). "Fatigue/fracture reliability and maintainability process for structural systems." in Computational Stochastic Mechanics (Cheng and Yang, eds.), Elsevier, London, pp. 369 - 393.

5.76 Yao, J.T.P. et al (1986). "Stochastic fatigue, fracture and damage analysis. " Struct. Safety 3(4):231 - 267. 
5.77 Torng, T.Y. and Wirsching, P.H. (1991). "Fatigue and fracture reliability and maintainability process." $J$. Struct. Engrg. ASCE 117(12):3804-3822, American Society of Civil Engineers, New York, New York.

5.78 Lutes, L.D., Corazao, J., Hu, S.J., and Zimmerman, J (1984). "Stochastic fatigue damage accumulation." J. Struct. Engrg. ASCE 110(11): 2585-2601, American Society of Civil Engineers, New York, New York.

5.79 Sarkani, S., Buresli, N. and Michaelov, G. (1994). "Fatigue damage accumulation under stochastic stress histories." Proc. Structures Congress XII. Vol. 1, American Society of Civil Engineers, New York, NY, pp. 833-838.

5.80 Wirsching, P. and Light, M. (1980). "Fatigue under wide band random stresses." J. Struct. Div. ASCE 106(7):1593-1607.

5.81 Casciati, F., and Colombi, P. (1993). "Load combination and fatigue reliability problems." Struct. Safety 13(1):93-112.

5.82 Holman, G.S. (1989). "Application of reliability techniques to prioritize BWR recirculation loop welds for inservice inspection." NUREG/CR-5486, Washington, DC.

5.83 Oswald, G.F. and Schueller, G.I. (1984). "Reliability of deteriorating structures." Engrg. Fract. Mech. 20(3):479488.

5.84 Ortiz, K. and Kiremidjian, A.S. (1986). "Time series analysis of fatigue crack growth rate data." Engrg. Fract. Mech., vol. 24, no. 5, pp. 657-675.

5.85 Rocha, M.M., Schueller, G.I. and Okamura, H. (1993). "The fitting of one- and two-dimensional fatigue crack growth laws." Engrg. Fract. Mech., vol 44, no 3, pp 473-480, 1993.

5.86 Ihara, C. and Misawa, T. (1991). "Stochastic models related to fatigue damage of materials". J. of Energy Resources Tech., 113(4), pp 215-21.

5.87 Lin, Y.K. and Yang, J.N. (1983). "On statistical moments of fatigue crack propagation", Engrg. Frac. Mech. Mechaqnics, vol. 18, no. 2, pp. 243-256, 1983.

5.88 Spencer, B.F. Jr. and Tang, J. (1988). "Markov process model for fatigue crack growth." J. of Engrg. Mech. ASCE 114,(12):2134-57.

5.89 Ditlevsen, O. (1986). "Random fatigue crack growth - a first passage problem." Engrg. Fract. Mech. $23(2467477$.

5.90 Dolinski, K. (1992). "Stochastic modeling and statistical verification of crack growth under constant amplitude loading." Engrg. Fract. Mech., 43(2) 195-216.

5.91 Nienstedt, J., Tsurui, A., Tanaka, H. and Schueller, G.I. (1990). "Time-variant structural reliability analysis using bivariate diffusive crack growth models." Int. J. Fatigue 12(2):83-89.

5.92 Ishikawa, H., et al (1993). "Reliability assessment of structures based on probabilistic fracture mechanics." Probabilistic Engrg. Mech. 8(1):43-56.

5.93 Zhu, W.Q., Lin, Y.K. and Lei, Y. (1992). "On fatigue crack growth under random loading." Engrg. Fract. Mech., 43(1), pp. 1-12.

5.94 Bogdanoff, J. and Kozin, F. (1985). Probabilistic models of damage accumulation. Wiley-Interscience, New York, NY.

5.95 Zhao, H. (1993). "An improved probabilistic model of fatigue crack growth." Engrg. Fract. Mech. 46(5): 773780 . 
5.96 Kennedy, R.P. and Ravindra, M.K. (1984). "Seismic fragilities for nuclear power plant studies." Nuc. Engrg. and Des. 79(1):47-68.

5.97 Ellingwood, B. (1994). "Validation of seismic probabilistic risk assessments of nuclear power plants." Report NUREG/GR-0008, Washington, DC, $130 \mathrm{pp}$.

5.98 ASCE (1986). "Uncertainty and Conservatism in the Seismic Analysis and Design of Nuclear Facilities." (1986). Prepared by the Working Group on Quantification of Uncertainties, American Society of Civil Engineers, New York, New York.

5.99 Ellingwood, B.R. and Song, R. (1996). "Impact of Structural Aging on Seismic Risk Assessment of Reinforced Concrete Structures in Nuclear Power Plants," NUREG/CR-6425, U.S. Nuclear Regulatory Commission, Washington, DC.

5.100 USNRC (1981). Standard Review Plan for the Review of Safety Analysis Reports for Nuclear Power Plants, NUREG-0800, U.S. Nuclear Regulatory Commission, Washington, DC.

5.101 ASME (1995). ASME Boiler and Pressure Vessel Code, American Society of Mechanical Engineers, New York, New York.

5.102 Jung, J. (1984). "Ultimate strength analysies of the Watts Bar, Maine Yankee, and Bellefonte containments." NUREG/CR-3725 (SAND84-0660), U.S. Nuclear Regulatory Commission, Washington, DC.

5.103 Sharma, S., Wang, Y.K. and Reich, M. (1985). "Ultimate pressure capacity of reinforced and prestressed concrete containments." NUREG/CR-4149, BNL-51857, U.S. Nuclear Regulatory Commission, Washington, DC.

5.104 Walther, H.P. (1992). "Evaluation of behavior and radial shear strength of a reinforced concrete containment structure." NUREG/CR-5674, Washington, DC.

5.105 Amin, M., Eberhardt, A.C. and Erler, B.A. (1992). "Design considerations for concrete containments under severe accident loads." Proc. 5th Workshop on Containment Integrity, NUREG/CP-0120, pp. 157- 162, U.S. Nuclear Regulatory Commission, Washington, DC.

5.106 Greimann, L., Fanous, F. and Bluhm, D. (1984). "Final report: containment analysis techniques, a state-of-theart summary." NUREG/CR-3653, U.S. Nuclear Regulatory Commission, Washington, DC.

5.107 Klamerus, E.W. et al. (1996). "Containment performance of prototypical reactor containment subjected to severe accident conditions.” NUREG/CR-6433, U.S. Nuclear Regulatory Commission, Washington, DC.

5.108 von Riesemann, W.A. and Parks, M.B. (1995). "Current state of knowledge on the behavior of steel liners in concrete containments subjected to overpresurization loads." Nuclear Engr. \& Des. 157:481-487.

5.109 Clauss, D.B., Horschel, D.S. and Blejwas, T.E. (1987). "Insights into the behavior of LWR steel containment buildings during severe accidents." Nuclear Engrg: and Des. 100:189-204.

5.110 USNRC (1990). "Severe Accident Risks: An asseeement for five U.S. nuclear power plants, Final Summary Report," NUREG-1150, U.S.Nuclear Regulatory Commission, Washington, DC.

5.111 Kulak, R.F., Hsieh, B.J., Ash, J.E., Kennedy, J.M., McLennan, G.A. and Pan, Y.C. (1985). "Structural response of large penetrations and closures for containment vessels subjected to loadings beyond design basis." NUREG/CR4064 (SAND84-7177), U.S. Nuclear Regulatory Commission, Washington, DC.

5.112 Horschel, D.S. (1992). "Experimental results from pressure testing a 1:6-scale nuclear power plant containment." NUREG/CR-5121, U.S. Nuclear Regulatory Commission, Washington, DC. 
5.113 Walser, A. (1984). "Capability of a prestressed concrete containment for internal pressure load." Nuclear Engr. \& Des. 82:25-35

5.114 Nam, H.T., et al (1993). "Probabilistic evaluation of ultimate internal pressure capacity of a prestressed concrete containment." Trans., 12th Int Conf. on Struct. Mech. in Reactor Tech., Vol. M, Elsevier, Amsterdam, the Netherlands, pp. 13 - 18.

5.115 Lambert, L.D. and Parks, M.B. (1994). "Experimental results from containment piping bellows subjected to severe accident conditions." NUREG/CR-6154, Vol. 1, U.S. Nuclear Regulatory Commission, Washington, DC.

5.116 Mangoine, M.J. (1982). "Creep-rupture behavior of weldments." Welding J. Research Supp. 61(2):50-57. American Welding Soc.

5.117 Hancock, J.W. and MacKenzie, A.C. (1976). "On the mechanisms of ductile failure in high-strength steels subjected to multi-axial stress states." J. Mech. Phsy. Solids 24: 147-169.

5.118 Orisamilu, I.R. (1998). "Stochastic finite element method for the probabilistic residual strength assessment of corroded structures." In Structural Satety and Reliability, Proc. ICOSSAR'97, Vol. 2, A.A. Balkema, Rotterdam, pp. 875 - 882.

5.119 Ellingwood, B.R., Bhattacharya B., and Zheng, R. (1996). Reliability-Based Condition Assessment of Steel Containment and Liners, NUREG/CR-5442, U.S. Nuclear Regulatory Commission, Washington, DC.

5.120 Tsai, C.-H. and Wu, W.-F. (1993). "Application of probabilistic fracture mechanics to risk assessment of pressure vessels." Trans., 12th Int'l Conf. on Struct. Mech. in Reactor Tech., Vol. M, Elsevier, Amsterdam, the Netherlands, pp. 135 - 140.

5.121 Cherry, J. (1997). "Analyses of containment structures with corrosion damage." Proc. 24th water Reactor Safety Information Meeting, NUREG/CP-0157, U.S. Nuclear Regulatory Commission, pp. 333-352.

5.122 Bruneau, M. and Zahrai, S.M. (1997). "Effect of severe corrosion on cyclic ductility of steel." J. Struct. Engrg. 123(11), pp. 1478-1486, American Society of Civil Engineers, New York, New York.

5.123 Miller, J.D. (1990)."Analysis of shell-rupture failure due to hypothetical elevated-temperature pressurization of the Sequoyah Unit I steel containment building." NUREG/CR-5405, U.S. Nuclear Regulatory Commission, Washington, DC.

5.124 Tan, C.P. and Bagchi, G. (1996). "BWR steel containment Corrosion.” NUREG 1540, U.S. Nuclear Regulatory Commission, Washington, DC.

5.125 Holt, J.M. (1963). "Short-time elevated temperature properties of USS Cor-ten, Man-ten, Tri-ten and A36 steel." U.S.Steel Applied Research Laboratory Project 57.19-A01, Pittsburgh, Pennsylvania.

5.126 Mizra, S.A. and MacGregor, J.G. (1979). "Variations in dimensions of Reinfoced Concrete Members, J. Struct. Div. 105(4), pp. 751-766, American Society of Civil Engineers, New York, New York.

5.127 Rubenstein, R.Y. (1981). Simulation and the Monte Carlo Method. John Wiley, New York.

5.128 Iman, R.L. and Conover, W.J. (1980). "Small sample sensitivity analysis techniques for computer models with an application to risk assessment." Communications in Statistics: Part A - Theory and Methods A9(17):17491842 .

5.129 USNRC (1990). "Severe Accident Risks: An Asseeement for Five U.S. Nuclear Power Plants, Final Summary Report," NUREG-1150, U.S.Nuclear Regulatory Commission, Washington, DC. 
5.130 Pilch, M.M., Allen, M.D. and Klamerus, E.W. (1995). "Resolution of the direct containment heating issue for all Westinghouse plants with large dry containments or subatmospheric containments." NUREG/CR-6338, U.S. Nuclear Regulatory Commission, Washington, DC.

5.131 Tang, H.T., Dameron, R.A. and Rashid, Y.R. (1995). "Probabilistic evaluation of concrete containment capacity for beyond design basis internal pressures." Nuclear Engr and Des. 157:455-467.

5.132 Naus, D.J., Oland, C., Ellingwood, B. and Norris, W. (1997). "Aging of the containment pressure boundary in light-water reactor plants." Proc. 24th water reactor safety information meeting, NUREG/CP-0157, U.S. Nuclear Regulatory Commission, pp. 309-332.

5.133 Bjerager, P. (1990). "On computation methods for structural reliability analysis." Struct. Safety 9(2):79-96.

5.134 Bucher, C. and Bourgund, U. (1990). "A fast and efficient response surface approach for structural reliability problems." Struct. Safety 7(1):57-66.

5.135 Rajashekhar, M.R. and Ellingwood, B.R. (1995). "Reliability of reinforced-concrete cylindrical shells." J. Struct. Engrg. 121(2):336-347, American Society of Civil Engineers, New York, New York.

5.136 Moses, F. (1990). "New directions and research needs in system reliability research." Struct. Safety 7(2):93-100.

5.137 Schueller, G.I. and Stix, R. (1987). "A critical appraisal of methods to determine failure probabilities." Struct. Safetv 4(4):293-310.

5.138 Melchers, R.G. (1990). "Search-based importance sampling." Struct. Safety 9(2):117-128.

5.139 Engelund, S. and Rackwitz, R. (1993). "A benchmark study on importance sampling techniques in structural reliability." Struct. Safety 12(4):255-276. 

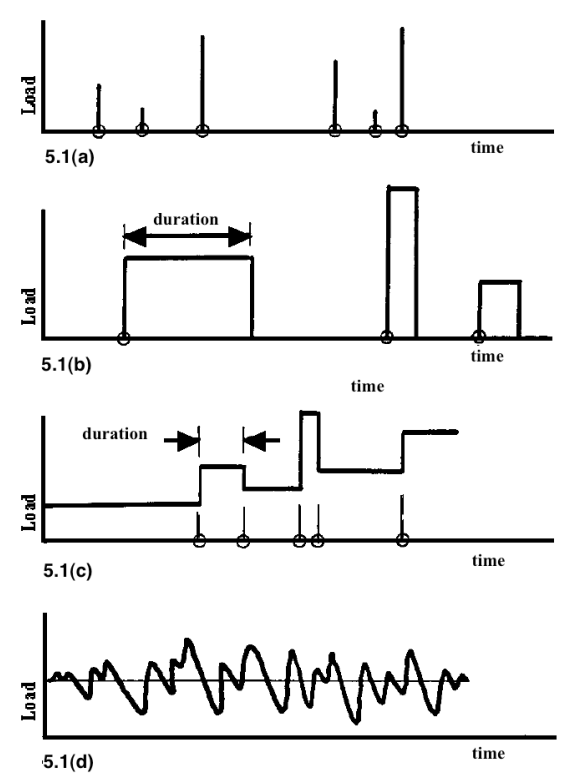

Figure 5.1 Structural load stochastic models.
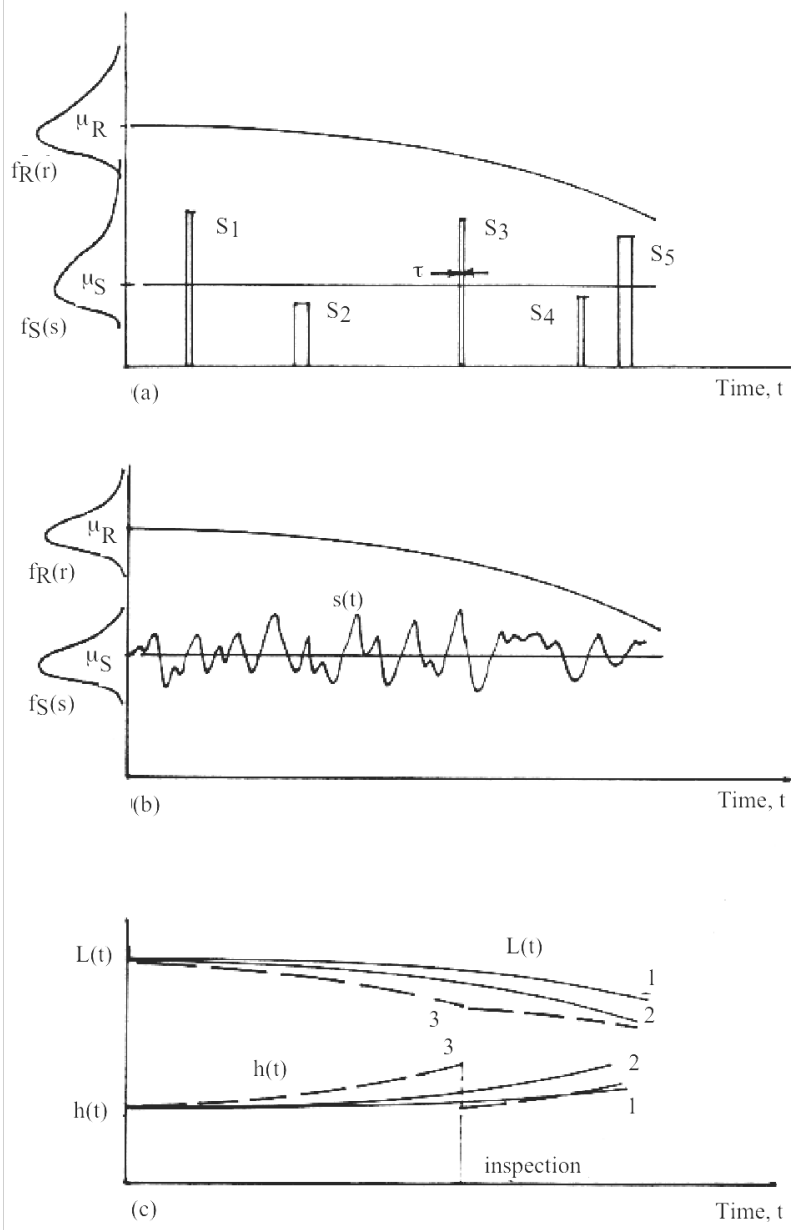

Figure 5.2 Sample functions representing structural loads and degrading resistance. 


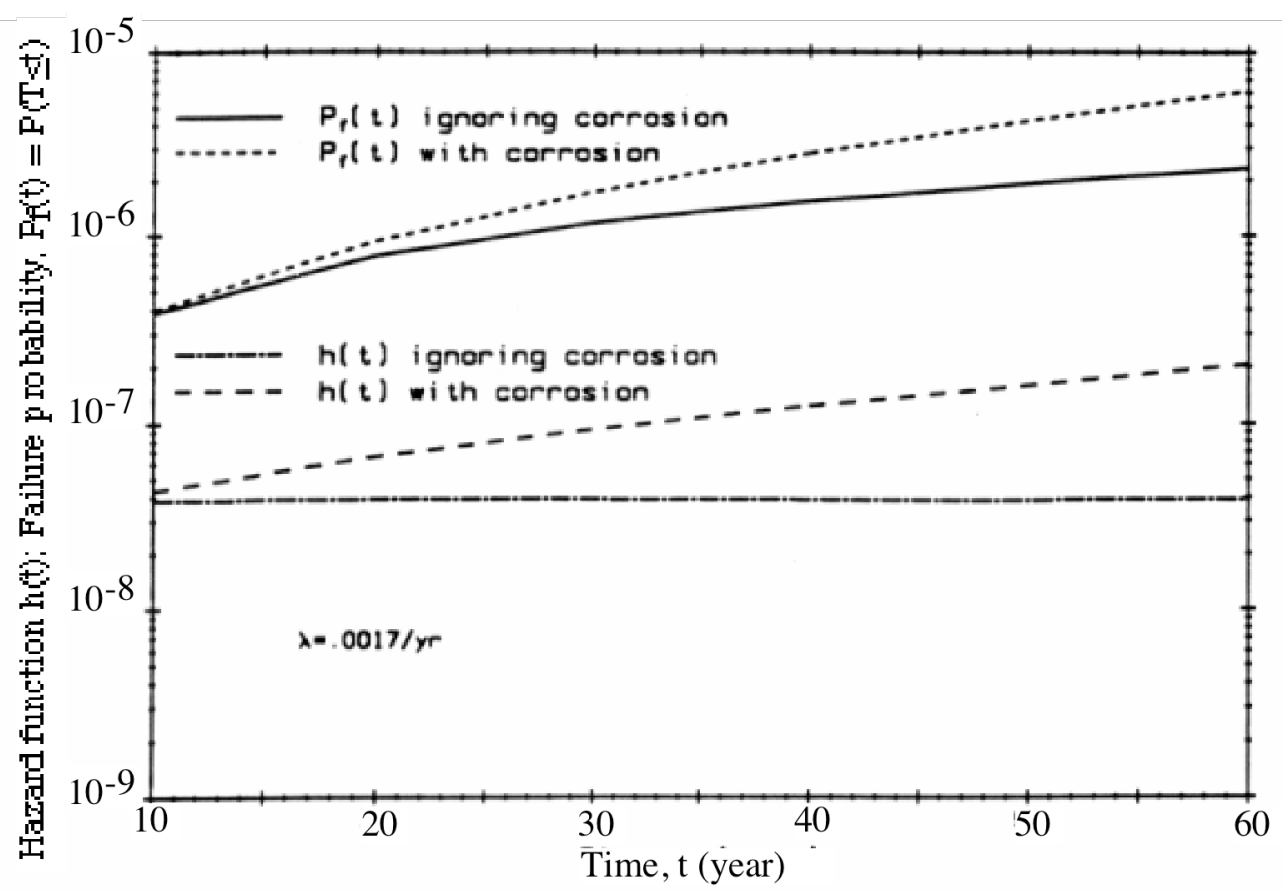

(a) Deterministic corrosion growth.

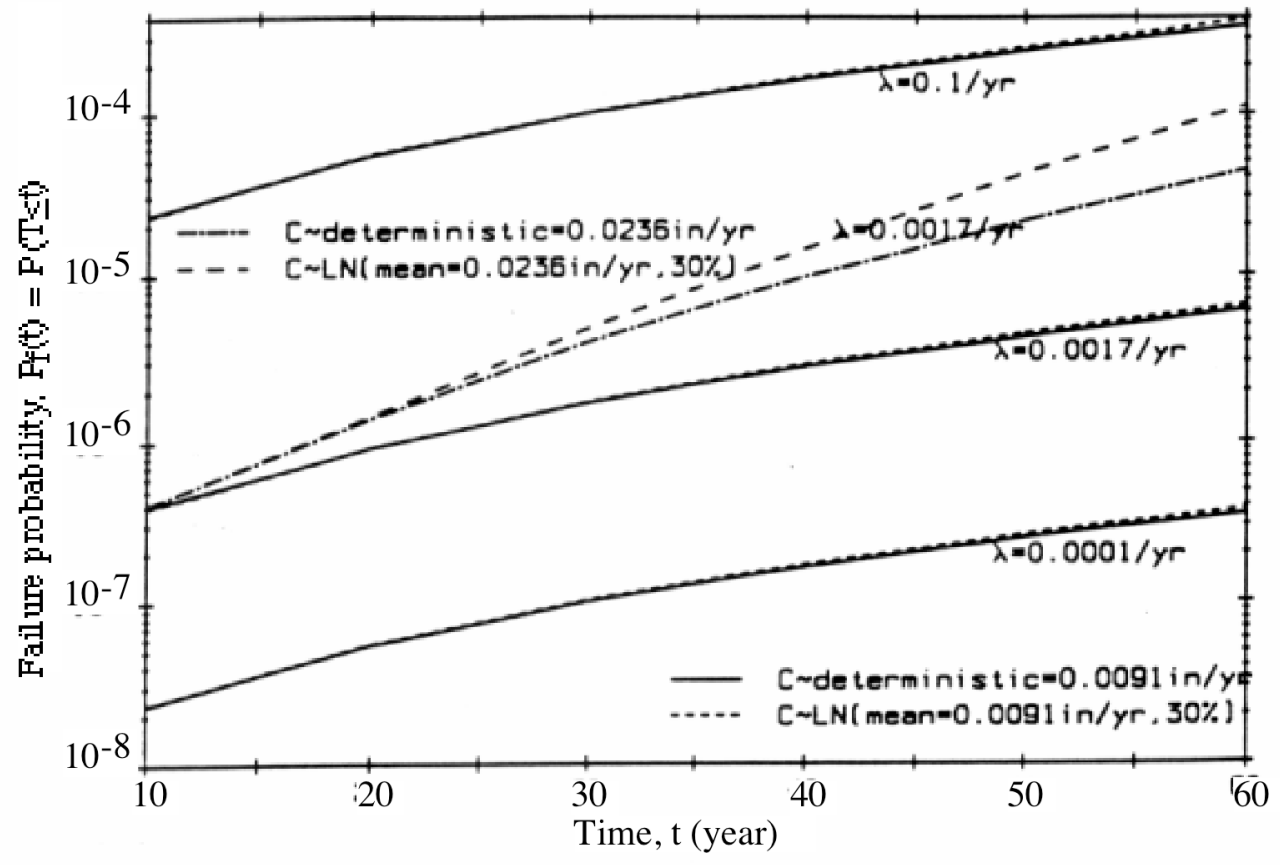

(b) Random corrosion growth.

Fig. 5.3 Time-dependent reliability in tension $\left(\mathrm{D}+\mathrm{P}_{\mathrm{a}}\right)$. 


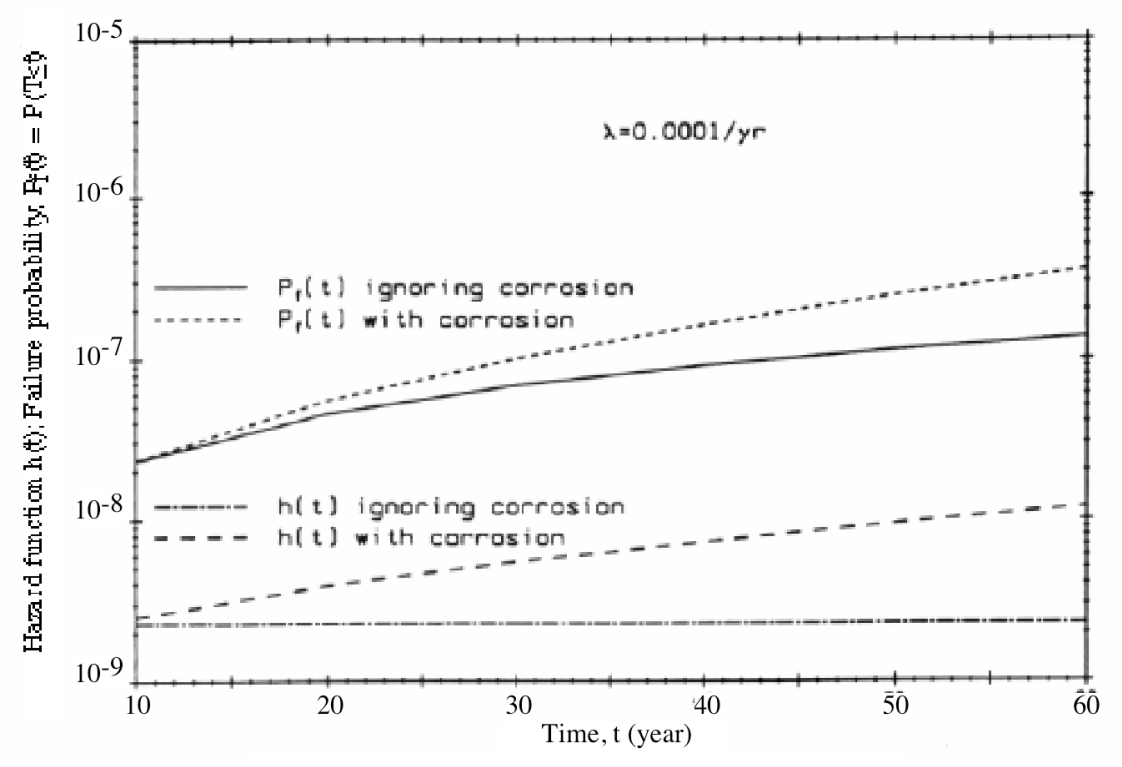

Fig. 5.4 Time-Dependent reliability in tension $(\mathrm{D}+\mathrm{Pa}) ; \lambda=0.001 / \mathrm{yr}$.

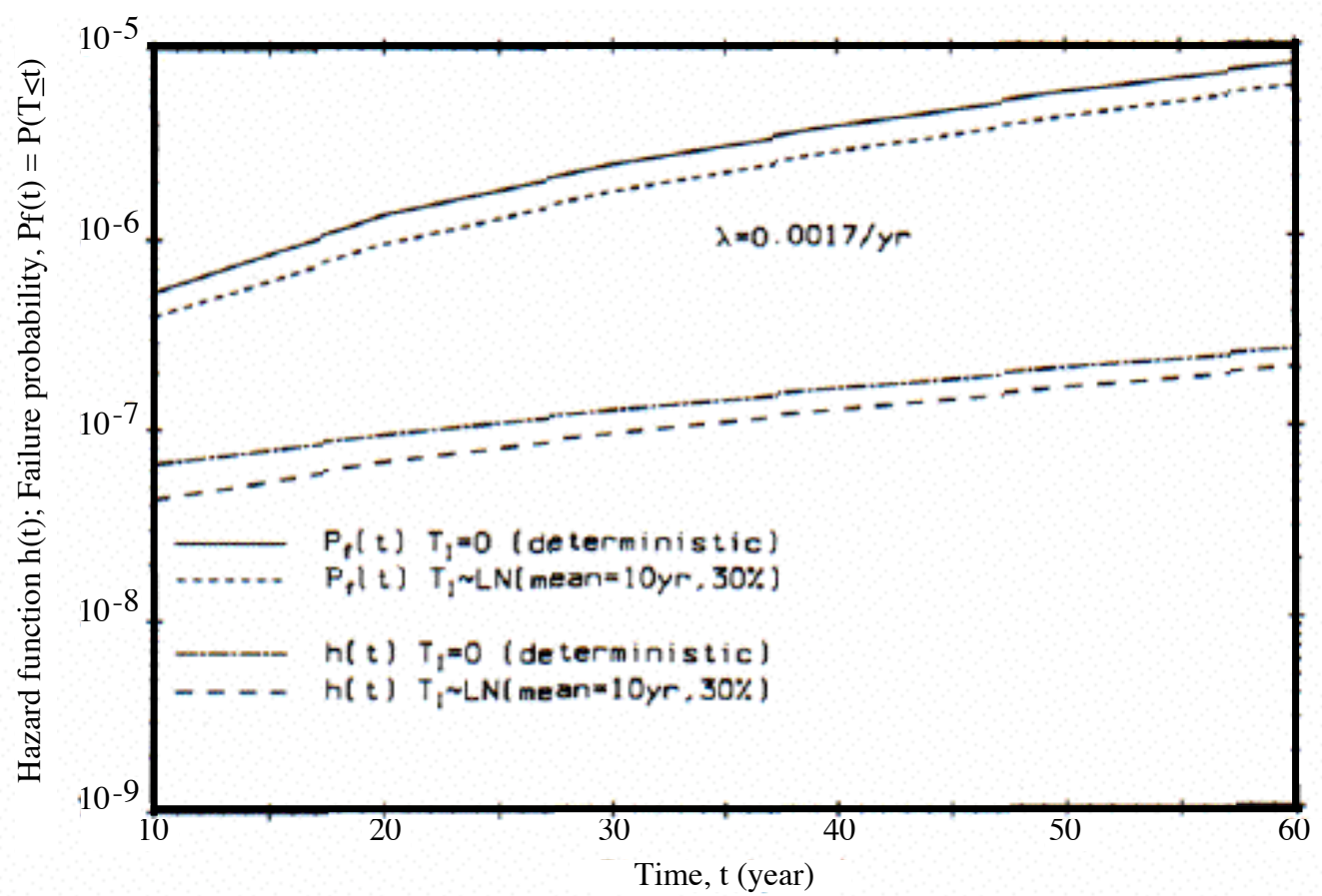

Fig. 5.5 Time-dependent reliability, with and without induction period for corrosion. 


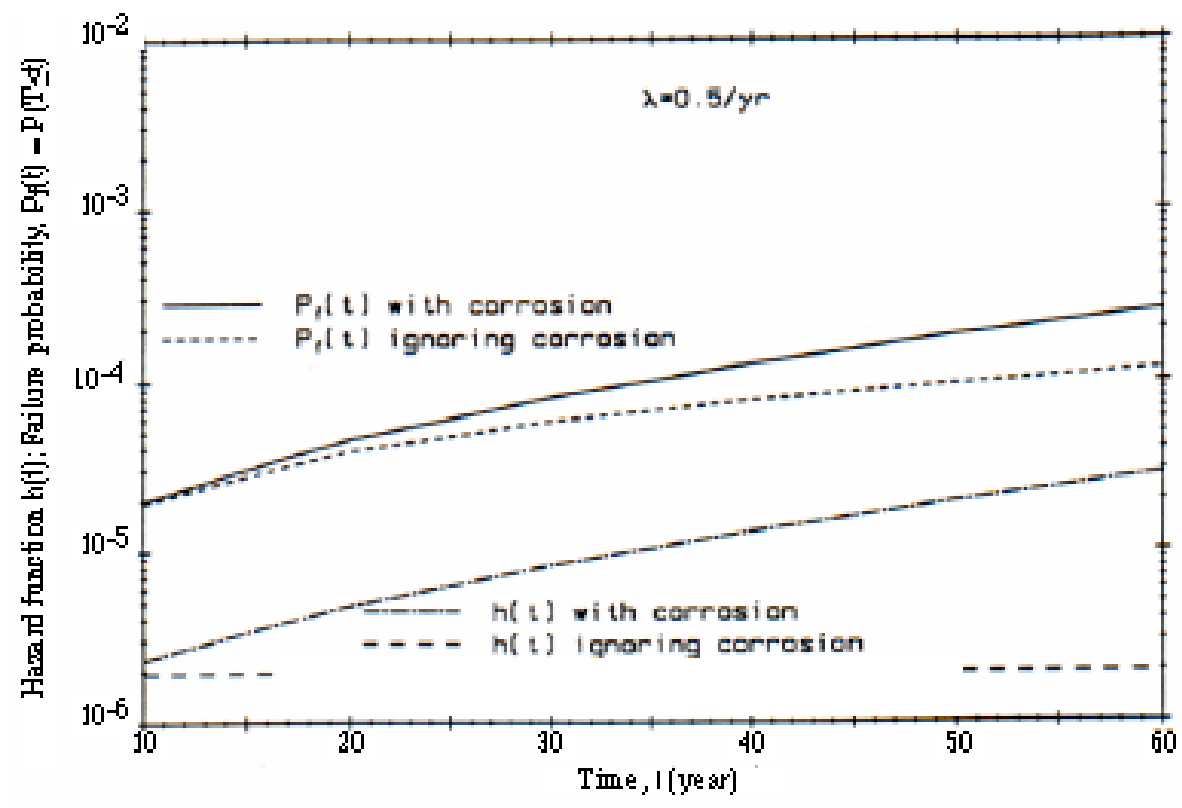

Fig. 5.6 Time-dependent reliability in flexure $(\mathrm{D}+\mathrm{L})$.

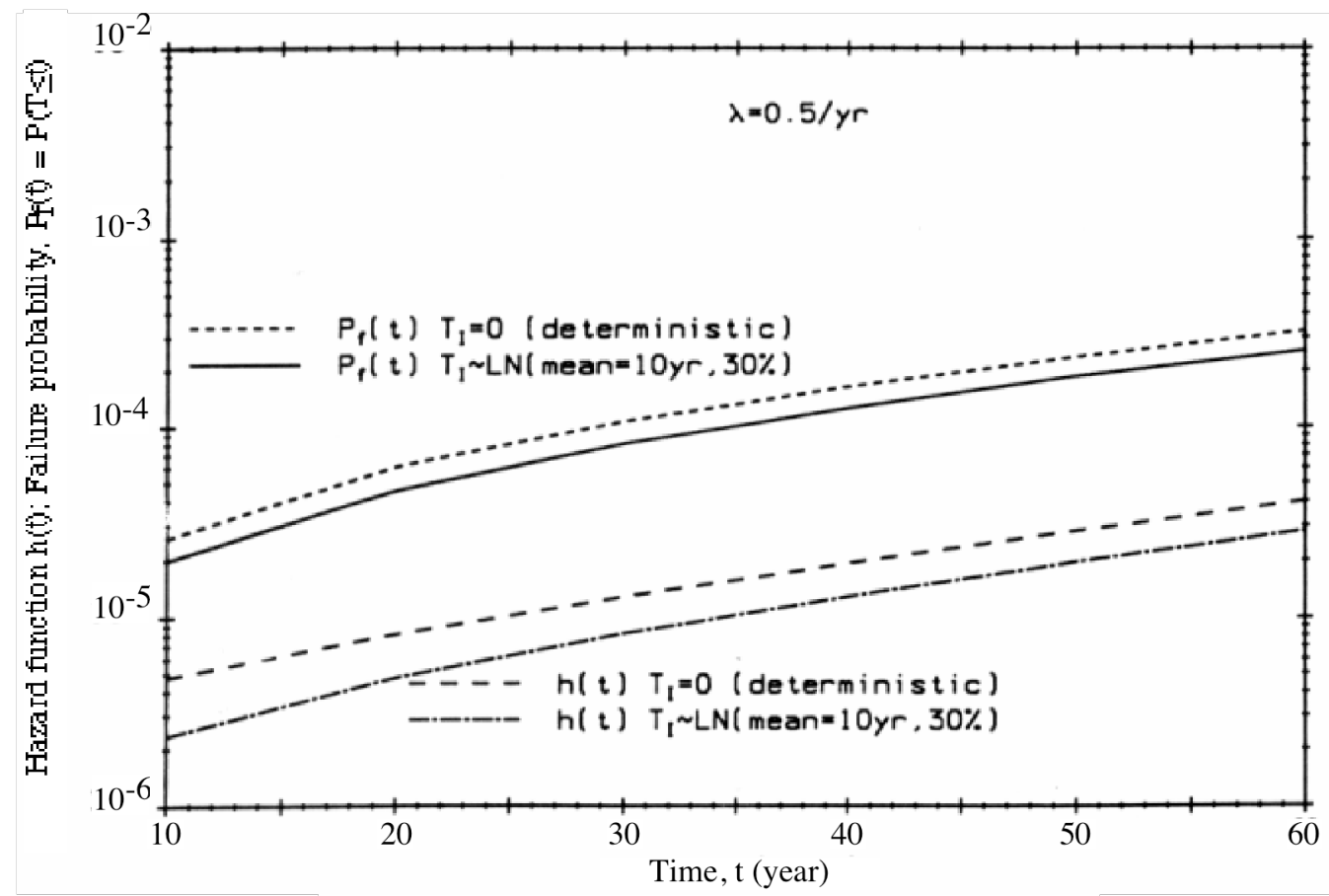

Fig. 5.7 Time-dependent reliability in flexure without induction period for corrosion. 


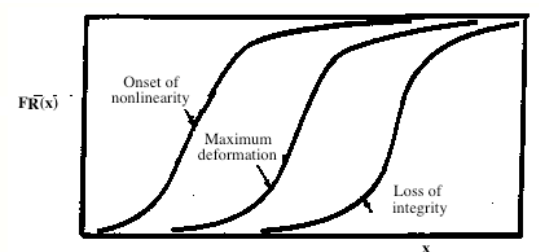

a. Good design and fabrication

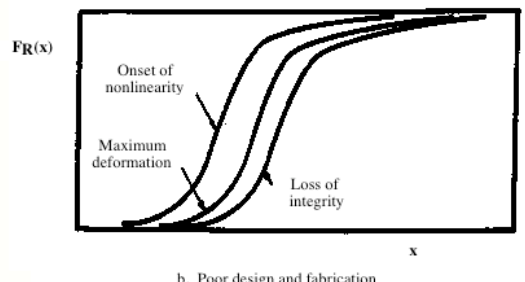

Fig. 5.8 Fragilities for progressive performance limits.
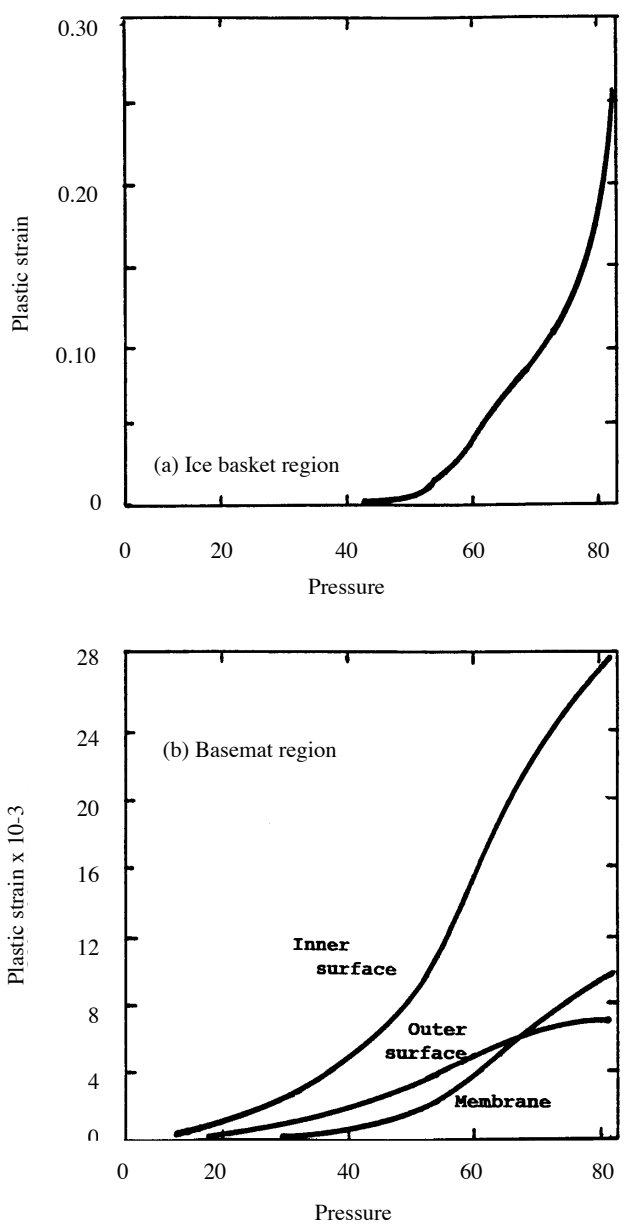

Fig. 5.9 Pressure versus strain in Table 5.7. 


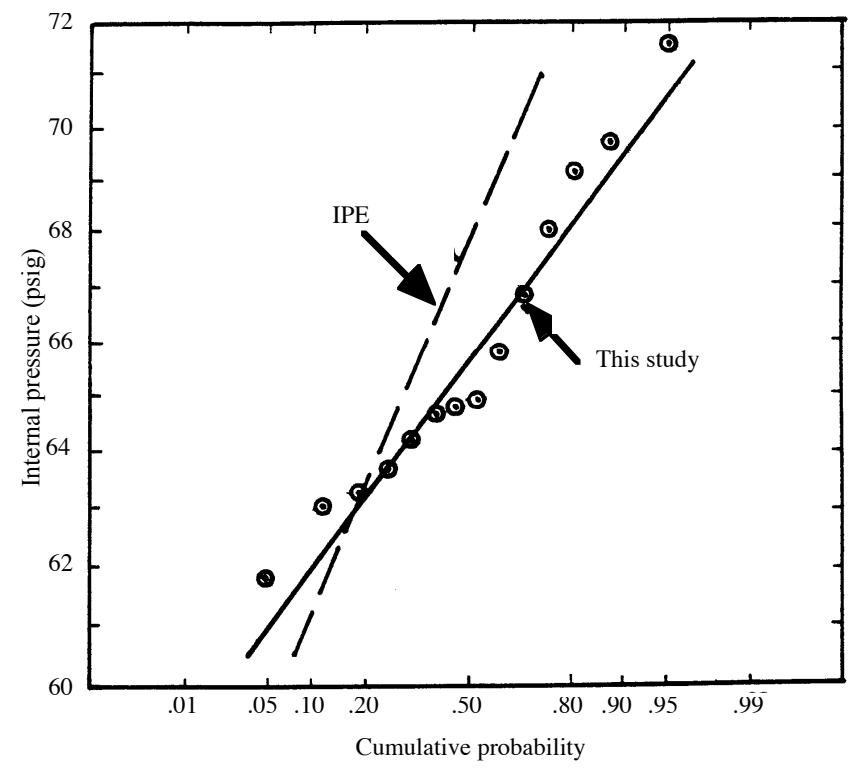

Fig. 5.10 Benchmark fragility of steel ice condenser containment.

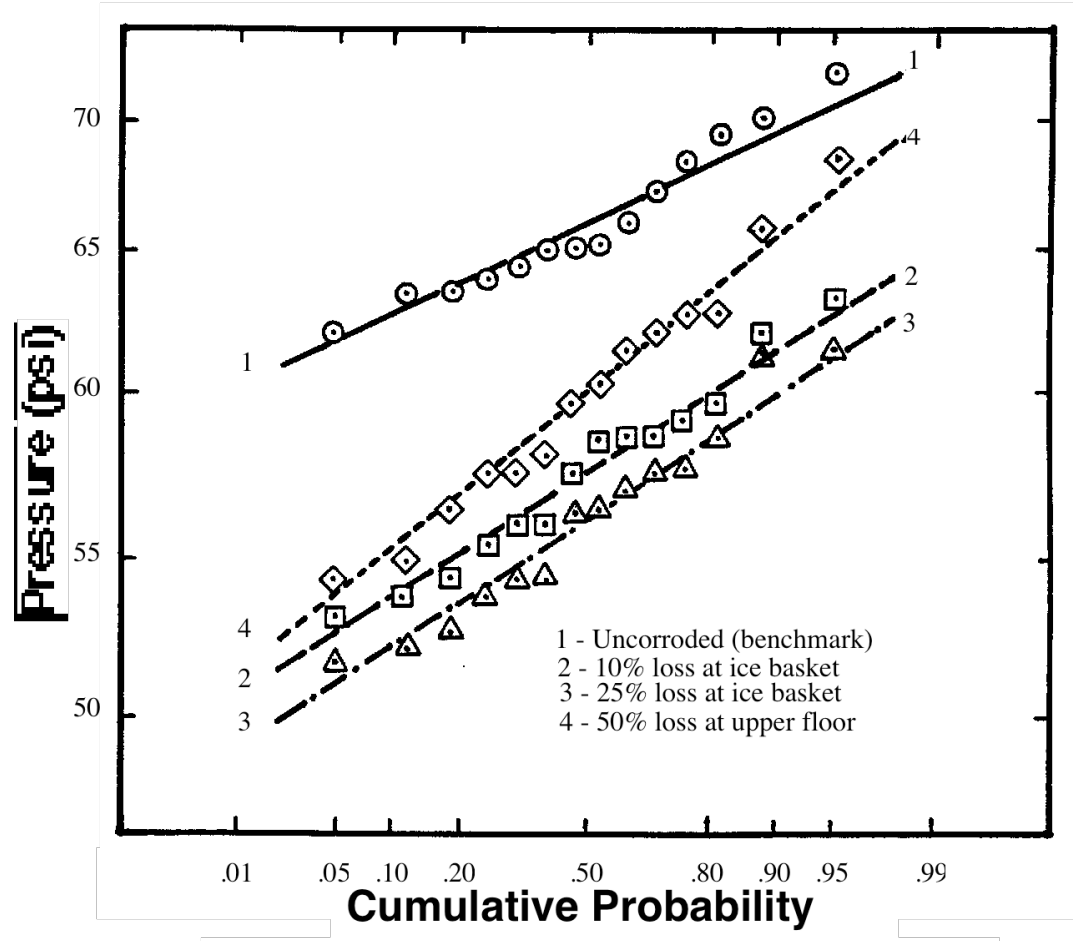

Fig. 5.11 Containment fragility for postulated corrosion patterns. 


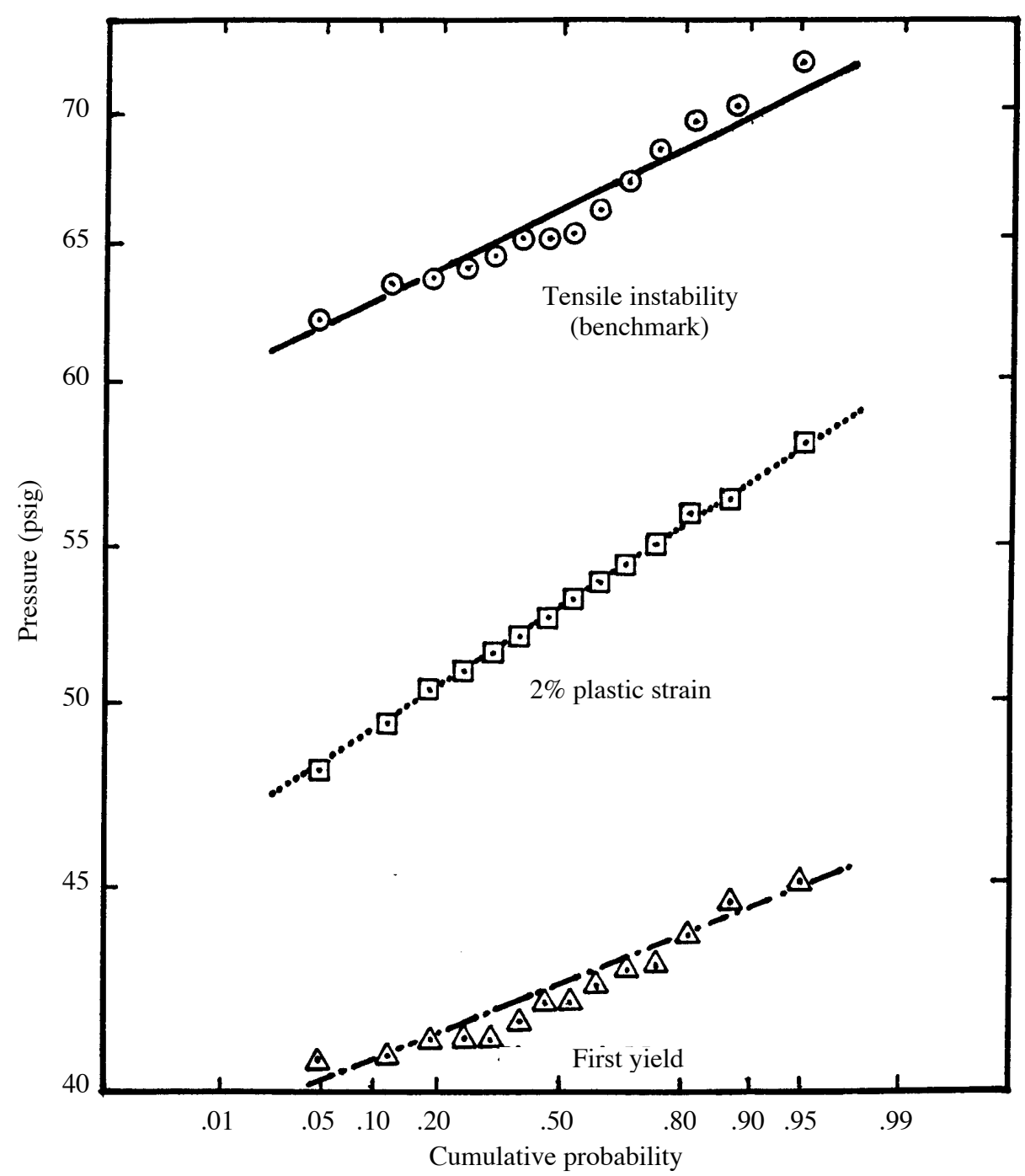

Fig. 5.12 Containment fragilities based on first yield and plastic strain of 0.02 . 
Table 5.1 Uniform corrosion parameters in Eqn. 5.1.

\begin{tabular}{|llllc|}
\hline \multicolumn{1}{|c}{ Environment } & \multicolumn{1}{c}{ Steel } & C & $\alpha$ & Reference \\
\hline Rural & Carbon & 34 & 0.65 & 4.19 \\
Urban & Carbon & 80 & 0.59 & 4.19 \\
Marine & Carbon & 71 & 0.79 & 4.19 \\
Rural & Weathering & 33 & 0.50 & 4.19 \\
Urban & Weathering & 51 & 0.57 & 4.19 \\
Marine & Weathering & 40 & 0.56 & 4.19 \\
Industrial & Carbon & 51 & 0.42 & 4.20 \\
Industrial & USS Cor-Ten & 25 & 0.17 & 4.20 \\
& & 70 & 0.40 & 4.20 \\
Ocean (1675 m) & A36 & 138 & 0.25 & 4.20 \\
Ocean (1675 m) & A36 & 229 & 0.69 & 4.20 \\
Ocean (Surface) & Carbon & 200 & 0.62 & 4.20 \\
Ocean (Surface) & Carbon & 144 & 0.79 & 4.13 \\
Ocean (Surface) & Carbon & & \\
\hline
\end{tabular}

Table 5.2 Pitting corrosion parameters in Eqn. 5.1.

\begin{tabular}{|c|c|c|c|c|}
\hline Environment & Steel & C & $\boldsymbol{\alpha}$ & Reference \\
\hline $40^{\circ} \mathrm{C}$ to $80^{\circ} \mathrm{C}$ & AISI 316 Stainless & 1000 & 1.0 & 5.13 \\
\hline $\mathrm{NaHCO}_{3}$ & Carbon & 7000 & 0.42 & 5.28 \\
\hline $\mathrm{NaHCO}_{3}+\mathrm{NaCl}$ & Carbon & 8350 & 0.46 & 5.25 \\
\hline
\end{tabular}

Table 5.3 Statistical properties of nuclear power plant loads.

\begin{tabular}{|l|c|c|c|c|c|}
\hline \multicolumn{1}{|c|}{ Load } & $\begin{array}{c}\text { Rate of } \\
\text { Occurrence, } \lambda \\
\left(\mathrm{yr}^{-1}\right)\end{array}$ & $\begin{array}{c}\text { Duration, } \\
\tau\end{array}$ & Mean & COV & PDF \\
\hline Dead, D & - & - & $1.0 \mathrm{D}_{\mathrm{n}}$ & 0.7 & Normal \\
Live, $\mathrm{L}$ & 0.5 & $0.25 \mathrm{yr}$ & $0.3 \mathrm{~L}_{\mathrm{n}}$ & 0.50 & Type I \\
Pipe, $\mathrm{R}_{0}$ & - & - & $0.85 \mathrm{R}_{0}$ & 0.30 & Normal \\
Temperature, $\mathrm{T}_{0}$ & - & - & $0.85 \mathrm{~T}_{0}$ & 0.16 & Normal \\
SRV Discharge & - & $1 \mathrm{sec}$ & $0.8 \mathrm{P}_{\mathrm{SRV}}$ & 0.14 & Normal \\
Accid. Press, $\mathrm{P}_{\mathrm{a}}$ & $1.7 \times 10^{-3}$ & $20 \mathrm{~min}$ & $0.8 \mathrm{P}_{\mathrm{a}}$ & 0.20 & Type I \\
Accid. Temp., $\mathrm{T}_{\mathrm{a}}$ & $10^{-4}$ & $20 \mathrm{~min}$ & $0.9 \mathrm{~T}_{\mathrm{a}}$ & 0.10 & Type I \\
Earthquake, $\mathrm{E}$ & 0.05 & $30 \mathrm{sec}$ & $0.08 \mathrm{E}_{\mathrm{ss}}$ & 0.90 & Type II \\
\hline
\end{tabular}

${ }^{+} D_{n}, L_{n}, Q_{n}, P_{a}$, and $T_{a}$ are nominal loads. $E_{s s}$ is safe-shutdown earthquake.

${ }^{\wedge}$ For the PDF of annual maximum values, $\mathrm{F}_{\mathrm{E}_{\text {ann }}}$ 
Table 5.4 Initial resistance of steel shapes and plates.

\begin{tabular}{|c|c|c|c|c|c|}
\hline Element & Steel & Property & $\begin{array}{c}\text { Nominal } \\
(\mathrm{ksi})\end{array}$ & $\begin{array}{l}\text { Mean } \\
(\mathrm{ksi})^{*}\end{array}$ & $\mathrm{COV}$ \\
\hline Flanges, rolled shapes & Carbon & $\mathrm{F}_{\mathrm{y}}$ & - & $1.05 \mathrm{~F}_{\mathrm{yn}}$ & 0.10 \\
\hline Webs, rolled shapes & " & $\mathrm{F}_{\mathrm{y}}$ & - & $1.10 \mathrm{~F}_{\mathrm{yn}}$ & 0.11 \\
\hline Plates, flanges & $"$ & $\mathrm{~F}_{\mathrm{U}}$ & - & $1.10 \mathrm{~F}_{\text {un }}$ & 0.11 \\
\hline Plates & " & $\tau_{\mathrm{y}}$ & - & $0.64 \mathrm{~F}_{\mathrm{yn}}$ & 0.10 \\
\hline Tension coupon & $"$ & E & - & $1.0 \mathrm{E}$ & 0.06 \\
\hline Tension coupon & " & $v$ & - & 0.3 & 0.03 \\
\hline \multirow[t]{2}{*}{$7 / 16-13 / 8$ in. plate } & SA $516 /$ Gr 60 & $\mathrm{~F}_{\mathrm{y}}$ & 32 & 47 & 0.05 \\
\hline & $"$ & $\mathrm{~F}_{\mathrm{U}}$ & 60 & 66 & 0.03 \\
\hline \multirow[t]{2}{*}{$11 / 4-13 / 4$ in. plate } & SA $516 /$ Gr 60 & $\mathrm{~F}_{\mathrm{y}}$ & 36 & 48 & 0.07 \\
\hline & " & $\mathrm{F}_{\mathrm{U}}$ & 70 & 74 & 0.03 \\
\hline \multirow[t]{2}{*}{$1 / 4$ in. liner plate } & A 285 & $\mathrm{~F}_{\mathrm{y}}$ & 24 & 37 & 0.04 \\
\hline & " & $\mathrm{F}_{\mathrm{U}}$ & 45 & 48 & 0.02 \\
\hline
\end{tabular}

*1 ksi = 6.89 MPa.

Table 5.5 Statistical data for reinforced concrete.

\begin{tabular}{|c|c|c|c|}
\hline Parameter & Mean & COV & PDF \\
\hline Material Strength & & & \\
$\mathrm{f}_{\mathrm{c}}$ (4000 psi concrete) & 3400 & 0.18 & Normal \\
$\mathrm{f}_{\mathrm{t}},(4000$ psi concrete) & 339 & 0.20 & Normal \\
$\mathrm{f}_{\mathrm{c}}$ (5000 psi concrete) & 4000 & 0.15 & Normal \\
$\mathrm{f}_{\mathrm{t}},(5000$ psi concrete) & 366 & 0.20 & Normal \\
$\mathrm{f}_{\mathrm{y}}$ (ASTM A 615/Gr. 60) & $67 \mathrm{ksi}$ & 0.11 & Lognormal \\
$\mathrm{f}_{\mathrm{t}}$ (ASTM A 615/Gr. 60) & $104 \mathrm{ksi}$ & 0.11 & Lognormal \\
$\mathrm{f}_{\mathrm{u}}$ (ASTM A 416/A 421) & $270 \mathrm{ksi}$ & 0.04 & Lognormal \\
$\mathrm{f}_{\mathrm{t}}$ (Grade 270 strand) & $281 \mathrm{ksi}$ & 0.03 & Lognormal \\
Dimensions & & & \\
Overall dimensions (in.) & Nominal, $\mathrm{h}$ & $0.4 / \mathrm{h}$ & Normal \\
Placement of Reinforcement (in). & Nominal, d & $0.6 / \mathrm{d}$ & Normal \\
\hline
\end{tabular}


Table 5.6 Measures of Uncertainty for Fragility Assessment

\begin{tabular}{|c|c|c|c|c|}
\hline Property & Median (ksi) & $\beta_{\mathrm{R}}$ & $\beta U$ & $\mathrm{CDF}$ \\
\hline Yield strength, $\mathrm{F}_{\mathrm{y}}$ & 44 & 0.06 & - & Log Normal \\
\hline Ultimate strength, $\mathrm{F}_{\mathrm{u}}$ & 65 & 0.05 & - & Log Normal \\
\hline Failure strain, $\varepsilon_{\mathrm{f}}$ & 0.28 & 0.14 & - & Normal \\
\hline Modulus of elasticity, $\mathrm{E}$ & 29,000 & 0.06 & - & Normal \\
\hline Poisson's ratio, $v$ & 0.3 & - & - & Not Applicable \\
\hline \multirow[t]{4}{*}{ Corrosion penetration, $\mathrm{C}$} & $0.10 \mathrm{~T}$ & 0.60 & - & Uniform \\
\hline & $0.25 \mathrm{~T}$ & 0.50 & - & Uniform \\
\hline & $0.40 \mathrm{~T}$ & 0.30 & - & Uniform \\
\hline & $0.50 \mathrm{~T}$ & 0.25 & - & Uniform \\
\hline $\mathrm{f}_{1} / \mathrm{m}_{\mathrm{fl}}$ & 1.00 & - & - & Not Applicable \\
\hline \multicolumn{5}{|l|}{$\mathrm{f}_{2} / \mathrm{m}_{\mathrm{f} 2}$ (modeling) } \\
\hline Membrane & 0.50 & - & 0.10 & Normal \\
\hline Bending & 0.75 & - & 0.10 & Normal \\
\hline \multicolumn{5}{|l|}{$\mathrm{f}_{4} / \mathrm{m}_{\mathrm{f} 4}$} \\
\hline Undamaged & 1.00 & - & - & Not Applicable \\
\hline Corroded & 0.50 & - & - & Not Applicable \\
\hline
\end{tabular}

Table 5.7 Latin Hypercube samples (LHS) used in fragility analysis.

\begin{tabular}{ccccccc}
\hline LHS & $\begin{array}{c}\mathrm{E} \\
(1)\end{array}$ & $\begin{array}{c}\mathrm{F}_{\mathrm{y}} \\
(2)\end{array}$ & $\begin{array}{c}\mathrm{F}_{\mathrm{u}} \\
(3)\end{array}$ & $\begin{array}{c}\varepsilon_{\mathrm{f}} \\
(4)\end{array}$ & $\begin{array}{c}\mathrm{C} / \mathrm{T}^{1} \\
(5)\end{array}$ & $\begin{array}{c}\text { Model } \\
(6)\end{array}$ \\
\hline 1 & 28,843 & 46.5 & 71.1 & 0.21 & 0.32 & 0.97 \\
2 & 31,158 & 45.2 & 65.9 & 0.32 & 0.21 & 0.99 \\
3 & 29,470 & 40.8 & 67.3 & 0.28 & 0.38 & 0.88 \\
4 & 329132 & 45.8 & 61.1 & 0.27 & 0.35 & 1.09 \\
5 & 28,200 & 42.8 & 68.1 & 0.25 & 0.26 & 0.93 \\
6 & 30,601 & 47.4 & 62.8 & 0.35 & 0.06 & 0.95 \\
7 & 27,817 & 49.0 & 66.5 & 0.33 & 0.29 & 1.03 \\
8 & 27,399 & 39.5 & 64.7 & 0.28 & 0.12 & 0.91 \\
9 & 28,530 & 44.2 & 64.1 & 0.26 & 0.15 & 1.18 \\
10 & 29,800 & 43.3 & 59.4 & 0.30 & 0.09 & 1.05 \\
11 & 29,157 & 42.2 & 62.1 & 0.31 & 0.18 & 0.82 \\
12 & 25,869 & 44.7 & 69.2 & 0.29 & 0.24 & 0.99 \\
13 & 26,842 & 41.6 & 65.3 & 0.24 & 0.41 & 1.07 \\
14 & 30,183 & 43.8 & 63.5 & 0.23 & 0.44 & 1.12 \\
\hline
\end{tabular}

${ }^{\mathrm{l}}$ For corrosion penetration $25 \%$ of shell thickness (see Table 5.6) 
Table 5.8 Summary of IPE Fragilities for Undegraded Containments

5.8(a) PWR Steel Containments

\begin{tabular}{llcrrrrr}
\hline Plant & Type & $\mathrm{P}_{\mathrm{a}}(\mathrm{psi})$ & 0.05 & $\begin{array}{l}0.50 \\
(\mathrm{psi})\end{array}$ & $\begin{array}{c}0.95 \\
(\mathrm{psi})\end{array}$ & $\begin{array}{c}\beta_{\mathrm{c}} \\
(\mathrm{psi})\end{array}$ & $\begin{array}{c}\mathrm{T}^{1} \\
\end{array}$ \\
& & & & & & & \\
\hline Catawba & Ice & 30 & 67 & 85 & 100 & 0.12 & $\mathrm{~N}$ \\
Davis Bessie & Dry & 40 & 64 & 84 & 108 & 0.16 & $\mathrm{Y}$ \\
Kewaunee & Dry & 46 & 123 & 150 & 177 & 0.11 & $\mathrm{~N}$ \\
Prairie Island & Dry & 41 & 123 & 151 & 178 & 0.11 & $\mathrm{~N}$ \\
Sequoyah $^{2}$ & Ice & 11 & 59 & 68 & 77 & 0.08 & $\mathrm{Y}$ \\
St. Lucie & Dry & 44 & 81 & 95 & 118 & 0.11 & $\mathrm{~N}$ \\
Waterford & Dry & 44 & 105 & 135 & 173 & 0.15 & $\mathrm{~N}$ \\
Watts Bar & Ice & 15 & 65 & 90 & 113 & 0.17 & $\mathrm{Y}$ \\
\end{tabular}

5.8(b) Other Containments

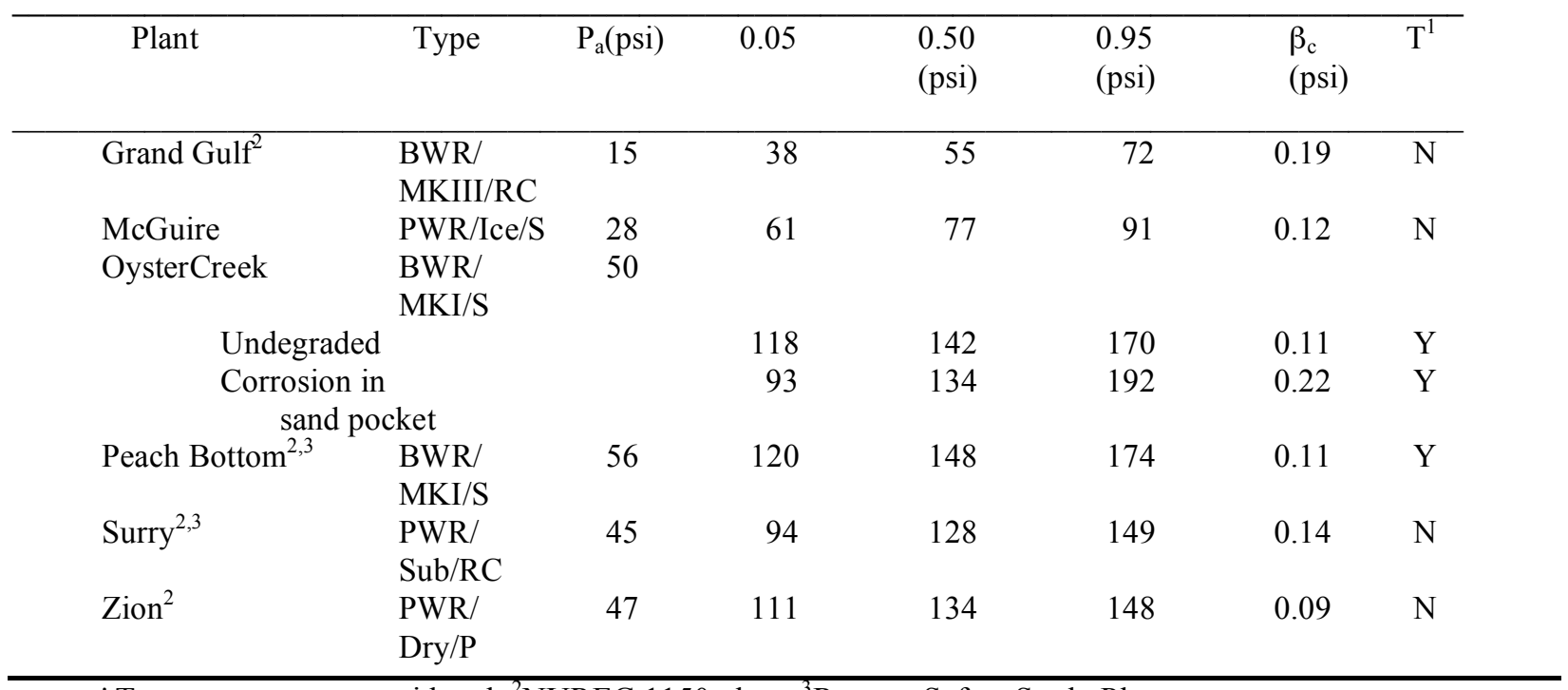

' Temperature was considered; ${ }^{2}$ NUREG 1150 plant; ${ }^{3}$ Reactor Safety Study Plant

Table 5.9 Fragilities for corroded steel ice-condenser containment

\begin{tabular}{|c|c|c|c|c|c|}
\hline \multirow[b]{2}{*}{ Damage state } & \multirow[b]{2}{*}{ Thicknes } & \multirow[b]{2}{*}{$\begin{array}{l}0.05 \\
\text { (psi) }\end{array}$} & \multicolumn{3}{|c|}{ Fragility fractiles } \\
\hline & & & $\begin{array}{l}0.50 \\
\text { (psi) }\end{array}$ & $\begin{array}{l}0.95 \\
\text { (psi) }\end{array}$ & $\beta_{\mathrm{c}}$ \\
\hline Uncorroded (benchmark) & $16 \mathrm{~mm}$ & 427 & 455 & 490 & 0.04 \\
\hline $10 \%$ loss at ice basket & $16 \mathrm{~mm}$ & 389 & 393 & 434 & 0.06 \\
\hline $25 \%$ loss at ice basket & $16 \mathrm{~mm}$ & 352 & 386 & 421 & 0.06 \\
\hline $50 \%$ loss at upper floor & $19 \mathrm{~mm}$ & 372 & 414 & 462 & 0.07 \\
\hline $\begin{array}{l}50 \% \text { loss at basemat }{ }^{1} \\
0.29\end{array}$ & $30 \mathrm{~mm}$ & - & 400 & - & \\
\hline
\end{tabular}

'Union of two failure modes - failure in basemat and/or uncorroded ice basket region 


\section{TECHNICAL INTEGRATION OF RESULTS}

Throughout the conduct of this program a major activity has been the transfer of data and information to the technical community through publications and participation in technical committees. In addition, there have been a number of technical briefings to domestic and foreign research organizations as well as presentations at national and international conferences and workshops.

\subsection{DOCUMENTATIN AND TECHNLOGY TRANSFER}

Under this program, 38 papers have been published in conference proceedings; 7 NUREG reports were published; 8 letter reports were published; 15 foreign trip reports were prepared; 19 journal articles were published; 1 Doctoral thesis was prepared; 7 books/reports were edited; 10 articles or chapters were published in books with 1 additional chapter in publication; 2 teaching modules were prepared for the IAEA workshop on safety aspects of aging in nuclear power plants; 33 presentations were made at national or international technical meetings; and 34 program briefings were made to USNRC personnel and national or international research organizations. Appendix A provides a listing of program reports, papers, and publications; and Appendix B contains a listing of program-related presentations.

This program has been carried out in cooperation and coordination with other research contracts sponsored by the Federal Government, private institutions, and industry. Oak Ridge National Laboratory-related programs have included the Structural Aging Program, Nuclear Plant Aging Research Program, Heavy-Section Steel Technology Program, Heavy-Section Steel Irradiation Program, and Nuclear Operations Analysis Center. Program personnel have also worked in cooperation with researchers at Sandia National Laboratories (Capacity of Degraded Containments) and Brookhaven National Laboratory (Assessment of Aged and Degraded Structures and Components). Close cooperation has also been maintained with industry-sponsored activities (e.g., Electric Power Research Institute, EPRI) as well as those sponsored by other government agencies (e.g., Joint Department of Energy-EPRI Program to Optimize Operations of Current U.S. Nuclear Power Plants). Technology exchange also has taken place at the international level with program personnel involved in activities of the International Atomic Energy Agency (IAEA), International Union of Laboratories and Experts in Construction Materials, Systems, and Structures (RILEM), Committee on the Safety of Nuclear Installations of NEA/OECD, and code-based technical committees.

Program personnel have participated in two IAEA-sponsored activities related to aging management of containment buildings. The objectives of the first activity, which addressed concrete containment buildings, were to produce a summary report on current aging-management practices and experience, compile a state-of-the-art report on concrete repair techniques and materials, develop crack mapping techniques and acceptance/repair guidelines, and formulate a set of condition indicators for monitoring aging. The report prepared to meet these objectives (6.1) provided: an overview of various concrete containment buildings, including descriptions, design standards, and regulatory requirements; information on potential degradation mechanisms and locations where these mechanisms are most likely to manifest; descriptions of various techniques that may be used to detect aging degradation in concrete structures, as well as advantages and disadvantages of each of the techniques; potential materials and techniques suitable for repair of specific types of degradation; operating experience related to performance, inspection, and repair of concrete containment buildings; key elements to be included in a systematic aging management program for concrete containment buildings; and conclusions and recommended follow-up activities. The second IAEA activity addressed aging management of metal components of boiling-water reactor (BWR) containment systems. Objectives of this investigation were to document current practices for the assessment and management of aging of the metal components employed in BWR nuclear power plant containments. The report prepared to meet these objectives (6.2) provides: a general description of BWR containments, including design basis and materials of construction; information on potential degradation mechanisms and environmental conditions; an overview of various techniques used to detect aging degradation and assess its significance; a review of methods for prevention or mitigation of aging effects; key elements of aging management and how they fit within a systematic aging management program; and conclusions.

Program personnel developed RILEM technical committee that addressed development of a methodology for life prediction of concrete structures in nuclear power plants. Primary objectives of this activity were to review existing guidelines and procedures used to monitor and evaluate concrete structures in nuclear power plants, as well as the history of performance of these structures, and to provide the basis for development of guidelines and recommendations, including assessment criteria and methods for service life prediction, for application to both new and existing concrete structures. In order to meet these objectives, the initial activity addressed preparation of a series of state-of-the-art papers related to current practices for aging management of concrete structures in nuclear power plants (6.3). Topics 
addressed in these papers included use of concrete and longevity considerations, methodologies for service life prediction, instrumentation systems, concrete and concrete materials-related databases, creep methodologies, repair materials and methods, probabilistic methods for assessment of current and future performance, and national and international aging management programs. Although the information contained in these papers is aimed at nuclear power plant concrete structures, it is equally applicable to general civil engineering structures as well as decommissioning-related activities. The second activity involved hosting The International Conference on Life Prediction and Aging Management of Concrete Structures that was held in Bratislava, Slovakia on July 6-8, 1999. Objectives of the conference were to update participants on current research, present novel ideas and strategies for implementation, provide an opportunity for exchanging practical experiences on execution of aging management policies, and initiate new approaches to aging management through technical presentations and publication of the conference proceedings. As a result, the conference was intended to advance the goal of safe, functional, and economical operation of civil infrastructure facilities by providing an international forum for highlighting recent advances in the technology underlying aging management and service life prediction of concrete structures. The conference was attended by approximately 80 delegates from 25 countries with 40 papers presented. Technical sessions were organized around five main topics. Session 1 addressed durability and service life of concrete structures. Session 2 covered assessment methods, instrumentation, maintenance, and repair activities. Session 3 presentations were related to aging management activities. Session 4 papers provided information on reliability, probability, and materials. Finally, Session 5 covered case histories and risk-informed decision making. Proceedings of the conference have been published (6.4). The third RILEM activity involved organizing and hosting The International Workshop on Life Prediction and Aging Management of Concrete Structures. The workshop was held in Cannes, France on October 16-17, 2000. Topics addressed were similar to the prior conference held in Bratislava. Approximately 35 delegates from 15 countries attended the two-day workshop in which over 20 papers were presented. Proceedings of the workshop are available (6.5). The fourth activity of this committee involved organizing and hosting The Second International Workshop on Life Prediction and Aging Management of Concrete Structures that was held in Paris, France on May 5-7, 2003. A third workshop of this type has been planned and will be held in Paris, France during the Spring of 2005. Under the final RILEM activity program personnel have developed a technical committee that will address the use of concrete in radioactive waste management facilities. The first meeting of this committee will be in October 2004.

The Committee on the Safety of Nuclear Installations (CSNI) of the OECD-NEA has established a task group to study aging of nuclear power plant concrete structures. The basic mandate of this task group is to review current international (and, where appropriate, national) activities in the area of aging (both structural and functional), and to formulate recommendations for a medium-to-long term program of work. A task group report has been prepared that addresses the mandated items [6.6]. Recommendations of this group have been implemented through a series of workshops addressing specific issues associated with aging: prestress losses in nuclear power plant containments, development priorities for non-destructive examination of concrete structures, response of degraded structures (including finite-element analysis techniques), instrumentation and monitoring of concrete structures, and repair and condition assessment of concrete structures. Program personnel have participated in several of the workshops. Recently a second task group report has been published that addresses aging of concrete structures used to construct nuclear power plant fuel cycle facilities [6.7]. As a follow-on to this report, a workshop was held in Madrid, Spain on March 15-16, 2004. Program personnel helped organize the workshop and presented the introductory paper.

ORNL personnel have also been actively involved in a number of American Concrete Institute and American Society of Mechanical Engineers technical committees. This has included Chairpersons of two committees (ACI 361, "Composite Concrete and Steel Pressure Vessels for General Industrial Use," and ACI 126, "Database Formats for Concrete Materials Properties") and Secretary of ACI 365, "Service Life Prediction." While serving on these committees, program personnel have been one of the primary authors of several technical reports that have been issued [ACI 361 R86, "Composite Concrete and Steel High-Pressure Vessels for General Industrial Use;" ACI 365.1 R-00 "State-of-the-Art Report on Service Life of Concrete;" ACI 126.1R-97, "Guide to a Recommended Format for the Identification of Concrete in a Materials Property Database;" and ACI 126.3-99, "Guide to Recommended Format for Concrete in a Materials Property Database"). Program personnel also participate in American Society of Mechanical Engineers Section XI technical committees (Working Group on Containment and Subgroup on Plant Life Extension).

\subsection{REFERENCES}

6.1 Assessment and Managing of Ageing of Major Nuclear Power Plant Components Important to Safety: Concrete Containment Buildings, IAEA-TECDOC-1025, International Atomic Energy Agency, Vienna, Austria (June 1998). 
6.2 Assessment and Management of Ageing of Major Nuclear Power Plant Components Important to Safety: Metal Components of BWR Containment Systems, IAEA-TECDOC-1181, International Atomic Energy Agency, Vienna, Austria (October 2000).

6.3 Naus, D. J. (Editor), State-Of-The-Art: Considerations for Use In Managing the Aging of Nuclear Power Plant Concrete Structures, Report No. 19, International Union of Testing and Research Laboratories for Materials and Structures (RILEM), Cachan Cedex, France (September 1999).

6.4 Javor, T. (Editor), Life Prediction and Aging Management of Concrete Structures, Proceedings of an International Conference, EXPERTCENTRUM, Bratislava, Slovakia (July 6-8, 1999).

6.5 Naus, D. J. (Editor), Proc. of International RILEM Workshop on Aging Management and Life Prediction of Concrete Structures, Cannes, France, PRO 16, RILEM Publications S.A.R.L., Cachan, France (2000).

6.6 Report of the Task Group Reviewing International Activities in the Area of Ageing of Nuclear Power Plant Concrete Structures, NEA/CSNI/R(95)19, Nuclear Energy Agency of the Organisation of Economic Cooperation and Development, Issy-les-Moulineaux, France (November 1995).

6.7 Report of Task Group Reviewing Activities in the Area of Ageing of Concrete Structures Used to Construct Nuclear Power Plant Fuel Cycle Facilities, NEA/CSNI/R(2002)14, Nuclear Energy Agency, Organization for Economic Cooperation and Development, Paris, France (July 2002). 


\section{APPENDIX A}

\section{REPORTS, PAPERS, AND PUBLICATIONS DEVELOPED UNDER THE INSPECTION OF AGED/DEGRADED CONTAINMENTS PROGRAM}

1 D. J. Naus, C. B. Oland, B. R. Ellingwood, H. L. Graves, III, and W. E. Norris, "Aging Management of Containment Structures in Nuclear Power Plants," Proceedings of The Third International Conference on Containment Design and Operation, held October 21-21, 1994 at Toronto Hilton Hotel, Toronto, Ontario, Canada (October 1994).

C. B. Oland, "Nuclear Power Plant Containment Metallic Pressure Boundary Materials and Plans for Collecting and Presenting Their Properties, ORNL/NRC/LTR-95/2, Oak Ridge National Laboratory, Oak Ridge, Tenn. (April 1995).

C. B. Oland and D. J. Naus, "Degradation Assessment Methodology for Application to Steel Containments and Liners of Reinforced Concrete Structures in Nuclear Power Plants," ORNL/NRC/LTR-95/29, Lockheed Martin Energy Research Corp., Oak Ridge National Laboratory, Oak Ridge, Tenn. (March 1996).

B. Bhattacharya and B. Ellingwood, "A Damage Mechanics-Based Approach to Structural Deterioration," Proceedings of the $11^{\text {th }}$ American Society of Civil Engineers (ASCE) Engineering Mechanics Conference, held 1922 May 1996 at Fort Lauderdale, Florida, pp. 170-173 (May 1996).

D. J. Naus, Report of Foreign Travel of D. J. Naus, Engineering Technology Division, May 31-June 5,1996, ORNL/FTR-5813, Lockheed Martin Energy Research Corp., Oak Ridge National Laboratory, Oak Ridge, Tenn. (June 14, 1996).

D. J. Naus, Report of Foreign Travel of D. J. Naus, Engineering Technology Division, July 8-14, 1996, ORNL/FTR-5867, Lockheed Martin Energy Research Corp., Oak Ridge National Laboratory, Oak Ridge, Tenn. (July 24, 1996).

B. Bhattacharya and B. Ellingwood, "A CDM-Based Approach to Stochastic Damage Growth," pp. $772-775$ in Proceedings of the $7^{\text {th }}$ American Society of Civil Engineers EMD/STD Joint Conference on Probabilistic Mechanics and Structural Reliability held 7-9 August 1996, Worcester Polytechnic Institute, Worcester, Mass. (August 1996).

D. J. Naus, C. B. Oland, B. R. Ellingwood, and W. E. Norris, "Aging of Containment Pressure Boundary in LightWater Reactor Plants," Proceedings of United States Nuclear Regulatory Commission Twenty-Fourth Water Reactor Safety Information Meeting held at Marriott Hotel, Bethesda, Maryland (October 21-23, 1996).

9 D. J. Naus, C. B. Oland, B. R. Ellingwood, and H. L. Graves, III, "Structural Aging Program - A Summary of Activities, Results, and Conclusions," Proceedings of United States Nuclear Regulatory Commission TwentyFourth Water Reactor Safety Information Meeting held at Marriott Hotel, Bethesda, Maryland (October 21-23, 1996).

10 D. J. Naus, C. B. Oland, B. R. Ellingwood, H. L. Graves, III, and W. E. Norris, "Aging Management of Containment Structures in Nuclear Power Plants," International Journal of Nuclear Engineering and Design, NEDA 166(3) 367 - 379, North-Holland, Amsterdam, The Netherlands (November 1996).

11 D. J. Naus, Report of Foreign Travel of D. J. Naus, Engineering Technology Division to Participate in IAEA Meeting in Prague, Czech Republic, November 11-15, 1996, ORNL/FTR-6016, Lockheed Martin Energy Research Corp., Oak Ridge National Laboratory, Oak Ridge, Tenn. (November 27, 1996).

12 B. R. Ellingwood, B. Bhattacharya and R-H Zheng, "Reliability-Based Condition Assessment of Steel Containments and Liners," NUREG/CR-5442, The Johns Hopkins University, Baltimore, Mary. (November 1996). 
13 D. J. Naus, C. B. Oland, and B. R. Ellingwood, “Aging Management of NPP Reinforced Concrete Structures," Proc. of Sixth Symposium on Current Issues Related to Nuclear Power Plant Structures, Equipment, and Piping held at North Carolina State University in Raleigh (December 4-6, 1996).

14 P. D. Krauss and D. J. Naus., "Repair Materials and Techniques for Reinforced Concrete Structures in Nuclear Power Plants," Proc. of Sixth Symposium on Current Issues Related to Nuclear Power Plant Structures, Equipment, and Piping held at North Carolina State University in Raleigh (December 4-6, 1996).

15 B. R. Ellingwood, "Reliability Framework for Managing Risk of Aging Structures, Proc. Structures Congress $X I V$, pp. 590-596, American Society of Civil Engineers, New York, New York (1996).

16 B. R. Ellingwood and Y. Mori, "Reliability-Based Service Life Assessment of Concrete Structures in Nuclear Power Plants: Optimum Inspection and Repair," International Journal of Nuclear Engineering and Design, NEDA 175, 247 - 258, North-Holland, Amsterdam, The Netherlands (1997).

17 B. Bhattacharya, “A Damage Mechanics Based Approach to Structural Deterioration and Reliability,” Doctoral Thesis, The Johns Hopkins University, Baltimore, Mary. (April 1997).

18 B. R. Ellingwood, "Optimum Strategies for Maintaining Reliability of Aging Concrete Structures," Proc. Structures Congress XV held 14-16 April 1997 in Portland, Oregon,, pp. 228-232, American Society of Civil Engineers, New York, New York (1997).

19 D. J. Naus, Report of Foreign Travel of D. J. Naus, Engineering Technology Division to Participate in RILEM Meeting in Rome, Italy, and IAEA Meeting in Vienna, Austria, May 19-30, 1997, ORNL/FTR-6099, Lockheed Martin Energy Research Corp., Oak Ridge National Laboratory, Oak Ridge, Tenn. (June 2, 1997).

20 H. L. Graves, L. C. Shao, T. Y. Chang, J. F. Costello, D. J. Naus and C. B. Oland, "Structural Issues and Research," Transactions of the 14th International Conference on Structural Mechanics in Reactor Technology, Session H, Paper H04/1, pp. 131-138, Lyon, France, A. A. Belkema Publisher (August 1997).

21 B. R. Ellingwood and B. Bhattacharya, "Reliability-Based Condition Assessment and Service Life Prediction of Steel Containments and Liners," Transactions of the 14th International Conference on Structural Mechanics in Reactor Technology, Session M, pp. 39-46, Lyon, France, A. A. Belkema Publisher (August 1997).

B. R. Ellingwood, “Time-Dependent Reliability Analysis and Condition Assessment of Structures,”NUREG/CP0157, Vol. 1, pp. 297-309 in Proceedings of the $24^{\text {th }}$ Water Reactor Safety Information Meeting, U.S. Nuclear Regulatory Commission, Washington, D.C. (1997).

23 J. Kandra, R. Iwasaki, H Kobayashi, and B. R. Ellingwood, "Probability-Based Seismic Safety Evaluation of Existing Buildings,” Engineering Structures 19(9), pp. 708-717, Elsevier Science Ltd., United Kingdom (1997).

B. Bhattacharya and B. Ellingwood, "A Damage Mechanics Based Approach to Structural Deterioration and Reliability, “ NUREG/CR-6546, The Johns Hopkins University, Baltimore, Mary. (February 1998).

C. B. Oland and D. J. Naus, "A Survey of Repair Practices for Nuclear Power Plants Containment Metallic Pressure Boundaries,” NUREG/CR-6615 (ORNL/TM-13601), Lockheed Martin Energy Research Corp., Oak Ridge National Laboratory, Oak Ridge, Tenn. (May 1998).

P. D. Krauss and D. J. Naus., "Repair Materials and Techniques for Reinforced Concrete Structures in Nuclear Power Plants," International Journal of Nuclear Engineering and Design, NED 181(1-3), 171 - 189, NorthHolland, Amsterdam, The Netherlands (May 1998).

27 B. R. Ellingwood, “Condition Assessment of Existing Structures in Nuclear Power Plants: Optimum Inspection and Repair,” Structural Engineer Worldwide 1998, Paper T132-4, Elsevier Science Ltd., United Kingdom (1998). 
B. R. Ellingwood, "Safety Assessment of Structures in Nuclear Facilities: Application of Probabilistic Methods," Progress in Structural Engineering and Materials 1(2), pp. 207-213 (1998).

D. J. Naus, C. B. Oland, B. R. Ellingwood, W. E. Norris, and H. L. Graves, III, "Factors Related to Aging Management of Nuclear Power Plant Containment Structures, Proc. of 6th International Conference on Nuclear Engineering May 10-15, 1998, ICONE-6135, Japanese Society of Mechanical Engineers, San Diego, California (May 1998).

30 D. J. Naus et al., "IAEA Coordinated Research Program on Aging Management of Concrete Containment Buildings, Proc. of 6th International Conference on Nuclear Engineering May 10-15, 1998, Paper No. ICONE6298, Japanese Society of Mechanical Engineers, San Diego, California (May 1998).

31 D. J. Naus et al., "Assessment and Management of Ageing of Major Nuclear Power Plant Components Important to Safety: Concrete Containment Buildings," IAEA-TECDOC-1025, International Atomic Energy Agency, Vienna, Austria (June 1998).

32 B. Bhattacharya and B. R. Ellingwood, "A CDM Analysis of Stochastic Damage Growth and Reliability, Probability Engineering Mechanics 14(1), pp. 45-54 (1998).

33 D. J. Naus, C. B. Oland, B. R. Ellingwood, and W. E. Norris, “Aging of Steel Containments and Liners in Nuclear Power Plants, PVP-Vol. 362, Technical Session on Integrity of Containment Structures Under Severe Accident Conditions, , ASME/JSME Pressure Vessel and Piping Conference, July 26 - 30, 1998, pp. 199-210, San Diego, CA (July 1998).

34 J. E. Bondaryk, "High Frequency Imaging of Thickness Degrdation in Steel Containment Vessels and Liners," PVP-Vol. 379, Technical Session on NDE Research and Development, ASME/JSME Pressure Vessel and Piping Conference, July 26 - 30, 1998, San Diego, CA (July 1998).

J. E. Bondaryk, C. N. Corrado, and V. Godino, "Feasibility of High Frequency Acoustic Imaging for Inspection of Containments,” NUREG/CR-6614, Engineering Technology Center, Mystic, Conn. (August 1998).

36 D. J. Naus, C. B. Oland, B. R. Ellingwood, W. E. Norris, and H. L. Graves, III, "Management of Aging of Nuclear Power Plant Containment Structures," Fourth International Conference on Engineering Structural Integrity Assessment, Churchill College, Risley, Warrington, Cheshire, United Kingdom(22-24 September 1998).

37 D. J. Naus, "Report of Foreign Travel of D. J. Naus, Engineering Technology Division, to the UK and France, September 21 - October 2, 1998” ORNL/FTR-6737, Lockheed Martin Energy Research Corp., Oak Ridge National Laboratory, Oak Ridge, Tenn. (October 14, 1998).

38 J. Rudzinsky, M. Conti, and J. Bondaryk, "Feasibility Study on the Use of Ultrasonic Technology on Embedded Corrosion Detection of Nuclear Containment Units, Phase II," in Proceedings of the $26^{\text {th }}$ Water Reactor Safety Information Meeting, U.S. Nuclear Regulatory Commission, Washington, D.C. (October 1998).

39 B. Bhattacharya and B. R. Ellingwood, "Stochastic Fatigue Crack Initiation Based on Continuum Damage Mechanics," Proceedings of ICOSSAR '97 - The $7^{\text {th }}$ International Conference on Structural Safety and Reliability, Kyoto, Japan, held on 24-28 November 1997, A. Balkema Publishers, Rotterdam, The Netherlands (November 1998).

40 Y. Mori and B. R. Ellingwood, "Reliability-Based Condition Assessment of Degrading Concrete Shear Walls," Proceedings of ICOSSAR '97 - The $7^{\text {th }}$ International Conference on Structural Safety and Reliability, Kyoto, Japan, held on 24-28 November 1997, Vol 1., pp. 129-136, A. Balkema Publishers, Rotterdam, The Netherlands (November 1998).

41 W. E. Norris, D. J. Naus, and H. L. Graves, III, "Inspection of Nuclear Power Plant Containment Structures," Proc. of Seventh Symposium on Current Issues Related to Nuclear Power Plant Structures, Equipment, and Piping held at North Carolina State University in Raleigh (December 2-4, 1998). 

Reliability Engineering and System Safety 62, pp. 171-183, Elsevier Science Ltd., Northern Ireland (1998).

43 B. Bhattacharya and B. R. Ellingwood, "Continuum Damage Mechanics Analysis of Fatigue Crack Initiation," International Journal of Fatigue 20 (9), pp. 631-639, Elsevier Science Ltd., United Kingdom (1998).

44 B. Bhattacharya and B. R. Ellingwood, "Continuum Damage Mechanics-Based Model of Stochastic Damage Growth,” Journal of Engineering Mechanics 124(9), pp. 1000-1009, American Society of Civil Engineers, New York, New York (1998).

45 B. R. Ellingwood, "Optimal Policies for Reliability Assurance of Aging Concrete Structures," in Optimal Performance of Civil Infrastructure Systems (D. Frangopol Editor), pp. 88-97, American Society of Civil Engineers, New York, New York (1998).

46 B. R. Ellingwood, "Damage Mechanics-Based Assessment of Time-dependent Structural Deterioration and Reliability," in Proceedings of the $26^{\text {th }}$ Water Reactor Safety Information Meeting, NUREG/CP-0166, Vol. 2, pp. 147-156, U.S. Nuclear Regulatory Commission, Washington, D.C. (1999).

47 B. Bhattacharya and B. R. Ellingwood, "CDM Analysis of Fatigue Crack Initiation Under Random Loading, " Stochastic Structural Dynamics (Ed. Spencer and Johnson), pp. 273-280, A. A. Balkema, Rotterdam, The Netherlands (1999).

48 H. Kwun, "Feasibility of Magnetostrictive Sensor Inspection of Containments," NUREG/CR-5724, Southwest Research Institute, San Antonio, Tex. (March 1999).

49 D. J. Naus, "Report of Foreign Travel of D. J. Naus, Engineering Technology Division, to visit Japanese Utilities and Research Organizations, April 15-23, 1999” ORNL/FTR-102249, Lockheed Martin Energy Research Corp., Oak Ridge National Laboratory, Oak Ridge, Tenn. (May 10, 1999).

50 J. Rudzinsky, J. Bondaryk, and M. Conti, "Feasibility of High Frequency Acoustic Imaging for Inspection of Containments: Phase II," ORNL/NRC/LTR-99/11, Subcontract report from Cambridge Accoustical Associates, Cambridge, Mass.) to Oak Ridge National Laboratory, Oak Ridge, Tenn, (July 1999).

51 D. J. Naus, C. B. Oland, and J. F. Costello, "An Investigation of Tendon Corrosion-Inhibitor Leakage Into Concrete," Proceedings of International Conference on Life Prediction and Aging Management of Concrete Structures, Bratislava, Slovakia (July 6-8, 1999).

52 D. J. Naus, "Report of Foreign Travel of D. J. Naus, Engineering Technology Division, to Participate in International Conferences, attend a RILEM Committee Meeting, and Visit IAEA, July 4-16, 1999," ORNL/FTR100607, Lockheed Martin Energy Research Corp., Oak Ridge National Laboratory, Oak Ridge, Tenn. (July 30, 1999).

53 D. J. Naus, B. R. Ellingwood, J. L. Cherry, N. C. Chokshi, and J. F. Costello, "Nuclear Power Plant Containment Pressure Boundary Aging Research," Transactions of the 15th International Conference on Structural Mechanics in Reactor Technology, Session D-07, Paper D07/1, Seoul, Korea, A. A. Belkema Publisher (August 1999).

54 B. R. Ellingwood, J. L. Cherry, and D. J. Naus, "Fragility Modeling of Steel Containments with Localized Corrosion," PVP Vol. 385 Computer Technology, ASME/JSME Pressure Vessel and Piping Conference held 26 August 1999 in Boston, Massachusetts, pp. 101-105 (August 1999).

55 B. R. Ellingwood and D. J. Naus, "Condition Assessment and Maintenance of Aging Structures in Critical Facilities - A Probabilistic Approach," ASCE Special Publication, Case Studies on Optimal Design and Maintenance Planning of Civil Infrastructure Systesm (D. M. Frangopol Ed., pp. 45-56, American Society of Civil Engineers, Reston, Virginia (1999). 
B. Bhattacharya and B. R. Ellingwood, "A New CDM-Based Approach to Structural Deterioration," International Journal of Solids and Structures 36, pp. 1757-1779, Pergamon Press, Elsevier Science Ltd., United Kingdom (1999).

57 B. R. Ellingwood and J. L. Cherry, "Fragility Modeling of Aging Containment Metallic Pressure Boundaries," NUREG/CR-6631, U. S. Nuclear Regulatory Commission, Washington, D.C. (1999).

W. E. Norris, D. J. Naus, and H. L. Graves, III, "Inspection of Nuclear Power Plant Containment Structures," International Journal of Nuclear Engineering and Design, NEDA 192(2-3), pp. 303-329, North-Holland, Amsterdam, The Netherlands (September 1999).

59 D. J. Naus, C. B. Oland, B. R. Ellingwood, C. J. Hookham, and H. L. Graves, III, "Summary and Conclusions of a Program Addressing Aging of Nuclear Power Plant Concrete Structures," International Journal of Nuclear Engineering and Design, NEDA 194 (1), pp. 73-96, North-Holland, Amsterdam, The Netherlands (November 1999).

60 D. J. Naus (Editor), State-Of-The-Art: Considerations for Use In Managing the Aging of Nuclear Power Plant Concrete Structures, Report No. 19, International Union of Testing and Research Laboratories for Materials and Structures (RILEM), Cachan Cedex, France (September 1999).

61 D. J. Naus, "Preface," in State-Of-The-Art: Considerations for Use In Managing the Aging of Nuclear Power Plant Concrete Structures, Report No. 19, International Union of Testing and Research Laboratories for Materials and Structures (RILEM), Cachan Cedex, France (September 1999).

62 D. J. Naus, "Concrete Structures in Nuclear Power Plants - Their Use and Longevity Considerations," in StateOf-The-Art: Considerations for Use In Managing the Aging of Nuclear Power Plant Concrete Structures, Report No. 19, International Union of Testing and Research Laboratories for Materials and Structures (RILEM), Cachan Cedex, France (September 1999).

63 D. J. Naus and C. J. Hookham, "Condition Assessment of Concrete Structures in Nuclear Power Plants," in StateOf-The-Art: Considerations for Use In Managing the Aging of Nuclear Power Plant Concrete Structures, Report No. 19, International Union of Testing and Research Laboratories for Materials and Structures (RILEM), Cachan Cedex, France (September 1999).

64 D. J. Naus, P. D. Krauss and C. Seni, "Repair Techniques and Materials for Degraded Nuclear Power Plant Concrete Structures," in State-Of-The-Art: Considerations for Use In Managing the Aging of Nuclear Power Plant Concrete Structures, Report No. 19, International Union of Testing and Research Laboratories for Materials and Structures (RILEM), Cachan Cedex, France (September 1999).

65 M. Ciampoli and B. R. Ellingwood, "Probabilistic Methods for Assessing the Performance of Concrete Structures in Nuclear Power Plants," in State-Of-The-Art: Considerations for Use In Managing the Aging of Nuclear Power Plant Concrete Structures, Report No. 19, International Union of Testing and Research Laboratories for Materials and Structures (RILEM), Cachan Cedex, France (September 1999).

66 D. J. Naus, M. Johnston, L. Granger and A. G. Miller, “An Overview of Several National and International Programs That Address Aging Management of Nuclear Power Plant Concrete Structures," in State-Of-The-Art: Considerations for Use In Managing the Aging of Nuclear Power Plant Concrete Structures, Report No. 19, International Union of Testing and Research Laboratories for Materials and Structures (RILEM), Cachan Cedex, France (September 1999).

67 D. J. Naus, "Considerations for Use in Assessment of Age-Related Degradation of Nuclear Power Plant Concrete Structures, ORNL/NRC/LTR-99/25, Lockheed Martin Energy Research Corporation, Oak Ridge National Laboratory, Oak Ridge, Tennessee (October 1999).

D. J. Naus, "RILEM TC 160-MLN, Methodology for Life Prediction of Concrete Structures in Nuclear Power Plants; Progress Report," Materials and Structures 33, pp. 98-100, RILEM, Cachan, France (March 2000). 
D. J. Naus and H. L. Graves, III, "Detection of Aging of Nuclear Power Plant Structures," Proceedings of the OECD-NEA Workshop on the Instrumentation and Monitoring of Concrete Structures, Tractabel Offices, Brussels, Belgium (March 22-23, 2000).

70 D. J. Naus, "Report of Foreign Travel of D. J. Naus, Engineering Technology Division, to Visit Swiss and Spanish Research Organizations and to Participate in an OECD Workshop on NPP Instrumentation," March 2024, 2000” ORNL/FTR-118274, UT- Battelle LLC., Oak Ridge National Laboratory, Oak Ridge, Tenn. (April 7, 2000).

71 J. I. Braverman, C. A. Miller, B. R. Ellingwood, D. J. Naus, C. H. Hofmayer, P. Bezler, and T. Y. Chang, "Structural Response of Degraded Reinforced Concrete Components, Proc. of 8th International Conference on Nuclear Engineering April 2-6, 2000, ICONE-8344, Japanese Society of Mechanical Engineers, Baltimore, Maryland (2000).

72 D. J. Naus (Editor), "State-of-the-Art Report on Service Life of Concrete," ACI 365.1R-00, American Concrete Institute, Farmington Hills, Mi. (April 2000).

73 D. J. Naus, J. I. Braverman, C. A. Miller, B. R. Ellingwood and C. H. Hofmayer, "Factors Related to Degradation of Nuclear Power Plant Concrete Structures," Proc. of International RILEM Workshop on Aging Management and Life Prediction of Concrete Structures, Cannes, France (October 16-17, 2000).

74 D. J. Naus et al., "Assessment and Management of Ageing of Major Nuclear Power Plant Components Important to Safety: Metal Components of BWR Containment Systems," IAEA-TECDOC-1181, International Atomic Energy Agency, Vienna, Austria (October 2000).

75 D. J. Naus, "Report of Foreign Travel of D. J. Naus, Engineering Technology Division, to Attend International RILEM Workshop and to visit Research Institutions in Czech Republic," October 16-25, 2000" ORNL/FTR126664, UT- Battelle LLC., Oak Ridge National Laboratory, Oak Ridge, Tenn. (November 8, 2000).

D. J. Naus and B. R. Ellingwood, "Managing Concrete Structures Aging - One Approach," $6^{\text {th }}$ International Conference on Deterioration and Repair in the Arabian Gulf," Manama, Bahrain, November 20-22, 2000.

77 D. J. Naus (Editor), Proc. of International RILEM Workshop on Aging Management and Life Prediction of Concrete Structures, Cannes, France, PRO 16, RILEM Publications S.A.R.L., Cachan, France (2000).

D. J. Naus, "Report of Foreign Travel of D. J. Naus, Engineering Technology Division, to Attend Task Group Meeting at the Nuclear Energy Agency of the Organization for Economic Cooperation and Development in Paris,” ORNL/FTR-136072, UT- Battelle LLC., Oak Ridge National Laboratory, Oak Ridge, Tenn. (April 12, 2001).

79 J. I. Braverman, C. A. Miller, B. R. Ellingwood, D. J. Naus, C. H. Hofmayer, S. Shteyngart, and P. Bezler, "Probability-Based Evaluation of Degraded Reinforced Concrete Components in Nuclear Power Plants, NUREG/CR-6715, U.S. Nuclear Regulatory Commission, Washington, DC (April 2001).

80 D. J. Naus, "Report of Foreign Travel of D.J. Naus, Engineering Technology Division, to Attend Subgroup on Aging of Concrete Structures Meeting At the Nuclear Energy Agency of the Organization for Economic Cooperation and Development in Paris, France," ORNL/FTR-137794, UT- Battelle LLC., Oak Ridge National Laboratory, Oak Ridge, Tenn. (June 1, 2001).

81 J. Li and J. I. Rose, “Guided Wave Inspection of Containment Structures,” Materials Evaluation 59(6), pp. 783787 (June 2001).

82 J. I. Braverman, C. A. Miller, B. R. Ellingwood, D. J. Naus, C. H. Hofmayer, P. Bezler and T. Y. Chang, "Structural Performance of Degraded Reinforced Concrete Members," Proc. Of the $16^{\text {th }}$ International Conference on Structural Mechanics in Reactor Technology, Paper H07/01, Washington, DC (August 2001). 
83 D. J. Naus, B. R. Ellingwood and H. L. Graves, III, "Assessing the Integrity of NPP Containment Pressure Boundaries," Proc. Of the $16^{\text {th }}$ International Conference on Structural Mechanics in Reactor Technology, Paper D04/01, Washington, DC (August 2001).

84 J. L. Rose and X. Zhao, "Anomaly Through-Wall Depth Measurement Potential with Shear Horizontal Guided Waves,” Materials Evaluation 59(10), pp. 1234-1238, October 2001.

85 D. J. Naus "Report of Foreign Travel of D.J. Naus, Engineering Technology Division, to Attend RILEM Annual Week in Stuttgart, Germany, and Visit Fraunhofer Institut Zerstörungsfreie Prüfverfahren in Saarbrücken, Germany," ORNL/FTR-143319, UT- Battelle LLC., Oak Ridge National Laboratory, Oak Ridge, Tenn. (September 27, 2001).

86 D. J. Naus and M. W. Johnston, "International RILEM Workshop on Life Prediction and Aging Management of Concrete Structures," Materials and Structures 34(242), pp. 458-466, RILEM Publications S.A.R.L., Cachan, France (October 2001).

87 M. Ciampoli and B. R. Ellingwood, "Probabilistic Methods for Assessing Current and Future Performance of Concrete Structures in Nuclear Power Plants, Materials and Structures 35(255), pp. 3-14, RILEM Publications S.A.R.L., Cachan, France (January-February 2002).

88 D. J. Naus, B. R. Ellingwood and H. L. Graves,III, “Assessment of Aging of Nuclear Power Plant Civil Structures," Paper 22067, Proc. Of Tenth International Conference on Nuclear Engineering, American Society of Mechanical Engineers, New York, New York (2002).

89 D. J. Naus, H. L. Graves, III and J. F. Costello, "Inspection, Assessment, and Repair of Nuclear Power Plant Concrete Structures," Proc. of OECD-NEA Workshop on the Evaluation of Defects, Repair Criteria, and Methods of Repair of Concrete Structures of Nuclear Power Plants, DIN Institute, Berlin, Germany (April 2002).

90 D. J. Naus, “An Overview of Activities in North America Related to Aging Management of NPP Containments and Other Structures," Proc. Of Workshop on the Concrete Containments in the Swedish NPP, Swedish Nuclear Power Inspectorate, Stockholm, Sweden (April 2002).

91 D. J. Naus, "Report of Foreign Travel of D.J. Naus, Metals and Ceramics Division, to Attend OECD-NEA Workshop University and visit Researchers at University of Karlsruhe and Bundesanstalt für Materialforschung und Prüfung (BAM) ORNL/FTR-156967, UT- Battelle LLC., Oak Ridge National Laboratory, Oak Ridge, Tenn. (May 7, 2002).

92 D. J. Naus, "Inspection of Inaccessible Regions of Nuclear Power Plant Containment Metallic Pressure Boundaries," ORNL/NRC/LTR-02/02, Oak Ridge National Laboratory, UT-Battelle, LLC, Oak Ridge, Tennessee (June 2002).

93 "Report of Task Group Reviewing Activities in the Area of Ageing of Structures Used to Construct Nuclear Power Plant Fuel Cycle Facilities," NEA/CSNI(2002)14, Nuclear Energy Agency, Organization for Economic Cooperation and Development, Paris, France (10 July 2002).

94 D. J. Naus et al, "Nuclear Power Plant Concrete Structures - Aging Considerations," Concrete for Extreme Conditions, Proc. Of International Congress on Challenges of Concrete Construction," University of Dundee, Scotland (5-11 September 2002).

95 B. R. Ellingwood and D. J. Naus, "Reliability-Based Safety Assessments of Nuclear Power Plant Structures Review and Aging Perspectives," ORNL/NRC/LTR-01/04, Oak Ridge National Laboratory, Oak Ridge, Tennessee (September 2002).

96 D. J. Naus, "Activities Under the Concrete and Containment Technology Program at ORNL," ORNL/TM2002/213, Oak Ridge National Laboratory, Oak Ridge, Tennessee (December 2002). 

December 31, 2002," ORNL/NRC/LTR-03/02, Oak ridge National Laboratory, Oak ridge, Tenn. (February 2003).

98 D. J. Naus. "Report of Foreign Travel of D.J. Naus, Metals and Ceramics Division, to Attend American Concrete Spring Convention in Vancouver, British, Columbia, Canada," ORNL/FTR-169255, UT- Battelle LLC., Oak Ridge National Laboratory, Oak Ridge, Tenn. (April 23, 2003).

99 D. J. Naus (Editor), "Proceedings of $2^{\text {nd }}$ International Workshop on Life Prediction and Aging Management of Concrete Structures held 5-6 May 2003," Proceedings PRO 29, RILEM Publications S.A.R.L., Bagneux, France (May 2003).

100 D. J. Naus. "Report of Foreign Travel of D.J. Naus, Metals and Ceramics Division, to Attend $2^{\text {nd }}$ International Workshop on Aging Management and Life Prediction of Concrete Structures and visit Researchers at University of Lund, Sweden," ORNL/FTR-169786, UT- Battelle LLC, Oak Ridge National Laboratory, Oak Ridge, Tenn. (June 4, 2003).

101 D. J. Naus et al., "Assessment and Management of Aging of Nuclear Power Plant Safety-Related Structures," Proc. Of the $17^{\text {th }}$ International Conference on Structural Mechanics in Reactor Technology, Paper D457, Prague, Czech Republic (August 2003).

102 D. J. Naus, "2 ${ }^{\text {nd }}$ International RILEM Workshop on Life Prediction and Aging Management of Concrete Structures,” Materials and Structures 263, RILEM Publications S.A.R.L., Bagneaux, France (2003).

103 J. I. Braverman, C. A. Miller, C. H. Hofmayer, B. R. Ellingwood, D. J. Naus and T.Y. Chang, "Age-Related Degradation of Structures and Passive Components at Nuclear Power Plants," International Journal of Nuclear Engineering and Design, NEDA 228(1-3), pp. 283-304, North-Holland, Amsterdam, The Netherlands (2004).

104 D. J. Naus, B. R. Ellingwood and H. L. Graves, III, "NPP Containment Pressure Boundary Integrity," International Journal of Nuclear Engineering and Design, NEDA 228(1-3), pp. 55-72, North-Holland, Amsterdam, The Netherlands (2004).

105 D. J. Naus, "Task Group Report on Aging of Concrete Structures Used to Construct Nuclear Power Plant FuelCycle Facilities," Proceedings of CSNI/RILEM Workshop on Use and Performance of Concrete in NPP FuelCycle Facilites," Iccet, Madrid, Spain, Paper 1 (March 2004).

106 D. J. Naus, B. R. Ellingwood, and H. L. Graves, III, "Structural Integrity Assessments of Nuclear Power Plant Containments," ASCE 2004 Structures Congress, Track 8: Long-Term Durability of Structural Systems and Materials, Nashville, Tennessee (May 22-26, 2004).

107 B. R. Ellingwood and D. J. Naus, "Chapter 10, Aging Nuclear Structures, "Computational Analysis of Complex Structures, American Society of Civil Engineers, New York, New York, 2004.

108 D. J. Naus. "Task Group Report on Aging of Concrete Structures Used to Construct Nuclear Power Plant FuelCycle Facilities," Proceedings of CSNI/RILEM Workshop on Use and Performance of Concrete in NPP Fuel Cycle Facilities," Instituto Ciencias de la Construccíon, “Eduardo Torroja,” Madrid, Spain (March 2004).

109 D. J. Naus. "Report of Foreign Travel of D.J. Naus, Metals and Ceramics Division, to Participate in CSNI/RILEM Workshop on Use and Performance of Concrete in NPP Fuel Cycle Facilities, visit the El Cabril Disposal, and OXAND," ORNL/FTR-207687, UT- Battelle LLC, Oak Ridge National Laboratory, Oak Ridge, Tenn. (April 1, 2004).

110 D. J. Naus and M. Brusin, "Summary Report on 2 nd International RILEM Workshop on Life Prediction and Aging Management of Concrete Structures," Journal of Cement and Concrete Composites XX(X), Elsevier Publishers, North-Holland, Amsterdam (2004). 
111 D. J. Naus et al., "Summary Report on CSNI/RILEM Workshop on Use and Performance of Concrete in NPP Fuel-Cycle Facilities, Materials and Structures xxx, RILEM Publications S.A.R.L., Bagneaux, France (2004). 


\section{APPENDIX B \\ PRESENTATIONS MADE UNDER THE INSPECTION OF AGED/DEGRADED CONTAINMENTS PROGRAM}

1. D. J. Naus, "Structural Aging Program Approach to Providing an Improved Basis for Aging Management of SafetyRelated Concrete Structures," Twenty-First Water Reactor Safety Information Meeting, Marriott Hotel,Bethesda, MD (October 27, 1993).

2. D. J. Naus, "Summary Status Report: Inspection of Steel Containments and Liners Program, Job Code J6043," Presented at Sandia National Laboratories, Albuquerque, New Mexico (January 27, 1994).

3. D. J. Naus, "A Status Report on the Inspection of Steel Containments and Liners of Reinforced Concrete Containments Program," Presentation to Nuclear Electric Personnel and Associated Organizations, Berkeley Technology Center, Berkeley, Gloucestershire, United Kingdom (May 26, 1994).

4. D. J. Naus, "An Overview of the Steel Containments and Liners Program," NRC Program Review, Office of Nuclear Regulatory Research, presented to J. W. Craig, U.S. Nuclear Regulatory Commission, Rockville, Md. (January 11, 1995).

5. B.R. Ellinwood, "Reliability-Based Condition Assessment and Service Life Prediction of Steel Structures," NRC Program Review, Office of Nuclear Regulatory Research, presented to J. W. Craig, U.S. Nuclear Regulatory Commission, Rockville, Md. (January 11, 1995).

6. D. J. Naus, "Summary Status Report: Inspection of Steel Containments and Liners Program," NRC Program Review, Office of Nuclear Regulatory Research, presented to E. S. Beckjord and D. L. Morrison, Oak Ridge National Laboratory, Oak Ridge, Tenn., March 30, 1995.

7. B. R. Ellingwood, "Reliability Framework for Managing Risk of Aging Structures," American Society of Civil Engineers Structures Conference, Chicago, Illinois (April 15-18, 1996).

8. B. R. Ellingwood, “A Damage Mechanics-Based Approach to Structural Deterioration," $11^{\text {th }}$ American Society of Civil Engineers Engineering Mechanics Conference, held at Fort Lauderdale, Florida (May 19-22, 1996).

9. D. J. Naus, "Aging Management Practices and Performance of Nuclear Power Plant Concrete Structures," International Union of Testing and Research Laboratories for Materials and Structures Committee TC-MLN, Laboratorie Central des Ponts et Chaussées, Paris, France (June 3, 1996).

10. D. J. Naus, “Condition Assessments of Concrete Structures in Nuclear Power Plants," International Union of Testing and Research Laboratories for Materials and Structures Committee TC-MLN, Laboratorie Central des Ponts et Chaussées, Paris, France (June 3, 1996).

11. D. J. Naus, “An Overview of Programs Addressing Aging of Nuclear Power Plant Concrete Structures," O\&M Technical Subcommittee, Electric Power Research Institute, Charlotte, North Carolina (August 12, 1996).

12. D. J. Naus, "Structural Aging Program - A Summary of Activities, Results, and Conclusions," Twenty-Fourth Water Reactor Safety Information Meeting, Marriott Hotel, Bethesda, MD (October 22, 1996).

13. D. J. Naus, "Aging of the Containment Pressure Boundary in Light-Water Reactor Plants," Twenty-Fourth Water Reactor Safety Information Meeting, Marriott Hotel, Bethesda, MD (October 22, 1996).

14. D. J. Naus, “Aging Management of NPP Reinforced Concrete Structures," Proc. of Sixth Symposium on Current Issues Related to Nuclear Power Plant Structures, Equipment, and Piping, North Carolina State University in Raleigh, North Carolina (December 4, 1996) 
15. B. R. Ellingwood, "A CDM-Based Approach to Stochastic Damage Growth," $7^{\text {th }}$ American Society of Civil Engineers EMD/STD Joint Conference on Probabilistic Mechanics and Structural Reliability held at Worcester Polytechnic Institute, Worcester, Mass. (August 7-9, 1996).

16. D. J. Naus, "Structural Aging Program - A Summary of Activities, Results, and Conclusions," Twenty-Fourth Water Reactor Safety Information Meeting, Marriott Hotel, Bethesda, MD (October 22, 1996).

17. B. R. Ellingwood, Time-Dependent Reliability Analysis and Condition Assessment of Structures," Twenty-Fourth Water Reactor Safety Information Meeting, Marriott Hotel, Bethesda, MD (October 22, 1996).

18. D. J. Naus, “Aging of containment Pressure Boundary in Light-Water Reactor Plants," Twenty-Fourth Water Reactor Safety Information Meeting, Marriott Hotel, Bethesda, MD (October 22, 1996).

19. D. J. Naus, "Inspection of Steel Containments and Liners," Peer Review Meeting, Sandia National Laboratories, Albuquerque, New Mexico (March 22, 1997).

20. B. R. Ellingwood, Reliability-Based Condition Assessment," Peer Review Meeting, Sandia National Laboratories, Albuquerque, New Mexico (March 22, 1997).

21. B. R. Ellingwood, "Time-Dependent Reliability Analysis and Condition Assessment of Structures," ASCE Structures Congress, Portland, Oregon (April 17, 1997).

22. D. J. Naus, "Overview of IAEA Report on Ageing of Concrete Containment Buildings," IAEA Technical Committee Meeting on Safety Aspects of Ageing Management for BWR Internals and Concrete Containment Buildings, International Atomic Energy Agency, Vienna, Austria (May 26, 1997).

23. D. J. Naus, "Management of Aging of Metallic Containment Structures," IAEA/USA Interregional Training Course on Management of Safety Aspects of Ageing in NPPs, Argonne National Laboratory, Argonne, Illinois (June 5, 1997).

24. D. J. Naus, "Management of Ageing of Safety-Related Concrete Structures," IAEA/USA Interregional Training Course on Management of Safety Aspects of Ageing in NPPs, Argonne National Laboratory, Argonne, Illinois (June 5, 1997).

25. D. J. Naus, "Service Life of Nuclear Power Plant Concrete Structures - From Condition Assessment to Service Life Estimations," American Concrete Institute Fall Convention, Atlanta, Georgia (November 12, 1997).

26. B. R. Ellingwood, "Reliability-Based Condition Assessment and Service Life Prediction of Steel Containments and Liners," 14th International Conference on Structural Mechanics in Reactor Technology, Session M, Lyon, France (August 18-22, 1997).

27. D. J. Naus, "Inspection of Aged/Degraded Containments," Program Review, presented to M. R. Knapp, Director, Office of Nuclear Regulatory Research, U.S. Nuclear Regulatory Commission, Oak Ridge National Laboratory, Oak Ridge, TN (November 13, 1997).

28. B. R. Ellingwood, "Stochastic Fatigue Crack Initiation Based On Continuum Mechanics," $7^{\text {th }}$ International Conference on Structural Safety and Reliability, Kyoto, Japan (November 14-17, 1997).

29. D. J. Naus, "Summary of ETC Feasibility Study on Use of High Frequency Acoustic Imaging Technology for Inspection of Aged/Degraded Containments," Program Review, U.S. Nuclear Regulatory Commission, Rockville, Maryland (February 19, 1998).

30. B. R. Ellingwood, "Fragility Modeling of Steel Containments and Liners," Program Review, U.S. Nuclear Regulatory Commission, Rockville, Maryland (February 19, 1998). 
31. C. B. Oland, “Containment Pressure Boundary Repair Practices and Recommendations," Program Review, U.S. Nuclear Regulatory Commission, Rockville, Maryland (February 19, 1998).

32. D. J. Naus, "Factors Related to Aging Management of Nuclear Power Plant Containment Structures," Proc. of 6th InternationalConference on Nuclear Engineering, Paper No. ICONE-6135, American Society of Mechanical Engineers/Japanese Society of Mechanical Engineers, San Diego, California (May 13, 1998).

33. D. J. Naus, "IAEA Coordinated Research Program on Aging Management of Concrete Containment Buildings," Proc. of 6th International Conference on Nuclear Engineering, Paper No. ICONE-6298, American Society of Mechanical Engineers/Japanese Society of Mechanical Engineers, San Diego, California (May 13, 1998).

34. D. J. Naus, "Aging of Steel Containments and Liners of Reinforced Concrete Containments," Session 1.1D, American Society of Mechanical Engineers/Japanese Society of Mechanical Engineers Joint Pressure Vessels and Piping Conference, Sheraton San Diego Hotel and Marina, San Diego, California (July 27, 1998).

35. B. R. Ellingwood, "Condition Assessment of Existing Structures in Nuclear Power Plants: Optimum Inspection and Repair,” Structural Engineers World Conference, San Francisco, California (July 19-23, 1998).

36. J. E. Bondaryk, "High Frequency Imaging of Thickness Degrdation in Steel Containment Vessels and Liners," Session 1.4D, American Society of Mechanical Engineers/Japanese Society of Mechanical Engineers Joint Pressure Vessels and Piping Conference, Sheraton San Diego Hotel and Marina, San Diego, California (July 27, 1998).

37. D. J. Naus, "Management of Aging of Nuclear Power Plant Containment Structures," Fourth International Conference on Engineering Structural Integrity Assessment, Churchill College, Risley, Warrington, Cheshire, United Kingdom (September 24, 1998).

38. D. J. Naus, “Aging Management of Nuclear Power Plant Concrete Structures,” University of Sheffield, Department of Civil Engineering, Sheffield, United Kingdom (September 25, 1998).

39. D. J. Naus, "An Overview of the Structural Aging Program," Mechanics and Component Technology Branch, Electricite de France, Site des Renardieres, France (October 1, 1998)

40. B. R. Ellingwood, "Damage Mechanics-Based Assessment of Time-dependent Structural Deterioration and Reliability," $26^{\text {th }}$ Water Reactor Safety Information Meeting, Marriott Hotel, Bethesda, Maryland (October 27, 1998).

41. J. Rudzinsky, "Feasibility Study on the Use of Ultrasonic Technology on Embedded Corrosion Detection of Nuclear Containment Units: Phase II," $26^{\text {th }}$ Water Reactor Safety Information Meeting, Marriott Hotel, Bethesda, Maryland (October 27, 1998).

42. D. J. Naus, "Inspection of Nuclear Power Plant Containment Structures," Proc. of Seventh Symposium on Current Issues Related to Nuclear Power Plant Structures, Equipment, and Piping held at North Carolina State University in Raleigh (December 4, 1998).

43. H. Kwun, "Feasibility of Magnetostrictive Sensor Inspection of Containments," Program Review, NRC Offices, Rockville, Maryland (January 21, 1999).

44. D. J. Naus, “An Overview of the Structural Aging Program,” Nuclear Power Engineering Corporation, Tokyo, Japan (April 19, 1999).

45. D. J. Naus, “An Overview of the Structural Aging Program,” Obayashi Corporation, Tokyo, Japan (April 22, 1999).

46. D. J. Naus, “An Overview of the Structural Aging Program,” Tokyo Electric Power Corporation, Tokyo, Japan (April 22, 1999). 
47. D. J. Naus, “An Investigation of Tendon Corrosion Inhibitor Leakage Into Concrete," International Conference on Life Prediction and Aging Management of Concrete Structures, Bratislava, Slovakia (July 6,1999).

48. B. R. Ellingwood, "Fragility Modeling of Steel Containments with Localized Corrosion," American Society of Mechanical Engineers/Japanese Society of Mechanical Engineers Joint Pressure Vessels and Piping Conference, Boston, Massachusetts (August 4, 1999).

49. N. C. Chokshi, "Nuclear Power Plant Containment Pressure Boundary Aging Research," Transactions of the 15th International Conference on Structural Mechanics in Reactor Technology, Session 8, Paper D8-A1-US, Seoul, Korea (August 20, 1999).

50. D. J. Naus, "Summary: Inspection of Aged/Degraded Containments Project(J6043)," Review of NRC/RES Project, Presented to Mr. M. E. Mayfield and Dr. S. Bahadur, Office of Nuclear Regulatory Research, U.S. Nuclear Regulatory Commission, Oak Ridge, Tennessee (February 23, 2000).

51. D. J. Naus, "Detection of Aging of Nuclear Power Plant Structures," OECD-NEA Workshop on the Instrumentation and Monitoring of Concrete Structures, Tractabel Offices, Brussels, Belgium (March 22, 2000).

52. D. J. Naus, "Factors Related to Degradation of Nuclear Power Plant Concrete Structures," Proc. of International RILEM Workshop on Aging Management and Life Prediction of Concrete Structures, Cannes, France (October 16, 2000).

53, D. J. Naus, "Aging Management of Concrete Structures to Help Assure Continued Safe and Reliable Nuclear Power Plant Operation," Czech Technical University, Prague, Czech Republic (October 19, 2000).

54. D. J. Naus, "Aging Management of Nuclear Power Plant concrete Structures," State Office for Nuclear Safety, Prague, Czech Republic (October 20, 2000).

55. D. J. Naus, "Overview of Report of Task Group Reviewing Activities in the Area of Ageing of Structures Used to Construct Nuclear Power Plant Fuel Cycle Facilities," Nuclear Energy Agency, Organization for Economic Cooperation and Development, Paris, France (May 15, 2001).

56. D. J. Naus, "Assessing the Integrity of NPP Containment Pressure Boundaries," $16^{\text {th }}$ International Conference on Structural Mechanics in Reactor Technology, Washington, DC, August 13, 2001.

57. D. J. Naus, "Continuing the Service of NPP Containments and Other Structures - Perspectives and Insights," $16^{\text {th }}$ International Conference on Structural Mechanics in Reactor Technology, License Renewal and Life Extension Workshop, Washington, DC, August 16, 2001.

58. D. J. Naus, "An Overview of Concrete Research at ORNL," Visitors from Civil and Environmental Engineering Department, Vanderbilt University, Oak Ridge, Tennessee (October 22, 2001).

59. D. J. Naus, "Research Addressing Aging Management of NPP Structures," Department of Civil and Environmental Engineering, Vanderbilt University, Nashville, Tennessee (February 18, 2002).

60. D. J. Naus, "Inspection, Assessment, and Repair of Nuclear Power Plant Concrete Structures," Proc. of OECD-NEA Workshop on the Evaluation of Defects, Repair Criteria, and Methods of Repair of Concrete Structures of Nuclear Power Plants, DIN Institute, Berlin, Germany (April 10, 2002).

61. D. J. Naus, "An Overview of Activities in North America Related to Aging Management of NPP Containments and Other Structures," Proc. Of Workshop on the Concrete Containments in the Swedish NPP, Swedish Nuclear Power Inspectorate, Stockholm, Sweden (April 25, 2002).

62. D. J. Naus, "An Overview of Activities Conducted Under the ORNL Concrete and Containment Technology Program," American Concrete Institute Strategic Development Council Eleventh General Session, Rosemont, Illinois (May 21, 2002). 
63. D. J. Naus, "Nuclear Power Plant Concrete Structures - Aging Considerations," International Congress Challenges of Concrete Construction," University of Dundee, Scotland (11 September 2002).

64. D. J. Naus, "Aging Management of concrete structures to Assure Continued Safe and Reliable Nuclear Power Plant Operation," Department of Ceramic Engineering, University of Missouri at Rolla (December 5, 2002)

65. D. J. Naus, “Inspection of Aged/Degraded Containments," NRC/RES Review, Oak Ridge National Laboratory, Oak Ridge, Tennessee (November 4, 2003).

66. D. J. Naus, "Task Group Report on Aging of Concrete Structures Used to Construct Nuclear Power Plant FuelCycle Facilities," Proceedings of CSNI/RILEM Workshop on Use and Performance of Concrete in NPP Fuel Cycle Facilities," Instituto Ciencias de la Construccíon, "Eduardo Torroja," Madrid, Spain (March 15, 2004).

67. D. J. Naus, “CSNI/RILEM Workshop on Use and Performance of Concrete in NPP Fuel Cycle Facilities,” RILEM TAC Meeting, Northwestern University, Evanston, Illinois (March 25, 2004).

68. D. J. Naus, Structural Integrity Assessments of Nuclear Power Plant Containments," ASCE 2004 Structures Congress, Track 8: Long-Term Durability of Structural Systems and Materials, Nashville, Tennessee (May 24, 2004). 


\section{APPENDIX C}

\section{APPROXIMATE FRAGILITY ANALYSIS}

The fragilities illustrated in Section 5.2.4 were developed using the nonlinear finite- element program, ABAQUS. Such analyses can be quite accurate but are costly to perform, even with the use of efficient experimental sampling plans. Moreover, a large number of such analyses might be required in support of risk-based decision making. The question arises: can a relatively simple approach to fragility modeling of containments be devised by scaling the design calculations upward using a number of appropriately derived and defensible multiplicative random constants? Such an approach has been found useful in seismic margin studies (C.1). This question is explored in the following paragraphs.

\section{C.1 Conceptual Model}

As a conceptual illustration, suppose that it is desired to perform a margins analysis of a containment subjected to internal pressure, $\mathrm{P}_{\mathrm{a}}$. The capacity (in units of pressure) can be analyzed as the product of a series of factors,

$$
\mathrm{m}_{\mathrm{R}}=\prod_{\mathrm{i}=1}^{\mathrm{n}} \mathrm{F}_{\mathbf{i}} \mathrm{P}_{\mathrm{a}}
$$

in which $\mathrm{P}_{\mathrm{a}}=$ design-basis pressure and $\mathrm{F}_{\mathrm{i}}, \mathrm{i}=1, \ldots, \mathrm{n},=$ random factors which, collectively, represent the difference between strength of the containment in-service and the assumed design strength. Assuming that the factors $F_{i}$ are mutually statistically independent, the median and inherent variability in $\mathrm{R}$ are,

$$
\begin{aligned}
& \mathrm{m}_{\mathrm{R}}=\prod_{\mathrm{i}=1}^{\mathrm{n}} \mathrm{m}_{\mathrm{i}} \mathrm{P}_{\mathrm{a}} \\
& \beta_{\mathrm{R}}=\left(\sum_{\mathrm{i}=1}^{\mathrm{n}} \beta_{\mathrm{Ri}}^{2}\right)^{1 / 2}
\end{aligned}
$$

in which $\mathrm{m}_{\mathrm{i}}=$ median of factor $\mathrm{i}$ and $\beta_{\mathrm{Ri}}=$ logarithmic standard deviation describing inherent variability in factor $\mathrm{i}$ (cf Eqn. (5.59)). (The knowledge-based uncertainties, $\beta_{\mathrm{Ui}}$, can be combined using an equation similar to Eqn. (C2.b). As the product of independent factors, $\mathrm{R}$ can be modeled by a lognormal distribution by virtue of the central limit theorem of probability theory. The parameters $m_{R}, \beta_{R}$ and $\beta_{U}$ can be substituted into Eqn. (5.57) to determine the HCLPF of the containment: It remains to determine the medians and variability measures, $\mathrm{m}_{\mathrm{i}}$ and $\beta_{\mathrm{i}}$. This determination requires an audit and supplemental analyses of the design calculations of a specific containment. This is illustrated in the following.

\section{C.2. Illustration}

The following illustrates the above concepts for the ice condenser steel containment addressed in Section 5.2.4. The medians and uncertainties are consistent with the previous discussion.

The starting point of the containment fragility analysis is the containment-specific design calculations, which usually are available. The product of factors in Eqn. (C.1) is expressed as,

$$
\prod \mathrm{F}_{\mathrm{i}}=\mathrm{F}_{\mathrm{s}} \mathrm{F}_{\mu} \mathrm{F}_{\mathrm{rs}}
$$

Factor $\mathrm{F}_{\mathrm{s}}=\mathrm{P}_{\mathrm{y}} / \mathrm{P}_{\mathrm{a}}$, in which $\mathrm{P}_{\mathrm{a}}=$ design-basis pressure, and $\mathrm{P}_{\mathrm{y}}=$ pressure at which first yield occurs; $\mathrm{F}_{\mathrm{u}}=\mathrm{P}_{\mathrm{u}} / \mathrm{P}_{\mathrm{y}}$, in which $\mathrm{P}_{\mathrm{u}}=$ pressure at which limit strain or excessive inelastic deformation of the shell occurs; and $\mathrm{F}_{\mathrm{rs}}=$ structural response analysis factor, describing the relative accuracy of the analysis used to determine containment response to internal pressure. If containment thickness is the minimum required by Code (Eqn. (5.60)), $\mathrm{F}_{\mathrm{s}}=\mathrm{F}_{\mathrm{y}} / \mathrm{S}_{\mathrm{mc}}$; otherwise $\mathrm{F}_{\mathrm{s}}$ is greater. The median values of these factors, illustrated in Figure C.1, can be estimated from nonlinear finite-element analysis. 
Structural analyses performed in the process of containment design are elastic, and the design is based on allowable stress concepts. Assuming SA 516/60 steel, the minimum median of $\mathrm{F}_{\mathrm{s}}$ thus would be approximately 47/16.5 =2.85. However, the shell thickness in the ice basket region is $16 \mathrm{~mm}$, approximately $39 \%$ higher than would be required from simply considering response to internal pressure. Thus, the median of $F_{s}$ is 3.96 . The COV would equal the COV in yield strength, or about 0.08 .

The containment capacity is not reached when first yield occurs. Rather, stresses redistribute due to the ductility of the steel, while deformations increase in the radial and meridional directions. Eventually a point is reached where effective strains reach an unacceptable level or the tensile strength at stress raisers is approached. The pressure at which this behavior occurs is well beyond the design basis, at a level F times initial yield. One properly performed mediancentered finite-element analysis would identify this factor with sufficient accuracy to determine the median of $F$. The median of $\mathrm{F}$ typically would be on the order of 1.5 , with modeling uncertainty of 0.15 .

Modern finite-element codes are highly sophisticated and are capable of analyzing nonlinear static and dynamic effects very accurately. A typical median value of $\mathrm{F}_{\mathrm{rs}}$ thus might be 1.0, with modeling uncertainty $\beta_{\mathrm{u}}=0.10$.

Collecting this information, one would have,

$$
\begin{aligned}
& \mathrm{m}_{\mathrm{R}}=3.96 \times 1.5 \times 10 \mathrm{P}_{\mathrm{a}}=5.94 \mathrm{P}_{\mathrm{a}}=442 \mathrm{kPa} \\
& \beta_{\mathrm{R}}=0.08 \\
& \beta_{\mathrm{U}}=\sqrt{0.15^{2}+0.10^{2}}=0.18 \\
& \beta_{\mathrm{c}}=\sqrt{0.08^{2}+0.18^{2}}=0.20
\end{aligned}
$$

Note that $\beta_{\mathrm{c}}$ is larger here than the values in Section 5.2.4 because of the approximate nature of the analysis. On the other hand, it is consistent, in an overall sense, with the variabilities reported in the Individual Plant Examinations Program (C.2); note that aging was not addressed in the IPE Program.

The HCLPF capacity, from Section 5.2.4, would be $277 \mathrm{kPa}$, well above the design-basis pressure of $74 \mathrm{kPa}$. This $277 \mathrm{kPa}$ capacity could be compared to the pressure from a review-level event to determine suitability for service. For example, the failure probability of the containment given a pressure of $2.0 \mathrm{P}_{\mathrm{a}}$, would be virtually zero.

If the containment were found to be corroded during in-service inspection, the loss of section must be reflected in the median factors; this would entail one median-centered finite-element analysis of the containment under observed degraded conditions to revise the estimated median, $F$. The modeling uncertainties, $\beta_{\mathrm{U}}$, also would be increased by the presence of the uncertainty in corrosion. Suppose that as a result of analysis of the data gathered during the inspection, $\beta_{\mathrm{c}}$ increased to 0.30 , and the median in the product $\mathrm{F}_{\mathrm{s}} \mathrm{F}$ decreased by $15 \%$ from 5.94 to 5.05 (see, e.g., Table 5.9). The median capacity $m_{R}$ would be reduced from $442 \mathrm{kPa}$ to $375 \mathrm{kPa}$, and the HCLPF would decrease from $277 \mathrm{kPa}$ to $185 \mathrm{kPa}$. The conditional structural failure probability of the containment during an accident developing a pressure of $2.0 \mathrm{~Pa}$ would increase to 0.001 .

\section{C.3 References}

C.1 Kennedy, R.P. and Ravindra, M.K. (1984). "Seismic fragilities for nuclear power plant studies." Nuc. Engrg. and Des. 79(1):47-68.

C.2 USNRC (1996). "Individual plant examination program: perspectives on reactor safety and plant performance." NUREG-1560, Vols. 1 and 2, U.S. Nuclear regulatory commission, Washington, DC. 


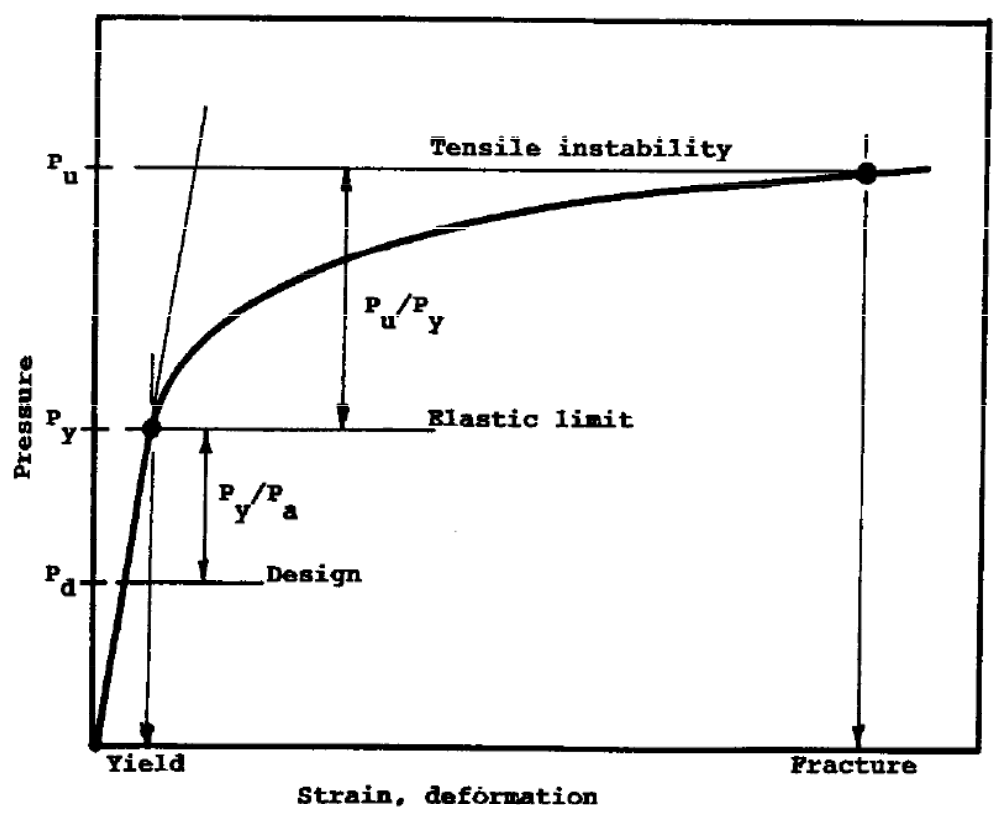

Fig. C.1 Scaling factors for approximate containment fragility analysis. 
ORNL//TM-2005/520

Internal Distribution

September 2005

1. E. E. Bloom

2. J. M. Corum

3. E. Lara-Curzio

4. S. Greene

5-10. D. J. Naus

11. C. B. Oland
12. A. E. Pasto

13-14. J. J. Simpson

15. ORNL Patent Section

16. Central Research Library

17. ORNL Laboratory Records

18. ORNL Laboratory Records-OSTI

\section{External Distribution}

19. S. Ali, NRC

20. C. Andrade, Ietcc

21. H. G. Ashar, NRC

22. G. Bagchi. NRC

23. Z. Bittnar, Czech Technical University

24. J. Carey, EPRI

25. T-Y. Chang, NRC

26. N. C. Chokshi, NRC

27. Commander and Director, USAE Waterways Experiment Station

28. R. Danisch, Framatome

29. B. R. Ellingwood, Georgia Tech

30. M. Evans, NRC

31. W. L. Gamble, University of Illinois

32-40. H. L. Graves, III, NRC

41. F. E. Gregor, LCM Engineering

42. W. Heep, NOK

43. W. G. Imbro, NRC

44. D. C. Jeng, NRC

45. P-T Kuo, NRC

46. H. Kwun, Southwest Research Institute

47. K. Manoly, NRC

48. H. W. Massie, DNFSB

49. T. McNulty, HSE

50. H. Müller, Universität Karlsruhe

51. W. E. Norris, NRC

52. J. Philip, NRC

53. V. Schmitz, IzfP

54. S. P. Shah, Northwestern University

55. R. E. Shewmaker, NRC

56. H. Stephens, EPRI

57. J. P. Vora, NRC

58. H. Wiggenhauser, BAM 
